\title{
Rocky Flats Environmental Technology Site Ecological Monitoring Program 1995 Annual Report
}

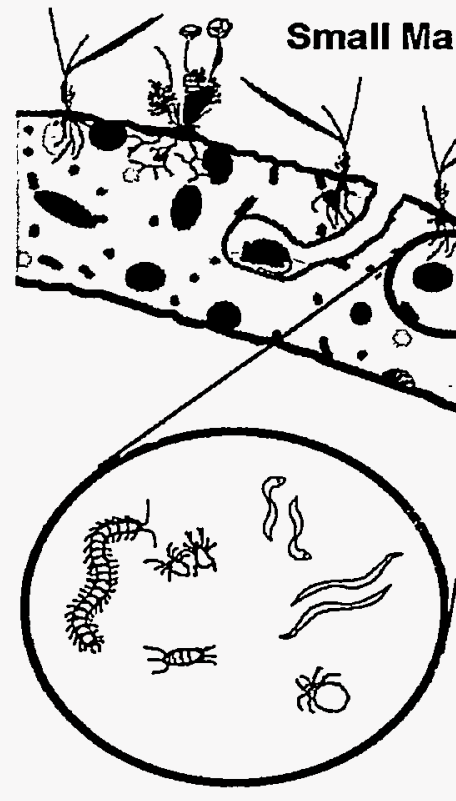

Soil and other

\section{Terrestrial Invertebrates}

\section{Ecosystem Functions}

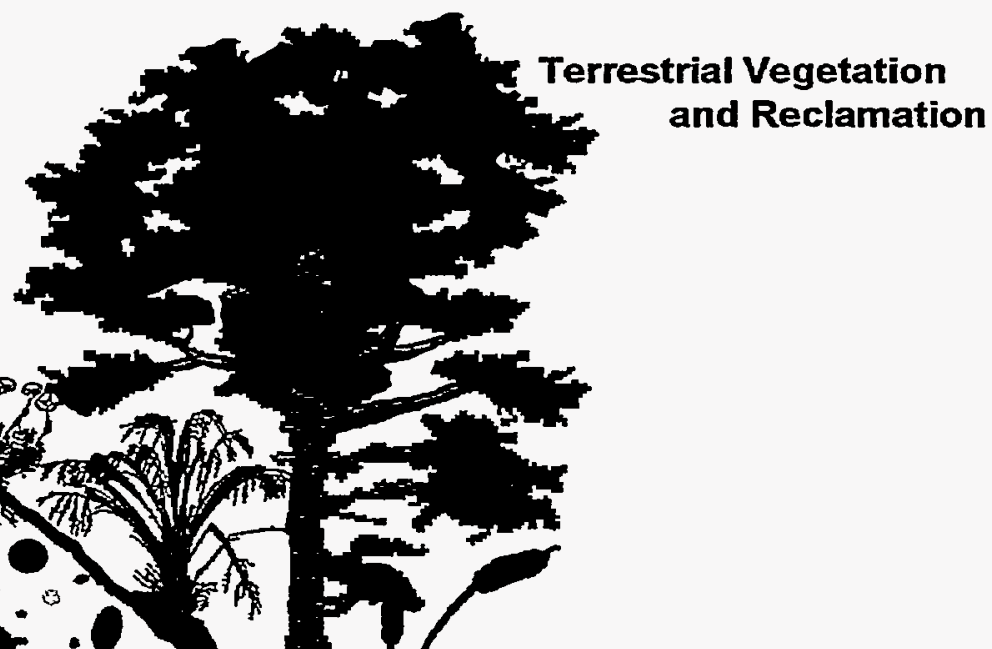

Emergent Insects
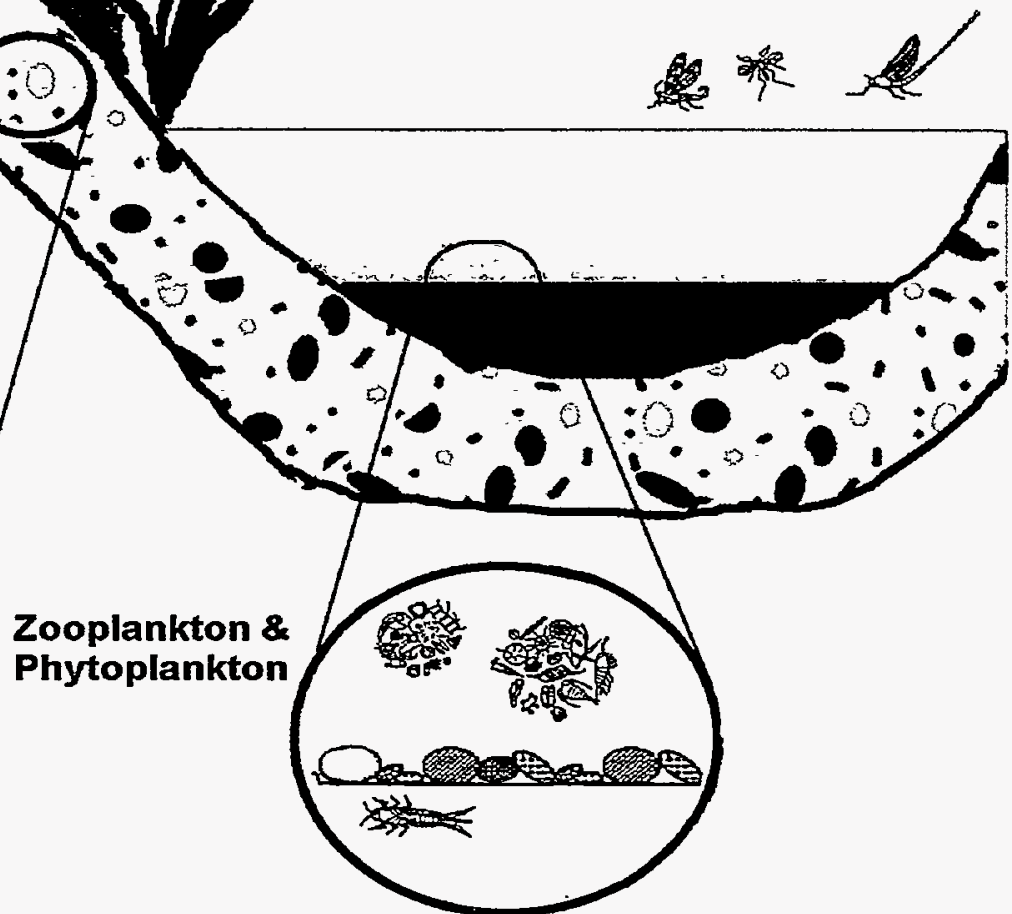

Macrobenthic Invertebrates

Rocky Flats Field Office

U.S. Department of Energy Golden, CO 


\section{TABLE OF CONTENTS}

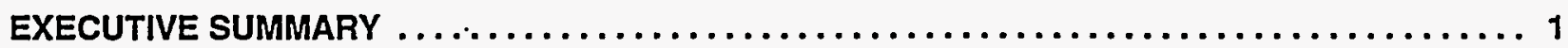

PROGRAMITECHNICAL SUMMARY $\ldots \ldots \ldots \ldots \ldots \ldots \ldots \ldots \ldots \ldots \ldots \ldots \ldots \ldots \ldots \ldots \ldots$

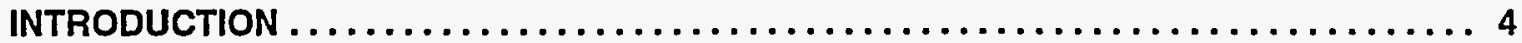

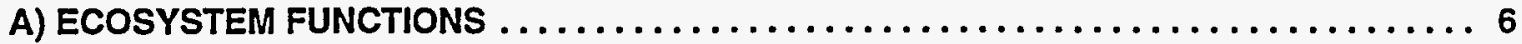

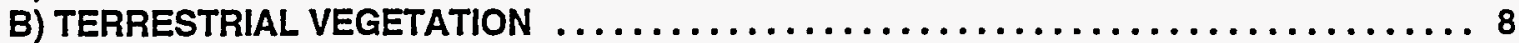

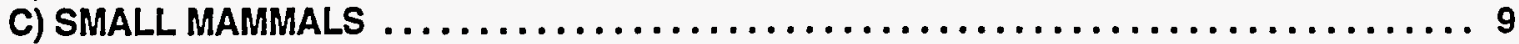

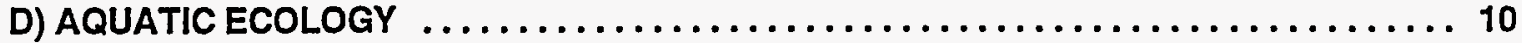

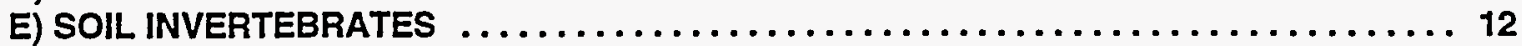

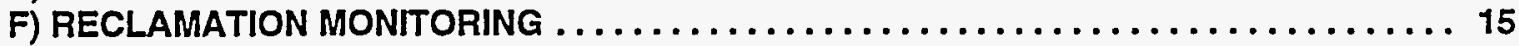

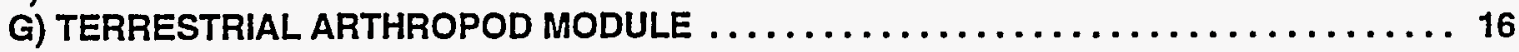

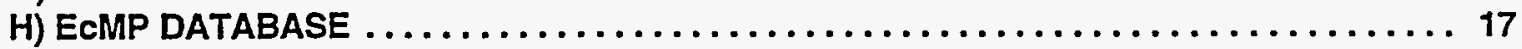

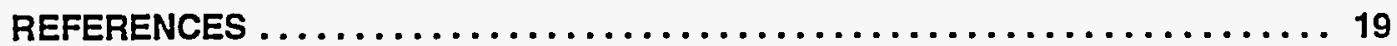

1) OPERABLE UNIT 11 ECOLOGICAL EFFECTS $\ldots \ldots \ldots \ldots \ldots \ldots \ldots \ldots \ldots \ldots \ldots \ldots \ldots \ldots$

\section{LIST OF FIGURES}

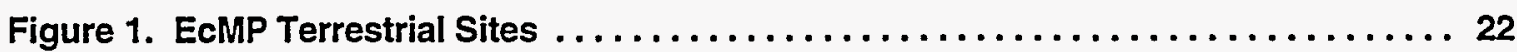

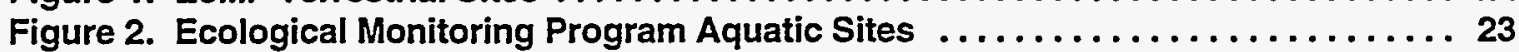

Figure 2A. Aquatic Site Descriptions ........................... 24

RECEIVED

DISCLAIMER

This report was prepared as an account of work sponsored by an agency of the United States Government. Neither the United States Government nor any agency thereof, nor any of their employees, makes any warranty, express or implied, or assumes any legal liability or responsibility for the accuracy, completeness, or usefulness of any information, apparatus, product, or process disclosed, or represents that its use would not infringe privately owned rights. Reference herein to any specific commercial product, process, or service by trade name, trademark, manufacturer, or otherwise does not necessarily constitute or imply its endorsement, recommendation, or favoring by the United States Government or any agency thereof. The views and opinions of authors expressed herein do not necessarily state or reflect those of the United States Government or any agency thereof. 


\section{DISCLAIMER}

Portions of this document may be illegible in electronic image products. Images are produced from the best available original document. 


\section{EXECUTIVE SUMMARY}

The Ecological Monitoring Program (EcMP) was established at the Rocky Flats Environmental Technology Site (Site) in September, 1992. At that time, EcMP staff developed a Program Plan that was peerreviewed by scientists from western universities before submittal to DOE RFFO in January, 1993.

The intent of the program is to measure several quantitative variables at different ecological scales in order to characterize the Rocky Flats ecosystem. This information is necessary to document ecological conditions at the Site in impacted and nonimpacted areas to determine if Site practices have had ecological impacts, either positive or negative. This information can be used by managers interested in future use scenarios and CERCLA activities. Others interested in impact analysis may also find the information useful. In addition, these measurements are entered into a database which will serve as a long-term information repository that will document long-term trends and potential future changes to the Site, both natural and anthropogenic.

Because ecological data may be extremely variable, it is often difficult to determine departures from "normal" or "natural" conditions from those that may be due to various activities at the Site. Every effort has been made to summarize the range and variability associated with important ecological variables to enhance their utility in as many practical situations as possible. Managers needing quick information on representative sites and community types will be able to refer to tables presented in this document.

All terrestrial sampling (ecosystem functions, terrestrial vegetation, small mammals, soil invertebrates, and terrestrial arthropods) has been based on the designation of four community groups or types: xeric mixed grasslands, mesic mixed grasslands, reclaimed grasslands, and riparian complexes. Aquatic sampling has been based on individual sampling units of ponds, streams, and seeps after earlier data analyses showed that variability in measurements prevented grouping of sample units into broader types. Staff are continually refining ideas of community types and variability within types; this has particular relevance in the selection of proper reference areas for comparison to impacted sites.

The majority of the terrestrial sampling has taken place at twelve sites in the four community types mentioned above. These sites are in nonimpacted areas and will serve to provide baseline ecological information needed for ecological risk assessments, determination of Natural Resource Damage injuries, and guidance for future use. Other terrestrial areas sampled were in Operable Unit 11, to support the Environmental Evaluation conducted there. Aquatic sites sampled include a variety of nonimpacted and impacted Site ponds and streams, and offsite stream areas.

Ecological Monitoring Program staff completed the second year of data collection at the Site in September, 1994. This report includes analyses and interpretation of these data, as well as selected data collected in 1993 that were not available until recently. The majority of these data were collected from sites in the Buffer Zone, although 1993 activities in Operable Unit 11 are also reported in a separate appendix. Data were collected from the following technical modules: ecosystem functions, terrestrial vegetation, small mammals, aquatic ecology, soil invertebrates, reclamation monitoring, and terrestrial arthropods. Collectively, these technical areas represent population, community, and ecosystem levels of ecological organization at Rocky Flats and provide "the big picture" of the ecological health of the site. Each of these modules is briefly summarized in the following paragraphs.

Ecosystem functions were measured at three sites in each of the four community types. None of the sites are known to have been contaminated or otherwise disturbed. Of the variables measured, microbial biomass, potential respiration, potential nitrogen mineralization, and fine particulate organic matter are of most interest. Total soil organic carbon and nitrogen were measured on each sample so that differences in soil organic matter quality as well as concentrations could be estimated. The most obvious finding for total organic matter and microbial biomass concentrations was that differences between sites exceeded the differences between communities. The same was true for respirable carbon. Mineralizable nitrogen concentrations were the highest in xeric community types and lowest in reclaimed types. The fraction of 
total organic carbon in microbial biomass was lowest in xeric, but highest in reclaimed community types. In contrast, the fraction of total organic nitrogen in mineralizable forms was similar among undisturbed sites, but was much lower in the reclaimed community. Reclaimed community sites had microbial biomass concentrations similar to all other sites, even though total carbon concentrations were lower. That biomass was, however, much less able to mineralize organic nitrogen. It appears that these measurements provide a very sensitive indication of ecosystem disturbance. Perhaps they will be sensitive enough to allow clear demonstrations that no effects have accrued from contamination or disturbances in unaffected areas; a concept which has been very difficult to establish to the regulators' satisfaction.

During 1994, EcMP personnel measured terrestrial vegetation parameters at 12 permanent monitoring sites. Species richness and cover were measured using belt transects and point-intercept transects at 60 permanent transects ( 5 transects per site). In addition, biomass production was measured in 225 production plots at 45 transects at all 9 of the grassland sites. A total of 271 species in 51 families and 73 genera were recorded from the EcMP sites. Species richness increased along the hydrologic gradient from xeric (dry), to mesic (moderate), to riparian (wet) communities (excluding reclaimed). Significant differences were found in the percent cover for different cover classes and biomass amounts between sites and between communities. Plant associations were determined for sites based on basal vegetation cover. Results of ordination and classification analyses based on species presence/absence data revealed differences in the community types studied by EcMP staff. The success of these analyses in distinguishing differences between the EcMP sites demonstrated the applicability of the analyses to remediation and revegetation efforts on Site.

Small mammal populations were monitored at the 12 permanent terrestrial sites during 2 trapping sessions: one in the spring and one in the fall. Four-hundred and twenty-three individuals of 9 species were recorded during the spring session and 661 individuals of 11 species were recorded during the fall session. Two new species were documented for the Site, the Plains Pocket Mouse (Perognathus flavescens) and the House Mouse (Mus musculus). The Deer Mouse (Peromyscus maniculatus) was the most common small mammal in all habitat types and during both trapping sessions. The highest small mammal populations were recorded in riparian complex communities and the lowest populations were recorded in reclaimed communities. Habitat characterization of successful and unsuccessful trap sites was conducted to determine habitat preferences of the Site's small mammal populations. Habitat data were collected at 233 trap stations. A special study designed to determine the status of the Preble's Meadow Jumping Mouse (Zapus hudsonius preblei) was conducted during the summer of 1994 in areas that this mouse is most likely to occupy. Thirty-four captures of 23 individuals were recorded during this effort.

Biotic analyses of aquatic communities revealed that there is much inter-as well as intra-community variability in Site ponds and streams. Variation in the numbers and kinds of biological receptors is due not only to the presence/absence of contaminants, but also to the "natural" biological/physical conditions at each site. No group of ponds shared more than $45 \%$ of any of the biota sampled (zooplankton, phytoplankton, macrobenthic invertebrates, emergent insects), indicating that these systems are so biologically diverse that the selection of reference sites must be done on a case-by-case basis. The most biologically diverse OU site for overall biotic community composition is Pond A-2 (mean of 57.4 biotic taxa sampled). The most diverse reference (unimpacted) site is Pond D-2 (mean of 53 biotic taxa). Biological data summaries are now available for all Site ponds, as well as selected offsite stream areas.

Analysis of soil invertebrates showed that reclaimed grassland and riparian vegetation community types have distinct populations of selected soil invertebrate groups and that these community types can be distinguished from other community types at the Site. Thus, if similar communities are suspected of being injured by activities at the Site, a biological baseline of a sensitive invertebrate receptor can be used to determine if injury and damage have occurred. Other grassland community types were difficult to distinguish using these methods, but future analyses and new sampling techniques may elucidate additional community differences. 
Revegetation efforts on the 881 Hillside (Hillside) were monitored by EcMP personnel in late fall of 1994. The results reveal that the success of the revegetation effort thus far has been poor. Of the 13 species seeded on the Hillside, only six were recorded during the 1994 sampling and these provide only $3.5 \%$ of the cover on the Hillside. The Hillside is dominated by non-native, annual species and $63 \%$ of the.species recorded there are considered "weeds." Vegetation cover, although having increased from 1993, is still less than half that found in reference areas on the Site. The significance of the problem should not be underestimated. With no action, the domination of the Hillside by non-native, annual species will continue to persist and provides the potential to spread throughout the Woman Creek drainage, downstream and downwind. Other studies have shown that the competitive influences of plant communities dominated by annual species prevent the reestablishment of native plant communities and often lead to lower quality watersheds by increasing the potential for erosion and typically increasing the frequency of wildfires. It is recommended that additional reseeding of the Hillside be commenced as soon as possible with a seed mixture of native, perennial grass and forb species like those found in the reference areas of the mesic grassland community at the Site.

Terrestrial arthropod communities were sampled for the first time under EcMP in August 1994. The objective of this module is to characterize the diversity and biomass of above-ground arthropods. Arthropods were collected from all 12 permanent monitoring sites along vegetation transects using a variety of methods. Results of taxonomic analyses measuring taxon richness and abundance are expected from the laboratory subcontractor after the delivery of this report. Biomass was inadequate as a measurement endpoint due to the dry weather of the 1994 summer. Three sampling sessions are planned for the spring and summer of 1995.

The EcMP Database has been designed and developed as a tool for entering, assuring the quality of, and storing data collected under the EcMP. Database development began with the objective of capturing the data collected for the terrestrial vegetation module. The database was initially designed and created in the spring of 1993 and was extensively revised and updated in summer and fall of 1994 to increase efficiency and accommodate other EcMP modules. The revised code uses approximately $13 \%$ of the disk space that the original code occupied and is composed of about 100 fewer files. Ecology and Watershed Management (EWM) was asked by the Environmental Restoration Program Division (ERPD) in October, 1994 to create a Sitewide Ecological Database (SED) for the Site. The purpose of the SED is to support environmental management and remediation efforts for the Site. The SED is expected to be complete by August, 1995. 


\section{PROGRAM/TECHNICAL SUMMARY}

\section{INTRODUCTION}

The Ecological Monitoring Program (EcMP) finished the second full year of data collection at the close of 1994 , and this report contains analyses and interpretations of those data.

The program was established for a variety of reasons, some of which are:

- $\quad$ to collect, analyze, and interpret baseline ecological data against which changes can be measured;

- to describe and better understand Site natural resources so that informed management decisions can be made;

- $\quad$ to assess potential impacts to ecological receptors, and;

- to provide biological/ecological expertise on special projects.

Terrestrial sampling occurred at 12 permanent sites, where observational data were recorded and soil, vegetation, invertebrate, and other biotic samples were collected and sent to laboratories for analysis (see Figure 1).

Aquatic sampling occurred at a variety of Rocky Flats Technology Site (Site) pond and stream habitats, and a few offsite locations (Figure 2 and 2A). Water and a variety of biota samples were collected from these areas and shipped to laboratories for analysis.

In addition to the monitoring activities described above, EcMP personnel were involved in a number of special projects. These are briefly described below.

- $\quad$ Extensive trapping surveys for the Preble's Meadow Jumping Mouse (Zapus hudsonius preblei) (PMJM), were conducted on the Site. This animal is a Colorado species of special concern, for which a petition has been submitted to the U.S. Fish and Wildlife Service to list the species under the Endangered Species Act. Traps were placed at riparian sites which were believed to contain good PMJM habitat as well as at sites where PMJM had been captured historically. Prior to the onset of this study, it was believed that the Western Jumping Mouse (Zapus princeps) also occupied the drainages within Rocky Flats. However, after study of two specimens collected from the Site (one assigned to Z.h. preblei and the other to $Z$. princeps), it was determined that both specimens should be assigned to Z.h. preblei. Additionally, only PMJM were trapped at the Site during 1994. All sites where a PMJM had been captured onsite, both prior to and during 1994, were characterized in order to obtain an understanding of PMJM habitat requirements.

- An EcMP team member assisted in the development of a current vegetation map utilizing multispectral imagery data. Previous vegetation maps were developed several years ago and are no longer accurate. An effort was made to assign a vegetation classification scheme to the images. It was determined that either color resolution was not high enough in the imagery for discriminating general habitat types or the combined images were too complex to be of use without more colors for resolution.

- Information was provided to the Safety Analysis group on metal contents of Rocky Flats vegetation and litter. This information was needed to estimate airborne releases of these metals in the event of a wildfire at the Site. 
The goal of complete internalization of field work was achieved during 1994. All 1994 EcMP field data were collected by the following personnel:

Mark Bakeman, Ph.D, Soil edaphic relations, nutrient cycling; M.S., Forest Science; B.S. Resource Management

Mark D'Agostino, B.S., Forestry

Alison Deans, M.S., Mineral Resources Ecology; B.A., Environmental, Population, and Organismic Biology and Geological Sciences

Michelle Fink, M.S., Ecology (landscape speciality); B.S., Wildlife Biology William Freeman, M.S., Biology; B.S., Biology June Haines, M.S., Natural Science, B.S., Botany, A.A., Math Education

Fred Harrington, Ph.D, Wildlife Biology; M.S.,Natural Resource Administration; B.S., Wildlife Biology

Jody Nelson, M.A., Biology; B.A., Biology; A.A., Photography

Tom Ryon, M.S., Environmental Science (in progress); B.S., Wildlife Biology

Lawrence Woods, Certified Sr. Ecologist, Ph.D, Soil Ecology; M.S., Soil Science; B.S., Biology

Additionally, some staff were matrixed in on an as-needed basis:

Marcia Murdock, M.A., Zoology and Botany

Frank Vertucci, Certified Sr. Ecologist, Ph.D, Aquatic Ecology; M.S., Soil Science; B.S., Biology and Science Education

Not all data used in the EcMP were generated from field work. Some modules required the services of offsite laboratories to provide the data presented in this document. These laboratories are:

- Natural Resource Ecology Laboratory, Colorado State University, Ecosystem Functions

- SECA Inc., University of Northern Colorado, Soil Invertebrates

- Global Geochemistry, Water Chemistry

- Ecosystem Testing and Design, Aquatic Biology

- $\quad$ Entomology Department, Colorado State University, Terrestrial Arthropods

Each of the technical modules has been briefly summarized in the following pages to provide an outline on module activities and accomplishments. The Appendices which follow this section contain detailed module information for readers desiring a more complete explanation of technical activities. References cited in the following paragraphs may be found in the corresponding Appendix. 


\section{A) ECOSYSTEM FUNCTIONS}

Ecosystems comprise biotic (individuals, populations and communities) and abiotic (soil minerals, water, soil organic matter) components. Ecosystem studies generally discuss either biotic components or ecosystem processes, but not both. Ecosystem processes, called functions in this report, include energy transformations, nutrient cycling, soil development and organic matter turnover. Ecosystem functions are included in the ECMP to balance the population and community approaches of the other modules and because processes can be sensitive indicators of subtle changes not reflected in populations and communities. Ecosystem functions also integrate all the changes in individuals, populations and communities because every individual participates in some way in each process.

Objectives for this study are to establish baseline concentrations for undisturbed areas, to describe natural differences between biotic communities, locations, seasons and years, and to provide benchmarks to assess revegetated areas when remediation and restoration are completed. A related goal is to evaluate the potential of ecosystem function measurements, which are inexpensive and sensitive, to be indicators of ecosystem health.

Other EcMP modules measure populations, communities and selected abiotic factors. Responses to perturbations, either natural or anthropogenic, must be evaluated consistent with their normal variations in time and space. We believe that these ecosystem-level measurements, together with concurrent studies at lower levels of organization, will allow us to interpret ecological patterns at RFETS.

The 12 EcMP permanent sites (TR01-TR12) were sampled. One sample was collected at each of five permanent transects within each site. Each sample consisted of five subsamples.

Results presented in this report include particle size distribution, total organic carbon (C) and nitrogen (N), microbial biomass carbon and nitrogen, potentially mineralizable carbon and nitrogen, fine particulate organic carbon and nitrogen, and some associated abiotic parameters. Results obtained, but not yet completely analyzed, included estimates of denitrification, dinitrogen fixation and rates of carbon dioxide and methane production under both anaerobic and aerobic incubation.

All data represent the top $10 \mathrm{~cm}$ (4 inches) of soil only. Characteristics of deeper soil layers are important to plant growth, water and soluble contaminant movement and other aspects of ecosystem processes. Nevertheless, attention is focussed where most of the soil organic matter is found, and where most of the $\mathrm{N}$ mineralization, soil respiration, decomposition and other biological processing are concentrated. Most contaminants, where they are of concern, are spilled on the soil surface. Knowledge of populations, microbial biomass and processes in the surface soil layer is essential to monitoring any ecosystem.

Soil texture (particle size distribution of the particles smaller than $2 \mathrm{~mm}$ ) controls many ecosystem functions: plant growth, organic matter decomposition, microbial biomass, soil respiration. Soil texture tended to become finer moving from xeric to mesic to riparian to reclaimed sites. This trend also moves downslope and away from the mountains. All of the soils contained a significant volume of coarse fragments. Because these fragments prevented measurement of bulk densities, only the most general extrapolations from concentration to unit area can be made.

Soil organic $C$ and $N$ are the largest reservoirs of $C$ and $N$ in any ecosystem. These measurements include all of the active pools and the less-active organic matter. Rough calculations suggest that soil organic $C$ ranges from $20 \mathrm{Mg}$ per hectare (10 tons per acre) in riparian sites to $50 \mathrm{Mg}$ per hectare (25 tons per acre) in xeric sites. Soil organic $N$ ranges from $2000 \mathrm{~kg}$ per hectare (1 ton per acre) to $5000 \mathrm{~kg}$ per hectare (2.5 tons per acre). This is sufficient organic matter to sustain healthy ecosystem functions in all communities and to provide the nutrients for the plant community. Often, there were greater differences between sites or between watersheds than between comrnunities. Spatial heterogeneity between field sites is substantial, but was not explicitly addressed by the current sampling design. 
Microbial biomass $\mathrm{C}$ and $\mathrm{N}$ concentrations also reflected spatial heterogeneity. In xeric sites, the differences between Walnut Creek and Rock Creek were greater than any differences between communities in any watershed, or between average concentrations of any two communities. On average, based on rough estimates of bulk density, the top $10 \mathrm{~cm}$ of soil contained about $2000 \mathrm{~kg}$ per hectare ( 1 ton per acre) of microbial biomass. These sites were chosen to avoid any potential effects from Site activities. Individual locations can be quite different from each other, but all EcMP sites appear to contain healthy amounts of microbial biomass.

Potential $C$ and $N$ mineralization were measured in the laboratory after a 1 -week preincubation. Like total organic $\mathrm{C}$ and $\mathrm{N}$ concentrations, respirable $\mathrm{C}$ concentrations varied substantially between sites. Communities in Walnut Creek differed more from each other than those in Rock Creek. Communities were most similar to each other in Woman Creek. Average mineralizable $\mathrm{N}$ concentrations were higher in Rock Creek than in Walnut Creek because of spatial heterogeneity. Xeric sites had higher concentrations of mineralizable $\mathrm{N}$ than mesic or riparian sites. Mineralizable $\mathrm{N}$ concentrations, but not respirable $\mathrm{C}$ concentrations were much lower in reclaimed sites. Reclaimed sites appear to have qualitatively different soil organic matter even after 20 years in grass.

Fine particulate organic $C$ and $N$ are the total organic $C$ and $N$ in sand-sized particles. Sand-sized particles are larger than $53 \mu \mathrm{m}$ but smaller than $2 \mathrm{~mm}$. This part of the soil organic matter is thought to be quite decomposable. Differences between communities and between native soil and previously farmed soil (reclaimed) might be principally in this size fraction. Our results show than xeric sites had the highest concentrations and reclaimed sites had the lowest, but differences were not dramatic. These data also show a high degree of spatial heterogeneity.

To find out if differences in concentrations of active organic matter represented qualitative differences, active fractions of total organic $\mathrm{C}$ and $\mathrm{N}$ were calculated. The only active fraction that had a communityby-watershed interaction effect significant at less than $\alpha=0.05$ was Respirable $C$. This interaction resulted from Walnut Creek riparian sites having more total organic $C$ in respirable $C$ fractions than any other community in any other watershed, except mesic sites in Woman Creek.

Communities differed from each other significantly in the fractions of their organic matter that occurred as microbial biomass $\mathrm{C}$, but not microbial biomass $\mathrm{N}$; and in mineralizable $\mathrm{N}$, but not respirable $\mathrm{C}$. Watersheds differed significantly in the fractions of their organic matter that occurred as microbial biomass $\mathrm{C}$ and $\mathrm{N}$; and in respirable $\mathrm{C}$, but not mineralizable $\mathrm{N}$. The biological significance of the statistically significant differences between watersheds is not clear. They apparently resulted from inherent spatial variability.

Organic matter in reclaimed soil might be qualitatively different from soil in the other treatments, although it has been a grassland for 20 years. A larger fraction of its total organic $C$ is found in microbial biomass, but a smaller fraction is in fine particulate organic matter. A smaller fraction of the total $\mathrm{N}$ was mineralized in laboratory incubations in reclaimed sites than in any other sites.

Reclaimed sites were probably similar to the mesic grassland sites before they were plowed and planted to small grains. They have similar slope positions, aspect and general soil properties. If the soils were initially similar, they were fundamentally changed by agricultural activities and have not returned to their original state after $\mathbf{2 0}$ years in grass. The changes apparently do not reduce the ability of the ecosystem to support plant and animal life or to prevent wind and water erosion.

It is encouraging to think that these measurements can provide a very sensitive indication of ecosystem disturbance. Perhaps they will be sensitive enough to allow clear demonstrations of no effects from disturbances or contaminants. This has been a very difficult thing to establish for relatively clean sites, which are common at the Site. 


\section{B) TERRESTRIAL VEGETATION}

The diversity of plant communities associated with the Site are a result of the ecotonal effect found along the Front Range of Colorado. The mixing of prairie and foothills species in the diverse habitats provided by the varied physical environment has resulted in a vegetational mosaic which is rapidly disappearing as human encroachment along the Front Range continues.

Plant distribution, composition, and abundance are influenced by many environmental factors. Local climate, topography, and geology affect abiotic factors such as light, temperature, moisture, and nutrients, which in turn directly affect plant growth. In addition, biotic factors such as competition, herbivory, availability of pollinators, and nitrogen fixation by bacteria, interact with the abiotic factors to create habitats. Plant survival in these habitats depends upon the availability of natural resources necessary for them to grow and reproduce. The spatial and temporal variation of biotic and abiotic factors found at the Site allow for the diversity of distinct plant communities found here. Additionally, the human impact at the Site, involving physical disturbance and/or contamination of soils and groundwater, interacts with the preexisting biotic and abiotic factors to modify plant habitats in measurable ways.

The objective of this study is to characterize and monitor changes in the composition, distribution, and production of plant species within the major plant communities located at the Site. In addition, the information gathered can be used to assess qualitative and quantitative changes in the vegetation resulting from human activities and/or natural disturbances and processes occurring at the Site.

During the 1994 field season, EcMP personnel collected terrestrial vegetation data during two sampling sessions. The first occurred in the spring, from May 3 through May 25. The second sampling session ran from August 8 through October 4. Twelve permanent sites, each with five 50-m long permanent transects were sampled. At the riparian sites, these transects were halved, with one half on each side of the stream channel. Three different sampling methods were employed during 1994. The spring sampling consisted of only belt transect sampling for species richness at all 12 EcMP sites. For the late summer sampling, three different methods were used at the nine grassland study sites: belt transect, point-intercept transect, and production plot. This provided data on species richness, cover, and biomass production. Sampling at the three riparian sites during the late summer differed frorn the grasslands in that no production plot data were taken. Data were entered into electronic files and quality assured for accuracy and then reduced and analyzed.

A total of 271 plant species in 51 families and 73 genera were recorded from the 12 EcMP sites in 1994. Twenty-one previously unreported species from the Site were documented for the Site in 1994. Results showed that differences in species richness occur between the sites and communities sampled. Species richness increases along a hydrologic gradient from xeric to mesic to hydric. Associated with this increase in species richness however, is a decrease in the percentage of native species along the same hydrologic gradient. Significant differences ( $\alpha=0.05$ level) were found for vegetation, rock, and bare ground cover between sites. A mesic site, TR04, had the highest vegetation cover of all the sites. Significant differences ( $\alpha=0.05$ level) were also found for vegetation, litter, rock, and bare ground cover between communities. Vegetation cover was highest in the mesic community and least in the reclaimed community. Significant differences ( $\alpha=0.05$ level) were also found between sites for current year production and litter amounts. Current year production between the mesic and reclaimed communities was also found to differ significantly ( $\alpha=0.05$ level), with the reclaimed community having the higher mean production values. No significant differences ( $\alpha=0.05$ level) were found between communities for litter mass.

The xeric community had the highest native species richness and the highest biomass value produced by native species. The data also revealed that two plant associations make up the xeric community as studied by EcMP personnel. An Andropogon scoparius association best describes TR01 and a Stipa comata-Bouteloua gracilis association best describes TR06. TR12 seems to be intermediate between the two. The larger presence of Pleistocene tallgrass prairie relict species (Andropogon scoparius, 
Andropogon gerardii, Sorghastrum nutans, Sporobolus heterolepis) found on the Rocky Flats Alluvium at the western edge of the Site suggests that there is a greater moisture availability for plant use there than on the eastern edge of the alluvial deposits. The eastern edge of the alluvium has very little of the tallgrass species and an abundance of Yucca glauca. The presence of the tallgrass prairie relict on the Site, which has been identified as a habitat of special concern in the state due to its rarity, warrants its protection from disturbance as much as possible.

The mesic community is more uniform than the xeric community, being predominantly an Agropyron smithii-Bouteloua gracilis association. Although this association is present, its quality varies considerably across the Site. Cover and biomass amounts in the mesic community have become dominated at some sites by Bromus japonicus, an annual cheatgrass, along with large amounts of other non-native species. Only $63 \%$ of the total biomass produced in the mesic community is from native species. The competitive influences of the non-native species present suggests that continuing study is necessary to determine if these species are expanding their ranges and displacing native species.

The reclaimed community, formerly agricultural land, is an artificial community which remains dominated by the non-native, planted perennial grasses, Bromus inermis and Agropyron intermedium. These two species account for $80-100 \%$ of the vegetation cover and $95 \%$ of the current year production biomass at these sites. The reclaimed community has the least amount of basal vegetation cover of all the communities studied. Attempts could be made to convert this community back to a more native, mesic mixed grassland by seeding with native species or to evaluate successional trends.

The riparian community is the only community with any real vertical stratification monitored at the Site. The canopy is primarily Populus deltoides-Salix amygdaloides with a shrub layer of Salix exigua and Amorpha fruiticosa. The herbaceous layer is primarily Juncus balticus, with locally high amounts of Carex nebraskensis and Poa pratensis. It has the highest species richness of all the communities, but also has the lowest percentage of native species (excluding the reclaimed community).

Results of the ordinations and classification analyses based on species presence/absence data, reveal differences in the community types studied by EcMP. The individual communities were shown to cluster individually. Variations within the communities were also detected. Most noticeably was the association of TR06 (a xeric site) with the mesic community. The success of these analyses in distinguishing differences between the EcMP sites, demonstrates the applicability of the analyses to remediation and revegetation efforts on Site. The analyses will be able to associate remediation areas to reference sites, providing information for remediation seed mixes and other information pertinent to successful revegetation, as well as providing continuing information on the success and progress of remediation activities.

\section{C) SMALL MAMMALS}

The primary objective of the Small Mammal study module is to assess the dynamics of small mammal populations at the Site and the relationship of these populations to specific habitat characteristics in order to determine if populations have been affected by Site activities and to provide guidelines for reclaiming sites which have been disturbed. The Small Mammal report is broken into three sections: small mammal capture, habitat characterization, and Preble's Meadow Jumping Mouse (Zapus hudsonius preblel) (PMJM) studies (including PMJM habitat characterization). Capture information is used to determine the diversity, abundance, and distribution of small mammals at the Site. Small mammals can be good indicators of contaminants because they occupy small home ranges, live in close contact with the soil, and consume a variety of foods. They are also a primary food source for predators. Habitat characterization of successful and unsuccessful trapsites was conducted to determine habitat preferences of the Site's small mammal populations. The PMJM is a state species of special concern and a petition to list it as threatened or endangered under the Endangered Species Act was submitted to the U.S. Fish and Wildlife Service in the Fall of 1994. The PMJM study was implemented to determine if sympatry exists between 
PMJM and Zapus princeps (Western Jumping Mouse) and to perform a status survey of PMJM on the Site.

Small mammal trapping occurred from April 19, 1994 to May 5, 1994 and from October 4, 1994 to October 20,1994 . Both sampling sessions followed the procedures presented in the EcMP Program Management/Technical Performance Report, 1993, Appendix 16, and occurred on all 12 permanent terrestrial sites. Longworth live traps were used during both sessions making the 1994 data comparable to the Fall 1993 data. The Spring 1993 data were collected from 9 of the 12 sites using Sherman live traps which do not capture as many species or as many individuals as the Longworth traps (EcMP 1994 Report). Habitat data were collected from stations where only the Deer Mouse (Peromyscus maniculatus) were captured and were compared to trapsites where no small mammal was captured. All data were collected by EcMP personnel. Four-hundred and twenty-three individuals of 9 species were recorded during the Spring session and 661 individuals of 11 species were recorded during the Fall session. Habitat data were collected at 233 trap stations. Two new species were documented for the Site, the Plains Pocket Mouse (Perognathus flavescens) and the House Mouse (Mus musculus). The Deer Mouse (Peromyscus maniculatus) was the most common small mammal in all habitat types and during both trapping sessions. It was the only species present in high enough numbers for age and sex ratio calculations. The highest small mammal populations were found in riparian community complex sites and the lowest were found at reclaimed grassland sites. Higher populations were found in the Fall than in the Spring. The difference in number of individuals captured in 1993 and 1994 was not statistically significant.

Several statistical analyses were performed on the Habitat Characterization data to determine if any statistical differences between successful and unsuccessful trap stations occurred. A variety of plant species showed an association with either successful or unsuccessful trap stations but these species had little in common and the associations appeared to be purely random. This is probably because the Deer Mouse, the only small mammal species for which habitat characterization was performed, is a generalist and is capable of exploiting nearly every habitat in the Site's Buffer Zone. Significant correlations emerged between three of the physical characteristics measured at each trap station, distance to canopy edge, siope angle and slope aspect, indicating that they may be redundant measurements.

During the summer of 1994, 34 captures of 23 PMJM individuals were recorded. All of these captures were recorded during a study which focused on capturing PMJM by placing a fairly high density of traps in areas of prime habitat. The data indicated a preference of PMJM for areas near streams which have abundant Salix exigua and Symphoricarpos occidentalis and in the vicinity of mesic mixed grassland vegetation. The data also suggest that PMJM are not discouraged by the presence of weeds such as Canadian thistle (Cirsium arvense) and Japanese brome (Bromus japonicus) and may even have an affinity toward them.

\section{D) AQUATIC ECOLOGY}

The EcMP Aquatic Ecology Module had three main objectives for the 1994 season: 1) long-term ecological monitoring, 2) bioassessment of Walnut Creek, and 3) tissue sampling for the Woman and Walnut Creek Drainages and offsite reservoirs. This section is devoted primarily to the reporting and discussion of the aquatic ecological monitoring program. Results and discussion of the bioassessment are available in Wright Water Engineers, Inc. (1995). Results and discussion of the tissue sampling study are available in EG\&G (1994).

Four major biological components of aquatic systems were sampled; macrobenthic invertebrates (insect nymph and larvae), phytoplankton (algae), zooplankton (diatoms and other microscopic animals), and emergent insect (adult mayflies, mosquitoes, etc.) populations. Abundance, taxonomic composition, and taxonomic richness were the main parameters measured from each. The sampling season was from April through September, 1994. A total of 346 biological samples were taken. 
For macrobenthic invertebrates overall, sites differed in the number of macrobenthic families collected regardless of sampling method $(p=0.0001)$ and no sampling method stood out from the others in capturing more or less macrobenthic families.

Analysis of phytoplankton samples shows that community composition and relative abundance of algae varies widely between ponds, evén those ponds closely in series to one another. No two ponds are more than $65 \%$ alike in the composition of algal genera. Overall, Cyanophytes were the most abundant algae on the Site, making up $47.1 \%$ of the algae sampled.

There was a highly significant difference in zooplankton taxonomic richness and emergent insect taxonomic richness between sites $(p=0.0000)$. Pond $D-2$ was significantly greater than most other sites in zooplankton richness.

In the A-Pond series, there was a statistically significant decline in macrobenthos richness from Pond A-1 (upstream) to Pond A-4 (terminal pond), as determined by the core method. This trend was not observed in any other pond series or with any other biotic community. The core method proved to be the most reliable and sensitive sampling method of several methods tested. The surber and the drift net method are both dependent on flowing water and would therefore be limited to sampling in streams. The handpicked dip net method is designed to be a surface sweeper and would not accurately sample mud and gravel bottoms. There could be any number of reasons for the decline of macrobenthic invertebrates in the A-series ponds. Pond A-1 is partly fed by a seep that could account for a healthier aquatic environment. A limiting factor to macrobenthic invertebrate taxonomic richness may be industrial practices that progressively degrade the ponds. Further analysis of this trend is warranted.

A survey of the macrobenthic invertebrate taxa sampled from Pond D-2 showed that approximately $60 \%$ were pollution intolerant and only $30 \%$ were facultatively intolerant (EPA, 1973). A survey of the macrobenthic taxa sampled from Pond A-2 showed that equal numbers (33\% each of the total taxa collected) were pollution intolerant and facultatively intolerant (EPA, 1973). A facultatively intolerant organism has inherent characteristics or demonstrates a facility for tolerance to pollutants under certain conditions such as water temperature, dissolved oxygen level or the presence of the pollutant at a particular point in the life cycle. An intolerant organism is sensitive to pollution and shows no facility to tolerate the contamination under most circumstances.

The composition and enumeration of emergent insects were studied from Site ponds. The sum of all individuals within the orders Ephemeroptera, Plecoptera, and Tricoptera was divided by the sum of individuals within the Chironomidae family to create the biotic EPT/C index. The EPT/C index was calculated for every sample taken as a representation of aquatic ecosystem health. Pond D-2 is a potential reference pond for aquatic ecological studies. It has the highest mean value for the EPT/C index (2.172) of all the ponds, which is directly correlated to the presence of all four target taxa (Ephemeroptera, Plecoptera, and Tricoptera orders and the Chironomidae family). Although D-2 does not show the highest value for macrobenthic invertebrate family richness (13.4), an analysis of the taxonomic composition of families reveals a comparatively well balanced ecosystem.

Site phytoplankton (algae) were analyzed for composition and abundance. Cyanophytes decreased in A4, B-5, and D-1 from 1993 to 1994, while Chlorophytes increased in D-1, Chrysophytes increased in B-5, and Euglenophytes increased in A-4. Chlorophytes replaced Cyanophytes in D-1. Seasonal algal fluctuations called blooms are dependent upon nutrient availability (nitrates, phosphates) and other limiting factors such as $\mathrm{pH}$, temperature and available sunlight. An increase in the frequency of sampling at different times of the growth season is necessary to understand what limiting factors are primary in seasonal taxonomic richness.

The most diverse OU site for overall biotic community composition is Pond A-2 (mean of 57.4 biotic taxa sampled). The most diverse reference site is Pond D-2 (53 biotic taxa). The least diverse OU site is B-4 (25.2 taxa). The fact that an OU site is slightly more diverse than a reference site would seem to indicate 
that the effects of contamination in the OU ponds are not a major consideration. However, this is probably more a reflection of the many variables that affect biotic cornmunity composition and indicates the difficulty in determining the extent of damages to biotic communities from Site activities.

EcMP's use of the EPT/C index is to compare this metric with other indicators and to perform analyses of a composite of the Site's aquatic profile. A ranking can be derived from the ratio of the target site EPT/C index value to a reference site EPT/C value and then multiplying the ratio by 100 (EPA, 1989). To receive a top score of 6 the result must be $>90 \%$. To receive a minimum score of 3 the result must be between $70 \%-90 \%$. Any result $<70 \%$ is scored 0 . When using Pond D-2 as the reference site, Pond $\mathrm{B}-1$ was the only pond to receive the minimum score of 3 with a ratio of $86.37 \%$ (Table D-14). Pond B-2 was only $10.13 \%$, followed by $A-1(3.6 \%), B-3(0.46 \%), B-4(0.32 \%), A-2(0.14 \%)$ and $A-3(0.09 \%)$. To test the integrity of this method, the ratios were re-calculated by alternately using ponds $A-2, B-1$, and streamsite BD1 (as the designated reference site). With Pond A-2 (the most diverse pond onsite) and Pond B-1 as the reference sites, all scoring results were either 0 or non-applicable. Pond $A-3$ (with a $66.7 \%$ ratio) came the closest to a non-zero score when compared with A-2. When site BD2 was used as the reference site, site GW3 had a score of 3; other streamsites scored 0 . This calculated ratio method was used in Wright Water Engineers (1995) bioassessment study. Results from that paper and from the above ratio calculations indicate that this ratio method is most effective as a bioassessment value when used strictly on streamsites, and not ponds. The EPT/C index value by itself seems to be a good overall indicator of aquatic ecosystem health when used in conjunction with other analyses, such as ANOVAs, Ttests, Jaccard coefficient of similarity, and Pearson's correlation coefficient. However, the use of this index to calculate a ranking value is probably not appropriate for the Site, due to the nonrepresentative status of the reference sites.

For remediation purposes, EcMP staff can provide DOE and regulatory agencies with information on the spatial and temporal variability of Rocky Flats biotic aquatic systems and how these resources will respond to present or future stressors, either natural or anthropogenic. Following remediation, monitoring efforts could focus on the aquatic community successional changes of the pond ecosystems.

\section{E) SOIL INVERTEBRATES}

Soil invertebrates are common, numerous, and massive components of terrestrial ecosystems, and play several important roles. They affect biological, chemical, and physical soil properties, primarily by their relationships with bacterial and fungal communities, litter comminution, and maintenance of soil structure (Dindal, 1990). Soil invertebrates include earthworms, mites, insects, protozoa, nematodes, flatworms, and several other forms. They range in size from microns to centimeters in length, and numbers may run from a few to millions per gram of soil. They are particularly useful organisms for biologic monitoring purposes because their abundances are relatively easy to measure, they are in intimate contact with soil particles, soil water and contaminants, and they exhibit a wide range of trophic groups that are affected by soil perturbations.

The objectives of this study included:

1) To characterize the taxa and functional groups of soil invertebrates from several terrestrial vegetation communities and determine sources of variation that affect seasonal, annual, and long-term changes in each community. This information can be used to assess the structure of invertebrate communities associated with native vegetation and anthropogenically disturbed sites. At this time, data are only available to assess differences in community structure. Annual and long-term variations will be determined as more data are collected and analyzed.

2) To determine if the Site has a unique soil fauna when compared to other offsite areas. It is anticipated that offsite data will not be collected until summer 1995, at the earliest. 
3) To determine if soil faunal community structure can be correlated with other biological indices, such as ecosystem functional measurements and vegetation species diversity. In this way a conceptual model of the Rocky Flats ecosystem can be refined, and the relationships between populations, communities, and processes clarified.

Invertebrates were collected from three major taxonomic groups: protozoa, nematodes (roundworms), and arthropods.

Soil invertebrate samples were collected from 12 terrestrial sites (Figure 1) in August and September of 1993. Three-hundred forty soil invertebrate samples were collected from the 12 EcMP sites. The sampling at a single site consisted of a separate arthropod sample at two different depths and a protozoa + nematode sample at both depths; samples were composited from five transect locations on the EcMP terrestrial sites. The north and south sides of riparian areas were sampled separately because all variables measured were expected to have greater variation than grassland sites. Living organisms were extracted from samples, identified, and enumerated. Laboratory data for the 1993 session became available in late 1994 and early 1995.

Protozoa samples were identified and enumerated to three phyla or subphyla: ciliates, flagellates, and amoebae. Organisms were plated in a dilution series and enumerated by a most probable number technique.

Nematodes were dynamically extracted, enumerated, and classified into four functional groups: bacterial feeders, fungal feeders, omnivore/predators, and plant parasites.

Soil arthropods were also dynamically extracted, enumerated and identified into several functional groups and taxa divisions. Analyses were conducted primarily on the functional groups.

Statistical tests were conducted to determine if there were significant differences between invertebrate counts in: 1) terrestrial community types (mesic mixed grassland, xeric mixed grassland, reclaimed grassland, riparian north, and riparian south); 2) the EcMP sites, and; 3$)$ the two sample depths (0-5 and $5-10 \mathrm{~cm})$.

For protozoa, surface horizons are dominated by amoebae and flagellates, with mean values of 6799 and 6776 organisms $\mathrm{g}^{-1}$ soil, respectively (all samples). Ciliates are much less abundant, with a mean of 34 ciliates $\mathrm{g}^{-1}$ soil. These data are extremely variable, especially the amoebae and flagellate data, with ranges from a few dozen to values in the tens of thousands. These same general relationships hold for the subsurface horizon, except that all counts are less than the surface horizon (5126 amoebae $\mathrm{g}^{-1}$ soil, 5269 flagellates $\mathrm{g}^{-1}$ soil, and 14 ciliates $\mathrm{g}^{-1}$ soil, all samples).

Surface horizon mean nematode numbers were dominated by the bacterial and fungal feeder functional groups (4846 and 4264 nematodes $\mathrm{g}^{-1}$ soil, respectively, all samples). Mean plant parasite counts were ranked next highest ( $988 \mathrm{~g} \mathrm{~g}^{-1}$ soil ), followed by omnivore/predators $\left(803 \mathrm{~g}^{-1}\right.$ soil ). On the average, a single gram of dry soil ( $0-5 \mathrm{~cm}$ depth) harbors approximately 10,901 nematodes. Average subsurface nematode functional group distribution follows the same general trend, except that bacterial feeder, fungal feeder, and plant parasite numbers all diminish with depth; omnivore/predator counts are relatively insensitive to depth. Subsurface means are 3848 bacterial feeders $\mathrm{g}^{-1}$ soil, 3147 fungal feeders $\mathrm{g}^{-1}$ soil, 485 omnivore/predators $\mathrm{g}^{-1}$ soil, and 982 plant parasites $\mathrm{g}^{-1}$ soil.

Surface horizon mean functional group arthropod numbers were dominated by the total fungivore group, with 3645 fungivores $\mathrm{m}^{-2}$, all samples. Small detritivores (detritivore 1 ) were the fewest in number (mean $140 \mathrm{~m}^{-2}$ ), but total detritivores were numerous (mean $1704 \mathrm{~m}^{-2}$ ). Total predators were the fewest of these three functional groups (mean $874 \mathrm{~m}^{-2}$ ), as expected. Within surface horizon mite taxa, the Prostigmata were the most numerous (mean $\left.3209 \mathrm{~m}^{-2}\right)$, and the Astigmata the least $\left(207 \mathrm{~m}^{-2}\right)$. These same relative 
relationships hold for the subsurface horizon, but all functional group and taxa counts were fewer than the surface horizon.

Seventeen separate functional group variables were analyzed for community differences. Eleven of the 17 variables showed a significant community effect; 3 of the 11 significant variables also showed a significant depth by community interaction, so that statements regarding the main effect of community cannot be made about those three analyses. Significant community effects were found for amoebae, flagellates, and six arthropod functional groups (none of the nematode functional groups showed a significant community effect). The reclaimed grassland community type showed surprisingly high arthropod predator and herbivore means, being statistically different at the $\alpha=0.10$ level than almost all other community types. It appears that this community type can be distinguished from all others by these variables. The riparian North community type had the highest mean protozoa counts; the flagellate riparian North type was significantly different than mesic and xeric grassland types, and the amoebae riparian North type was significantly different than the mesic type. Riparian community types were also higher for all arthropod detritivore functional group means than the other community types. The riparian South type could be distinguished from all grassland types by Detritivore 1 and Total Detritivore functional groups. Several other arthropod functional groups that did not show a statistically significant community effect also had the highest mean counts in these types (fungal feeders 1, total fungivores, and general predators). Thus, it appears that in general, riparian community types often have the highest protozoa and arthropod populations, which are statistically different in some cases from all grassland community types.

Site was explored as a factor to determine if the 12 EcMP sites could be distinguished from one another through several functional variables. Seventeen functional group analyses were conducted for these taxa; 13 showed a significant site effect at an $\alpha=0.10$ level. This included two of the three protozoa, four of four nematode functional groups, and seven of the ten arthropod functional groups. Both Cryptostigmatid and Prostigmatid mite richness values also showed significant site differences. Protozoa showed a general site trend, with highest mean counts of amoebae and flagella in the TR05 sites (Walnut Creek), and the remaining sites clustered together. The TR05N site was significantly higher in flagellate counts than all grassland sites.

Nematode site means generally fell into two site groupings; group one consisted of a few sites that were significantly greater than all other sites, which constituted group 2 . A riparian site functional group mean was always ranked as one of the greatest 3 out of 15 possible site means for the 4 functional groups, and was also ranked as one of the lowest three mean values for 3 functional groups. Omnivore/predators were the only functional group that did not have any significant differences between any of the grassland sites. For fungal feeders, TR11 (a mesic community type) was significantly greater than TR01, TR02, TR03N and S, TR07, TR1ON and S, and TR12. A very similar relationship existed between TR11 and the other site means for bacterial feeders. Site TR07 mean plant parasitic nematode counts were significantly greater than most other grassland sites and two of the riparian sites as well. These data illustrate that sites within a particular community type can have significant differences in functional group counts, and that variation between sites within a community type may exceed sites between community types.

Arthropod functional groups had more consistent site differences than did nematode functional groups. Site differences were often due to one or more riparian sites that had higher mean values that were significantly different than all other sites. Arthropod predators were the only functional group that had a significant difference between grassland sites (TR07 was significantly greater than four other grassland sites).

These data have applicability for activities at the Site in several ways. The most obvious application is to determine if adverse ecological effects have occurred as a result of Site activities, such as construction, remediation, or accidental contamination. In the injury definition section of Natural Resource Damage Assessment guidelines (43 CFR 11.62), "concentrations in the soil of substances sufficient to cause a toxic response to soil invertebrates" are specifically mentioned. These data are the beginning of the baseline information that is necessary to determine if injury has occurred. 
Means and $90 \%$ confidence intervals of several soil invertebrate functional group variables are available for some community types. For other community types where this resolution is not yet available, ranges and variabilities have been established that can guide interpretation of potential injury. For instance, if an area is damaged in some way where injury to ecological receptors is suspected (or claimed by Natural Resource Trustees), soil invertebrate measurements of the area may be taken. If the appropriate organism counts are below the known range of values for the Site, then injury may have occurred. If values fall within the Site range, ecologists may determine if comparisons to appropriate sites are available.

\section{F) RECLAMATION MONITORING}

Human disturbance of the landscape often results in removal of the native vegetation, either leaving the soil exposed to erosion or replaced by non-native, exotic species. This has resulted in large scale alterations to native ecosystems which were once present and often leads to the extinction of some components of localized floras. Environmental regulations and laws have become necessary to provide for revegetation of areas disturbed by mining, logging, and other activities which result in the loss of vegetation from the land. At the Site, a variety of activities occur which require remediation for disturbance and loss of the native vegetation.

The 881 Hillside is a southfacing slope in the Woman Creek watershed on the south side of the industrial complex at the Site. During 1991-1992, much of the Hillside was disturbed during the construction of the French Drain. As a result, a revegetation program was initiated to provide ground cover to stabilize the soil on the Hillside and reduce the potential for erosion. The objective of this module is to monitor the revegetation of the 881 Hillside (Hillside) since the area was disturbed by the construction of the French Drain.

During the 1994 field season, data were collected by EcMP personnel on the 881 Hillside from November 30 through December 22, 1994. Twenty-five, $50 \mathrm{~m}$ transects placed end to end were sampled across the Hillside in an east-west direction with the transects located generally perpendicular to the slope angle. Two different types of measurements were taken at the 25 transects: species richness and basal cover. The data were entered into electronic files and reviewed for accuracy. Data reduction, analysis, and interpretation were then done to determine the effectiveness of the revegetation effort.

The success of the revegetation effort thus far has been rather dismal. Of the 13 species seeded on the Hillside, only 6 were reported during the 1994 sampling and these only provided $3.5 \%$ of the cover on the Hillside. A total of 68 species from 19 families were reported from the Hillside, however only $48 \%$ of these were native species. Annual species represented $29 \%$ of the total Hillside species richness. Basal vegetation cover was only $14 \%$, up from $4.7 \%$ in 1993 . Litter provided the greatest amount of cover $(58.9 \%)$. Native species accounted for only $4.3 \%$ of the total vegetation cover on the Hillside. Annual species accounted for $91.6 \%$ of the Hillside's vegetation cover. The Hillside is dominated by two nonnative, annual species - Bromus tectorum and Alyssum minus. In addition, $63 \%$ of the species found on the Hillside are considered "weeds" and six species are considered to be either prohibited or restricted noxious weed seed producers by Colorado state law.

The mesic mixed grassland which provides a reference area for comparison of the Hillside data reveals that the Hillside has less than half the vegetation cover (14\%) than is found in the mesic grassland community (29\%). Bare ground on the Hillside (19.4\%) is 11 times that found in the mesic community $(1.7 \%)$. Species richness on the Hillside (68 species) is much less than that found in the mesic community (combined richness $=143$ species or mean richness $=102$ species).

The domination of the Hillside by annual species and the lack of success of the seeded species is a significant problem not to be underestimated. If this situation is not rectified, the Hillside will act as a weed seed source, spreading weed seed potentially downstream and downwind into the Woman Creek 
drainage. Studies have shown that the competitive influences of weedy annuals such as are present on the Hillside may prevent the natural recovery of native species and require extensive controls and management for the establishment of other native species. Dominance by annuals has also been shown to alter ecosystem functions. The conversion of sites to annual communities usually results in lower quality watersheds by increasing the potential for soil erosion and, typically, increasing the frequency of wildfires. One of the primary concerns on the Site is to limit the potential movement of plutonium in contaminated soils. The chief mechanism on Site for this has been identified as wind erosion. So it is important to maintain a good vegetation cover on the soils. The present state of the 881 Hillside compromises that position and should be dealt with in a timely manner. It is recommended that the Hillside be reseeded as soon as possible with a mixture of native, perennial grasses and forbs, similar to what are found elsewhere in the mesic grassland community on the Site.

\section{G) TERRESTRIAL ARTHROPOD MODULE}

The Terrestrial Arthropod Module was established in June, 1994 with the delivery of the Ecological Monitoring Program Final Terrestrial Arthropod Field Procedure, DOE (deliverable \#61405206-E). The first sample collections were conducted in August and Sepiember of 1994. A laboratory contract with Colorado State University was established in January, 1995 to provide expertise in the identification and enumeration of arthropods.

The objective of this study is to characterize the diversity and biomass of insects, spiders, and other above-ground terrestrial arthropods, collectively called terrestrial arthropods. Characterization of arthropods is conducted within and among vegetation communities. Data will be used to establish the natural variation in arthropod diversity among vegetation communities, document taxa richness by community types, and develop a listing of arthropod taxa present at Rocky Flats. A number of methods were tested to determine the most effective methodologies and equipment to conduct sampling.

Methods used to date have been sweep netting, beating trays, pitfall traps, and Malaise traps. All methods, with the exception of the beating trays, have worked well in gathering samples for taxonomic information (richness and diversity). Sweep netting methods have not provided adequate biomass samples, however. This may be due to the area sampled or the lack of moisture during the growing season (i.e., 1994 had below average rainfall). A new method for sampling biomass is being devised. It includes using D-vac samplers or a direct current insect vacuum, whichever is most effective and economical. This methodology is considered superior to sweep netting in that it samples a well-defined area, is easily replicated, and captures arthropods more completely when used properly. The deterring factor may be cost, however. Sweep netting is considerably less expensive, samples a larger area and collects a sample in less time. Field trials in 1995 (late summer) will determine the best method.

A total of 24 sweep net samples, 4 pitfall samples, and 4 malaise trap samples were collected from the 12 EcMP permanent sampling sites. Communities where arthropods were sampled were xeric, mesic, and reclaimed mixed grasslands, and riparian areas. All sampling was conducted adjacent to the permanent vegetation transects, previously described in the terrestrial vegetation section.

The laboratory contract requires samples to be delivered no later than June 16, 1995. Data from 13 samples were recently delivered, and are undergoing data quality control measures. Therefore, results from the 1994 field season will be reported at a later date.

Three sampling sessions are planned for 1995. During all three sessions, 32 samples will be collected for taxonomic analysis. A session will include 24 sweep net samples, 4 pitfall trap samples, and 4 Malaise trap samples. Sessions are planned for the following time frames:

- Session 1 - May/June (3-week period including a training day)

- Session 2 - July/August (2-week period)

- Session 3 - August/September (3-week period) 
Additionally, the third sampling session will include the collection of 24 biomass samples. The results from this effort will determine if biomass is a viable measurement for terrestrial arthropods at the Site.

\section{H) ECMP DATABASE}

The EcMP Database has been designed and developed as a tool for entering, assuring the quality of, and storing data collected under the EcMP. In addition, the database provides the flexibility to export data into software applications, such as FoxPro, StatGraphics, and Excel, for statistical analysis and manipulation. The software platform is $\mathrm{dBASE} I \mathrm{~V}^{1}$, version 2.0. This software runs on IBM and IBM compatible PCs. Database development began with the objective of capturing the data collected for the Terrestrial Vegetation Module. The database was initially designed and created in the spring of 1993 and was extensively revised and updated in summer and fall of 1994 to increase efficiency and accommodate other EcMP modules.

The data entry screens have been designed to minimize keystrokes, automatically input default values (either system or user-defined), and to limit entry choices to valid parameter values. Before, during, and after data entry, data undergo Quality Assurance/Quality Control (QAQC) to identify missing, incorrect, and inconsistent data. Data entry is menu driven, so that the user need not be familiar with dBASE IV to input data. The database is divided into discrete modules, or sections, that reflect the technical modules of the ECMP. Each database module contains one or more files that use a standardized set of data fields which store the information for that module. These fields are defined in a glossary that is distributed to all users and updated as necessary. Leads for each of the EcMP technical modules are responsible for adhering to the glossary when deciding on the content of new data files. All data files contain one or more standard fields that identify and describe the informational content of the file, such as date, location, and type of study. This consistency of data file design creates what is known as a relational database, allowing cross-referencing and dynamic retrieval of data for integrated analysis and reporting.

In 1994, the existing program code was simplified to improve the user interface and to conserve space on the computers. The revised code uses approximately $13 \%$ of the disk space that the original code occupied and is composed of about 100 fewer files. One reason for the dramatic difference between the old and new code is that both working and compiled program files of the old code were kept on the data entry computers, which doubles the number of files and approximately doubles the kilobytes used. In the interest of space and neatness, only compiled program files of the revised code were put in the data entry computers and all old program files were removed.

To accommodate changes in code, changes in field methods, and in the spirit of simplification, most of the existing data file structures were also revised. Several unnecessary fields were removed, some fields changed definition, and a few fields were added. This revision did not affect files containing data from previous sampling sessions, only subsequent data files reflect the change. Revisions do not affect data integrity and most improve Quality Assurance.

Documentation for the new code and file structures was begun in late 1994, and was completed in February, 1995. Documentation includes a revised User's Guide; hard copy printouts of all file structures, all program code, an updated field glossary, and a printout of program files involved and their interrelations.

After the code was modified for the existing database modules, Terrestrial Vegetation and Small Mammal modules, additional modules were added to accommodate other EcMP data. Reclamation Monitoring data and program files were added, Ecosystem Functions and Soil Physical/Chemical data files were added, and a weather data submodule to the Small Mammal module was added.

\footnotetext{
${ }^{1} \mathrm{dBASE}$ and dBASE IV are registered trademarks of Borland International, Inc.
} 
Ecology and Watershed Management (EWM) was assigned a Computer Systems Security Officer (CSSO) in August to comply with EG\&G Computer Security Policy. The CSSO classified the EcMP database archive computer as "Mission-essential" because it is the sole location for the complete EcMP database. Mission-essential is defined as data and/or data systems that are determined to have a high importance related to accomplishing a DOE mission and therefore requires a greater degree of protection than non-essential systems (EG\&G, 1994). Loss or corruption of all or part of the EcMP database could adversely affect EG\&G's ability to comply with DOE Order 5400.1 .

Security measures taken to protect the EcMP database are documented on the Certification for Level 1 Unclassified Sensitive Systems form for this system. These basic security measures are deemed sufficient as the data contained within the EcMP database are considered Unclassified Non-sensitive information.

Backups of the EcMP database are performed weekly. Backup copies of the database programming code, data files, and related files are sent in a compressed form via a direct connect MODEM to a subdirectory of the Rocky Flats Environmental Database System (RFEDS) computer mainframe ("Hobbes"). This subdirectory is itself stored onto tape on a weekly basis. These tapes are stored in a locked cabinet at EG\&G's Interlocken offices.

EWM was asked by the Environmental Restoration Program Division (ERPD) in October, 1994 to create a Sitewide Ecological Database (SED) for the Site. The purpose of the SED is to support environmental management and remediation efforts for the Site. The goal of EWM in doing this project is to compile, organize and review the quality of relevant ecological data in order to facilitate the retrieval and analysis of these data for scientific and regulatory compliance purposes.

Much of the existing ecological data have been stored in smaller databases, individual diskettes, or only in hard copy format scattered throughout the different divisions and branches of EG\&G and several subcontractors. Relevant data sources include the Environmental Evaluation (EE) studies conducted separately for each Operable Unit (OU), the "Baseline Biological Characterization of the Terrestrial and Aquatic Habitats at the Rocky Flats Plant" (hereafter referred to as "the Baseline study"), the EcMP and the Natural Resource Policy Compliance Program (NRPCP). The SED will help promote consistency between OUs, employ proper quality controls, and allow for the implementation of data usability criteria. Data will become much more readily available for retrieval and analysis by interested parties and will be securely stored within the RFEDS.

The "Rocky Flats Plant Comprehensive Risk Assessment (CRA) Scoping Document" (July 26, 1993) states that OU EE and sitewide monitoring data will serve as the primary data sources for the Comprehensive Risk Assessment (CRA). However, this document notes that OU field study methodologies are inconsistent, data gaps exist, and that retrieval of data currently in RFEDS is difficult and labor intensive. Therefore, one of the objectives of the CRA is the development of a database management system that will facilitate the recognition of data gaps, the retrieval of existing data, and the consistency of future measurements. The SED will fulfill this objective in regards to ecologically relevant data.

The DOE Data Quality Investigation of the Rocky Flats Environmental Restoration Program (December, 1994) noted that there is a general deficiency in Quality Assurance (QA) implementation of the OU EEs. The creation of the SED is a direct response by ERPD to the audit. The SED will provide a level of QA/QC and format consistency previously absent among the EE data.

The Baseline Study was completed September 1992 and served as the initial comprehensive study of Rocky Flats biota and associated habitats. The ECMP and NRPCP are ongoing programs that are directed by DOE Order 5400.1 and 10 CFR Part 834. The data from the two programs are contained in two separate databases with different formats and levels of QA. Integrating these databases as well as 
the data derived from the Baseline Study would greatly facilitate analysis and interpretation of the ecological state of the Site Buffer Zone.

The ECMP database coordinator has designed the structure of the SED, written the Statement of Work subcontracting data compilation and transformation to the S. M. Stoller Corp., is acting as the Contract Technical Representative (CTR) in supervising Stoller personnel, and is working in cooperation with RFEDS/Information Resources (IR) personnel in implementing the SED into the RFEDS system. Once the SED is completed, EWM may remain the point of contact for data search and retrieval requests by other groups or agencies.

Initial organization meetings were held with DOE and RFEDS/IR personnel December 7. The S. M. Stoller Corp. was awarded the contract to locate and transform existing relevant ecological data for the SED on December 6 and a kick-off meeting was held with Stoller personnel December 9. In accordance with the contract, Stoller personnel have delivered the three original deliverables, the "Prototype Data Set," the "Main Data Set," and the "Remaining Data Set." A third task, with a fourth deliverable was added to the contract on April 20,1995. This additional task requires Stoller personnel to assimilate all existing spatial coordinates of ecological sample sites into a location look-up data file and deliver it to the EG\&G CTR by June 1, 1995. The contract was extended for this task, and will now expire on May 31, 1995.

As of May, 1995, RFEDS/IR personnel, in cooperation with the EcMP database coordinator, have completed the SED Functional Requirements Document, an approved schedule for completing the SED, and initial organizational diagrams for the SED. The SED is expected to be ready to receive the data provided as deliverables from Stoller by August, 1995.

\section{REFERENCES}

DOE. 1994. Data Quality Investigation; Rocky Flats Environmental Restoration Program. U.S. Department of Energy, Oak Ridge Operations, Oak Ridge, TN.

EG\&G, Rocky Flats, Inc. 1993. Rocky Flats Plant Comprehensive Risk Assessment (CRA) Scoping Document. U.S. Department of Energy, Rocky Flats Plant, Golden, CO.

EG\&G, Rocky Flats, Inc. 1994. Handbook For Users and CSSOs of Unclassified Computer Systems. U.S. Department of Energy, Rocky Flats Plant, Golden, CO.

\section{I) OPERABLE UNIT 11 ECOLOGICAL EFFECTS}

Between April, 1982 and October, 1985, three areas in the Rocky Flats Buffer Zone were sprayed with water from the Solar Ponds. This was done to remove excess water when the ponds became full. Because the water was contaminated, the site was identified as a hazardous waste management unit under the Resource Conservation and Recovery Act (RCRA) in 1986. Through a series of regulatory actions, the three areas were combined to create Operable Unit (OU) 11 of the Rocky Flats Interagency Agreement (IAG). Designation as an OU under the IAG required a RCRA Facility Investigation/Remedial Investigation (RFI/RI) to be carried out. an Ecological Risk Assessment (ERA) is part of that investigation.

In late summer of 1993, EcMP staff were asked by the OU 11 manager to investigate the possibility of conducting the ERA for this site. Ecology staff had contracts with several laboratories at that time whose analytical work might contribute to the assessment of ecological effects. Staff then devised a sampling program to determine ecological effects of several potential receptors.

The approach taken was to conduct a quantitative effects assessment on several potential ecological receptors, and to provide evidence from population, community, and ecosystem levels of organization as 
to whether an effect(s) was present 8 years following the treatment application. If differences did persist, which ones demonstrated the clearest differences? A related purpose was to determine if these relatively inexpensive and quick tests could provide a sensitive measurement of contaminant effects. If similar trends were to emerge from this wide array of receptors, it might be possible to draw conclusions regarding the presence or absence of significant effects.

The receptors evaluated include:

A) Soil Physical and Chemical Properties

1) Total soil organic carbon

2) Total soil nitrogen

3) Soil exchangeable potassium

4) Soil extractable phosphorus

5) Soil calcium concentration

6) Soil particle size (texture)

7) Soil cation exchange capacity

Some of these properties ( $\mathrm{C}$ and $\mathrm{N}$ ) and other soil properties (particle size) were also measured under the ecosystem function section of this report.

B) Vegetation and Litter

1) Vegetation biomass.

2) Vegetation carbon, nitrogen, potassium and phosphorus concentrations (mg element $\mathrm{kg}^{-1}$ vegetation) and element contents ( $\mathrm{mg}$ element $\mathrm{m}^{-2}$ ).

3) Litter mass.

4) Litter carbon, nitrogen, potassium and phosphorus concentrations (mg element $\mathrm{kg}^{-1}$ vegetation) and element contents ( $\mathrm{mg}$ element $\mathrm{m}^{-2}$ ).

C) Soil Invertebrates

1) Soil invertebrate nematodes from the $0-5$ and the $5-10 \mathrm{~cm}$ depths, classified into several functional groups.

2) Soil invertebrate arthropods from the $0-5$ and the $5-10 \mathrm{~cm}$ depth, analyzed both taxonomically and by functional groups.

D) Ecosystem Functions

1) Extractable soil nitrate $\left(\mathrm{NO}_{3}\right)$

2) Extractable soil ammonium $\left(\mathrm{NH}_{4}\right)$

3) Total soil nitrogen

4) Total soil carbon

5) Fine Particulate Soil Organic Carbon

6) Fine Particulate Soil Organic Nitrogen

7) Microbial carbon concentration (direct extraction)

8) Potentially mineralizable nitrogen (10-day incubation at field capacity water content at $25^{\circ} \mathrm{C}$ followed by $\mathrm{NO}_{3}$ and $\mathrm{NH}_{4}$ analysis

9) Potentially respirable carbon $\left(\mathrm{CO}_{2}\right.$ analysis during a 10-day incubation at field capacity water content and $25^{\circ} \mathrm{C}$ )

10) Nitrogen fixation rate (ethylene production)

11) Denitrification rate (nitrous oxide production under $10 \%$ acetyiene)

Twelve sites from OU 11 were sampled: three treatments (Sprayed, Nonsprayed and Reference), four replicate sites within each treatment, and five plots per site. Sprayed plots were exposed to high levels of nitrate. Non-sprayed plots were initially thought to not have been exposed to nitrates; but were 
subsequently found to have received some spray. Reference sites were outside the spray area, just north of the McKay ditch, but were in the same soil series and vegetation community (xeric mixed grassland).

All hypotheses tested were related to significant differences between treatment means. The null hypothesis was that the treatment means of the variable in question were equal, and the alternative hypothesis was that at least two of the treatment means were significantly different at the stated alpha level.

Soil physical properties were found to be very similar among the three treatments, indicating that conditions were fairly uniform in treated and reference areas prior to the Spray treatment. Soil chemical properties were considerably more variable, and most had a statistically significant replicate within treatment effect. Soil carbon and nitrogen concentrations at $0-10 \mathrm{~cm}$ depth were the only elements that showed a significant elevated response to the Spray treatment.

Vegetation and litter biomass did not have statisticaily significant treatments effects, although both of these variables were highest in the Sprayed treatment. Most element concentrations also did not show significant effects, although vegetation carbon concentration was greatest in the Non-sprayed treatment. Vegetation potassium concentration and content and phosphorus concentration were also highest in the Non-sprayed treatment; the meaning of these results is not clear.

Changes in both arthropod and nematode functional groups were generally not evident as a result of the Sprayed treatment. Six of a total of 35 soil invertebrate variables had a statistically significant treatment effect. Detectable changes were only found where organisms in the Sprayed treatment were significantly more abundant than either Non-sprayed or Reference treatments. There was not a consistent ranking of treatment means in the expected order (Sprayed > Non-sprayed > Reference, or the reverse). However, it can be stated that preliminary analyses have not shown any statistically significant or dramatic (more than 10x) nematode or arthropod functional group declines in areas where the Spray treatment was thought to be heaviest.

Several ecosystem function measurements were found to have a significant treatment effect. Eight years after spraying ceased, soil $\mathrm{C}$ and $\mathrm{N}$ concentrations are greater in Sprayed than in non-sprayed treatments. Nitrate-N concentrations were also greater 8 years after spraying $(14.0 \mu \mathrm{g} / \mathrm{g})$ than in reference soil $(6.4$ $\mu \mathrm{g} / \mathrm{g}$ ). Concentrations of nitrate- $\mathrm{N}$ greater than $10 \mu \mathrm{g} / \mathrm{g}$ are unusually high for grassland soils, although they are common in agricultural soils. Although potentially mineralizable $\mathrm{N}$ concentrations were not different at $\alpha=0.05$, they were significantly different at $\alpha=0.10$. Sprayed soils mineralized the least $N$ ( 8.9 $\mu \mathrm{g} / \mathrm{g})$ and reference soils the most $\mathrm{N}(13.7 \mu \mathrm{g} / \mathrm{g})$. There are $7.6 \mu \mathrm{g} / \mathrm{g}$ more nitrate and $4.8 \mu \mathrm{g} / \mathrm{g}$ less mineralizable $N$. Possibly $N$ that was mineralizable $N$ in reference soil was already mineralized in sprayed soil.

Microbial biomass $\mathrm{C}$ was not significantly different in sprayed soils, but microbial biomass $\mathrm{N}$ was significantly greater. At first, this suggested that microbial populations changed, changing the microbial $\mathrm{C}: \mathrm{N}$ ratio. For example, fungi have wider $\mathrm{C}: \mathrm{N}$ ratios than bacteria and as fungi become relatively more abundant, microbial $\mathrm{C}: \mathrm{N}$ ratios increase. There were, however, no statistical differences between treatments in microbial $\mathrm{C}: \mathrm{N}$ ratio.

In conclusion, a total of 74 variables were analyzed to assess the ecological effects of a spray treatment to OU 11 , and 18 variables showed statistically significant differences at the $\alpha=0.10$ level of significance. The most biologically significant effects were the increase in soil $\mathrm{C}$ and $\mathrm{N}$ in the Sprayed treatment. This effect was also seen in elevated amounts of nitrate in the Sprayed treatment. Of seven soil invertebrate variables that were found to have a significant treatment effect, six functional or taxa groups showed increases in the Sprayed treatment areas. Variables that showed statistically significant decreases in the Sprayed treatment were not thought to have deleterious ecological effects. Although the spray treatment has altered some of the nutrient pools and cycling processes, the result has not caused any ecosystem damage. 


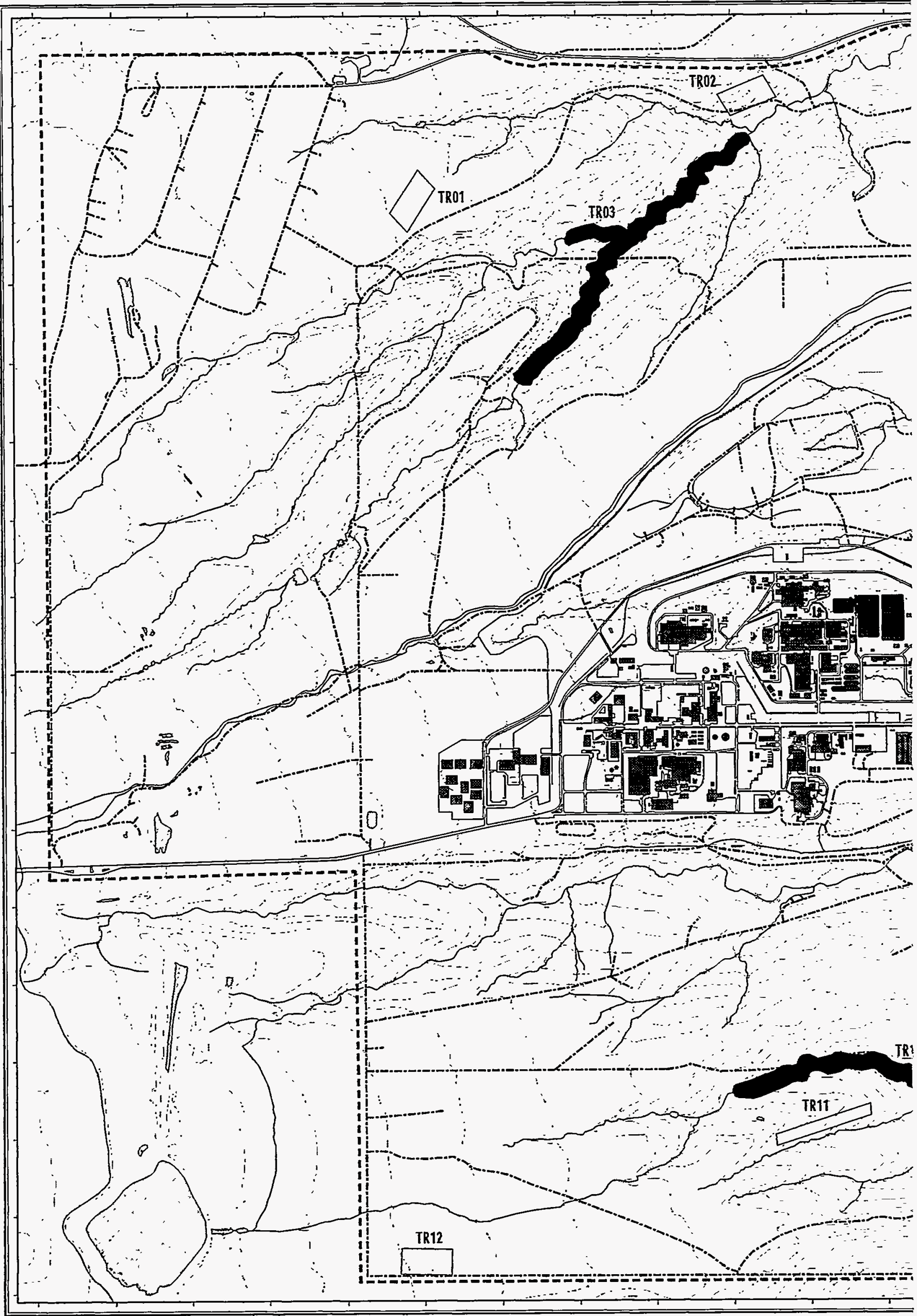




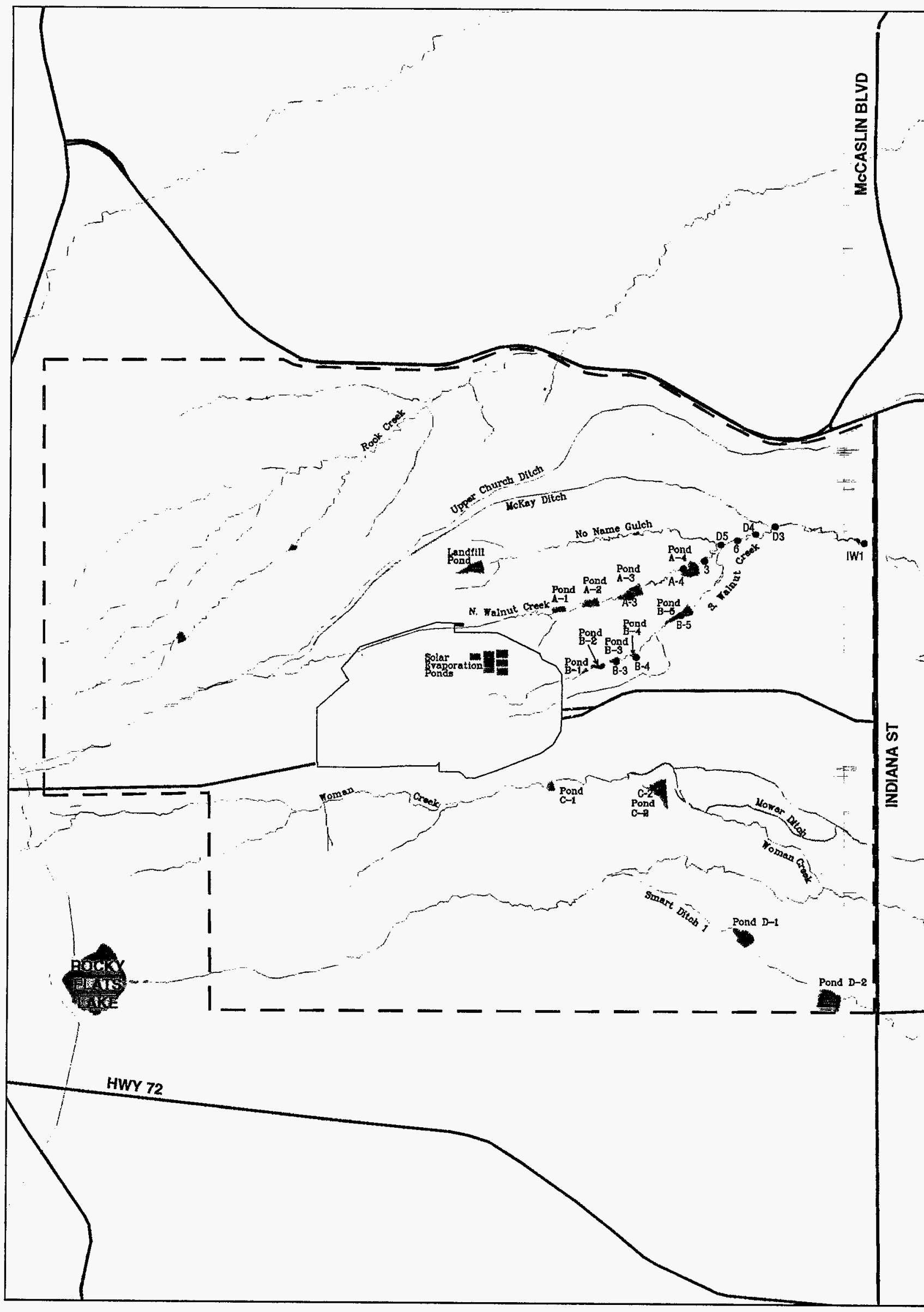




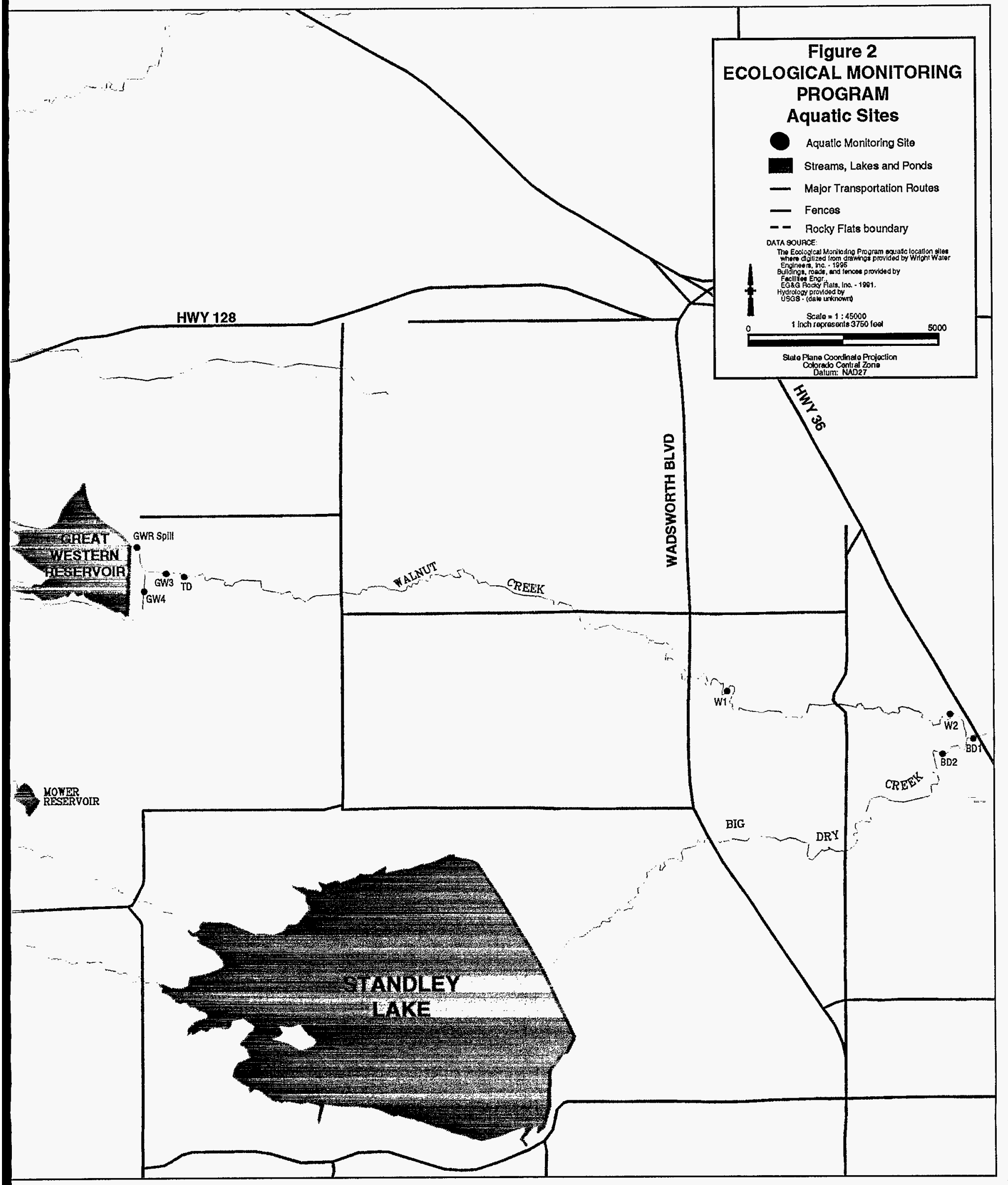




\section{Figure 2A. Aquatic Site Descriptions.}
A-1
A-1 pond, North Walnut Creek drainage
A-2
A-2 pond, North Walnut Creek drainage
A-3
A-3 pond, North Walnut Creek drainage
A-4
A-4 pond, North Walnut Creek drainage
$B-1$
B-1 pond, South Walnut Creek drainage
B-2
B-2 pond, South Walnut Creek drainage
B-3
B-3 pond, South Wainut Creek drainage
B-4
B-4 pond, South Walnut Creek drainage
B-5
B-5 pond, South Walnut Creek drainage
BD1
Big Dry Creek downstream of Wainut Creek confluence
$\mathrm{BD2}$
Big Dry Creek upstream of Walnut Creek confluence
C-1
C-1 pond, Woman Creek drainage
C-2
C-2 pond, Woman Creek drainage
D-1
D-1 pond, Smart ditch drainage
D-2
D-2 pond, Smart ditch drainage
D3
Walnut Creek downstream of Mckay confluence
D4
Walnut Creek upstream of Mckay confluence
D5 Walnut Creek downstream of A-4 pond dam
GW1
GW2
Runoff stream from GWR located east of GWR at the service road culvert
GW3
GW4 Overflow pipe emptying into Walnut Creek east of GWR
Walnut Creek east of Great Western Reservoir (GWR), downstream of diversion ditch, upstream of GWR overflow pipe
IW1
SW039
Downstream or at the end of Walnut diversion ditch at 2 small culverts
SW033
Walnut Creek west of Indiana at the culvert just inside Rocky Flats fence boundaries
SW026
Woman Creek, surface water site
Woman Creek, surface water site
SW05
W1
Woman Creek, east of $\mathrm{C}-2$ pond, surface water site
Lindsay Pond
W2
Walnut Creek west of culvert at 105 th St. and Old Wadsworth intersection
Walnut Creek upstream of confluence with Big Dry Creek 


\section{A) ECOSYSTEM FUNCTIONS}

Authors: L.E. Woods and M.E. Bakeman 


\section{TABLE OF CONTENTS}

,

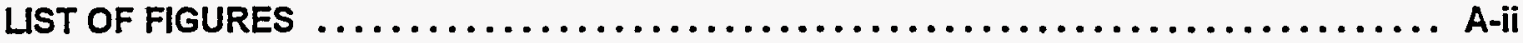

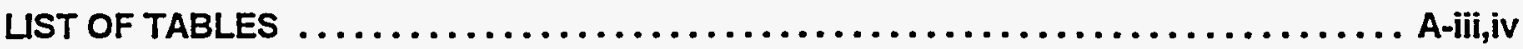

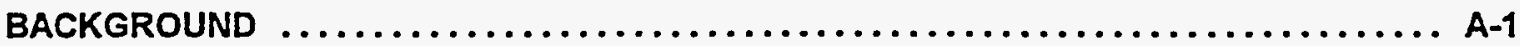

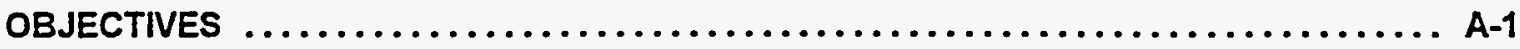

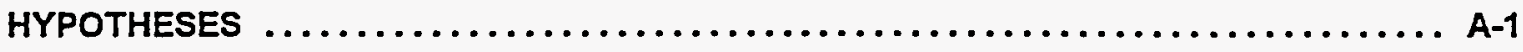

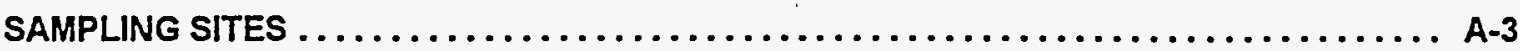

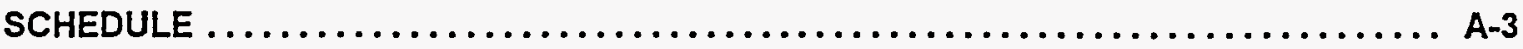

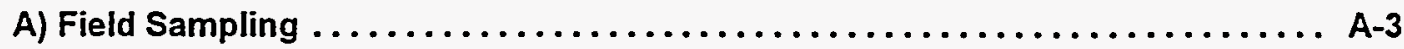

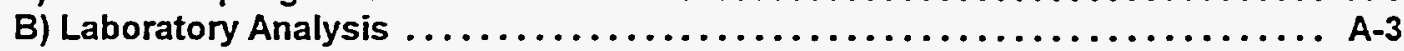

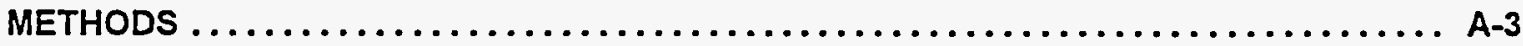

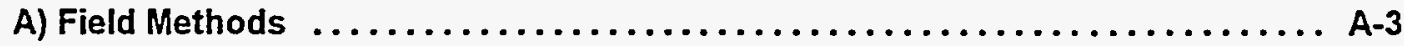

B) Laboratory Analysis . .............................. A

1) Ecosystem Function Parameters $\ldots \ldots \ldots \ldots \ldots \ldots \ldots \ldots \ldots \ldots$ A 4

2) Soil Physical and Chemical Properties.$\ldots \ldots \ldots \ldots \ldots \ldots \ldots \ldots$ A 4 -

3) Vegetation and Litter Analyses $\ldots \ldots \ldots \ldots \ldots \ldots \ldots \ldots \ldots \ldots$ A-5

4) Statistical Analyses ............................ A-5

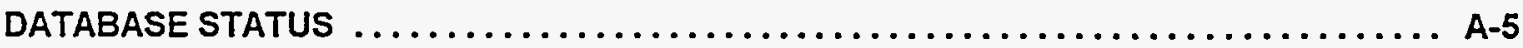

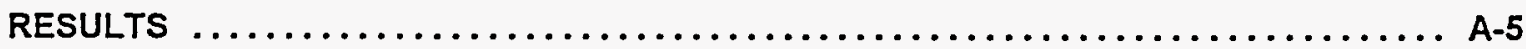

A) Ecosystem Function Parameters $\ldots \ldots \ldots \ldots \ldots \ldots \ldots \ldots \ldots \ldots \ldots \ldots \ldots$ A-5

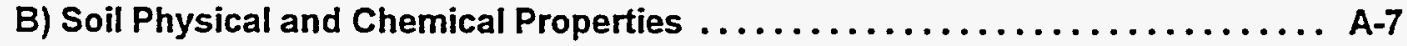

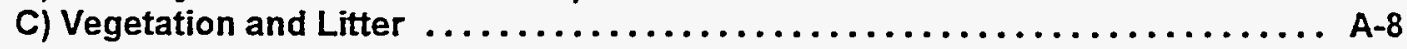

INTERPRETATION AND RECOMMENDATIONS $\ldots \ldots \ldots \ldots \ldots \ldots \ldots \ldots \ldots \ldots \ldots \ldots$

A) Ecosystem Function Parameters $\ldots \ldots \ldots \ldots \ldots \ldots \ldots \ldots \ldots \ldots \ldots \ldots \ldots \ldots \ldots$

B) Soil Physical and Chemical Properties .................... A-10

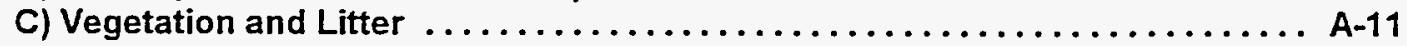

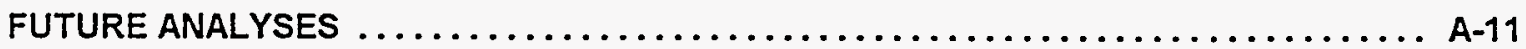




\section{LIST OF FIGURES}

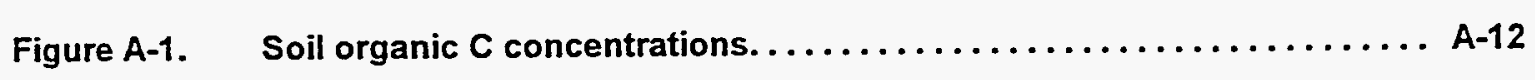

Figure A-2. Soil organic $\mathrm{N}$ concentrations. $\ldots \ldots \ldots \ldots \ldots \ldots \ldots \ldots \ldots \ldots \ldots \ldots \ldots$

Figure A-3. Microbial biomass $\mathrm{C}$ concentrations. ................. A-14

Figure A-4. Microbial biomass $\mathrm{N}$ concentrations. .................... A-15

Figure A-5. Respirable $\mathrm{C}$ concentrations. $\ldots \ldots \ldots \ldots \ldots \ldots \ldots \ldots \ldots \ldots \ldots \ldots \ldots$

Figure A-6. Mineralizable $\mathrm{N}$ concentrations. $\ldots \ldots \ldots \ldots \ldots \ldots \ldots \ldots \ldots \ldots \ldots \ldots \ldots$

Figure A-7. Fine particulate organic $\mathrm{C}$ concentrations $\ldots \ldots \ldots \ldots \ldots \ldots \ldots \ldots \ldots$

Figure A-8. Fine particulate organic $\mathrm{N}$ concentrations. $\ldots \ldots \ldots \ldots \ldots \ldots \ldots \ldots$ A-19

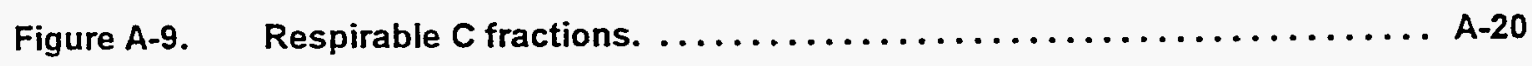

Figure A-10. Microbial biomass $\mathrm{C}$ fractions. $\ldots \ldots \ldots \ldots \ldots \ldots \ldots \ldots \ldots \ldots \ldots \ldots \ldots \ldots \ldots$

Figure A-11. Mineralizable $\mathrm{N}$ fractions. $\ldots \ldots \ldots \ldots \ldots \ldots \ldots \ldots \ldots \ldots \ldots \ldots \ldots \ldots \ldots$

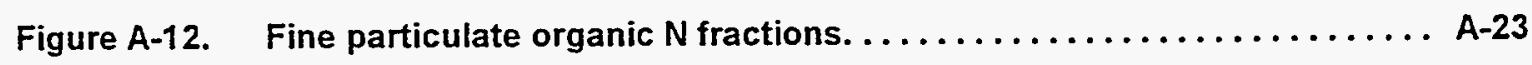

Figure A-13. Fine particulate organic $N$ fractions. . . . . . . . $\ldots \ldots \ldots \ldots \ldots \ldots$ 


\section{LIST OF TABLES}

Table A-1 . Soil Texture of the surface $10 \mathrm{~cm}$ of Ecological Monitoring Program Sites by Community and Watershed. ..........................

Table A-2. Analysis of Variance for Total Soil Organic Carbon by Community and Watershed. .................................... A-26

Table A-3. Analysis of Variance for Total Soil Organic Nitrogen by Community and Watershed. .................................... A-26

Table A-4. Analysis of Variance for Microbial Biomass Carbon by Community and

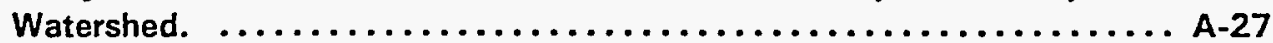

Table A-5. Analysis of Variance for Microbial Biomass Nitrogen by Community and Watershed. .......................................

Table A-6. Analysis of Variance for Respirable Carbon by Community and Watershed.

Table A-7. Analysis of Variance for Mineralizable Nitrogen by Community and Watershed.

Table A-8. Analysis of Variance for Fine Particulate Organic Carbon by Community and Watershed. ...................................... A-29

Table A-9. Analysis of Variance for Fine Particulate Organic Nitrogen by Community

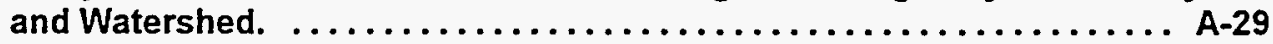

Table A-10. Analysis of Variance for the fraction of the total soil organic $C$ found in microbial biomass: Microbial biomass percent by Community by Watershed.

Table A-11. Analysis of Variance for the fraction of the total soil organic $\mathrm{N}$ found in microbial biomass: Microbial biomass $\mathrm{N}$ percent by Community by Watershed.

Table A-12. Analysis of Variance for the fraction of the total soil organic $C$ in respirable C: Respirable $C$ percent by Community by Watershed. .......... A-31

Table A-13. Analysis of Variance for the fraction of the total soil organic $\mathrm{N}$ mineralized: Mineral $N$ percent by Community by Watershed. ..............A-31

Table A-14. Analysis of Variance for the fraction of the total soil organic $C$ in fine particulate organic $\mathrm{C}$ : percent fine particulate organic $\mathrm{C}$ by Community by Watershed.

Table A-15. Analysis of Variance for the fraction of the total soil organic $N$ in fine particulate organic N: percent fine particulate organic $\mathrm{N}$ by Community by Watershed.

Table A-16. Analysis of Soil Properties. 


\section{LIST OF TABLES (CONTINUED)}

Table A-17. Soil Properties for EcMP Community Types. ............... A-34

Table A-18. Summary Statistics for Rocky Flats Vegetation. ............. A-35-39

Table A-19. Summary Statistics for Rocky Flats Litter. . . . . . . . . . . . A A $40-44$ 


\section{BACKGROUND}

Ecosystems are comprised of biotic (individuals, populations and communities) and abiotic components. Ecosystems are generally studied in either one of two ways: based on their biotic components or based on their processes. Ecosystem processes, called functions in this report, include energy transformations, nutrient cycling, soil development and organic matter turnover.

Ecosystem functions are included in the Ecological Monitoring Program (ECMP) to balance the population and community approaches of the other modules and because they may be sensitive indicators of subtle changes in ecosystems that are not reflected in measurable changes in populations and communities. Natural Resource Damage Assessment (NRDA) Regulations, a responsibility of the Ecology and Watershed Management (EWM) Branch, list two Ecosystem Function measurements as specific methods of injury determination: impeded soil microbial respiration, and reduced respiration from reduced soil microbial populations. These measurements are made in the EcMP to provide a baseline description of undisturbed soil at RFETS, including normal ranges and seasonal and annual trends.

Several other measurements related to nutrient cycling were also analyzed: soil physical and chemical properties, and estimates of vegetation and litter nutrient contents. Some of the soil variables represent baseline ecological conditions that help explain results from other analyses. Differences in vegetation and litter nutrient contents can affect other variables like soil invertebrates, and biogeochemical cycling.

\section{OBJECTIVES}

Objectives for measuring ecosystem function properties are to establish baseline concentrations for undisturbed areas, to describe natural differences between biotic communities, locations, seasons and years, and to provide benchmarks to asses revegetated areas when remediation and restoration are completed. A related goal is to evaluate the potential of ecosystem function measurements, which are inexpensive and sensitive, as indicators of ecosystem health.

Populations, communities and selected abiotic factors will be measured in other modules. Attention will be focused on indicators of nutrient cycling processes as suggested by O'Neill, et al. (1977). Responses to perturbations, either natural or anthropogenic can only be evaluated in light of their normal variations in time and space. We believe that these ecosystem-level measurements, in conjunction with concurrent studies at lower levels of organization, will allow us to interpret ecological patterns at RFETS.

\section{HYPOTHESES}

Several questions framed the hypotheses:

a) What are characteristic potential respiration rates of the four community types of terrestrial vegetation?

b) Are potential respiration rates similar in reclaimed sites and undisturbed sites?

c) Are similar fractions of the total organic matter potentially active in all communities?

d) What is the "normal" range of variation for each type of measurement?

e) Is the potential for $\mathrm{N}_{2}$-fixation appreciable in any habitat?

f) What are the characteristic potential $\mathrm{N}$ mineralization rates of the four community types?

g) Is there a potential for $\mathrm{NO}_{3}^{-}$to accumulate in soils in any of the community types?

h) If pools represent potential fluxes, what are the relationships between fluxes and pools?

i) Between pools and habitats?

j) Between pools and abiotic parameters? 
Hypotheses related to soil physical and chemical properties include: do these properties differ by community type, and are the sample sites used to calculate community soil means a significant factor in evaluating variation in the overall statistical model used.

Specific hypotheses include:

$\mathrm{H}_{\mathrm{a}}$ : Potential soil respiration does not differ significantly between sites.

$\mathrm{H} 1_{\mathrm{A}}$ : Potential soil respiration differs significantly between sites.

Basis for hypothesis: Respiration represents the integration of most ecosystem functions.

Locations with larger amounts of primary productivity also must have larger amounts of respiration, must have other carbon export mechanisms, or must be sites of carbon accumulation.

$\mathrm{H}_{\mathrm{o}}$ : $\quad$ Soil respiration rates exhibit similar seasonal patterns in all habitats.

$\mathrm{H}_{\mathrm{A}}$ : Soil respiration rates exhibit different seasonal patterns in riparian communities than in grassland communities.

Basis for hypothesis: Respiration is limited by the availability of substrate, by water and by edaphic factors. The available water will probably show much stronger seasonal trends in the grassland sites than in the riparian sites. Seasonal data are not available at this time to evaluate these trends.

$\mathrm{H}_{0}$ : $\quad$ Potential soil respiration does not vary significantly between sites or between communities. $\mathrm{H}_{\mathrm{A}}$ : Potential soil respiration varies by more than $100 \%$ between sites and between habitats.

Basis for hypothesis: The "normal" range of variation in respiration potential within a site is probably less than the differences between sites. Probably the greatest differences will be in the grassland sites which vary widely in water status.

$\mathrm{H}_{0}$ : $\quad \mathrm{N}_{2}$-fixation is not significantly greater than zero at any site.

$\mathrm{H}_{4}$ : $\quad \mathrm{N}_{2}$-fixation is greater than zero in one cornmunity type.

Basis for hypothesis: Nitrogen is the most common limiting nutrient in almost any terrestrial ecosystem. $\mathrm{N}_{2}$-fixation depends on several edaphic and biotic factors that will probably be different in riparian areas than in grassland sites.

$\mathrm{H}_{0}: \quad \mathrm{N}$ mineralization potentials are similar in all community types.

$\mathrm{H}_{\mathrm{A}}$ : $\quad \mathrm{N}$ mineralization potentials are higher in riparian than in other community types.

Basis for hypothesis: $\mathrm{N}$ mineralization is limited by substrate quantity, substrate chemical characteristics, soil water, and edaphic factors. Nearly all of these factors are less limiting in the riparian zone than in the other community types.

$\mathrm{HG}_{0}: \quad \mathrm{NO}_{3}^{-}$is not accumulating in the soils of any community.

$\mathrm{H}_{\mathrm{A}}$ : $\quad \mathrm{NO}_{3}{ }^{-}$is either moving out of the watersheds in stream water or is accumulating in soils.

Basis for hypothesis: Increased $\mathrm{N}$ mineralization at the expense of immobilization indicates that ecosystem functions are disturbed. This imbalance can quickly result in increased nitrate concentrations in soil or stream water. Ecosystem function disturbances can, of course, occur without causing increased nitrate concentrations, but if nitrate concentrations do increase, something is amiss. 


\section{SAMPLING SITES}

One hundred fifty one samples for Ecosystem Function parameters were taken from 24 field sites. The 12 EcMP permanent sites (TR01-TR12) sampled for vegetation production measurements were also sampled for ecosystem functions. One sample was collected at each of five transects within each site. This sample consisted of five subsamples. Additional sites were sampled to provide field replicates for quality assurance. Another 12 sites from Operable Unit (OU) 11 were sampled. Results from OU11 are discussed in Appendix 1 of this report. A total of 151 samples was sent to the Natural Resource Ecology Laboratory at Colorado State University in Fort Collins, Colorado for analysis.

Vegetation and litter data reported in this section were collected to satisfy objectives outlined in other sections of this report. These data are summarized here by community to allow comparison with the ecosystem functions data. Data were collected at grassland, but not riparian sites; and sample sizes were unequal because species were analyzed separately for plant tissue conecntrations. For plant tissue concentrations, mesic and reclaimed grassland had 20 observations each ( 1 site each), and xeric grassland had 7 observations (from 3 sites). For litter analysis, mesic and xeric grasslands had 35 observations each. Reclaimed grasslands had 55 observations. Litter analysis was from three sites in each grassland community.

\section{SCHEDULE}

\section{A) Field Sampling}

All samples were collected in early August or in September, 1993.

\section{B) Laboratory Analysis}

All analyses were completed on schedule. Data were delivered on schedule.

\section{METHODS}

\section{A) Field Methods}

Detailed descriptions of the soils sampling procedures have been provided in "Procedures for Sampling Soil Invertebrates and Ecosystem Function Measurements, Appendix 11 of the Ecological Monitoring Program Management/Technical Performance Report-GHS-462-93 (93-RF11615)." Samples were collected by excavating a $10 \times 10 \times 10 \mathrm{~cm}$ cube of soil from the selected location. All samples represented the surface $10 \mathrm{~cm}$. Samples were composited from the five quadrat locations on each transect adjacent to vegetation production plots. Sample collection was complicated by the large amount of coarse fragments (cobbles and stones). Large rocks were removed and weighed separately. Samples were immediately transferred to coolers containing ice (Blue lce or its equivalent). They were maintained in coolers until they were transported to the laboratory. In the laboratory they were maintained in a $4^{\circ} \mathrm{C}$ cold room until analysis.

Vegetation and litter samples were collected from $0.25 \mathrm{~m}^{-2}$ quadrats. All current-year's growth and litter inside the quadrat frame were harvested and bagged separately. They were then dried in a forced draft oven to constant weight. Samples were weighed, then sent to the analytical laboratory. 


\section{B) Laboratory Analysis}

\section{1) Ecosystem Function Parameters}

Detailed procedures for the analyses performed by the Natural Resource Ecology Laboratory are on file with EWM personnel. For initial processing at the laboratory, samples were sorted and laboratory identification numbers assigned. Five separate field bags held each sample. Their contents were mixed and coarse mineral and organic matter fragments were removed. These coarse fragments were later weighed. The soil was then sieved through a $2 \mathrm{~mm}$ sieve. Water content of the sieved soil at field capacity was measured.

Incubations were then initiated using sieved soil. Field nitrate and ammonium concentrations were measured. Three subsamples were prepared for each sample date. All extractions and incubations were carried out for each soil sample and for selected duplicates and three blanks. Fifty grams of soil was weighed into appropriate containers. Water was added to bring the soil to the water content at field capacity. The cups were placed into respiration chambers with several $\mathrm{ml}$ of water to prevent desiccation of the soil. A vial containing a known volume of $3 \mathrm{M} \mathrm{NaOH}$ (usually $1.275 \mathrm{ml}$ ) was place in each chamber. The chambers were sealed and incubated at $25^{\circ} \mathrm{C}$. On the third, sixth and tenth days, the vials of $\mathrm{NaOH}$ were titrated with $1 \mathrm{M} \mathrm{HCl}$ in the presence of $\mathrm{BaCl}_{2}$. The vials were replaced on the third and sixth days. On the tenth day, the soil was removed and subsampled for water content, mineralized $\mathrm{N}$, and microbial biomass $\mathrm{C}$ and $\mathrm{N}$.

Water content was measured gravimetrically. Mineralized $\mathrm{N}$ was measured by analyzing for ammonium and nitrate+nitrite on an auto-analyzer. Microbial biomass $\mathrm{C}$ and $\mathrm{N}$ were estimated by measuring the differences in soluble $\mathrm{C}$ and $\mathrm{N}$ between a control and a chloroform fumigated subsample of each sample. In this report, microbial biomass is presented as the difference between these subsamples. No correction was made for the efficiency of extraction. It is more common in scientific reporting to divided the difference in extractable carbon between chloroformed and unchloroformed soil by 0.41 or some other factor. That is to say, exposure to chloroform renders $41 \%$ of the microbial carbon extractable. Nitrogen is calculated by various formulae, because the extractability of nitrogen is not straightforward. Details of these corrections are not explored for this report.

Texture and Particulate Organic Carbon and Nitrogen were measured by suspending soil samples in $5 \%$ sodium hexametaphosphate. Sand sized particles are collected on a $53 \mu \mathrm{m}$ sieve. The remaining sample is placed in 1 I sedimentation cylinders and measured by hydrometer. Particulate organic carbon and nitrogen are then measured on the sand fraction collected on the sieve.

\section{2) Soil Physical and Chemical Properties}

Soil samples for physical and chemical properties analysis were shipped to the University of Idaho Analytical Laboratory in plastic-lined sample bags provided by the laboratory. Each sample consisted of approximately $1 \mathrm{~kg}$ of soil. Soil samples were passed through a $2-\mathrm{mm}$ sieve. Water content was determined gravimetrically. Micronutrients, such as $\mathrm{Zn}, \mathrm{Mn}, \mathrm{Cu}, \mathrm{Fe}, \mathrm{Pb}$, and $\mathrm{Cd}$ were extracted by DTPA at pH 7.3, and analyzed on an ICP-AES. Exchangeable cations such as $\mathrm{Ca}$, $\mathrm{Mg}, \mathrm{Na}$, and $\mathrm{K}$, were extracted with $1.0 \mathrm{~N}$ ammonium acetate and analyzed on the ICP-AES. Phosphorus was extracted with $0.5 \mathrm{M}$ sodium bicarbonate and then analyzed on a spectrophotometer. Soil sulfate was determined by shaking the sample with deionized water with 1 drop of concentrated $\mathrm{HCL}$, filtered, and $\mathrm{BaCl}_{2}$ was added to form $\mathrm{BaSO}_{4}$, which was then measured on a Turbidometer. Cation exchange capacity was determined by extraction with 
ammonium acetate at $\mathrm{pH} 7$, followed by measurement of extractable cations by ICP. Total carbon and nitrogen concentrations were determined using an automated CHN Analyzer (McGeehan and Naylor, 1988). Quality control was ensured by the use of laboratory blanks, spikes, and certified standard materials. All laboratory procedures are on file with EcMP staff.

\section{3) Vegetation and Litter Analyses}

All vegetation samples were dried at $65^{\circ} \mathrm{C}$ in a forced-air drying oven until they had reached constant weight, and then weighed on a top loading balance to the nearest $0.1 \mathrm{~g}$. Samples were then shipped to the University of Idaho Analytical Laboratory in paper bags for elemental analysis. All laboratory procedures are on file with EcMP staff. Dried samples were first ground in a Wiley mill, weighed ( $0.25-0.50 \mathrm{~g}$ of tissue), and digested in $3.0 \mathrm{ml}$ of reagent grade nitric acid. Samples were centrifuged and the resulting solutions were analyzed on a Perkin Elmer P-40 ICP for cation elements, phosphorus, and sulfur. Total carbon and nitrogen concentrations were determined using an automated CHN Analyzer (McGeehan and Naylor, 1988). Quality control was ensured by the use of laboratory blanks, spikes, and certified standard materials.

\section{4) Statistical Analyses}

Statistical analyses for the ecosysem funtion parameters consisted of a two-factor Analyses of Variance; the two factors were community and watershed. The design was five communities (xeric, mesic, riparian-north side, riparian-south side and revegetated) in three watersheds (Rock, Walnut and Woman Creeks). Each community, except revegetated, was sampled at one site in each watershed. The three sites of the revegetated community were all in Woman Creek. Five samples were collected in each site. Means were separated by Tukey's Honestly Significant Differences (HSDs) at $p \leq 0.05$, where appropriate.

Statisitical analyses for soil physical and chemical data consisted of nested analyses of variance, with communities as the main effect. Sites were considered to be nested within communities. Residual sums of squares were from transects within sites. Differences for these variables were considered to be different if they were significant at $\alpha=0.10$. Vegetation and litter nutrient content data were not statistically analyzed because of diesgn imbalance and lack of communiy replicates.

\section{DATABASE STATUS}

Field formats were developed with the EcMP database coordinator. The first data were received in January, 1994, as scheduled. No field records other than field sample sheets and sample chain of custody (COC) records are used in this module. Field records were combined with laboratory results using the assigned observation number (OBSNUM) as the common variable.

\section{RESULTS}

\section{A) Ecosystem Function Parameters}

Results presented here include particle size distribution, total organic carbon and nitrogen, microbial biomass carbon and nitrogen, potentially mineralizable carbon and nitrogen, fine particulate organic carbon and nitrogen, and some associated abiotic parameters. Results obtained, but not yet completely analyzed, include estimates of denitrification, dinitrogen fixation and rates of carbon dioxide and methane production under both anaerobic and aerobic incubation. These results will be presented in future reports. 
Soil textures of the surface $10 \mathrm{~cm}$ were different in the different community types of the EcMP: Xeric sites were generally sandier (coarser) and reclaimed sites were more clayey (finer) (Table A1). Coarse fragment content was high. Xeric sites, for example, were in Flatirons soil, which by definition contains at least $85 \%$ cobble or stone in the surface horizon. Because measurement difficulties associated with the abundance of coarse fragments rendered accurate determination of bulk densities impossible, concentrations but not distributions are presented.

Analysis of Variance revealed highly significant treatment by watershed interactions for total soil organic $C$ and $N$ (Table A-2). These interactions reflect the different patterns in the concentrations of organic $C$ and $N$ in the three watersheds depending on the plant community. The Xeric site in Walnut Creek has the highest organic $\mathrm{C}$ and $\mathrm{N}$ concentrations, but it has the lowest concentrations in Mesic and Riparian sites. Rock Creek has higher concentrations than Woman Creek in all communities except Riparian B (south of the creek). Organic matter concentrations were generally higher in Xeric sites than in the other communities and, not surprisingly, were lower in reclaimed sites (Figures $A-1$ and $A-2$ ).

Microbial biomass $\mathrm{C}$ and $\mathrm{N}$ concentrations also reflected highly statistically significant Community by Watershed interactions (Tables A-4 and A-5). Microbial biomass also responded differently to differences between communities, depending on which watershed was sampled (Figures A-3 and A-4). Although microbial biomass concentrations were, on average, greater in Xeric than in other communities, Walnut Creek alone caused most of the difference. Microbial biomass concentrations in reclaimed sites were more similar to the other communities than total organic $\mathrm{C}$ and $\mathrm{N}$ concentrations.

Potentially active $C$ and $N$ concentrations (Respirable $C$ and Mineralizable $N$ ) had different patterns with community type. Respirable $C$ demonstrated a significant Community by Watershed interaction, but Mineralizable $N$ did not (Tables $A-6$ and A-7). Respirable $C$ concentrations in Wainut Creek were highest in Xeric Sites, but by far the lowest in Mesic sites (Figure A-5). Respirable $C$ concentrations were more similar between communities in Woman Creek than in either of the other watersheds. Mineralizable $\mathrm{N}$ concentrations demonstrated no significant Community by Watershed interaction or Watershed Main effect (Table A-7). Mineralizable $N$ concentrations were considerably higher in Xeric sites and considerable lower in Reclaimed than in Mesic or Riparian sites (Figure A-6).

Fine particulate organic $C$ and $N$ concentrations both manifested highly significant Community by Watershed interactions (Tables A-8 and A-9). Rock Creek and Walnut Creek sites had opposite concentration patterns (Figures A-7 and A-8). Woman Creek sites were more similar across all sites except for reclaimed sites. In general, Xeric sites had higher concentrations of Fine Particulate Organic $\mathrm{C}$ and $\mathrm{N}$ than did the other sites. Reclaimed sites had the lowest concentrations.

The fractions of the total soil organic $\mathrm{C}$ or $\mathrm{N}$ in microbial biomass, in potentially mineralizable forms, or in fine particulate organic matter revealed only one treatment by watershed interaction: potentially respirable carbon ( $F=3.06 ; P=0.011$ ) (See Tables $A-10$ through $A-15$ ). By inspection of Figure A-9, this interaction resulted because Walnut Creek had lower fractions of the Total Organic Carbon in Respirable forms in Xeric and Mesic communities, but much higher fractions in riparian communities.

Fractions of Total organic $C$ and $N$ in microbial biomass showed different patterns. Microbial $C$ had statistically significant community effects $(F=4.12 ; P=0.005)$ and watershed effects $(F=11.42$; $P=0.000$ ). Figure $A-10$ demonstrates that Reclaimed sites had a higher fraction of soil $C$ in microbial biomass. Xeric sites had the smallest fraction. Microbial $\mathrm{N}$ had only significant watershed effects. Potentially mineralizable $N$ had significant community effects $(F=10.03$; 
$P=0.000$ ). Figure $A-11$ shows that this effect is caused by the very low percent of the total nitrogen that is mineralizable in reclaimed sites.

We examined the fractions of the total organic $C$ and $N$ in fine particulate organic matter.. This fraction of both $C$ and $N$ had statistically significant community effects: $F=8.00 ; P=0.000$ for $C$ and $F=12.37 ; P=0.000$ for $N$. Figure $A-12$ shows that $X$ eric sites had a larger fraction and Reclaimed sites had a smaller fraction of total $C$ in this form than Mesic or Riparian sites. Figure $A-13$ reveals similar relationships for $N$.

\section{B) Soil Physical and Chemical Properties}

Soil element concentrations and physical properties were analyzed for a significant community effect using a Nested Analysis of Variance (ANOVA) model. If this effect was statistically significant, it indicated that at least two of the community means were significantly different at the stated $\alpha$ level ( 0.10 unless otherwise stated). The same model was also used to assess if there were significant differences in the sites within each community. If this effect was significant, it indicated that there was a significant component of variation within the sites within each community.

Soil total carbon and nitrogen were analyzed and discussed with ecosystem function measurements because of their important relationships to those data. Data for phosphorus, potassium, calcium, magnesium, sulfate, sodium, and cation exchange capacity ANOVAs are given in Table A-16. Soil property means and summary statistics by community type are given in Table $A-17$. This table includes summary statistics for $C$ and $N$, and values are generally greater than the functional analyses for these elements, due to differences in laboratory handling and sample variation.

Soil extractable phosphorus had a significant community effect $(p=0.0408)$, with riparian north and south types having the highest mean values (19.45 and $16.46 \mathrm{mg} \mathrm{kg}^{-1}$, respectively), and the reclaimed community having the lowest $\left(7.82 \mathrm{mg} \mathrm{kg}^{-1}\right)$. The site within community effect was not significant $(p=0.2540)$.

Soil exchangeable potassium had a significant community effect $(p=0.0059)$, and the site within community effect was not significant $(p=0.4136)$. Community means were ordered opposite from phosphorus means; the reclaimed community had the highest mean $\left(1.22 \mathrm{mg} \mathrm{kg}^{-1}\right)$, and the riparian north and south types having the lowest $\left(0.825\right.$ and $0.843 \mathrm{mg} \mathrm{kg}^{-1}$, respectively).

Soil exchangeable calcium did not have a statistically significant community effect $(p=0.3533)$, but the site within community effect was extremely significant $(p=0.000)$. Calcium community means did not display much variation, ranging from $11.27 \mathrm{mg} \mathrm{kg}^{-1}$ (mesic type) to $15.90 \mathrm{mg} \mathrm{kg}^{-1}$ (reclaimed type).

Soil exchangeable magnesium showed both significant community and site within community effects. Magnesium concentrations were lowest in the xeric community type $\left(1.80 \mathrm{mg} \mathrm{kg}^{-1}\right)$ and highest in the reclaimed and riparian types (approximately $4.3 \mathrm{mg} \mathrm{kg}^{-1}$ ).

The soil extractable sulfate community effect was significant at the $\alpha=0.1$ level $(p=0.0525)$. Mean sulfate was extremely high in the riparian north community $\left(149.67 \mathrm{mg} \mathrm{kg}^{-1}\right)$, followed by the riparian south type $\left(64.93 \mathrm{mg} \mathrm{kg}^{-1}\right)$. The site within community effect was not significant $(p=0.6332)$.

Soil sodium showed a significant community effect $(p=0.006)$, with the riparian areas having the highest concentrations $\left(0.40 \mathrm{mg} \mathrm{kg}^{-1}\right)$, and the xeric type having the lowest concentration $(0.11)$. The site within community effect was not significant $(p=0.1639)$. 
Cation exchange capacity did not show a significant community effect ( $p=0.1887$ ), although the site within community effect was extremely significant $(p=0.0000)$. Cation exchange means ranged from $19.78 \mathrm{cmol} \mathrm{kg}^{-1}$ (xeric type) to $30.23 \mathrm{cmol} \mathrm{kg}^{-1}$ (reclaimed type).

\section{C) Vegetation and Litter}

Statistical analysis was not conducted on either vegetation or litter nutrient concentrations or contents for two reasons: 1) the design was very unbalanced in multiple areas, such as unequal observations within community levels, and unequal observations between community levels, and 2) for vegetation, some community levels were not replicated, and the means presented are representative of only a single site within that community. Therefore, these results are exploratory at best. Despite these shortcomings, these data are a useful glimpse at vegetation and litter element pools and may reveal gross trends that will help in the interpretation of other relationships.

Element contents were calculated by taking tissue concentration (corrected for ash) $\mathrm{x}$ biomass =element content. The equation is:

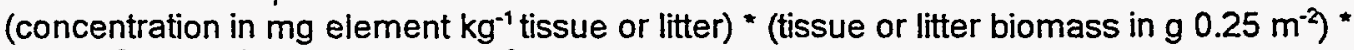
(4) ${ }^{*} 10^{6} \mathrm{mg} \mathrm{kg}^{-1}=\mathrm{mg}$ element $\mathrm{m}^{-2}$.

Vegetation data for three community types are presented in Table A-18. Total estimated element pools are also estimated for each community type, based on the area of each type at RFETS. In general, the xeric type was lower in most element contents than the other types, even though biomass production did not differ significantly among the three types. Differences are expected not only because of differences in the amount of biomass produced, but aiso because of differences in species composition; species vary tremendously in their element concentrations. Most of the mean element pools among the community types were vithin 1 order of magnitude of each other, however, some of the differences are surprising. For instance, mesic mixed grassiands showed almost $5 \times$ more total carbon and nitrogen per unit area than did the xeric type, which would not be expected based on production values.

Total mean element pools in litter were almost always higher than in the above-ground vegetation. Litter nutrient summaries are presented in Table A-19. Differences between litter and vegetation ranged from $<2 x$ to $>20 x$. Again, the xeric community type often had the lowest total element pools of the three types examined. Potassium was the only element that was higher in vegetation than litter, for the mesic and reclaimed community types.

\section{INTERPRETATION AND RECOMMENDATIONS}

\section{A) Ecosystem Function Parameters.}

All data presented in this report are for the top ten $\mathrm{cm}$ ( 4 inches) of soil only. Characteristics of deeper soil layers are important to plant growth, water and soluble contaminant movement and other aspects of ecosystem processes. Nevertheless, most of the soil organic matter is found in the top few inches of the soil. Most of the $\mathrm{N}$ mineralization, soil respiration, decomposition and other biological processing are concentrated there. Most contaminants, where they are of concern, are spilled on the soil surface. Knowledge of populations, microbial biomass and processes in the surface soil layer is essential to monitoring any ecosystem.

Soil texture (particle size distribution of the fines) controls many ecosystem functions: plant growth, organic matter decomposition. microbial biomass, soil respiration. Clay content generally increased from xeric to mesic to riparian to reclaimed sites. This trend also moves downslope and 
away from the mountains. All of the soils contained a significant volume of coarse fragments. Because these fragments prevented measurement of bulk densities, only the most general extrapolations from concentration to unit area are discussed.

Soil organic $C$ and $N$ are the largest reservoirs of $C$ and $N$. These measurements include all of the active pools reported below and all of the less active organic matter. Rough calculations suggest that soil organic $C$ ranges from $20 \mathrm{Mg}$ per hectare (ten tons per acre) in Riparian sites to $50 \mathrm{Mg}$ per hectare (25 tons per acre) in Xeric sites. Soil organic $N$ ranges from $2000 \mathrm{~kg}$ per hectare (one ton per acre) to $5000 \mathrm{~kg}$ per hectare (2.5 tons per acre). This is sufficient organic matter to sustain healthy ecosystem functions in all communities and to provide the nutrients for the plant community. In many cases, there were greater differences between watersheds than between communities. Spatial heterogeneity between field sites is obviously substantial, but was not explicitly addressed in the current sampling design.

Microbial biomass $\mathrm{C}$ and $\mathrm{N}$ concentrations also reflected spatial heterogeneity. In Xeric sites, the differences between Walnut and Rock Creek were greater than any differences between communities in any watershed, or between average concentrations of any two communities. On average, based on rough estimates of bulk density, the top ten $\mathrm{cm}$ of soil contained about $2000 \mathrm{~kg}$ per hectare (one ton per acre) of microbial biomass. These sites were chosen to avoid any potential effects from RFETS activities. Individual locations can be quite different from each other, but all EcMP sites appear to contain healthy amounts of microbial biomass.

More direct measures of ecosystem functions include potentially mineralizable $\mathrm{C}$ and $\mathrm{N}$ concentrations. The main limiting factors for microbial activity are available water content and soil temperature. These factors fluctuate widely and frequently. Microbial activity increases dramatically and unpredictably following sample collection and soil manipulation. Therefore, potential $\mathrm{C}$ and $\mathrm{N}$ mineralization were measured in the laboratory after $\mathrm{a}$ one week preincubation. Again, there was substantial activity in the range expected for undisturbed grasslands. And, like total organic $\mathrm{C}$ and $\mathrm{N}$ concentrations, respirable $\mathrm{C}$ concentrations varied substantially between sites. Communities were more different from each other in Walnut Creek than in Rock Creek, and were most similar to each other in Woman Creek. Average mineralizable $\mathrm{N}$ concentrations were higher in Rock Creek than in Walnut Creek, also suggesting substantial spatial heterogeneity. Xeric sites had higher concentrations of mineralizable $N$ than Mesic or Riparian sites. Mineralizable $N$ concentrations, but not respirable $C$ concentrations were much lower in Reclaimed sites. Reclaimed sites appear to have qualitatively different soil organic matter even after 20 years in smooth brome.

Fine particulate organic $C$ and $N$ are the soil organic $C$ and $N$ of sand size. Sand sized particles are larger than $53 \mu \mathrm{m}$ but smaller than $2 \mathrm{~mm}$. This part of the soil organic matter is thought to be the most decomposable. If so, differences between communities and between native soil and previously farmed soil (reclaimed) might lie principally in this fraction. Our results show than xeric sites had the highest concentrations and reclaimed sites had the lowest, but differences were not dramatic. These data too show a high degree of spatial heterogeneity.

To find out if differences in concentrations of active organic matter represented qualitative differences, active fractions of total organic $\mathrm{C}$ and $\mathrm{N}$ were calculated. The only active fraction that had a community-by-watershed interaction effect significant at less than $\alpha=0.05$ was Respirable $C$. This interaction resulted from Walnut Creek Riparian sites having more total organic $C$ in respirable $C$ fractions than any other community in any other watershed, except Mesic sites in Woman Creek.

Communities differed from each other significantly in the fractions of their organic matter that occurred as microbial biomass $\mathrm{C}$, but not microbial biomass $\mathrm{N}$ - and in mineralizable $\mathrm{N}$, but not respirable $C$. Watersheds differed significantly in the fractions of their organic matter that occurred as microbial biomass $\mathrm{C}$ and $\mathrm{N}$ - and in respirable $\mathrm{C}$, but not mineralizable $\mathrm{N}$. The biological 
significance of the statistically significant differences between watersheds is not clear. They apparently resulted from inherent spatial variability.

General trends in Figures $A-10, A-11, A-12$ and $A-13$ suggest that organic matter in reclaimed soil is qualitatively different than in the other treatments even though it has been a grassland for twenty years. A larger fraction of its total organic $C$ is found in microbial biomass, but a smaller fraction is in fine particulate organic matter. A smaller fraction of the total $\mathrm{N}$ was mineralized in laboratory incubations in reclaimed sites than in any other site.

The reclaimed sites were probably similar to the mesic sites before they were plowed and planted to small grains. They have similar slope positions, aspect and general soil properties. If the soils were initially similar, they were fundamentally changed by agricultural activities and have not returned to their original state after twenty years in grass. The changes are not reducing the ability of the ecosystem to support plant and animal life or to prevent wind and water erosion.

It is encouraging to think that these measurements can provide a very sensitive indication of ecosystem disturbance. Perhaps they will be sensitive enough to allow clear demonstrations of no effects from disturbances or contaminants. This has been a very difficult thing for relatively clean sites to establish.

\section{B) Soil Physical and Chemical Properties}

Many of the soil concentrations of plant nutrients had significant community effects, indicating that there are significant differences in concentration values among some of the community types. Elements that showed these differences (at $\alpha=0.10$ ) include $\mathrm{P}, \mathrm{K}, \mathrm{Mg} \mathrm{SO}_{4}{ }^{-2}$, and $\mathrm{Na}$.

Community types that often displayed either high or low mean values were often the reclaimed or riparian north or south types. This is not surprising, given the historical anthropogenic manipulations of the reclaimed areas (plowing, cropping, irrigation, fertilization?), and the generally finer particle size distributions than in the grassland types. Riparian types also differ from grassland types in available soil water, organic matter inputs (and vegetation composition), topographic position, and age of materials. In short, it would be surprising if effects were not found.

Reclaimed areas had higher exchangeable $\mathrm{K}$ and $\mathrm{Mg}$ concentrations than other community types. The difference between the reclaimed type and the xeric and mesic types for $\mathrm{Mg}$ was significant at the $\alpha=0.10$ level (means $4.54,1.80$, and $3.10 \mathrm{mg} \mathrm{kg}^{-1}$ respectively). Mean potassium concentration in the reclaimed type was significantly greater than the two riparian types, but not the other grassland types.

Riparian types had significantily greater soil $P$ concentrations than the reclaimed type, but not the other grassland types. Phosphorus is a relatively insoluble element, and riparian types are probably sinks for erosional particles that contribute $P$ to the profile. Soil sulfate and sodium concentrations were greatest in the riparian types, and also much more variable in this community type than the others (the standard deviation in the riparian types for $\mathrm{SO}_{4}^{-2}$ was approximately $6 \mathrm{x}$ greater than grassland standard deviations). The trend of greatest variability in the riparian types was observed for many variables, and is not surprising given the complexity of both the physical and biological conditions in these areas.

Some of the soil analyses also showed significant site-within-community effects. This indicates considerable variation within community types. This is probably related to significant watershed $x$ community interactions that were seen for other variables, but not analyzed for this set. Future sampling may see experimental designs change to a watershed basis, or the analysis of riparian community types separately from grassland types. 


\section{C) Vegetation and Litter}

Total element pools of above-ground vegetation are factors of element concentration and biomass (or littermass) production as previously explained. By collecting tissue on an area basis and analyzing a homogenized sample for element concentrations, an integrated value for that area is obtained. The variation of this variable is considerably less than those of species nutrient concentrations, and it provides a ready estimate of each community's element pool(s). It also more closely represents the diet available for indiscriminant hervibores like cattle or bison.

A surprising amount of variation was found in element pools among the 3 community types analyzed. At this time, it is not known if these differences are real, or sampling artifacts. However, if community types have distinct element distributions, this may be used as a relatively easy tool to not only distinguish community types from one another, but to potentially assess long term changes in community element distributions.

The data do show the very consistent relationship that the majority of the element pools are in litter mass, not above-ground vegetation.

\section{FUTURE ANALYSES}

Data on gaseous transformations of $\mathrm{C}$ and $\mathrm{N}$, specifically carbon dioxide, methane, nitrogen fixation and dentirification under both anaerobic and aerobic conditions are now available. These data are not presented here but will be analyzed for future reports.

These data represent a single year and a single season. Differences between years and between seasons are large for some other parameters of the EcMP. Ecosystem functions will be measured along with the other population measurements. If contamination effects are less than normal and natural fluctuations in the ecosystem, that needs to be known before actions are undertaken or Natural Resource Damages are assessed.

This section of the report covered only ecosystem function measurements and some auxiliary measurements. Future reports will combine these data with data from soil fauna, vegetation, small mammals and other modules and with more general soil properties. The functioning and sensitivity of the whole ecosystem to contamination and perturbation need to be understood to provide solid background data and avoid costly remediation activities where they are not needed. 
Figure A-1. Soil organic C concentrations.

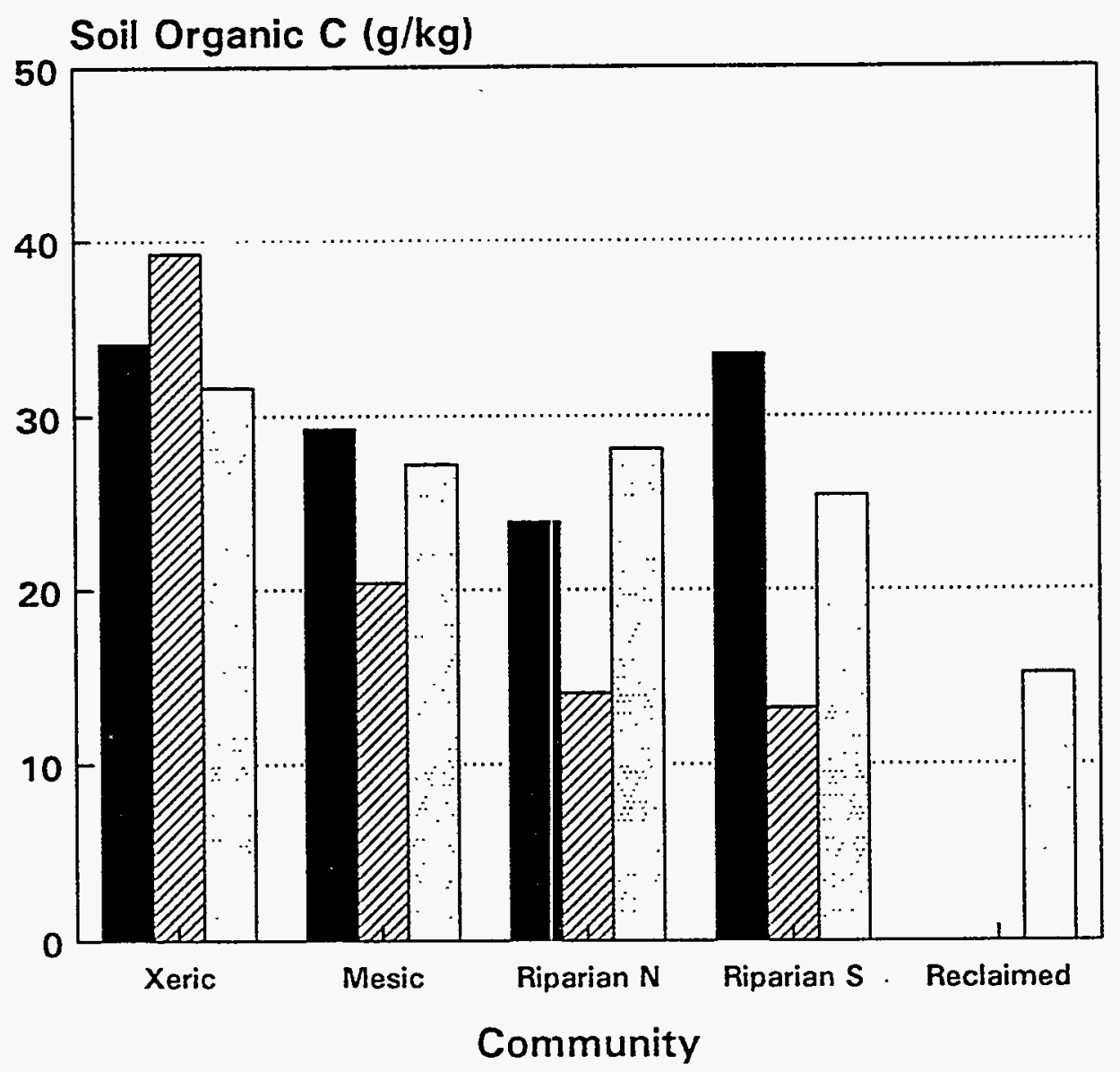

Rock Creek

EIIX Walnut Creek

Woman Creek 
Figure A-2. Soil organic N concentrations.

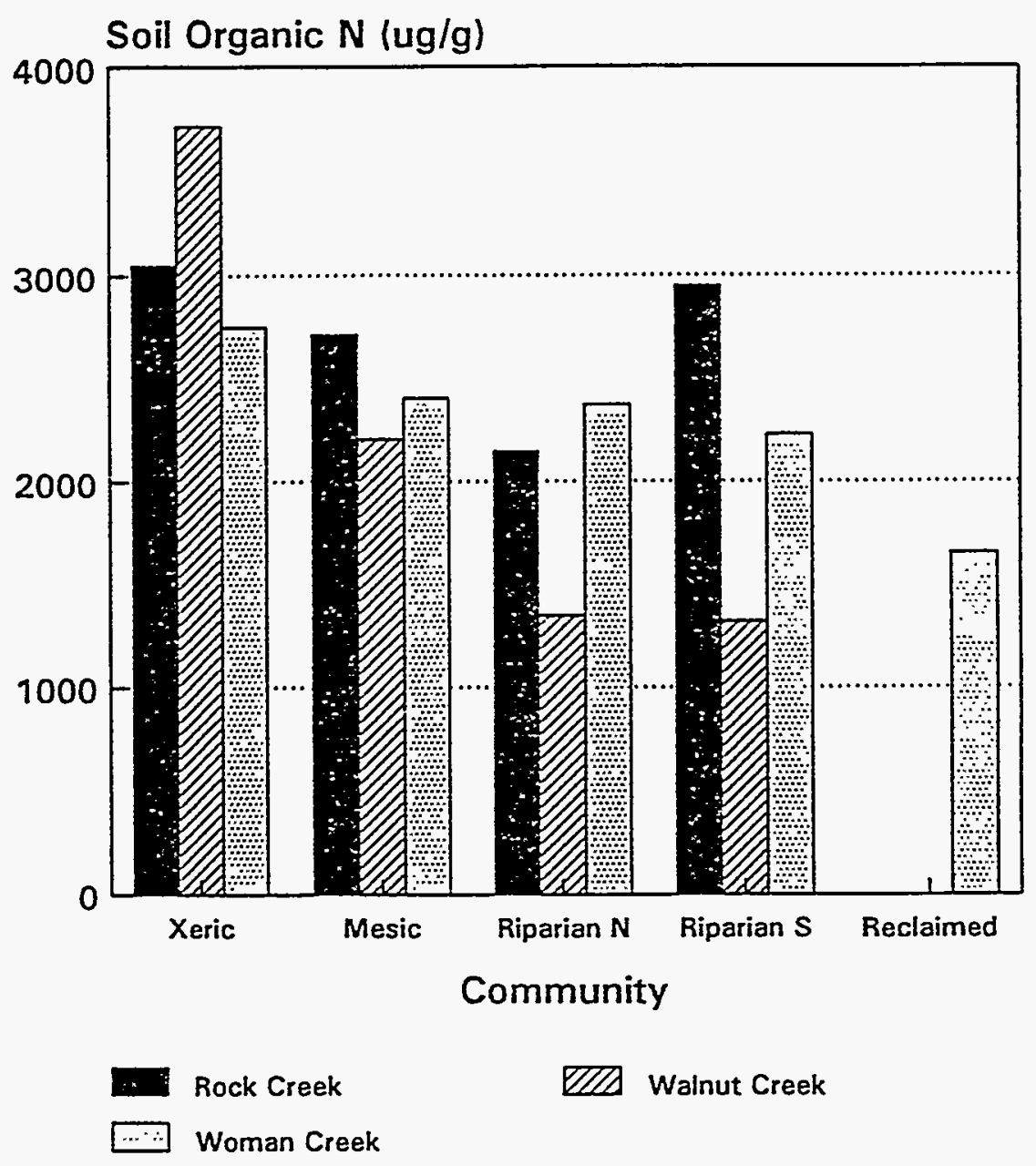


Figure A-3. Microbial biomass $C$ concentrations.

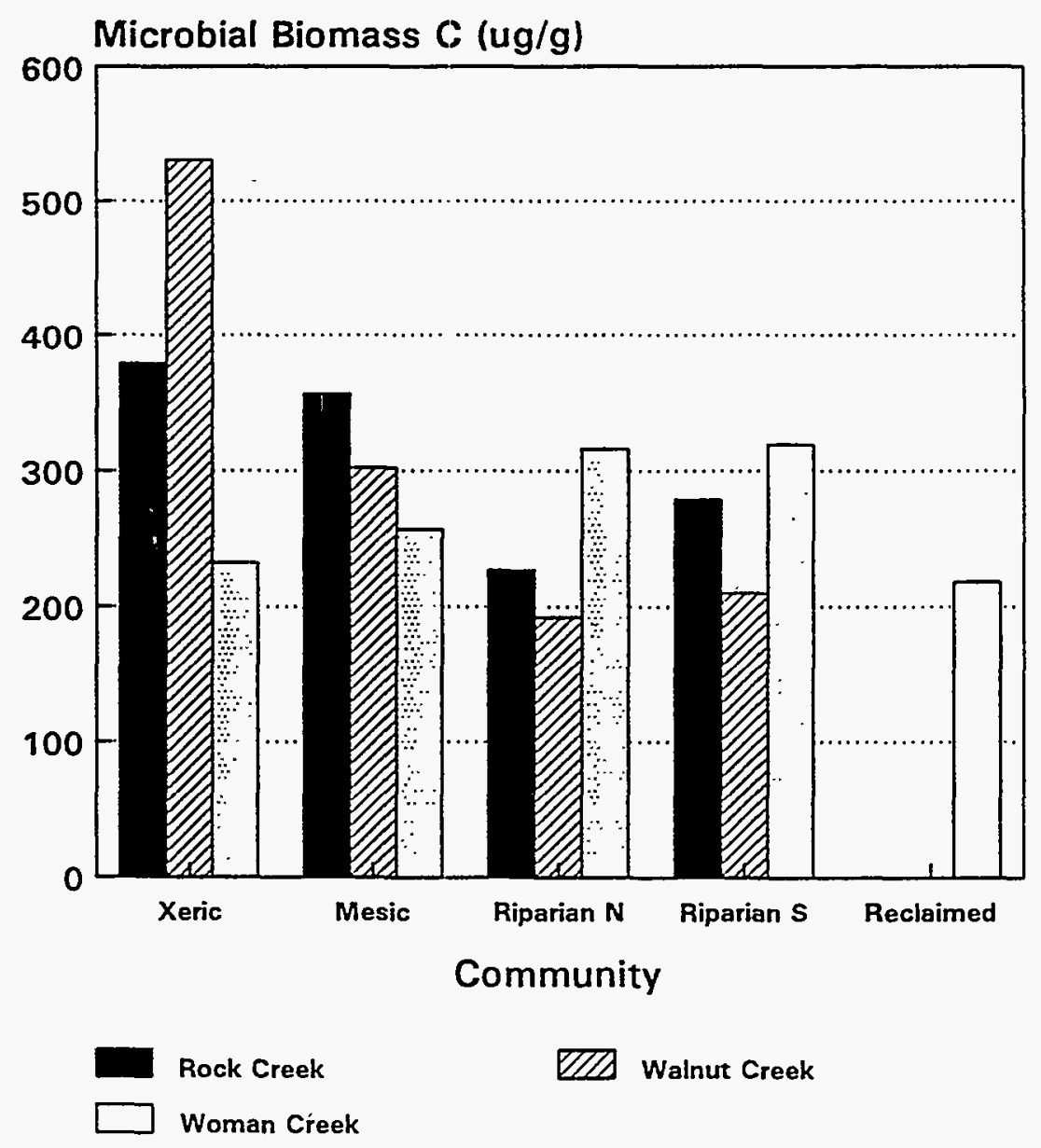


Figure A-4. Microbial Biomass N concentrations.

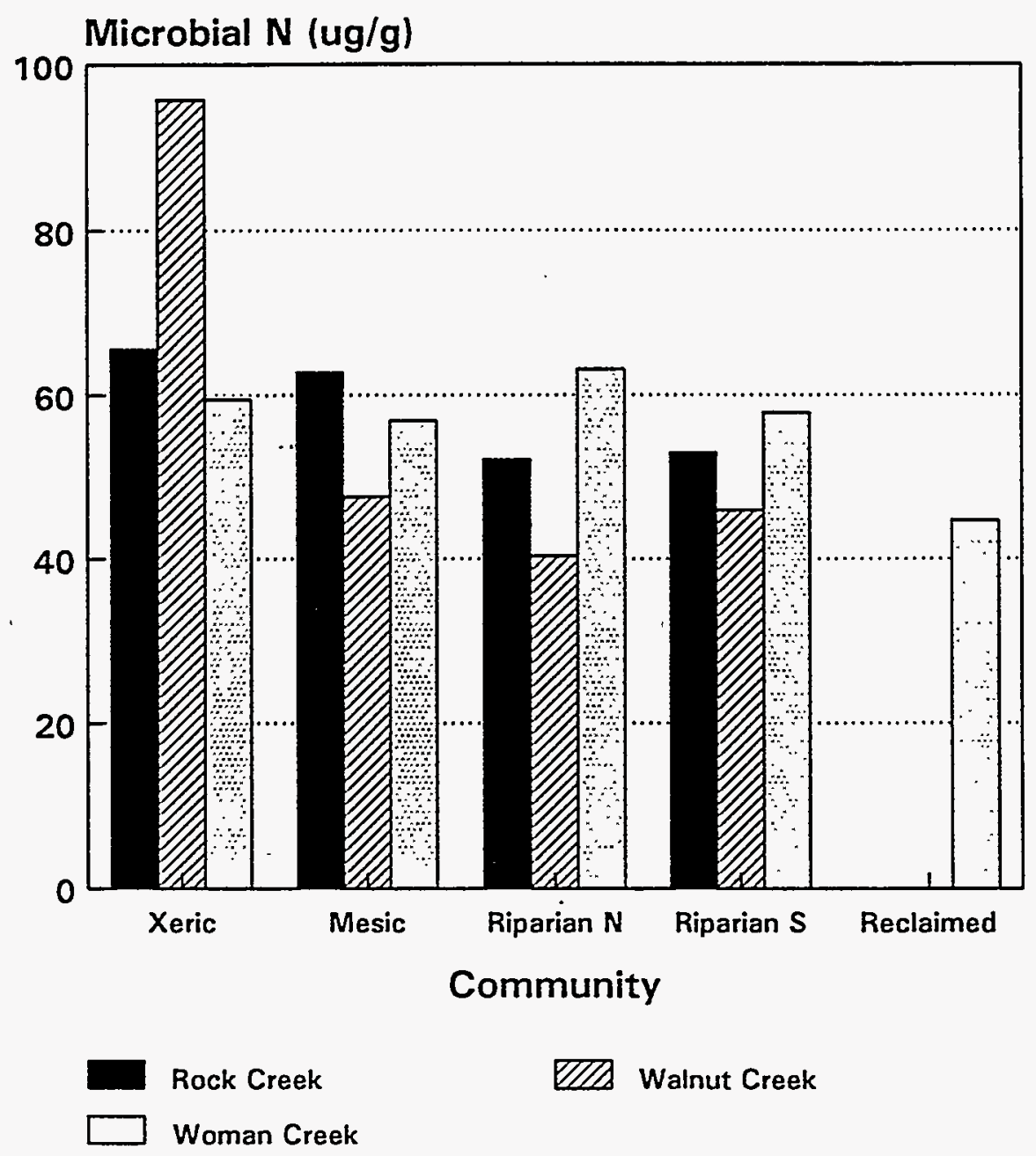


Figure A-5. Respirable C concentrations.

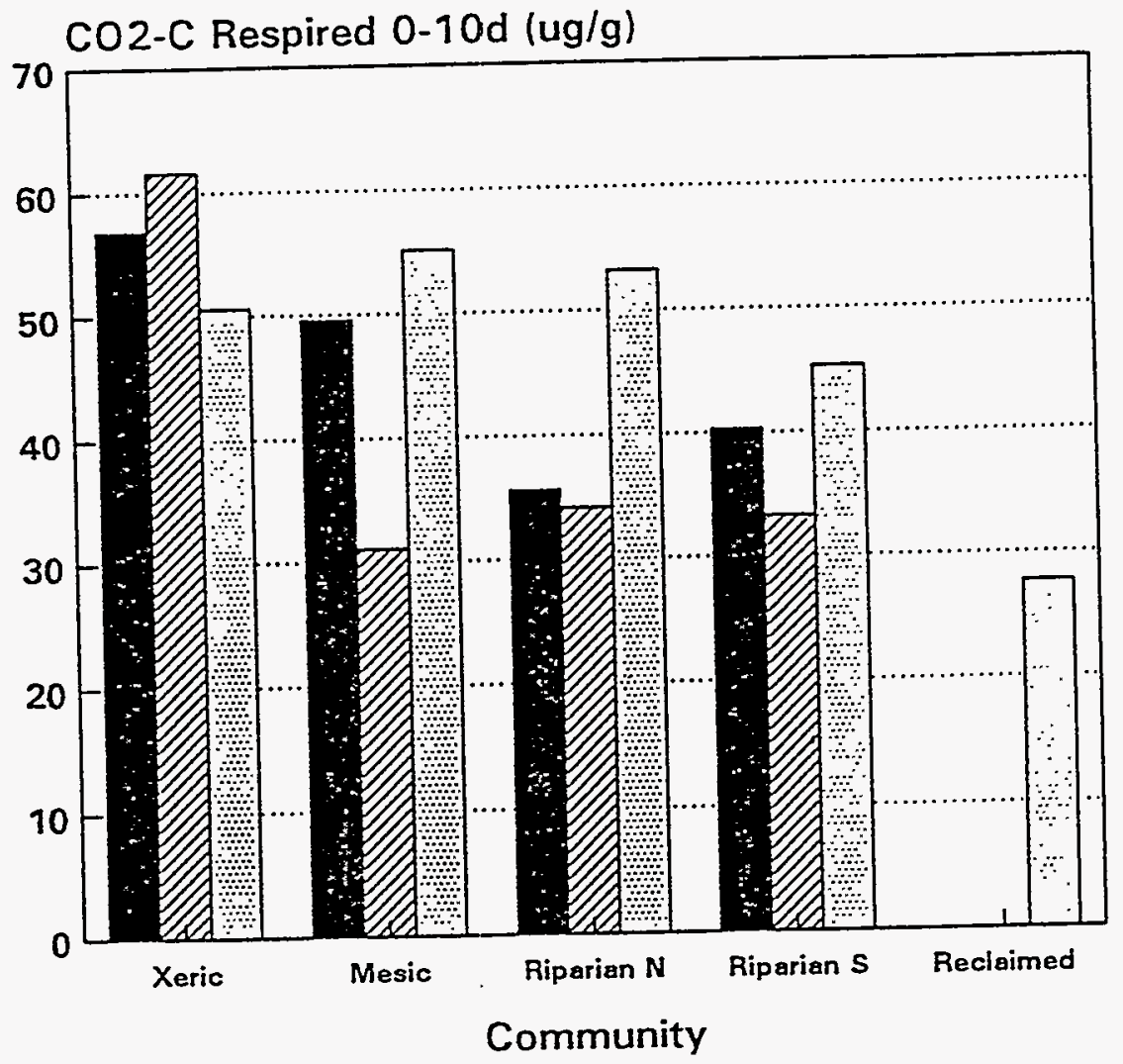

$\square$ Rock Creek
$\square$ Womand Creek


Figure A-6. Mineralizable N concentrations.

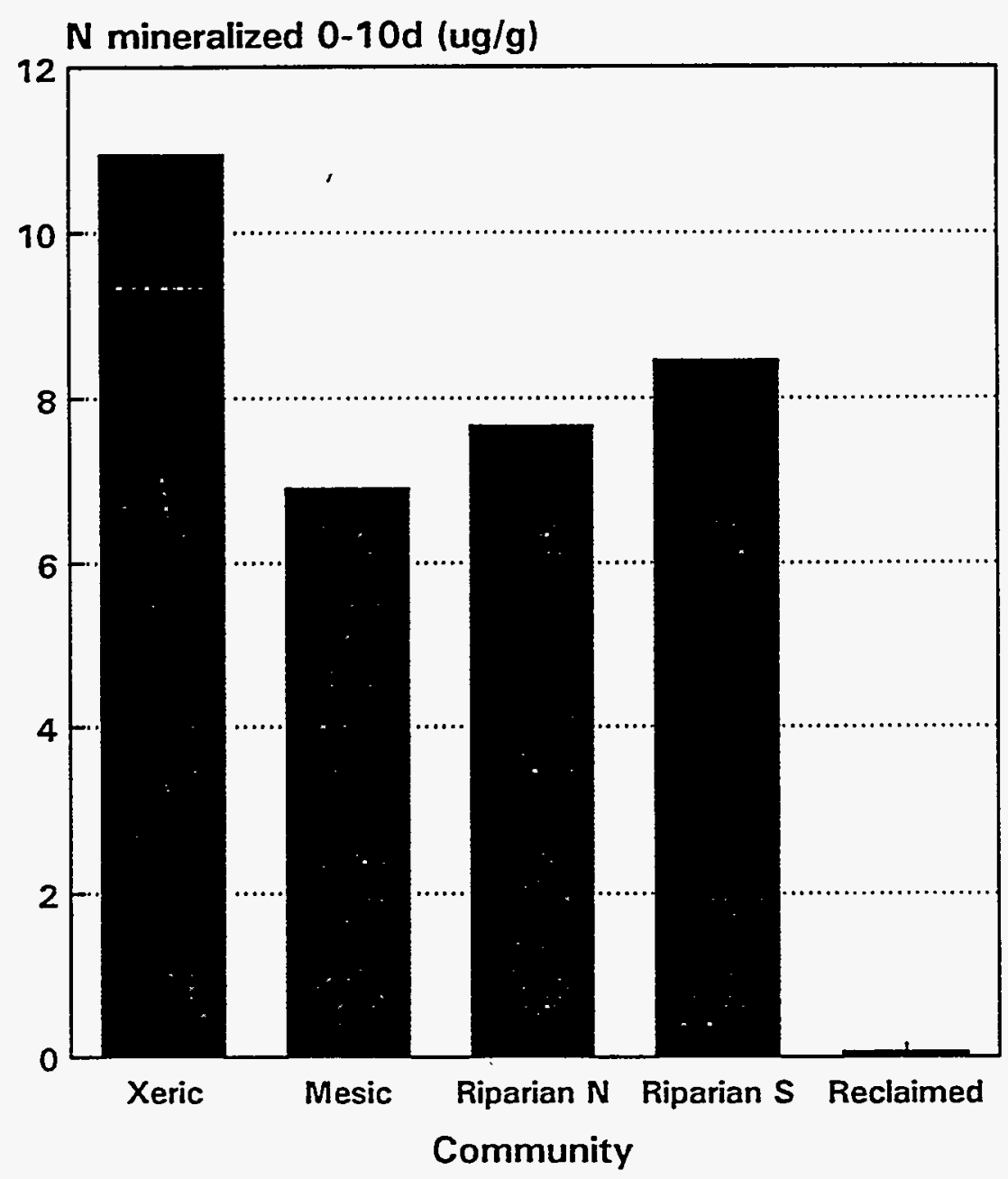


Figure A-7. Fine particulate organic C concentrations.

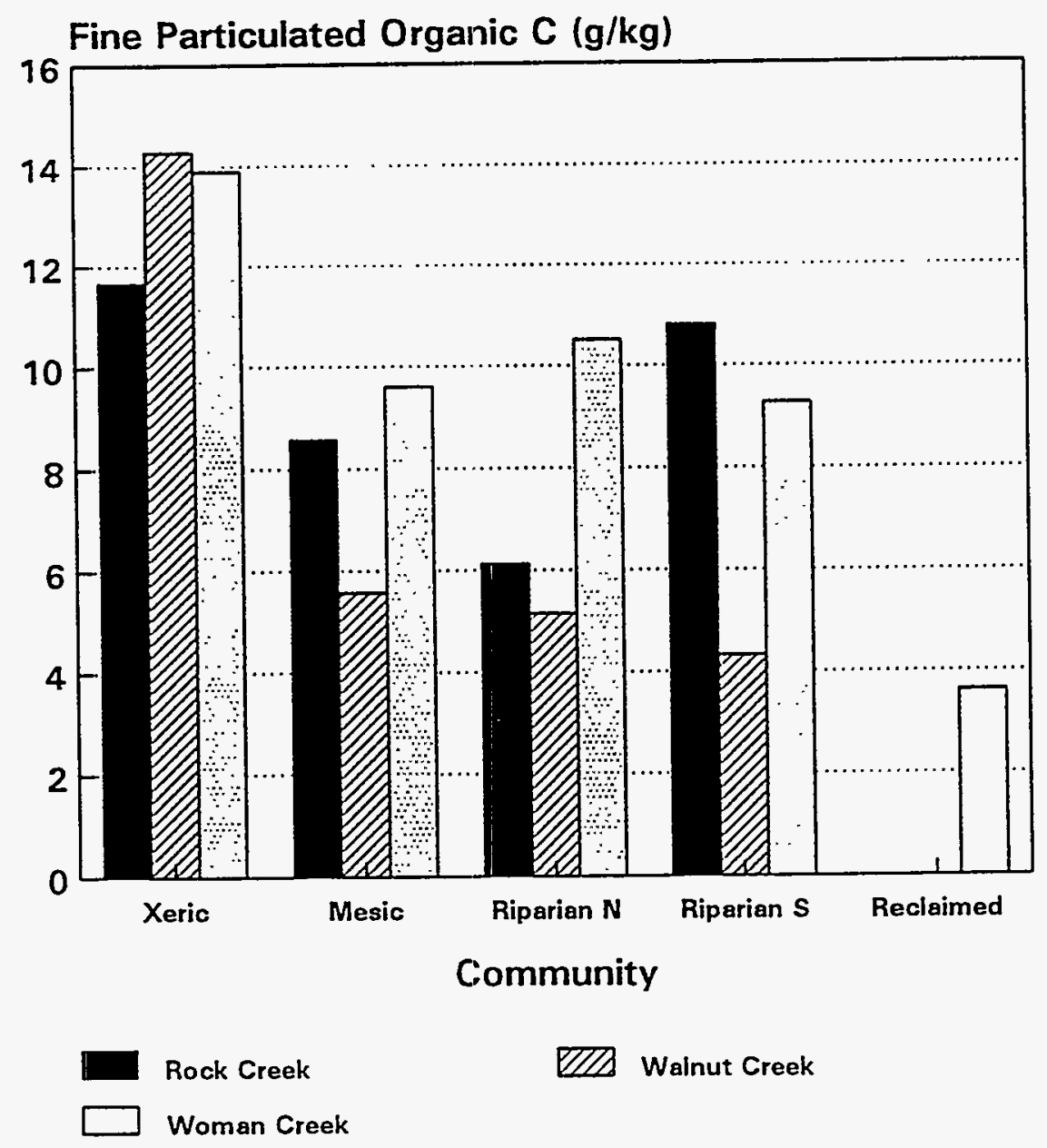


Figure A-8. Fine particulate organic $\mathbf{N}$ concentrations.

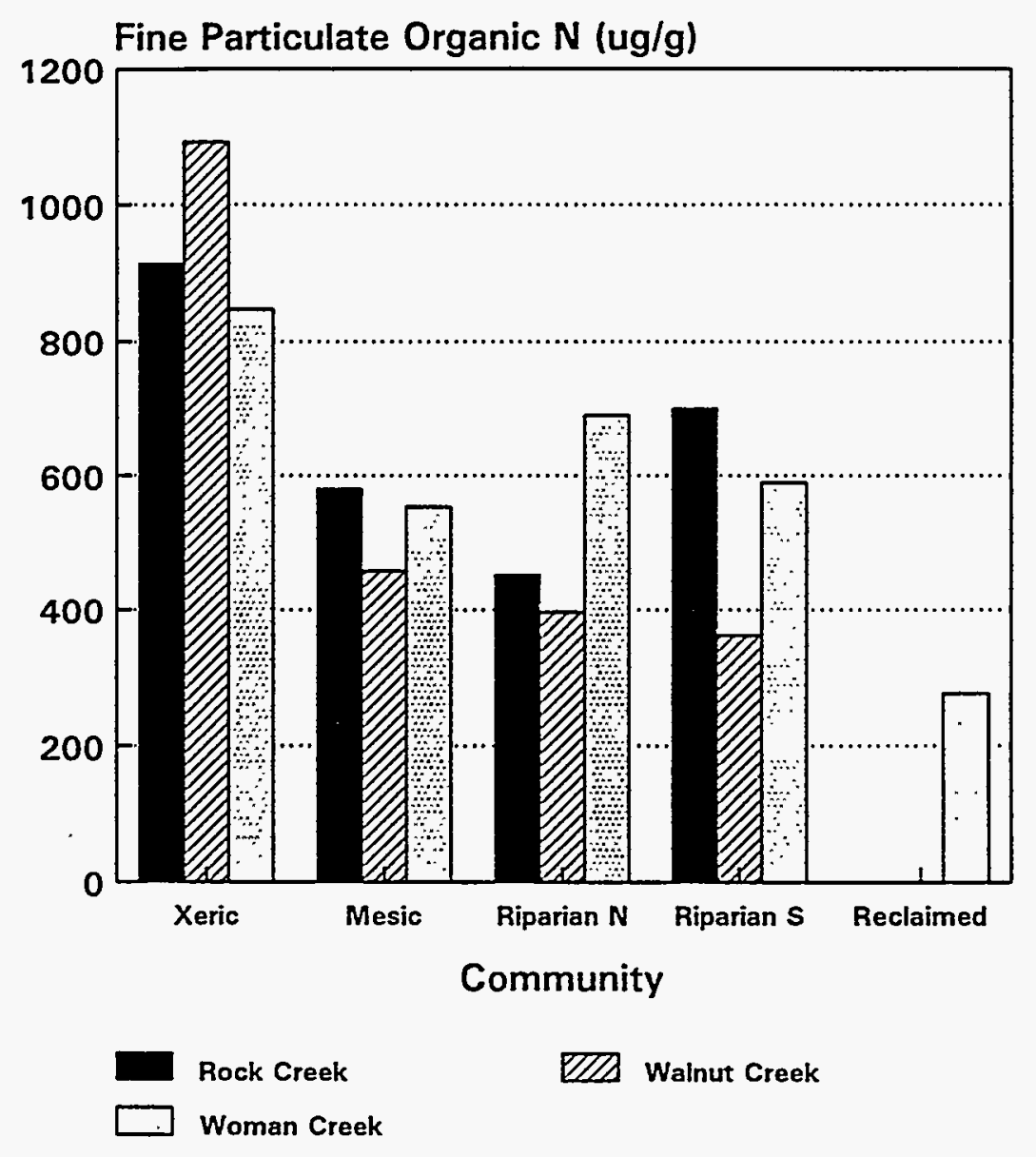


Figure A-9. Respirable C fractions.

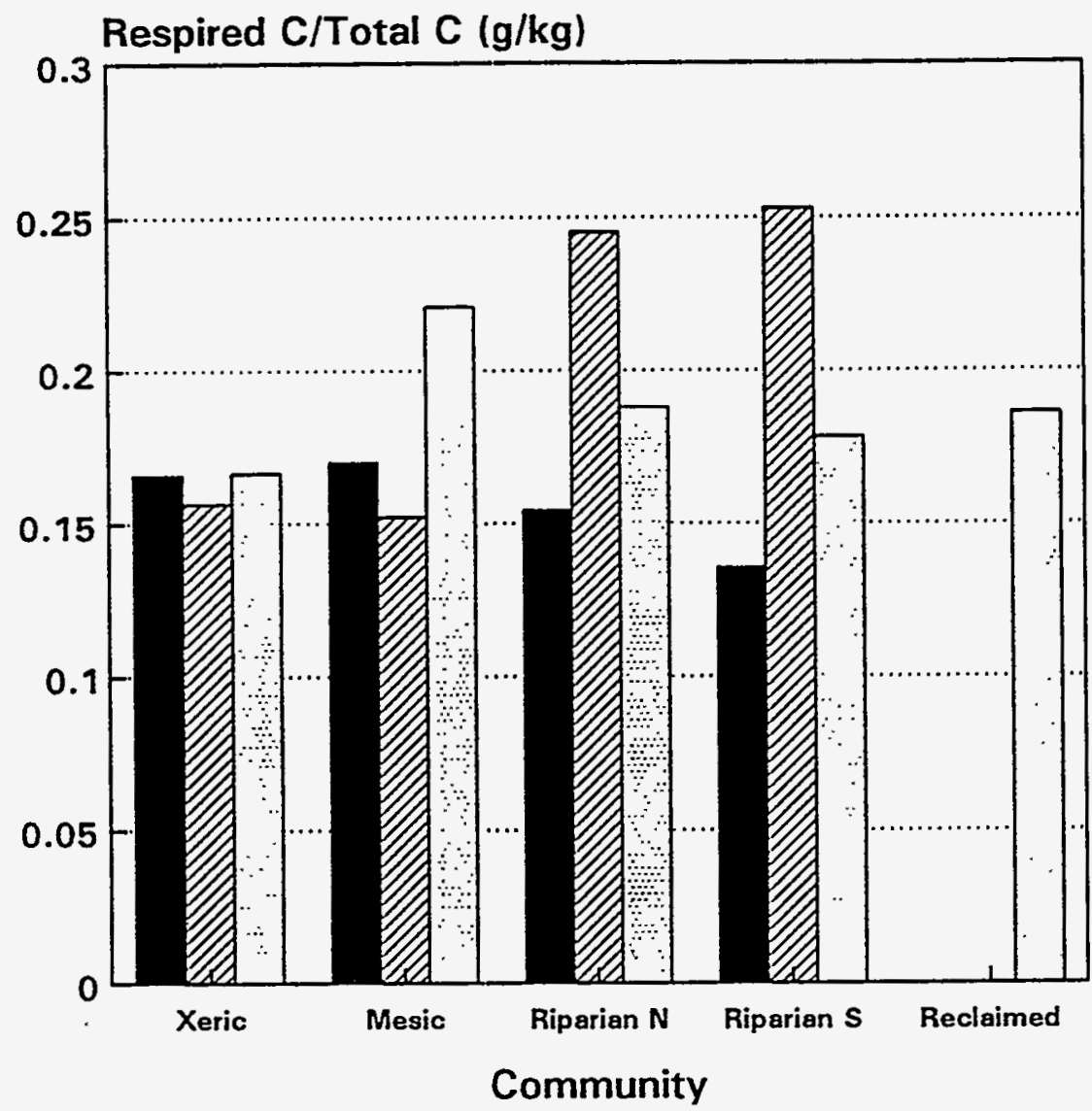

$\square$ Rock Creek
$\square$ Woman Creek

EZD Walnut Creek

$F(6,62)=3.06$

Sig. of $F=0.01$

$\operatorname{HSD}(13,60)=0.11$ 
Figure A-10. Microbial biomass $C$ fractions.

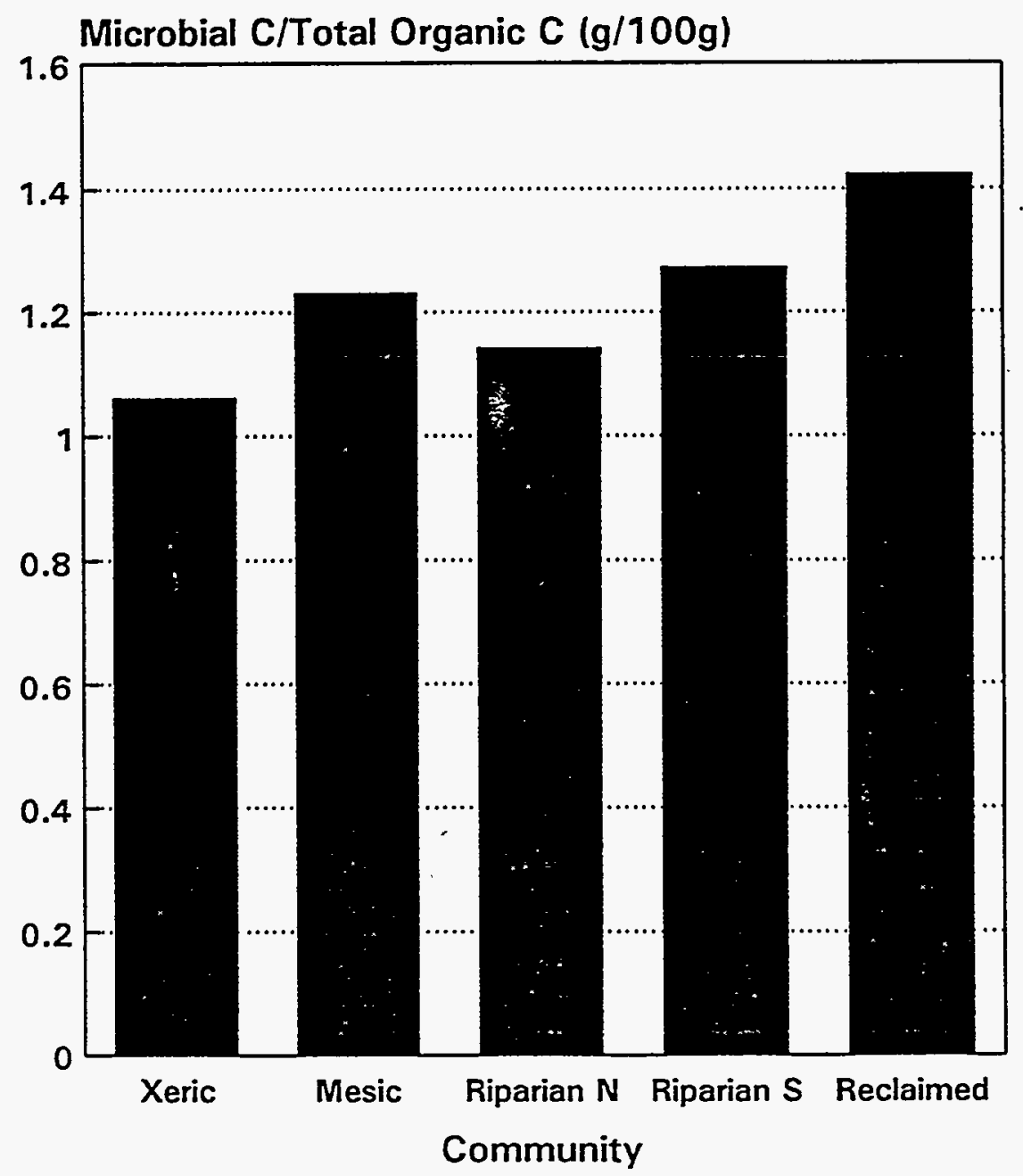


Figure A-11. Mineralizable $\mathbf{N}$ fractions.

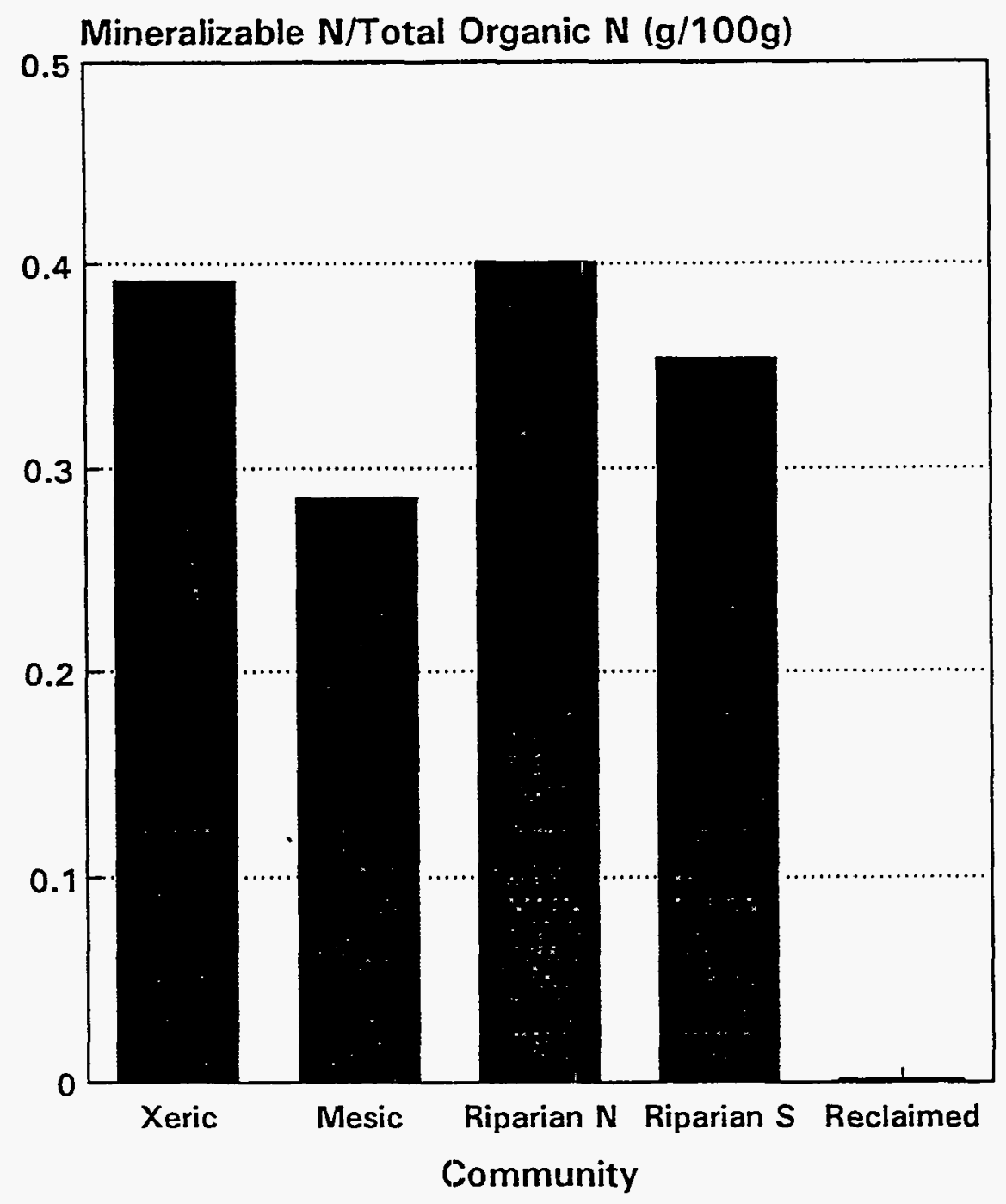


Figure 12. Fine particulate organic $\mathrm{C}$ fractions.

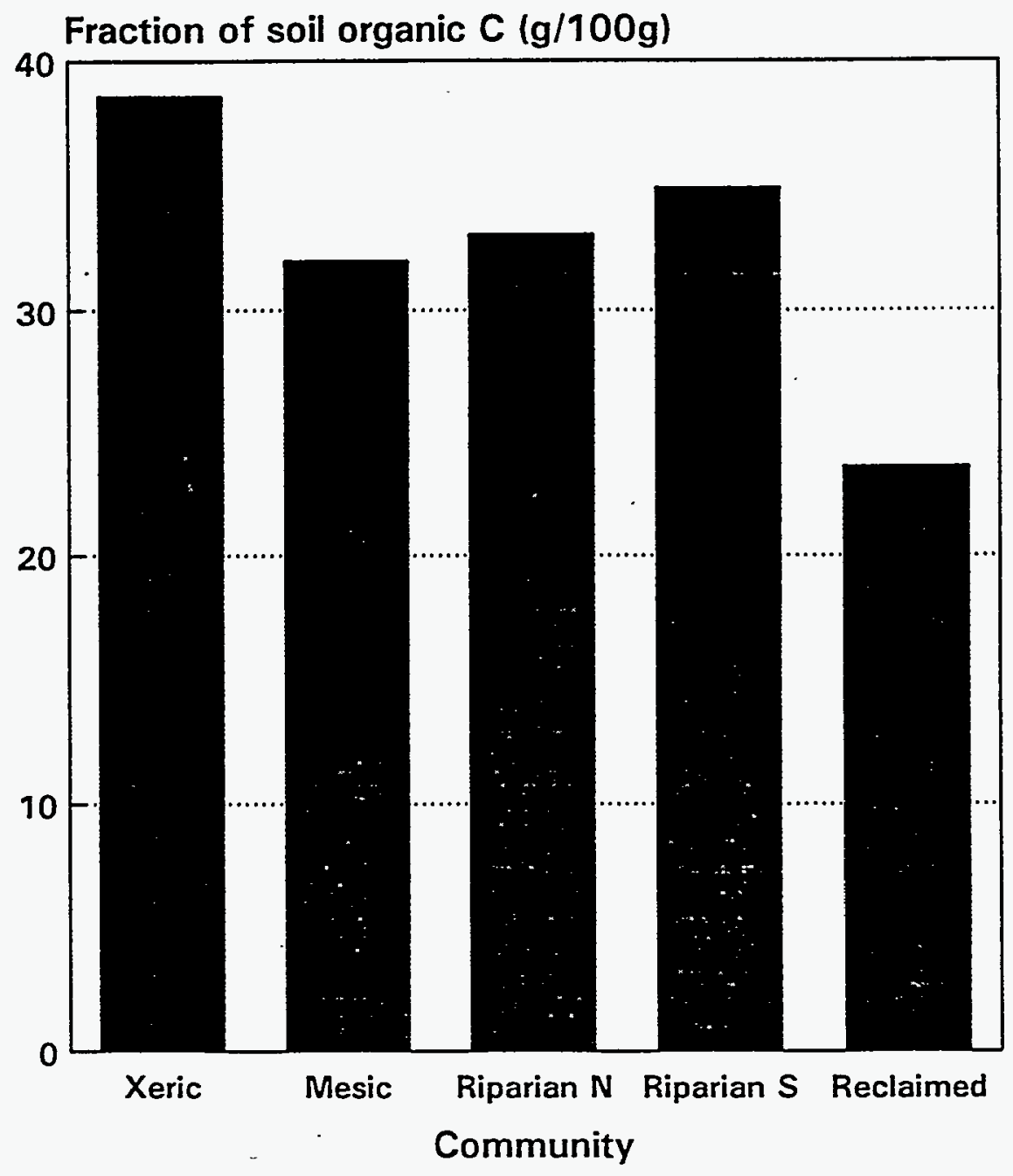


Figure $\mathrm{A}-13$. Fine particulate organic $\mathbf{N}$ fractions.

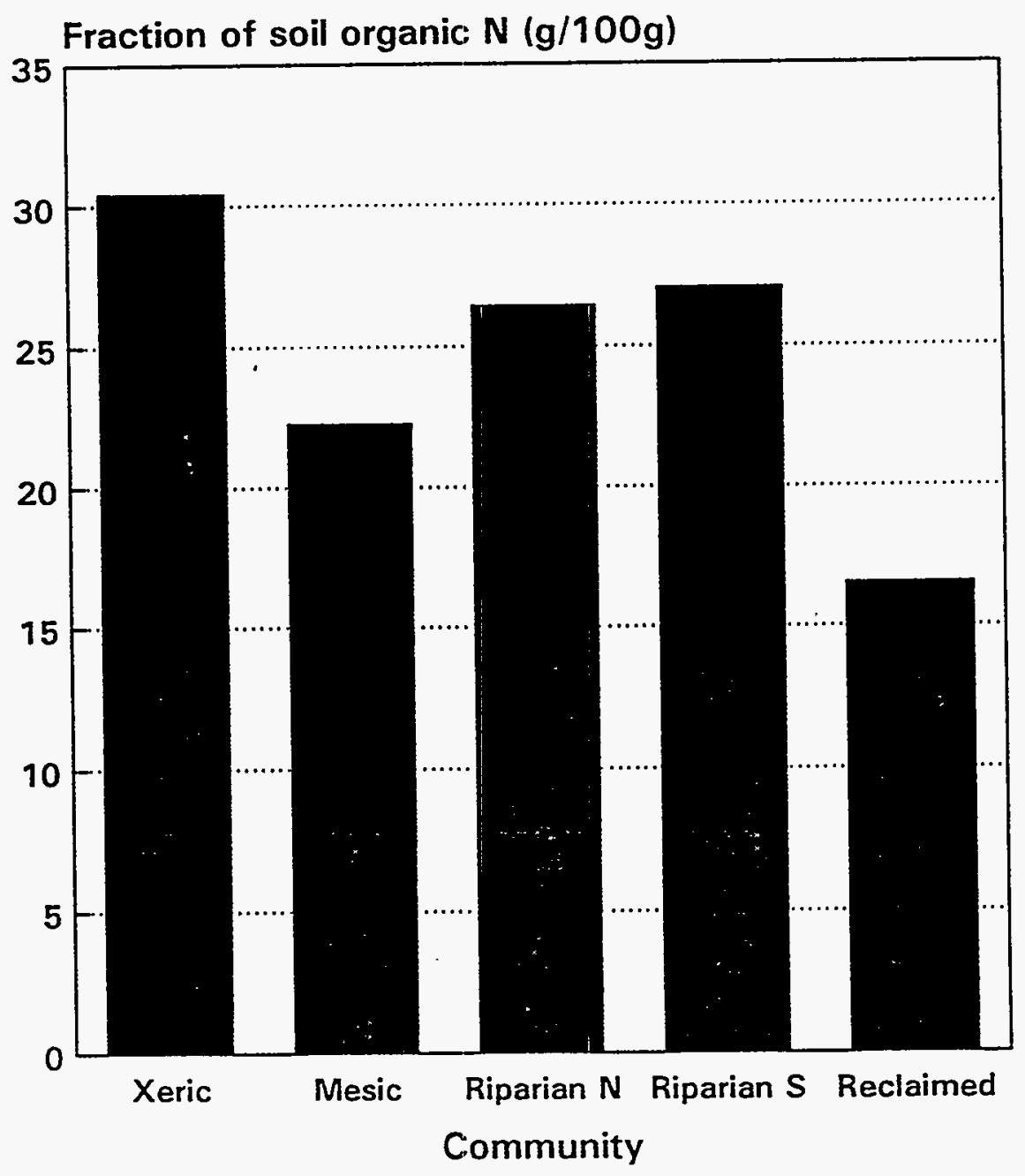


Table A-1. Soil Texture of the surface $10 \mathrm{~cm}$ of Ecological Monitoring Program Sites by Community and Watershed.

\begin{tabular}{|c|c|c|c|c|c|c|}
\hline \multirow[b]{2}{*}{$\begin{array}{l}\text { Community } \\
\text { Watershed } \\
\text { Watershed } \\
\text { Watershed }\end{array}$} & \multirow[b]{2}{*}{ Xeric } & \multirow[b]{2}{*}{$\begin{array}{l}\text { Rock } \\
\text { Walnut } \\
\text { Woman }\end{array}$} & Sand & \multicolumn{2}{|c|}{ Silt Clay } & Texture \\
\hline & & & $\begin{array}{l}0.634 \\
0.541 \\
0.668\end{array}$ & $\begin{array}{l}0.147 \\
0.130 \\
0.117\end{array}$ & $\begin{array}{l}0.219 \\
0.329 \\
0.215\end{array}$ & $\begin{array}{l}\text { sandy clay loam } \\
\text { sandy clay loam } \\
\text { sandy clay loam }\end{array}$ \\
\hline \multicolumn{3}{|c|}{ Average } & 0.615 & 0.131 & 0.254 & sandy clay loam \\
\hline $\begin{array}{l}\text { Community } \\
\text { Watershed } \\
\text { Watershed } \\
\text { Watershed }\end{array}$ & Mesic & $\begin{array}{l}\text { Rock } \\
\text { Walnut } \\
\text { Woman }\end{array}$ & $\begin{array}{l}0.339 \\
0.441 \\
0.457\end{array}$ & $\begin{array}{l}0.234 \\
0.223 \\
0.209\end{array}$ & $\begin{array}{l}0.427 \\
0.335 \\
0.333\end{array}$ & $\begin{array}{l}\text { clay } \\
\text { clay loam } \\
\text { sandy clay loam }\end{array}$ \\
\hline \multicolumn{3}{|c|}{ Average } & 0.413 & 0.222 & 0.365 & clay loam \\
\hline $\begin{array}{l}\text { Community } \\
\text { Watershed } \\
\text { Watershed } \\
\text { Watershed }\end{array}$ & Riparie & $\begin{array}{l}\text { North } \\
\text { Rock } \\
\text { Walnut } \\
\text { Woman }\end{array}$ & $\begin{array}{l}0.501 \\
0.519 \\
0.412\end{array}$ & $\begin{array}{l}0.157 \\
0.141 \\
0.180\end{array}$ & $\begin{array}{l}0.342 \\
0.341 \\
0.408\end{array}$ & $\begin{array}{l}\text { sandy clay } \\
\text { sandy clay loam } \\
\text { clay }\end{array}$ \\
\hline \multicolumn{3}{|c|}{ Average } & 0.477 & 0.159 & 0.363 & sandy clay \\
\hline
\end{tabular}

$\begin{array}{lccccl}\text { Community } & \text { Riparian South } & & & & \\ \text { Watershed } & \text { Rock } & 0.470 & 0.183 & 0.347 & \text { sandy clay loam } \\ \text { Watershed } & \text { Walnut } & 0.512 & 0.145 & 0.343 & \text { sandy clay loam } \\ \text { Watershed } & \text { Woman } & 0.353 & 0.208 & 0.439 & \text { clay } \\ & \text { Average } & 0.445 & 0.179 & 0.376 & \text { clay loam }\end{array}$

\begin{tabular}{lccccc}
$\begin{array}{c}\text { Community } \\
\text { Watershed }\end{array}$ & $\begin{array}{c}\text { Reclaimed } \\
\text { Woman }\end{array}$ & 0.292 & 0.208 & 0.500 & clay \\
\hline & Average & 0.292 & 0.208 & 0.500 & clay
\end{tabular}

Average of all sites

$\begin{array}{lll}0.448 & 0.180 & 0.372 \\ \text { clay loam }\end{array}$ 
Table A-2. Analysis of Variance for Total Soil Organic Carbon by Community and Watershed.

\begin{tabular}{llclll} 
Source of Variation & $\begin{array}{l}\text { Sum of } \\
\text { Squares }\end{array}$ & DF & $\begin{array}{l}\text { Mean } \\
\text { Square }\end{array}$ & F & $\begin{array}{l}\text { Signif } \\
\text { of F }\end{array}$ \\
Main Effects & 862295797.37 & 6 & 643715966.23 & 16.310 & 0.000 \\
Community & 2924654951.02 & 4 & 731163737.76 & 18.526 & 0.000 \\
Watershed & 783343705.633 & 2 & 391671852.82 & 9.924 & 0.000 \\
$\begin{array}{l}\text { 2-way Interactions } \\
\text { Community } \\
\text { By Watershed }\end{array}$ & 1160047826.37 & 6 & 193341304.39 & 4.899 & 0.000 \\
Residual & 2446993970.93 & 62 & 39467644.69 & & \\
Total & 7469337594.67 & 74 & 100936994.52 & & \\
\hline
\end{tabular}

Table A-3. Analysis of Variance for Total Soil Organic Nitrogen by Community and Watershed.

\begin{tabular}{|c|c|c|c|c|c|}
\hline Source of Variation & $\begin{array}{l}\text { Sum of } \\
\text { Squares }\end{array}$ & DF & $\begin{array}{l}\text { Mean } \\
\text { Square }\end{array}$ & $\mathrm{F}$ & $\begin{array}{l}\text { Sign:- } \\
\text { of } F\end{array}$ \\
\hline Main Effects & 23257499.980 & 6 & 3876249.997 & 13.650 & 0.000 \\
\hline Community & 18003952.319 & 4 & 4500988.080 & 15.850 & 0.000 \\
\hline Watershed & 3240954.433 & 2 & 1620477.217 & 5.706 & 0.005 \\
\hline \multicolumn{6}{|l|}{$\begin{array}{l}\text { 2-way Interaction } \\
\text { Community }\end{array}$} \\
\hline By Watershed & 9464545.967 & 6 & 1577424.328 & 5.555 & 0.000 \\
\hline Residual & 17606468.400 & 62 & 283975.297 & & \\
\hline Total & 50328514.347 & 74 & 680115.059 & & \\
\hline
\end{tabular}


Table A-4. Analysis of Variance for Microbial Biomass Carbon by Community and Watershed.

\begin{tabular}{|c|c|c|c|c|c|}
\hline Source of Variation & $\begin{array}{l}\text { Sum of } \\
\text { Squares }\end{array}$ & DF & $\begin{array}{l}\text { Mean } \\
\text { Square }\end{array}$ & $F$ & $\begin{array}{l}\text { Signif } \\
\text { of } F\end{array}$ \\
\hline $\begin{array}{l}\text { Main Effects } \\
\text { Community } \\
\text { Watershed }\end{array}$ & $\begin{array}{r}247967.647 \\
191031.736 \\
10643.033\end{array}$ & $\begin{array}{l}6 \\
4 \\
2\end{array}$ & $\begin{array}{r}41327.941 \\
47757.934 \\
5321.517\end{array}$ & $\begin{array}{l}5.723 \\
6.614 \\
0.737\end{array}$ & $\begin{array}{l}0.000 \\
0.000 \\
0.483\end{array}$ \\
\hline $\begin{array}{l}\text { 2-way Interaction } \\
\text { Community } \\
\text { By Watershed }\end{array}$ & 308347.767 & 6 & 51391.294 & 7.117 & 0.000 \\
\hline Residual & 447686.933 & 62 & 7220.757 & & \\
\hline Total & 1004002.347 & 74 & 13567.599 & & \\
\hline
\end{tabular}

Table A-5. Analysis of Variance for Microbial Biomass Nitrogen by Community and Watershed.

\begin{tabular}{llrrrr} 
Source of Variation & $\begin{array}{l}\text { Sum of } \\
\text { Squares }\end{array}$ & $\begin{array}{l}\text { Mean } \\
\text { DF }\end{array}$ & Square & $F$ & Signif \\
Main Effects & 7083.847 & 6 & 1180.641 & 6.165 & 0.000 \\
Community & 6624.393 & 4 & 1656.098 & 8.648 & 0.000 \\
Watershed & 40.300 & 2 & 20.150 & 0.105 & 0.900 \\
$\begin{array}{l}\text { 2-way Interaction } \\
\text { Community } \\
\quad \text { By Watershed }\end{array}$ & 6002.767 & & & & \\
Residual & 11873.333 & 6 & 1000.461 & 5.224 & 0.000 \\
Total & 24959.947 & 62 & 191.505 & & \\
\hline
\end{tabular}


Table A-6. Analysis of Variance for Respirable Carbon by Community and Watershed.

\begin{tabular}{|c|c|c|c|c|c|}
\hline Source of Variation & $\begin{array}{l}\text { Sum of } \\
\text { Squares }\end{array}$ & DF & $\begin{array}{l}\text { Mean } \\
\text { Square }\end{array}$ & $F$ & $\begin{array}{l}\text { Signif } \\
\text { of } F\end{array}$ \\
\hline $\begin{array}{l}\text { Main Effects } \\
\text { Community } \\
\text { Watershed }\end{array}$ & $\begin{array}{l}763023.020 \\
726665.971 \\
121771.900\end{array}$ & $\begin{array}{l}6 \\
4 \\
2\end{array}$ & $\begin{array}{r}127170.503 \\
181666.493 \\
60885.950\end{array}$ & $\begin{array}{r}10.181 \\
14.544 \\
4.874\end{array}$ & $\begin{array}{l}0.000 \\
0.000 \\
0.011\end{array}$ \\
\hline $\begin{array}{c}\text { 2-way interaction } \\
\text { Community } \\
\text { By Watershed }\end{array}$ & 218025.700 & 6 & 36337.617 & 2.909 & 0.015 \\
\hline Residual & 774448.800 & 62 & 12491.110 & & \\
\hline Total & 1755497.520 & 74 & 23722.939 & & \\
\hline
\end{tabular}

Table A-7. Analysis of Variance for Mineralizable Nitrogen by Community and Watershed.

\begin{tabular}{|c|c|c|c|c|c|}
\hline Source of Variation & $\begin{array}{l}\text { Sum of } \\
\text { Squares }\end{array}$ & DF & $\begin{array}{l}\text { Mean } \\
\text { Square }\end{array}$ & $\mathrm{F}$ & $\begin{array}{l}\text { Signif } \\
\text { of } F\end{array}$ \\
\hline $\begin{array}{l}\text { Main Effects } \\
\text { Community } \\
\text { Watershed }\end{array}$ & $\begin{array}{r}6228.048 \\
5708.142 \\
594.566\end{array}$ & $\begin{array}{l}6 \\
4 \\
2\end{array}$ & $\begin{array}{r}1038.008 \\
1427.035 \\
297.283\end{array}$ & $\begin{array}{r}11.214 \\
15.416 \\
3.212\end{array}$ & $\begin{array}{l}0.000 \\
0.000 \\
0.047\end{array}$ \\
\hline $\begin{array}{l}\text { 2-way Interaction } \\
\text { Community } \\
\text { By Watershed }\end{array}$ & 596.994 & 6 & 99.499 & 1.075 & 0.387 \\
\hline Residual & 5739.185 & 62 & 92.568 & & \\
\hline Total & 12564.227 & 74 & 169.787 & & \\
\hline
\end{tabular}


Table A-8. Analysis of Variance for Fine Particulate Organic Carbon by Community and Watershed.

\begin{tabular}{|c|c|c|c|c|c|}
\hline Source of Variation & $\begin{array}{l}\text { Sum of } \\
\text { Squares }\end{array}$ & DF & $\begin{array}{l}\text { Mean } \\
\text { Square }\end{array}$ & $F$ & $\begin{array}{l}\text { Signif } \\
\text { of } F\end{array}$ \\
\hline $\begin{array}{l}\text { Main Effects } \\
\text { Community } \\
\text { Watershed }\end{array}$ & $\begin{array}{l}837050447.620 \\
792386317.069 \\
122247210.633\end{array}$ & $\begin{array}{l}6 \\
4 \\
2\end{array}$ & $\begin{array}{r}139508407.94 \\
198096579.27 \\
61123605.32\end{array}$ & $\begin{array}{l}23.618 \\
33.536 \\
10.348\end{array}$ & $\begin{array}{l}0.000 \\
0.000 \\
0.000\end{array}$ \\
\hline $\begin{array}{l}\text { 2-way Interaction } \\
\text { Community } \\
\text { By Watershed }\end{array}$ & 137961392.567 & 6 & 22993565.43 & 3.893 & 0.002 \\
\hline Residual & 366228843.600 & 62 & 5906916.83 & & \\
\hline Total & 1341240683.79 & 74 & 18124874.10 & & \\
\hline
\end{tabular}

Table A-9. Analysis of Variance for Fine Particulate Organic Nitrogen by Community and Watershed.

\begin{tabular}{|c|c|c|c|c|c|}
\hline Source of Variation & $\begin{array}{l}\text { Sum of } \\
\text { Squares }\end{array}$ & DF & $\begin{array}{l}\text { Mean } \\
\text { Square }\end{array}$ & $\mathrm{F}$ & $\begin{array}{l}\text { Signif } \\
\text { of } F\end{array}$ \\
\hline $\begin{array}{c}\text { Main Effects } \\
\text { Community } \\
\text { Watershed }\end{array}$ & $\begin{array}{r}3642720.153 \\
3314619.938 \\
105136.633\end{array}$ & $\begin{array}{l}6 \\
4 \\
2\end{array}$ & $\begin{array}{r}607120.026 \\
828654.985 \\
52568.317\end{array}$ & $\begin{array}{r}30.778 \\
42.009 \\
2.665\end{array}$ & $\begin{array}{l}0.000 \\
0.000 \\
0.078\end{array}$ \\
\hline \multicolumn{6}{|l|}{$\begin{array}{l}\text { 2-way Interaction } \\
\text { Community }\end{array}$} \\
\hline By Watershed & 636605.500 & 6 & 106100.917 & 5.379 & 0.000 \\
\hline Residual & 1222995.733 & 62 & 19725.738 & & \\
\hline Total & 5502321.387 & 74 & 74355.694 & & \\
\hline
\end{tabular}


Table A-10. Anaiysis of Variance for the fraction of the total soil organic $C$ found in microbial biomass: Microbial biomass percent by Community by Watershed.

\begin{tabular}{lccccc} 
Source of Variation & $\begin{array}{c}\text { Sum of } \\
\text { Squares }\end{array}$ & DF & $\begin{array}{l}\text { Mean } \\
\text { Square }\end{array}$ & $F$ & $\begin{array}{l}\text { Significance } \\
\text { of F }\end{array}$ \\
$\begin{array}{l}\text { Main Effects } \\
\text { Community }\end{array}$ & 3.600 & 6 & 0.600 & 5.530 & 0.000 \\
Watershed & 1.787 & 4 & 0.447 & 4.118 & 0.005 \\
$\begin{array}{l}\text { 2-way Interaction } \\
\text { Community } \\
\text { By Watershed }\end{array}$ & 2.477 & 2 & 1.238 & 11.415 & 0.000 \\
$\begin{array}{l}\text { Residual } \\
\text { Total }\end{array}$ & 1.037 & 6 & 0.173 & 1.593 & 0.164 \\
\hline
\end{tabular}

Table A-11. Analysis of Variance for the fraction of the total soil organic $\mathrm{N}$ found in microbial biomass: Microbial biomass $\mathrm{N}$ percent by Community by Watershed.

\begin{tabular}{|c|c|c|c|c|c|}
\hline Source of Variation & $\begin{array}{l}\text { Sum of } \\
\text { Squares }\end{array}$ & DF & $\begin{array}{l}\text { Mean } \\
\text { Square }\end{array}$ & $F$ & $\begin{array}{l}\text { Significance } \\
\text { of } F\end{array}$ \\
\hline Main Effects & 6.130 & 6 & 1.022 & 2.369 & 0.040 \\
\hline Community & 2.672 & 4 & 0.668 & 1.550 & 0.199 \\
\hline Watershed & 3.390 & 2 & 1.695 & 3.932 & 0.025 \\
\hline \multicolumn{6}{|l|}{$\begin{array}{l}\text { 2-way Interaction } \\
\text { Community }\end{array}$} \\
\hline By Watershed & 3.535 & 6 & 0.589 & 1.366 & 0.242 \\
\hline Residual & 26.733 & 62 & 0.431 & & \\
\hline Total & 36.397 & 74 & 0.492 & & \\
\hline
\end{tabular}


Table A-12. Analysis of Variance for the fraction of the total soil organic $\mathrm{C}$ in respirable $\mathrm{C}$ : Respirable $C$ percent by Community by Watershed.

\begin{tabular}{|c|c|c|c|c|c|}
\hline Source of Variation & $\begin{array}{l}\text { Sum of } \\
\text { Squares }\end{array}$ & DF & $\begin{array}{l}\text { Mean } \\
\text { Square }\end{array}$ & $F$ & $\begin{array}{l}\text { Significance } \\
\text { of } F\end{array}$ \\
\hline $\begin{array}{l}\text { Main Effects } \\
\text { Community } \\
\text { Watershed }\end{array}$ & $\begin{array}{l}0.031 \\
0.009 \\
0.022\end{array}$ & $\begin{array}{l}6 \\
4 \\
2\end{array}$ & $\begin{array}{l}0.005 \\
0.002 \\
0.011\end{array}$ & $\begin{array}{l}1.973 \\
0.871 \\
4.148\end{array}$ & $\begin{array}{l}0.083 \\
0.486 \\
0.020\end{array}$ \\
\hline $\begin{array}{c}\text { 2-way Interaction } \\
\text { Community } \\
\text { By Watershed }\end{array}$ & 0.048 & 6 & 0.008 & 3.048 & 0.011 \\
\hline Residual & 0.162 & 62 & 0.003 & & \\
\hline Total & 0.240 & 74 & 0.003 & & \\
\hline
\end{tabular}

Table A-13. Analysis of Variance for the fraction of the total soil organic $\mathrm{N}$ mineralized: Mineral $\mathrm{N}$ percent by Community by Watershed.

\begin{tabular}{|c|c|c|c|c|c|}
\hline Source of Variation & $\begin{array}{l}\text { Sum of } \\
\text { Squares }\end{array}$ & DF & $\begin{array}{l}\text { Mean } \\
\text { Square }\end{array}$ & $F$ & $\begin{array}{l}\text { Significance } \\
\text { of } F\end{array}$ \\
\hline $\begin{array}{l}\text { Main Effects } \\
\text { Community } \\
\text { Watershed }\end{array}$ & $\begin{array}{l}4.011 \\
2.129 \\
2.362\end{array}$ & $\begin{array}{l}6 \\
4 \\
2\end{array}$ & $\begin{array}{l}0.669 \\
0.532 \\
1.181\end{array}$ & $\begin{array}{r}11.466 \\
9.131 \\
20.258\end{array}$ & $\begin{array}{l}0.000 \\
0.000 \\
0.000\end{array}$ \\
\hline $\begin{array}{l}\text { 2-way Interaction } \\
\text { Community } \\
\text { By Watershed }\end{array}$ & 6.732 & 6 & 1.122 & 19.243 & 0.000 \\
\hline Residual & 3.615 & 62 & 0.058 & & \\
\hline Total & 14.358 & 74 & 0.194 & & \\
\hline
\end{tabular}


Table A-14. Analysis of Variance for the fraction of the total soil organic $C$ in fine particulate organic $C$ percent fine particulate organic $\mathrm{C}$ by Community by Watershed.

\begin{tabular}{|c|c|c|c|c|c|}
\hline Source of Variation & $\begin{array}{l}\text { Sum of } \\
\text { Squares }\end{array}$ & DF & $\begin{array}{l}\text { Mean } \\
\text { Square }\end{array}$ & $\mathrm{F}$ & $\begin{array}{l}\text { Significance } \\
\text { of } F\end{array}$ \\
\hline $\begin{array}{l}\text { Main Effects } \\
\text { Community } \\
\text { Watershed }\end{array}$ & $\begin{array}{r}2578.498 \\
2541.707 \\
741.770\end{array}$ & $\begin{array}{l}6 \\
4 \\
2\end{array}$ & $\begin{array}{l}429.750 \\
635.427 \\
370.885\end{array}$ & $\begin{array}{l}5.411 \\
8.001 \\
4.670\end{array}$ & $\begin{array}{l}0.000 \\
0.000 \\
0.013\end{array}$ \\
\hline $\begin{array}{l}\text { 2-way Interaction } \\
\text { Community } \\
\text { By Watershed }\end{array}$ & 407.623 & 6 & 67.93 & 0.855 & 0.533 \\
\hline Residual & 4924.046 & 62 & 79.420 & & \\
\hline Total & 7910.167 & 74 & 106.894 & & \\
\hline
\end{tabular}

Table A-15. Analysis of Variance for the fraction of the total soil organic $\mathrm{N}$ in fine particulate organic $\mathrm{N}$ : percent fine particulate organic $\mathrm{N}$ by Community by Watershed.

\begin{tabular}{|c|c|c|c|c|c|}
\hline Source of Variation & $\begin{array}{l}\text { Sum of } \\
\text { Squares }\end{array}$ & DF & $\begin{array}{l}\text { Mean } \\
\text { Square }\end{array}$ & $F$ & $\begin{array}{l}\text { Significance } \\
\text { of } F\end{array}$ \\
\hline Main Effects & 1808.435 & 6 & 301.406 & 9.275 & 0.000 \\
\hline Community & 1607.309 & 4 & 401.827 & 12.366 & 0.000 \\
\hline Watershed & 101.456 & 2 & 50.728 & 1.561 & 0.218 \\
\hline \multicolumn{6}{|l|}{$\begin{array}{l}\text { 2-way Interaction } \\
\text { Community }\end{array}$} \\
\hline By Watershed & 141.255 & 6 & 23.542 & 0.724 & 0.631 \\
\hline Residual & 2014.698 & 62 & 32.495 & & \\
\hline Total & 3964.387 & 74 & 53.573 & & \\
\hline
\end{tabular}




\section{Table A-16. Analysis of Soil Properties}

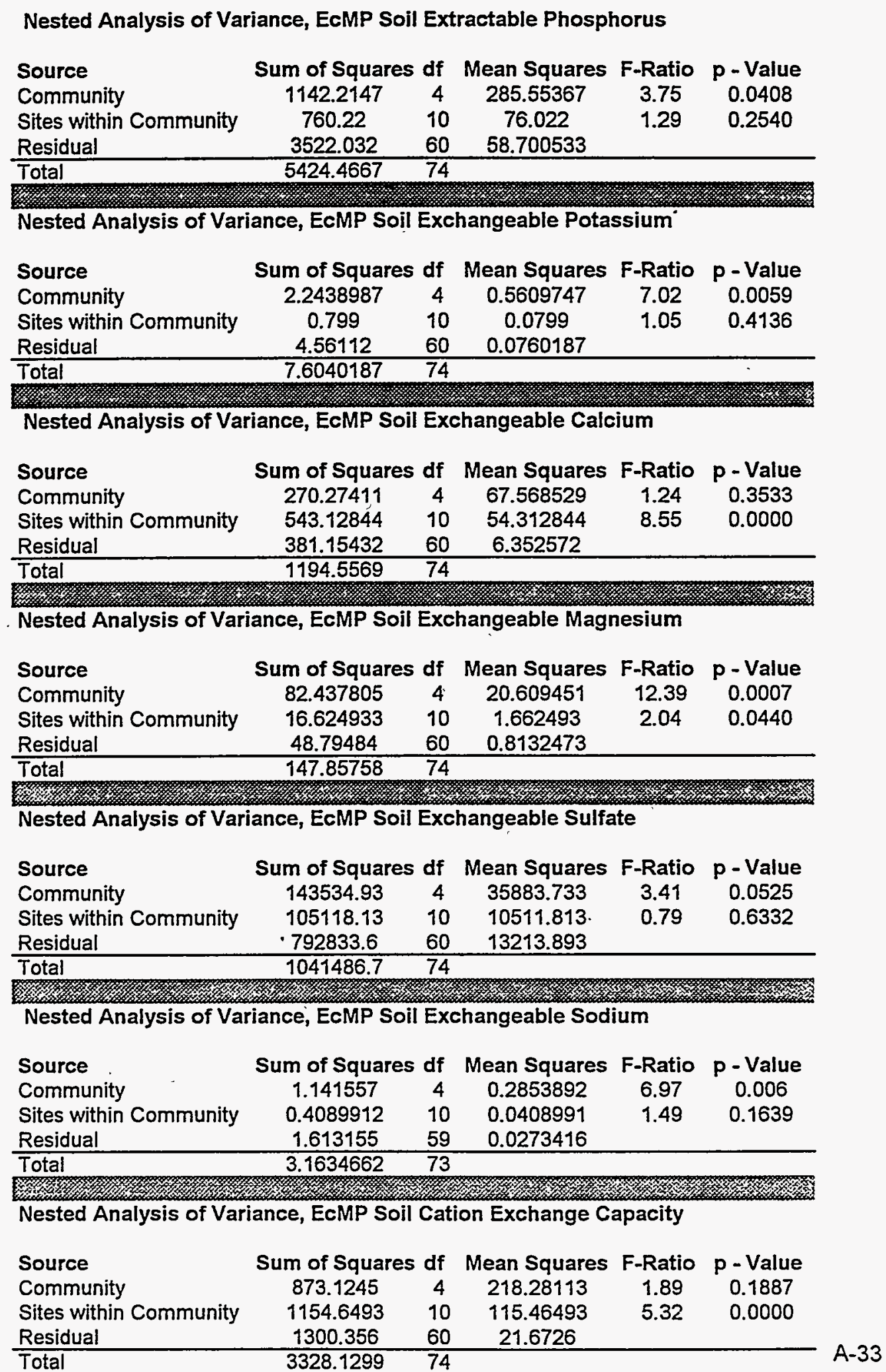


Table A-17. Soil Properties for EcMP Community Types

Mesic Community

\begin{tabular}{|l|c|c|c|c|c|}
\hline Soil Property & Count $(\mathrm{n})$ & Average & Standard Deviation & Minimum & Maximum \\
\hline Carbon Concentration & 15 & 3.32867 & 0.732646 & 2.08 & 4.25 \\
\hline Nitrogen Concentration & 15 & 0.282667 & 0.0601743 & 0.15 & 0.39 \\
\hline Phosphorus Concentration & 15 & 11.5867 & 21.3512 & 7.2 & 25.4 \\
\hline Potassium Concentration & 15 & 1.18267 & 0.409537 & 0.13 & 1.83 \\
\hline Calcium Concentration & 15 & 11.27 & 2.99884 & 6.22 & 16.8 \\
\hline Magnesium Concentration & 15 & 3.10533 & 0.895432 & 1.73 & 4.65 \\
\hline Sodium Concentration & 15 & 0.202667 & 0.0830924 & 0.09 & 1.24 \\
\hline Sulfate Concentration & 15 & 16.9333 & 3.45309 & 9 & 23 \\
\hline Cation Exchange Capacity & 15 & 23.7333 & 6.91114 & 11.5 & 34.7 \\
\hline
\end{tabular}

Reclaimed Community \begin{tabular}{|l|c|c|c|c|c|}
\hline Soil Property & Count (n) & Average & Standard Deviation & Minimum & Maximum \\
\hline Carbon Concentration & 15 & 2.12467 & 0.750703 & 1.51 & 4.45 \\
\hline
\end{tabular} Carbon Concentration Nitrogen Concentren

Phosphorus Concentration

Potassium Concentration

Calcium Concentration

Magnesium Concentration

Sodium Concentration

Sulfate Concentration

\begin{tabular}{|c|c|c|c|c|}
\hline 15 & 2.12467 & 0.750703 & 1.51 & 4.45 \\
\hline 15 & 0.207333 & 0.0832781 & 0.13 & 0.44 \\
\hline 15 & 7.82 & 3.45171 & 5.8 & 10.9 \\
\hline 15 & 1.21867 & 0.107628 & 1.07 & 1.44 \\
\hline 15 & 15.9027 & 4.27479 & 9.84 & 21 \\
\hline 15 & 4.53933 & 0.772283 & 3.25 & 5.99 \\
\hline 15 & 0.164667 & 0.00412667 & 0.09 & 0.32 \\
\hline 15 & 20.9333 & 12.0799 & 5 & 44 \\
\hline 15 & 30.2267 & 3.88412 & 22.2 & 34.9 \\
\hline
\end{tabular}

Riparian North Community

\begin{tabular}{|l|c|c|c|c|c|}
\hline Soil Property & Count (n) & Average & Standard Deviation & Minimum & Maximum \\
\hline Carbon Concentration & 15 & 2.81533 & 1.38559 & 1.27 & 5.36 \\
\hline Nitrogen Concentration & 15 & 0.256667 & 0.122105 & 0.11 & 0.5 \\
\hline Phosphorus Concentration & 15 & 19.4533 & 136.811 & 5.9 & 54.5 \\
\hline Potassium Concentration & 15 & 0.824667 & 0.324761 & 0.44 & 1.46 \\
\hline Calcium Concentration & 15 & 15.0967 & 2.70149 & 10.7 & 19.3 \\
\hline Magnesium Concentration & 15 & 4.51333 & 1.54127 & 3.08 & 9.57 \\
\hline Sodium Concentration & 15 & 0.408 & 0.0198457 & 0.15 & 0.58 \\
\hline Sulfate Concentration & 15 & 149.667 & 241.448 & 15 & 937 \\
\hline Cation Exchange Capacity & 15 & 25.52 & 7.25841 & 14 & 38.9 \\
\hline
\end{tabular}

Riparian South Community

\begin{tabular}{|c|c|c|c|c|c|}
\hline Soil Property & Count (n) & Average & Standard Deviation & Minimum & Maximum \\
\hline Carbon Concentration & 15 & 2.75133 & 1.41495 & 0.98 & 4.64 \\
\hline Nitrogen Concentration & 15 & 0.264667 & 0.10412 & 0.12 & 0.43 \\
\hline Phosphorus Concentration & 15 & 16.46 & 118.293 & 8.3 & 52.9 \\
\hline Potassium Concentration & 15 & 0.842667 & 0.215422 & 0.41 & 1.17 \\
\hline Calcium Concentration & 15 & 14.4753 & 2.33947 & 9.73 & 19.3 \\
\hline Magnesium Concentration & 15 & 4.19267 & 0.88135 & 2.7 & 5.76 \\
\hline Sodium Concentration & 15 & 0.400667 & 0.0385495 & 0.11 & 0.71 \\
\hline Sulfate Concentration & 15 & 64.9333 & 46.0395 & 12 & 200 \\
\hline Cation Exchange Capacity & 15 & 26.4133 & 6.79358 & 16.2 & 41.7 \\
\hline
\end{tabular}

Xeric Community

\begin{tabular}{|l|c|c|c|c|c|}
\hline Soil Property & Count $(\mathrm{n})$ & Average & St:andard Deviation & Minimum & Maximum \\
\hline Carbon Concentration & 15 & 5.134 & 1.14292 & 3.35 & 7.28 \\
\hline Nitrogen Concentration & 15 & 0.410667 & 0.0704543 & 0.29 & 0.55 \\
\hline Phosphorus Concentration & 15 & 12.9133 & 21.3512 & 7.6 & 25.2 \\
\hline Potassium Concentration & 15 & 1.144 & 0.230211 & 0.87 & 1.72 \\
\hline Calcium Concentration & 15 & 11.514 & 5.09126 & 7.9 & 21.5 \\
\hline Magnesium Concentration & 15 & 1.802 & 0.272716 & 1.44 & 2.18 \\
\hline Sodium Concentration & 14 & 0.110714 & 0.000145604 & 0.09 & 0.13 \\
\hline Sulfate Concentration & 15 & 21.2 & 9.48081 & 9 & 35 \\
\hline Cation Exchange Capacity & 15 & 19.78 & 3.67699 & 15.2 & 26.4 \\
\hline
\end{tabular}


Table A-18. Summary Statistics for Rocky Flats Vegetation

Summary Stallstlcs for Vegetation Aluminum at Rocky Flats

\begin{tabular}{|c|c|c|c|c|c|c|c|c|}
\hline Vegetallon Commurilty Type & Number of samples (n) & Average & Varlance & Minimum & Maximum & Range & Acres at RFETS & kg element in community type \\
\hline Mesic Mixed Grassland & 20 & 26.144 & 636.113 & 4.58 & 88.38 & 83.8 & 3554 & 376.15 \\
\hline Reclaimed Grassland & 20 & 26.207 & 89.263 & 11.52 & 45.29 & 33.77 & 565 & 59.94 \\
\hline Xeric Mixed Grassland & 7 & 3.64429 & 1.73983 & 1.85 & 5.46 & 3.61 & 1174 & 17.32 \\
\hline
\end{tabular}

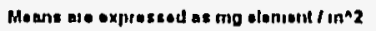

Summary Slatlstics for Vegetatlon Calclum at Rocliy Flats

\begin{tabular}{|c|c|c|c|c|c|c|c|c|}
\hline Vegetatlon Community Type & Number of samples (n) & Average & Varlance & Minimum & Maxlmum & Range & Acres at RFETS & kg element in community type \\
\hline Mesic Mixed Grassland & 20 & 882.903 & $1.06287 \mathrm{E} 6$ & 186.69 & 4024.33 & 3837.64 & 3554 & 12702.99 \\
\hline Roclaimed Grassland & 20 & 461.482 & 16609.0 & 300.07 & 856.86 & 556.79 & 565 & 1055.55 \\
\hline Xoric Mixed Grassland & 7 & 152.58 & 4535.57 & 73.88 & 275.79 & 201.91 & 1174 & 725.17 \\
\hline
\end{tabular}

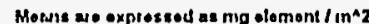

Summary Statlstics for Vegetation Cadmium at Rocky Flats

\begin{tabular}{|c|c|c|c|c|c|c|c|c|}
\hline Vegetatlon Community Type & Number of samples (n) & Average & Varlance & Minimum & Maximum & Range & Acres at RFETS & $\mathrm{kg}$ element In community type \\
\hline Mosic Mixed Grassland & 20 & 0.05 & 0.00502395 & 0.0 & 0.25 & 0.25 & 3554 & 0.77 \\
\hline Reclaimed Grassland & 20 & 0.00 & 0.0 & 0.0 & 0.0 & 0.0 & 565 & 0.00 \\
\hline Xeric Mixed Grassland & 7 & 0.01 & 0.0002 & 0.0 & 0.04 & 0.04 & 1174 & 0.05 \\
\hline
\end{tabular}

Moans aro oxproused as ma olemont $1 \mathrm{~m}^{\wedge} \mathrm{z}$

Summary Statlstics for Vegetatlon Cobalt at Rocky Flats

\begin{tabular}{|c|c|c|c|c|c|c|c|c|}
\hline Vegetation Community Type & Number of samples (n) & Average & Varlance & Minimum & Maximum & Range & Acres at RFETS & $\mathrm{kg}$ element In community type \\
\hline Mosic Mixed Grassland & 20 & 0.05 & 0.0063053 & 0 & 0.29 & 0.29 & 3554 & 0.72 \\
\hline Reclaimed Grassland & 20 & 0 & $\underline{0}$ & 0 & 0 & 0 & 565 & 0.00 \\
\hline Xeric Mixed Grassland & 7 & 0.01 & 0.0002 & 0 & 0.04 & 0.04 & 1174 & 0.05 \\
\hline
\end{tabular}

Xoric Mixed Grasslanc

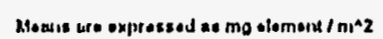

$\underset{⿱ 乛 龰}{P}$ 
Table A-18 Cont'd. Summary Statistics for Rocky Flats Vegetation

Sunimary Statistics for Vegetatlon Chromlum at Rocky Flats

\begin{tabular}{|c|c|c|c|c|c|c|c|c|}
\hline Vegetation Community Type & Number of samples ( $n$ ) & Average & Varlance & Minimum & Maximum & Range & Acres at RFETS & kg element In community type \\
\hline Mosic Mixed Grassland & 20 & 0.3145 & 0.104005 & 0.04 & 1.05 & 1.01 & 3554 & 4.52 \\
\hline Reclaimed Grassland & 20 & 0.7325 & 0.0526934 & 0.42 & 1.14 & 0.72 & 565 & 1.68 \\
\hline Xeric Mixod Grassland & 7 & 0.218571 & 0.0073476 & 0.08 & $\overline{0.3}$ & 0.22 & 1174 & 1.04 \\
\hline
\end{tabular}

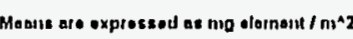

Summary Statlstics for Vegetation Copper at Rocky Flats

\begin{tabular}{|c|c|c|c|c|c|c|c|c|}
\hline Vegetatlon Communlty Type & Number of samples $(n)$ & Average & Varlance & Minimum & Maximum & Range & Acres at RFETS & kg element in community type \\
\hline Mesic Mixed Grassland & 20 & 1.1805 & 0.983016 & 0.15 & 3.17 & 3.02 & 3554 & 16.98 \\
\hline Reclaimed Grassland & 20 & 0.1665 & 0.0034134 & 0.09 & 0.37 & 0.28 & 565 & 0.38 \\
\hline Xeric Mixod Grassiand & 7 & 0.12 & 0.0048 & 0.06 & 0.21 & 0.15 & 1174 & 0.57 \\
\hline
\end{tabular}

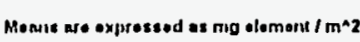

Summary Statistles for Vegetation Iron at Rocky Flats

\begin{tabular}{|c|c|c|c|c|c|c|c|c|}
\hline Vegetation Community Type & Number of samples (n) & Average & Varlance & Minimum & MaxImum & Range & Acres at RFETS & $\mathrm{kg}$ element In community type \\
\hline Mesic Mixed Grassland & 20 & 29.3705 & 974.505 & 5.83 & 134.67 & 128.84 & 3554 & 422.58 \\
\hline Reclaimed Grassland & 20 & 19.5175 & 36.304 & 11.52 & 37.17 & 25.65 & 565 & 44.64 \\
\hline Xeric Mixed Grassland & 7 & 4.10143 & 1.03655 & 2.93 & 5.46 & 2.53 & 1174 & 19.49 \\
\hline
\end{tabular}

Xeric Mixed Grassiand

Means are explyos sod as mo oteniont / maz

Summary Statistlos for Vegetation Potasslum at Rocky Flats

\begin{tabular}{|c|c|c|c|c|c|c|c|c|}
\hline Vegetatlon Community Type & Number of samples (n) & Average & Varlance & Minimum & Maximum & Range & Acres at RFETS & kg element In community type \\
\hline Mesic Mixed Grassland & 20 & 1668.33 & 3662240 & 251.69 & 7706.16 & 7454.47 & 3554 & 24003.52 \\
\hline Reclaimed Grassland & 20 & 951.484 & 73730.5 & 669.39 & 1641.73 & 972.34 & 565 & 2176.33 \\
\hline Xeric Mixed Grassland & 7 & 300.763 & 13578 & 187.58 & 471.74 & 284.16 & 1174 & 1429.45 \\
\hline
\end{tabular}

Masis aso expresed as mg ollement / m²

$\stackrel{\vec{\omega}}{\leftrightarrow}$ 
Table A-18 Cont'd. Summary Statistics for Rocky Flats Vegetation

Summary Statlstles for Vegetation Magneslum at Rocky Flats

\begin{tabular}{|c|c|c|c|c|c|c|c|c|}
\hline Vegetation Communilty Type & Number of samples $(n)$ & Average & Varlance & Minimum & Maximum & Range & Acres at RFETS & $\mathrm{kg}$ element in community type \\
\hline Mesic Mixed Glassland & 20 & 231.268 & 63827.6 & 45.92 & 984.68 & 938.76 & 3554 & 3327.43 \\
\hline Reclaimed Grassland & 20 & 172.275 & 3946.66 & 102.14 & 379.46 & 277.32 & 565 & 394.05 \\
\hline Xeric Mixed Grassland & 7 & 45.6557 & 984.479 & 18.76 & 105.24 & 86.48 & 1174 & 216.99 \\
\hline
\end{tabular}

Menis are expressed as mu olonient / m²

Sumniary Statistics for Vegetation Manganese at Rocky Flats

\begin{tabular}{|c|c|c|c|c|c|c|c|c|}
\hline Vegetation Conmunlty Type & Number of samples $(n)$ & Average & Varlance & Minimum & Maximum & Range & Acres at RFETS & $\mathrm{kg}$ element in community type \\
\hline Mesic Mixed Grassland & 20 & 4.46 & 10.9903 & 0.75 & 11.99 & 11.24 & 3554 & 64.17 \\
\hline Reclaimed Grassland & 20 & 11.4995 & 5.83666 & 7.54 & 16.58 & 9.04 & 565 & 26.30 \\
\hline Xeric Mixed Grassland & 7 & 0.997143 & 0.201057 & 0.43 & 1.64 & 1.21 & 1174 & 4.74 \\
\hline
\end{tabular}

Roans are oxprossod as ing oteunont $1 \mathrm{~m} \wedge \mathbf{2}$

Summary Statistles for Vegetation Molybdenum at Rocky Flats

\begin{tabular}{|c|c|c|c|c|c|c|c|c|}
\hline Vegetation Coininunify Type & Number of samples (n) & Average & Variance & Minimum & Maximum & Range & Acres at RFETS & $\mathrm{kg}$ element In community type \\
\hline Mesic Mixed Grassland & 20 & 0.0525 & 0.0066513 & $\overline{0}$ & 0.31 & 0.31 & 3554 & 0.76 \\
\hline Reclaimed Grassland & 20 & 0.233 & 0.0100326 & 0.12 & 0.43 & 0.31 & 565 & 0.53 \\
\hline Xoric Mixed Grassland & 7 & 0.01 & 0.0001667 & 0 & 0.03 & 0.03 & 1174 & 0.05 \\
\hline
\end{tabular}

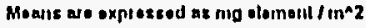

Summary Statlstles for Vegetation Sodlum at Rocky Flats

\begin{tabular}{|c|c|c|c|c|c|c|c|c|}
\hline Vegetatlon Community Type & Number of samples (n) & Average & Varlance & Minimum & Maximum & Range & Acres at RFETS & $\mathrm{kg}$ element in community type \\
\hline Mosic Mixed Grassland & 20 & 9.8215 & 65.3394 & 2.41 & 35.53 & 33.12 & 3554 & 141.31 \\
\hline Roclaimed Grassland & 20 & 6.193 & 11.7119 & 2.71 & 17.87 & 15.16 & 565 & 14.17 \\
\hline Xeric Mixed Grassland & 7 & 1.78571 & 0.253929 & 1.07 & 2.54 & 1.47 & 1174 & 8.49 \\
\hline
\end{tabular}

Meass aco oxpressod as ing olomont / man

$\stackrel{p}{\dot{d}}$ 
Table A-18 Cont'd. Summary Statistics for Rocky Flats Vegetation

\begin{tabular}{|c|c|c|c|c|c|c|c|c|}
\hline Vegetallon Community Type & Number of samples (n) & Average & Varlance & Minimum & Maximum & Range & Acres at RFETS & kg element in community type \\
\hline Mesic Mixed Grassland & 20 & 0.167 & 0.0102432 & 0.02 & 0.37 & 0.35 & 3554 & 2.40 \\
\hline Reclaimed Grassland & 20 & 0.2425 & 0.0081566 & 0.11 & 0.4 & 0.29 & 565 & 0.55 \\
\hline Xeric Mixod Grassland & 7 & 0.102857 & 0.0006905 & 0.06 & 0.13 & 0.07 & 1174 & 0.49 \\
\hline
\end{tabular}

Mogiss are oxpressod as mig olornont f manz

Summary Statlstics for Vegetatlon Nitrogen at Rocky Flats

\begin{tabular}{|c|c|c|c|c|c|c|c|c|}
\hline Vegetation Communlty Type & Number of samples $(n)$ & Average & Variance & Minimum & MaxImum & Range & Acres at RFETS & kg element In community type \\
\hline Mesic Mixed Grassiand & 20 & 1.481 & 1.12213 & 0.45 & 4.25 & 3.8 & 3554 & 21308.26 \\
\hline Reclaimed Grassland & 20 & 0.874 & 0.868057 & 0.36 & 4.54 & 4.18 & 565 & 1999.10 \\
\hline Xeric Mixed Grassland & 7 & 0.302857 & 0.0028238 & 0.24 & 0.39 & 0.15 & 1174 & 1439.40 \\
\hline
\end{tabular}

Moass are axprotsed an o olemiont $/ \mathrm{m}^{\wedge} \mathrm{z}$

Summary Statistics for Vegetation Lead at Rocky Flats

\begin{tabular}{|c|c|c|c|c|c|c|c|c|}
\hline Vegetation Community Type & Number of samples $(n)$ & Average & Variance & Minimum & Maximum & Range & Acres at RFETS & kg element in community type \\
\hline Mesic Mixed Grassland & 20 & 0.069 & 0.0124516 & 0 & 0.39 & 0.39 & 3554 & 0.99 \\
\hline Reclaimed Grassland & 20 & 0.0135 & 0.0017503 & 0 & 0.15 & 0.15 & 565 & 0.03 \\
\hline Xeric Mixed Grassland & 7 & 0.0185714 & 0.0007476 & 0 & 0.07 & 0.07 & 1174 & 0.09 \\
\hline
\end{tabular}

Moars are expressed as ing olomont $/ \mathrm{m}^{\wedge} \mathbf{2}$

Summary Statlstics for Vegetation Phosphorus at Rocky Flats

\begin{tabular}{|c|c|c|c|c|c|c|c|c|}
\hline Vegetatlon Community Type & Number of samples (n) & Âverage & Variance & Minimum & Maximum & Range & Acres at RFETS & $\mathrm{kg}$ element in community type \\
\hline Mesic Mixed Grassland & 20 & 154.637 & 31358 & 32.54 & 770.62 & 738.08 & 3554 & 2224.88 \\
\hline Reclaimed Grassland & 20 & 54.1835 & 184.107 & 32.62 & 86.91 & 54.29 & 565 & 123.93 \\
\hline Xeric Mixed Grassland & 7 & 22.3143 & 32.8384 & 17.56 & 34.47 & 16.91 & 1174 & 106.05 \\
\hline
\end{tabular}

Moals are exprossed as mg olomont $/ m^{\wedge} 2$

$\underset{\infty}{\dot{1}}$ 
Table A-18 Cont'd. Summary Statistics for Rocky Flats Vegetation

Summary Statlstlcs for Vegetation Sulfur at Rocky Flats

\begin{tabular}{|c|c|c|c|c|c|c|c|c|}
\hline Vegetation Communlty Type & Number of samples (n) & Average & Variance & Minimum & Maximum & Range & Acres at RFETS & kg element In community type \\
\hline Mesic Mixed Grassland & 20 & 210.176 & 24981.4 & 70.76 & 642.18 & 571.42 & 3554 & 3023.96 \\
\hline Reclaimed Grassland & 20 & 124.249 & 1949.56 & 76.61 & 269.3 & 192.69 & 565 & 284.20 \\
\hline Xeric Mixed Grassland & 7 & 41.1757 & 380.027 & 25.7 & 79.83 & 54.13 & 1174 & 195.70 \\
\hline
\end{tabular}

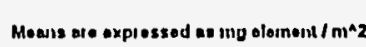

Summary Statlstles for Vegetation Vanadlum at Rocky Flats

\begin{tabular}{|c|c|c|c|c|c|c|c|c|}
\hline Vegetation Community Type & Number of samples ( $n$ ) & Average & Varlance & Minimum & Maximum & Range & Acres at RFETS & kg element in community type \\
\hline Mesic Mixed Grassland & 20 & 0.2455 & 0.0618155 & 0 & 1.03 & 1.03 & 3554 & 3.53 \\
\hline Reclaimed Grasstand & 20 & 0.0395 & 0.0008471 & 0 & 0.09 & 0.09 & 565 & 0.09 \\
\hline Xeric Mixed Grassland & 7 & $\overline{0.0285714}$ & 0.0008476 & 0 & $0 . \overline{07}$ & 0.07 & 1174 & 0.14 \\
\hline
\end{tabular}

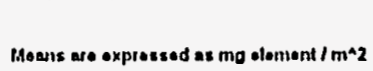

Summary Statlstles for Vegetatlon Zine at Rocky Flats

\begin{tabular}{|c|c|c|c|c|c|c|c|c|}
\hline Vegetatlon Community Type & Number of samples $(n)$ & Average & Varlance & Minimum & Maximum & Range & Acres at RFETS & kg element in community type \\
\hline Mosic Mixed Grassland & 20 & 3.5285 & 6.15128 & 0.62 & 9.29 & 8.67 & 3554 & 50.77 \\
\hline Reclaimed Grassland & 20 & 0.8535 & 0.0941818 & 0.34 & 1.64 & 1.3 & 565 & 1.95 \\
\hline Xeric Mixed Grassland & 7 & 0.551286 & 0.0393619 & 0.29 & 0.83 & 0.54 & 1174 & 2.63 \\
\hline
\end{tabular}

Maens ere expressed as ing oloment $/ \mathrm{m}^{\wedge} \mathbf{z}$

Suinmary Statistics for Vegetation Carbon at Rocky Flats

\begin{tabular}{|c|c|c|c|c|c|c|c|c|}
\hline Veyetation Community Type & Number of samples (n) & Average & Varlance & Minimum & Maximum & Range & Acres at RFETS & $\mathrm{kg}$ element In community type \\
\hline Mesic Mixed Grassland & 20 & 65.0105 & 1837.53 & 20.19 & 185.38 & 165.19 & 3554 & 935355.09 \\
\hline Reclaimed Grassland & 20 & 38.301 & 116.272 & 21.96 & 68.95 & 46.99 & 565 & 87606.06 \\
\hline Xeric Mixod Grassland & 7 & 12.8614 & 4.57385 & 9.79 & 16.07 & 6.28 & 1174 & 61126.84 \\
\hline
\end{tabular}

Meane are oxprossed as a stoment/m^z 
Table A-19. Summary Statistics for Rocky Flats Litter

Summary Statistics for Litter Aluminum at Rocky Flats

\begin{tabular}{|c|c|c|c|c|c|c|c|c|}
\hline Vegetation Community Type & Number of samples (n) & Average & Variance & Minimum & Maximum & Range & Acres at RFETS & kg element in community type \\
\hline Mesic Mixed Grassland & 35 & 1431.53 & 5059150 & 59.51 & 9209.57 & 9150.06 & 3554 & 20596.50 \\
\hline Reclaimed Grassland & 55 & 1861.38 & 15096800 & 217.86 & 24414.5 & 24196.7 & 565 & 4257.54 \\
\hline Xeric Mixed Grassland & 35 & 888.86 & 666029 & 73.66 & 3346.1 & 3272.44 & 1174 & 4224.52 \\
\hline
\end{tabular}

Means aro oxprossed as mg olemont $/ \mathrm{m}^{\wedge} \mathrm{z}$

Summary Statistics for Litter Calclum at Rocky Flats

\begin{tabular}{|l|c|c|c|c|c|c|c|c|}
\hline Vegetation Community Type & Number of samples $(\mathrm{n})$ & Average & Variance & Minimum & Maximum & Range & Acres at RFETS & kg element in community type \\
\hline Mesic Mixed Grassland & 35 & 1948.91 & 5777650 & 71.3 & 8081.87 & 8010.57 & 3554 & \\
\hline Reclaimed Grassland & 55 & 122.47 & 1856730 & 337.69 & 7546.31 & 7208.62 & 565 \\
\hline Xeric Mixed Grassland & 35 & 1355.03 & 1686430 & 178.4 & 4431.32 & 4252.92 & 1174 \\
\hline
\end{tabular}

Moans asc oxprossod as mg olomont $/ m^{\wedge}$

Summary Statistics for Litter Cadmium at Rocky Flats

\begin{tabular}{|l|c|c|c|c|c|c|c|c|}
\hline Vegetation Community Type & Number of samples $(\mathrm{n})$ & Average & Varlance & Minimum & Maximum & Range & Acres at RFETS & kg element In community type \\
\hline Mesic Mixed Grassland & 35 & 0.446571 & 0.502917 & 0 & 2.83 & 2.83 & 3554 \\
\hline Reclaimed Grassland & 55 & 0.200545 & 0.0903015 & 0 & 1.56 & 1.56 & 565 \\
\hline Xeric Mixed Grassland & 35 & 0.206286 & 0.041677 & 0 & 0.86 & 0.86 & 1174 \\
\hline
\end{tabular}

Moans aro exprossod as mg olement / $m^{\wedge} z$

Summary Statistics for Litter Cobalt at Rocky Flats

\begin{tabular}{|l|c|c|c|c|c|c|c|c|}
\hline Vegetation Community Type & Number of samples (n) & Average & Variance & Minimum & Maximum & Range & Acres at RFETS & kg element In community type \\
\hline Mesic Mixed Grassland & 35 & 0.226857 & 0.297357 & 0 & 2.93 & 2.93 & 3554 \\
\hline Reclaimed Grassland & 55 & 0.002 & $8.667 \mathrm{E}-05$ & 0 & 0.06 & 0.06 & 565 \\
\hline Xeric Mixed Grassland & 35 & 0.086 & 0.0119953 & 0 & 0.38 & 0.38 & \\
\hline
\end{tabular}

Moans aro expressed as mg olement $/ m^{\wedge} 2$

$\frac{b}{b}$ 
Table A-19 Cont'd. Summary Statistics for Rocky Flats Litter

Summary Statistics for Litter Nickel at Rocky Flats

\begin{tabular}{|l|c|c|c|c|c|c|c|c|}
\hline Vegetatlon Community Type & Number of samples (n) & Average & Variance & Minimum & Maximum & Range & Acres at RFETS & kg element In community type \\
\hline Mesic Mixed Grassland & 35 & 1.12486 & 2.79473 & 0.05 & 6.58 & 6.53 & 3554 \\
\hline Reclaimed Grassland & 55 & 1.614 & 6.39146 & 0 & 14.43 & 14.43 & 565 \\
\hline Xeric Mixed Grassland & 35 & 1.22886 & 2.1468 & 0.07 & 6.91 & 6.84 & 16.18 & \\
\hline
\end{tabular}

35

1.2288

Means aro exprossod as mg olement $/ m^{\wedge}$

Summary Statistics for Litter Nitrogen at Rocky Flats

\begin{tabular}{|l|c|c|c|c|c|c|c|c|}
\hline Vegetation Community Type & Number of samples $(\boldsymbol{n})$ & Average & Varlance & Minimum & Maximum & Range & Acres at RFETS & kg element In community type \\
\hline Mesic Mixed Grassland & 35 & 3.542 & 19.6353 & 0.15 & 19.43 & 19.28 & 355 \\
\hline Reclaimed Grassland & 55 & 1.71509 & 2.37588 & 0.44 & 7.75 & 7.31 & 565 \\
\hline Xeric Mixed Grassland & 35 & 2.93257 & 8.90718 & 0.32 & 11.88 & 11.56 & 1174 \\
\hline
\end{tabular}

Means nro expressed as g olement $/ m^{n} z$

Summary Statistics for Litter Lead at Rocky Flats

\begin{tabular}{|l|c|c|c|c|c|c|c|c|}
\hline Vegetation Community Type & Number of samples (n) & Average & Variance & Minimum & Maximum & Range & Acres at RFETS & kg element in community type \\
\hline Mesic Mixed Grassland & 35 & 3.02857 & 21.0007 & 0.21 & 18.24 & 18.03 & 3554 \\
\hline Reclaimed Grassland & 55 & 1.57727 & 4.47288 & 0 & 12.21 & 12.21 & 565 \\
\hline Xeric Mixed Grassland & 35 & 3.30771 & 11.6536 & 0.27 & 13.57 & 13.3 & 117 & \\
\hline
\end{tabular}

Xeric Mixed Grassland 35

13.57

1174

3.61

Means aro expressod as mg olement / mª

Summary Statistics for Litter Phosphorus at Rocky Flats

\begin{tabular}{|l|c|c|c|c|c|c|c|c|}
\hline Vegetation Community Type & Number of samples (n) & Average & Varlance & Minimum & Maximum & Range & Acres at RFETS & kg element In community type \\
\hline Mesic Mixed Grassland & 35 & 284.255 & 158607 & 11.41 & 1635.17 & 1623.76 & 3554 \\
\hline Reclaimed Grassland & 55 & 160.881 & 20150.8 & 35.79 & 787.92 & 752.13 & 565 \\
\hline Xeric Mixed Grassland & 35 & 198.769 & 44241.5 & 18.46 & 786.79 & 768.33 & 1174 \\
\hline
\end{tabular}

Mosns aro exprossed as mg olement / $m^{\wedge 2}$

$\stackrel{p}{\square}$ 
Table A-19 Cont'd. Summary Statistics for Rocky Flats Litter

Summary Statistics for Litter Sulfur at Rocky Flats

\begin{tabular}{|l|c|c|c|c|c|c|c|c|}
\hline Vegetation Community Type & Number of samples (n) & Average & Varlance & Minimum & Maximum & Range & Acres at RFETS & kg element In community type \\
\hline Mesic Mixed Grassland & 35 & 430.138 & 308089 & 18.54 & 2443.36 & 2424.82 & 3554 & \\
\hline Reclaimed Grassland & 55 & 239.579 & 34652.2 & 60.35 & 826.11 & 765.76 & 565 \\
\hline Xeric Mixed Grassland & 35 & 370.262 & 136728 & 40.29 & 1446.96 & 1406.67 & 1174 \\
\hline
\end{tabular}

xeric Mixed

Maens are oxprossed as mg element $/ \mathrm{m}^{\wedge} \mathbf{2}$

Summary Statistles for Litter Vanadlum at Rocky Flats

\begin{tabular}{|l|c|c|c|c|c|c|c|c|}
\hline Vegetation Community Type & Number of samples ( $)$ & Average & Variance & Minimum & Maximum & Range & Acres at RFETS & kg element In community type \\
\hline Mesic Mixed Grassland & 35 & 3.09571 & 25.7377 & 0.11 & 20.67 & 20.56 & 3554 & \\
\hline Reclaimed Grassland & 55 & 4.64564 & 79.643 & 0.13 & 53.27 & 53.14 & 565 \\
\hline Xeric Mixed Grassland & 35 & 1.72229 & 2.59031 & 0.12 & 6.33 & 6.21 & 10.63 \\
\hline
\end{tabular}

Moans aro oxprossed as mg olement $/ m^{\wedge 2}$

Summary Statistics for Litter Zinc at Rocky Flats

\begin{tabular}{|l|c|c|c|c|c|c|c|c|}
\hline Vegetation Community Type & Number of samples ( $)$ & Average & Varlance & Minimum & Maximum & Range & Acres at RFETS & kg element in community type \\
\hline Mesic Mixed Grassland & 35 & 15.4934 & 365.797 & 1.13 & 65.78 & 64.65 & 3554 \\
\hline Reclaimed Grassland & 55 & 9.19291 & 142.067 & 1.82 & 67.69 & 65.87 & 565 \\
\hline Xeric Mixed Grassland & 35 & 9.66686 & 77.6139 & 1.11 & 36.17 & 35.06 & 1174 \\
\hline
\end{tabular}

Moans aro exprossod as mg olement / $m^{\wedge} 2$

Summary Statistics for Litter Carbon at Rocky Flats

\begin{tabular}{|l|c|c|c|c|c|c|c|c|}
\hline Vegetation Community Type & Number of samples $(\mathrm{n})$ & Average & Varlance & Minimum & Maximum & Range & Acres at RFETS & kg element In community type \\
\hline Mesic Mixed Grassland & 35 & 160.421 & 37012.4 & 5.6 & 781.91 & 776.31 & 3554 & \\
\hline Reclaimed Grassland & 55 & 90.7382 & 4230.27 & 23.23 & 317.11 & 293.88 & 565 \\
\hline Xeric Mixed Grassland & 35 & 118.102 & 11223.5 & 14.94 & 362.66 & 347.72 & 1174 & 208097.91 \\
\hline
\end{tabular}

Xeric Mixed Grassland

\begin{tabular}{|l|l|l|}
\hline 118.102 & 11223.5 & 14.94 \\
\hline
\end{tabular}

362.66

347.72

Means are expressed as $g$ olement $/ m^{\wedge} 2$

$\frac{P}{N}$ 


\section{Table A-19 Cont'd. Summary Statistics for Rocky Flats Litter}

Summary Statistics for Litter Chromlum at Rocky Flats

\begin{tabular}{|l|c|c|c|c|c|c|c|c|}
\hline Vegetation Community Type & Number of samples ( $\mathbf{n}$ ) & Average & Variance & Minimum & Maximum & Range & Acres at RFETS & kg element In community type \\
\hline Mesic Mixed Grassland & 35 & 1.43743 & 5.01505 & 0.08 & 9.21 & 9.13 & 3554 & 20.68 \\
\hline Reclaimed Grassland & 55 & 2.55073 & 16.9498 & 0 & 24.41 & 24.41 & 565 & \\
\hline Xeric Mixed Grassland & 35 & 2.138 & 9.46179 & 0.08 & 14.3 & 14.22 & 1174 & \\
\hline
\end{tabular}

Moans are expressed as ing element / m^z

Summary Statistics for Litter Copper at Rocky Flats

\begin{tabular}{|l|c|c|c|c|c|c|c|c|}
\hline Vegetation Community Type & Number of samples ( $(\mathbf{)}$ & Average & Variance & Minimum & Maximum & Range & Acres at RFETS & kg element In community type \\
\hline Mesic Mixed Grassland & 35 & 4.35857 & 23.4865 & 0.17 & 18.8 & 18.63 & 3554 & \\
\hline Reclaimed Grassland & 55 & 2.50491 & 8.95751 & 0.36 & 16.65 & 16.29 & 565 \\
\hline Xeric Mixed Grassland & 35 & 2.95171 & 7.94448 & 0.26 & 12.66 & 12.4 & 117 \\
\hline
\end{tabular}

Moans aro exprossod as $\mathrm{mg}$ oloment $/ \mathrm{m}^{\wedge} \mathbf{2}$

Summary Statistics for Litter Iron at Rocky Flats

\begin{tabular}{|l|c|c|c|c|c|c|c|c|}
\hline Vegetation Community Type & Number of samples $(\mathrm{n})$ & Average & Variance & Minimum & Maximum & Range & Acres at RFETS & kg element in community type \\
\hline Mesic Mixed Grassland & 35 & 1220.43 & 4089020 & 51.72 & 8519.02 & 8467.3 & 3554 \\
\hline Reclaimed Grassland & 55 & 1608.19 & 5942480 & 152.5 & 13317 & 13164.5 & 565 \\
\hline Xeric Mixed Grassland & 35 & 710.867 & 436037 & 60.93 & 2622.62 & 2561.69 & 1755.25 \\
\hline
\end{tabular}

Moans aro exprossod as mg element $/ m^{\wedge} 2$

Summary Statistics for Litter Potassium at Rocky Flats

\begin{tabular}{|l|c|c|c|c|c|c|c|c|}
\hline Vegetatlon Community Type & Number of samples $(n)$ & Average & Varlance & Minimum & Maximum & Range & Acres at RFETS & kg element in community type \\
\hline Mesic Mixed Grassland & 35 & 977.753 & 1976080 & 34.22 & 6202.36 & 6168.14 & 3554 \\
\hline Reclaimed Grassland & 55 & 657.953 & 505294 & 161.41 & 4217.06 & 4055.65 & 565 \\
\hline Xeric Mixed Grassland & 35 & 685.585 & 341355 & 63.79 & 1989.57 & 1925.78 & 1174 \\
\hline
\end{tabular}

Means are exprossed as mg oloment $/ m^{\wedge} 2$

$\underset{\omega}{b}$ 
Table A-19 Cont'd. Summary Statistics for Rocky Flats Litter

Summary Statistles for Litter Magnesium at Rocky Flats

\begin{tabular}{|c|c|c|c|c|c|c|c|c|}
\hline Vegetation Community Type & Number of samples $(n)$ & Average & Varlance & Minimum & Maximum & Range & Acres at RFETS & $\mathrm{kg}$ element In community type \\
\hline Mesic Mixed Grassland & 35 & 431.723 & 338271 & 24.24 & 2067.45 & 2043.21 & 3554 & 6211.52 \\
\hline Reclaimed Grassland & 55 & 404.189 & 342227 & 91.23 & 3551.21 & 3459.98 & 565 & 924.50 \\
\hline Xeric Mixed Grassland & 35 & 260.144 & 52135.5 & 29.88 & 813.92 & 784.04 & 1174 & 1236.40 \\
\hline
\end{tabular}

Menis aro expressed as mg element $/ \mathrm{m}^{\wedge} \mathbf{2}$

\section{Summary Statistics for Litter Manganese at Rocky Flats}

\begin{tabular}{|c|c|c|c|c|c|c|c|c|}
\hline Vegetation Community Type & Number of samples (n) & Average & Varlance & Minimum & Maximum & Range & Acres at RFETS & kg element in community type \\
\hline Mesic Mixed Grassland & 35 & 35.1646 & 3384.2 & 1.56 & 219.78 & 218.22 & 3554 & 505.94 \\
\hline Reclaimed Grassland & 55 & 42.9404 & 2732.61 & 7.85 & 288.54 & 280.69 & 565 & .98 .22 \\
\hline Xeric Mixed Grassland & 35 & 22.8289 & 358.861 & 2.55 & 76.87 & 74.32 & 1174 & 108.50 \\
\hline
\end{tabular}

Means are expressed as mg olement $/ m^{\wedge} \mathbf{2}$

Summary Statistics for Litter Molybdenum at Rocky Flats

\begin{tabular}{|c|c|c|c|c|c|c|c|c|}
\hline Vegetation Community Type & Number of samples (n) & Average & Variance & Minimum & Maximum & Range & Acres at RFETS & $\mathrm{kg}$ element in community type \\
\hline Mesic Mixed Grassland & 35 & 0.0017143 & 0.0001029 & 0 & 0.06 & 0.06 & 3554 & 0.02 \\
\hline Reclaimed Grassland & 55 & 0.0110909 & 0.0030469 & 0 & 0.38 & 0.38 & 565 & 0.03 \\
\hline Xeric Mixed Grassland & 35 & 0 & 0 & 0 & 0 & $\overline{0}$ & 1174 & 0.00 \\
\hline
\end{tabular}

Means are expressod as $\mathrm{mg}$ olement $/ \mathrm{m}^{\wedge} \mathbf{z}$

Summary Statistics for Litter Sodium at Rocky Flats

\begin{tabular}{|c|c|c|c|c|c|c|c|c|}
\hline Vegetation Community Type & Number of samples (n) & Average & Variance & Minimum & Maximum & Range & Acres at RFETS & kg element in community type \\
\hline Mesic Mixed Grassland & 35 & 27.9186 & 1314.3 & 1.04 & 156 & 154.96 & 3554 & 401.69 \\
\hline Reclaimed Grassland & 55 & 23.864 & 478.905 & 6.74 & 122.07 & 115.33 & 565 & 54.58 \\
\hline Xeric Mixed Grassland & 35 & 20.9994 & 376.277 & 2.42 & 68.77 & 66.35 & 1174 & 99.80 \\
\hline
\end{tabular}

Moans nro expressed as mg elomont $/ m^{\wedge} 2$

$\underset{P}{P}$ 


\section{APPENDIX B) TERRESTRIAL VEGETATION}

AUTHORS:

JODY K. NELSON

JUNE D. HAINES 


\section{TABLE OF CONTENTS}

\section{APPENDIX B) TERRESTRIAL VEGETATION}

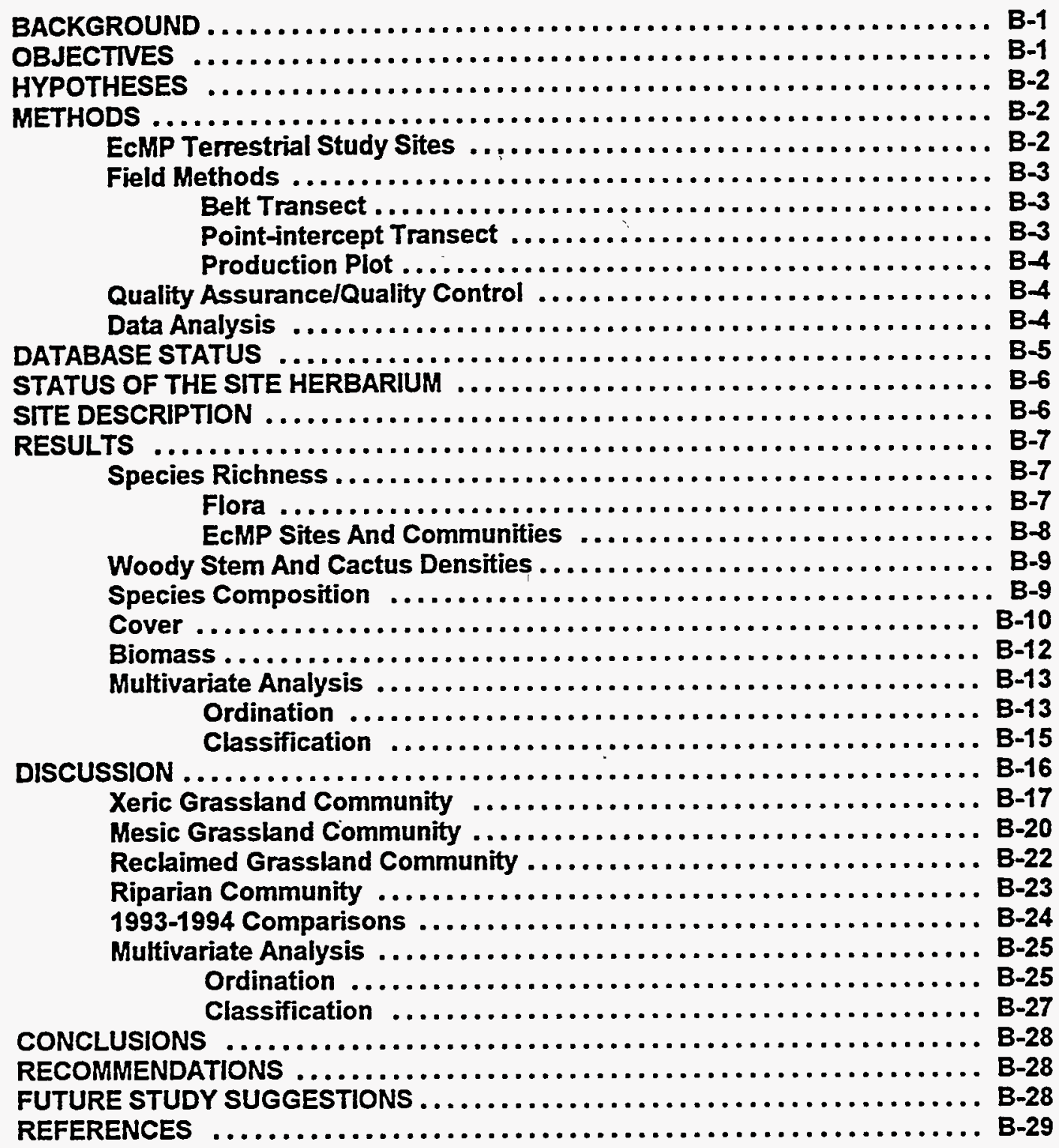


List of Figures

Figure B-1. 1994 Species Richness by EcMP Site.............................................................. B-31

Figure B-2. 1994 Species Richness by Community....................................................... B-31

Figure B-3. 1994 Woody Stem and Cactus Density Mean Values

by EcMP Site.............................................................................................. B-32

Figure B-4. 1994 \% Native Species by EcMP Site.......................................................... B-33

Figure B-5. 1994 Annual, Biennial, and Perennial Life Forms by EcMP Site............................................................................................ B-34

Figure B-6. 1994 Growth Forms by EcMP Site.............................................................. B-35

Figure B-7. 1994 Dicots/Monocots by EcMP Site........................................................ B-36

Figure B-8. 1994 Life Forms by EcMP Site....................................................................... B-37

Figure B-9. $\quad 1994 \%$ Native Species by Community....................................................... B-38

Figure B-10. 1994 Life Forms by Community ................................................................ B-38

Figure B-11. 1994 Growth Forms by Community................................................................ B-39

Figure B-12. 1994 Dicots/Monocots by Comrnunity...................................................... B-39

Figure B-13. 1994 Basal Cover Percentages by EcMP Site.......................................... B-40

Figure B-14. 1994 Basal Cover Percentages by Community....................................... B-41

Figure B-15. 1994 Biomass Amounts from EcMP Sites............................................. B-42

Figure B-16. 1994 Biomass Amounts by Community................................................. B-43

Figure B-17. 1994 Native vs. Non-native Current Year Production Biomass by EcMP Site............................................................................. B-44

Figure B-18. 1994 Native vs. Non-native Current Year Production Biomass by Community............................................................................. B B-45

Figure B-19. Terrestrial Vegetation DECORANA Ordination by EcMP

Transects - Species Presence/Absence Data, Axes 1 and 2............... B B-46

Figure B-20. Terrestrial Vegetation DECORANA Ordination by EcMP

Transects - Species Presence/Absence Data, Axes 1 and 3............... B B-47

Figure B-21. Terrestrial Vegetation DECORANA Ordination by EcMP

Transects - Species Presence/Absence Data, Axes 1 and 4............... B-48

Figure B-22. Terrestrial Vegetation Ordination (Reciprocal Averaging) -

Species Presence/Absence Data, Axes 1 and 2 
Figure B-23. Terrestrial Vegetation Ordination (Reciprocal Averaging) -

Species PresencelAbsence Data, Axes 1 and 3.

Figure B-24. Terrestrial Vegetation Ordination (Reciprocal Averaging) -

Species Presence/Absence Data, Axes 1 and 4.

Figure B-25. Terrestrial Vegetation DECORANA Ordination by Species -

Presence/Absence Data, Axes 1 and 2

Figure B-26. Terrestrial Vegetation DECORANA Ordination by Species -

PresencelAbsence Data, Axes 1 and 3.

Figure B-27. Terrestrial Vegetation DECORANA Ordination by Species -

Presence/Absence Data, Axes 1 and 4

Figure B-28. Terrestrial Vegetation Ordination by Species

(Reciprocal Averaging) - Presence/Absence Data, Axes 1 and 2.......

Figure B-29. Terrestrial Vegetation Ordination by Species

(Reciprocal Averaging) - Presence/Absence Data, Axes 1 and 3.......

B-56

Figure B-30. Terrestrial Vegetation Ordination by Species

(Reciprocal Averaging) - Presence/Absence Data, Axes 1 and 4.......

Figure B-31A. TWINSPAN Classification Dendrogram and Legend for 1994

EcMP Transects - Species Presence/Absence Data.

B-58

Figure B-31B. TWINSPAN Classification Dendrogram and Legend for 1994

EcMP Transects - Species Presence/Absence Data.

B-59

Figure B-32. 1993 and 1994 Current Year Production Biomass Amounts

by Community.

B-61

Figure B-33. 1993 and 1994 Current Year Production Biomass Amounts

by EcMP Site.

Figure B-34. 1993 and 1994 Litter Amounts by Community

B-63

Figure B-35. 1993 and 1994 Litter Amounts by EcMP Site

B-64

List of Tables

Table B-1.

Site Flora Summary.

$B-65$

Table B-2.

1994 Species Richness Across EcMP Sites.

B-66

Table B-3.

1994 Woody Stem and Cactus Density Mean Values by

EcMP Site and Community

B-76

Table B-4. 1994 Species Restricted by Community

B-77

Table B-5. 1994 Species Richness Summary at EcMP Sites

and Communities.

B-82 
Table B-6. $\quad 1994$ EcMP Site Summary Statistics for Biomass

and Cover.........................................................................................................................

Table B-7. 1994 Community Summary Statistics for Biomass

and Cover................................................................................................... B-88

Table B-8. $\quad 1994 \%$ Native versus Non-native Species by

Community from Basal and Foliar Cover.

Table B-9. 1994 Basal and Foliar Cover Dominant Species

by Community

Table B-10. 1994 Basal Cover Dominant Species at EcMP Sites.............................. B-92

Table B-11. 1994 Foliar Cover Dominant Species by EcMP Site................................ B-94

Table B-12. 1994 Native vs. Non-native Current Year Production

Biomass at EcMP Sites and Connmunities................................................. B-97

Table B-13. 1994 Leading Biomass Producers by EcMP Site................................... B-98

Table B-14. Terrestrial Vegetation DECORANA Ordination by EcMP

Transect - Based on Species Presence/Absence Data...................... B-100

Table B-15. Terrestrial Vegetation Ordination by EcMP Transect -

Reciprocal Averaging Method - Species Presencel

Absence Data.

Table B-16. 1994 DECORANA Ordination by Species Presencel

Absence Data

B-104

Table B-17. 1994 Reciprocal Averaging Ordination by Species

Presence/Absence Data

B-109

Table B-18. 1993 and 1994 Biomass Comparisons by

Community and EcMP Site.

B-114 


\section{BACKGROUND}

The diversity of plant communities at the Rocky Flats Environmental Technology Site (Site) are a result of the ecotonal effect found along the Front Range of Colorado. The mixing of prairie and foothills species in the diverse habitats provided by the varied physical environment has resulted in a vegetational mosaic which is rapidly disappearing with human encroachment along the Front Range.

Plant distribution, composition, and abundance are influenced by many environmental factors. Local climate, topography, and geology, all part of the physical environment, control abiotic factors such as light, temperature, moisture, and nutrients, which directly affect plant growth. In addition, biotic factors such as competition, herbivory, availability of pollinators, and nitrogen fixation by bacteria, interact with the abiotic factors to create habitats. Plant survival in these habitats requires availability of natural resources necessary for them to grow and reproduce. The spatial and temporal variation of biotic and abiotic factors found at the Site allow for the diversity of the distinct plant communities found here. Additionally, the human impact at the Site involving physical disturbance and/or contamination of soils and groundwater interacts with the pre-existing biotic and abiotic factors to modify plant habitats in measurable ways.

Ecological monitoring of the abundance and distribution of plant species is important to the Environmental Restoration Mission at the Site for several reasons. Variation in plant species composition may indicate human disturbance at a given site. The composition, abundance, and dispersion of plant species at a site determine the quality of wildife habitat at a site and strongly affect soil stabilization. Since vegetation ground cover is the primary factor in soil stabilization, effective establishment of vegetation may be the first concern in reclaiming a contaminated site. As primary producers, plants are the first link in terrestrial food chains. In addition to any direct effects on plant growth (e.g., phytotoxicity), metals or other contaminants present in the soil may accumulate in plant tissue and be transferred to herbivores and their predators. Finally, it provides a general description of the Site and serves as a model from which all other terrestrail sampling is derived.

The data collected in this Ecological Monitoring Program (EcMP) Study Module will be used to document patterns of association among plant species at the Site, which will contribute to the further definition of the distinct plant communities at the Site (identified in the Baseline Report, U.S. Department of Energy, 1992). Long-term data sets from this program will be used to quantify both spatial and temporal variation in these associations. By correlating variation in plant species distribution and abundance with physical factors at a given site, it may be possible to predict changes ih plant communities with various types of anthropogenic disturbance. Thus, the findings of this study module could aid in the development and evaluation of reclamation procedures, as well as the future management of the Site.

\section{OBJECTIVES}

The objective of this study is to characterize and monitor changes in the composition, distribution, and production of plant species within the major plant communities located at the Site (Baseline Study(U.S. Department of Energy, 1992)). In addition, the information gathered can be used to assess qualitative and quantitative changes in the vegetation resulting from human activities and/or natural disturbances and processes occurring at the Site. 


\section{HYPOTHESES}

A number of hypotheses, some of which are listed in the EcMP Program Plan, may be addressed by data collected by the Terrestrial Vegetation Module. The data were used to test hypotheses concerning the plant distribution, species richness, basal cover types, percent native species, and production of plant species by site and communities represented by the 12 EcMP study sites. They include:

1) $H_{0}:$ Species richness does not vary among sites and communities at the Site.

$\mathrm{H}_{\mathrm{A}}$ : $\quad$ Species richness does vary among sites and communities at the Site.

2) $H_{0}$ : Composition and relative importance of basal cover types do not vary among sites and communities at the Site.

$H_{A}$ : Composition and relative importance of basal cover types do vary among sites and communities at the Site.

3) $\quad H_{0}: \quad$ Species composition by native species versus non-native species does not vary by site and community at the Site.

$H_{A}$ : $\quad$ Species composition by native species versus non-native species does vary by site and community at the Site.

4) $H_{0}: \quad$ Herbaceous plant production does not vary among the grassland sites communities at the Site.

$H_{A}$ : Herbaceous plant production does vary among the grassland sites communities at the Site.

5) $\quad H_{0}$ : Litter production does not vary among grassland sites and communities at the Site. $H_{A}$ : Litter production does vary among grassiand sites and communities at the Site.

\section{METHODS}

\section{EcMP Terrestrial Study Sites}

The EcMP Terrestrial Vegetation Module monitors 12 permanent study sites located in the buffer zone at the Site (Figure 1). The study sites are located in uncontaminated areas and represent three replicates of four community types. Included are nine grassland sites and three riparian sites. The grassland sites are divided into 3 community types, roughly following the hydrologic gradient zones (xeric=dry, mesic=moderate moisture, hydric=wet) defined in the Baseline Report (U.S. Department of Energy, 1992). Xeric grasslands are the driest of the communities and occur at the highest elevations on Site. Found on the hilltops in the buffer zone, the xeric community comprises approximately $18 \%$ ( 481 ha; $1,189 \mathrm{ac}$ ) of the Site. The mesic community has an intermediate moisture availability and is primarily found on hillsides at the Site. Comprising $77 \%$ of the land on Site, it represents the largest of the community types $(2,038$ ha; $5,033 \mathrm{ac})$. Two types of mesic communities (mesic mixed grassland and reclaimed grassland) were of interest here. Differences between the two communities are related to past management practices. The reclaimed community was previously farmed agricultural land, while the mesic community was grazed lands. Neither use has occurred on Site for the past 20 years. The riparian community represents the most hydric of the communities. It has the most available moisture and is found along the streams and at seeps which flow from the hillsides. The riparian community is the smallest of the communities sampled, representing only $5 \%$ (133 ha; 329 ac) of the Site. 


\section{Field Methods}

The field sampling methodology used for the spring 1994 sampling session is described in the Ecological Monitoring Program - Program Management/Technical Performance Report - GHS462-93 (Appendices 2 and 4, Ecological Monitoring Program, 1993). The field sampling methodology used for the late summer sampling session is described in the Vegetation Sampling Standard Operating Procedure (SOP) (4-H64-ENV-ECOL.10, Revision 0). In addition, more specific, detailed field instructions (although following the SOP methods) were written for the belt transect, point-intercept transect, and production plot methods for use as field training manuals for the late summer sampling.

During the 1994 field season, data were collected during two sampling sessions. The first occurred in the spring, from May 3 through May 25. The second sampling session ran from August 8 through October 4. Five 50-m long permanent terrestrial vegetation transects, located at each of the twelve sites, were sampled. At the riparian sites, these transects were haived, with one half on each side of the stream channel. Three different sampling methods were employed during 1994. The spring sampling consisted of belt transect sampling at all 12 EcMP sites. For the late summer sampling, three different types of measurements were taken at the nine grassland study sites: belt transect, point-intercept transect, and production plot. Sampling at the three riparian sites during the late summer differed from the grasslands in that no production plot data were taken. A brief description of the sampling methods follows. For more details, refer to the Program Management/Technical Performance Report, Terrestrial Vegetation SOP, and field training manuals, mentioned above.

\section{Belt Transect}

Species richness was determined in a 2-m wide belt centered along each permanent $50-\mathrm{m}$ transect. Every plant species observed within this $100 \mathrm{~m}^{2}$ area was recorded and its phenological state noted, and the densities of woody and succulent species determined. Densities were determined for the grassland sites during the spring sampling only. Densities were determined at the riparian sites for both the spring and late summer sampling, since some adjustment of the actual transect lines had taken place after the spring sampling to make them follow the stream channel more closely. Density measurements will hereafter be done on an annual basis. A total of 60 belt transects, five at each site were sampled during both the spring and late summer sessions.

\section{Point-intercept Transect}

Transects at all 12 EcMP terrestrial sites were sampled by the point-intercept method during the late summer session. Basal and foliar cover were determined at 50-cm increments along each transect for a total of 100 "hits" per transect. A 2-m long rod with 0.25 inch diameter, was dropped along the right side of a tape measure stretched along the $50-\mathrm{m}$ length of the transect. Two types of hits were observed: basal and foliar. Material at ground level was recorded for the basal hit. A basal hit could be vegetation (live plant), litter (fallen dead material), rock (greater than the diameter of the point-intercept rod), bare ground, or water in that order of importance. Importance was determined by a cover type's potential to protect the soil from erosion.

Three categories of foliar hits were defined by height and growth form. The topmost hit of each growth form was recorded. The growth forms measured were herbaceous, woody $<2-m$ in height, and woody $>2-m$ in height. A total of 60 point-intercept transects were sampled, five at each of the 12 sites. 


\section{Production Plot}

Production plots were sampled only at the nine grassland EcMP sites during the late summer sampling. No production plot sampling was done at the three riparian sites. Five randomly located $0.25 \mathrm{~m}^{-2}$ quadrats were placed outside each belt transect for a total of five quadrats/transect, times five transect/site, times 12 sites $=225$ quadrats.. The height of the three tallest graminoid individuals of each species was measured. Biomass was determined by clipping all herbaceous material within the quadrat. Clipped material was sorted into two biomass classes: current year dead (CYD) and current year live (CYL). Both CYl_ and CYD were sorted by species. Litter was also collected from the quadrats. Oven dry weights were determined for each sample collected and recorded on drying forms. Biomass results, given in grams $/ \mathrm{meter}^{2}\left(\mathrm{gm}^{-2}\right)$, were calculated from the actual quadrat values.

\section{Quality Assurance/Quality Control}

Data were collected onsite by EcMP personnel. Nomenclature was standardized using the Flora of the Great Plains (Great Plains Flora Association, 1991) as the primary reference, and data were recorded on field sheets in the form of unique site, wildlife habitat, and species codes. If a plant species could not be identified with confidence in the field, plant species were recorded as unknowns on the field data sheets. Voucher specimens were made of unknown species and later identified by keying, making comparisons with known specimens in the reference collection or herbarium collection, or by trips to the University of Colorado Herbarium in Boulder. In some cases due to lack of key characteristics, specimens were only identified to the family or genus level. If a specimen could not even be identified to that level it was ignored. Taxa identified to the family or genus level were only included in calculations when there were no verified species from the same family or genus present at the site.

Prior to data entry, all unknown specimens were identified and corrections made to the field data sheets. Data entry and QA of database files were done by EcMP personnel. The QA process used for data entry was as follows:

-data entry, -printout hardcopy of electronic file for proofreading, -initial $100 \%$ proofreading of hardcopy, -corrections made to the database from the corrected hardcopy proofreading pages, -second hardcopy printout after corrections made to database, -second proofreading consisting of checking corrections made to database, -if errors still found another round of correcting and proofreading followed, if no errors were found then a spot check of two records from each page of the final proofreading printout were made.

Each stage of the QA process was documented by a signature on a Quality Assurance Form.

\section{Data Analysis}

Data analysis of the 1994 Terrestrial Vegetation data was conducted during the winter of 1994 1995 and consisted of the following reductions and analyses:

\section{- $\quad$ Species Richness}

-Species lists by site and by community in tabular form -number of families, number of species, percent natives, number of annuals, number of biennials, number of perennials, growth form (forb, graminoid, cactus, shrub, vine, tree), type (dicot, monocot, pteridophyte), form (herbaceous, succulent, woody), by site, by community -Woody stem and cactus densities by site and by community 
Cover

-Basal cover (vegetation, litter, rock, bare ground, water) summaries by site and by community

-Foliar, shrub, and tree cover by site and by community

- Basal cover dominant species by site and by community

-Foliar, shrub, and tree cover dominant species by site and by community

-Percent native basal and foliar cover by community

- Biomass

-Current year production by site and community

- Litter by site and community

-Percent native biomass by site and community

-Biomass dominant species by site

- Ordination and Classification

-Community ordination and classification using the following statistical programs:

-DECORANA - Detrended Correspondence Analysis and reciprocal averaging methods by overall species richness at EcMP sites and by transects (Hill, 1979a) -TWINSPAN - Two - way Indicator Species Analysis (Hill, 1979b)

Both of these analyses are explained further in the results section.

One-way analysis of variance (ANOVA), using a Tukey means separation, was performed on cover and biomass data to determine if differences between sites and differences between communities were significant at the $\alpha=.05$ level. Variances were checked and a Cochran's $C$ test run to determine if the variances were equal. In addition, residuals were plotted against predicted values to make sure they were evenly distributed. Site and community were considered separately as the factors. Analyses were performed using the statistical program Statgraphics, on an IBM compatible computer. Correlation analysis was also performed using Statgraphics between current year production and litter biomass amounts to see how they were related to each other.

In addition, the Current Approved Species List (CASCL) list, the official fiora list for the Site, was also analyzed. Determinations were made for number of families, number of genera, number of species, percent native, number of annuals, number of biennials, number of perennials, numbers for growth form and life form categories, number of endemics, and number of species of special concern. A list of plant species found in 1994 and not previously recorded for the Site was also generated.

\section{DATABASE STATUS}

Data from the 1994 sampling sessions were originally recorded on field data sheets by hand in black ink. After the identification of unknown plant specimens were made, the data from the field data sheets were entered into one of three types of terrestrial vegetation database files. The files were for belt transect, point-intercept transect, and production plot data and were generated separately for spring and fall sampling. The process of data entry and QA was done as mentioned previously in the Quality Assurance/Quality Control section. Four electronic database files were made from the 1994 field season terrestrial vegetation sampling. They are:

Belt941.dbf - 2788 records - spring 1994 belt transect data, Belt942.dbf - 3660 records - fall 1994 beit transect data, PIT942.dbf - 990 records - fall 1994 point intercept data, and Quad942.dbf - 1832 records - fall 1994 production plot data. 


\section{STATUS OF THE SITE HERBARIUM}

The Site herbarium is currently incomplete. During 1994, an inventory of the specimens found in the herbarium revealed that the only mounted specimens in the collection were those which were given to the Site by the University of Colorado after an initial botanical inventory in 1974 . Since that time collections which have been made of the Site flora have not been labelled, mounted, or placed in the collection. Attempts have been made to identify and locate necessary information needed for labeis for numerous plant specimens found in newspapers in the herbarium cabinet. However, progress is slow and many specimens are not of high enough quality to make herbarium mounts. The result is that there are no voucher specimens for many of the species on the CASCL which lists all the currently accepted species for the Site. This represents a problem, since the accepted standard botanical practice is to create a species list based on collected specimens, which documents the occurrence of a species at a site. This is the scientifically accepted method because it allows for independent verification of the species on the plant list, should there ever be concern whether a given species actually occurs at a site or if a misidentification was made. At present, this independent verification is not possible.

In order to remedy the situation the following steps have been taken. In 1994, a database was set up for the herbarium collection and all the current herbarium specimens were entered into it. A list of the specimens contained in the database was printed out and compared to the CASCL list. Then a collection list of those species which need a specimen for documentation was made. During the 1995 field season, collections will be made of those species needed to complete the collection in order to bring the collection up to date. These will then be labelled, mounted, and filed in the herbarium collection. This will greatly enhance and facilitate vegetation work at the Site.

\section{SITE DESCRIPTION}

Community types were named and defined using terminology from the Baseline Report (U.S. Department of Energy, 1992). The three xeric grassland sites (TR01, TR06, and TR12) are all located on relatively flat ridgetops (Figure 1). TR01 is located in the Rock Creek watershed in the northwestern corner of the Site. This area is relatively undisturbed although a gravel mining operation exists to the west of this site and the site may be destroyed by mining activities in the near future. TRO6 is located on the eastern portion of the Site just north of the East Access Road on the edge of the montane-plains ecotone in which the Site lies. Its vegetation differs from the other two xeric sites. TR12 is located in the southwestern portion of the Site on a terrace. It is also undisturbed, but gravel mining is planned for the area. All three of the xeric sites are located in the land area acquired in 1974 and were grazed until that time.

The mesic grassland sites (TR02, TR04, and TR11) are all located on gently sloping southeast facing slopes. Slope angles range from 6-16 . TR02 lies in the Rock Creek watershed east of TR01. TR06 lies in the Walnut Creek watershed and TR11 lies in the southern portion of the Buffer Zone in the Smart Ditch drainage of the Woman Creek Watershed. These sites also lie within the land area acquired in 1974.

The reclaimed grassland sites (TR07, TR08, and TR09) are all located in the southeastern portion of the Site which was farmed prior to 1974. It has since been reseeded. The topography is rather flat with gentle slopes of $7-8^{\circ}$.

The riparian sites are TR03, TR05, and TR10. TR03 is located in the Rock Creek drainage, which has remained relatively undisturbed by Site activities. One TR03 transect, transect 5 , is located within the boundaries of the 1952 acquisition and has not been grazed in over 40 years. The other four transects are located in the area acquired in 1972. TR05 is located in Walnut Creek downstream from the industrial area. Portions of this site have been riprapped with boulders of 
sandstone and basalt. All of the TR05 transects are located in the land area acquired in 1974. Water entering the Walnut Creek channel is controlled by plant personnel. TR10 is located in the southern side of the Site in the Smart Ditch drainage, which is a natural drainage with controlled flow from Rocky Flats Lake. Two of the TR10 transects, transects 1 and 2 , are located within the boundaries of the 1952 Site land acquisition. All riparian sites slope gently at $2-3^{\circ}$; one transect at TR03 lies on a steeper slope with an angle of $19^{\circ}$.

All EcMP site corners and transects have been located using a Global Positioning System (GPS) and mapped. Slope angle and aspect were recorded at each end of each of the Terrestrial Vegetation transects. All site location information has been entered into the database and may be used to determine height above water, horizontal distance to water, and distance to human activity. This information may correlate with community composition.

\section{RESULTS}

This section summarizes the belt transect, point-intercept, and production plot data. Ordination and classification results are also presented. In addition, a list of plant species collected for the first time on Site is presented. Summaries are presented by the use of tables and figures primarily, with the text highlighting some of the important facts. The interpretation, discussion, and comparison of the results with other studies may be found in the discussion.

NOTE: For the analyses which are presented, the following "rules" were applited. Taxa identified only to the family or genus level were only included in the calculations which follow when there were no verified species from the same family or genus present at the same site or community. When determining the percent of native species at a site or community, since no genera or families have a species status, they were left out of the determinations altogether. When counting the number of annuals, biennials, and perennials, plants identified to genus were included in the counts only if the species known to occur here could be placed in one category or another. In cases where a species could be an annual, biennial, perennial, or a combination of these, (as listed in plant manuals), the following rules were applied. A biennial was counted as biennial when it was considered to be only a biennial. Plants were counted annuals only when considered an annual or annual/biennial. Plants were counted perennial whenever they were considered to be perennials, even though they may occur as annuals or biennials also. As used in the results and discussion which follow, totals for sites are based upon a mean from data from five transects $(n=5)$. If a mean is given for the community total, it is based on the means for the three sites that represent that community (i.e. TR01, TR06, and TR12 = the xeric community). In other cases, however, the community value is based on a combination all three sites for the given community to determine the total value for the variable being considered for that community (i.e., total species richness for the xeric community $=133$ as compared to the xeric mean species richness $=89$ ). If a mean value is given in the text, it will be designated as a mean value. If no such designation is given, it is a combined value.

\section{Species Richness}

Flora

During the 1994 field season, 21 plant species previously unknown from the Site were collected, identified, verified at the University of Colorado Herbarium in Boulder, and assigned unique species codes. These new species include those collected both inside and outside the Ecological Monitoring Program permanent transects. They are:

Draba reptans (Lam.) Fern.

DRRE1

Microsteris gracilis (Hook.) Greene

MIGR1 
Euphorbia spathulata Lam.

Erysimum repandum $L$.

Hybanthus verticillatus (Ort)Baill.

Asperugo procumbens $L$.

Senecio tridenticulatus Rydb.

Senecio fendleri Gray

Astragalus parryi Gray

Potentilla pensylvanica L.

Solidago rigida $\mathrm{L}$.

Picradeniopsis oppositifolia (Nutt.)Rydb.

Triodanis sp. Raf.

Agrostis scabra Willd.

Parietaria pensylvanica Muhl. ex Willd.

Aster fendleri A. Gray

Triticum aestivum $L$.

Aster hesperius A. Gray

Asclepias stenophylla Gray

$X$ Agrohordeum macounii (Nasey) Lepage

Agropyron spicatum(Pursh) Schrib. and Sm.
EUSP1

ERRE1

HYVE1

ASPR1

SETR1

SEFE1

ASPA1

POPE1

SORI1

PIOP1

TRI2

AGSC1

PAPE1

ASFE1

TRAE1

ASHE1

ASST1

AGMA1

AGSP1

The new species were added to the CASCL, bringing the total to 512 species for the Site. A summary table of the Site flora is found in Table B-1. Endemic species were determined by reference to Weber and Wittman (1992). Species of concern were determined using an unpublished list from the Colorado Natural Heritage Program (1994). During the 1995 field season herbarium quality specimens of these new species will be collected if one has not already been collected. (Often the identifications from 1994 were made using lesser quality specimens. Properly collected specimens will be labelled and mounted and placed in the Site herbarium.) The specimen of Triodanis was only identifiable to genus, since it lacked the key characteristics necessary for species determination.

\section{EcMP Sites And Communities}

A total of 271 species of vascular plants representing 51 families and 73 genera were documented from the EcMP terrestrial vegetation permanent transect sites during the 1994 field season (Table B-2). Native species represented $81 \%$ of the total flora. Thirty-nine species were annuals, three species were biennials, and 228 species were perennials. Of the 271 species, 199 were dicots, 68 monocots, and four were pteridophytes. Classified by life form, 251 species were herbaceous, 15 were woody, and five were succulent. Classified by growth form, the flora included 190 forbs, 61 graminoids, nine shrubs, five trees, five cacti, and one vine. These data were obtained by combining the species lists from belt transects $\left(100 \mathrm{~m}^{2} /\right.$ belt $\times 5$ belts/site $\times 12$ sites $=6000 \mathrm{~m}^{2}$ sampled) and production plot samples $\left(0.25 \mathrm{~m}^{2}\right.$ quadrats $\times 5$ quadrats/belt $\times 5$ belts/site $\times 9$ grassland sites $=56.25 \mathrm{~m}^{2}$ ). The total number of species found at the EcMP sites comprises approximately $52 \%$ of the total flora for the Site. Presently the total Site flora has 512 species, as listed on the CASCL.

None of the species documented at the EcMP sites were listed as threatened or endangered, however, one species (Carex oreocharis Holm.) was present at TR02 and was listed as a species of concern by the Colorado Natural Heritage Program (Colorado Natural Heritage Program, 1994). It was listed with a global ranking of $G 3$ which means it is considered rare to uncommon. The state listing was an $S$ ? which means it is believed to be rare, but it is awaiting formal rarity ranking.

Summaries of species richness data are reported for the EcMP study areas by both site and by community in Table B-2 and Figures B-1 and B-2. The highest species richness occurred at the 
riparian sites and communities (based on site means and combined site values, respectively), followed by the mesic, xeric, and reclaimed sites and communities. The difference in mean species richness was only one species between the mesic and riparian community (103 and 104 species, respectively). However, at the community level, the combined total differences between the mesic and riparian communities were greater - 143 and 163 respectively. Species richness at the xeric sites and communities fell between that for the mesic and reclaimed sites, with a mean of 89 and a total of 133 species, respectively.

\section{Woody Stem And Cactus Densities}

Stem densities were determined for woody stems and cact from the belt transects (Table B-3 and Figure B-3). The greatest density of cacti was found at the xeric community which had a mean density of 0.65 cacti $\mathrm{m}^{-2}$. The highest site density was at TR12 which had 0.95 cacti $\mathrm{m}^{-2}$. The lowest cactus density was found at the reclaimed communities with a density of 0.01 cact m m. $^{-2}$. Only the riparian community had a woody density of any sizable amount $\left(6.42\right.$ stem $\left.\mathrm{m}^{-2}\right)$. Of the riparian sites, TR10 had the highest woody stem density with 9.13 stems $\mathrm{m}^{-2}$.

\section{Species Composition}

Although 271 species of vascular plants were documented at the EcMP study sites, the species found in the various communities differed considerably. The range of tolerance of different plant species varies considerably in response to factors such as soil moisture, light, temperature, slope, aspect, wind, competition, and herbivory. As Table B-2 shows, certain species are common across different habitats while others are restricted to the specific habitat requirements found only at certain sites. The arrangement of sites in the table is from xeric to mesic to hydric (riparian). The reclaimed sites fit the mesic category, but have been isolated in the table due to their great difference in species richness.

Three species were found to occur at all 12 EcMP study sites - Tragopogon dubius, Poa pratensis, and Bromus japonicus. All three species (one forb and two graminoids, respectively) are nonnative, adventive species. Three other forbs, Aster ericoides, Camelina microcarpa, and Alyssum minus, were found at every site except one. Of these three, only Aster ericoides, a composite, is native. The other two are non-native, adventive mustards.

The riparian community with the highest species richness also had the greatest number of species (88) restricted to that community. The xeric and mesic communities each had 22 species restricted to them and the reclaimed community had only six species restricted to it. The species restricted to each community type are listed in Table B-4.

The species composition of a site or community may also be examined in terms of the growth form (forb, graminoid, cactus, shrub, vine, or tree), percent native species, life form (annual, biennial, or perennial or herbaceous, succulent, or woody), and type (dicot, monocot, or pteridophyte).

Summaries of the 1994 EcMP terrestrial site species compositions by these categories are found in Table B-5 and Figures B-4, B-5, B-6, B-7, and B-8. Summaries by community are found in Table B-5 and Figures B-9, B-10, B-11, and B-12. Community summaries were determined by combining the three site floras for that community - not based on the mean values for the sites making up the community.

Forbs and graminoids made up the largest portion of the flora at the Site in all communities and at all sites (Figures B-6 and B-11). The number of graminoid species averaged about 21 at the xeric and mesic sites with two to five additional species found at the riparian sites (Figure B-6). The reclaimed sites were rather depauparate in terms of number of graminoid species (five to eight species). Forb numbers were relatively consistent at the xeric sites (62-66) and mesic sites (7079), but varied most at the riparian sites, ranging from 48-80 (Fgiure B-6). Shrub and tree species 
were most abundant at the riparian sites and comrnunity (Fgiure B-6). The greatest percentage of native species were found in the xeric community. In general, the percent native species decreased by community type in the order xeric, mesic, riparian, reclaimed Figure B-9). However, on a site basis, two of the mesic sites (TR02 and TR11) had a greater percentage of native species than TRO6 (a xeric site, Figure B-4). Perennial species far outnumbered annual species present at the sites and at the communities (Figures B-5 and B-10, respectively). The highest numbers of annual species were found at the mesic sites and community. The dicot versus monocot figures (Figures B-7 and B-12) showed a strong similarity to the forb versus graminoid figures (Figures B-6 and $B-11$ ) at the site and community levels, in that forbs and dicots outnumbered graminoids and monocots by factors greater than two or three to one.

\section{Cover}

Basal cover is a measure of the amount of vegetation cover at the ground's surface. This measure is important, because vegetation acts to protect the soil from wind and water erosion. Basal cover point-intercept sampling records the cover at the soil's surface as either vegetation, litter, rock, bare ground, or water. The results of the point-intercept sampling for basal cover are presented by site and by community in Tables B-6 and B-7 and Figures B-13 and B-14. A one-way ANOVA (factor=site or community, Tukey means separation procedure) was done for the basal cover classes vegetation, litter, rock, and bare ground at both the site and community levels. Water was not analyzed since it only occurred at the riparian community. Results exhibited in Figures B-13 and B-14, showed that significant differences existed between sites and between communities for each cover class. The missing letters in Figure B-13 for litter and rock at TR05 are due to the fact that the variances for each of these cover classes at TR05 were much larger than those of the other sites (Table B-6). The ANOVA was run without the data for TR05 for these two cover classes.

At the community level, the highest vegetation basal cover was found in the mesic community (mean $=29 \%$, Table B-7). This difference was found to be significant $(\alpha=0.05$ level), compared to the reclaimed community (11.2\%), but not to the riparian or xeric communities (Figure B-14). The reclaimed community had the lowest amount of vegetation cover $(11.2 \%)$ and the greatest amount of litter cover $(70.4 \%$, Tabie B-7). This only differed significantly ( $\alpha=0.05$ level) from the mesic community $(55.3 \%)$, but not significantly from the xeric or riparian communities (Figure B-14). The lowest amount of litter cover was found in the mesic community. Rock cover was highest in the mesic and xeric communities (14\% and $13.9 \%$ respectively, Table B-7). These two communities differed significantly ( $\alpha=0.05$ level) from the riparian community which had the lowest mean rock cover (5.2\%, Figure B-14). The reclaimed community was intermediate in terms of rock cover. The highest amount of bare ground cover occurred in the reclaimed community $(5.1 \%$, Table B-7) and was significantly higher than any other community ( $\alpha=0.05$ level, Figure $B-14)$. The lowest amount of bare ground cover occurred in the riparian community (1.3\%).

Between sites, TR04, a mesic community site, had the highest amount of vegetation basal cover $(40 \%$, Table B-6) and it was significantly different ( $\alpha=0.05$ level) from seven of the other sites studied (Figure B-13). TRO4 did not differ significantly from any of the other mesic sites, however. It was significantly different from all of the reclaimed sites. TR08 (a reclaimed community site), had the lowest amount of vegetation cover (6.8\%, Table B-6). Significant differences ( $\alpha=0.05$ level) were found for litter cover between TR04 and four other sites (Figure B-13). TR04 had the lowest amount of litter cover $(51 \%)$ and TR03, a riparian community site, had the highest amount at $74 \%$ (Table B-6). Significant differences $(\alpha=0.05$ level) were also found for rock cover between sites. Rock cover at TR01, a xeric community site, and TR02, a mesic community site, was found to be significantly higher than four other sites (Figure B-13). Although rock cover was greatest at TR05, a riparian community site, it was not included in the ANOVA because the variances were extremely large compared to the other sites (Table B-6). Of those sites analyzed by ANOVA, TR01, had the 
highest amount of rock cover (21.6\%) while TR06, a xeric community site, had the lowest amount $(3.4 \%$, Table B-6). Bare ground cover was highest at TR08, a reclaimed community site (Table B6 ) and was found to differ significantly ( $\alpha=0.05$ level) from 10 other sites (Figure $B-13$ ). The only site it did not differ significantly from was TR07, another reclaimed community site. Water cover was only found at the riparian community type (Table B-6) and was not analyzed statistically.

Foliar, shrub, and tree cover are measures of the amount of vegetation cover above the ground's surface (the canopy as projected vertically to the ground). The amount of cover present is important as it affects the amount of light reaching the ground surface, the temperature of the ground surface, the amount of moisture reaching the ground in a precipitation event, the rate of moisture loss from the surface, and the wind speed at ground surface. The results of the sampling for foliar, shrub, and tree cover are summarized by site and by community in Tables B-6 and B-7. The foliar cover in the three grassland communities was highest in the mesic community $(91.3 \%)$ followed by the xeric community $(87 \%)$ and reclaimed community $(80.2 \%$, Table B-7). A one-way ANOVA (factor=site or community, Tukey means separation procedure) was done for foliar cover at both the site and community levels. Results from the ANOVA on foliar cover by site and by community revealed variances at the riparian sites, TR03, TR05, and TR10, to be extremely high compared to the non-riparian sites (Tables B-6 and B-7) and model assumptions were violated. Therefore the results were not used.

The only community with any significant vertical stratification was the riparian community. It had the lowest amount of foliar cover of grasses and forbs $(66.5 \%)$, but the highest amounts of both shrub and tree cover $(39.8 \%$ and $18.6 \%$ respectively, Table B-7). Although the xeric and mesic communities did have a shrub layer, the shrubs were sparsely distributed, and the amount of cover provided by this layer was less than $2 \%$ in each community (Table B-7). A check of the variances for the shrubs present at both the xeric and mesic sites and communities revealed that their variances were not close to that of the riparian community (Tables B-6 and B-7) and so they were not included in the ANOVA. Therefore, shrub and tree cover were tested for significance only for the riparian sites. The results showed that between the three riparian sites, both shrub and tree cover were highly non-significant. The ANOVA for the shrub cover had an F-ratio of 0.210 with a significance level of 0.8132 and the ANOVA for the tree cover had an F-ratio of 0.439 with a significance level of 0.6545 .

Species richness (combined) from the point-intercept sampling data alone (basal and foliar cover) increased from the reclaimed to xeric to mesic and then to the riparian communities (Table B-8). This paralleled the findings of the combined belt transect and point-intercept species richness data, in which species richness increased in the same community order (Table B-5). The highest percentage of native species, in terms of species richness from cover data, was found in the xeric communities, followed by mesic, riparian, and reclaimed communities in that order. However, the percentages of native versus non-native species comprising the basal and foliar cover varied considerably between the different communities (Table B-8). In the xeric community, native species made up over $80 \%$ of both relative native basal and foliar cover. This declined to just over $50 \%$ for the riparian and mesic communities. In the reclaimed community, native species made up only $2 \%$ of the total relative basal and foliar cover.

The dominant species by community (means) based on basal and foliar cover are shown in Table B-9. Dominant species by site (means) for basal cover are shown in Table B-10 and for foliar cover in Table B-11. In the xeric community, Stipa comata was the dominant species for both basal and foliar cover. However, differences were found to exist between the three sites which have been designated as the xeric community. Although Stipa comata was dominant at TR06 and TR12, it was not even in the top five at TR01. TR01 was dominated by Andropogon scoparius. At the xeric sites, TR06 had the highest non-native cover, based on the top five cover species, in terms of both basal and foliar cover. The mesic community, was dominated largely by Bromus japonicus 
- a non-native annual grass, however Andropogon smithii and Bouteloua gracilis, both natives, were common in terms of basal and foliar cover. The reclaimed sites were completely dominated by Bromus inermis and Agropyron intermedium - both non-native, planted species. In the riparian community, foliar cover was dominated by Juncus balticus. However, non-native species such as Poa pratensis, Poa compressa, and Cirsium arvense also comprised a large part of both the basal and foliar cover. Dominant species for shrub and tree cover are only presented for the riparian sites since significant stratification was found only at these sites. Salix exigua was the dominant shrub at TR05, while at TR10 it shared its dominance with Amorpha fruticosa. At TR03, Amorpha fruticosa is the dominant. Tree cover at the riparian sites was dominated by Populus deltoides at TR03 and TR10, while at TR05, Salix exigua, ( $>2 \mathrm{~m}$ tall) comprised more of the cover than Populus deltoides. (Shrubs were considered woody species $<2 \mathrm{~m}$ tall; trees were considered woody species $>2 \mathrm{~m}$ tall).

\section{Biomass}

Biomass is a measure of the amount of above ground vegetation produced during a given growing season. The vegetation is clipped at ground level at the time of maximum growth (usually late summer for grasslands), then sorted by species for current year live and current year dead, dried, and weighed. The resulting weights in grams per square meter provide a means of comparing the production from one site or community to that of another. The results from the nine EcMP grassland sites are found in Table B-6 and Figure B-15. Biomass comparisons by community are presented in Table B-7 and Figure B-16. No biomass data were gathered from the riparian sites

Of the three grassland communities studied, the reclaimed community had the highest amount of current year production (145.8 $\mathrm{gm}^{-2}$, Table B-7). The lowest amount of current year production was found in the mesic community (120.1 gm-2 Table B-7). A one-way ANOVA (factor=community, Tukey means separation procedure) showed a significant difference $(\alpha=0.1$ level) in current year production between the reclaimed and mesic communities (Figure B-16). The xeric community had the highest amount of litter $\left(262.9 \mathrm{gm}^{-2}\right)$ and the mesic communities had the least $\left(225 \mathrm{gm}^{-2}\right)$. No significant differences ( $\alpha=0.1$ level) were found for litter between communities. No production plot data was gathered at the riparian community type. For this analysis the five quadrat values for each transect were averaged for each transect. Then the analysis was done with an $n=15$ (fifteen transects per community).

Significant differences ( $\alpha=0.05$ level) were shown to exist between sites for both current year production and litter using a one-way ANOVA (factor=site, Tukey means separation procedure, Figure B-15). This analysis was done after averaging five quadrat values for each transect. Then the analysis was done with an $n=5$ (five transects per site). TRO9 (a reclaimed site) had the highest site current year production value $\left(177.71 \mathrm{gm}^{-2}\right.$, Table B-6). TR09 differed significantly $(\alpha=0.05$ level) for current year production from five other sites (Figure B-15). Within the reclaimed community, TR09 (178 $\left.\mathrm{gm}^{-2}\right)$ differed significantly from TR08 (120 $\mathrm{gm}^{-2}$, Figure B-15). In the xeric community, TR01 $\left(102 \mathrm{gm}^{-2}\right)$ had significantly lower current year production than TR06 $\left(157 \mathrm{gm}^{-2}\right.$, Figure B-15). No significant differences for current year production occurred between the mesic community sites (Figure B-15).

Significant differences ( $\alpha=0.05$ level) were also found for litter biomass between sites (Figure B15). The site with the highest litter biomass was TR06 $\left(342.8 \mathrm{gm}^{-2}\right)$, while TR04 had the least $\left(148.5 \mathrm{gm}^{-2}\right.$, Table B-6). No significant differences for litter biomass were found between any of the reclaimed sites (Figure B-15), however significant differences were found between sites in the xeric community and in the mesic community. In the xeric community, TR01 $\left(179 \mathrm{gm}^{-2}\right)$ differed significantly from TR06 $\left(342.8 \mathrm{gm}^{-2}\right)$. In the mesic community, TRO4 $\left(148.5 \mathrm{gm}^{-2}\right)$ differed significantly from TR11 (319.4 $\mathrm{gm}^{-2}$, Figure B-16). A correlation analysis calculated from the 225 
quadrats of 1994 production plot data revealed that current year production and litter amounts had a correlation coeffiecient of $R^{2}=0.3387(p<0.000)$.

The biomass amounts produced by native versus non-native species by site and by community varied considerably (Table B-12, Figures B-17 and B-18). The xeric community had the highest amount of biomass produced by native species $(71 \%)$. This compared to $63 \%$ and $0.22 \%$ at the mesic and reclaimed communities respectively. Within the xeric community, native species biomass accounted for $91 \%$ and $87 \%$ at TR01 and TR12, respectively. But at TR06, native species biomass accounted for only $46 \%$ of the total. This was largely due to high biomass amounts of non-native species, Linaria dalmatica, Poa compressa, Alyssum minus, and Sisymbrium altissimum, found at TR0.6 (Table B-13). In the mesic community, native species biomass accounted for $74 \%$ and $66 \%$ at TR02 and TR11, respectively, while they made up only $48 \%$ at TR04. Bromus japonicus found at TR04 accounted for a high percentage of the non-native species biomass found there (Table B-13). Native species biomass accounted for less than $1 \%$ at each of the reclaimed sites. This was due mostly to the large amounts of non-native Agropyron intermedium and Bromus inermis, which have been planted at these sites (Table B-14).

\section{Multivariate Analysis}

\section{Ordination}

Ordination is a method commonly used by community ecologists to organize plant community data based on species presence/absence exclusively. It does not take into account other environmental data, but instead leaves environmental interpretation to the expertise of the scientists involved and often requires supplemental studies to relate the ordination axes to their appropriate environmental parameters. The result of an ordination analysis are an arrangement of species and/or samples in two-dimensional space such that closely related groups of species or samples are clustered together and those not closely related are further apart. The first step in the ordination produces a graphical representation of the species or samples. The second step is the interpretion of the graphical representation in terms of environmental factors, to explain the patterns that have been revealed (Gauch, 1982).

One of the goals of ordination analysis is the production of a grouping of related samples (transects or species in this study) based on the type of data used (in this case species presence/absence data). The results commonly display a continuum between transects (or species) which is representative of the relationships between the transects (or species) in their environmental setting. A continuum is displayed along each axis, with each axis representing a unique environmental parameter. The $x-y$ plot of transect (or species) points in two-dimensional space, clusters the transects (or species) which are closely related, based on the two unknown environmental factors represented by the $x$-and $y$-axes. With the availability of this information for reference site transects, it is possible to incorporate information from remediation sites (transect data based on species presence/absence taken prior to, during, and after remediation activities) to determine where the remediation site transects fit in relation to the reference transects from the different plant communities at the Site. If, for example, a remediation site was sampled prior to disturbance and found to belong to the mesic community, it would be possible to sample the site every year (or every $x$ years) during or subsequent to the disturbance, ordinate the data with the reference site transect information, and see how much the natural community has been altered. Transect data taken after remediation has begun can be analyzed to see how the remediation and revegetation efforts are progressing. It will yield information on the current status of the remediation work and also serve as an indicator of how long it will take to return the site to a state similar to its predisturbance state. It may also produce significant information as to what steps may be needed to speed up the remediation/revegetation process. The end goal of the reclamation/remediation project would be to have the remediation site transects grouped closely with the reference mesic community transects. Such a grouping would indicate that the remediation site had been returned 
to its natural community type or state. Additionally, it should be possible to relate soil, ecosystem function, and other ecological information from the reference transects to the remediation transects (without actualiy sampling the remediation sites for these factors) based on the transect (or species) groupings in the ordination. For example, if a series of remediation transects cluster with the reference mesic community transects, it can be assumed that the environmental factors of that particular ordination analysis at both sites are similar. If a series of remediation transects from a site which was once determined to be a mesic community do not cluster with the reference mesic community transects, it is evident that remediation processes have not yet achieved their goal of returning the site to its pre-disturbance state. This type of information will then be available to assist those making management decisions concerning remediation seed mixes, fertilizers, and other factors relating to the revegetation of the area.

The Comell Ecology Program DECORANA (Hill, 1979a) was used to analyze the Site plant species presence/absence data. 1994 species ricliness data from the belt transects and the production plots were combined into one data set to provide overall species richness for each transect. The data matrix consisted of an alphabelized list of all species (271 total) present in one or more belt transects or in one or more production plot quadrat. Taxa identified only to genus or family were not generally included in this analysis. The one exception was the Triodanus sp., which was included because it was the only representative of this genus found during the study and, consequently, represented an additional species, oven if it was not identifiable to species at the time of sampling. The second "axis" of this matrix corresponded to 60 transects, recorded in the following order, TR01 T1, TR01 T2, TR01 T3, TR01 T4, TR01 T5, TR02 T1, ... , TR11 T5, TR12 T1, TR12 T2, TR12 T3, TR12 T4, and TR12 T5. This file was then run through the Cornell Ecology Program, COMPOSE (Mohler, 1987), to produce a data matrix with a format acceptable to DECORANA. The COMPOSE-created matrix was then run through the two ordination options provided by DECORANA, 1) the Detrended Correspondence Analysis (DCA) option and 2) the reciprocal averaging analysis (RAA) option. The DICA and the RAA each produced two ordinations of the data, one by species and the other by transect (samples). The RAA has two weaknesses when compared to the DCA. First, the scaling of the axes in RAA does not have any clear meaning and often is different for different parts of the axis. This commonly results in contraction of the ends of the axis, which gives the impression that the points at the ends are closer together than they actually are or would be if they were spread out along an axis scaled with uniformly sized units. The second major weakness of the RAA is that the second axis (and often subsequent axes) may be strongly related to the first axis. This results in the production of a graph whose points form a characteristic "horseshoe" or arch shape. The DCA is designed to overcome both of these problems. First, the axis ends are not contracted, producing a graph which better shows the true relationship and separation of the points with respect to one another. Second, the DCA avoids the arch effect by ensuring that there is no correlation between the first and higher axes (Hill, 1979a).

Graphs of the DCA and RAA results by transect (sample) and by species were plotted for three different axis combinations in Figures B-19 through B-30. Only the axes which showed the greatest clustering of transects as relating to the four community types were plotted. For the ordinations done by transect, the actual transect numbers for the points on the figures can be determined from the axis coordinates found in Tables B-14 and B-15 for the respective type of ordinations. Lines were drawn around the clusters of points which represent different community types. For the figures of the DCA and RAA results by species, the species code for each point may be determined from the axis coordinates found in Tables B-16 and B-17. The scientific name for each species code may be determined by looking at Table B-2. For both the DCA and RAA figures by transect and by species, only figures for axis one plotted against axes two, three, and four are presented, because they showed the greatest amount of clustering of points (Figures B-19 through B-30). The higher axes (two, three, and four) plotted against one another did not show much clustering or separation of the transects, but had most of the transects lumped together as a large mass (not shown), making it difficult to interpret the differences displayed. 
Ordinations done by both DCA and RAA techniques revealed very similar patterns for both the ordinations by transect (sample) and ordinations by species (Tables B-14 through B-17, Figures B19 through B-30). DCA and RAA ordinations by transect grouped the transects from each given community - xeric, mesic, riparian, and reclaimed - together with the other transects from that community (Figures B-19 through B-24). The contraction of the axis ends was more apparent in the RAA results (Figures B-22 through B-24) where the transect points at the ends of the axes tended to group closer together than those of the DCA (Figures B-19 through B-21). The DCA results show the transects at the ends of the axes to be more spread out and in fact show some differences in grouping among transects within communities. The riparian community tended to have the greatest amount of spread among the transects and occurred on the far right in the figures (Figures B-19 through B-21). The xeric and mesic transects grouped together fairly close and in some cases were almost intermixed near their common border. The reclaimed transects fell out in between these two broad groups. The DCA and RAA results by species showed some grouping of certain species, but the grouping was not as distinct as that found in the ordinations by transect, possibly due to the larger number of species as compared to the number of transects (Figures B-25 through B-30). In general, two groups of species can be recognized. There are, however, a number of species which fall out in between these two groups. The DCA results (Figures B-25 through B-27) show more distinct groupings than do the RAA results (Figures B-28 through $B-30$ ). The RAA results show the contraction of points at the axis ends much more than the DCA results. However, some generalizations and discussion of these results can be made. Interpretation of these results are discussed in the ordination subsection of the discussion section.

\section{Classification}

Classification is another tool used by community ecologists to see patterns in vegetation. It involves assigning different entities or samples (in this case transects) to different classes or groups (Gauch, 1982). Three different purposes for classification are given by Gauch (1982). First, it allows the researcher to summarize large, complex sets of data. Second, it helps in the interpretation of environmental factors influencing community variation. Third, it helps refine understanding and models of community structure. All three of these purposes influenced the decision to use this type of analysis on the terrestrial vegetation data collected at the Site. Like ordination, classification is a useful tool for remediation monitoring and can be utilized in much the same manner as ordination for this purpose. In fact, classification techniques are often used in conjunction with ordination techniques to see the patterns in vegetation from the different perspectives each technique offers.

The classification analysis used on the 1994 EcMP terrestrial vegetation data was The Cornell Ecology Program, TWINSPAN (Hill, 1979b). TWINSPAN is a hierarchical classification analysis which groups transects together and arranges them into a hierarchy that shows relationships between the transects (Hill, 1979b; Gauch, 1982). It is also a polythetic divisive classification technique which uses information on all the species in the data set, rather than just one species as monothetic divisive classification analyses do. The basic principle involved is that the analysis begins with all transect species presence/absence data in a single large set. It then begins to divide the transects into a hierarchy of smaller and smaller groups until each group contains just one transect or a predetermined number of transects (Gauch, 1982). The TWINSPAN program first constructs a classification of the transects and then using this classification prepares a classification of the species based on their ecological preferences (Hill, 1979b). The end result is an ordered two-way table which shows the relationships between the trasnsects and between species. The hierarchical relationships between transects are often displayed as a dendrogram to show the relationships more clearly.

Species presence/absence data were arranged in the same manner as previously described for ordination techniques. This matrix was then run through The Cornell Ecology Program, COMPOSE (Mohler, 1987) to prepare the format in a form acceptable to the TWINSPAN program. The results for the TWINSPAN classification by transect are shown in Figures B-31A and B-31B. Figure B-31A 
is a dendrogram which shows how the transects were broken into smaller and smaller groups by the TWINSPAN program. Figure B-31B is a legend that lists what transects were grouped together for each of the divisions.

Division 1 ( $B$ and $C$ in Figure $B-31 A$ ) split the grassland sites (TR01, TR02, TR04, TR06, TR07, TR08, TR09, TR11, and TR12) from the riparian sites (TR03, TR05, and TR10). AGST1 and JUBA1 (see Table B-2 for scientific names), each with occurrence in 14 of the 15 riparian transects, and CANE1 and MEAR1, each with occurrence in 12 of the 15 riparian transects) were identified as indicator species for the riparian sites.

Division 2 (D and E in Figure B-31A) split the reclaimed grassland sites (TR07, TR08, and TR09) from the mesic and xeric grassland sites (TR01, TR02, TR04, TR06, TR11, and TR12). BOGR1 served as the indicator species for the mesic and xeric grassland sites and occurred in 30 of the 30 mesic and xeric transects. BOGR1 did not occur at all in the reclaimed grassland transects.

Division 3 ( $F$ and $G$ in Figure B-31A) split the riparian sites into two groups, TR05 and ITR03 and TR10]. This division was based on the indicator species, GABO1's, occurrence in all 10 of the TR03 and TR10 transects but its absence from all TR05 transects.

Division 4 ( $\mathrm{H}$ and $\mathrm{I}$ in Figure $\mathrm{B}-31 \mathrm{~A}$ ) divided the reclaimed grassland sites into two groups, [TR07 and TR08] and TR09. The indicator species was GUSA1, which occurred in all 10 transects at TR07 and TR08 and in none of the 5 transects from TR09.

Division 5 ( $\mathrm{J}$ and $\mathrm{K}$ in Figure $\mathrm{B}-31 \mathrm{~A}$ ) divided the xeric and mesic grassland sites such that the 3 mesic sites (TR02, TR04, and TR11) and one xeric site (TRO6) formed one group and the two xeric sites (TR01 and TR12) formed the second group. The basis for this division was the presence of the indicator species, ARFE2, in the 10 transects at TR01 and TR12 and its absence from the transects at TR02, TR04, TR06, and TR11.

Within the group, TR02, TR04, TR06, and TR11, division 10 (P and $Q$ in Figure $B-31 A)$ produced the two subgroups [TR02 T2, T4, T5; TR04 T1, T2, T3, T4, T5; and TR11 T2, T4] and TTR02 T1, T3; TR06 T1, T2, T3, T4, T5; and TR11 T1, T3, T5]. This division was based on the three indicator species, DAPU1, LEMO1, and LEMO2, which occurred in 10,9, and 8 of the transects in the second subgroup, respectively. If two or three of these indicator species were present at a transect, that transect was placed in subgroup two. If only one or no indicator species was present in a transect, that transect was placed in subgroup one.

The final divisions produced groups (N,O,R,S,T,U,V, and ). Each contained between four and six transects which are listed in the legend (Figure B-31B) by their respective division letters.

\section{DISCUSSION}

The four communities (xeric grassland, mesic grassland, reclaimed grassland, and riparian community complex) chosen for study by EcMP personnel at the Site generally follow the hydrologic gradient from dry to mesic to wet as indicated in the Baseline Report (U.S. Department of Energy,1992). The following discussion will look at each of the communities individually based on the 1994 data collected from each of the three sites which make up those communities. Comparison to other studies from the literature will be made where possible, to put the Site vegetation into the larger regional context. Suggestions for the use and application of these data for decision-making are made where pertinent. 


\section{Xeric Grassland Community}

The xeric grassland community (xeric community) on the Site represents approximately $18 \%$ of the land area of the Site (U.S. Department of Energy, 1992) and is the driest of the communities. The species found in this community must be able to withstand the harshest conditions on the Site. Located on the tops of mesas and on ridgetops, the xeric grasslands are subject to desiccating winds, high solar radiation, and generally dry conditions. The three xeric sites studied are TR01, TR06, and TR12. TR01 and TR12 are in the western portion of the Site with TR01 in the northwest corner and TR12 in the southwest comer. TR06 is near the eastern boundary of the Site and is approximately centered in the north to south direction. All three sites are found on mesa tops and all are underlain by Rocky Flats Alluvium. Each of these sites was grazed until the early 1970s' when the land was purchased by DOE and became part of the buffer zone. These sites have been free from grazing and have had little disturbance of any other type for the past 20 years.

The xeric plant community has the lowest species richness of the three natural communities (the reclaimed community was not considered natural since it was previously agricultural land and is composed mainly of planted species) studied, with a mean species richness of 89 species and a combined richness of 133 (Table B-2). Although the xeric community has the lowest species richness, it also has the highest percentage of native species (84\%) (Table B-5). A total of 22 species are restricted to the xeric community (Table B-4). Cactus density is highest in the xeric community with a mean density of 0.65 cacti m$^{-2}$ (Table B-3). Basal and foliar vegetation cover averages $19.3 \%$ and $87 \%$ respectively (Table B-7). Current year biomass production and litter production averages $128.6 \mathrm{gm}^{-2}$ and $262.9 \mathrm{gm}^{-2}$ respectively at the xeric community (Table B-7). The xeric community produces the highest amount of current year biomass by native species $(71 \%$, Table B-12) of all the communities sampled.

Some interesting differences are apparent between the three xeric sites representing the xeric community. The dominant species found at each of the sites, based on relative basal cover, are of primary interest (Table B-10). TR01 is dominated by Andropogon scoparius, however, Andropogon gerardii, Carex heliophila, and Muhlenbergia montana also have large cover values for this site. TR06 and TR12 are both dominated by Stipa comata. However, TR12 seems to be intermediate between TR01 and TR06 in that it also includes a relatively large cover of Andropogon gerardii, Andropogon scoparius, and Carex heliophila. TR06 has only very small amounts of Andropogon gerardii and Andropogon scoparius, totaling about $1 \%$ of the relative basal cover (not shown in table), but instead has large amounts of Bouteloua gracilis, Poa pratensis, and Poa compressa.

The cover data show that there are no sinificant differences ( $\alpha=0.05$ level) for bare ground or litter cover (Figure B-13) between the xeric sites. However, the amount of rock cover between TR01 and TR06 and between TR06 and TR12 was significantly different ( $\alpha=0.05$ level)(Figure B-13). The rock cover at TR01 (21.6\%) was over six times that found at TR06 (3.4\%)(Table B-6). One possible explanation for this might be that because TR06 is much further east than TR01 and TR12 (both of which had higher rock cover than TR06), the Rocky Flats Alluvium which underlies all three sites thins out to the east. It may also indicate that differences in the soils may be a factor in the different types of vegetation found at these two sites.

Biomass data from the xeric sites also reveals interesting differences. TR01 produced the least biomass $\left(102.5 \mathrm{gm}^{-2}\right)$, with TR12 intermediate $\left(125.6 \mathrm{gm}^{-2}\right)$, and TR06 having the greatest biomass (157.7 $\mathrm{gm}^{-2}$, Table B-6). Statistically significant differences were found for current year biomass and litter production between sites TR01 and TR06 at the $\alpha=0.05$ level (Figure B-15). Although the percentage of native species making up the species richness at each of the three xeric sites is very similar, ranging from $80-84 \%$ (Table B-5), the total biomass produced by native species at each site varies considerably (Table B-12 and Figure B-17). TR01 and TR12 are similar in total native 
biomass produced, at $91 \%$ and $87 \%$ respectively. However, at TR06, only $46 \%$ of the total biomass is produced by native species. Four of the top five biomass producers at TR06, Linaria dalmatica, Poa compressa, Alyssum minus, and Sisymbrium altissimum, are all non-natives (Table B-13). This indicates that some type of disturbance has probably occurred at TR06 at some time in the past and has allowed the invasion of non-native species at the site. These species also probably account for the significant difference in current year biomass production between these two sites, especially since two of the top five biomass producers, Linaria dalmatica and Sisymbrium altissimum, are both large plants which add considerably to the biomass values of an individual quadrat. The density of cactus is also much lower and the density of woody stems much higher at TR06 than at either TR01 or TR12 (Table B-4). The dominant woody species at TR06 is Yucca glauca (no data shown).

Previous vegetation studies in Colorado have suggested that available soil moisture is the predominant factor in permiting the development and maintaining the tallgrass prairie remnants in the Front Range area (Livingston, 1952; Branson et al., 1965; Hanson and Dahl, 1956). Livingston (1952) suggests that "neither precipitation, temperature, nor evaporation appears to be the causal factor influencing or limiting the presence of these communities." He found that soil moisture was available at the tallgrass sites on dates sampling took place, but was unavailable at mixed prairie communities at the same time. The decrease in relative basal cover percentages and current year biomass amounts of Andropogon gerardii and Andropogon scoparius, both tallgrass prairie remnants, from TR01 to TR12 to TR06, would seem to indicate that available soil moisture levels decrease along similar lines at these sites. The fact that Yucca glauca is only found at TR06 (Table B-2) and typically only grows in, "well drained soils that have little or no subsurface water,"(Webber, 1953) would also support this idea. Sorghastrum nutans and Sporobolis heterolepis, both true prairie relicts (Livingston, 1952), only occur at TR01 and TR12. This also supports the idea that differences in the species composition at each of the three xeric sites may in part be explained by soil moisture differences betiveen the sites.

The differences in species composition, cover, and biomass, at the three xeric sites would tend to indicate that at least two different plant associations are present at these sites. TR01, with the high amounts of Andropogon scoparius and associated species such as Andropogon gerardii, Carex heliophila, Muhlenbergia montana, Aster porteri, Eriogonum alatum, and Arenaria fendleri, fits the xeric tall grassland plant association given by Bunin (1985) for the xeric tall grasslands found on Boulder County Open Space just to the north of the Site. No description is given by Bunin however, for a Stipa comata plant association such as is found at TR06. However, TR06 does seem to match the description given by Hanson (1955) for the Stipa comata-Bouteloua gracilis-Bouteloua curtipendula association of the Colorado Front Range. In addition, he mentions that it is closely related to the Andropogon scoparius association found in this region. This would seem to describe the situation here at the Site quite well. The fact that TR12 seems to be the intermediate between TR01 and TR06 would support the idea of the close relationship between the two associations.

Clark et al. (1980) describes the vegetation of the buffer zone and surrounding private lands, as of 1974. Based on the descriptions given for the areas where the three xeric sites are located, it appears that some changes have taken place in the vegetation over the past 20 years. Although differences in methodology were used, some generalizations can be made. At TR01, the vegetation 20 years ago was described as over-grazed pasture, dominated by Hypericum perforatum-Paronychia jamesii and Heterotheca (Chrysopsis) villosa-Buchloe dactyloides associations. The area of TR06 was described as a dry, Heterotheca (Chrysopsis) villosa-Buchloe dactyloides pasture. In the TR12 area, the vegetation was listed as a dry, Stipa comata-Koeleria macrantha (pyrimidata) prairie, and described as representing the mapping unit which most closely represented the former native prairie. This information provides an interesting historical context and indicates that TR01 and TR06 were more similar to each other at that point in time than to TR12, possibly due to heavy grazing which occurred previous to and during the 1974 study, and which 
stopped after DOE purchased the property in 1974-1975. What is interesting is that with the loss of grazing pressure and 20 years of time, TR01 and TR06 have become so different. A number of questions can be raised concerning this. Were the grazing pressures so different at the different sites (TR01 and TR06) and/or did some other type of disturbance occur which would account for the high cover and production values of non-native species at TR06? Perhaps the moisture differences previously mentioned could partly explain the differences now seen in the vegetation at these sites. The topography of the sites is very similar, but TR06 sits over 100 feet lower in elevation. All three sites are underlain by Rocky Flats Alluvium. Perhaps there are differences in subsurface moisture movement between the sites. Maybe higher precipitation is received on the western edge of the Site due to a closer proximity to the mountain front than is received on the eastern edge. But, if moisture differences were present at the sites in the past, wouldn't there have been different plant communities then also? Perhaps differences in soils or soil compaction can help explain the differences? Further study is needed to determine the reasons for this documented change in vegetation over the last 20 years.

Information concerning differences in vegetation in relation to environmental and/or physical conditions, has importance for decision-making concerning reclamation seed choices for revegetation of the xeric community areas on the Site. Broad generalizations concerning the xeric community as a whole may need further refinement for reclamation work in specific xeric areas on Site. Other environmental or physical factors may need to be considered. Further study is recommended concerning the soils and soil moisture availability in relation to plant communities or associations in the xeric areas on Site.

Direct comparisons of the vegetation on the Site to other studies found in the literature are not easily made due to differences in methodology, substrate type, precipitation events, topography, and other factors which influence final values. However, some generalizations may be made. Branson et al. (1965) studied plant communities in relation to soil conditions on Rocky Flats alluvium and shale derived soils just south of the Site. The species composition given for the stony soil on top of the Rocky Flats Alluvium (Andropogon gerardii, Andropogon scoparius, Bouteloua gracilis, and Muhlenbergia montana, leading cover and biomass producers) and shale derived soil (Agropyron smithii, Buchloe dactyloides, and Bromus japonicus, leading cover and biomass producers) vegetation are similar to the xeric grassland and mesic grassland communities respectively, found at the Site. Dry weights of $111 \mathrm{gm}^{-2}$ and $155 \mathrm{gm}^{-2}$ are given for the stony soil and shale derived soil vegetation, respectively. The xeric community on Site produced a higher mean current year biomass of $128.6 \mathrm{gm}^{-2}$ and the mesic community a lower value of $120.1 \mathrm{gm}^{-2}$ (Table B-7). Interpretation is difficult however, since Branson et al. (1965) mentioned that the fall, winter, and spring preceding sampling was especially wet. For the 1994 Site data, the fall, winter, and spring, precipitation data are not much different than normal (Balint, 1995). However, May, June, July, and September precipitation amounts were far below normal. When higher amounts of moisture are available, biomass values for vegetation on both types of soils would be higher and, when lower moisture is available, biomass values would be lower for both soil types. That the 1994 biomass amounts at the xeric community were higher than those given by Branson et. al.(1965) is interesting, because, due to the lack of summer moisture in 1994, most of the late season grasses did not put up very many flowering stalks which would have increased the biomass values. Under these same conditions, it seems to make more sense that the biomass in the mesic community on Site in 1994 would be lower than that found by Branson et. al. (1965) on the similar shale derived soil, since more summer moisture was available then. Perhaps other as yet undetermined factors (topography, solar radiation, slope angle) differ between the sites which account for these differences.

Moir (1969) found that biomass production values for Andropogon gerardii-Poa pratensis and Stipa comata-Bouteloua gracilis associations near Boulder were much higher than that of similar communities located elsewhere in Colorado. The biomass values of TR01 and TR12, $102.5 \mathrm{gm}^{-2}$ and $125.6 \mathrm{gm}^{-2}$, respectively (Table $\mathrm{B}-6$ )(most similar to the Andropogon gerardii-Poa pratensis 
association), are only approximately one-third of the $340 \mathrm{gm}^{-2}$ Moir found. But TR01 and TR12 have very little Poa pratensis. At TR06, where Stipa comata and Bouteloua gracilis are dominant species (Table B-13), a.biomass of $157.7 \mathrm{gm}^{-2}$ was found, which is far less than the $257 \mathrm{gm}^{-2}$ Moir found. Moir attributes the high biomass values he found to high precipitation from April to July. This is in stark contrast to the below normal precipitation received at the Site from May to July in 1994 (Balint, 1995). A more normal precipitation average over the summer at the Site would probably increase the biomass production faund at the xeric sites considerably.

A comparison of biomass amounts for current year production and litter from the Site with other prairie areas (in midwestern and western North America) studied as part of the International Biome Program (IBP)(Coupland, 1979), shows the Site values to be closest to those found on the Pawnee National Grassland in northeastern Colorado. Current year production and litter biomass amounts from ungrazed grassland sites on the Pawnee were $135 \mathrm{gm}^{-2}$ and $251 \mathrm{gm}^{-2}$ respectively. Current year production values for the different communities on Site in 1994 range from 120 to $145 \mathrm{gm}^{-2}$ and litter amounts from 225 to $262 \mathrm{gm}^{-2}$ (Table B-7). Most of the other prairies studied by the IBP had much higher current year production and litter amounts, with the exception of some desert grassland and shrub steppe prairies. This would indicate that overall the biomass amounts produced at the Site tend to be fairly low in comparison with other prairies across the country, but in relation to the Pawnee, the closest of the IBP areas studied, the Site is very similar. Low precipitation and moisture availability are probably the biggest reason for the low biomass amounts.

A valuable and important aspect of the xeric community at the Site is represented by the presence of relict portions of tallgrass prairie. Found primarily along the western edge of the Site, where both TR01 and TR12 are located, taligrass prairie species such as Andropogon scoparius, Andropogon gerardii, Sorghastrum nutans, and Sporobolis heterolepis, represent Pleistocene relict populations (Livingston, 1952) of the tallgrass prairie which remain confined to the moist, cobbly soils found in a narrow band paralleling the Front Range. The uniqueness of this habitat in Colorado, much of which has been lost due to increasing pressure from human development, has been recognized by the Colorado Natural Heritage Program (Kettler et al., 1994) and the assignment of G2/S2, rankings for the tallgrass prairies in the Rocky Flats area. This ranking indicates that, because of rarity and/or other factors, the habitat is facing potential extinction throughout its range. In addition, Stipa comata communities, part of the Great Plains mixed grass prairies, have also been ranked G2/S2, and representatives of this community also occur on the Site (TR06 being one location). The xeric community in general at the Site contains sizable portions of tallgrass prairie relicts and mixed grass prairie and as such should be disturbed as little as possible to preserve this habitat and its associated species for future generations to enjoy.

\section{Mesic Grassland Community}

The mesic grassland community (mesic community) is the most extensive of all community types present at the Site and covers approximately $54 \%$ of the total land area at the Site (U. S. Department of Energy, 1992). It represents the moderate hydrologic gradient zone between the dry (xeric community) and the wet (riparian communities) zones found at the Site. The higher soil moisture available to plants found in the mesic community (as compared to the xeric community) is due to a number of environmental factors. Slope, aspect, protection from desiccating winds, greater snow accumulation, subirrigation by seeps, and general soil characteristics, all are factors providing a higher soil moisture availability to the vegetation found there. The mesic community is found on moist hillsides on the Site (U.S. Department of Energy, 1992). The three EcMP mesic sites are located across the Site in three different watersheds, each on generally south facing slopes. TR02 is located in the Rock Creek watershed, TRO4 is in the Walnut Creek watershed, and TR11 is in the Smart Ditch drainage of Woman Creek.

The mesic community has a higher species richness than does the xeric community. The three ECMP sites in the mesic community have a mean species richness of 103 species with a combined 
species richness of 143 species (Table B-2). Native species comprise $81 \%$ of the species found in the mesic community, which is only $3 \%$ less than the xeric community (Table B-5). Bromus japonicus, an annual, non-native grass, is the dominant species (based on basal and foliar cover measurements) in the mesic community (Table B-9). No significant differences ( $\alpha=0.05$ level) were found for vegetation, litter, or bare ground cover between these three sites. Rock cover was the only cover class with any significant differences and these were between TR02 and TRO4 (Figure B-13). The highest number of annual species are found in the mesic community (Table B5). The mesic community has approximately half the cactus density $\left(0.32\right.$ cacti $\left.\mathrm{m}^{-2}\right)$ and approximately eight times the woody plant density $\left(0.83\right.$ stem $\left.\mathrm{m}^{-2}\right)$ of the xeric community (Table B3). Twenty-two species occur only in the mesic community (Table B-4). Basal and foliar vegetation cover is higher in the mesic community at $29 \%$ and $91 \%$, respectively, than at any of the other communities (Table B-7), while current year biomass and litter amounts (120.12 and $225 \mathrm{gm}^{-2}$, respectively) are lower than any other community (Table B-7). No significant differences ( $\alpha=0.05$ level) were found for current year production between the mesic sites, however, litter amounts were significantly different between TR02 and TR04 (207.1 gm-2 and $148.5 \mathrm{gm}^{-2}$, respectively). Native species produce only $63 \%$ of the current year biomass in the mesic community (Table B-12).

The differences between the three EcMP mesic sites are generally less distinct than those distinguishing the three xeric sites. Bromus japonicus, Agropyron smithii, and Bouteloua gracilis are the dominant species at the mesic sites, based on relative basal cover, although their order of importance varies between the sites (Table B-10 and B-11). TR04 differs from the other two mesic sites in that it has an abundance of Bromus japonicus, an annual, non-native species. TR04 has twice the Bromus japonicus basal cover that TR11 has and five times the Bromus japonicus basal cover found at TRO2 (Table B-10). At TR04, Bromus japonicus is also the leading current year biomass producer with over twice the production of that species at TR11 and three times that found at TR02 (Table B-13). Native species current year biomass production comprises only $48 \%$ of the total current year biomass at TR04 (Table B-12), the lowest native production of the mesic sites. The high annual production from annuals such as Bromus japonicus, Bromus tectorum, and Alyssum minus, is not an uncommon problem on western rangelands. The competitive influences of these annuals are well known and in many areas these species are dominants in the community, often displacing the native species (Haferkamp et al., 1994; Monsen, 1994; Rosentreter, 1994). Areas converted to annuals often have lower species richness and diversity, resulting in lost genetic and structural diversity, ecosystem instability, a low-quality watershed with increased susceptibility to soil erosion, and an increased potential for more frequent wildfires (Rosentreter, 1994).

Currently the mesic community is the grassland community on Site which is most affected by the presence of exotic annuals. The potential for increased frequency of wildfires created by the high cover and biomass values for the annual species in the mesic community is of concern, because it would result in the loss of ground cover, exposing the soil to erosion processes. Wind erosion is considered a major mechanism of potential plutonium movement in contaminated soils (Little et al., 1980 ) on Site. With loss of ground cover, wind driven plutonium movement could become a distinct possibility in contaminated areas. Control of these species and the management of the vegetation to aid its return to a more natural, native, perennial, mesic mixed grassland would help reduce this as a potential problem. It would also prevent the spread of these exotics to other parts of the Site.

Although the mesic community does have a problem with "weeds," the community is essentially an Agropyron smithii-Bouteloua gracilis association, in various states of quality on the Site. It seems to match the description given for the mid-height grassland, Agropyron smithii-Bouteloua gracilis association, given by Bunin (1985) as occurring on Boulder Open Space lands. It also matches to some extent, the Bromus tectorum-Agropyron smithii-Bouteloua gracilis association of Hanson and Dahl (1956) which they studied between Boulder and Big Thompson Canyon. The major difference would be that on Site the Bromus tectorum has been replaced by Bromus japonicus. 
The Colorado Natural Heritage Program says this shortgrass/mixedgrass prairie association is believed to be fairly common, but is highly impacted throughout much of its range (Kettler, 1994). As a result, it ranks this association as $\mathrm{G} 5 / \mathrm{S4}$, indicating that globally it is very common and in the state it is common, although restricted to certain areas, and at present not susceptible to any immediate threats. Through proper management, the mesic community on Site could probably be returned to a higher quality shortgrass/mixedgrass prairie.

\section{Reclaimed Grassland Community}

The reclaimed grassland community (reclaimed community) at the Site represents approximately $9 \%$ of the total area at the Site (U.S. Department of Energy, 1992). It is an area previously used as agricultural land that was planted with seed mixtures of one to several species over 20 years ago. The three reclaimed sites, TR07, TR08, and TR09, are located on gentle east, southeast facing slopes in the southeastern corner of the Site. The pre-agricultural vegetation is thought to have been mesic mixed grassland (U.S. Department of Energy, 1992). No farming has taken place on the land in the past 20 years.

The fact that the reclaimed community represents an attificial community is apparent from the data from the three EcMP reclaimed sites. The reclaimed community has the lowest mean number of species (37) and combined number of species (61) of all the grassland communities at the Site (Table B-5). Oniy $62 \%$ of the species present are native species (Table B-5 and Figure B-9). The reclaimed community is dominated by two of the non-native, seeded species, Bromus inermis and Agropyron intermedium, which were planted as ground cover approximately 20 years ago. The two dominant species mentioned above account for $80-100 \%$ of the basal cover (Table B-10) and over $95 \%$ of the current year biomass (Table B-13) at the reclaimed sites. Basal vegetation cover is the lowest of all communities $(11.2 \%$, Table B-7). The reclaimed community has the highest current year biomass production of all the communities at $147.8 \mathrm{gm}^{-2}$ (Table B-7).

TR09 differs considerably from TR07 and TR08 in that it shows the least amount of successional progression back toward the native, mesic mixed prairie. It has the lowest species richness and lowest percent of native species (Table B-5), the highest basal cover (Table B-6), and highest current year production for biomass (Table B-6) of all the reclaimed sites. The current year biomass production for 1994 was significantly higher at TR09 than at TR08 ( $\alpha=0.05$ level), which may suggest that some factor differed between these sites during 1994, allowing for better growing conditions at TRO9. No significant differences were found for vegetation, litter, or rock cover between the three sites (Flgure B-13). However, bare ground cover was significantly higher at TR08 than at TR09 (Figure B-13). Further study is needed to investigate why TR09 is different from TRO7 and TRO8 in terms of its successional stage since, all three sites were reseeded at the same time 20 years ago.

The impact of these two non-native planted species totally dominating the sites after approximately 20 years demonstrates the competitive edge these two species have over the native vegetation. The successional progression back to the native mixedgrass prairie, which was present prior to agricultural use (U. S. Department of Energy, 1992) is going to take a very long time. Wilson (1989) found that alien (non-native) species introduced for revegetation purposes actually suppressed revegetation by native prairie species. He found that, "naturally regenerating native vegetation was as efficient as any commercial mixture at producing plant biomass, and was most efficient at covering bare ground where it was not faced with competition from introduced species." This is of special concern at the Site because these sites were revegetated with the seed mixture to provide ground cover to prevent potential erosion, especially wind erosion. As previously mentioned, wind erosion is of special concern at the Site since it is considered the major mechanism of plutonium transport for plutonium in contaminated soils (Little et al., 1980). Although no contamination has been noted in these soils, erosion is still an important concern. 
At the reclaimed community, total basal cover is only approximately one-third (11.2\%) of that found in the mesic community $(29 \%$, Table B-6). This difference between the mesic and reclaimed communities (Figure B-14) for total basal vegetation cover was found to be significantly different $(\alpha=0.05$ level). At the site level, a significant difference ( $\alpha=0.05$ level) was also found between TR04 (mesic site) and two of the reclaimed sites, TR07 and TR08 (Table B-6 and Figure B-14). The reclaimed community also differs significantly ( $\alpha=0.05$ level) from the mesic community in that it has less litter cover and more bare ground cover (Figure B-14). The percentage of bare ground at the reclaimed community is three times higher than that of the mesic community $(1.7 \%$ and $5.1 \%$ respectively, Table B-7). A factor explaining some of the lower vegetation cover at the reclamimed community may be that Bromus inermis and Agropyson intermedium are rhizomatous graminoids. Because of this individual plants tend to grow father apart from one another than many of the other graminoids and forbs found in the mesic community. Because these two species dominate the reclaimed community and few other species provide any cover, there is more bare ground present. This implies that, if the reclaimed sites were converted to the original native mixed prairie, there would be more ground cover, less bare ground, and higher species richness than there is presently at the reclaimed sites.

This raises an important concern with regard to reclamation at the Site, suggesting that revegetation with a diversity of native species is preferable to using non-native species for providing ground cover to prevent soil erosion. The lack of species richness in the reclaimed community as compared to the other communities puts the reclaimed community at a serious disadvantage from an ecological standpoint. The di-culture formed by the two dominant species, Bromus inemis and Agropyron intermedium, means the vegetation there does not form a very stable community. If disease, drought, or some other condition, proved detrimental to the survival of either of these two species, the land would be essentially denuded and left barren. A higher species richness and cover and biomass spread out over more species tends to lessen the impact of the loss of one or two species to disease or some other cause. This means the community is much more stable and resistant to collapse should some unforeseen event occur. Attempts could be made to convert this community back to a more native, mesic mixed grassland by seeding with native species. Until then however, the community can be used to evaluate successional trends.

\section{Riparian Community}

The riparian community represents approximately $5 \%$ of the total area at the Site (U.S. Department of Energy, 1992). Although it is the smallest of the communities monitored by EcMP, it is one of the most important in terms of the plants present and the habitat it provides for the wildlife at the Site. The three EcMP Sites are located in three different watersheds which flow generally west to east across the Site. TR03 is located along Rock Creek, TR05 along Walnut Creek, and TR10 along the Smart Ditch drainage in Woman Creek.

The riparian community has the highest species richness of all the communities monitored by ECMP on Site. The three ECMP sites have a mean species richness of 104 species and a combined richness of 163 species (Table B-5). Only $74 \%$ of the species found in the riparian community are native species. This is the lowest percentage of native species of all the natural communities monitored (Table B-5). (The reclaimed community is the lowest of all communities monitored.) The data show that although there is an increase in the number of species along the hydrologic gradient from dry to wet, there is an accompanying decrease in the percentage of native species in the natural communities at the Site (Figures B-1, B-2, B-4, B-9). One possible explanation for this is that more disturbance has taken place in the riparian areas on Site allowing for the invasion and establishment of non-native species. It may also be that the riparian is more susceptible to disturbance, which would create openings for non-native species. For example, TR05 has the lowest number of species and lowest percentage of native species of the three riparian sites monitored (Table B-5) and it is the only riparian site of the three monitored which has had any significant disturbance to the stream channel (i.e. riprap placed along the channel, stream 
water level controlled by upstream pond discharges). Another possible explanation is related to past livestock usage. Cattle may have preferred the shaded riparian areas during the hot summer months and/or the more lush vegetation which occurred in the riparian areas, so higher grazing and trampling took place in the riparian areas, causing greater disturbance which allowed the invasion of non-native species. One other possible explanation is that due to the dry, harsh conditions present in the xeric community, fewer non-native species have been able to invade and establish themselves, whereas in the more protected hydric areas, non-natives have been more successful.

Of the communities monitored, the riparian community has the greatest vegetational stratification and highest number of woody species present (Table B-5). Vertical stratification includes herbaceous, shrub, and tree layers. The basal vegetation cover mean is $19.2 \%$ at the riparian community (Table B-7), with woody plant stem densities averaging 6.42 stems $\mathrm{m}^{-2}$ (Table B-3). Foliar cover (another measure of the herbaceous layer) averages $66.5 \%$, the lowest foliar cover of all the communities (Table B-7). The shrub cover (woody plants $<2 \mathrm{~m}$ tall) averages $39.8 \%$ and tree cover (woody plants $>2 \mathrm{~m}$ tall) averages $18.6 \%$ (Table B-7). The herbaceous layer in the riparian community is dominated by Juncus balticus, based on basal and foliar cover (Table B-9), however some differences exist between sites (Table B-10). At TR10, the herbaceous layer is dominated by two non-native grasses, Poa pratensis and Poa compressa (basal cover). The shrub layer is dominated by Salix exigua and then Amompha fruticosa at TR05 and TR10, although TR05 has a high percentage of Populus dettoides saplings. At TR05, Salix exigua provides nearly three times as much cover as Amorpha fruticosa, whereas at TR10 the cover of each is almost equal. At TR03, Amorpha fruticosa provides twice as much cover as Salix exigua. The higher cover of Amorpha fruticosa than Salix exigua at TR03 may indicate that the water table is somewhat lower there than at TR05 and TR10, where Salix is more prevalent, since the Amorpha tends to occur in dryer locations (U.S. Department of Energy, 1992). Some of these differences could however also be due the subjective locations of the transects. The dominant tree at all three sites is Populus deltoides, although at TR05 some very tall Salix exigua ( $>2 \mathrm{~m}$ tall) actually have a higher "tree" cover than the Populus.

The Populus deltoides-Salix amygdaloides/S. exigua (Plains cottonwood riparian woodland) and Amorpha fruticosa shrublands which both occur in the riparian community on the Site are plant communities of concern as determined by the Colorado Natural Heritage Program (Kettler, 1994). The former has been given a ranking of $G 2 / G 3, S 2 / S 3$, indicating that the community is very rare to rare at both the global and state levels. Although the report states that the Rock Creek community has been impacted, it is believed to be restorable. The Amorpha shrubland community is ranked as GU, SU, indicating that its overall status is not well known. Throughout most of their ranges both of these communities are thought to be highly impacted. Through proper management, these increasingly rare communities can be preserved and maintained as high quality examples of these community types, which were previously more common along the Front Range.

\section{3-1994 Comparisons}

Species richness differed considerably at the monitored sites and communities between 1993 and 1994. In 1993, 198 species in 43 families were recorded from the EcMP terrestrial vegetation sites (Ecological Monitoring Program, 1994). In 1994, 271 species in 51 families were found at the same sites. Most of this difference was due to the late sampling times for the 1993 field season. Since the first sampling in 1993 took place in late July, most of the early spring ephemeral species which were found in the early sampling of 1994 were not observed. It is recommended that sampling be conducted at the same time of the year, each year, so that equal comparisons may be made.

A comparison of the current year production and litter biomass values from 1993 and 1994 by community and ECMP terrestrial site are found in Table B-18. Current year production biomass 
values from the two years show the amounts produced to be nearly the same for the sites and communities (Figure B-32). Significant differences ( $\alpha=0.1$ level) were shown to exist for current year production amounts from the two different years only at the reclaimed community. No significant differences ( $\alpha=0.1$ level) in current year production were found between the two years in the xeric or mesic grassland communities. An examination of the current year production amounts by site for the two different years reveals the only significant difference ( $\alpha=0.05$ level) occurred at TR09 (a reclaimed site, Figure B-33). This one site probably accounts for the significant difference found at the community level for the reclaimed community as well. The factors that make TR09 different from the other reclaimed sites is not known at this time, since as previously mentioned it also has the lowest species richness, lowest percentage of native species, and the highest amount of basal cover of all the reclaimed sites. In general, however, values for these two years suggest that current year production at these sites does not vary much. It would be interesting to see how over a number of years current year production would correlate with precipitation. Similar comparison of litter data by community for the two years (Figure B-34) revealed however, that significant differences were found at the xeric and reclaimed communities for 1993 and 1994 . The best explanation for these differences is the fact that different personnel conducted field work for the studies during the two field seasons and the quality of litter removal varied between years. During the second year litter was meticulously removed from the quadrats to obtain accurate results. Litter amounts between years by site were found to be significantly different ( $\alpha=0.05$ level) for only three sites (Figure B-35). Two of these sites were xeric sites, TR06 and TR12, and one was a mesic site, TR11. Whether or not these differences were real or not is questionable for the same reasons given above. Data collected in 1995 by the same personnel who did the 1994 sampling should show if the differences noted in litter at both the community and site levels were attributable to different personnel doing the sampling or were in fact real.

\section{Multivariate Analysis}

\section{Ordination}

Ordination results by both the DCA and RAA techniques by species and by transect (both based on species presence/absence data) reveal some interesting patterns about the sites, transects, and species. Ordinations by transect (Figures B-19 through B-24) seem to confirm the distinctiveness of the four communities - xeric, mesic, riparian, and reclaimed - studied by the EcMP. The figures show certain transects fend to group together into discrete clumps, indicating that based on this analysis using species presence/absence data, the vegetation studied on Site is composed of discrete units and is not a continuum. The results, however, also show that variation exists within the communities. This is discussed below. Both DCA and RAA techniques show the transects of the different communities (circled on the Figures B-19 through B-24) to be grouped together, with the xeric community found on the far left and the riparian community on the far right. The different axes (one through four) plotted on the different figures can represent environmental variables, community variables, or both. For both analyses, axis one plotted against axes two, three, and four, all show the same general community pattern. The xeric or driest community is on the left and the riparian or wettest community is on the far right. This seems to indicate that axis one may be the hydrologic gradient. This same pattern is shown in the DCA and RAA by species results (Figures B-25 through B-30). The species found on the left side of the figures are largely xeric species such as Koleria pyrimidata, Townsendia hookeri, and Oxytropis lambert, while those on the right side of the figures are hydric species such as Carex nebraskensis, Equisetum lavigatum, and Salix exigua. What axes two, three, and four might represent however, will require further study of environmental and community data to determine this more precisely. Some clues however, can be found in examining some the grouping of particular transects within the larger community groups. In a number of cases, the specific grouping of certain transects reveals some of the variation found within the different communities. Many of these differences have been noted previously (see discussion sections by community types) for the different sites which make up communities, based on species richness, cover, and biomass data. 
In the six figures (Figures B-19 through B-24) showing the DCA and RAA by transect results, the transects from three sites seem to have patterns that repeat for a number of the axes combinations. The TR06 (a xeric site) transects in all six figures separate out as a distinct cluster within the xeric community. Associated with this is the fact that in five out of six instances, it is the site most closely positioned to the mesic community transects. It was previously mentioned that species richness, cover, and biomass data, had indicated that TR06 was different from TR01 and TR12 (both xeric sites). The ordination plots tends to support that idea. TR06 has been placed closer to the mesic community sites by the ordination because of the large number of species typical of the mesic community occurring in it (Table B-2). TR06 has a larger number of weedy species and non-natives than do the TR01 and TR12 (the other two xeric sites) and these species are more common in the mesic community. In the reclaimed community, the ordinations separate out the TRO9transectsfrom the other two reclaimed sites in all three of the DCA figures (Figures B19 through B-21). This corroborates previously mentioned observations that TRO9 has the lowest species richness, lowest percent of native species, highest basal cover, and the highest current year production biomass of all three reclaimed sites. In figure B-20, which plotted axis one with axis three, both TR06 and TR09 are grouped towards the top of the figures, quite separated from the other sites in their respective communities. Because this is the only one of the six figures shown in which both TR06 and TRO9 responded in the same manner, it may indicate that the same variable (axis three) is affecting both of these sites in a similar fashion. Further examination of environmental and/or community variables needs to be undertaken to see if such a variable exists for both of these sites that might explain this pattern.

In the riparian community, TR05 is grouped by itself in three out of the six figures (Figures B-19, B22 , and B-24). Two of the cases are found with the results of DCA and RAA when axis one was plotted with axis 2 . It also occurred when axis one was plotted with axis four for the RAA results. TR05's difference may be attributed to the fact that it is the only one of the three monitored riparian sites which has had much disturbance. The stream channel at TR05 has been considerably modified with riprap and waterflow is controlled from upstream water impoundments. It also had the lowest species richness and the lowest percentage of native species of all the riparian sites. Other variables should be examined to see if they could explain the separation of TR05 from the other riparian sites as well. Another point to keep in mind when interpreting these ordinations is that the tighter grouping of xeric, mesic, and riparian transects in the RAA figures (Figures B-22 and B24) may be largely due to the way in which the RAA scales the axes and tends to contract projected points near the ends of the axes. The DCA ordinations (in which the axis ends are not contracted)by transect (Figures B-19 through B-21) suggest that the transects in the riparian community are less closely related to each other (based on the environmental/ community gradients represented by axes two, three, and four) than those in the other three communities since these transects are spread further apart along the $x$-and $y$-axes.. This suggests that the environmental or community factors represented by these axes may be more variable or have a greater effect in the riparian community than in the other communities. Further inquiry is needed to determine if this is the case.

An examination of DCA and RAA ordinations by species (Figures B-25 through B-30, Tables B-16 and $B-17)$ reveal some similar trends. Due to lack of space on the figures only a few characteristic species have been listed for the general groups that were formed. (Speccodes for individual points may be determined by going to the appropriate table (Table B-16 or B-17) and finding the coordinates for the point. Then, the speccode information can be translated into a scientific name by going to Table B-2). All of the figures ordinate the more xeric species on the left side of axis one and the more hydric species on the right side. Therefore axis one is probably related to a hydrologic gradient which is similar to what was found for the ordinations by transects. The greater separation of points in the DCA ordination than in the RAA ordination is probably due to the characteristic RAA contraction of points at the axis ends. The DCA ordination reveals three or four general groups of species, depending on the axes plotted (Figures B-25 through B-27). The four groups found in Figures B-25 and B-27 are a xeric species group, mesic/reclaimed species group, 
and two distinct riparian species groups. Axes two and four when plotted with axis one (Figures B25 and B-27) showed the greatest separation of two riparian species groups. However, why this separation is present is unknown because no readily apparent differences seem to exist between the species which make up each group. Further examination of other environmental and/or community variables is needed to determine what variable(s) axes two and four represent. The RAA ordination by species (Figures B-28 through B-30) shows the species primarily spread out along axis one with only two general groups formed but many species in between. Only Figure B30 , which has axis one plotted against axis four, exhibits any spread of the riparian species group. What variable axis four might represent at this time is unknown.

One of the purposes of the ordination work, in addition to those mentioned earlier, is to elucidate different patterns in the vegetation monitored at the Site. It provides an additional tool to bring into focus things that may otherwise not be seen or overlooked. Once the patterns are found then the question of "Why?" may be asked. Consequently, ordinations commonly serve as a catalyst for further study which will provide a better understanding of the role of different variables in the ecosystem.

\section{Classification}

The results of the TWINSPAN classification (Figures B-31A and B-31B) on the ECMP transects placed the transects into groups similar to those as determined by the DECORANA and reciprocal averaging ordination techniques (all three methods based on species presence/absence data). Two points of major interest were noted. First, the TWINSPAN classification separates the four major community types - xeric, mesic, riparian, and reclaimed. This agrees with the ordination analyses. Secondly, within community types, TWINSPAN generally placed the transects into the same groups that the ordination analyses showed. TRO9 ( a reclaimed site) is different from TR07 and TR08 (also reclaimed sites). TR05 (a riparian site) is different from TR03 and TR10 (also riparian sites). However, within the xeric and mesic communities the TWINSPAN results reveal more detail concerning the clustering of site TRO6 (a xeric site). In the ordination results, TR06 was often more closely associated with the mesic community than the xeric community. In the TWINSPAN classification, TR06 is grouped completely with the mesic community and is closely associated with particular transects at TR02 and TR11 (mesic sites). One possible explanation for this is that TRO6 differs from the other xeric sites because of a high percentage of non-native species. Since the mesic community, in general, also has a higher percentage of non-native species than the xeric community, the specific transects at TR02 and TR11, with which all of the TR06 transects are most closely associated may also have a high percentage of the same species present. The locations of the specific TR02 and TR11 transects could also be a factor. Their locations on the hillsides or soil conditions may be similar to that found at TR06. These factors need to be examined further. However, this suggests that perhaps TR06 should be considered a mesic site, rather than a xeric site.

Finally, because the TWINSPAN results agree with the ordination results so well, all three of these analyses should prove useful for future ecological work here at the Site. Future applications could include ordination and classification of soil, invertebrate, aquatic, bird, and other environmental data. One of the things that both the classification and ordination results (in addition to the other data presented) point out, is that there are real differences between what are currently considered different communities - xeric, mesic, riparian, and reclaimed. However, within these communities and in some cases across community boundaries, considerable variation exists. This will always be the case since at every level (community, site, transect, or quadrat) change is always taking place, whether from natural or human causes. These types of ecological studies and the patterns they yield will provide a better understanding of the ecosystems here at the Site and provide important information for better managing and restoring the environment in places where is has been or will be disturbed. 


\section{CONCLUSIONS}

The terrestrial vegetation at the Site differs considerably between the sites and communities studied by the ECMP. Species richness was found to differ between communities and increased along the hydrologic gradient from xeric to mesic to riparian. The reclaimed community had the lowest species richness of all the communities. The percent of native species present at different communities was found to decrease along the hydrologic gradient from xeric to mesic to riparian. The reclaimed community had the lowest percent of native species of all the communities. The percent of native species present at different sites was found to differ between sites, but the difference did not directly follow along community differences. Significant differences ( $\alpha=0.5$ level) were found for basal cover classes (vegetation, litter, rock, and bare ground) between sites and between communities for each of the classes. Water was not analyzed since it only occurred at the riparian community. Herbaceous biomass production was found to be significantly different $(\alpha=0.1$ level) between the mesic and reciaimed communities. Significant differences ( $\alpha=0.05$ level) were also found for herbaceous biomass production between many of the sites. Litter production was not found to be statistically significant ( $\alpha=0.1$ level) between communities, but was significant $(\alpha=0.05$ level) between a number of the sites.

\section{RECOMMENDATIONS}

The following recommendations are made:

1) Revegetation and remediation aclivities at the Site should be done using only native perennial species of plants. Species such as Bromus inermis or Agropyron intermedium, while readily available and generally quick to establish, in the long run are less suitable and provide lower quality revegetation than the native species of plants that were present before remediation was needed. The non-native species mentioned above provide less basal cover (soil holding capability) than the native species, thus increasing erosion potential. In addition, they tend to dominate the plant community and do not allow the native vegetation to reestablish.

2) The xeric community (found primarily on the flat hiltops, pediment, and ridgetops) should be disturbed as little as possible. The relict tallgrass prairie plant communities are threatened here in Colorado and the Site contains one of the remaining areas where this type can be found.

3) Driving off roads in the buffer zone should be minimized at all costs. Once the vegetation has been damaged or destroyed, the environmental and economic costs of revegetation generally outweigh any inconvenience caused by walking.

4) Prior to disturbance of areas in the buffer zone, preliminary belt transect and pointintercept transect sampling should be done to get species richness and cover data. With this information it will be possible using the ordination and classification analyses to determine where the remediation site fits in with regard to reference vegetation areas at the Site. This will provide important information concerning revegetation seed mixes and other factors which could prove important in ensuring a successful remediation effort. Post-remediation transect sampling should also be done to document the success of the revegetation effort.

\section{FUTURE STUDY SUGGESTIONS}

The differences which have been shown to exist between the sites and communities studied at the Site are due to the diversity of abiotic and biotic factors which exist at the Site. Variation shown in species richness, vegetation cover, and biomass at the different grassland sites tends to suggest that a mosaic of plant associations from the tallgrass, mixed grass, short grass prairies, along with some species from the mountains and adventive or introduced species are present at the Site. In 
addition, the riparian community along with a number of other communities which are not monitored by the EcMP contribute to the high diversity of plant communities present. Each of these associations is restricted to given localities at the Site based on the habitat requirements of each. The vegetation at the Site needs to be classified and ordinated to prepare an up dated vegetation map based on plant associations for the entire Site. Further analysis of the Site flora should be done using phytogeographic information and similarity indices to determine how the Site flora fits in with the regional flora. Future study should also focus on some of the communities not presently monitored. These would include the wetlands (marshes, seeps, etc.), tall upland shrub, short upland shrub, and Ponderosa pine woodlands. Although some information on soils and other biotic and abiotic factors are available for the different EcMP terrestrial sites, further study is warranted to see how these factors are correlated to and potentially influence and affect the distribution of plant species and communities on the site.

\section{REFERENCES}

Balint, S.J. 1995. Personal correspondence, Rocky Flats meteorologist. 1993-1994 monthly precipitation and temperature data. Rocky Flats Environmental Technology Site. Golden, CO.

Branson, F.A., Miller, R.F., and I.S. McQueen. 1965. Plant communities and soil moisture relationships near Denver, Colorado. Ecology. 46(3):311-319.

Bunin J.E. 1985. Vegetation of the city of Boulder, Colorado Open Space Lands. Unpublished report prepared for city of Boulder, Real Estate/Open Space.

Clark, S.V., Webber, P.J., Komarkova, V., and W.A. Weber. 1980. Map of mixed prairie grassland vegetation, Rocky Flats, Colorado. Occasional Paper No. 35. Institute of Arctic and Alpine Research. University of Colorado, Boulder, CO.

Colorado Natural Heritage Program. 1994. Unpublished report. Plants of special concern. Fort Collins, CO.

Coupland, R.T. 1979. IBP 18. Grassland ecosystems of the world: Analysis of grasslands and their uses. Coupland, R.T., Ed. Cambridge University Press, Cambridge, UK.

Ecological Monitoring Program. 1993. EcMP - Program Management/Technical Perfomance Report - GHS-462-93. 93-RF-11615. Appendises 2 and 4.

Ecological Monitoring Program. 1994. Ecological Monitoring Program Annual Report. Rocky Flats Plant. U. S. Department of Energy, Golden, CO.

Gauch, H.G. Jr. 1982. Multivariate analysis in community ecology. Cambridge University Press. New York, NY.

Great Plains Flora Association. 1991. Flora of the Great Plains. University Press of Kansas, Lawrence, KS. 1402 p.

Haferkamp, M.R., Young, J.A., Grings, E.E., Karl, M.G., Heitschmidt, R.K., and M.D. MacNeil. 1994. Japanese Brome in the Northern Great Plains. Eds. Monsen, S.B. and S.G. Kitchen. U. S. Department of Agriculture, Forest Service, Intermountain Research Station, General Technical Report INT-GTR-313. p. 396-401.

Hanson, H.C. 1955. Characteristics of the Stipa Comata-Bouteloua gracilis-Bouteloua curtipendula association in Northern Colorado. Ecology. 36(2):269-280. 
Hanson, H.C. and E. Dahl. 1956. Some grassland communities in the mountain-front zone in northem Colorado. Vegetatio. 7:249-270.

Hill, M.O. 1979a. DECORANA: A Fortran prograrn for detrended correspondence analysis and reciprocal averaging. Ecology and Systematics. Cornell University, Ithaca, NY. 36p.

Hill, M.O. 1979b. TWINSPAN: A Fortran program for arranging multivariate data in an ordered two-way table by classification of the individuals and attributes. Ecology and Systematics. Cornell University, thaca, NY. 60p.

Kettler, S.M., Ellingson, A.R., Pague, C.A., Spackrnan, S.C., and S.E. Simonson. 1994. Significant Natural Heritage Resources of the Rocky Flats Plant Site and their conservation: The Rock Creek drainage. Draft. Unpublished report prepared by the Colorado Natural Heritage Program for Roçky Flats Environmental Technology Site.

Little, C.A., Whicker, F.W., and T.F. Winsor. 1980. Plutonium in a grassland ecosystem at Rocky Flats. Journal of Environmental Quality. 9(1):350-354.

Livingston, R.B. 1952. Relict true prairie communities in central Colorado. Ecology. 33:72-86.

Mohler, C.L. 1987. COMPOSE: A program for formatting and editing data matrices. Microcomputer Power. Ithaca, NY. 58p.

Moir, W.H. 1969. Steppe communities in the foothills of the Colorado Front Range and their relative productivities. The American Midland Naturalist. 81(2):331-340.

U.S. Department of Energy. 1992. Baseline biological characterization of the terrestrial and aquatic habitats at the Rocky Flats Plant. Final Report. U.S. Department of Energy, Golden, CO.

Vestal, A.G. 1914. Prairie vegetation of a mountain-front area in Colorado. The Botanical Gazette. 63(5):377-400.

Weber, W.A. and R.C. Wittman. 1992. Catalog of the Colorado Flora: a biodiversity baseline. Niwot, CO. University Press of Colorado.

Webber, J.M. 1953. Yuccas of the Southwest. Agriculture Monograph No. 17. U. S. Dept. of Agriculture. $97 p$.

Wilson, S.D. 1989. The suppression of native prairie by alien species introduced for revegetation. Landscape and Urban Planning. 17:113-119. 


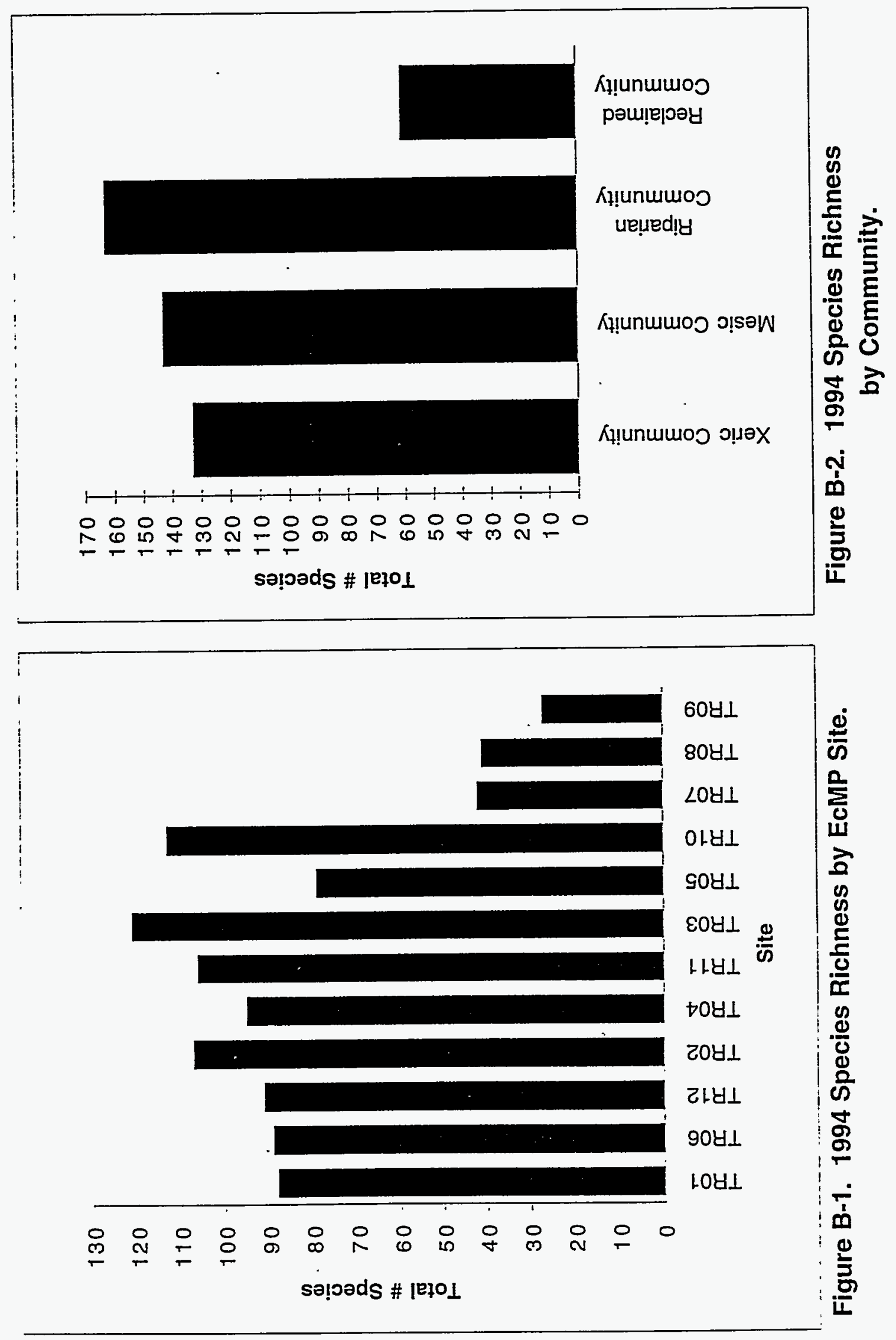




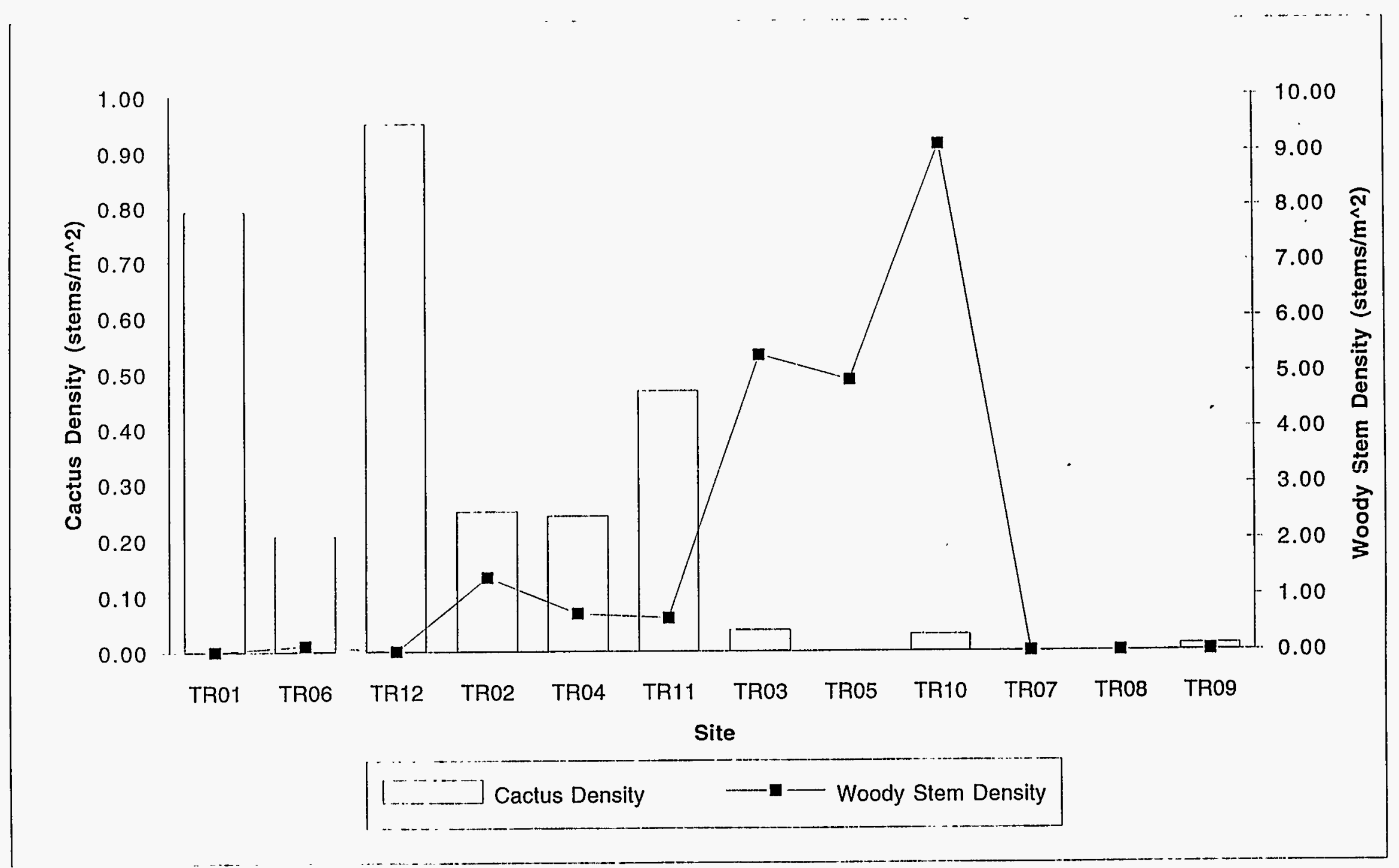

Figure B-3. 1994 Woody Stem and Cactus Density Mean Values by EcMP Site. 


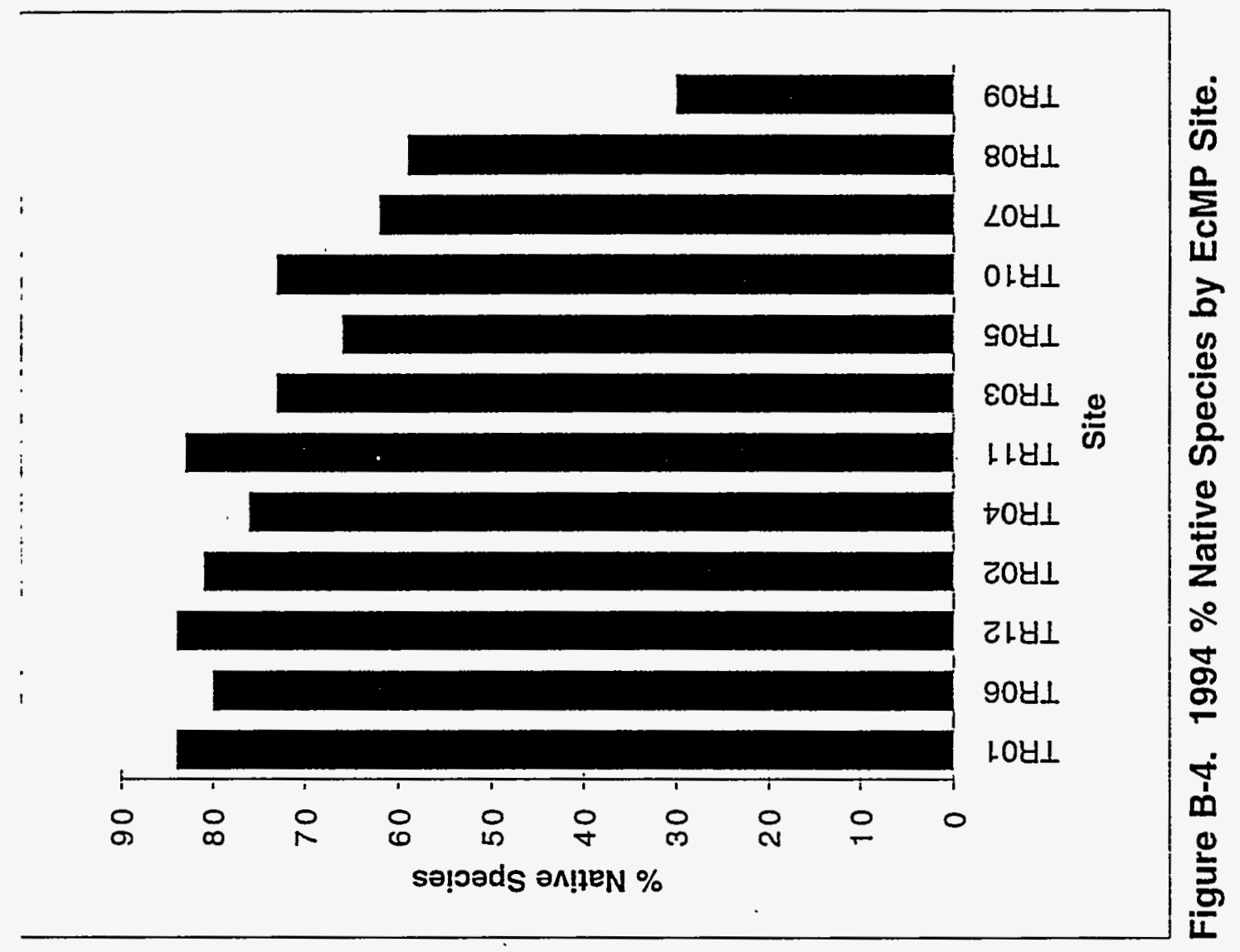




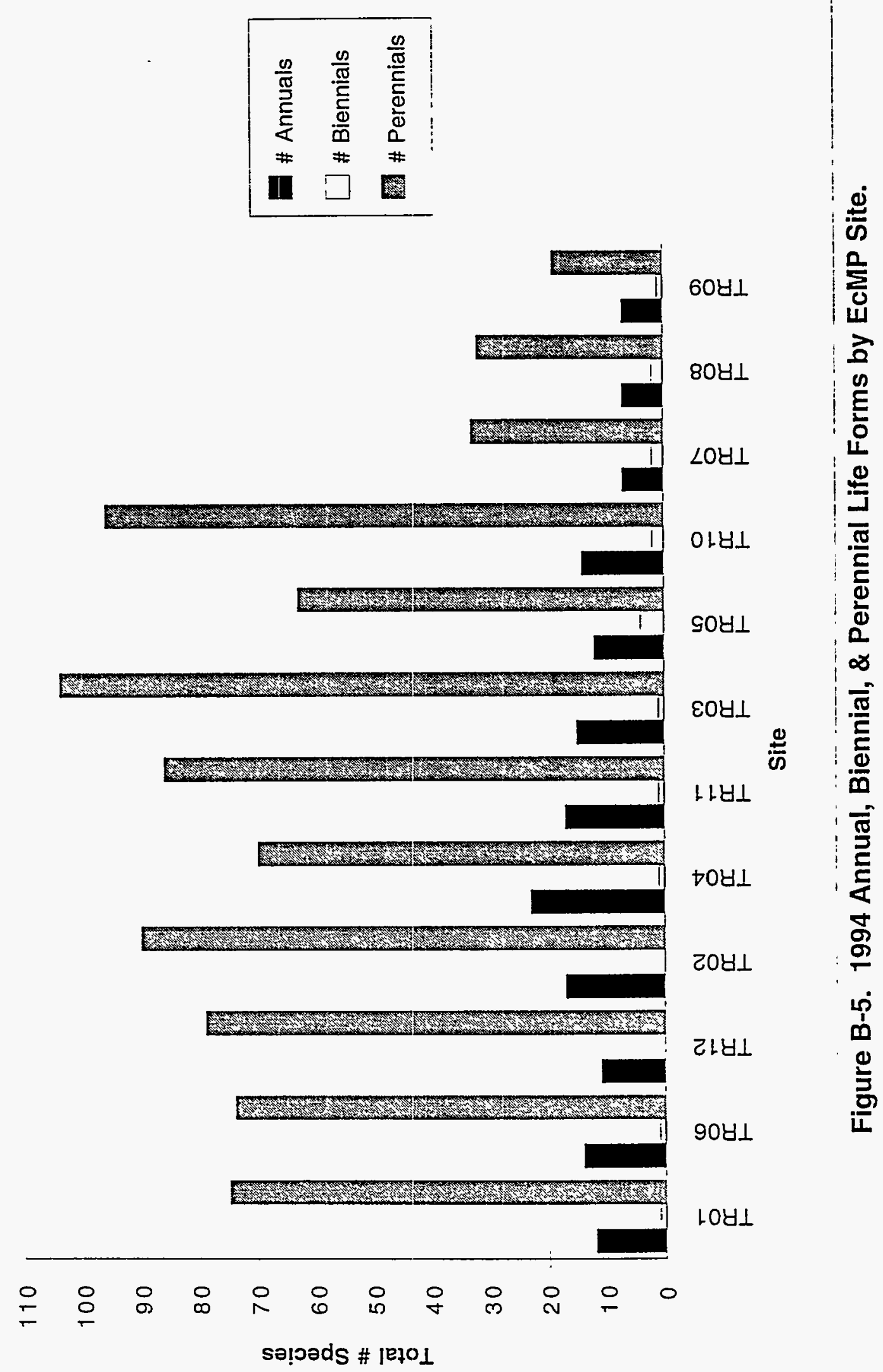


Total \# Species

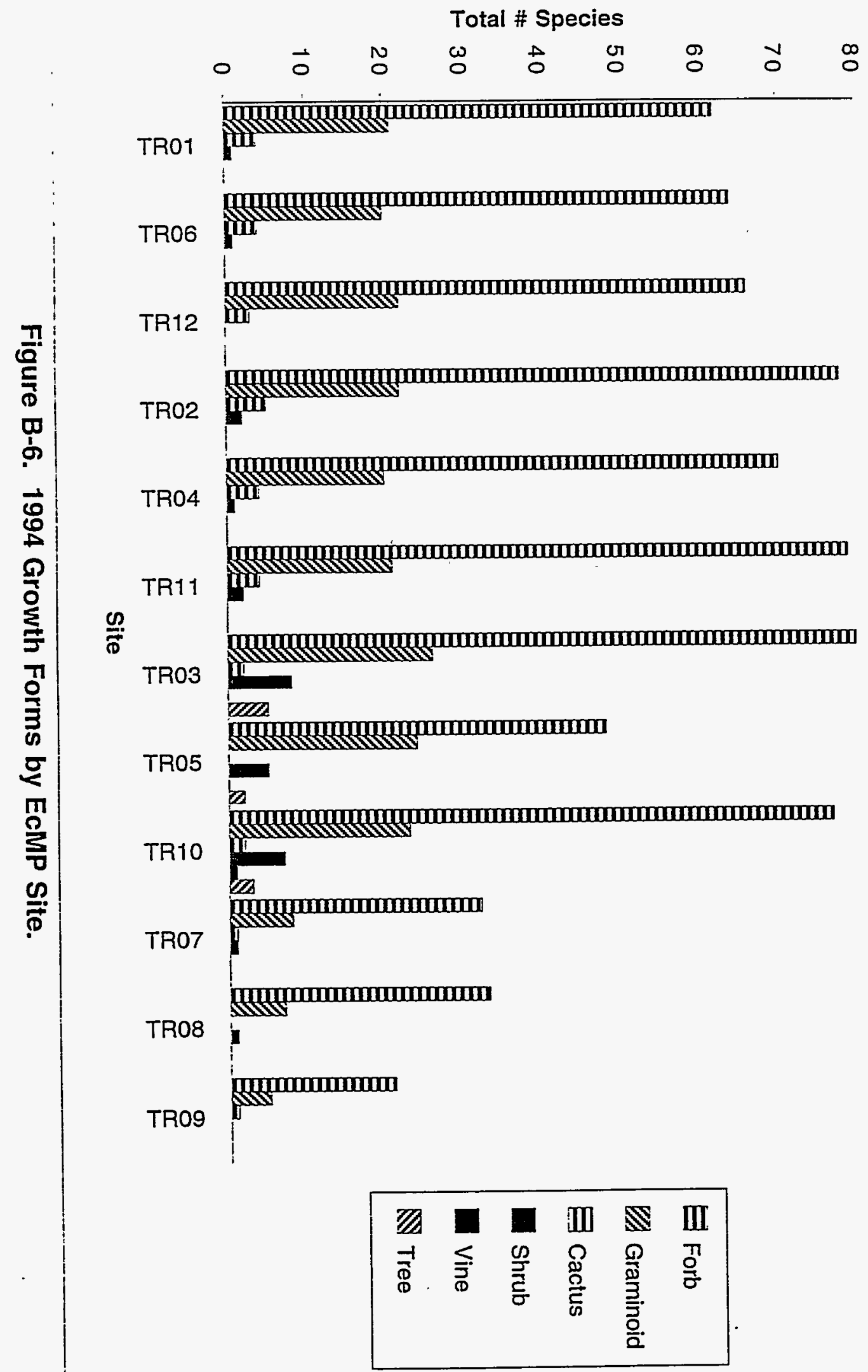


$9 \varepsilon-q$

Total \# Species

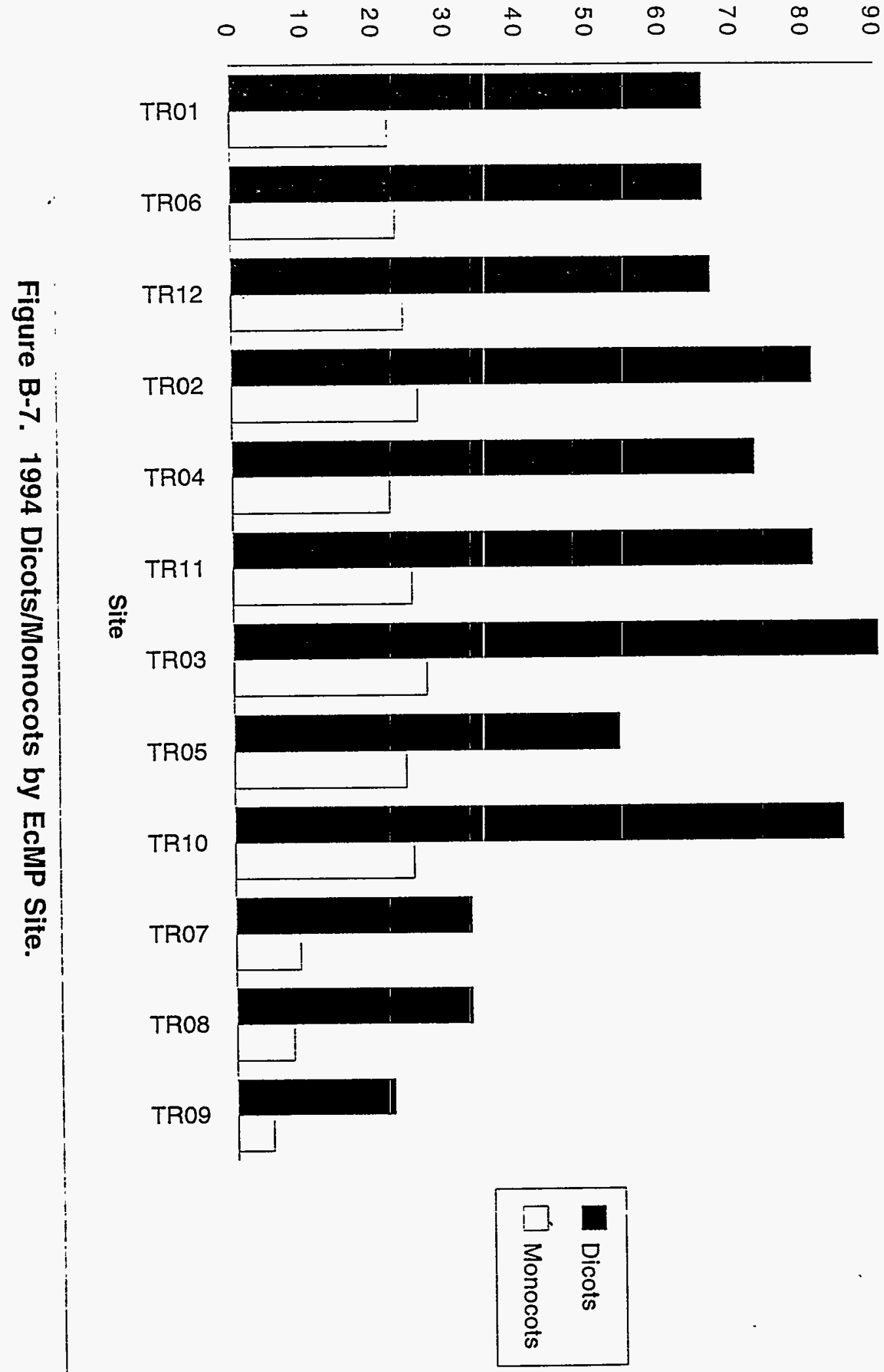




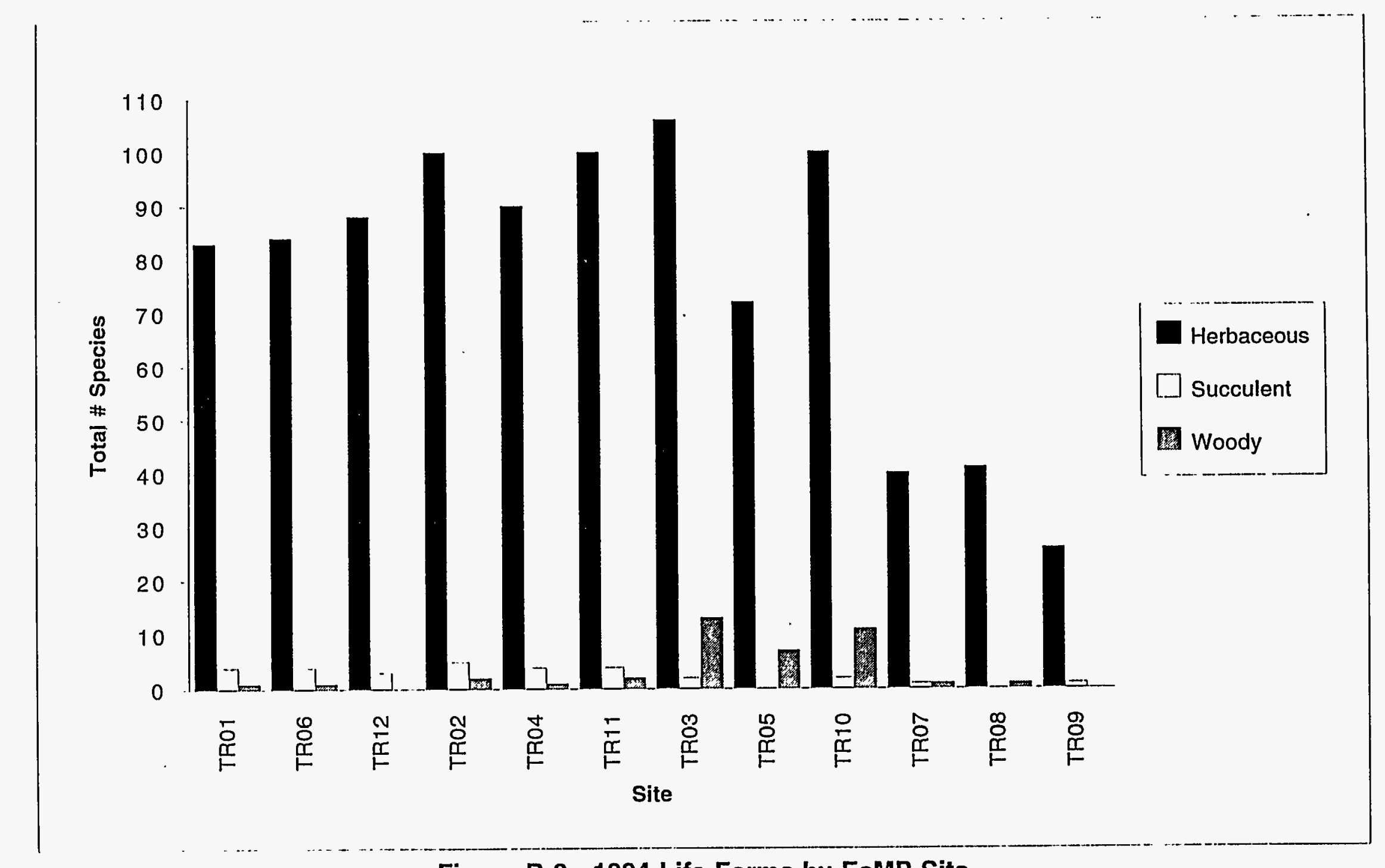

Figure B-8. 1994 Life Forms by EcMP Site. 

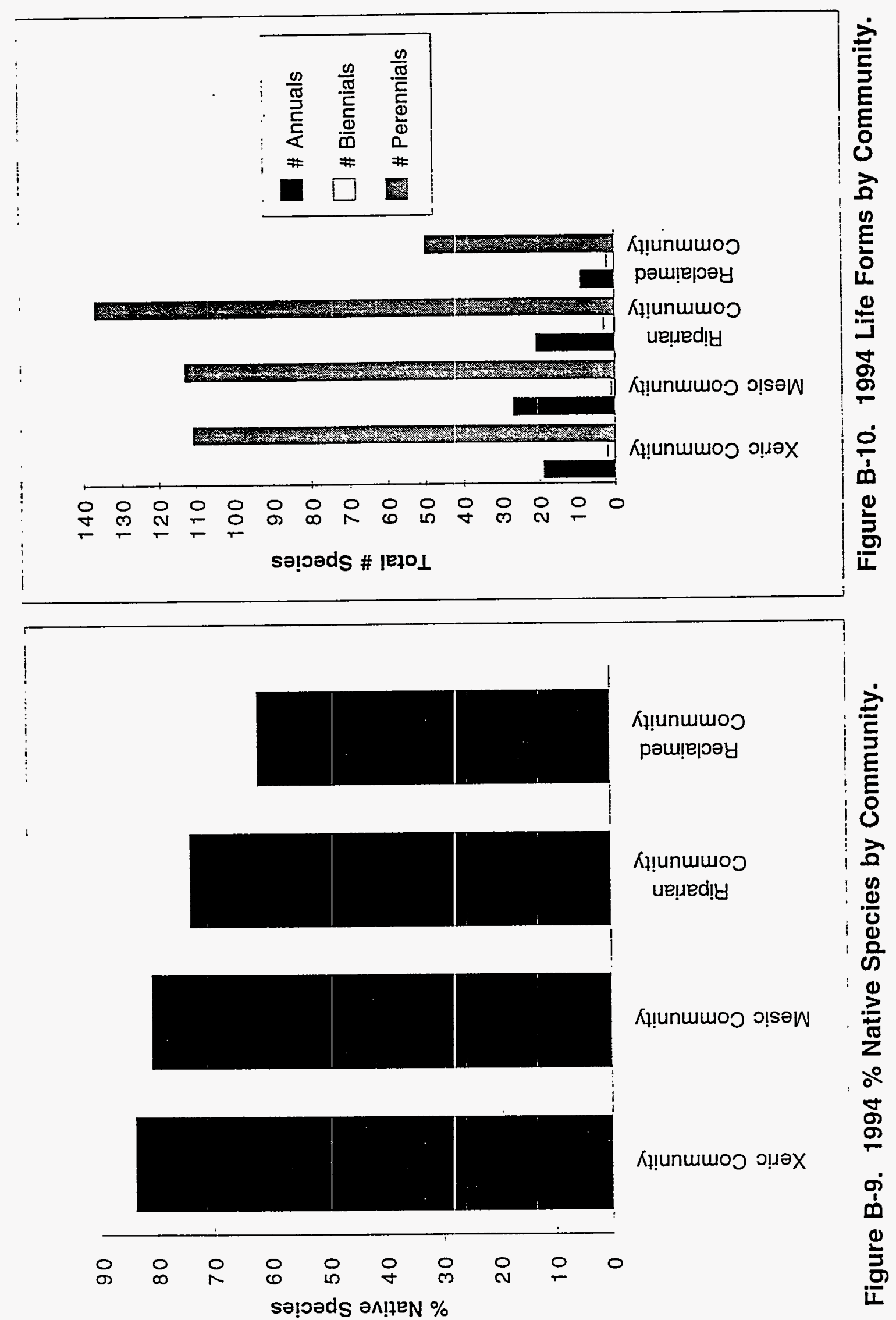
Total \# Species

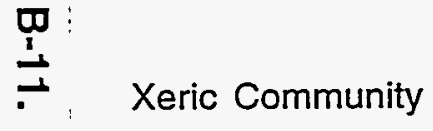

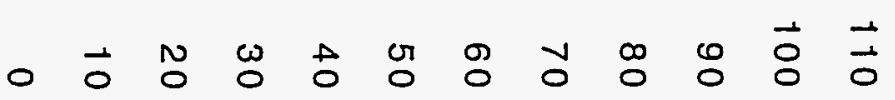

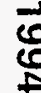

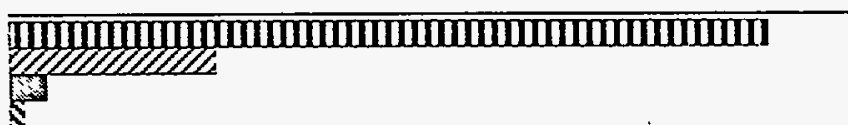

1

Community

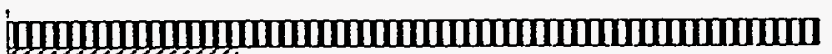

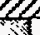

通

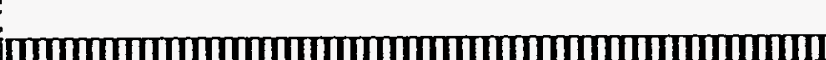

Riparian

Community

Reclaimed

Community

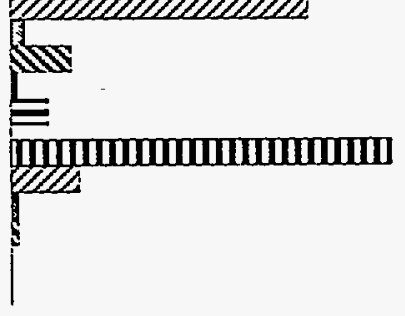

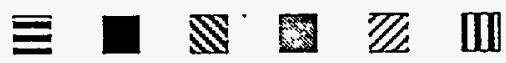

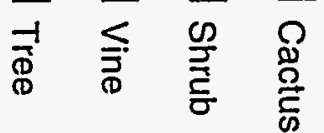

$$
\begin{aligned}
& \text { 呑 }
\end{aligned}
$$

Total \# Species

$$
\frac{\pi}{\frac{\pi}{0}}
$$

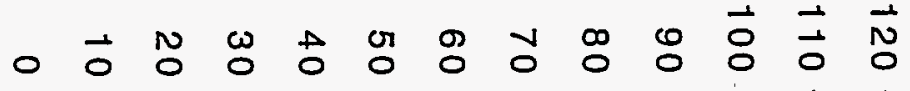

Xeric Community

Mesic

Community

Riparian

Community

Reclaimed

- Community
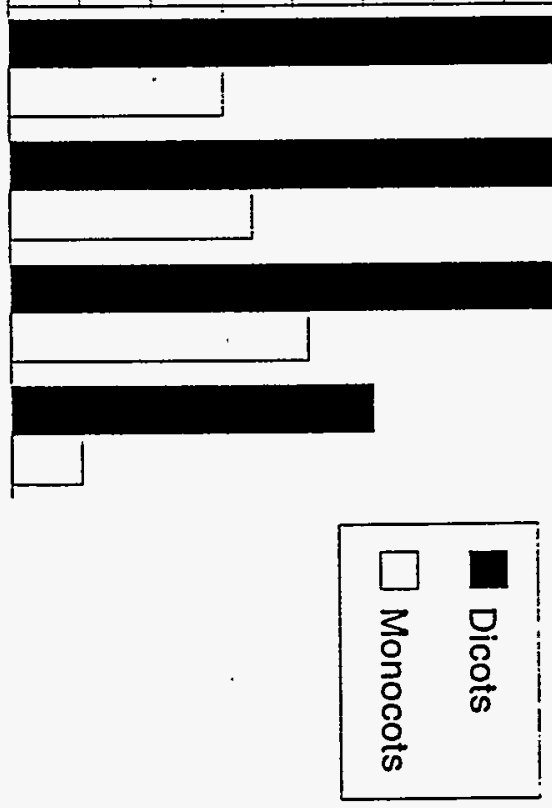
Letters on top of bars refer to Bare Ground cover class. No analysis was done for the Water cover class.

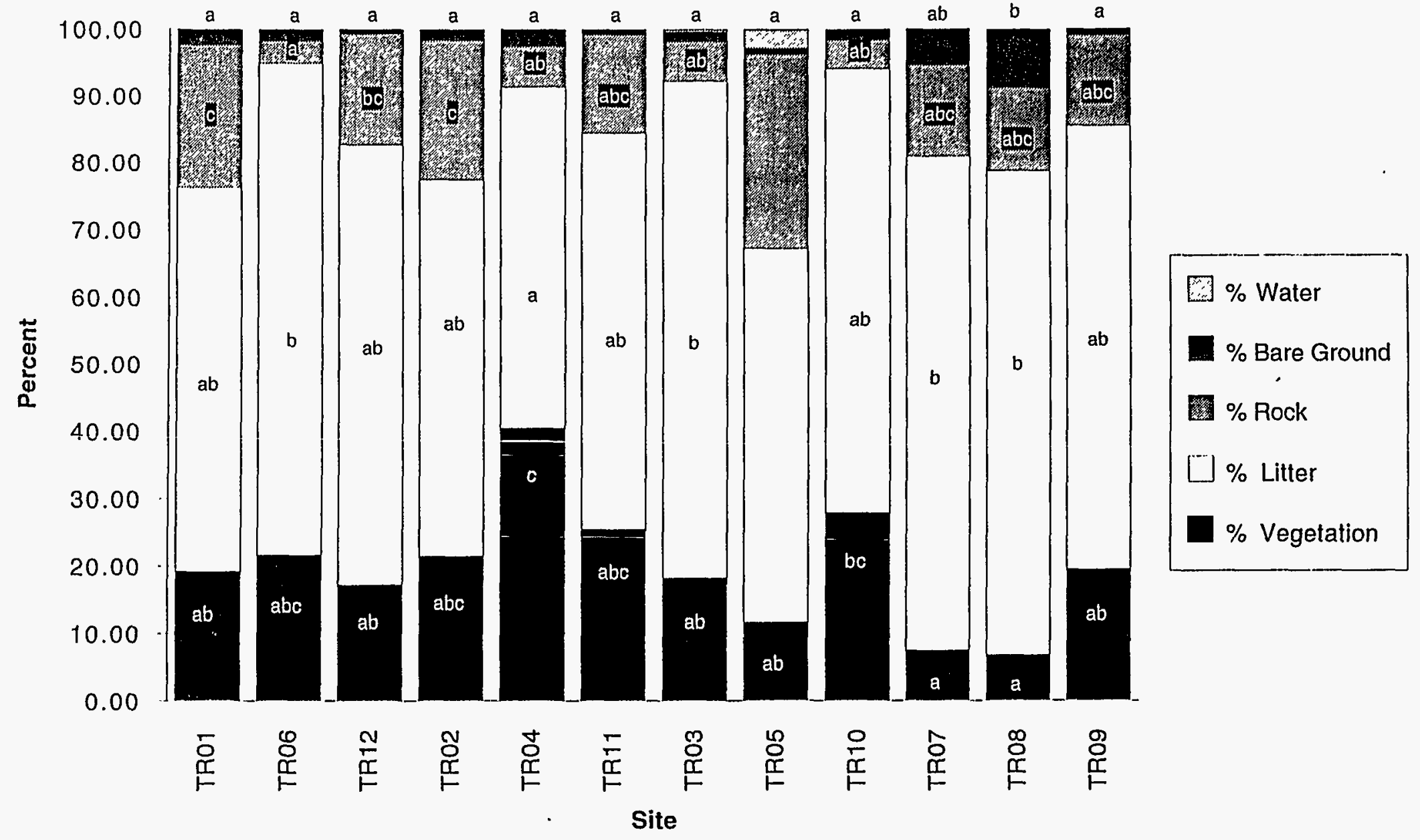

For each cover class, one or more common letters indicate no significant difference at the $\alpha=0.05$ level. See text for further discussion. 


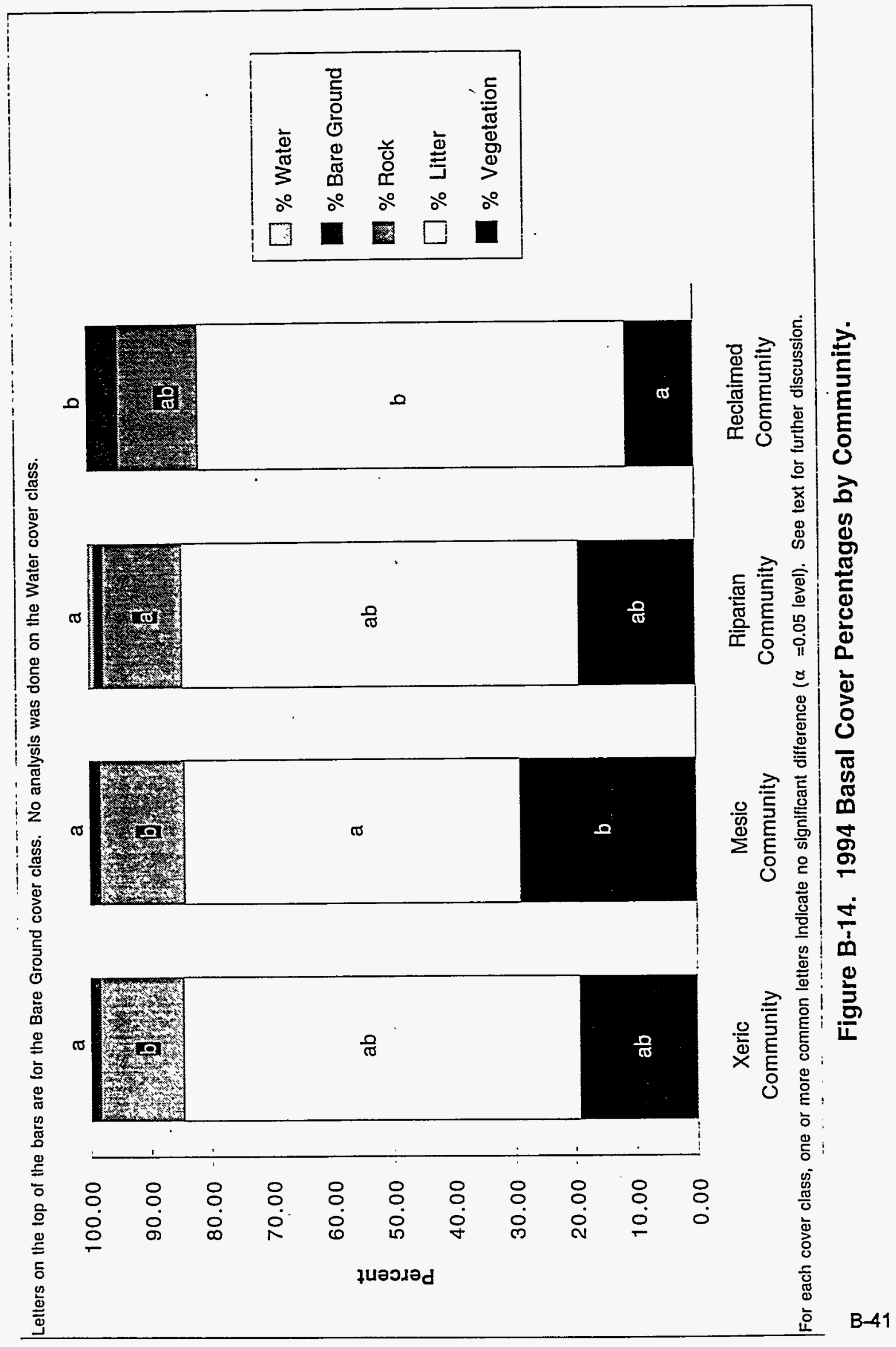




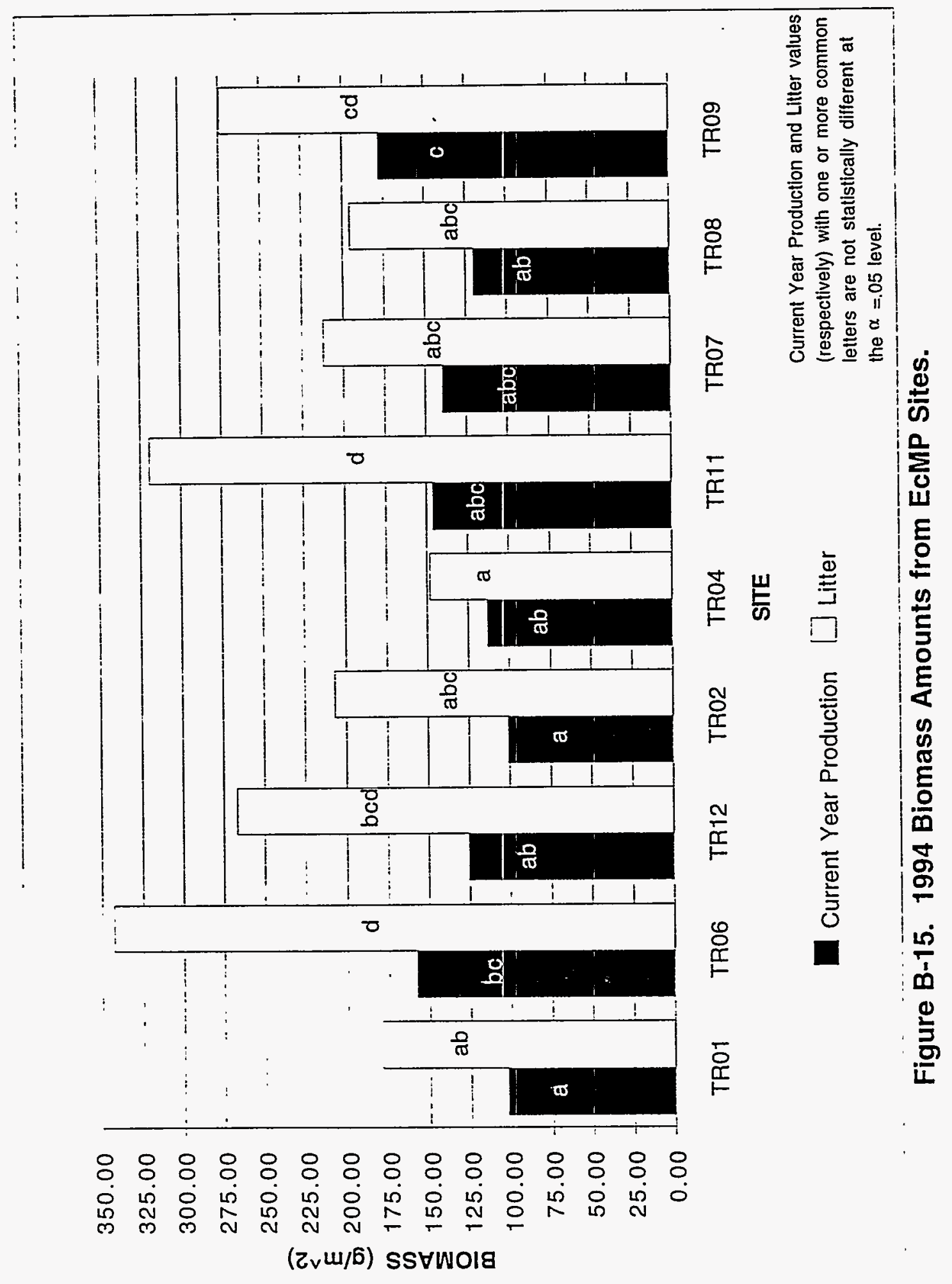




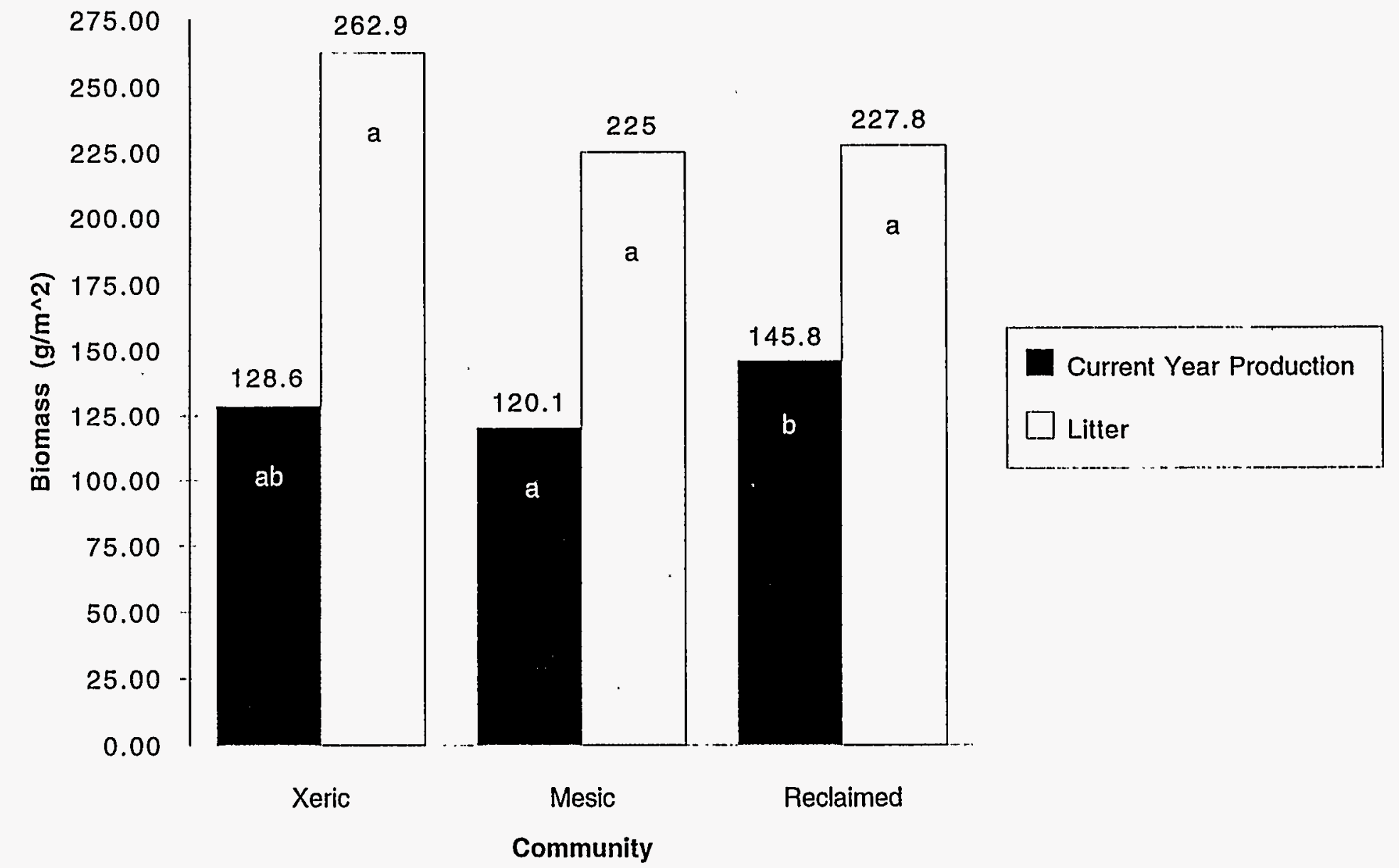

Bars having values with one or more common letters are not statistically different at the $\alpha=0.1$ level for each biomass type.

Figure B-16. 1994 Biomass Amounts by Community. 


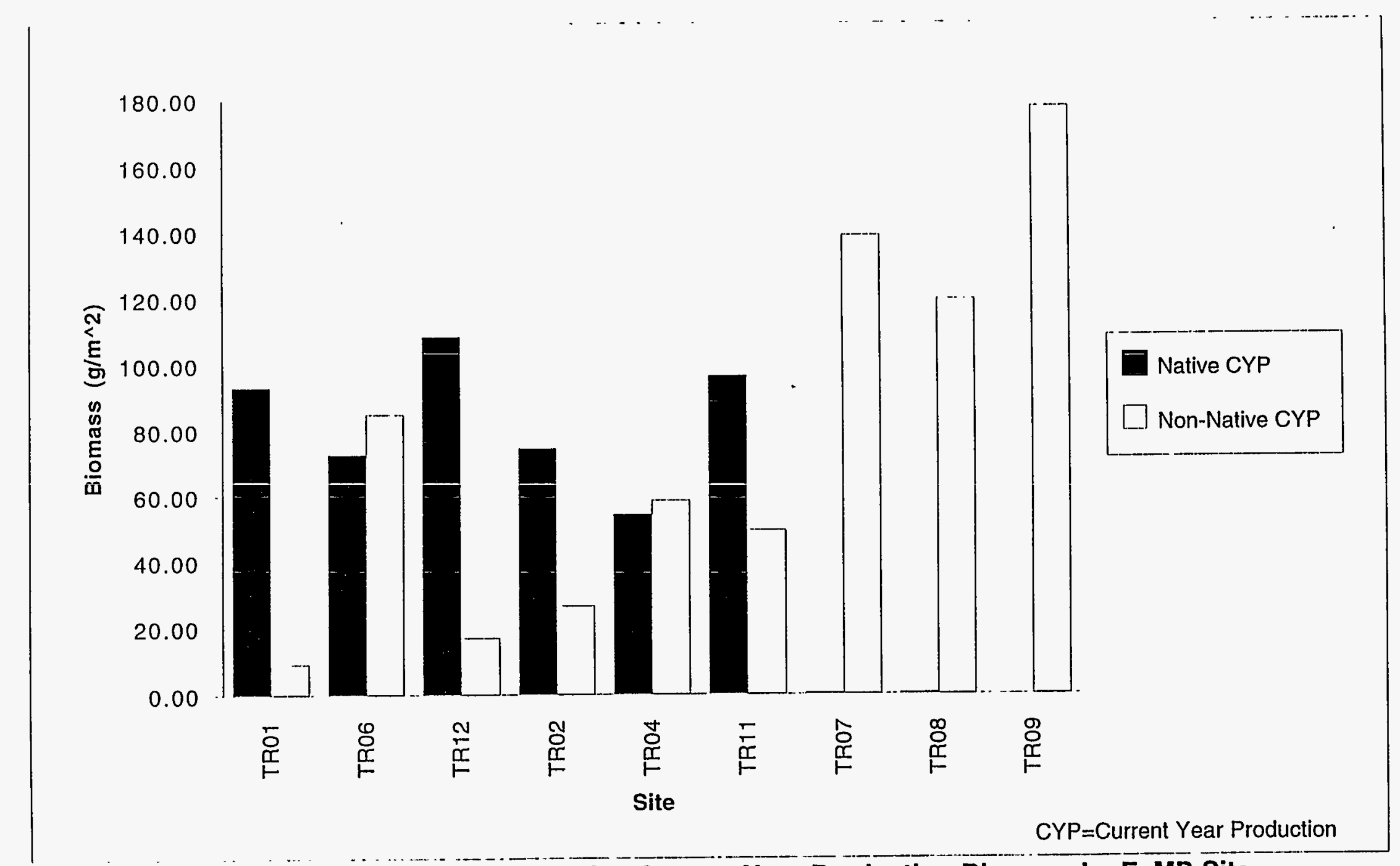

Figure B-17. 1994 Native vs. Non-Native Current Year Production Biomass by EcMP Site. 


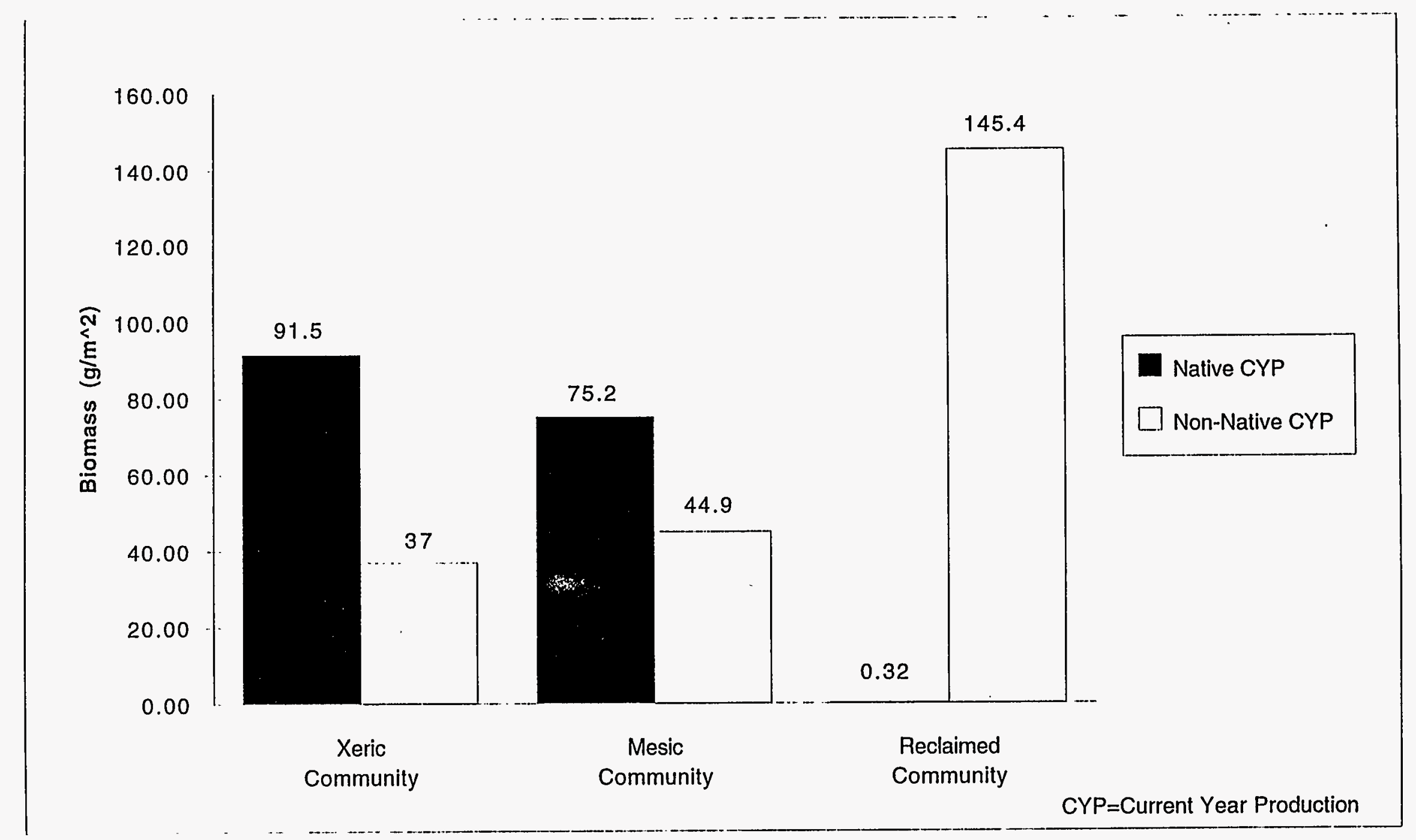

界

Figure B-18. 1994 Native vs. Non-Native Current Year Production Biomass by Community. 

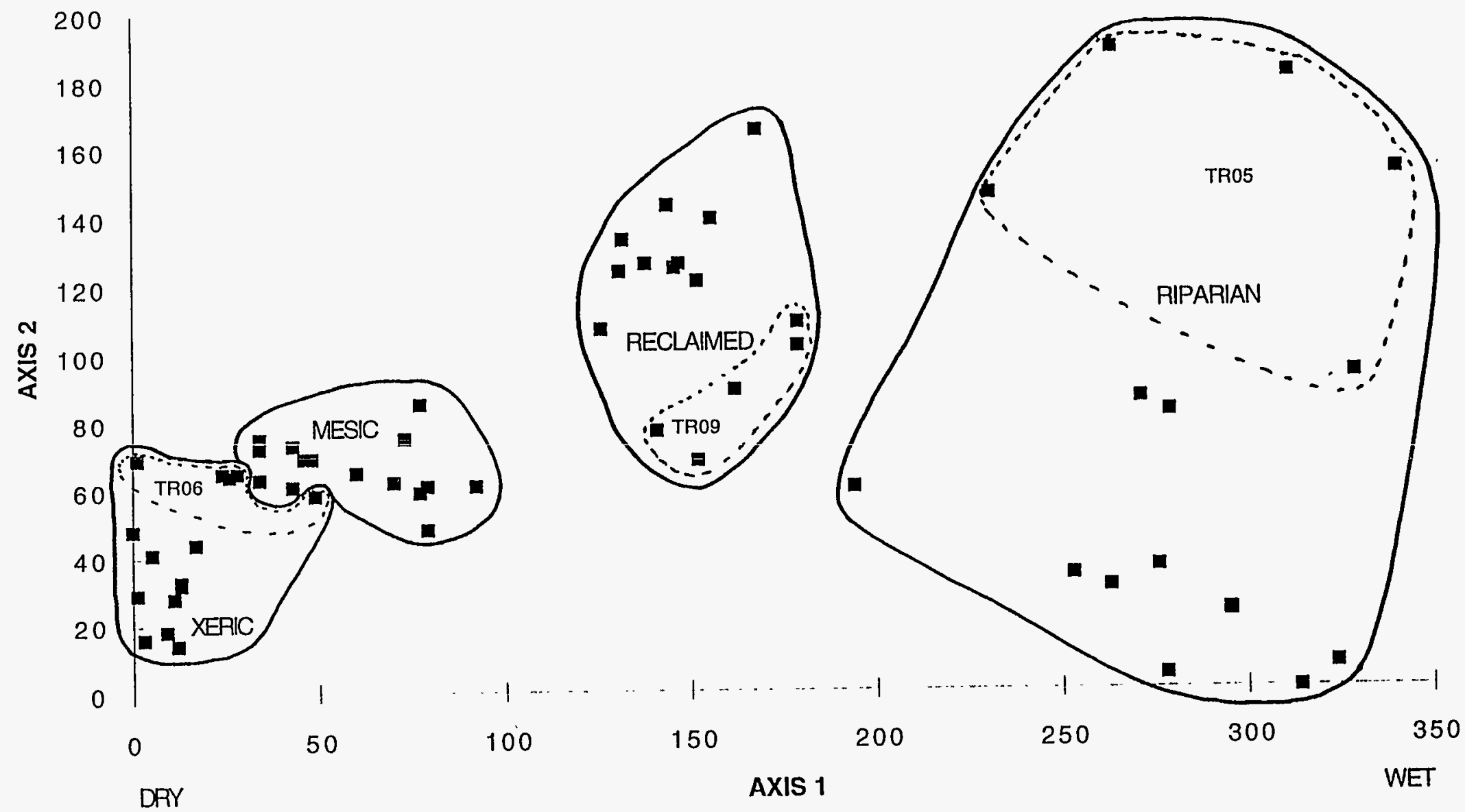

Figure B-19. Terrestrial Vegetation DECORANA Ordination by EcMP Transects - Species 点 Presence/Absence Data, Axes 1 and 2. 


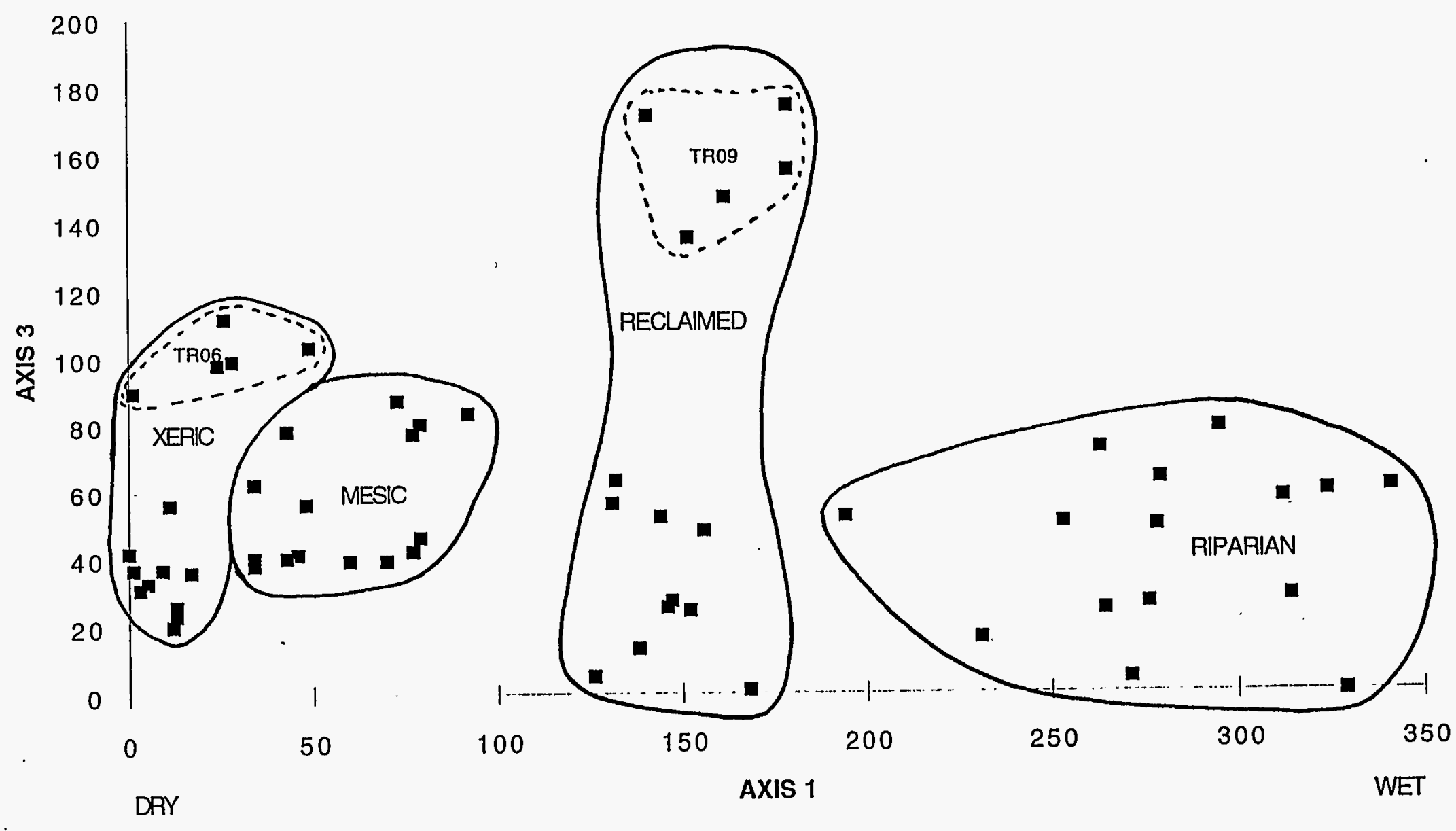

Figure B-20. Terrestrial Vegetation DECORANA Ordination by EcMP Transects - Species

$\stackrel{f}{\checkmark}$ Presence/Absence Data, Axes 1 and 3. 


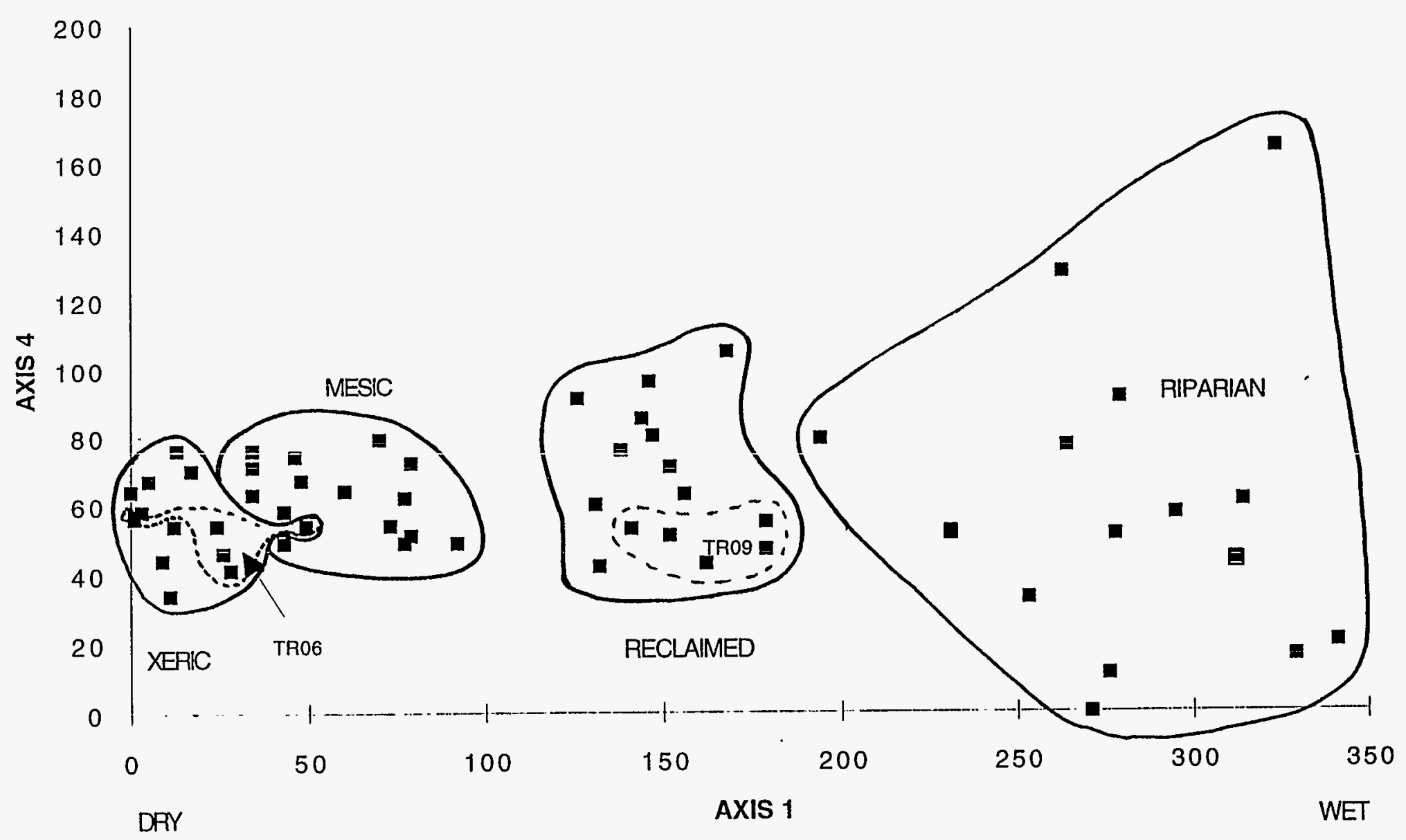

Figure B-21. Terrestrial Vegetation DECORANA Ordination by EcMP Transects - Species Presence/Absence Data, Axes 1 and 4.

$\underset{\infty}{\mathbb{p}}$ 


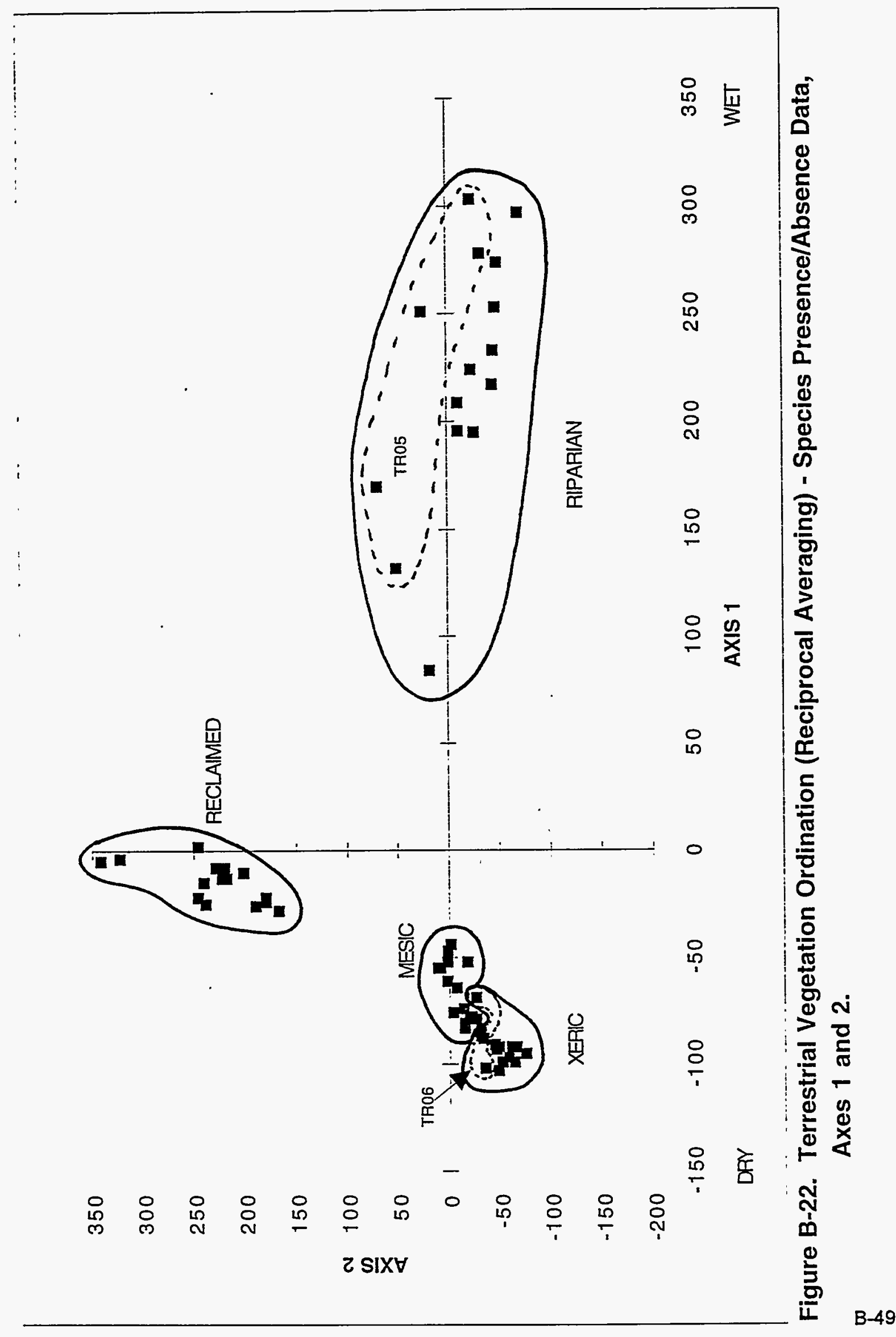




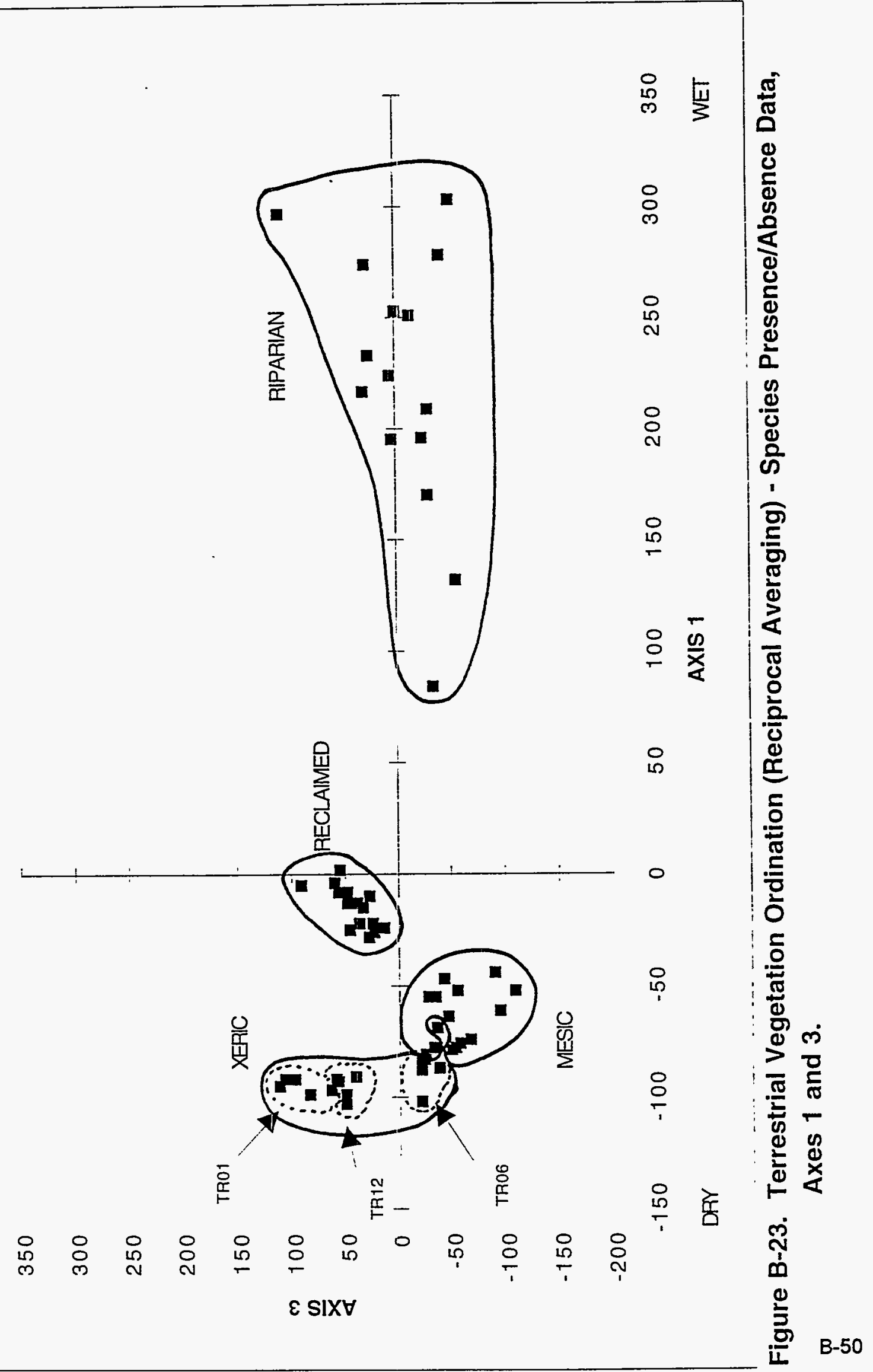




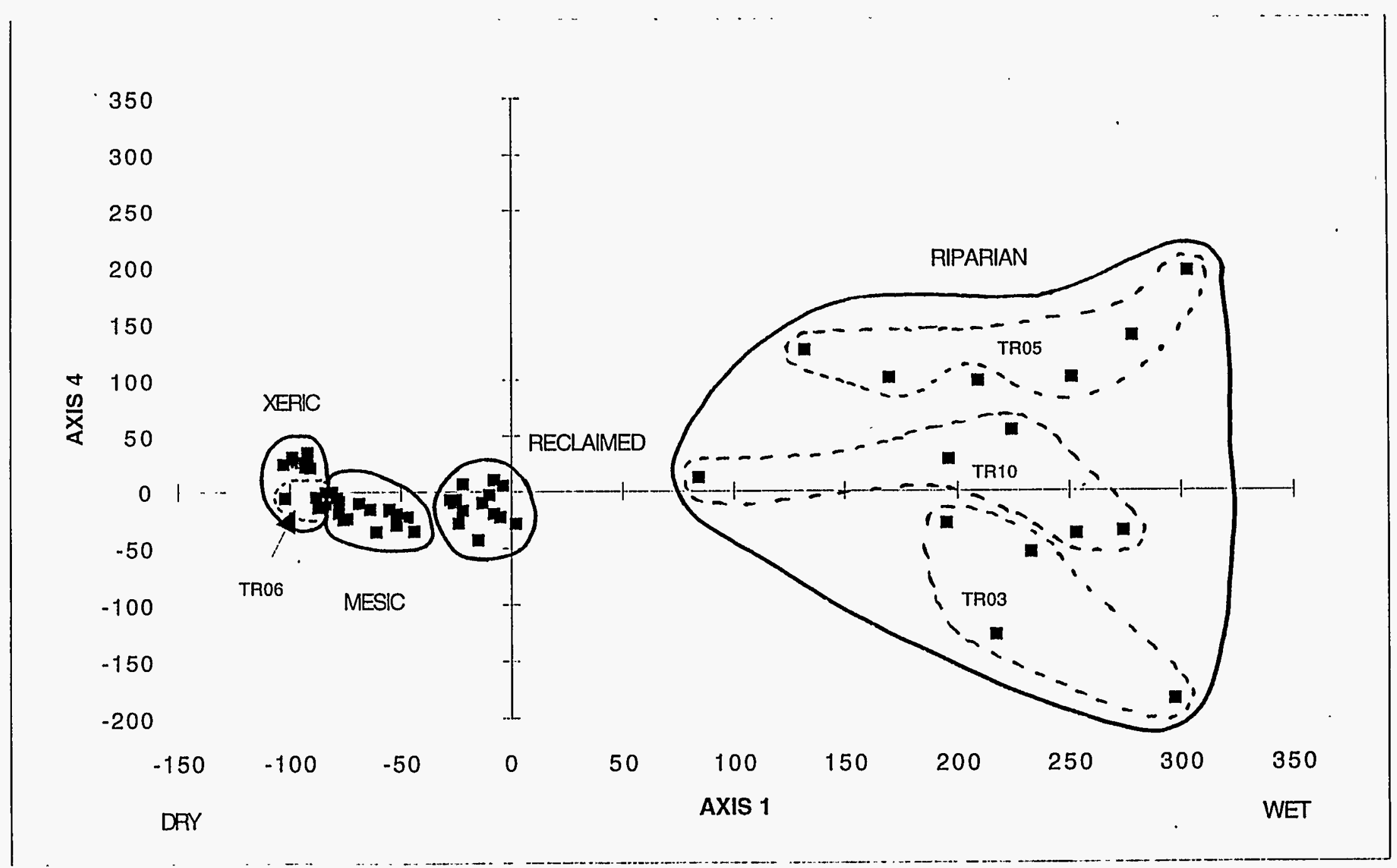

Figure B-24. Terrestrial Vegetation Ordination (Reciprocal Averaging) - Species Presence/Absence Data, wo Axes 1 and 4. 


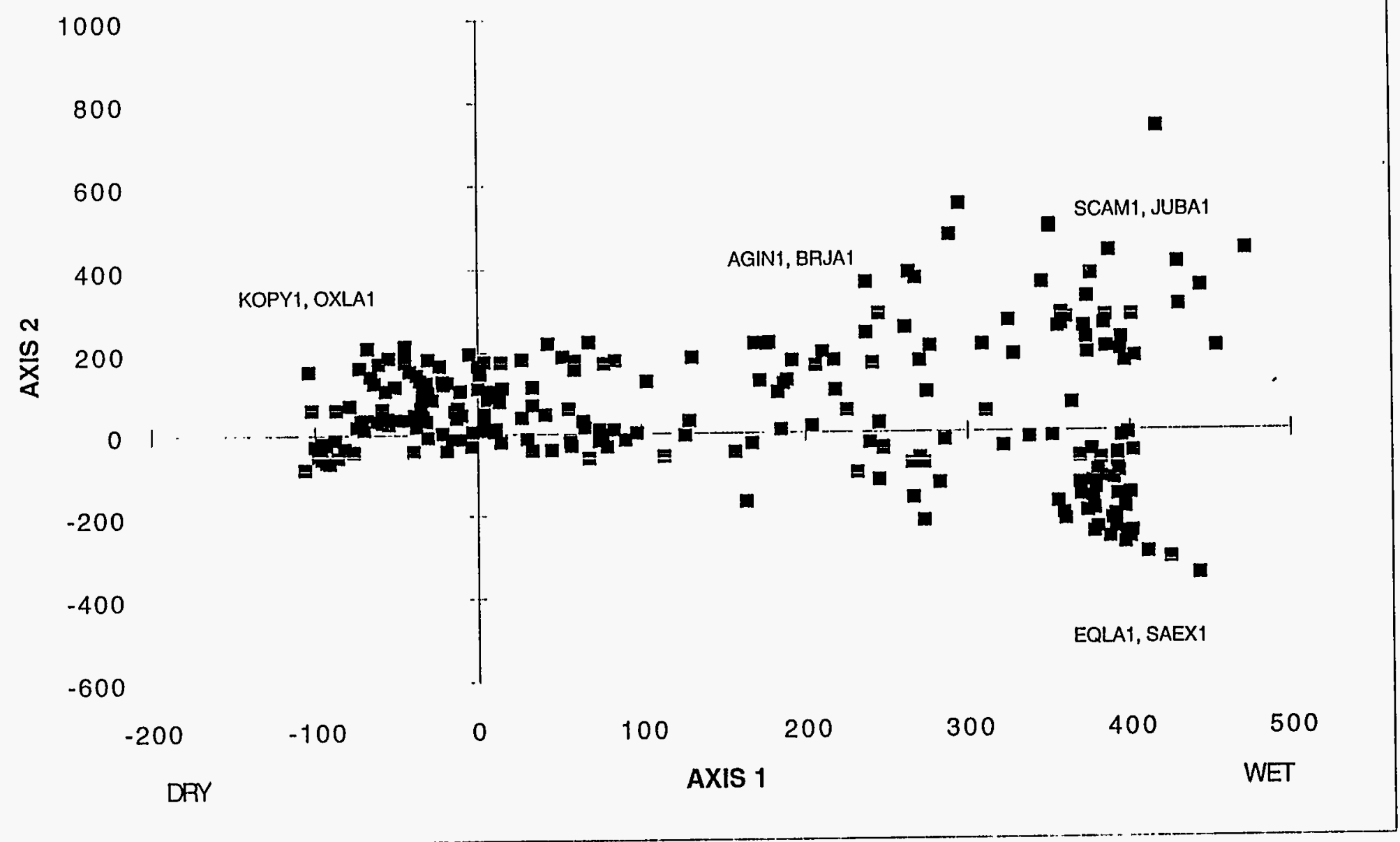

Figure B-25. Terrestrial Vegetation DECORANA Ordination by Species -

Presence/Absence Data, Axes 1 and 2.

w Note: Speccodes listed are examples of those typical of that part of the figure. See Table B-2 to determine scientilic names from speccodes. 


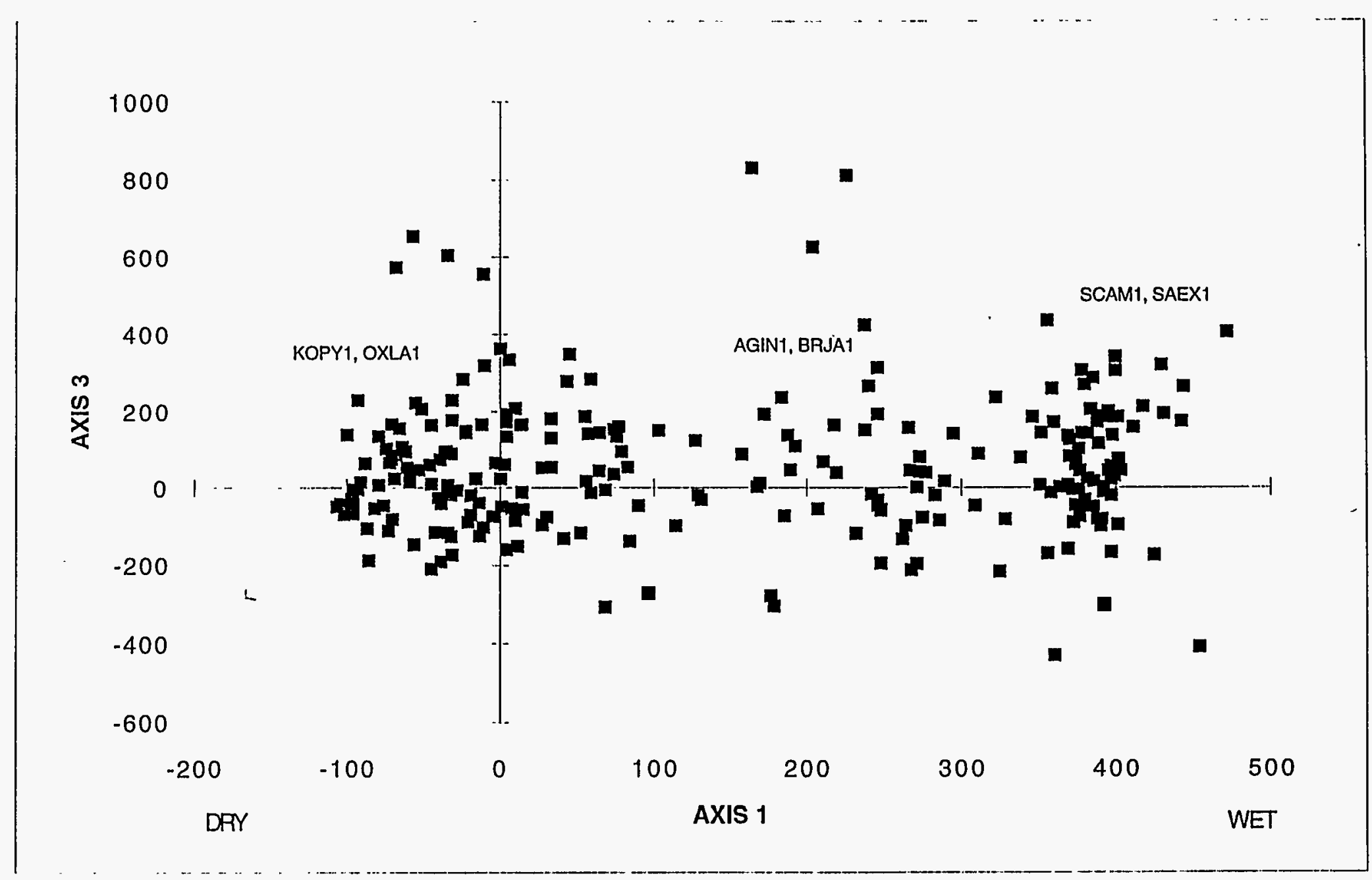

Figure B-26. Terrestrial Vegetation DECORANA Ordination by Species -

Presence/Absence Data, Axes 1 and 3. 


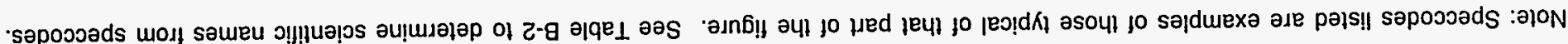

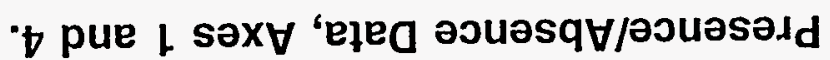

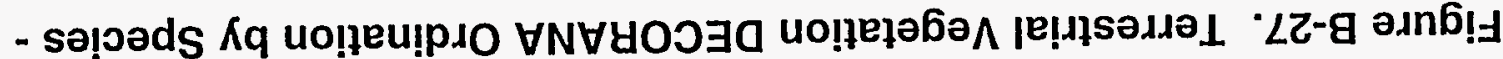

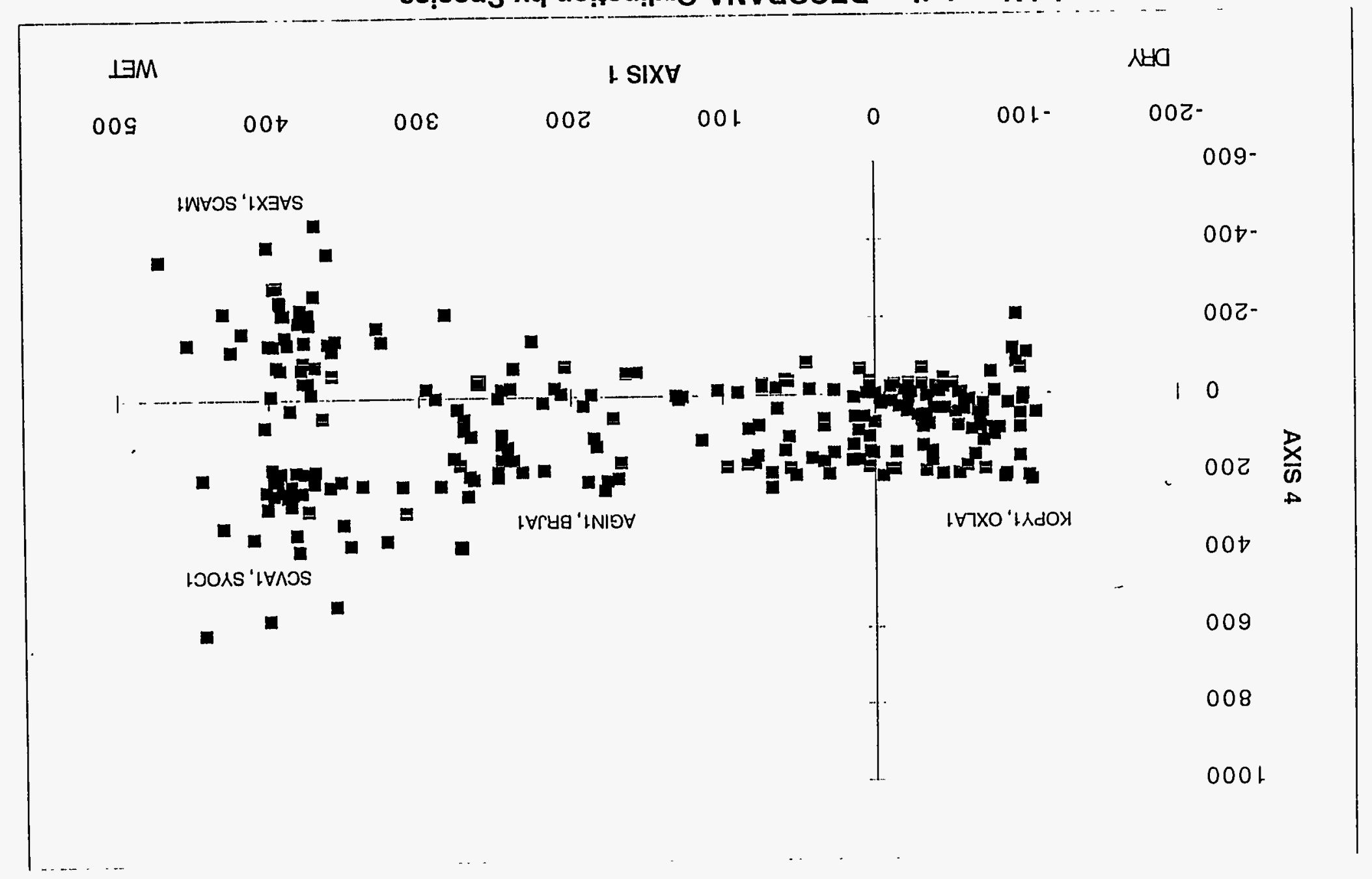




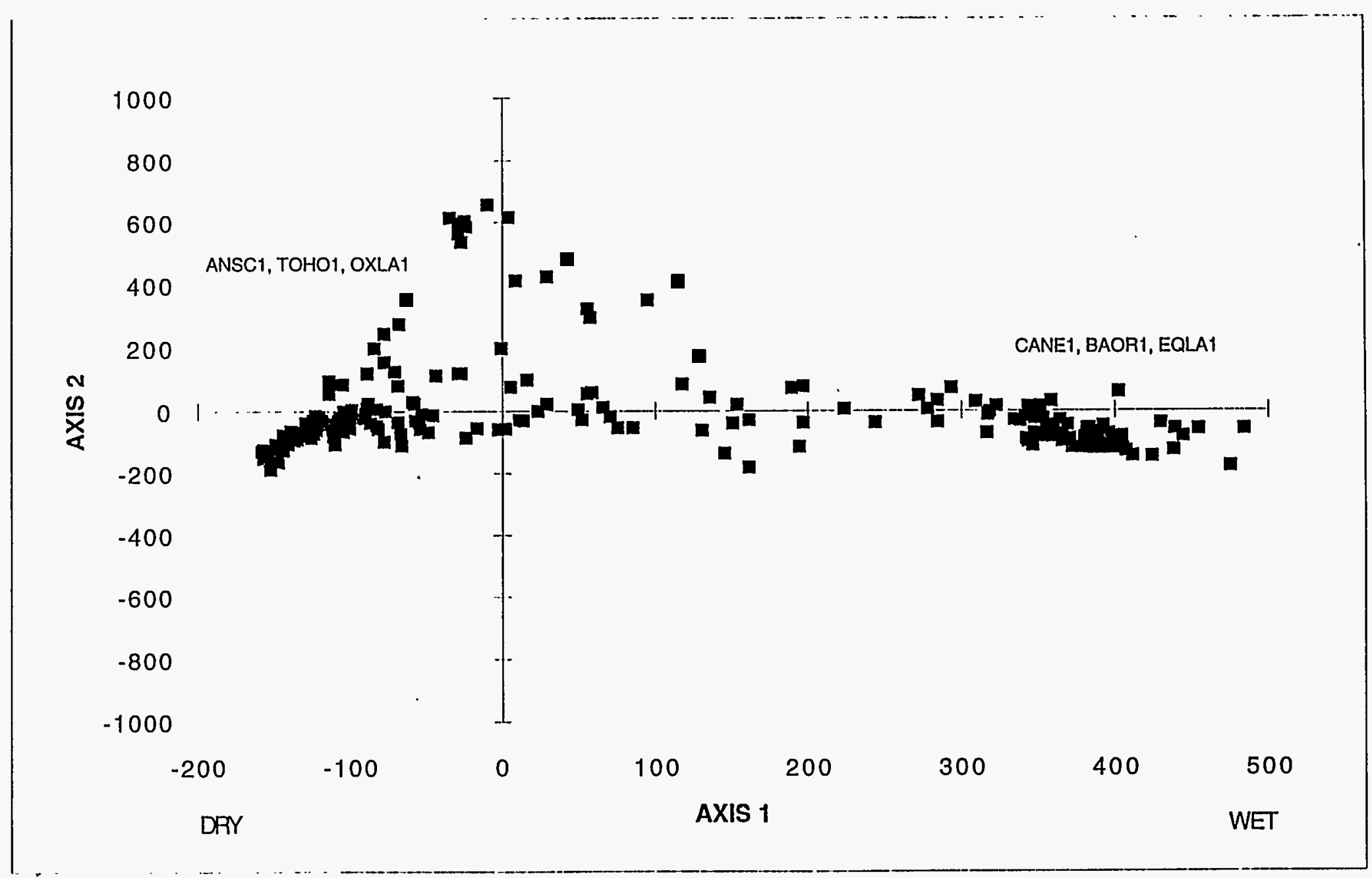

Figure B-28. Terrestrial Vegetation Ordination by Species (Reciprocal Averaging) Presence/Absence Data, Axes 1 and 2.

W Note: Speccodes listed are examples of those typical of that part of the figure. See Table B-2 to determine scientific names from speccodes. 


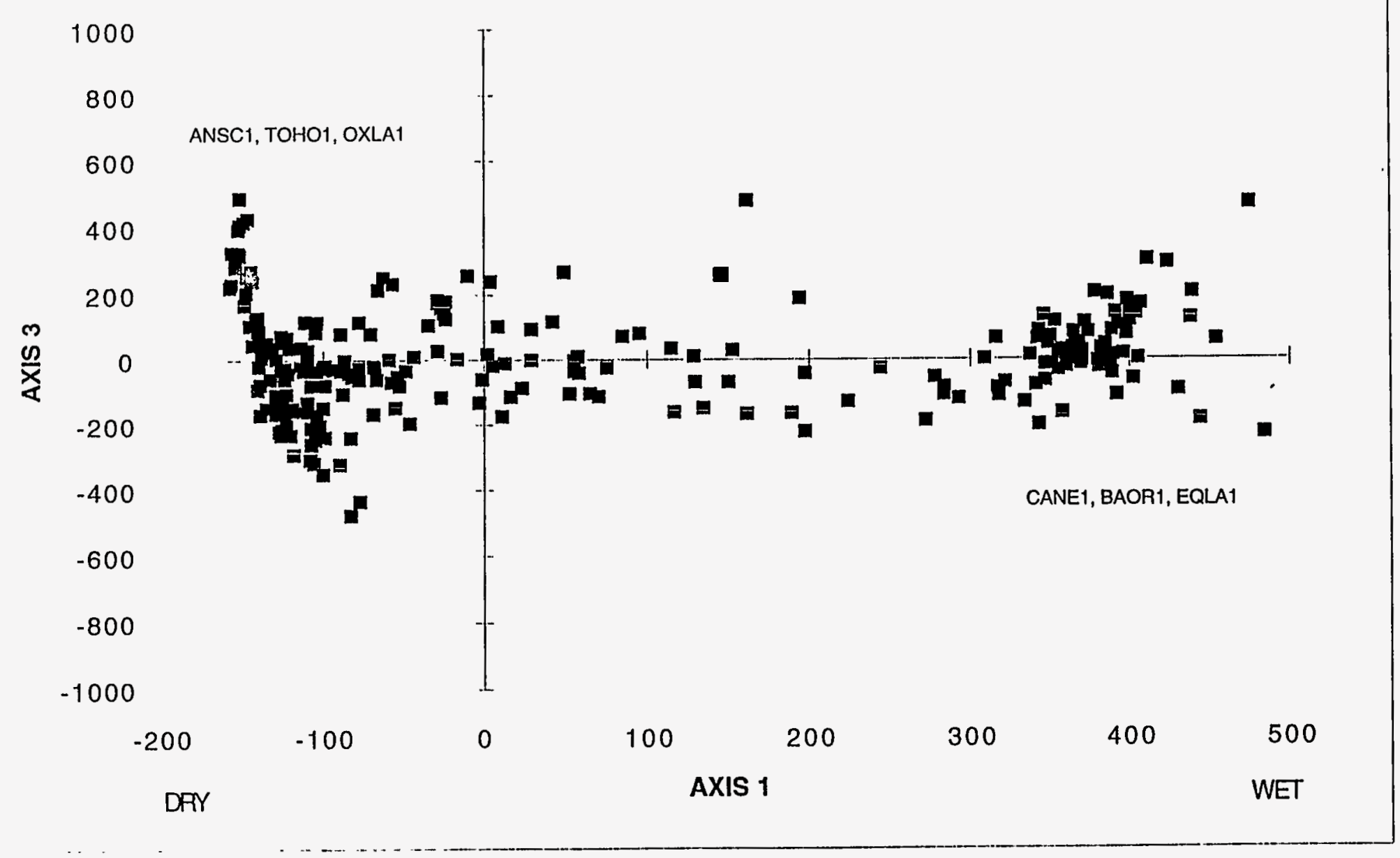

Figure B-29. Terrestrial Vegetation Ordination by Species (Reciprocal Averaging) Presence/Absence Data, Axes 1 and 3.

Note: Speccodes listed are examples of those typical of that part of the figure. See Table B-2 to determine scientific names from speccodes. 


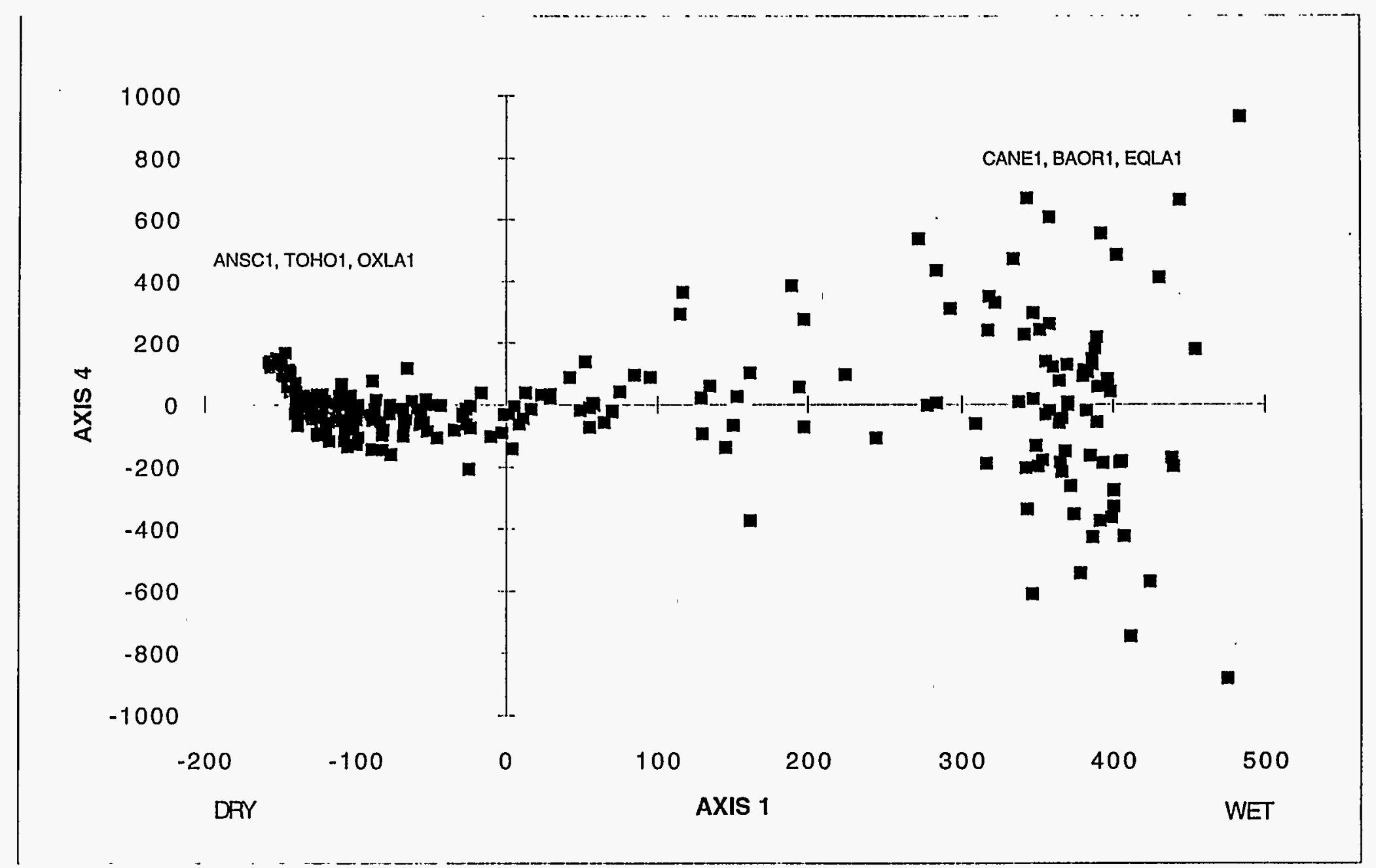

Figure B-30. Terrestrial Vegetation Ordination by Species (Reciprocal Averaging) Presence/Absence Data, Axes 1 and 4.

w Note: Speccodes listed are examples of those typical of that part of the figure. See Table B-2 to determine scientific names from speccodes. 


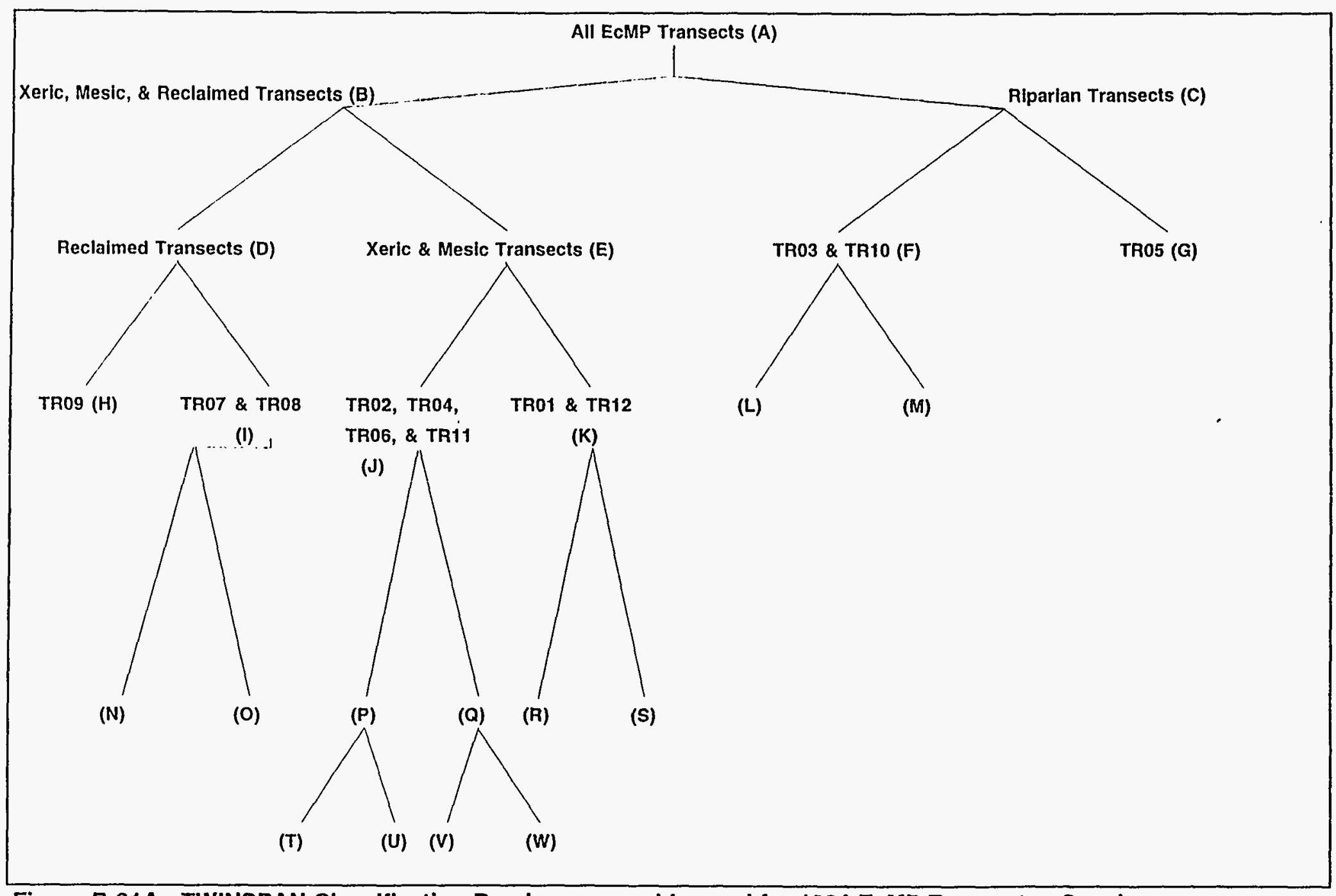

Figure B-31A. TWINSPAN Classification Dendrogram and Legend for 1994 EcMP Transects - Species

Presence/Absence Data. For transects represented by letters in parentheses see legend. 
Figure B-31B. TWINSPAN Classification Dendrogram and Legend for 1994 EcMP Transects - Species Presence/Absence Data.

\begin{tabular}{|c|c|c|c|c|c|}
\hline Alvion. & and Tra & ects & & & \\
\hline$A$ & TR01 T1 & TR01 T2 & TR01 T3 & TR01 T4 & TR01 T5 \\
\hline & TR02 T1 & TR02 T2 & TR02 T3 & TR02 T4 & TR02 T5 \\
\hline & TR03 T1 & TR03 T2 & TR03 T3 & TR03 T4 & TR03 T5 \\
\hline & TR04 T1 & TR04 T2 & TR04 T3 & TR04 T4 & TR04 T5 \\
\hline & TR05 T1 & TR05 T2 & TR05 T3 & TR05 T4 & TR05 T5 \\
\hline & TR06 T1 & TR06 T2 & TR06 T3 & TR06 T4 & TR06 T5 \\
\hline & TR07 T1 & TR07 T2 & TR07 T3 & TR07 T4 & TR07 T5 \\
\hline & TR08 T1 & TR08 T2 & TR08 T3 & TR08 T4 & TR08 T5 \\
\hline & TROO T1 & TR09 T2 & TR09 T3 & TR09 T4 & TR09 T5 \\
\hline & TR10 T1 & TR10 T2 & TR10 T3 & TR10 T4 & TR10 T5 \\
\hline & TR11 T1 & TR11 T2 & TR11 T3 & TR11 T4 & TR11 T5 \\
\hline & TR12 T1 & TR12 T2 & TR12 T3 & TR12 T4 & TR12 T5 \\
\hline & $\because \cdots \quad \vdots \cdots$ & $\because$ & $\because \because 92$ & $\because \because \cdots$ & \\
\hline$B$ & TR01 T1 & TR01 T2 & TR01 T3 & TR01 T4 & TR01 T5 \\
\hline & TR02 T1 & TR02 T2 & TR02 T3 & TR02 T4 & TR02 T5 \\
\hline & TR04 T1 & TR04 T2 & TR04 T3 & TR04 T4 & TR04 T5 \\
\hline & TR06 T1 & TR06 T2 & TR06 T3 & TR06 T4 & TR06 T5 \\
\hline & TR07 T1 & TR07 T2 & TR07 T3 & TR07 T4 & TR07 T5 \\
\hline & TR08 T1 & TR08 T2 & TR08 T3 & TR08 T4 & TR08 T5 \\
\hline & TR09 T1 & TR09 T2 & TR09 T3 & TR09 T4 & TRO9 T5 \\
\hline & TR11 T1 & TR11 T2 & TR11 T3 & TR11 T4 & TR11 T5 \\
\hline & TR12 T1 & TR12 T2 & TR12 T3 & TR12 T4 & TR12 T5 \\
\hline & 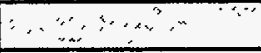 & $\therefore \quad \therefore: \cdots$ & 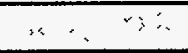 & $\therefore$ & $\therefore$ \\
\hline C & TR03 T1 & TR03 T2 & TR03 T3 & TR03 T4 & TR03 T5 \\
\hline & TR05 T1 & TR05 T2 & TR05 T3 & TR05 T4 & TR05 T5 \\
\hline & TR10 T1 & TR10 T2 & TR10 T3 & TR10 T4 & TR10 T5 \\
\hline$\because$ & $\because, \ldots$ & $\because x^{-\alpha+2)}$ & $m_{n} \quad x, \ldots$ & $\therefore$ & $\because \because \square_{z}, \therefore$ \\
\hline $\bar{D}$ & TR07 T1 & TR07 T2 & TR07 T3 & TR07 T4 & TR07 T5 \\
\hline & TR08 T1 & TR08 T2 & TR08 T3 & TR08 T4 & TR08 T5 \\
\hline & TR09 T1 & TRO9 T2 & TRO9 T3 & TR09 T4 & TR09 T5 \\
\hline 22 & 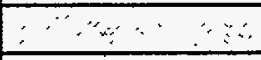 & $\therefore \therefore \div$ & $\therefore \therefore \because \cdots$ & 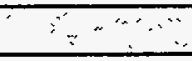 & \\
\hline $\bar{E}$ & TR01 T1 & TR01 T2 & TR01 T3 & TR01 T4 & TR01 T5 \\
\hline & TR02 T1 & TR02 T2 & TR02 T3 & TR02 T4 & TR02 T5 \\
\hline & TR04 T1 & TR04 T2 & TR04 T3 & TR04 T4 & TR04 T5 \\
\hline & TR06 T1 & TR06 T2 & TR06 T3 & TR06 T4 & TR06 T5 \\
\hline & TR11 T1 & TR11 T2 & TR11 T3 & TR11 T4 & TR11 T5 \\
\hline & TR12 T1 & TR12 T2 & TR12 T3 & TR12 T4 & TR12 T5 \\
\hline & & & $\therefore \because$ & . & \\
\hline $\bar{F}$ & TR03 T1 & TR03 T2 & TR03 T3 & TR03 T4 & TR03 T5 \\
\hline & TR10 T1 & TR10 T2 & TR10 T3 & TR10 T4 & TR10 T5 \\
\hline & & & $\ldots$ & $\because \because \because$ & \\
\hline$G$ & TR05 T1 & TR05 T2 & TR05 T3 & TR05 T4 & TR05 T5 \\
\hline & & & & & \\
\hline
\end{tabular}


Figure B-31B. TWINSPAN Classification Dendrogram and Legend for 1994 EcMP Transects - Species Presence/Absence Data.

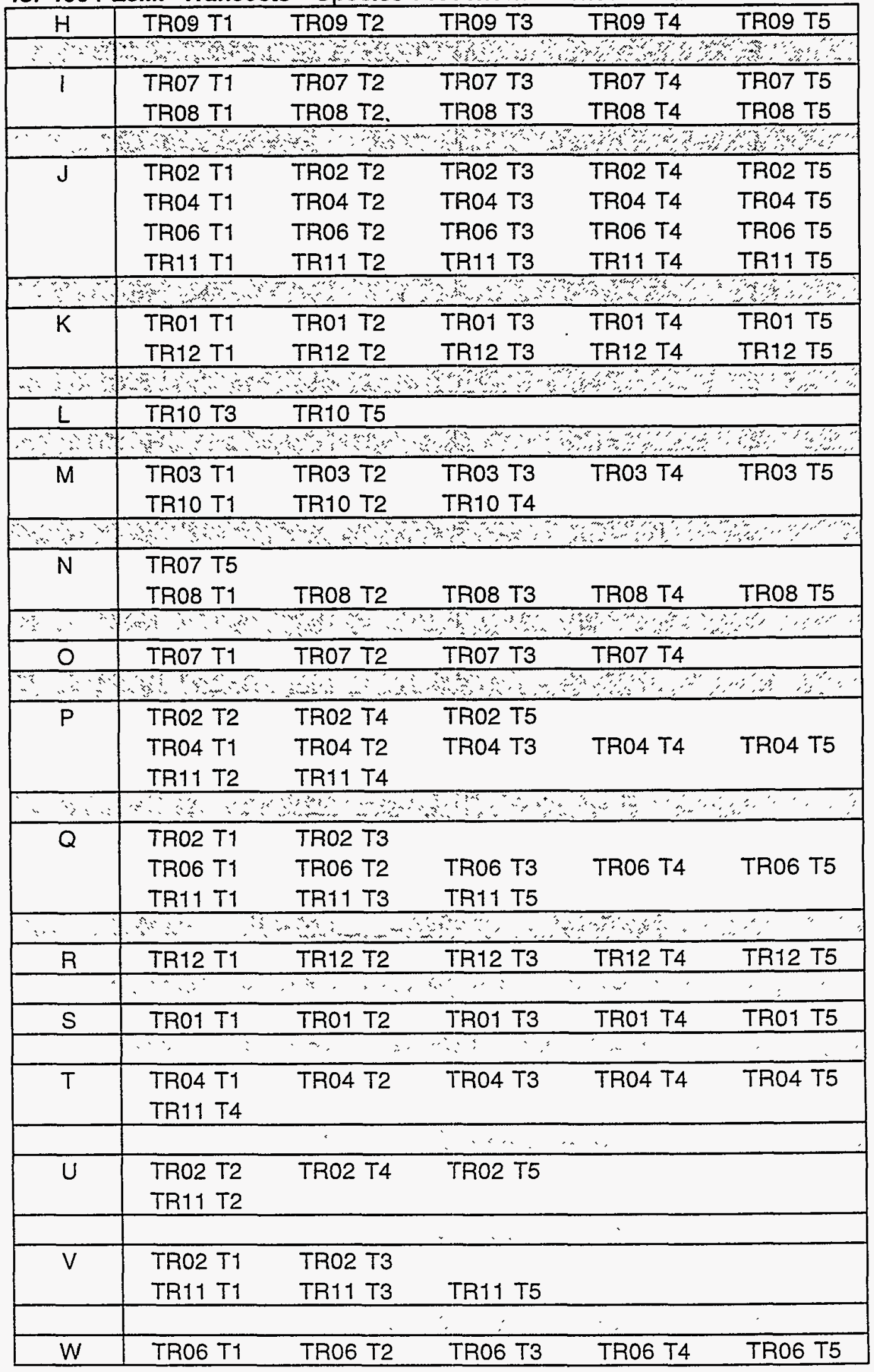




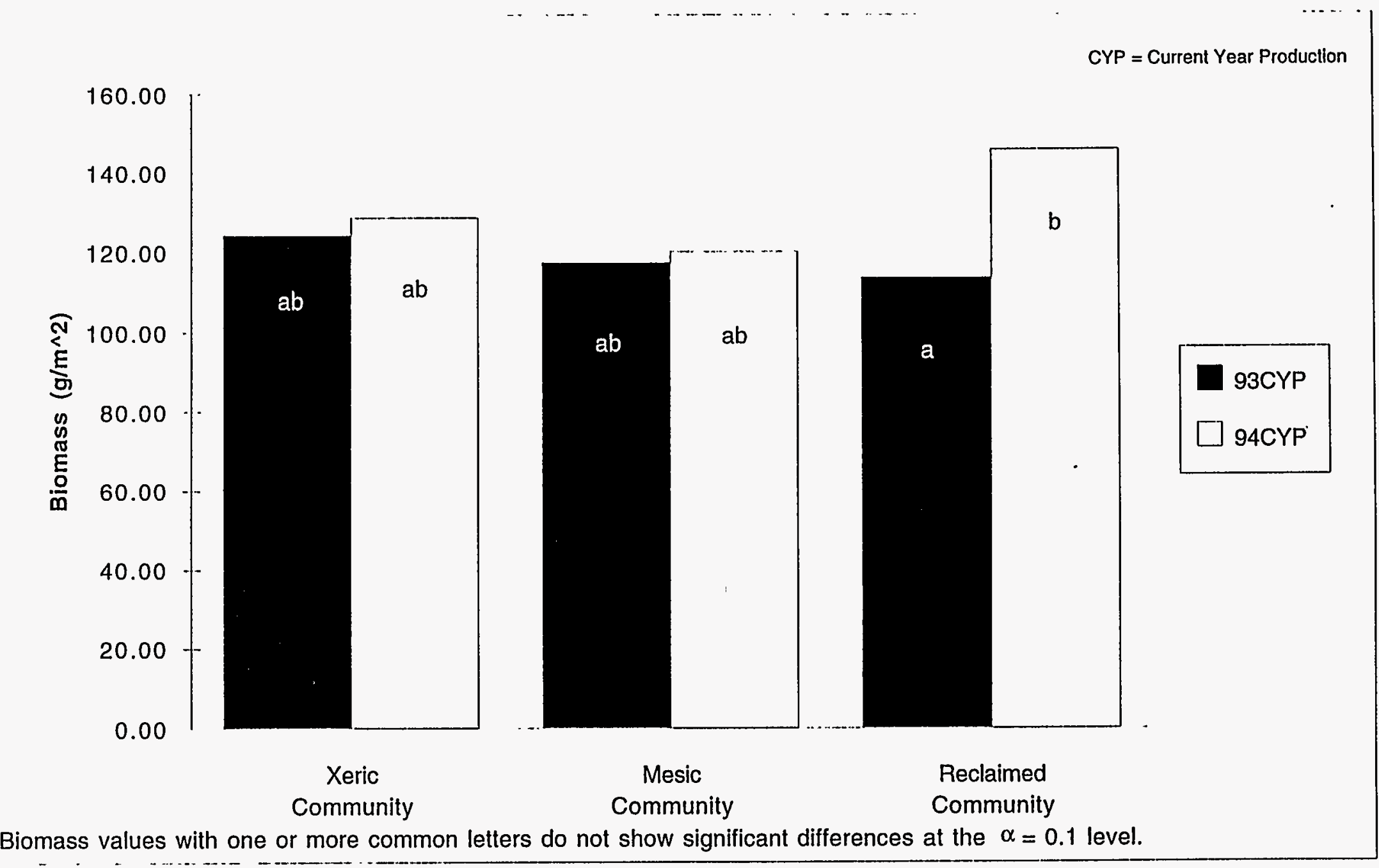

Figure B-32. 1993 and 1994 Current Year Production Biomass Amounts by Community. 


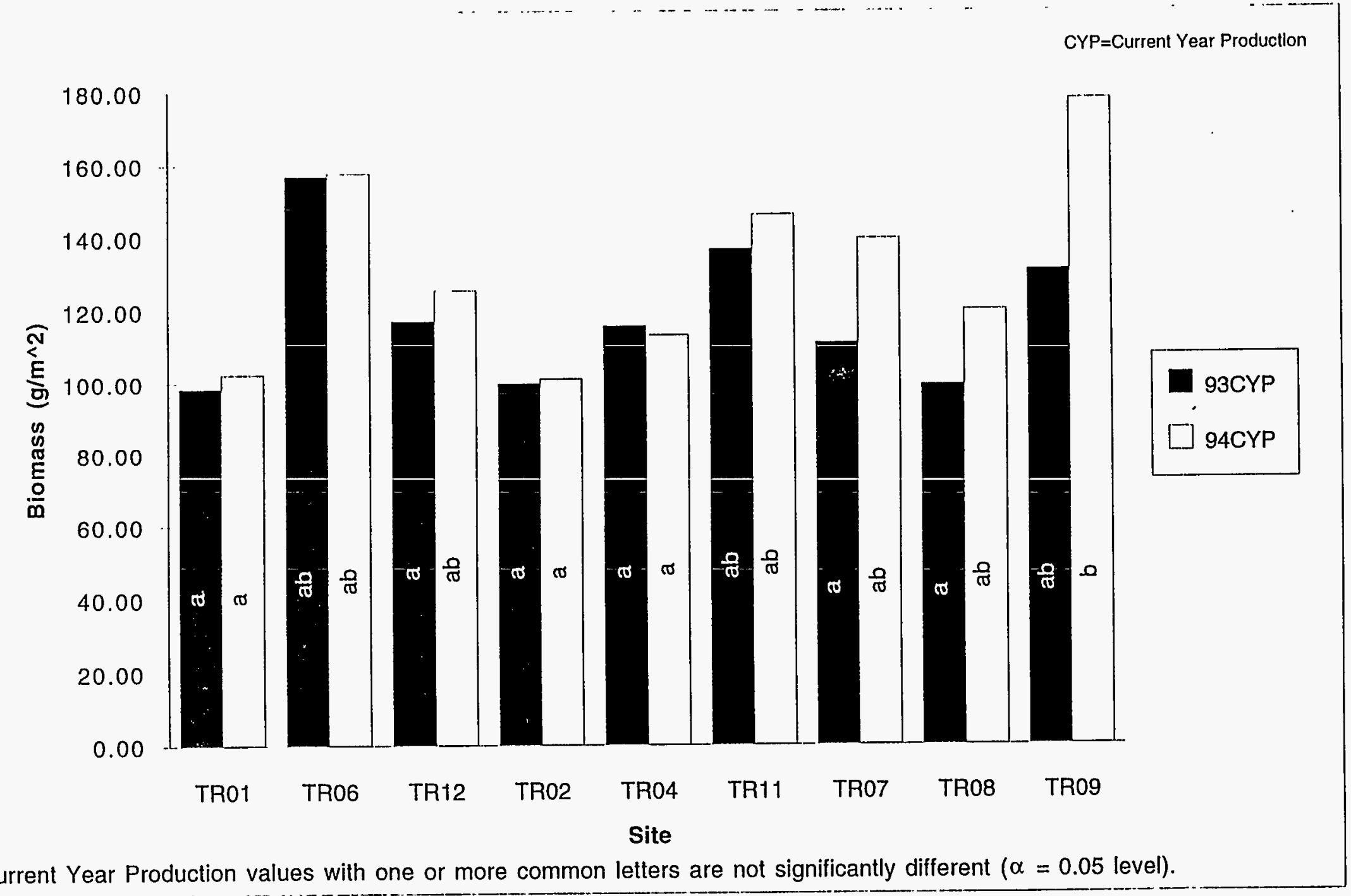

䍐

Figure B-33. 1993 and 1994 Current Year Production Biomass Amounts by EcMP Site. 


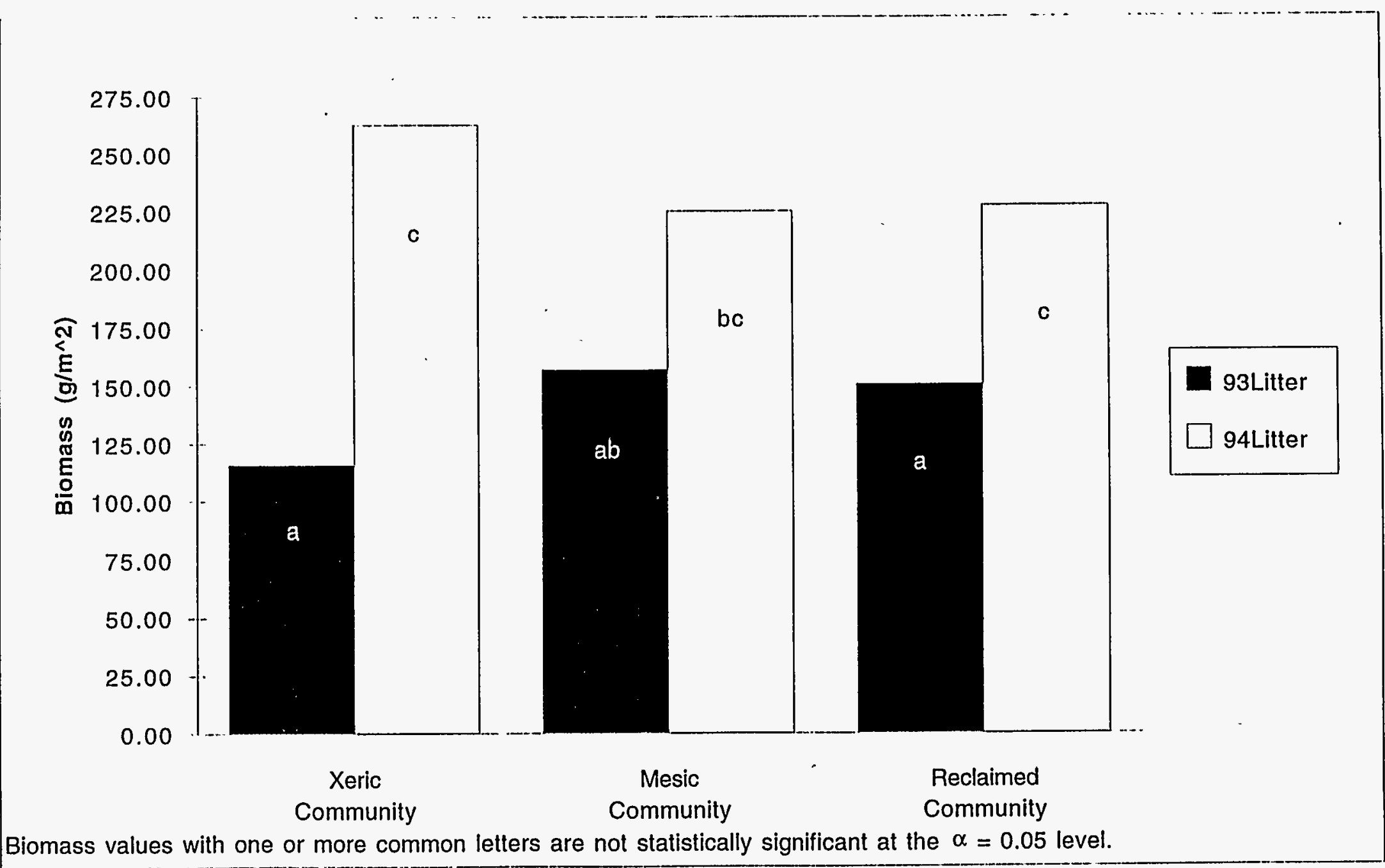

Figure B-34. 1993 and 1994 Litter Amounts by Community. 

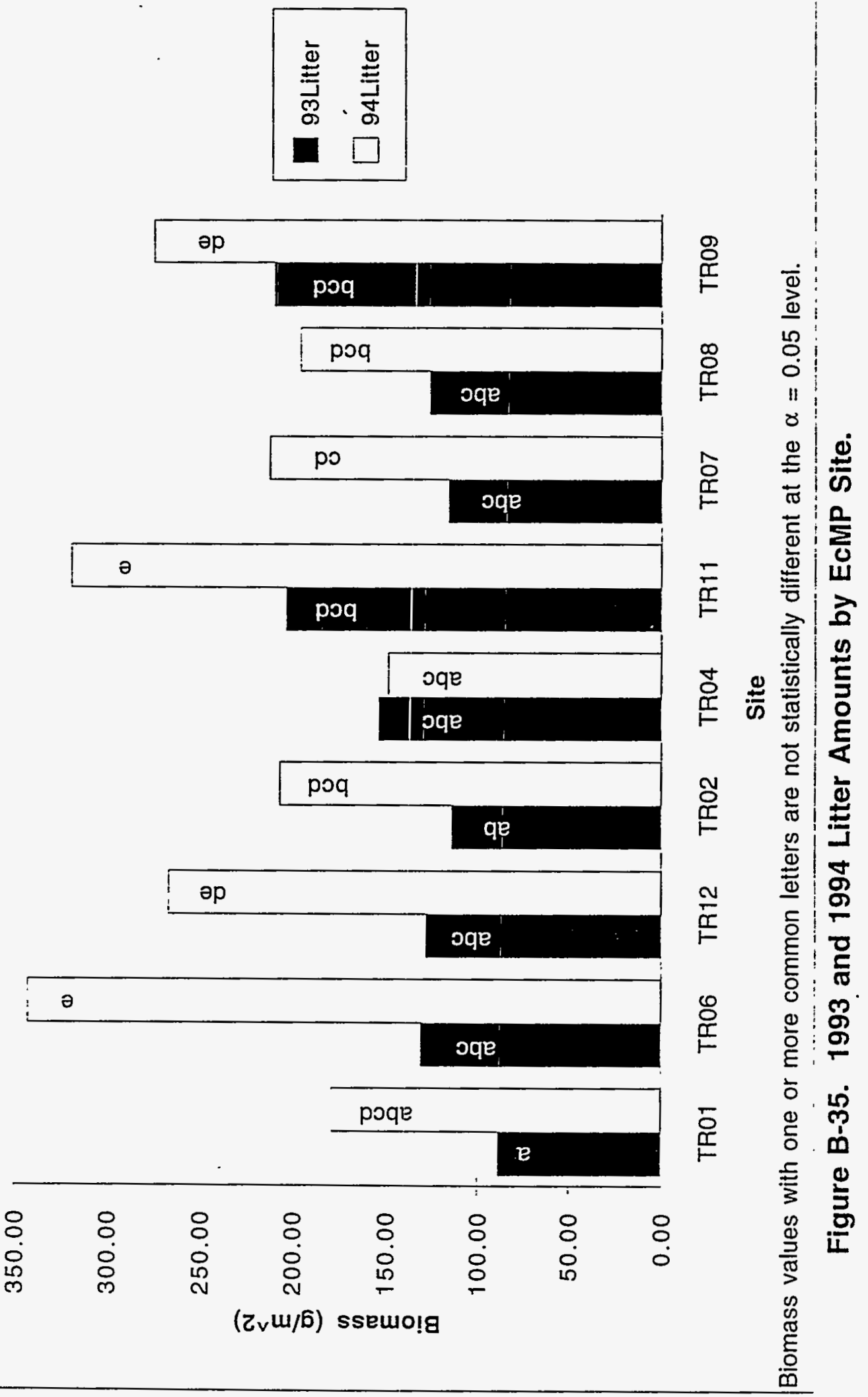
Table B-1. Site Flora Summary.

\begin{tabular}{|c|c|}
\hline \multicolumn{2}{|c|}{ son } \\
\hline \# Families & 77 \\
\hline \# Genera & 290 \\
\hline \# Species & 512 \\
\hline \multicolumn{2}{|c|}{$a^{\prime}$} \\
\hline \# Natives & 402 \\
\hline \#Non-natives & 109 \\
\hline$\%$ Native & 79 \\
\hline \multirow{2}{*}{\multicolumn{2}{|c|}{1 species ID'ed only to genus. No native designation }} \\
\hline & \\
\hline \# Herbaceous & 461 \\
\hline \# Succulent & 7 \\
\hline$\#$ Woody & 44 \\
\hline \multicolumn{2}{|c|}{ 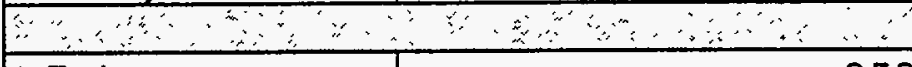 } \\
\hline \# Forbs & 353 \\
\hline \# Graminoids & 109 \\
\hline \# Shrubs & 22 \\
\hline \# Trees & 19 \\
\hline \# Cacti & $\theta$ \\
\hline \# Vines & 3 \\
\hline \multicolumn{2}{|l|}{ 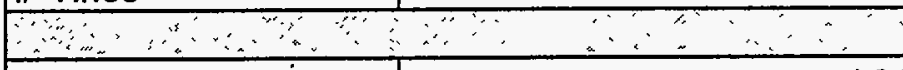 } \\
\hline \# Annuals & 102 \\
\hline \# Bien & \\
\hline \# Perennials & 406 \\
\hline \multicolumn{2}{|c|}{$4 y_{1}$} \\
\hline \# Dicots & 370 \\
\hline \# Monocots & 133 \\
\hline \# Gymnosperms & \\
\hline \# Pteridophytes & \\
\hline \multicolumn{2}{|c|}{ 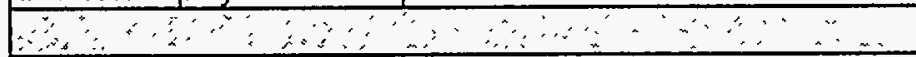 } \\
\hline \# Endemics & \\
\hline \multicolumn{2}{|l|}{ Aster porteri Gray } \\
\hline \multicolumn{2}{|c|}{ Physaria vitulifera Rydb. } \\
\hline \multicolumn{2}{|c|}{ Penstemon virens Penn. } \\
\hline \multicolumn{2}{|c|}{ Harbouria trachypleura (Gray) C.\&R. } \\
\hline \multicolumn{2}{|c|}{\begin{tabular}{|l|llll} 
& \\
Snecies of Concern & \\
\end{tabular}} \\
\hline \multicolumn{2}{|c|}{\begin{tabular}{|l} 
Aristida basiramea Engelm. (G5, S?) \\
\end{tabular}} \\
\hline \multicolumn{2}{|c|}{ Carex oreocharis Holm. (G3, S?) } \\
\hline T.\& E. Spe & \\
\hline
\end{tabular}




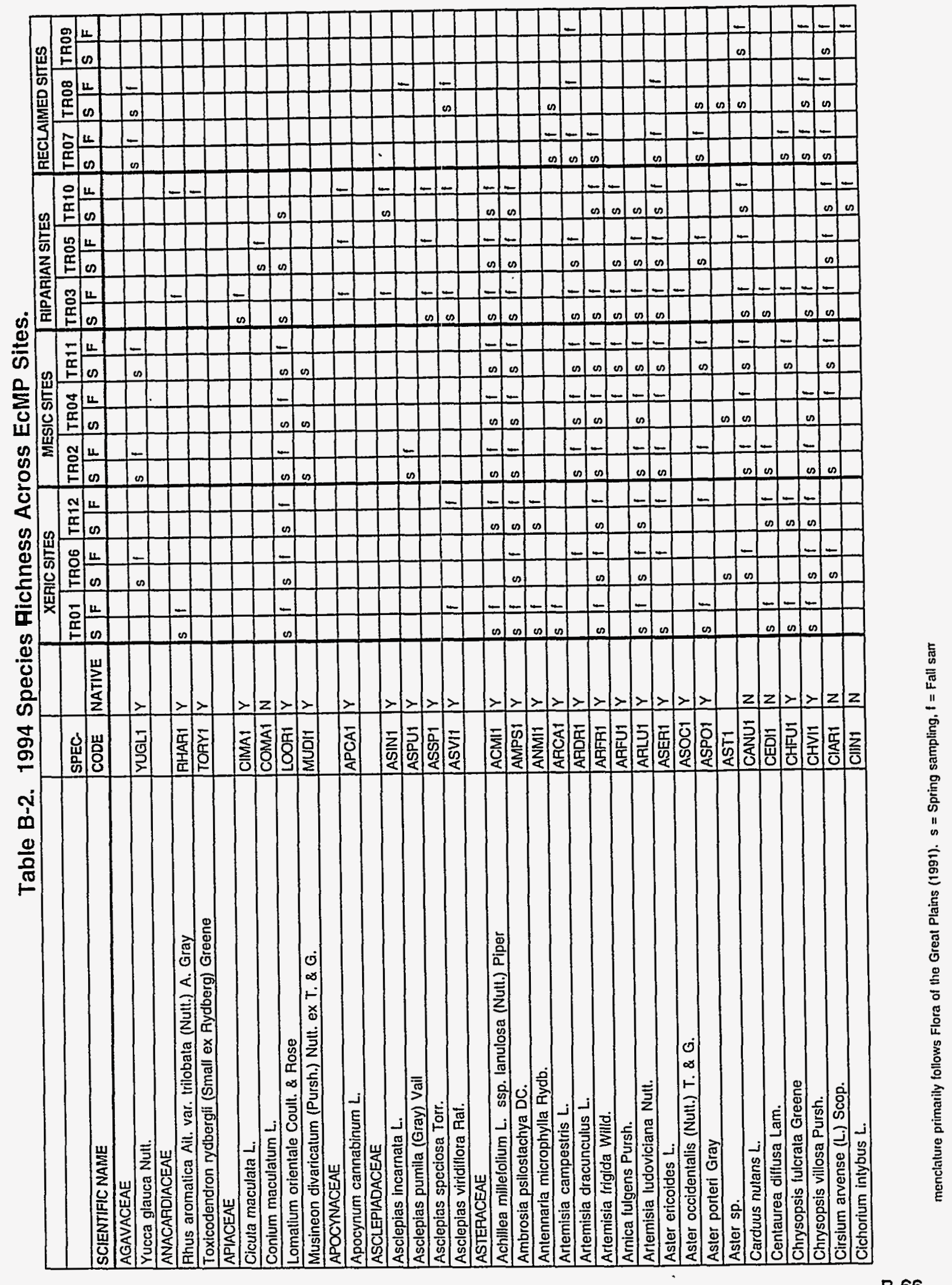


Table B-2. 1994 Species Richness Across EcMP Sites.

\begin{tabular}{|c|c|c|c|c|c|c|c|c|c|c|c|c|c|c|c|c|c|c|c|c|c|c|c|c|c|c|}
\hline \multirow[b]{3}{*}{ SCIENTIFIC NAME } & \multirow{3}{*}{ SPEC } & \multirow{3}{*}{\begin{tabular}{|l|} 
\\
NATIVE \\
\end{tabular}} & \multicolumn{6}{|c|}{ XERIC SITES } & \multicolumn{6}{|c|}{ MESICSITES } & \multicolumn{6}{|c|}{ RIPARIAN SITES } & \multicolumn{6}{|c|}{ RECLAIMED SITES } \\
\hline & & & \multicolumn{2}{|c|}{ TRO1 } & \multicolumn{2}{|c|}{ ThO6 } & \multicolumn{2}{|c|}{ TR12 } & \multicolumn{2}{|c|}{ TR02 } & \multicolumn{2}{|c|}{ TR04 } & \multicolumn{2}{|c|}{ TR11 } & \multicolumn{2}{|c|}{ TA03 } & \multicolumn{2}{|c|}{ TR05 } & \multicolumn{2}{|c|}{ TR10 } & TRO & & TRO & & TRO & \\
\hline & & & $s$ & $\mathbf{F}$ & s & $\mathbf{F}$ & $\mathbf{s}$ & $F$ & $\mathbf{s}$ & $\mathbf{F}$ & $\mathbf{s}$ & $F$ & $\mathbf{s}$ & $\mathbf{F}$ & $\mathbf{s}$ & $\mathbf{F}$ & $\mathbf{s}$ & $\mathbf{F}$ & 5 & $\mathbf{F}$ & s & $F$ & $\mathbf{s}$ & $\mathbf{F}$ & $\mathbf{s}$ & $\mathbf{F}$ \\
\hline Cirsium undulatum (Null.) Spreng. & CIUN1 & $\bar{Y}$ & $s$ & & s & 1 & $s$ & $f$ & $s$ & $I$ & s & $f$ & 5 & 1 & & & & & & & & & & & & \\
\hline Conyza canadensis (L.) Cronq. & COCA1 & $Y$ & & & & & & & & & & & & & $s$ & & $s$ & $f$ & $s$ & 1 & & & & & & \\
\hline Crepis occidentalis Nutt. & CROC1 & $Y$ & & & & & & & & & & & $\mathbf{s}$ & & & & & & & & & & & & & \\
\hline Erigeron divergens T. \& G. & ERDII & $Y$ & & & s & 1 & & $I$ & s & $i$ & s & 1 & $s$ & & $s$ & & & & & & $s$ & $f$ & & & s & \\
\hline Erigeron flagellaris Gray & ERFL1 & $Y$ & & & & $f$ & $s$ & 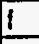 & s & $I$ & & 1 & & 1 & & 1 & & & & & & & & & & 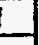 \\
\hline Erigeron sp. & ERI1 & & & & s & & & & & & & & & & & & & & & & & & & & & \\
\hline Gaillardia arislala Pursh. & GAAR1 & $Y$ & s & 1 & & & $s$ & 1 & & & & & & & & & & & & & & & & & & \\
\hline Grindella squarrosa (Pursh.) Dun. & GASQ1 & $Y$ & & & & & & & $\mathbf{s}$ & $f$ & s & 1 & $s$ & 1 & $\mathrm{~s}$ & $f$ & s & 1 & $s$ & $f$ & & 1 & s & 1 & & \\
\hline Gutierrezia sarothrae (Pursh.) Britt. \& Rusby & GUSA1 & $Y$ & & & $s$ & $f$ & $\mathrm{~s}$ & 1 & s & $f$ & s & 1 & s & $i$ & & & $s$ & 1 & & & s & $i$ & s & 1 & & \\
\hline Helianlhus annuus $\mathrm{L}$. & HEAN1 & $\bar{Y}$ & & & & & & & & & & & s & & & & & & & & & & & & & \\
\hline Helianthus sp. & HELI & 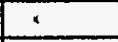 & & & & & & & & & & & $s$ & & & & & & & & & & & & & \\
\hline Helianthus petiolaris Nult. & HEPE1 & $Y$ & $s$ & & & & & & & & & & & & & & & & & & & & & & & \\
\hline Helianthus pumilus Nutt. & HEPU1 & $\bar{Y}$ & 5 & $i$ & s & $f$ & & & $s$ & $f$ & & $f$ & $\mathbf{s}$ & & & & & & & & & & & & & \\
\hline Kuhnia chlorolepis Wool. \& Standl. & KUCH1 & $Y$ & & & & & & & & & & & & & & & & & & & $s$ & $f$ & & 1 & & \\
\hline Kuhnia eupatorioides L. & KUEU1 & $\mathrm{Y}$ & & & & & & & & $f$ & & $f$ & & 1 & & & & & & & . & $f$ & & 1 & & \\
\hline Kuhnia sp. & KUH1 & & & & & & & & & & s & & $s$ & & & & & & & & s & & & & & \\
\hline Lactuca oblongifolla Nutt. & LAOB1 & $Y$ & & & & & & & & & & & & & & 1 & & & & & & & & & & \\
\hline Lacluca serriola L. & LASE1 & $N$ & & & $s$ & $f$ & $s$ & $i$ & s & $f$ & $\mathbf{s}$ & $f$ & $\mathbf{s}$ & $f$ & $s$ & $i$ & $\mathrm{~s}$ & $f$ & $\mathrm{~s}$ & 1 & $s$ & & & & & $i$ \\
\hline Liatris punctata Hook. & LIPU1 & $Y$ & s & $f$ & $\mathbf{s}$ & $f$ & $s$ & 1 & s & $t$ & s & $f$ & $s$ & 1 & & & & & & & 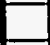 & $i$ & & $f$ & & \\
\hline Microseris cuspidala (Pursh.) Sch. Bip. & MICU1 & $Y$ & s & & $s$ & I & $\mathbf{s}$ & 1 & $s$ & & $\mathbf{s}$ & & $\mathbf{s}$ & $I$ & & & & & $s$ & & & & & & & \\
\hline Picradeniopsis oppositifolia (Nult.) Rydb. & PIOP1 & $Y$ & & & & & & & 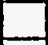 & & 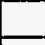 & & 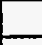 & $f$ & & & & & & & & & & & & \\
\hline Ratibida columnifera (Nutt.) Woot. \& Standl. & RACO1 & $Y$ & & $\mathrm{f}$ & & & & $f$ & s & $f$ & $\mathbf{s}$ & $f$ & $s$ & $f$ & & & & $f$ & & & & $f$ & & & & \\
\hline Scorzonera laciniata $L$. & SCLA1 & $N$ & & i & s & 1 & $\mathbf{s}$ & $f$ & s & i & $\mathbf{s}$ & $i$ & $s$ & $f$ & & & & & 5 & & s & $i$ & & $f$ & & $i$ \\
\hline Senecio integerrimus Nutt. & SEIN1 & $Y$ & & & & & $\mathrm{~s}$ & & s & & $s$ & & $s$ & & & & & & & & $\mathbf{s}$ & & & & & \\
\hline Senecio plallensis Null. & SEPL1 & $\mathrm{Y}$ & $s$ & $f$ & & & $s$ & $i$ & s & i & s & 1 & $\mathbf{s}$ & $f$ & $s$ & & & & & & & & $\mathbf{s}$ & $f$ & & \\
\hline Senecio spartioides T. \& G. & SESP1 & $Y$ & & & s & & $\mathbf{s}$ & 1 & $s$ & 1 & & & & 1 & & & & & & & 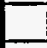 & $f$ & s & $f$ & & \\
\hline Senecio tridenticulalus Rydb. & SETR1 & $Y$ & & & & & & & & & & & & & 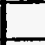 & & & & & & $s$ & $i$ & s & & & \\
\hline Solidago sp. & SOL2 & & & & & & & & & & s & $f$ & $s$ & & $\square$ & & & & 5 & & 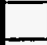 & + & & & & \\
\hline Solidago missouriensis Nult. & SOMI1 & $Y$ & & $f$ & & & & & & & & $f$ & & $f$ & $s$ & 1 & $s$ & & 5 & $f$ & $s$ & $i$ & & & & \\
\hline Solidago mollis Bart. & SOMO1 & $Y$ & & & & & & 1 & & & & & & & $s$ & 1 & & $i$ & s & & & & & & & \\
\hline Solidago nemoralls Ait. & SONE1 & $Y$ & & & & & $\mathrm{~s}$ & & & & & & & & 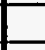 & & & & 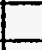 & & & & & & & \\
\hline Solidago rigida $\mathrm{L}$. & SORI1 & $Y$ & & & & & & & & 1 & & & & & & & & & & & & & & & 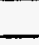 & \\
\hline Taraxacum oflicinale Weber & TAOF1 & $\mathrm{N}$ & $s$ & & $\mathbf{s}$ & 1 & $\mathrm{~s}$ & $f$ & $\mathbf{s}$ & $f$ & $s$ & $f$ & $s$ & $f$ & $s$ & 1 & s & $f$ & s & $f$ & & & & & s & 1 \\
\hline Thelesperma megapolanicum (Spreng.) O. KIze. & THME1 & $Y$ & & & & 1 & & & & & & & & & & & s & & & & & & & & & \\
\hline Townsendia grandiflora (Nutt.) & TOGR1 & $Y$ & & & & 1 & & & & & & & & & & & & & & & & & & & & \\
\hline Townsendia hookeri Beaman & TOHO1 & $Y$ & & $f$ & & & & & & & & & & & & & & & & & & & & & & \\
\hline
\end{tabular}

肾

Nomenclature primarily follows Flora of the Greal Plains (1991). s = Spring sampling. $f=$ Fall sampling 
Table B-2. 1994 Species Richness Across EcMP Sites.

\begin{tabular}{|c|c|c|c|c|c|c|c|c|c|c|c|c|c|c|c|c|c|c|c|c|c|c|c|c|c|c|}
\hline \multirow[b]{3}{*}{ SCIENTIFIC NAME } & \multirow{3}{*}{\begin{tabular}{|l} 
SPEC. \\
CODE
\end{tabular}} & \multirow[b]{3}{*}{ NATIVE } & \multicolumn{6}{|c|}{ XERIC SITES } & \multicolumn{6}{|c|}{ MESIC SITES } & \multicolumn{6}{|c|}{ RIPARIAN SITES } & \multicolumn{6}{|c|}{ RECLAIMED STTES } \\
\hline & & & \multicolumn{2}{|c|}{ TR01 } & \multicolumn{2}{|c|}{ ThO6 } & \multicolumn{2}{|c|}{ TR12 } & \multicolumn{2}{|c|}{ TR02 } & \multicolumn{2}{|c|}{ TR04 } & \multicolumn{2}{|c|}{ TR11 } & \multicolumn{2}{|c|}{ TR03 } & \multicolumn{2}{|c|}{ TR05 } & \multicolumn{2}{|c|}{ TR10 } & TAO & & TAO & & TRO & \\
\hline & & & s & $F$ & $\mathbf{s}$ & $F$ & $s$ & $\mathbf{F}$ & $\mathbf{s}$ & $\mathbf{F}$ & s & $F$ & $\mathbf{s}$ & $F$ & S & $\mathbf{F}$ & $\mathbf{s}$ & $F$ & 5 & $F$ & s & $\mathbf{F}$ & $\mathbf{s}$ & $\mathbf{F}$ & s & $F$ \\
\hline Tragopogon dubius Scop. & TRDU1 & $\sqrt{N}$ & $s$ & 1 & $s$ & 1 & $s$ & $i$ & $s$ & 1 & $s$ & $f$ & $s$ & 1 & $s$ & $f$ & $s$ & $f$ & s & $i$ & 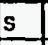 & 1 & $s$ & $f$ & $s$ & $f$ \\
\hline BORAGINACEAE & & & & & & & & & & & & & & & & & & & & & & & & & & \\
\hline Cynoglossum olficinale $L$. & CYOF1 & $N$ & & 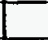 & & & & & & & & & & & & & $\mathrm{s}$ & $f$ & $s$ & 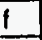 & & & & & & \\
\hline Lappula redowskii (Hornem.) Greene & LARE 1 & $\bar{Y}$ & & 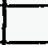 & $s$ & 1 & & & & 1 & $\underline{s}$ & $t$ & $s$ & 1 & & & & & & & F & & & & & \\
\hline Lithospermum incisum Lehm. & LIIN1 & $\mathrm{Y}$ & & & & $i$ & & & & $i$ & & & & 1 & & & & & & & & & & & & \\
\hline Merlensia lanceolata (Pursh.) A. DC. & MELA1 & $y$ & $s$ & $f$ & s & & s & & & & & & & & & & & & s & & & & & & & \\
\hline Onosmodium molle Michx. & ONMO1 & $Y$ & & & & & & & $\mathrm{~s}$ & $f$ & & & & - & $s$ & $f$ & & & & & 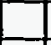 & & & & & \\
\hline BRASSICACEAE & & & & & & & & & & & & & & & & & & & & & & & & & & \\
\hline Alyssum minus (L.) Rothmaler & ALMI1 & $\mathrm{N}$ & $\mathrm{s}$ & $f$ & $\mathrm{~s}$ & $f$ & s & 1 & $\mathrm{~s}$ & $f$ & $\mathrm{~s}$ & $f$ & $s$ & $f$ & $s$ & f & & & s & 1 & s & $f$ & s & 1 & s & $f$ \\
\hline Arabis sp. & ARA1 & & & $f$ & & & & & & $f$ & & & & & & & & & & & L & L & & & & \\
\hline Arabis fendleri (Wats.) Greene & ARFE3 & $\mathrm{Y}$ & & & & & & & & & & & $\mathrm{s}$ & & & & & & & & & & & & & \\
\hline Arabis glabra (L.) Bernh. & ARGL1 & $\mathrm{N}$ & s & 1 & & & & & & & $\mathbf{s}$ & 1 & & & & & & & & & & & & & & \\
\hline Barbarea orthoceras Ledeb. & BAOA1 & $N$ & & & & & & & & & & & & & $\mathrm{~s}$ & 1 & $\mathrm{~s}$ & $f$ & & & & & & & & \\
\hline BRASSICACEAE sp. & BR1 & & & & & $i$ & & & & & & 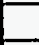 & & $f$ & & & & & & & $\because$ & & & & & \\
\hline Cardaria chalepensis (L.) Hand-Mazz & $\mathrm{CACHI}$ & $\mathrm{N}$ & & & & & & & & & & & & & - & & & & $s$ & & & & & & & \\
\hline Camelina microcarpa Andrz. & CAMI1 & $N$ & s & if & s & if & $\mathrm{s}$ & $i$ & s & $f$ & s & $i$ & $s$ & $f$ & 5 & 1 & & & s & $f$ & $\mathrm{~s}$ & 1 & & I & $s$ & 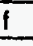 \\
\hline Descurainia sp. & DES1 & $:$ & & & & & & & & & & 1 & & & & & & & & & 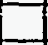 & & & & & \\
\hline Descurainia pinnata (Walt.) Britt. & DEPI1 & $Y$ & $s$ & & s & $f$ & s & $i$ & $s$ & $i$ & s & i & $s$ & 1 & $s$ & 1 & & & $s$ & $f$ & 5 & $f$ & & & s & 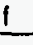 \\
\hline Descurainia richardsonil (Sweet) Schuliz & DERII & $\bar{Y}$ & & & & $f$ & & & & & s & $f$ & $s$ & $f$ & 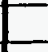 & & & & & & & & & & & \\
\hline Descurainia sophia (L.) Webb & DESO1 & $\mathrm{N}$ & & & & if & & & & & & & & & 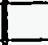 & & & & & & & & & & & \\
\hline Draba nemorosa $L$. & DRNE1 & $Y$ & s & & & & & & & & & & & & $\mathrm{s}$ & & & & & & & & & & & \\
\hline Draba replans (Lam.) Fern. & DRRE1 & $Y$ & $s$ & 1 & s & 1 & s & $f$ & $s$ & I & & $f$ & & $f$ & & & & & & & & & & & & \\
\hline Erysimum asperum (Nutt.) DC. & ERAS1 & $Y$ & $s$ & 1 & $\mathrm{~s}$ & f & $\mathrm{s}$ & 1 & $s$ & $f$ & $\mathrm{~s}$ & 1 & $s$ & $f$ & 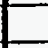 & & & & & & & $f$ & & & & \\
\hline Erysimum repandum L. & ERRE1 & $\mathrm{N}$ & & & & & & & & & $s$ & $f$ & & & & & & & & & & & & & & \\
\hline Lesquerella montana (A. Gray) Wals. & LEMO1 & $Y$ & s & 1 & s & $f$ & $\mathrm{~s}$ & $f$ & s & 1 & & & $s$ & 1 & 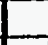 & & & & & & & & & & & \\
\hline Lepidium $\mathrm{sp}$. & LEP1 & & & & & & & $f$ & & & & $f$ & $s$ & 1 & & & & & s & & & & & & & \\
\hline Lepidium densillorum Schrad. & LEDE & $Y$ & & & & & & & & & & 1 & & & - & & & & & & & & & & & \\
\hline Nasturtium oflicinale R. Br. & NAOF1 & $\mathrm{N}$ & & & & & & & L & & 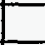 & & 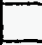 & & s & 1 & & & & & & & & & & \\
\hline Sisymbrium allissimum $\mathrm{L}$. & SIAL1 & $N$ & & & $s$ & $i$ & $\mathbf{s}$ & $f$ & s & $f$ & s & $f$ & $s$ & i & s & 1 & & $f$ & $s$ & & & & & & & \\
\hline Thlaspi arvense $\mathrm{L}$. & THAR1 & $\mathrm{N}$ & & & & & & & & & s & $f$ & & & $\mathrm{~s}$ & i & & 1 & $\mathbf{s}$ & & & & & & & \\
\hline CACTACEAE & & & & & & & & & & & & & & & & & & & & & & & & & & \\
\hline Coryphanlha missouriensis (Sweet) Britt. \& Rose & COMli & $Y$ & s & & $s$ & & & & & i & s & $f$ & $\mathbf{s}$ & 1 & & & & & & & & & & & & \\
\hline Echinocereus viridiflorus Engelm. & ECVII & $Y$ & $\mathrm{~s}$ & $f$ & s & 1 & s & $f$ & s & $i$ & s & $f$ & s & 1 & & & & & & & & & & & & \\
\hline Opuntia fragilis (Nutl.) Haw. & OPFR1 & $Y$ & $s$ & $f$ & & & 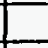 & & s & & s & i & s & 1 & s & 1 & & & & $f$ & & & & & & \\
\hline Opuntia humilusa (RaI.) Ral. & OPHU1 & $Y$ & $s$ & $f$ & s & 1 & s & 1 & s & 1 & s & $f$ & s & 1 & $s$ & $f$ & & & $\mathrm{~s}$ & $f$ & s & 1 & & & s & \\
\hline Pediocactus simpsonii (Engelm.) Britt. \& Rose & PESII & $Y$ & & & 5 & 1 & s & & s & & & & & & & & & & & & & & & & & \\
\hline
\end{tabular}

మ 
Table B-2. 1994 Species Richness Across EcMP Sites.

\begin{tabular}{|c|c|c|c|c|c|c|c|c|c|c|c|c|c|c|c|c|c|c|c|c|c|c|c|c|c|c|}
\hline \multirow[b]{3}{*}{ SCIENTIFIC NAME } & \multirow{3}{*}{$\frac{\text { SPEC- }}{\text { CODE }}$} & & \multicolumn{6}{|c|}{ XERIC SITES } & \multicolumn{6}{|c|}{ MESIC SITES } & \multicolumn{6}{|c|}{ RIPARIAN SITES } & \multicolumn{6}{|c|}{ RECLAIMED SITES } \\
\hline & & & \multicolumn{2}{|c|}{ TR01 } & \multicolumn{2}{|c|}{ TRO6 } & \multicolumn{2}{|c|}{ Th12 } & \multicolumn{2}{|c|}{ TRO2 } & \multicolumn{2}{|c|}{ TRO4 } & \multicolumn{2}{|c|}{ TR11 } & \multicolumn{2}{|c|}{ TR03 } & \multicolumn{2}{|c|}{ TR05 } & \multicolumn{2}{|c|}{ TR10 } & \multicolumn{2}{|c|}{ TRO7 } & TR & & TA & \\
\hline & & NATIVE & s & $\mathbf{F}$ & s & $\bar{F}$ & $s$ & TF & $\mathbf{s}$ & $F$ & $s$ & $F$ & $\mathbf{s}$ & $F$ & $s$ & $\mathbf{F}$ & s & $F$ & s & $\bar{F}$ & $\mathbf{s}$ & $\bar{F}$ & $\mathbf{s}$ & $\mathbf{F}$ & s & $\mathbf{F}$ \\
\hline CAMPANULACEAE & & & & & & & & & & & & & & & & & & & & & $L$ & & & & & \\
\hline Triodanus sp. & TRI2 & & L & & & & & & & f & & 1 & & & & & $L$ & 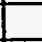 & $\ldots$ & & - & & & & & \\
\hline CAPRIFOLIACEAE & & & & & & & & & & & & & & & & & & 5 & + & & - & & 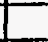 & & & \\
\hline Symphoricarpos occidentalis Hook. & SYOC1 & $\bar{Y}$ & & & & & & & & & & & & & s & 1 & s & $f$ & s & $i$ & & & & & & \\
\hline CARYOPHYLLACEAE & & & & & & & & & & & & & & & 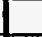 & & & & $L$ & & 1 & & & & & \\
\hline Arenaria fendleri A. Gray & ARFE2 & $Y$ & s & $f$ & & & s & If & & & & & & & 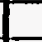 & & & & 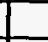 & & 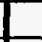 & & & & & \\
\hline Cerastium arvense $\mathrm{L}$. & CEAR1 & $Y$ & & & & & & & & & & & & & s & & & & . & & E & & & & & \\
\hline Paronychia jamesil T. \& G.James & PAJA1 & $Y$ & $\mathrm{~s}$ & $f$ & s & 1 & s & f & s & & & & & & & & & & F & & F & & & & & \\
\hline Silene antirmina $\mathrm{L}$. & SIAN1 & 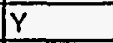 & s & $f$ & & & & $f$ & & $f$ & & $t$ & & $f$ & & & & & La & & & & & & & \\
\hline Silene drummondii Hook. & SIDRI & $Y$ & 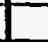 & $f$ & & 1 & & f & & & & & & $f$ & & & & ( & 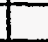 & & Z & & & & & \\
\hline CHENOPODIACEAE & & & & & & & & & & & & & & & & & & & 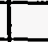 & & & & & & & \\
\hline Chenopodium leptophyllum Nult. ex Moq. & CHLE2 & $\mathrm{Y}$ & & & $\mathrm{s}$ & 1 & & & & $f$ & & 1 & & $f$ & & & & 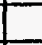 & $T$ & & - & & & & & \\
\hline CLUSIACEAE & & & & & & & & & & & & & & & & & & & & & 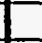 & & & & & \\
\hline Hypericum perforafum L. & HYPEI & $\mathrm{N}$ & s & If & s & $f$ & is & $f$ & s & If & s & $i$ & s & i & s & $f$ & s & & s & & s & 1 & & & & \\
\hline COMMELINACEAE & & & & & & & & & - & & & & & & + & & - & 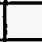 & 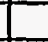 & 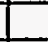 & L & 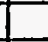 & & & & \\
\hline Tradescantia occidentalis (Britt.) Smyth & TROC1 & $Y$ & 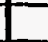 & & & & & & s & & s & 1 & s & & - & & & & $t$ & & 5 & & & & & \\
\hline CONVOLVULACEAE & & & & & & & & & & & & & & & & & & & & & L & & & & & \\
\hline Convolvulus anvensis $\mathrm{L}$. & COAR1 & $\mathrm{N}$ & & & & & & & 5 & $f$ & & & & & 5 & & & 1 & $s$ & & $s$ & 1 & s & 1 & 5 & $f$ \\
\hline Evolvulus nullallianus A. \& S. & EVNU1 & $Y$ & & & & & & & $\mathbf{s}$ & i & & & & 1 & & & 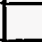 & & L & & L & & & & & \\
\hline CYPERACEAE & & & & & & & & & & & & & & & & & & & $t$ & & 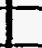 & & & & & \\
\hline Carex eleocharis Bailey & CAEL1 & $\mathrm{Y}$ & & & & & s & & s & & & 1 & & & W & & & & s & & 1 & & & & & \\
\hline Carex filifolia Nutt. & CAFI1 & $\bar{Y}$ & & & s & $i$ & & & & & & & & & & & & & 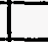 & & L & & & & & \\
\hline Carex hellophila Mack. & CAHE1 & $Y$ & 5 & $f$ & $s$ & 1 & & $f$ & & $f$ & & $i$ & s & 1 & & & 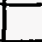 & & 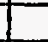 & & & & & & & \\
\hline Carex interior Bailey & CAIN1 & $Y$ & & & & & & & & & & & s & & & & 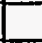 & & $T$ & & & & & & & \\
\hline Carex lanuginosa Michx. & CALA1 & $\bar{Y}$ & $L$ & & & & & & & & & & & & 5 & & s & $f$ & + & & & & & & & \\
\hline Carex nebraskensis Dew. & CANE1 & $Y$ & & & & & & & & & & & & & $s$ & $f$ & s & 1 & is & $f$ & & & & & & \\
\hline Carex oreocharis Holm. & CAOR1 & $\bar{\gamma}$ & & & & & s & & $\mathrm{s}$ & & & & & & 5 & & 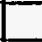 & & I & & & & & & & \\
\hline Carex praegracilis W. Boott. & CAPR1 & $Y$ & & & & & & & & & & & & & $s$ & 1 & - & & . & & L & & & & & \\
\hline Carex sp. & CAR1 & 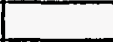 & & & & & & & & & s & & & & & & $\mathrm{s}$ & & $\mathrm{s}$ & & & & & & & \\
\hline Carex rostrala Slokes ex Willd. & CARO2 & $\bar{Y}$ & & & & & & & & & & & & & $\mathrm{~s}$ & & & & & & & & & & & \\
\hline Carex simulata Mack. & CASII & $Y$ & & & & & & & & & & & & & $\mathrm{~s}$ & & & & & & & & & & & \\
\hline Carex slipata Muhl. & CAST1 & $Y$ & & & & & & & & & & & & & & & & & s & f & & & & & & \\
\hline Eleocharis macrostachya Brilt. & ELMA1 & $Y$ & & & & & & & & & & & & & & & s & & $T$ & & & & & & & \\
\hline Eleocharis parvula (R. \& S.) Link ex Bluft & ELPA1 & $Y$ & & & & & & & & & & & & & $\mathbf{s}$ & $f$ & $s$ & $f$ & s & $f$ & & & & & & \\
\hline Scirpus americanus Pers. & SCAM1 & $Y$ & & & & & & & & & & & & & & & $\mathrm{~s}$ & $f$ & s & 1 & & & & & & \\
\hline Scirpus pallidus (Britt.) Fern & SCPA1 & $\bar{Y}$ & & & & & & & & & & & & & 5 & $f$ & $\mathrm{~s}$ & $i$ & s & 1 & & & & & & \\
\hline
\end{tabular}

ஹு 
Table B-2. 1994 Species Richness Across EcMP Sites.

\begin{tabular}{|c|c|c|c|c|c|c|c|c|c|c|c|c|c|c|c|c|c|c|c|c|c|c|c|c|c|c|}
\hline \multirow[b]{3}{*}{ SCIENTIFIC NAME } & \multirow{3}{*}{\begin{tabular}{|l|} 
SPEC \\
CODE \\
\end{tabular}} & \multirow{3}{*}{ NATIVE } & \multicolumn{6}{|c|}{ XEAIC SITES } & \multicolumn{6}{|c|}{ MESIC SITES } & \multicolumn{6}{|c|}{ RIPARIAN SITES } & \multicolumn{6}{|c|}{ RECLAIMED SITES } \\
\hline & & & \multicolumn{2}{|c|}{ TRO1 } & \multicolumn{2}{|c|}{ TRO6 } & \multicolumn{2}{|c|}{ TR12 } & \multicolumn{2}{|c|}{ TR02 } & \multicolumn{2}{|c|}{ TR04 } & \multicolumn{2}{|c|}{ TR11 } & \multicolumn{2}{|c|}{ TR03 } & \multicolumn{2}{|c|}{ TR05 } & \multicolumn{2}{|c|}{ TR10 } & Tho & & TRO & & Tho & \\
\hline & & & s & $F$ & s & $F$ & $s$ & $F$ & $\mathbf{s}$ & $\mathbf{F}$ & 5 & $F$ & $s$ & $\mathbf{F}$ & $\mathbf{s}$ & $\mathbf{F}$ & $s$ & $F$ & $s$ & $\mathbf{F}$ & s & $\mathbf{F}$ & s & $\mathbf{F}$ & $\mathbf{s}$ & $F$ \\
\hline Scirpus validus Vahl. & SCVA1 & $Y$ & & & & & & & & & & & & & & 1 & & $f$ & & & & & & & & \\
\hline EQUISETACEAE & & & & & & & & & & & & & & & & & & & & & & & & & & \\
\hline Equisetum arvense $\mathrm{L}$. & EQAR1 & $Y$ & & & & & & & & & & & & & s & & s & & $s$ & & & & & & & \\
\hline Equiselum hyemale $\mathrm{L}$. & EQHY1 & $Y$ & & & & & & & & & & & & & s & & & & & & & & & & & \\
\hline Equiselum laevigatum A. Br. & EQLA1 & $Y$ & & & & & & & & & & & & & & i & & & $s$ & $f$ & & & & & & \\
\hline EUPHORBIACEAE & & & & & & & & & & & & & & & & & & & & & & & & & & \\
\hline Euphorbia dentata Michx. & EUDE1 & $Y$ & & & & & & & & & & & & 1 & & & & & & 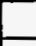 & 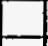 & & & & & \\
\hline Euphorbia robusta (Engelm.) Small & EURO1 & $Y$ & & & & & $s$ & $r$ & $s$ & 1 & & & & & & & & & & & & & & & & \\
\hline Euphorbla serpyllifolia Pers. & EUSE1 & $Y$ & & & & & & & & & 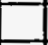 & & & & & & & & & i & & & & & & \\
\hline Euphorbia spathulata Lam. & EUSPI & $Y$ & & & & & & & & 1 & $\mathbf{s}$ & $f$ & s & $f$ & & & & & & & & & & & & \\
\hline FABACEAE & & & & & & & & & & & & & & & & & & & & & & & & - & & \\
\hline Amorpha fruticosa $\mathrm{L}$. & AMFA1 & $Y$ & & & & & & & & & & & & & $s$ & 1 & s & $f$ & $s$ & $f$ & & & & & & \\
\hline Astragalus agrestis Dougl. ex G. Don & ASAG1 & $Y$ & $s$ & 1 & $\mathbf{s}$ & $f$ & & & $s$ & & s & $i$ & $s$ & $f$ & & & 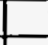 & & s & & & & & & & \\
\hline Astragalus crassicarpus Nutt. & ASCR1 & $Y$ & & & & & 5 & & $s$ & & s & & & & & & 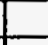 & ए & & & - & & $\underline{s}$ & $f$ & & \\
\hline Astragalus drummondil Dougl. ex Hook. & ASDR1 & $Y$ & & & & & & & & & $s$ & & & & & & & & & & 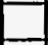 & & & & & \\
\hline Astragalus flexuosus (Hook.)G. Don & ASFL1 & $Y$ & & & s & & & & & $f$ & & & & & & & & & & & s & & & & & \\
\hline Astragalus missouriensis Nult. & ASMII & $Y$ & $s$ & & & & & & & & & & & & & & & & & & & & & & & \\
\hline Astragalus parryi Gray & ASPA1 & $Y$ & & - & & & & & & & & & & & & & Les & 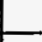 & & & L- & & $s$ & 1 & & \\
\hline Astragalus sericoleucus Gray & ASSE1 & $Y$ & & & $s$ & i & & & $s$. & & & & & & & & & ـ & & & & & & L & & \\
\hline Astragalus shortianus Nult. ex T.\&G. & ASSH1 & $Y$ & $s$ & $f$ & $s$ & \pm & s & 1 & $\mathrm{~s}$ & & $s$ & & $s$ & 1 & & & & & & & & & & & & \\
\hline Astragalus sp. & AST2 & & & $f$ & & & & & $\underline{s}$ & i & & & 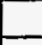 & & & & + & & & & & & & & & \\
\hline Dalea candida Willd. & DACA1 & $Y$ & & & & 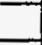 & T & & & & & & $s$ & 1 & 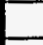 & & 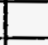 & & & & & & & $f$ & & \\
\hline Dalea purpurea Vent & DAPU1 & $Y$ & & i & & $f$ & $\mathrm{~s}$ & $f$ & s & 1 & & & $s$ & 1 & & & 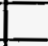 & 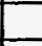 & & & & & & & & \\
\hline Glycyrrhiza lepidota Pursh. & GLLE1 & $Y$ & & & & & & & $F$ & & & & & & $s$ & I. & 5 & $f$ & $s$ & 1 & & & & & & \\
\hline Lalhyrus eucosmus Butters and St. John & LAEU1 & $Y$ & & & & & & & & & & & 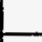 & & $\mathbf{s}$ & & s & 1 & & & & & & & & \\
\hline Lupinus argenteus Pursh. & LUARI & $Y$ & & & & & & & & & & & & & s & $f$ & & & _ & & & & & & & \\
\hline Melilotus alba Medic. & MEAL1 & $\mathrm{N}$ & & & & & & & - & & & & & & 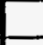 & & & 1 & 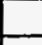 & & 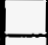 & & & 1 & & \\
\hline Medicago lupulina $\mathrm{L}$. & MELU1 & $N$ & & & & & & & 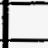 & & & & & & & $f$ & s & $i$ & $s$ & $f$ & 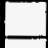 & $f$ & s & 1 & & \\
\hline Melilotus oflicinalis (L.) Pall. & MEOF1 & $N$ & & & & & & & & & & & & & & & s & 1 & & & $s$ & $f$ & $s$ & 1 & $\mathbf{s}$ & \\
\hline Medicago sativa $\mathrm{L}$. & MESA1 & $\mathrm{N}$ & & & & & & & - & & & & & & & & & & & & & & $s$ & & $s$ & $t$ \\
\hline Oxytropis lambertii Pursh. & OXLA1 & $Y$ & 5 & $f$ & $s$ & $f$ & s & $f$ & s & 1 & & & & & & & & & & & & & & & & \\
\hline Psoralea tenuillora Pursh. & PSTE1 & $Y$ & 5 & 1 & $s$ & $f$ & s & $\mathrm{f}$ & s & 1 & s & $f$ & s & 1 & s & & & & & 1 & & & $\mathrm{~s}$ & & & \\
\hline Thermopsis rhombifolia var. divaricarpa Nels. & THRH1 & $Y$ & & & & & & & 1 & & & & - & 5 & $\mathrm{~s}$ & 1 & s & $i$ & s & 1 & & & $\ldots$ & & & \\
\hline Trifolium sp. & TRl1 & & & & & & & & - & & & & & $i$ & & & & & 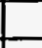 & & & & & & & \\
\hline Vicia americana Muhl. ex Willd. & VIAMI & $Y$ & & & & & & & 5 & $f$ & $s$ & $f$ & s & $f$ & & & $s$ & & 5 & $t$ & & & s & i & 5 & \\
\hline GERANIACEAE & & & & & & & & & & & & & & & & & & & & & & & & & & \\
\hline
\end{tabular}

0
1
0 
Table B-2. 1994 Species Richness Across EcMP Sites.

\begin{tabular}{|c|c|c|c|c|c|c|c|c|c|c|c|c|c|c|c|c|c|c|c|c|c|c|c|c|c|}
\hline \multirow{3}{*}{\begin{tabular}{|l|} 
\\
SCIENTIFIC NAME \\
\end{tabular}} & \multirow{3}{*}{$\begin{array}{l}\text { SPEC- } \\
\text { CODE }\end{array}$} & \multirow{3}{*}{ NATIVE } & \multicolumn{6}{|c|}{ XERIC SITES } & \multicolumn{6}{|c|}{ MESIC STIES } & \multicolumn{6}{|c|}{ RIPARIAN SITES } & \multicolumn{5}{|c|}{ RECLAIMED STTES } \\
\hline & & & \multicolumn{2}{|c|}{ TR01 } & \multicolumn{2}{|c|}{ TRO6 } & \multicolumn{2}{|c|}{ TR12 } & \multicolumn{2}{|c|}{ TR02 } & \multicolumn{2}{|c|}{ TR04 } & \multicolumn{2}{|c|}{ TR11 } & \multicolumn{2}{|c|}{ TR03 } & \multicolumn{2}{|c|}{ TR05 } & \multicolumn{2}{|c|}{ TR10 } & TR07 & & R०8 & TR & 109 \\
\hline & & & $\mathbf{s}$ & $\mathbf{F}$ & $\mathbf{s}$ & $\mathbf{F}$ & $\mathbf{s}$ & $\mathbf{F}$ & 5 & $F$ & 5 & $\mathbf{F}$ & $\mathbf{s}$ & $F$ & $\mathbf{s}$ & $F$ & $\mathbf{s}$ & $F$ & $\mathbf{s}$ & $F$ & \begin{tabular}{|l|l}
$\mathbf{S}$ & $\mathbf{F}$ \\
\end{tabular} & $=5$ & $\mid F$ & $\mathbf{s}$ & $\mathbf{F}$ \\
\hline Erodium cicularium (L.) L'Her. & ERCI1 & $N$ & & & & & & & $s$ & $f$ & $\mathrm{~s}$ & & & & $s$ & & & & & & & & & & \\
\hline Geranium caespilosum James & GECA1 & $\bar{Y}$ & & & & & & & & & & & & & $s$ & $f$ & & & $\mathbf{s}$ & $f$ & & & & & \\
\hline GROSSULARIACEAE & & & & & & & & & & & & & & & & & & & & & & & & & \\
\hline Pibes odoratum Wendl. & AIOD1 & $\bar{Y}$ & & & & & & & & & & & & & s & & & & s & $f$ & & & & & \\
\hline HYDAOPHYLLACEAE & & & & & & & & & & & & & & & & & & & & & & & & & \\
\hline Phacelia helerophylla Pursh. & PHHE1 & $\bar{Y}$ & s & $i$ & s & $f$ & s & 1 & & $f$ & & & s & $i$ & & & & & & & & & & & \\
\hline IRIDACEAE & & & & & & & & & & & & & & & - & & & & & & & & & & \\
\hline Sisyrinchium montanum Greene & SIMO1 & $\bar{Y}$ & & & & & & & & & & & & & 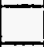 & & & & & $f$ & & & & & \\
\hline JUNCACEAE & & & & & & & & & . & & & & & & - & & & & & & & & & & \\
\hline Juncus ballicus Willd. & JUBA1 & $\bar{Y}$ & & & & & & & & & & & & & $s$ & $f$ & $s$ & 1 & $s$ & $f$ & & & & & \\
\hline Juncus dudleyi Wieg. & JUDU1 & $Y$ & & & & & & & & & & & & & s & & & & $s$ & & & & & & \\
\hline Juncus torreyi Cov. & JUTO1 & $Y$ & & & & & & & & & & & & & - & $i$ & s & 1 & & & & & & & \\
\hline LAMIACEAE & & & & & & & & & & & & & & & - & & & & & & & & & & \\
\hline Lycopus americanum Muhl. ex Barton & LYAM1 & $\bar{Y}$ & & & & & & & & & & & & & 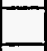 & & & 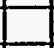 & & 1 & & & & & \\
\hline Mentha arvensis $\mathrm{L}$. & MEAR1 & $Y$ & & & & & & & & & & & & & s & 1 & s & $f$ & $\mathrm{~s}$ & 1 & & & & & \\
\hline Monarda fistulosa $\mathrm{L}$. & MOFI1 & 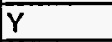 & & & & & & & & & & & & & $s$ & $f$ & & & $\mathrm{~s}$ & 1 & & & & & \\
\hline Nepeta calaria L. & NECA1 & $\mathrm{N}$ & $E$ & & & & & & 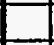 & & & & & & $s$ & 1 & & & s & 1 & & & & & \\
\hline Prunella vulgaris $L$. & PAVU1 & $Y$ & & & & & & & 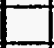 & & & & & & $s$ & & & & 5 & 1 & & & & & \\
\hline Scutellaria briltonil Porter & SCER1 & $Y$ & & & & & & & & & & & s & & 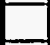 & & & & 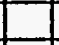 & $t$ & & & & & \\
\hline Stachys palustris $\mathrm{L}$. & STPA2 & $\bar{Y}$ & & & & & & & & & & & & & s & 1 & & & $\mathrm{~s}$ & 1 & & & & & \\
\hline LEMNACEAE & & & & & & & & & & & & & & & $=$ & & & & & & & & & & \\
\hline Lemna minor $\mathrm{L}$. & LEMI1 & $Y$ & & & & & & & & & & & & & $s$ & $f$ & & & & & & & & & \\
\hline LILIACEAE & & & & & & & & & & & & & & & 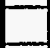 & & & & & & & & & & \\
\hline Allium lextile A. Nels. \& Macbr. & ALTE1 & $\bar{Y}$ & s & 1 & $\mathrm{~s}$ & $f$ & $\mathrm{~s}$ & $f$ & $s$ & 1 & $s$ & $f$ & $s$ & 1 & & & & & 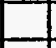 & & & & & & \\
\hline Asparagus oflicinalls $L$. & ASOF1 & $\mathrm{N}$ & & & & & & & 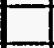 & & & & & & 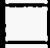 & & . & & $\mathrm{s}$ & 1 & & & & & \\
\hline Leucocrinum montanum Nutt. & LEMO2 & $Y$ & & & $\mathrm{~s}$ & & $s$ & & $\mathrm{~s}$ & & & & $s$ & & & & & & & & & & & & \\
\hline LINACEAE & & & & & & & & & & & & & & & L & & & & & & & & & & \\
\hline Linum perenne L. var. lewisli (Pursh.) Eal. \& Wright & LIPE1 & 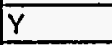 & & & $s$ & 1 & & & $\mathbf{s}$ & 1 & s & 1 & & & $s$ & $f$ & & & $\mathbf{s}$ & & & & & & \\
\hline MALVACEAE & & & & & & & & & + & & & & & & 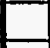 & & & & & & & & & & \\
\hline Sphaeralcea coccinea (Pursh.) Rydb. & SPCO1 & $Y$ & & & $\mathrm{~s}$ & 1 & & $f$ & $\mathrm{~s}$ & 1 & s & $f$ & s & $f$ & & & & & & & & & & & \\
\hline NYCTAGINACEAE & & & & & & & & & & & & & & & & & & & & & & & & & \\
\hline Mirabilis linearis (Pursh.) Heimerl & MILII & $\mathrm{Y}$ & & $f$ & & 1 & & $f$ & & 1 & s & $f$ & & 1 & & & & & & & & & & & \\
\hline ONAGRACEAE & & & & & & & & & & & & & & & & & & & & & & & & & \\
\hline Calylophus serrulalus (Nutt.) Raven & CASE2 & $\mathrm{Y}$ & $\mathbf{s}$ & $f$ & & & s & $f$ & & & & & & & & & & & & & & & & & \\
\hline Epilobium cilialum Ral. & EPCl1 & $Y$ & & & & & & & & & & & & & $\mathrm{~s}$ & & & & $\mathrm{~s}$ & $i$ & & & & & \\
\hline Epilobium paniculalum Null. & EPPA1 & $Y$ & & & & & & & & & & & & & & & s & & $s$ & $i$ & & & & & \\
\hline
\end{tabular}


Table B-2. 1994 Species Richness Across EcMP Sites.

\begin{tabular}{|c|c|c|c|c|c|c|c|c|c|c|c|c|c|c|c|c|c|c|c|c|c|c|c|}
\hline \multirow[b]{3}{*}{ SCIENTIFIC NAME } & \multirow{3}{*}{\begin{tabular}{|l} 
SPEC- \\
CODE \\
\end{tabular}} & & \multicolumn{5}{|c|}{ XERIC SITES } & \multicolumn{5}{|c|}{ MESIC SITES } & \multicolumn{6}{|c|}{ RIPARIAN SITES } & \multicolumn{5}{|c|}{ RECLAIMED SITES } \\
\hline & & & \multicolumn{2}{|c|}{ TR01 } & \multicolumn{2}{|c|}{ TRO6 } & TR12 & \multicolumn{2}{|c|}{ TR02 } & \multicolumn{2}{|c|}{ TRO4 } & TR11 & \multicolumn{2}{|c|}{ TRO3 } & \multicolumn{2}{|c|}{ TR05 } & \multicolumn{2}{|c|}{ TR10 } & \multicolumn{2}{|c|}{ TR07 } & TROB & \multicolumn{2}{|c|}{ TR09 } \\
\hline & & NATIVE & s & $\mathbf{F}$ & $s$ & $\mathbf{F}$ & \begin{tabular}{|l|l|}
$S$ & $F$ \\
\end{tabular} & $s$ & $F$ & s & $\mathbf{F}$ & \begin{tabular}{|l|l|}
$\mathbf{S}$ & $\mathbf{F}$ \\
\end{tabular} & s & $\mathbf{F}$ & $\mathbf{s}$ & $\mathbf{F}$ & $\mathbf{s}$ & $F$ & & & $F$ & $\mathbf{s}$ & $\mathbf{F}$ \\
\hline Gaura coccinea Pursh. & GACO1 & $Y$ & & i & $\mathrm{s}$ & 1 & & $s$ & fi & $\mathrm{s}$ & 1 & \begin{tabular}{l|l} 
& 1 \\
\end{tabular} & & & & & & & & & & & \\
\hline Gaura parvillora Dougl. & GAPA1 & $\bar{Y}$ & & & & & & & & & & & & & & $f$ & & f & & & & & \\
\hline Oenolhera biennis $L$. & OEBI1 & $\bar{Y}$ & & & & & & & & & & & $s$ & $i$ & $s$ & $t$ & $\mathrm{~s}$ & $f$ & & & & & \\
\hline Oenothera brachycarpa Gray & OEBR1 & $Y$ & & & s & 1 & & & & & $f$ & & & & & & & & & & & & \\
\hline Oenothera coronopilolia T. \& G. & OECO1 & $Y$ & & & & & s & & & & & & & & & & & & & & & & \\
\hline Oenothera sp. & OEN1 & & & & & & $f$ & & & & & & & & & & & & & & & & \\
\hline OROBANCHACEAE & & & & & & & & & & & & & & & & & & & & & & & \\
\hline Orobanche fasciculala Nult. & ORFA1 & $Y$ & s & 1 & 1 & $i$ & s If & & & & & $\begin{array}{ll}5 & f \\
\end{array}$ & & & & & & & 1 & & & & \\
\hline OXALIDACEAE & & & & & & & & & & & & & & & & & & & & & & & \\
\hline Oxalis dillenii Jacq. & OXDI1 & $\mathrm{N}$ & & & & & & & & & & & s & $f$ & & & & & & & & & \\
\hline PLANTAGINACE & & & & & & & & & & & & & & & & & & & & & & & \\
\hline Planlago lanceolata $\mathrm{L}$. & PLLA1 & $N$ & & & & & & & & & $i$ & & $s$ & & & & & i & & & & & \\
\hline \begin{tabular}{|l|} 
Plantago major $\mathrm{L}$. \\
\end{tabular} & PLMA1 & $\mathrm{N}$ & & & & & & & & & & & & & & & & & & & & s & \\
\hline Plantago patagonica Jacq. & PLPA1 & $\bar{Y}$ & & & 1 & $i$ & & & & & & & & & & & & & - & & & & \\
\hline POACEAE & & & & & & & & & & & & & & & & & & & & & & & \\
\hline Agropyron caninum (L.) Beauv. & AGCA1 & $\mathrm{Y}$ & & & & & & & & & & & & & & & s & & & & & & \\
\hline Agropyron cristatum (L.) Gaertn. & AGCA1 & $\mathrm{N}$ & & & & & & & & & & & & & & & & & $\begin{array}{ll}s \\
\end{array}$ & 5 & $f$ & 5 & i \\
\hline Agropyron intermedium (Host) Beauv. & AGIN1 & $N$ & & & & & & & & $\mathbf{s}$ & & & - & & & & & & \begin{tabular}{|l|l}
$s$ & 1 \\
\end{tabular} & s & 1 & s & 1 \\
\hline Agropyron repens (L.) Beauv. & AGREI & $\mathrm{N}$ & & & & & & 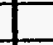 & & & & & $\mathrm{s}$ & $f$ & $s$ & $f$ & & 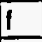 & & & & & \\
\hline Agropyron smithii Fydb. & AGSM1 & $y$ & & & 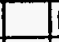 & 1 & $f$ & s & $i$ & s & $f$ & \begin{tabular}{l|l}
$\mathrm{s}$ \\
\end{tabular} & $\mathrm{s}$ & if & $\mathrm{s}$ & $f$ & $\mathbf{s}$ & 1 & & & & & \\
\hline Agrostis stolonifera L. & AGST1 & $N$ & & & & & & & & & & & $\mathrm{~s}$ & $f$ & & $i$ & s & $f$ & & & & & \\
\hline Andropogon gerardii Vitman & ANGE1 & $Y$ & $\mathrm{~s}$ & $f$ & $\mathbf{s}$ & 1 & s If & $s$ & 1 & & & \begin{tabular}{l|l}
$s$ & 1 \\
\end{tabular} & & & & & & & & & & & \\
\hline Andropogon scoparius Michx. & ANSC1 & $Y$ & $s$ & $f$ & & $i$ & $s \mid f$ & $\mathrm{~s}$ & $i$ & & & \begin{tabular}{l|l}
$s$ & 1 \\
\end{tabular} & & & & & & & & & & & \\
\hline Aristida purpurea Nult. var. longiseta (Steud.) Vasey & ARFE1 & $Y$ & & $f$ & & 1 & \begin{tabular}{l|l} 
& $f$ \\
\end{tabular} & s & 1 & 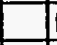 & 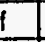 & 1 & & & & & & & & 5 & 1 & & \\
\hline Aristida sp. & ARI1 & & & & s & $i$ & & & & s & & & & & & & & & s & & & & \\
\hline Aristida purpurea Nult. var. robusta (Merrill) Holmgren \& Holmgren & ARLO1 & $Y$ & & $f$ & & $\mathrm{f}$ & \begin{tabular}{|l|l}
$s$ & $t$ \\
\end{tabular} & $\mathrm{~s}$ & 1 & & i & \begin{tabular}{l|l}
$\mathrm{i}$ \\
$\mathrm{y}$
\end{tabular} & & & & & & & 1 & $s$ & 1 & & \\
\hline \begin{tabular}{|l} 
Bouteloua curtipendula (Michx.) Torr. \\
\end{tabular} & BOCU1 & $Y$ & & $i$ & s & 1 & f & & i & & i & s & & & & & & & & & & & \\
\hline Bouteloua gracills (H. B. K.) Lag ex Grilfiths & BOGR1 & $Y$ & & $i$ & s & f & \begin{tabular}{l|l}
$\mathbf{s}$ & 1 \\
\end{tabular} & $\mathrm{~s}$ & $f$ & s & i & s if & & 1 & & & s & $f$ & & & & & \\
\hline \begin{tabular}{|l|} 
Bouteloua hirsuta Lag \\
\end{tabular} & BOHI1 & $Y$ & $s$ & 1 & $\mathrm{~s}$ & $f$ & 1 & & $f$ & & $i$ & f & & & & & & & & & & & \\
\hline \begin{tabular}{|l} 
Bouteloua sp. \\
\end{tabular} & BOU1 & & & & & & & & & $s$ & & & & & & & & & & & & & \\
\hline Bromus inermis Leyss. & BAIN1 & $N$ & & & & & & s & $f$ & & & & & & $\mathrm{~s}$ & $f$ & $s$ & 1 & \begin{tabular}{|l|l}
$s$ & $i$ \\
\end{tabular} & s & 1 & s & 1 \\
\hline Bromus japonicus Thunb. ex Murr. & BRJA1 & $\bar{N}$ & $\mathrm{~s}$ & $f$ & $s$ & 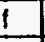 & \begin{tabular}{l|l}
$s$ & $f$ \\
\end{tabular} & $s$ & $f$ & s & 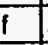 & \begin{tabular}{l|l}
$s$ & 1 \\
\end{tabular} & s & 1 & s & $f$ & $\mathrm{~s}$ & $f$ & \begin{tabular}{l|l}
$s$ & 1 \\
\end{tabular} & s & $f$ & s & i \\
\hline Bromus tectorum L. & BRTE1 & $N$ & & $\mathrm{f}$ & & $i$ & $f$ & & & & $f$ & fi & & + & & & & & & & & & \\
\hline Buchloe dactyloides (Nult.) Engelm. & BUDA1 & $Y$ & & $t$ & & I & fi & & 1 & & $f$ & \begin{tabular}{l|l} 
& 1 \\
\end{tabular} & & & & & & & & & & & \\
\hline Daclylis glomerata $\mathrm{L}$. & DAGL1 & $N$ & & & & & & & & & & & $\mathrm{~s}$ & $f$ & $s$ & & & & & & & & \\
\hline Elymus canadensis $\mathrm{L}$. & ELCA1 & Y & & & & & & & & & & & & $f$ & s & 1 & s & $f$ & & & & & \\
\hline
\end{tabular}

$\stackrel{\infty}{N}$

menciature primarily follows Flora of the Great Plains (1991). $s=$ Spring sampling, $f=$ Fall sarr 
Table B-2. 1994 Species Richness Across EcMP Sites.

\begin{tabular}{|c|c|c|c|c|c|c|c|c|c|c|c|c|c|c|c|c|c|c|c|c|c|c|c|c|c|}
\hline & \multirow{3}{*}{$\frac{\text { SPEC }}{\mid \text { CODE }}$} & \multirow[b]{3}{*}{ NATIVE } & & \multicolumn{6}{|c|}{ MESIC SITES } & \multicolumn{5}{|c|}{ RIPARIAN SITES } & \multicolumn{6}{|c|}{ AECLAIMED STIES } \\
\hline & & & \multicolumn{6}{|c|}{\begin{tabular}{c|c|c}
\multicolumn{3}{c}{ XERIC SITES } \\
TRO1
\end{tabular}} & \multicolumn{2}{|c|}{ TR02 } & \multicolumn{2}{|c|}{ TR04 } & \multicolumn{2}{|c|}{ TR11 } & TA03 & \multicolumn{2}{|c|}{ TR05 } & \multicolumn{2}{|c|}{ TR10 } & \multicolumn{2}{|c|}{ TR07 } & \multicolumn{2}{|c|}{ TA08 } & \multicolumn{2}{|c|}{ TRO9 } \\
\hline SCIENTIFIC NAME & & & $\mathbf{s}$ & $F$ & $\mathbf{s}$ & $F$ & s & $\mathbf{F}$ & 5 & $\mathbf{F}$ & \begin{tabular}{l|l}
$\mathbf{S}$ & $\mathbf{F}$ \\
\end{tabular} & $\overline{5}$ & $S \mid F$ & 5 & \begin{tabular}{l|l}
$S$ & $F$ \\
\end{tabular} & s & IF & $s$ & $F$ & \begin{tabular}{|l|l}
$S$ & $F$ \\
\end{tabular} & \begin{tabular}{|l|l}
$\mathbf{F}$ & \\
\end{tabular} & \begin{tabular}{|l|l}
$S$ & $F$ \\
\end{tabular} & Fis & 5 & \\
\hline Fesluca pratensis Huds. & FEPR1 & $Y$ & & & & & & & 5 & & - & & & & 1 & s & $f$ & & & & & & & & \\
\hline Hordeum jubalum L. & HOJU1 & $\mathrm{Y}$ & & & & & & & & & & $\mathbf{s}$ & 5 & & & & It & & & & & & & & \\
\hline Koeleria pyramidata (Lam.) Beauv. & KOPY1 & $Y$ & $s$ & 1 & s & $f$ & $\mathrm{~s}$ & $f$ & s & i & \begin{tabular}{l|l}
$s$ & $f$ \\
\end{tabular} & 15 & \begin{tabular}{l|l}
5 & $f$ \\
\end{tabular} & & & & & & 1 & & & & & & \\
\hline Muhlenbergia montana (Null.) Hitchc. & MUMO1 & $Y$ & s & $i$ & & & s & $f$ & & & s & & & & & & & & & & & & & & \\
\hline Muhlenbergia racemosa (Michx.) B. S. P. & MURA1 & $Y$ & & & & & & & & & & & & & & & $i$ & & & & & & & & \\
\hline Muhlenbergia wrighlii Vasey & MUWRI & $Y$ & & & & & & & & $f$ & & & $f$ & & & & & & & & & & & & \\
\hline Panicum virgalum $L$. & PAVI1 & $Y$ & & & & & & & & & & & & & & & & s & $f$ & & & & & & \\
\hline Phleum pratense $\mathrm{L}$. & PHPA1 & $\mathrm{N}$ & & & & & & & & & & & & & $f$ & $\mathbf{s}$ & 1 & & & & & & & & \\
\hline Poa canbyi (Scribn.) Piper & POCAI & $Y$ & & & $\mathbf{s}$ & & & & & & & & & & & & & & & & & & & & \\
\hline Poa compressa $\mathrm{L}$. & POCO1 & $\mathrm{N}$ & s & 1 & s & $f$ & 5 & $f$ & $s$ & if & si & s & $5 \sqrt{1}$ & $\underline{s}$ & 5 & $s$ & 1 & s & $f$ & & 1 & & & & \\
\hline Poa pratensis $\mathrm{L}$. & POPR1 & $N$ & $s$ & 1 & s & $f$ & & $f$ & s & $f$ & s 11 & 15 & 5 & & $5 / f$ & $\mathbf{s}$ & 1 & $\mathrm{~s}$ & $f$ & \begin{tabular}{|l|l}
$\mathbf{s}$ & 1 \\
\end{tabular} & 1 & s If & 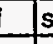 & $s$ f & \\
\hline Sitanion hystrix (Nutt.) $\mathrm{Sm}$. & SIHY1 & $Y$ & & 1 & & $f$ & & 1 & s & $t$ & & & & & & & & & $f$ & & & & & & \\
\hline Sorghastrum nutans (L.) Nash & SONU1 & $Y$ & & $i$ & & & $s$ & $t$ & & & & & & & & & & & & & & & & & \\
\hline Sporobolus cryptandrus (Torr.) A. Gray & SPCR1 & $Y$ & & & & & & & s & & & & & & & & 1 & & & & & & & & \\
\hline Sporobolus helerolepis (A. Gray) A. Gray & SPHE1 & $y$ & 1 & $t$ & & & & 1 & & & & & i & & & & & & & & & & & & \\
\hline Sphenopholis obtusata (Michx.) Scribn. & SPOB1 & $Y$ & & & & & & & & & & & & s & $s \sqrt{s}$ & & & & & & & & & & \\
\hline Sparlina pectinata Link & SPPE1 & $Y$ & & & & S & & & & & & & & $\mathrm{s}$ & 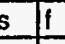 & & & & & & & & & & \\
\hline Stlpa comala Trin. \& Rupr. & STCO1 & $Y$ & $s$ & $f$ & s & $f$ & s. & 1 & & $f$ & $f$ & 15 & \begin{tabular}{l|l} 
\\
\end{tabular} & & & & & & & & & & & & \\
\hline Stipa sp. & STII & & & & s & & & & & & & s & s. & & & & & & & & & & & & \\
\hline Stipa neomexicana (Thur. ex Vasey.) Scribn. & STNE1 & $Y$ & & & & $f$ & & & & & & & & & & & & & & & & & & & \\
\hline Slipa robusla (Vasey) Scribn. & STRO1 & $Y$ & & & & & & & & & & & & & & & & & 1 & & & & & & \\
\hline Stipa viridula Trin. & STVII & $Y$ & & $f$ & & & & & $\mathrm{~s}$ & 1 & f & 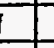 & 1 & & $f$ & & & & & & & & & & \\
\hline Trilicum aestivum $\mathrm{L}$. & TRAE1 & $\bar{N}$ & & $f$ & & & & & & & $f$ & & & & & & & & & & & & & & \\
\hline \multicolumn{26}{|l|}{ POLEMONIACEAE } \\
\hline Collomia linearis Nutt. & COLII & $\bar{Y}$ & - & & & & & & $s$ & & & s & \begin{tabular}{l|l}
$\mathbf{s}$ & 1 \\
\end{tabular} & & & & & & & & & & & & \\
\hline Ipomopsis spicata (Nutt.) V. Grant & IPSP1 & $Y$ & $s$ & $f$ & & & & & & & & & & & & & & & & & & & & & \\
\hline Microsteris gracilis (Hook.) Greene & MIGR1 & $Y$ & & & & & & & & & s & & & & & & & & & & & & & & \\
\hline POLYGONACEAE & & & & & & & & & & & & & & & & & & & & & & & & & \\
\hline Eriogonum alalum Torr. & ERAL1 & $Y$ & s & $f$ & s & 1 & $\mathrm{~s}$ & $f$ & 5 & $f$ & & & & & & & & & & & & & & & \\
\hline Polygonum lapathifolium L. & POLA1 & $\mathrm{N}$ & & & & & & & & & & & & & \begin{tabular}{l|l} 
& 1 \\
\end{tabular} & $\mathrm{~s}$ & & & & & & & & & \\
\hline Polygonum sawalchense Small & POSA1 & $Y$ & & & & & & & & & $f$ & 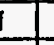 & & & & & & & & & & & & & \\
\hline Rumex crispus L. & RUCAI & $\mathrm{N}$ & & & & & & & & & & & & & \begin{tabular}{l|l}
$s$ & 1 \\
\end{tabular} & $s$ & $f$ & s & $f$ & & & & & & \\
\hline Rumex mexicanus Meisn. & FUME1 & $Y$ & & & & & & & & & & & & & \begin{tabular}{l|l}
$s$ & \\
\end{tabular} & s & $f$ & $s$ & $f$ & & & & & & \\
\hline Rumex oblusifolius L. & RUOB1 & $\mathrm{N}$ & & & & & & & & & & & & & \begin{tabular}{l|l} 
\\
\end{tabular} & & & & 1 & & & & & & \\
\hline POATULACACEAE & & & & & & & & & & & & & & & & & & & & & & & & & \\
\hline Talinum parvillorum Nutt. & TAPA1 & $Y$ & & $f$ & & & & & & & & & & & & & & & & & & & & & \\
\hline
\end{tabular}




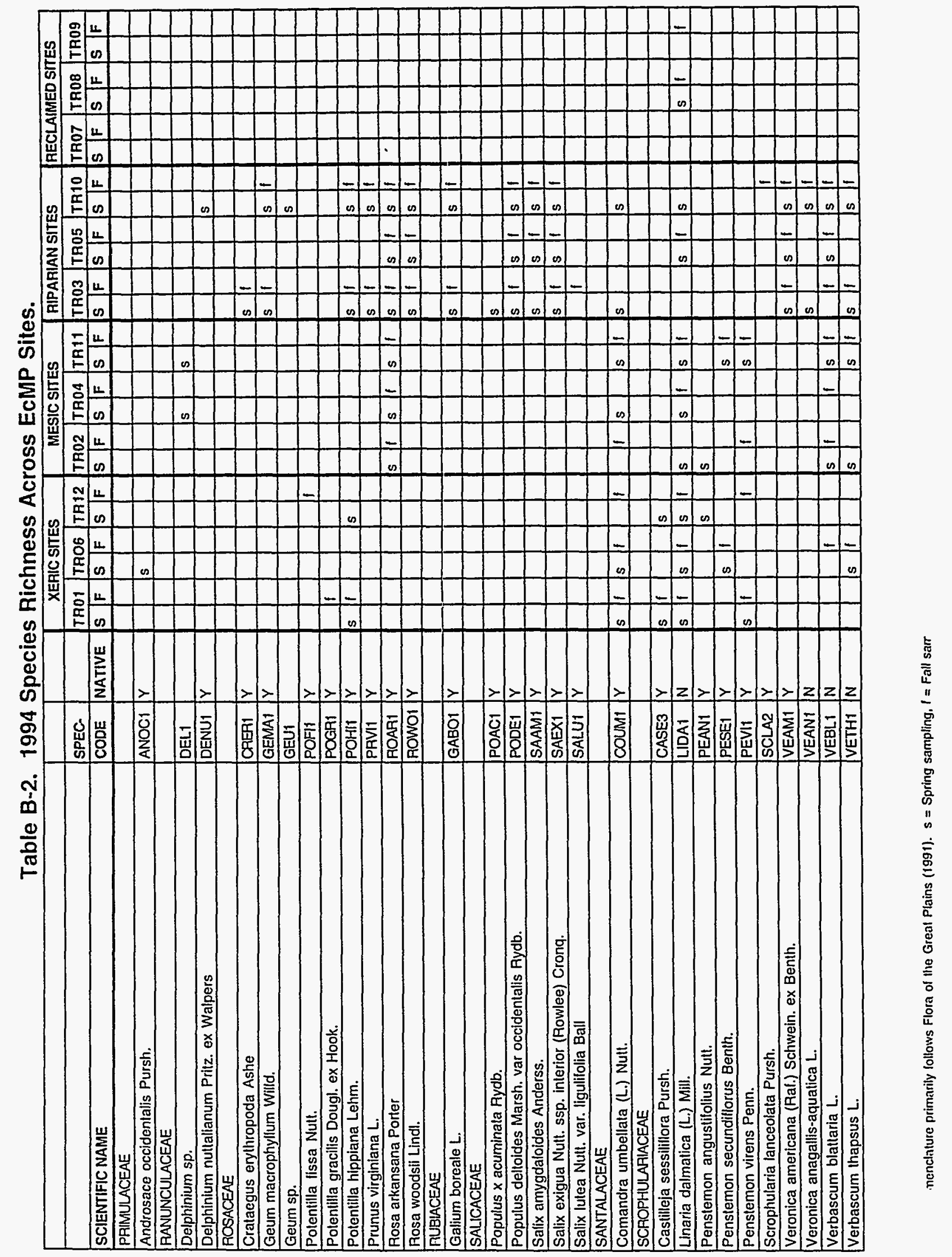


Table B-2. 1994 Species Richness Across EcMP Sites.

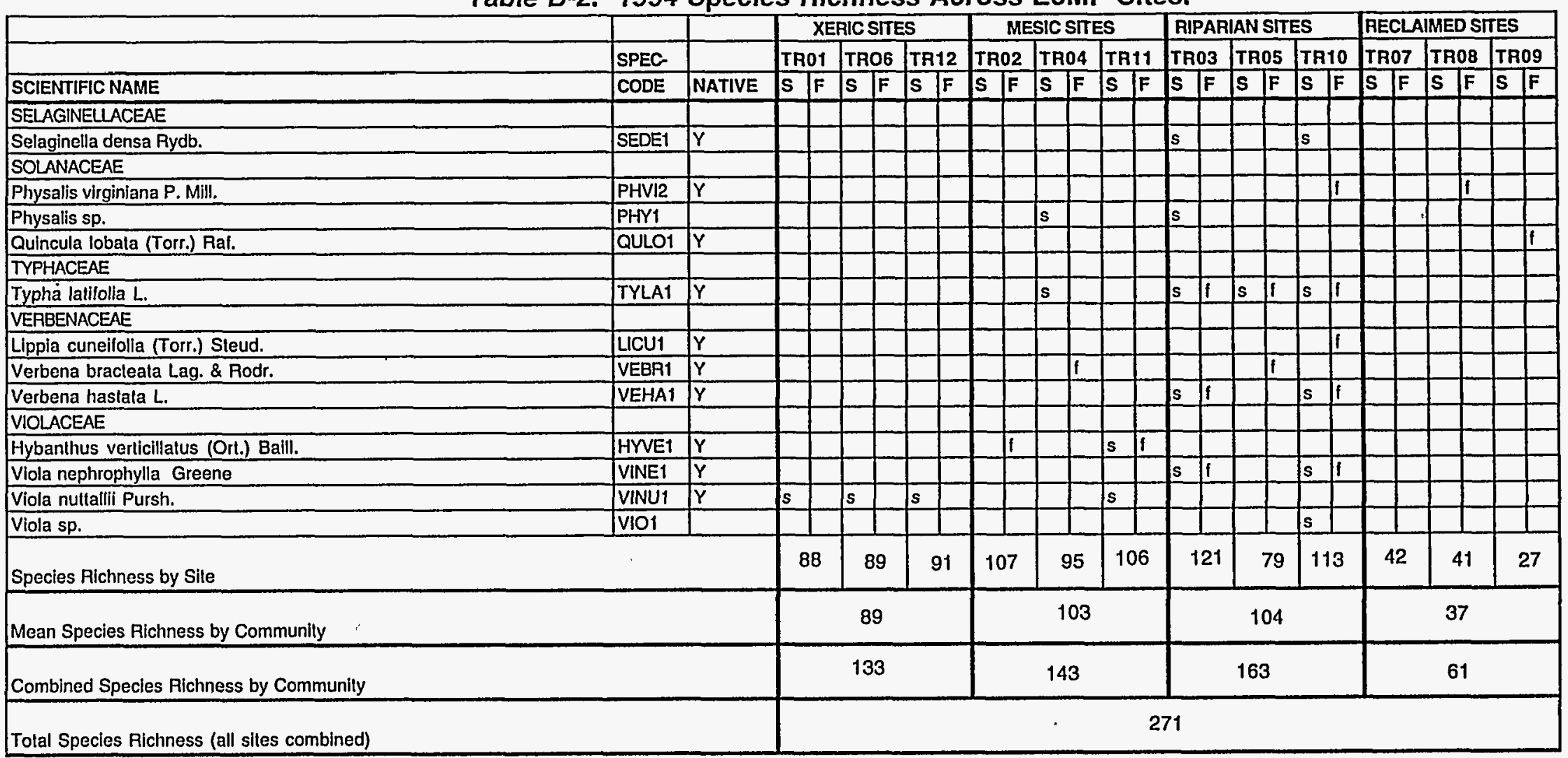

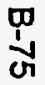


Table B-3. 1994 Woody Stem and Cactus Density Mean Values by

EcMP Site and Community.

\begin{tabular}{|c|c|c|}
\hline Site & Cactus Density (Stems $/ \mathrm{m}^{\wedge} 2$ ) & Woody Stem Density (Stems/m^2) \\
\hline Xeric Community : & $0,05,0,0,0$ & 0,004 \\
\hline TR01 & 0.79 & ${ }^{\star} 0.002$ \\
\hline TR06 & 0.21 & 0.11 \\
\hline TR12 & 0.95 & 0.00 \\
\hline Mesic Cóminứnity & $\hat{3} \cdots 0000$ & 0083 \\
\hline TR02 & 0.25 & 1.32 \\
\hline TR04 & 0.24 & 0.67 \\
\hline TR11 & 0.47 & 0.60 \\
\hline Riparian Community $\cdots$ & $\because \cdots 0_{0} 000300$ & a 6442 \\
\hline TR03 & 0.04 & 5.31 \\
\hline TR05 & 0.00 & 4.86 \\
\hline TR10 & 0.03 & 9.13 \\
\hline Reclàímed Commún nity & 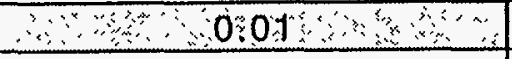 & 00002 \\
\hline TR07 & ${ }^{\star} 0.008$ & ${ }^{*} 0.002$ \\
\hline TR08 & 0.00 & ${ }^{*} 0.004$ \\
\hline TR09 & 0.01 & 0.00 \\
\hline
\end{tabular}

* = mean value was beyond 2 significant digits

Community means based on $n=15$

Site means based on $n=5$ 
Table B-4. 1994 Species Restricted by Community.

\begin{tabular}{|c|c|c|c|c|}
\hline Community & Family & Scientific Name & Speccode & Native \\
\hline XERKC & ASTERACEAE & Antennaria microphylla Rydb. & ANMI1 & $\mathrm{Y}$ \\
\hline XERTC & ASTERACEAE & Gaillardia aristata Pursh. & GAAR1 & $Y$ \\
\hline XEPRK & ASTERACEAE & Helianthus petiolaris Nutt. & HEPE1 & $Y$ \\
\hline XERIC & ASTERACEAE & Solidago nemoralis Ait. & SONE1 & Y \\
\hline XERIC & ASTERACEAE & Townsendia grandiflora (Nutt.) & TQGR1 & Y \\
\hline XERIC & ASTERACEAE & Townsendia hookeri Beaman & TOHOI & $Y$ \\
\hline XERIC & BRASSICACEAE & Descurainia sophia (L.) Webb & DESO1 & $N$ \\
\hline XERIC & CARYOPHYLLACEAE & Arenaria fendleri A. Gray & ARFE2 & Y \\
\hline XERIC & CYPERACEAE & Carex filifolia Nutt. & CAFII & Y \\
\hline XERIC & FABACEAE & Astragalus missouriensis Nutt. & ASMI1 & $Y$ \\
\hline XEAIC & ONAGRACEAE & Calylophus serrulatus (Nutt.) Raven & CASE2 & Y \\
\hline XERIC & ONAGRACEAE & Oenothera coronopifolia T. \& G. & OECO1 & Y \\
\hline XERIC & PLANTAGINACE & Plantago patagonica Jacq. & PLPA1 & $Y$ \\
\hline XERIC & POACEAE & Poa canbyi (Scribn.) Piper & POCA1 & $\mathrm{Y}$ \\
\hline XEAIC & POACEAE & Sorghastrum nutans (L.) Nash & SONU1 & $\mathrm{Y}$ \\
\hline XERIC & POACEAE & Stipa neomexicana (Thur. ex Vasey.) Scribn. & STNE1 & Y \\
\hline XERIC & POLEMONIACEAE & Ipomopsis spicata (Nutt.) V. Grant & IPSP1 & Y \\
\hline XERIC & PORTULACACEAE & Talinum parviflorum Nutt. & TAPA1 & Y \\
\hline XERKC & PRIMULACEAE & Androsace occidentalis Pursh. & ANOC1 & $\mathrm{Y}$ \\
\hline XERIC & ROSACEAE & Potentilla fissa Nutt. & POFI1 & Y \\
\hline XERIC & ROSACEAE & Potentilla gracilis Dougl. ex Hook. & POGR1 & Y \\
\hline XERIC & SCROPHULARIACEAE & Castilleja sessiliflora Pursh. & CASE3 & Y \\
\hline MESIC & APIACEAE & Musineon divaricatum (Pursh.) Nutt. ex T. \& G. & MUDI1 & Y \\
\hline MESIC & ASTERACEAE & Crepis occidentalis Nutt. & CROC1 & Y \\
\hline MESK & ASTERACEAE & Helianthus annuus $L$. & HEAN1 & $\mathrm{Y}$ \\
\hline MESKC & ASTERACEAE & Picradeniopsis oppositifolia (Nutt.) Rydb. & PIOP1 & $Y$ \\
\hline MESK & ASTERACEAE & Solidago rigida $\mathrm{L}$. & SORI1 & $Y$ \\
\hline MESK & BAASSICACEAE & Arabis fendleri (Wats.) Greene & ARFE3 & Y \\
\hline MESIC & BRASSICACEAE & Erysimum repandum $\mathrm{L}$. & ERRE1 & $N$ \\
\hline MESK & BRASSICACEAE & Lepidium densiflorum Schrad. & LEDE1 & Y \\
\hline MESK & CAMPANULACEAE & Triodanus & TRI2 & \\
\hline
\end{tabular}


Table B-4. 1994 Species Restricted by Community.

\begin{tabular}{|c|c|c|c|c|}
\hline Community & Family & Scientific Name & Speccode & Native \\
\hline MESIC & COMMELINACEAE & Tradescantia occidentalis (Britt.) Smyth & TROC1 & $\bar{Y}$ \\
\hline MESK & CONVOLVULACEAE & Evolvulus nuttallianus R. \& S. & EVNU1 & Y \\
\hline MESIC & CYPERACEAE & Carex interior Bailey & CAIN1 & Y \\
\hline MESIC & EUPHORBIACEAE & Euphorbia dentata Michx. & EUDE1 & Y \\
\hline MESIC & EUPHORBIACEAE & Euphorbia spathulata Lam. & EUSP1 & $\mathrm{Y}$ \\
\hline MESIC & FABACEAE & Astragalus drummondii Dougl. ex Hook. & ASDR1 & Y \\
\hline MESIC & FABACEAE & Trifolium & TRI1 & \\
\hline MESIC & LAMIACEAE & Scutellaria brittonii Porter & SCBR1 & Y \\
\hline MESK & POACEAE & Muhlenbergia wrightii Vasey & MUWR1 & $\mathrm{Y}$ \\
\hline MESKC & POLEMONIACEAE & Collomia linearis Nutt. & COLII & $Y$ \\
\hline MESIC & POLEMONIACEAE & Microsteris gracilis (Hook.) Greene & MIGR1 & $Y$ \\
\hline MESKC & POLYGONACEAE & Polygonum sawatchense Small & POSA1 & Y \\
\hline MESKC & VIOLACEAE & Hybanthus verticillatus (Ort.) Baill. & HYVE1 & $Y$ \\
\hline RECLAIMED & ASTERACEAE & Kuhnia chlorolepis Woot. \& Standl. & $\mathrm{KUCH}$ & $\bar{Y}$ \\
\hline RECLAIMED & ASTERACEAE & Senecio tridenticulatus Rydb. & SEIR1 & Y \\
\hline RECLAIMED & FABACEAE & Astragalus parryi Gray & ASPA1 & $Y$ \\
\hline RECLAIMED & FABACEAE & Medicago sativa $\mathrm{L}$. & MESA1 & $N$ \\
\hline RECLAIMED & PLANTAGINACE & Plantago lanceolata $\mathrm{L}$. & PLLA1 & $N$ \\
\hline RECLAIMED & POACEAE & Agropyron cristatum (L.) Gaertn. & AGCR1 & $N$ \\
\hline RECLAIMED & SOLANACEAE & Quincula lobata (Torr.) Raf. & QULO1 & $Y$ \\
\hline RIPARIAN & ANACARDIACEAE & Toxicodendron rydbergii (Small ex Rydberg) Greene & TORY1 & $\mathrm{Y}$ \\
\hline RIPARIAN & APIACEAE & Cicuta maculata $\mathrm{L}$. & CIMA1 & Y \\
\hline RIPARIAN & APIACEAE & Conium maculatum $\mathrm{L}$. & COMA1 & $N$ \\
\hline RIPARIAN & APOCYNACEAE & Apocynum cannabinum L. & APCA1 & Y \\
\hline RIPARIAN & ASCLEPIADACEAE & Asclepias incarnata L. & ASIN1 & $\mathrm{Y}$ \\
\hline RIPARIAN & ASCLEPIADACEAE & Asclepias speciosa Torr. & ASSP1 & Y \\
\hline RIPARIAN & ASTERACEAE & Aster occidentalis (Nutt.) T. \& G. & ASOC1 & $Y$ \\
\hline RIPARIAN & ASTERACEAE & Conyza canadensis (L.) Cronq. & COCA1 & $\mathrm{Y}$ \\
\hline RIPARIAN & ASTERACEAE & Lactuca oblongifolia Nutt. & LAOB1 & $Y$ \\
\hline RIPARIAN & ASTERACEAE & Scorzonera laciniata L. & SCLA1 & $N$ \\
\hline
\end{tabular}


Table B-4. 1994 Species Restricted by Community.

\begin{tabular}{|c|c|c|c|c|}
\hline Community & Family & Scientific Name & Speccode & Native \\
\hline RIPARIAN & BORAGINACEAE & Cynoglossum officinale $L$. & CYOF1 & $\mathrm{N}$ \\
\hline RIPARIAN & BRASSICACEAE & Barbarea orthoceras Ledeb. & BAOR1 & $\mathrm{N}$ \\
\hline RIPARIAN & BRASSICACEAE & Cardaria chalepensis (L.) Hand-Mazz & $\mathrm{CACH1}$ & $\mathrm{N}$ \\
\hline RIPARIAN & BRASSICACEAE & Nasturtium officinale R. Br. & NAOF1 & $\mathrm{N}$ \\
\hline RIPARIAN & CAPRIFOLIACEAE & Symphoricarpos occidentalis Hook. & SYOC1 & $\mathrm{Y}$ \\
\hline RIPARIAN & CARYOPHYLLACEAE & Cerastium arvense $L$. & CEAR1 & Y \\
\hline RIPARIAN & CYPERACEAE & Carex lanuginosa Michx. & CALA1 & Y \\
\hline RIPARIAN & CYPERACEAE & Carex nebraskensis Dew. & CANE1 & Y \\
\hline RIPARIAN & CYPERACEAE & Carex praegracilis $\mathrm{W}$. Boott. & CAPR1 & Y \\
\hline RIPARIAN & CYPERACEAE & Carex rostrata Stokes ex Willd. & CARO2 & $\mathrm{Y}$ \\
\hline RIPARIAN & CYPERACEAE & Carex simulata Mack. & CASI1 & $\mathrm{Y}$ \\
\hline RIPARIAN & CYPERACEAE & Carex stipata Muhl. & CAST1 & $\mathrm{Y}$ \\
\hline RIPARIAN & CYPERACEAE & Eleocharis macrostachya Britt. & ELMA1 & $\mathrm{Y}$ \\
\hline RIPARIAN & CYPERACEAE & Eleocharis parvula (R. \& S.) Link ex Bluff & ELPA1 & $\mathrm{Y}$ \\
\hline RIPARIAN & CYPERACEAE & Scirpus americanus Pers. & SCAM1 & $\mathrm{Y}$ \\
\hline RIPARIAN & CYPERACEAE & Scirpus pallidus (Britt.) Fern & SCPA1 & $\mathrm{Y}$ \\
\hline RIPARIAN & CYPERACEAE & Scirpus validus Vahl. & SCVA1 & $\mathrm{Y}$ \\
\hline RIPARIAN & EQUISETACEAE & Equisètum arvense $\mathrm{L}$. & EQAR1 & $\mathrm{Y}$ \\
\hline RIPARIAN & EQUISETACEAE & Equisetum hyemale $\mathrm{L}$. & EQHY1 & $\mathrm{Y}$ \\
\hline RIPARIAN & EQUISETACEAE & Equisetum laevigatum $\mathrm{A}$. $\mathrm{Br}$. & EQLA1 & Y \\
\hline RIPARIAN & EUPHORBIACEAE & Euphorbia serpyllifolia Pers. & EUSE1 & $\mathrm{Y}$ \\
\hline RIPARIAN & FABACEAE & Amorpha fruticosa $L$. & AMFR1 & $\mathrm{Y}$ \\
\hline RIPARIAN & FABACEAE & Glycyrrhiza lepidota Pursh. & GLLE1 & $\mathrm{Y}$ \\
\hline RIPARIAN & FABACEAE & Lathyrus eucosmus Butters and St. John & LAEU1 & $\mathrm{Y}$ \\
\hline RIPARIAN & FABACEAE & Lupinus argenteus Pursh. & LUAR1 & $\mathrm{Y}$ \\
\hline RIPARIAN & FABACEAE & Thermopsis rhombifolia var. divaricarpa Nels. & THRH1 & $\mathrm{Y}$ \\
\hline RIPARIAN & GERANIACEAE & Geranium caespitosum James & GECA1 & $\mathrm{Y}$ \\
\hline RIPARIAN & GROSSULARIACEAE & Ribes odoratum Wendl. & RIOD1 & $\mathrm{Y}$ \\
\hline RIPARIAN & IRIDACEAE & Sisyrinchium montanum Greene & SIMO1 & $\mathrm{Y}$ \\
\hline RIPARIAN & JUNCACEAE & Juncus balticus Willd. & JUBA1 & $\mathrm{Y}$ \\
\hline RIPARIAN & JUNCACEAE & Juncus dudleyi Wieg. & JUDU1 & $\mathrm{Y}$ \\
\hline
\end{tabular}


Table B-4. 1994 Species Restricted by Community.

\begin{tabular}{|c|c|c|c|c|}
\hline Community & Family & Scientific Name & Speccode & Native \\
\hline RIPARIAN & JUNCACEAE & Juncus torreyi Cov. & JUTO1 & $\bar{Y}$ \\
\hline RIPARIAN & LAMIACEAE & Lycopus americanum Muhl. ex Barton & LYAM1 & Y \\
\hline RIPARIAN & LAMIACEAE & Mentha arvensis $L$. & MEAR1 & Y \\
\hline RIPARIAN & LAMIACEAE & Monarda fistulosa $\mathrm{L}$. & MOFI1 & $\mathrm{Y}$ \\
\hline RIPARIAN & LAMIACEAE & Nepeta cataria L. & NECA1 & $N$ \\
\hline RIPARIAN & LAMIACEAE & Prunella vulgaris $\mathrm{L}$. & PRVU1 & Y \\
\hline RIPARIAN & LAMIACEAE & Stachys palustris $L$. & STPA2 & Y \\
\hline RIPARIAN & LEMNACEAE & Lemna minor $\mathrm{L}$. & LEMI1 & Y \\
\hline RIPARIAN & LILIACEAE & Asparagus officinalis $L$. & ASOF1 & $\mathrm{N}$ \\
\hline RIPARIAN & ONAGRACEAE & Epilobium ciliatum Raf. & EPCl1 & Y \\
\hline RIPARIAN & ONAGRACEAE & Epilobium paniculatum Nutt. & EPPA1 & Y \\
\hline RIPAPIAN & ONAGRACEAE & Gaura parviflora Dougl. & GAPA1 & Y \\
\hline RIPARIAN & ONAGRACEAE & Oenothera biennis $L$. & OEBI1 & Y \\
\hline RIPARIAN & OXALIDACEAE & Oxalis dillenii Jacq. & OXDH & N \\
\hline RIPAPIAN & POACEAE & Agropyron caninum (L.) Beauv. & AGCA1 & Y \\
\hline RIPAPIAN & POACEAE & Agropyron repens (L.) Beauv. & AGRE1 & $N$ \\
\hline RIPARIAN & POACEAE & Agrostis stolonifera L. & AGST1 & $N$ \\
\hline RIPARIAN & POACEAE & Dactylis glomerata L. & DAGL1 & N \\
\hline RIPARIAN & POACEAE & Elymus canadensis L. & ELCA1 & Y \\
\hline FIPARIAN & POACEAE & Festuca pratensis Huds. & FEPR1 & Y \\
\hline RIPARIAN & POACEAE & Muhlenbergia racemosa (Michx.) B. S. P. & MURA1 & Y \\
\hline RIPARIAN & POACEAE & Panicum virgatum $\mathrm{L}$. & PAVI1 & Y \\
\hline RIPARIAN & POACEAE & Phleum pratense L. & PHPR1 & $N$ \\
\hline RIPARIAN & POACEAE & Spartina pectinata Link & SPPE1 & Y \\
\hline RIPARIAN & POACEAE & Sphenopholis obtusata (Michx.) Scribn. & SPOB1 & Y \\
\hline RIPARIAN & POACEAE & Stipa robusta (Vasey) Scribn. & STRO1 & Y \\
\hline RIPARIAN & POLYGONACEAE & Polygonum lapathifolium L. & POLA1 & $N$ \\
\hline RIPARIAN & POLYGONACEAE & Rumex crispus L. & RUCR1 & $N$ \\
\hline RIPARIAN & POLYGONACEAE & Rumex mexicanus Meisn. & RUME1 & Y \\
\hline RIPARIAN & POLYGONACEAE & Rumex obtusifolius L. & RUOB1 & N \\
\hline RIPARIAN & RANUNCULACEAE & Delphinium nuttalianum Pritz. ex Walpers & DENU1 & Y \\
\hline
\end{tabular}


Table B-4. 1994 Species Restricted by Community.

\begin{tabular}{|c|c|c|c|c|}
\hline Community & Family & Scientific Name & Speccode & Native \\
\hline RIPARIAN & ROSACEAE & Crataegus erythropoda Ashe & CRERI & $\bar{Y}$ \\
\hline RIPARIAN & ROSACEAE & Geum macrophyllum Willd. & GEMA1 & $\mathrm{Y}$ \\
\hline RIPARIAN & ROSACEAE & Prunus virginiana $L$. & PRVI1 & $Y$ \\
\hline RIPARIAN & ROSACEAE & Rosa woodsil Lindl. & ROWO1 & Y \\
\hline RIPARIAN & RUBIACEAE & Galium boreale L. & GABO1 & $\mathrm{Y}$ \\
\hline RIPARIAN & SALICACEAE & Populus deltoides Marsh. var occidentalis Rydb. & PODE1 & $Y$ \\
\hline RIPARIAN & SALICACEAE & Populus $\mathrm{x}$ acuminata Rydb. & POAC1 & $\mathrm{Y}$ \\
\hline RIPARIAN & SALICACEAE & Salix amygdaloides Anderss. & SAAM1 & Y \\
\hline RIPARIAN & SALICACEAE & Salix exigua Nutt. ssp. interior (Rowlee) Cronq. & SAEX1 & $Y^{\prime}$ \\
\hline RIPARIAN & SALICACEAE & Salix lutea Nutt. var. ligulifolia Ball & SALU1 & Y \\
\hline RIPARIAN & SCROPHULARIACEAE & Veronica americana (Raf.) Schwein. ex Benth. & VEAM1 & $\mathrm{Y}$ \\
\hline RIPARIAN & SCROPHULARIACEAE & Veronica anagallis-aquatica $L$. & VEAN1 & $N$ \\
\hline RIPARIAN & SELAGINELLACEAE & Selaginella densa Rydb. & SEDE1 & $\mathrm{Y}$ \\
\hline RIPARIAN & VERBENACEAE & Lippia cuneifolia (Torr.) Steud. & LICU1 & $Y$ \\
\hline RIPARIAN & VERBENACEAE & Verbena hastata $\mathrm{L}$. . & VEHA1 & Y \\
\hline RIPARIAN & VIOLACEAE & Viola nephrophylla Greene & VINE1 & Y \\
\hline
\end{tabular}


Table B-5. 1994 Species Richness Summary at EcMP Sites and Communities.

\begin{tabular}{|c|c|c|c|c|c|c|}
\hline Sample Site & \# Families & \# Species & $\%$ Native & \# Annuals & \# Biennials & \# Perennials \\
\hline Xeric Community & 31 & 133 & $84 \%$ & 190 & $\therefore 2 \cdots$ & 111 \\
\hline TR01 & 24 & 88 & 84 & 12 & 1 & 75 \\
\hline TR06 & 25 & 89 & 80 & 14 & 1 & 74 \\
\hline TR12 & 23 & 91 & 84 & 11 & 0 & 79 \\
\hline Mean & 24.00 & 89.33 & 82.67 & 12.33 & 0.67 & 76.00 \\
\hline Mesic Community & $\therefore 37: 3$ & $\therefore 143$ & $\therefore 81 \cdots$ & 27 & $\because 2+1+3 x^{2}$ & $\therefore 113$ \\
\hline TR02 & 30 & 107 & 81 & 17 & 0 & 90 \\
\hline TR04 & 30 & 95 & 76 & 23 & 1 & 70 \\
\hline TR11 & 28 & 106 & 83 & 17 & 1 & 86 \\
\hline Mean & 29.33 & 102.67 & 80.00 & 19.00 & 0.67 & 82.00 \\
\hline Riparian Commúnity & 40 & 163 & $3 \times 743$ & $62+29+3$ & $3 \times 3$ & 2137 \\
\hline TR03 & 36 & 121 & 73 & 15 & 1 & 104 \\
\hline TR05 & 22 & 79 & 66 & 12 & 4 & 63 \\
\hline TR10 & 37 & 113 & 73 & 14 & 2 & 96 \\
\hline Mean & 31.67 & 104.33 & 70.67 & 13.67 & 2.33 & 87.67 \\
\hline Reclaimed Commúnity: & 13 & $\therefore 61, \cdots$ & $62 \quad$ & $\because y^{\prime \prime} \quad 9 \quad \cdots$ & 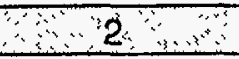 & 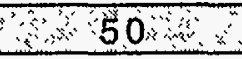 \\
\hline TR07 & 9 & 42 & 62 & 7 & 2 & 33 \\
\hline TR08 & 9 & 41 & 59 & 7 & 2 & 32 \\
\hline TR09 & 9 & 27 & 30 & 7 & 1 & 19 \\
\hline Mean & 9.00 & 36.67 & 50.33 & 7.00 & 1.67 & 28.00 \\
\hline
\end{tabular}

Community values based on all 3 sites combined.

Site values are the actual number of species except where column heading is different. 
Table B-5 (cont.). 1994 Species Richness Summary at EcMP Sites and Communities.

\begin{tabular}{|c|c|c|c|c|c|c|c|c|c|c|c|c|}
\hline & \multicolumn{6}{|c|}{ Growth Form } & \multicolumn{3}{|c|}{ Type } & \multicolumn{3}{|c|}{ Form } \\
\hline Sample Site & Forb & Graminoid & Cactus & Shrub & Vine & Tree & Dicots & Monocots & Pteridophytes & Herbaceous & Succulent & Woody \\
\hline Xeric Community & 99 & $\because 27$ & 5 & $\therefore 2 \therefore$ & $0: 3$ & $\therefore 0$ & $\therefore 103$ & 30 & $\because: " 60$ & $\therefore 126:$ & $\therefore 5$ & 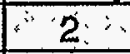 \\
\hline TR01 & 62 & 21 & 4 & 1 & 0 & 0 & 66 & 22 & 0 & 83 & 4 & 1 \\
\hline TH06 & 64 & 20 & 4 & 1 & 0 & 0 & 66 & 23 & 0 & 84 & 4 & 1 \\
\hline TR12 & 66 & 22 & 3 & 0 & 0 & 0 & 67 & 24 & 0 & 88 & 3 & 0 \\
\hline Mean & 64.00 & 21.00 & 3.67 & 0.67 & 0.00 & 0.00 & 66.33 & 23.00 & 0.00 & 85.00 & 3.67 & 0.67 \\
\hline Mesic Community $"$ & 106 & $30 \%$ & $\therefore 5 \cdots$ & 2 & $\therefore 0$ & 0 & $\therefore 109$ & $34 \cdots$ & $\therefore \because 0, \therefore$ & 136 & $\therefore 5^{\prime}$ & $\therefore 2: \div$ \\
\hline TR02 & 78 & 22 & 5 & 2 & 0 & 0 & 81 & 26 & 0 & 100 & 5 & 2 \\
\hline TR04 & 70 & 20 & 4 & 1 & 0 & 0 & 73 & 22 & 0 & 90 & 4 & 1 \\
\hline TR11 & 79 & 21 & 4 & 2 & 0 & 0 & 81 & 25 & 0 & 100 & 4 & 2 \\
\hline Mean & 75.67 & 21.00 & 4.33 & 1.67 & 0.00 & 0.00 & 78.33 & 24.33 & 0.00 & 96.67 & 4.33 & 1.67 \\
\hline Riparian Commúnity & 108 & 39 & $\therefore 2$ & 8 & 1 & 5 & 117 & $\therefore \quad 42: \therefore$ & 4 & $\therefore 147$ & $\therefore \therefore 2$ & $\because 4:$ \\
\hline TR03 & 80 & 26 & 2 & 8 & 0 & 5 & 90 & 27 & 4 & 106 & 2 & 13 \\
\hline TR05 & 48 & 24 & 0 & 5 & 0 & 2 & 54 & 24 & 1 & 72 & 0 & 7 \\
\hline TR10 & 77 & 23 & 2 & 7 & 1 & 3 & 85 & 25 & 3 & 100 & 2 & 11 \\
\hline Mean & 68.33 & 24.33 & 1.33 & 6.67 & 0.33 & 3.33 & 76.33 & 25.33 & 2.67 & 92.67 & 1.33 & 10.33 \\
\hline Reclaimed Comìnúnity & 50 & $\therefore 9:$ & 1.3 & $\because 1:$ & 0 & $\because 0$ & $\therefore 51$ & 70 & $\therefore$ & $\because 59$ & $\because 1 \therefore$ & $\because 1$ \\
\hline TR07 & 32 & 8 & 1 & 1 & 0 & 0 & 33 & 9 & 0 & 40 & 1 & 1 \\
\hline TR08 & 33 & 7 & 0 & 1 & 0 & 0 & 33 & 8 & 0 & 41 & 0 & 1 \\
\hline TH09 & 21 & 5 & 1 & 0 & 0 & 0 & 22 & 5 & 0 & 26 & 1 & 0 \\
\hline Mean & 28.67 & 6.67 & 0.67 & 0.67 & 0.00 & 0.00 & 29.33 & 7.33 & 0.00 & 35.67 & 0.67 & 0.67 \\
\hline
\end{tabular}

Community values based on all 3 sites combined.

Site values are the actual number of species except where column heading is different. 
Table B-6. 1994 EcMP Site Summary Statistics for Biomass and Cover.

Sample Site TR01, Xeric Community

\begin{tabular}{|c|c|c|c|c|c|}
\hline Biomass & Ans & Culvañ & Variance & Minimum & Maximum \\
\hline Current Year Production & 5 & 102.46 & 192.76 & 83.92 & 118.08 \\
\hline Litter & 5 & 179.01 & 3541.18 & 138.72 & 276.48 \\
\hline \multicolumn{6}{|c|}{ 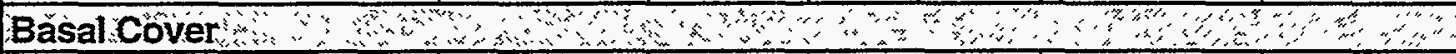 } \\
\hline Vegetation & 5 & 19.2 & 10.7 & 14 & 23 \\
\hline Litter & 5 & 57 & 7 & 53 & 60 \\
\hline Rock & 5 & 21.6 & 12.3 & 16 & 25 \\
\hline Bare Ground & 5 & 2.2 & 8.7 & 0 & 7 \\
\hline Water & 5 & 0 & 0 & 0 & 0 \\
\hline \multicolumn{6}{|c|}{ Foliar Cover } \\
\hline Foliar & 5 & 81.2 & 30.7 & 76 & 90 \\
\hline Shrub & 5 & 0 & 0 & 0 & 0 \\
\hline Tree & 5 & 0 & 0 & 0 & 0 \\
\hline
\end{tabular}

Sample Site TR02, Mesic Community

\begin{tabular}{|l|c|c|c|c|c|}
\hline Biomass & & Mean & Variance & Minimum & Maximum \\
\hline Current Year Production & 5 & 101.12 & 225.395 & 76.8 & 114.08 \\
\hline Litter & 5 & 207.1 & 2631.79 & 130.48 & 247.36 \\
\hline Basal Cover & 5 & 21.4 & 60.8 & 12 & 33 \\
\hline Vegetation & 5 & 56 & 50.5 & 49 & 66 \\
\hline Litter & 5 & 21 & 109 & 8 & 36 \\
\hline Rock & 5 & 1.6 & 3.3 & 0 & 4 \\
\hline Bare Ground & 5 & 0 & 0 & 0 & 0 \\
\hline Water & 5 & 88 & 13.5 & 82 & 91 \\
\hline Foliar Cover & 5 & 3.2 & 17.2 & 0 & 10 \\
\hline Foliar & 5 & 0 & 0 & 0 & 0 \\
\hline Shrub & & & & & \\
\hline Tree & & & & & \\
\hline
\end{tabular}

Sample Site TR03, Riparian Community

\begin{tabular}{|l|c|c|c|c|c|}
\hline Basal Cover & $\mathrm{n}$ & Mean & Variance & Minimum & Maximum \\
\hline Vegetation & 5 & 18.2 & 144.2 & 7 & 34 \\
\hline Litter & 5 & 74 & 75.5 & 63 & 84 \\
\hline Rock & 5 & 6 & 32 & 1 & 13 \\
\hline Bare Ground & 5 & 1.4 & 2.8 & 0 & 4 \\
\hline Water & 5 & 0.4 & 0.8 & 0 & 2 \\
\hline Foliar Cover & 5 & 75 & 546.5 & 39 & 97 \\
\hline Foliar & 5 & 42.4 & 958.3 & 0 & 71 \\
\hline Shrub & 5 & 17.6 & 559.3 & 0 & 53 \\
\hline Tree &
\end{tabular}


Table B-6 (cont.). 1994 EcMP Site Summary Statistics for Biomass and Cover.

Sample Site TR04, Mesic Community

\begin{tabular}{|c|c|c|c|c|c|}
\hline Biomáss & $\ldots n$ & Mean' & Variance & Minimum & Maximum \\
\hline Current Year Production & 5 & 113.17 & 652.828 & 72.08 & 141.12 \\
\hline Litter & 5 & 148.51 & 155.375 & 139.52 & 169.44 \\
\hline \multicolumn{6}{|l|}{ Basal Cover: } \\
\hline Vegetation & 5 & 40.4 & 274.3 & 24 & 61 \\
\hline Litter & 5 & 51 & 219.5 & 32 & 65 \\
\hline Rock & 5 & 6.2 & 14.7 & 1 & 11 \\
\hline Bare Ground & 5 & 2.6 & 5.8 & 0 & 6 \\
\hline Water & 5 & 0 & 0 & 0 & 0 \\
\hline \multicolumn{6}{|c|}{ Foliar Cover ${ }^{\alpha}$} \\
\hline Foliar & 5 & 91.6 & 39.3 & 81 & 96 \\
\hline Shrub & 5 & 0.2 & 0.2 & 0 & 1 \\
\hline Tree & 5 & 0 & 0 & 0 & 0 \\
\hline
\end{tabular}

Sample Site TR05, Riparian Community

\begin{tabular}{|l|c|c|c|c|c|}
\hline Basal Cover & 5 & 11.6 & 88.3 & 3 & 26 \\
\hline Vegetation & 5 & 55.6 & 1063.8 & 5 & 85 \\
\hline Litter & 5 & 29.2 & 1587.7 & 0 & 92 \\
\hline Rock & 5 & 0.8 & 3.2 & 0 & 4 \\
\hline Bare Ground & 5 & 2.8 & 32.7 & 0 & 13 \\
\hline Water & 5 & 53.2 & 1189.7 & 18 & 98 \\
\hline Foliar Cover & 5 & 32 & 1419 & 3 & 95 \\
\hline Foliar & 5 & 27.2 & 1388.7 & 0 & 90 \\
\hline Shrub & 5 & & & Mariance \\
\hline Tree & & & & & \\
\hline
\end{tabular}

Sample Site TR06, Xeric Community

\begin{tabular}{|l|c|c|c|c|c|}
\hline Biomass & $n^{\prime}$ & Mean & Variance & Minimum & Maximum \\
\hline Current Year Production & 5 & 157.7 & 1229.25 & 112 & 198 \\
\hline Litter & 5 & 342.8 & 2821.11 & 288.8 & 403.84 \\
\hline Basal Cover & 5 & 21.6 & 68.3 & 14 & 35 \\
\hline Vegetation & 5 & 73.4 & 96.8 & 57 & 82 \\
\hline Litter & 5 & 3.4 & -6.8 & 1 & 7 \\
\hline Rock & 5 & 1.6 & 3.8 & 0 & 5 \\
\hline Bare Ground & 5 & 0 & 0 & 0 & 0 \\
\hline Water & 5 & 89.4 & 38.3 & 84 & 97 \\
\hline Foliar Cover & 5 & 1.6 & 4.3 & 0 & 5 \\
\hline Foliar & 5 & 0 & 0 & 0 & 0 \\
\hline Shrub & 5 & & \multicolumn{3}{|c|}{} \\
\hline Tree & &
\end{tabular}

Cover means are percentages of cover. Biomass means are in $\mathrm{g} / \mathrm{m}^{\wedge} 2$. 
Table B-6 (cont.). 1994 EcMP Site Summary Statistics for Biomass and Cover.

Sample Site TR07, Reclaimed Community

\begin{tabular}{|l|c|c|c|c|c|}
\hline Biomass & $n$ & Mean & Variance & Mínimum & Maximum \\
\hline Current Year Production & 5 & 139.46 & 855.352 & 114.16 & 189.76 \\
\hline Litter & 5 & 212.37 & 910.492 & 180.24 & 243.52 \\
\hline Basal Cover & 5 & 7.4 & 6.3 & 5 & 11 \\
\hline Vegetation & 5 & 73.4 & 48.8 & 65 & 82 \\
\hline Litter & 5 & 13.8 & 32.2 & 6 & 20 \\
\hline Rock & 5 & 5.4 & 18.8 & 1 & 11 \\
\hline Bare Ground & 5 & 0 & 0 & 0 & 0 \\
\hline Water & 5 & & & & \\
\hline Follar Cover & 5 & 74.8 & 11.2 & 71 & 80 \\
\hline Foliar & 5 & 0 & 0 & 0 & 0 \\
\hline Shrub & 5 & 0 & 0 & 0 & 0 \\
\hline Tree & & & & & \\
\hline
\end{tabular}

Sample Site TR08, Reclaimed Community

\begin{tabular}{|l|c|c|c|c|c|}
\hline Biomass & n & Mean & Variance & Minimum & Maximum \\
\hline Current Year Production & 5 & 120.13 & 783.349 & 103.52 & 169.92 \\
\hline Litter & 5 & 195.62 & 940.977 & 153.6 & 228.16 \\
\hline Basal Cover & 5 & 6.8 & 5.7 & 3 & 9 \\
\hline Vegetation & 5 & 71.8 & 25.7 & 64 & 77 \\
\hline Litter & 5 & 12.6 & 11.8 & 8 & 16 \\
\hline Rock & 5 & 8.8 & 6.2 & 5 & 11 \\
\hline Bare Ground & 5 & 0 & 0 & 0 & 0 \\
\hline Water & 5 & & 5 & & \\
\hline Foliar Cover & 5 & 70 & 9 & 67 & 74 \\
\hline Foliar & 5 & 0 & 0 & 0 & 0 \\
\hline Shrub & 5 & 0 & 0 & 0 & 0 \\
\hline Tree & & & & & \\
\hline
\end{tabular}

Sample Site TR09, Reclaimed Community

\begin{tabular}{|l|c|c|c|c|c|}
\hline Biomass & $n$ & Mean & Variance & Minimum & Maximum \\
\hline Current Year Production & 5 & 177.71 & 271.676 & 149.2 & 189.28 \\
\hline Litter & 5 & 274.37 & 1254.17 & 242.08 & 334.32 \\
\hline Basal Cover & 5 & 19.4 & 20.3 & 14 & 23 \\
\hline Vegetation & 5 & 66 & 23.5 & 58 & 71 \\
\hline Litter & 5 & 13.6 & 22.8 & 7 & 19 \\
\hline Rock & 5 & 1 & 3 & 0 & 4 \\
\hline Bare Ground & 5 & 0 & 0 & 0 & 0 \\
\hline Water & & & & & \\
\hline Foliar Cover & 5 & 95.8 & 11.2 & 91 & 99 \\
\hline Foliar & 5 & 0 & 0 & 0 & 0 \\
\hline Shrub & 5 & 0 & 0 & 0 & 0 \\
\hline Tree & & & & & \\
\hline
\end{tabular}


Table B-6 (cont.). 1994 EcMP Site Summary Statistics for Biomass and Cover.

Sample Site TR10, Riparian Community

\begin{tabular}{|l|c|c|c|c|c|}
\hline Basal Cover & $n$ & Mean & Variance & Minimum & Maximum \\
\hline Vegetation & 5 & 27.8 & 121.7 & 11 & 38 \\
\hline Litter & 5 & 66.2 & 168.2 & 50 & 83 \\
\hline Rock & 5 & 4.4 & 4.8 & 1 & 7 \\
\hline Bare Ground & 5 & 1.6 & 4.3 & 0 & 5 \\
\hline Water & 5 & 0 & 0 & 0 & 0 \\
\hline Foliar Cover & 5 & 71.4 & 550.8 & 33 & 93 \\
\hline Foliar & 5 & 45 & 996 & 14 & 80 \\
\hline Shrub & 5 & 11 & 318 & 0 & 41 \\
\hline Tree & & & & & \\
\hline
\end{tabular}

Sample Site TR11, Mesic Community

\begin{tabular}{|l|c|c|c|c|c|}
\hline Biómás & $n$ & Mean & Variance & Minimum & Maximum \\
\hline Current Year Production & 5 & 146.06 & 800.731 & 119.84 & 184.32 \\
\hline Litter & 5 & 319.38 & 3667.87 & 269.92 & 420.64 \\
\hline Basal Cover & 5 & 25.4 & 207.8 & 14 & 50 \\
\hline Vegetation & 5 & 59 & 135 & 47 & 74 \\
\hline Litter & 5 & 14.8 & 149.2 & 3 & 32 \\
\hline Rock & 5 & 0.8 & 0.7 & 0 & 2 \\
\hline Bare Ground & 5 & 0 & 0 & 0 & 0 \\
\hline Water & 5 & 94.4 & 14.8 & 90 & 100 \\
\hline Foliar Cover & 5 & 0.6 & 1.8 & 0 & 3 \\
\hline Foliar & 5 & 0 & 0 & 0 & 0 \\
\hline Shrub & & & & & \\
\hline Tree & & & & & \\
\hline
\end{tabular}

Sample Site TR12, Xeric Community

\begin{tabular}{|c|c|c|c|c|c|}
\hline Biomass & $n$ & Mean & Variance & Miníimum: & Maximum \\
\hline Current Year Production & 5 & 125.62 & 248.209 & 105.36 & 146.72 \\
\hline Litter & 5 & 266.96 & 2040.84 & 220.4 & 338.64 \\
\hline Basal Covèr & $\because$ & 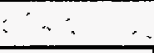 & $\because$ & $\because \vdots$ & \\
\hline Vegetation & 5 & 17.2 & 13.7 & 13 & 22 \\
\hline Litter & 5 & 65.4 & 5.3 & 63 & 69 \\
\hline Rock & 5 & 16.8 & 6.2 & 15 & 21 \\
\hline Bare Ground & 5 & 0.6 & 0.8 & 0 & 2 \\
\hline Water & 5 & 0 & 0 & 0 & 0 \\
\hline \multicolumn{6}{|l|}{ Foliar Cover } \\
\hline Foliar & 5 & 90.4 & 28.3 & 86 & 99 \\
\hline Shrub & 5 & 0 & 0 & 0 & 0 \\
\hline Tree & 5 & 0 & 0 & 0 & 0 \\
\hline
\end{tabular}

Cover means are percentages of cover. Biomass means are in $\mathrm{g} / \mathrm{m}^{\wedge} 2$. 
Table B-7 . 1994 Community Summary Statistics for Biomass and Cover.

\begin{tabular}{|c|c|c|c|c|c|}
\hline Biomass $\because \cdots$ & $n$ & Meañ & Variance & Mininumin & Máxinúmin \\
\hline Current Year Production & 15 & 128.592 & 1026.69 & 83.92 & 198 \\
\hline Litter & 15 & 262.923 & 7200.31 & 138.72 & 403.84 \\
\hline \multicolumn{6}{|c|}{ Basâl Cover, } \\
\hline Vegetation & 15 & 19.3333 & 29.9524 & 13 & 35 \\
\hline Litter & 15 & 65.2667 & 79.2095 & 53 & 82 \\
\hline Rock & 15 & 13.9333 & 70.781 & 1 & 25 \\
\hline Bare Ground & 15 & 1.46667 & 4.26667 & 0 & 7 \\
\hline Water & 15 & 0 & 0 & 0 & 0 \\
\hline \multicolumn{6}{|c|}{ Foliar Cover } \\
\hline Foliar & 15 & 87 & 46 & 76 & 99 \\
\hline Shrub & 15 & 0.53333 & 1.8381 & 0 & 5 \\
\hline Tree & 15 & 0 & 0 & $\underline{0}$ & 0 \\
\hline
\end{tabular}

\begin{tabular}{|c|c|c|c|c|c|}
\hline Biomass & $\therefore$ & Mean & Variancé & Mińimúm & Máximum \\
\hline Current Year Production & 15 & 120.117 & 866.28 & 72.08 & 184.32 \\
\hline Litter & 15 & 224.997 & 7229.12 & 130.48 & 420.64 \\
\hline \multicolumn{6}{|c|}{ Básal Cover $\because \cdots$} \\
\hline Vegetation & 15 & 29.0667 & 226.781 & 12 & 61 \\
\hline Litter & 15 & 55.3333 & 127.381 & 32 & 74 \\
\hline Rock & 15 & 14 & 117.429 & 1 & 36 \\
\hline Bare Ground & 15 & 1.66667 & 3.38095 & 0 & 6 \\
\hline Water & 15 & 0 & 0 & 0 & 0 \\
\hline Föliar Cover & 38 & 20 & & 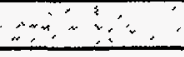 & $\because$ \\
\hline Foliar & 15 & 91.3333 & 26.6667 & 81 & 100 \\
\hline Shrub & 15 & 1.33333 & 7.38095 & 0 & 10 \\
\hline Tree & 15 & 0 & 0 & 0 & 0 \\
\hline
\end{tabular}


Table B-7 (cont.). 1994 Community Summary Statistics for Biomass and Cover.

Riparian Community
\begin{tabular}{|l|c|c|c|c|c|}
\hline Basal Cover & Mean & Variance & Minimum & Maximum \\
\hline Vegetation & 15 & 19.2 & 148.6 & 3 & 38 \\
\hline Litter & 10 & 70.1 & 125.211 & 50 & 84 \\
\hline Rock & 10 & 5.2 & 17.0667 & 1 & 13 \\
\hline Bare Ground & 15 & 1.26667 & 3.06667 & 0 & 5 \\
\hline Water & 15 & 1.06667 & 11.2095 & 0 & 13 \\
\hline Foliar Cover & 15 & 66.5333 & 750.981 & 18 & 98 \\
\hline Foliar & 15 & 39.8 & 997.6 & 0 & 95 \\
\hline Shrub & 15 & 18.6 & 694.829 & 0 & 90 \\
\hline Tree & &
\end{tabular}

\section{Reclaimed Community}

\begin{tabular}{|l|c|c|c|c|c|}
\hline Biomass & $n$ & Mean & Variance & Minimum & Maximum \\
\hline Current Year Production & 15 & 145.765 & 1159.28 & 103.52 & 189.76 \\
\hline Litter & 15 & 227.451 & 2116.67 & 153.6 & 334.32 \\
\hline Basal Cover & 15 & 11.2 & 45.3143 & 3 & 23 \\
\hline Vegetation & 15 & 70.4 & 38.8286 & 58 & 82 \\
\hline Litter & 15 & 13.3333 & 19.381 & 6 & 20 \\
\hline Rock & 15 & 5.06667 & 18.9238 & 0 & 11 \\
\hline Bare Ground & 15 & 0 & 0 & 0 & 0 \\
\hline Water & 15 & 80.2 & 143.457 & 67 & 99 \\
\hline Foliar Cover & 15 & 0 & 0 & 0 & 0 \\
\hline Foliar & 15 & 0 & 0 & 0 & 0 \\
\hline Shrub & & & & & \\
\hline Tree & & & & & \\
\hline
\end{tabular}


Table B-8. $1994 \%$ Native versus Non-native Species by Community from Basal and Foliar Cover.

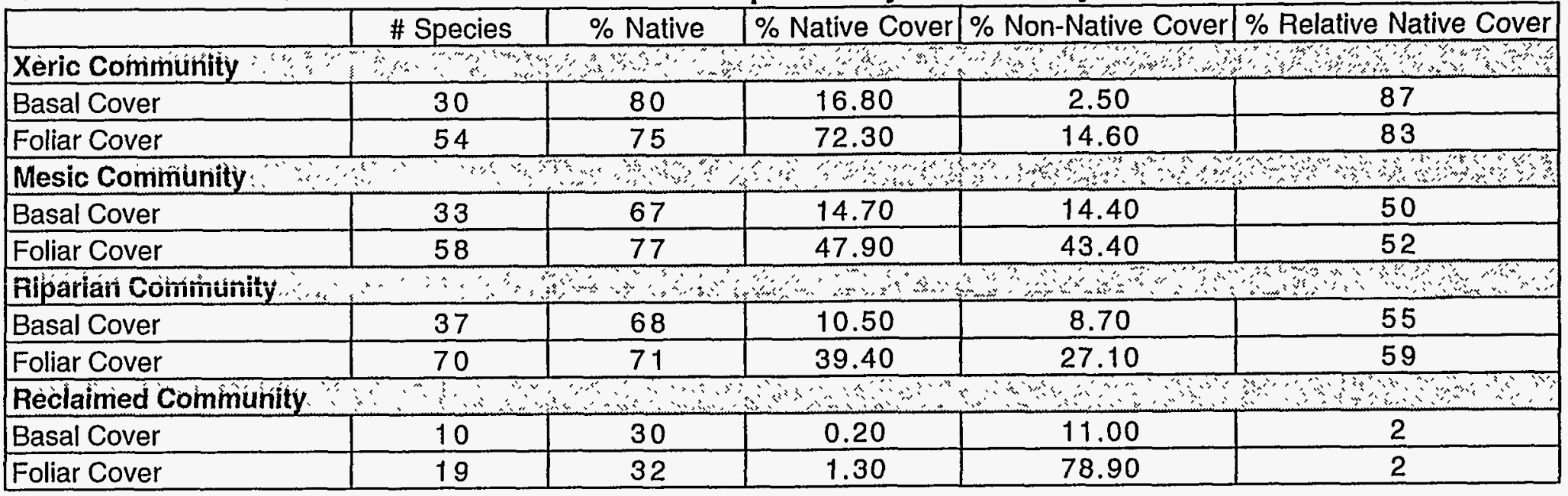

The above calculations for $\%$ native, $\%$ native cover, $\%$ non-native cover, and $\%$ relative native cover were made for those taxa identified to species only. Those identified only to the family or genera level were not included. Calculations are based on combined site species lists to determine \# species and \% native values. 
Table B-9. 1994 Basal and Foliar Cover Dominant Species by Community.

Basal Cover Dominant Species by Community

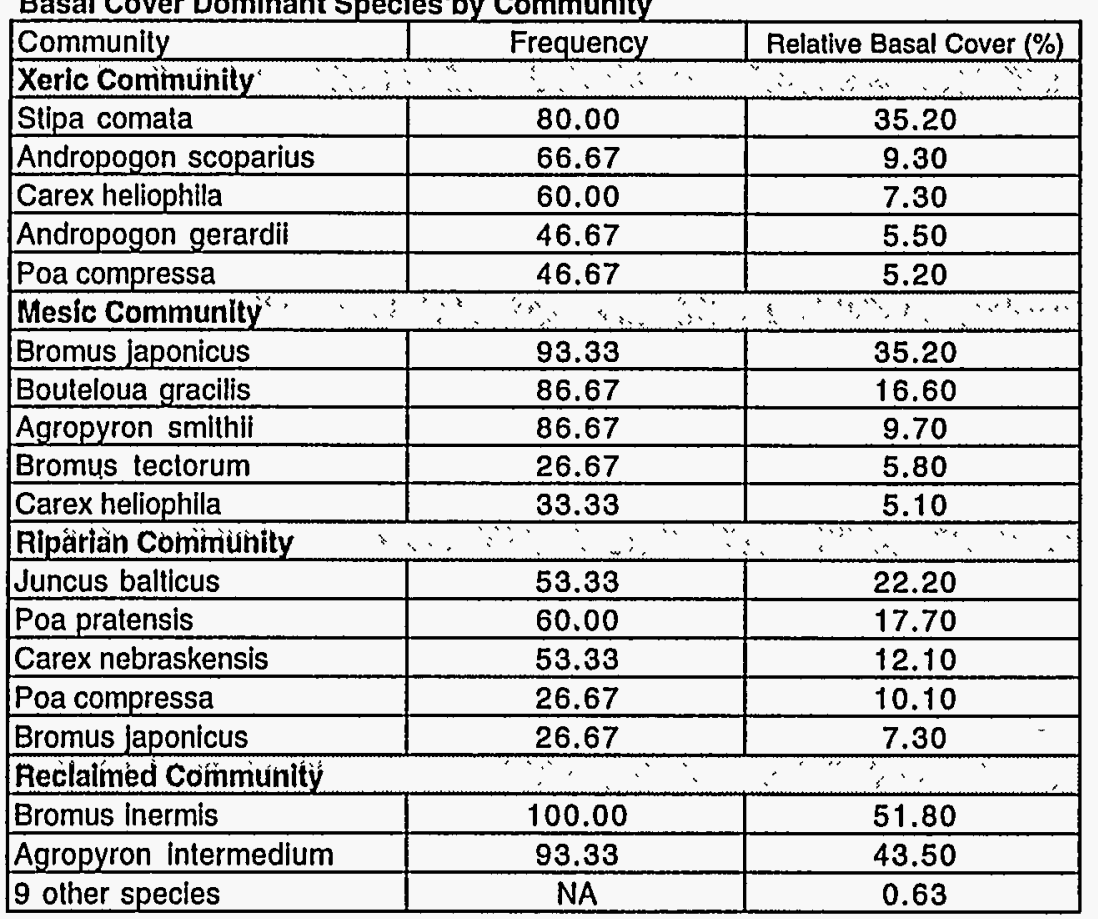

Foliar Cover Dominant Species by Community

\begin{tabular}{|c|c|c|}
\hline Community & Absolute Foliar Cover (\%) & Relative Foliar Cover (\%) \\
\hline \multicolumn{3}{|c|}{ Xeric Community } \\
\hline Stipa comata & 32.20 & 37.00 \\
\hline Andropogon gerardii & 6.80 & 7.80 \\
\hline Carex hellophila & 5.60 & 6.40 \\
\hline Andropogon scoparius & 3.93 & 4.50 \\
\hline Arenaria fendleri & 3.67 & 4.20 \\
\hline \multicolumn{3}{|c|}{ Mesic Comminúnity } \\
\hline Bromus japonicus & 29.13 & 31.90 \\
\hline Agropyron smithil & 18.13 & 19.90 \\
\hline Bouteloua gracilis & 6.53 & 7.20 \\
\hline Carex hellophila & 4.13 & 4.50 \\
\hline Bromus tectorum & 3.93 & 4.30 \\
\hline \multicolumn{3}{|c|}{ 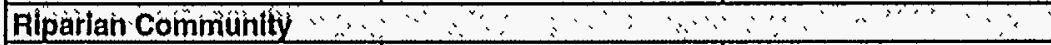 } \\
\hline Juncus balticus & 14.87 & 22.40 \\
\hline Cirsium arvense & 7.20 & 10.80 \\
\hline Poa compressa & 6.20 & 9.30 \\
\hline Carex nebraskensis & 5.93 & 8.90 \\
\hline Poa pratensis & 3.00 & 4.50 \\
\hline \multicolumn{3}{|l|}{ Feclaimed còmmúúíly } \\
\hline Bromus inermis & 44.67 & 55.70 \\
\hline Agropyron Intermedium & 30.07 & 37.50 \\
\hline Alyssum minus & 1.60 & 2.00 \\
\hline
\end{tabular}

Frequency based on $n=15$. Top five cover species listed only.

Absolute Foliar Cover = Mean number of hits for each species converted to a percentage.

Relative Foliar Cover $=$ Mean cover value of given species expressed as a proportion of the total coverage for all species.

Frequency $=$ Probability of getting a hit for that species. 
Table B-10. 1994 Basal Cover Dominant Species at at EcMP Sites.

\begin{tabular}{|l|c|c|}
\hline Xeric Community & & \\
\hline Sample Site & Frequency & Relative Basal Cover (\%) \\
\hline TR01 & 100.00 & 22.90 \\
\hline Andropogon scoparius & 60.00 & 7.30 \\
\hline Andropogon gerardii & 80.00 & 7.30 \\
\hline Carex heliophila & 80.00 & 7.30 \\
\hline Muhlenbergia montana & 80.00 & 6.30 \\
\hline Aster porteri & 100.00 & 56.50 \\
\hline TR06 & 80.00 & 10.20 \\
\hline Stipa comata & 20.00 & 9.30 \\
\hline Bouteloua gracilis & 20.00 & 7.40 \\
\hline Poa pratensis & 60.00 & 5.60 \\
\hline Poa compressa & 100.00 & 45.30 \\
\hline Carex heliophila & 40.00 & 9.30 \\
\hline TR12 & 60.00 & 8.10 \\
\hline Stipa comata & 60.00 & 5.80 \\
\hline Carex heliophila & 80.00 & 4.70 \\
\hline Andropogon gerardii & & \\
\hline Bouteloua curtipendula & & \\
\hline Andropogon scoparius & & \\
\hline
\end{tabular}

\begin{tabular}{|l|c|c|}
\hline Riparian Community & & \\
\hline Sample Site & Frequency & Relative Basal Cover (\%) \\
\hline TR03 & 80.00 & 36.30 \\
\hline Juncus balticus & 80.00 & 14.30 \\
\hline Poa pratensis & 60.00 & 12.10 \\
\hline Carex nebraskensis & 80.00 & 9.90 \\
\hline Barbarea orthoceras & 20.00 & 5.50 \\
\hline Salix exigua & 40.00 & 15.50 \\
\hline TR05 & 20.00 & 15.50 \\
\hline Festuca pratensis & 40.00 & 12.10 \\
\hline Juncus balticus & 40.00 & 8.60 \\
\hline Carex nebraskensis & 20.00 & 8.60 \\
\hline Agrostis stolonifera & & 25.90 \\
\hline Poa compressa & 80.00 & 17.30 \\
\hline TR10 & 60.00 & 15.80 \\
\hline Poa pratensis & 60.00 & 13.70 \\
\hline Poa compressa & 40.00 & 12.20 \\
\hline Juncus balticus & 60.00 & \\
\hline Bromus japonicus & & \\
\hline Carex nebraskensis & & \\
\hline
\end{tabular}

Frequency=Probability of getting a hit for a given species $(n=5)$.

Relative Basal Cover=mean cover value $(n=5)$ of given species expressed as a proportion of the total coverage for all species.

Top five cover species listed only. 
Table B-10 (cont.) 1994 Basal Cover Dominant Species at EcMP Sites.

\begin{tabular}{|l|c|c|}
\hline Mesic Community & & \\
\hline Sample Site & Frequency & Relative Basal Cover (\%) \\
\hline TR02 & 100.00 & 29.90 \\
\hline Bouteloua gracilis & 80.00 & 19.60 \\
\hline Agropyron smithii & 80.00 & 11.20 \\
\hline Bouteloua hirsuta & 80.00 & 10.30 \\
\hline Bromus japonicus & 60.00 & 5.60 \\
\hline Bouteloua curtipendula & 100.00 & 55.00 \\
\hline Tro4 & 80.00 & 15.30 \\
\hline Bromus japonicus & 40.00 & 8.40 \\
\hline Bouteloua gracilis & 80.00 & 5.40 \\
\hline Bromus tectorum & 80.00 & 3.00 \\
\hline Agropyron smithii & 100.00 & 24.40 \\
\hline Poa compressa & 80.00 & 15.00 \\
\hline TR11 & 100.00 & 7.90 \\
\hline Bromus japonicus & 80.00 & 7.10 \\
\hline Carex heliophila & 40.00 & 6.30 \\
\hline Agropyron smithii & 60.00 & 6.30 \\
\hline Bouteloua gracilis & & \\
\hline Bromus tectorum & & \\
\hline Poa pratensis & & \\
\hline
\end{tabular}

\begin{tabular}{|l|c|c|}
\hline Reclaimed Community & & \\
\hline Sample Site & Frequency & Relative Basal Cover (\%) \\
\hline TR07 & 100.00 & \\
\hline Bromus inermis & 100.00 & 43.20 \\
\hline Agropyron intermedium & & 37.80 \\
\hline All others combined & & 18.90 \\
\hline & 100.00 & \\
\hline TR08 & 80.00 & 70.60 \\
\hline Bromus inermis & & 29.40 \\
\hline Agropyron intermedium & & \\
\hline No others & 100.00 & \\
\hline & 100.00 & 50.50 \\
\hline TR09 & 20.00 & 48.50 \\
\hline Agropyron intermedium & & 1.00 \\
\hline Bromus inermis & & \\
\hline Convolvulus arvensis & & \\
\hline No others & & \\
\hline
\end{tabular}

Frequency=Probability of getting a hit for a given species $(n=5)$.

Relative Basal Cover=mean cover value $(n=5)$ of given species expressed as a proportion of the total coverage for all species.

Top five cover species listed only. 
Table B-11. 1994 Foliar Cover Dominant Species by EcMP Site.

\begin{tabular}{|l|c|c|}
\hline Xeric Community & Foliar Cover (\%) & Relative Foliar Cover (\%) \\
\hline Sample Site & & \\
\hline TR01 & 9.40 & 11.60 \\
\hline Andropogon gerardii & 8.40 & 10.30 \\
\hline Andropogon scoparius & 8.40 & 10.30 \\
\hline Aster porteri & 6.80 & 8.40 \\
\hline Muhlenbergia montana & 5.40 & 6.70 \\
\hline Arenaria fendleri & 55.80 & 62.40 \\
\hline TR06 & 7.20 & 8.10 \\
\hline Stipa comata & 5.20 & 5.80 \\
\hline Linaria dalmatica & 4.80 & 5.40 \\
\hline Poa pratensis & 2.40 & 2.70 \\
\hline Poa compressa & 35.60 & 39.40 \\
\hline Bouteloua gracilis & 10.20 & 11.30 \\
\hline TR12 & 9.40 & 10.40 \\
\hline Stipa comata & 5.60 & 6.20 \\
\hline Andropogon gerardii & 5.00 & 5.50 \\
\hline Carex heliophila & & \\
\hline Arenaria fendleri & & \\
\hline Alyssum minus & & \\
\hline
\end{tabular}

\begin{tabular}{|l|c|c|}
\hline Mesic Community & Foliar Cover (\%) & Relative Foliar Cover (\%) \\
\hline Sample Site & 29.00 & 33.00 \\
\hline TRo2 & 18.40 & 20.90 \\
\hline Agropyron smithii & 11.80 & 13.40 \\
\hline Bromus japonicus & 4.80 & 5.50 \\
\hline Bouteloua gracilis & 3.60 & 4.10 \\
\hline Bouteloua curtipendula & 44.60 & \\
\hline Carex heliophila & 14.40 & 48.70 \\
\hline TR04 & 6.20 & 15.70 \\
\hline Bromus japonicus & 4.20 & 6.80 \\
\hline Agropyron smithii & 2.80 & 4.60 \\
\hline Bouteloua gracilis & & 3.10 \\
\hline Bromus tectorum & 24.40 & 25.80 \\
\hline Scorzonera laciniata & 11.00 & 11.70 \\
\hline TR11 & 8.80 & 9.30 \\
\hline Bromus japonicus & 8.20 & 8.70 \\
\hline Agropyron smithii & 7.60 & 8.10 \\
\hline Carex heliophila & & \\
\hline Stipa comata & & \\
\hline Bromus tectorum & & \\
\hline
\end{tabular}

Relative Foliar Cover = mean cover value $(n=5)$ of a given species expressed as a proportion of the total coverage for all species.

Top five cover species listed only.

Frequency $=$ Probability of getting a hit for a given species $(n=5)$. 
Table B-11 (cont.). 1994 Foliar Cover Dominant Species by EcMP Site.

\begin{tabular}{|l|c|c|}
\hline Riparian Community & Foliar Cover (\%) & Relative Foliar Cover (\%) \\
\hline Sample Site & 27.80 & 37.10 \\
\hline TR03 & 7.40 & 9.90 \\
\hline Juncus balticus & 7.20 & 9.60 \\
\hline Cirsium arvense & 3.60 & 4.80 \\
\hline Carex nebraskensis & 3.60 & 4.80 \\
\hline Glycyrrhiza lepidota & 9.00 & 16.90 \\
\hline Poa pratensis & 7.80 & 14.70 \\
\hline TR05 & 6.40 & 12.00 \\
\hline Circium arvense & 5.20 & 9.80 \\
\hline Festuca pratensis & 4.40 & 8.30 \\
\hline Poa compressa & & \\
\hline Juncus balticus & 11.60 & 16.20 \\
\hline Agrostis stolonifera & 11.40 & 16.00 \\
\hline TR10 & $\vdots$ \\
\hline Juncus balticus & 6.80 & 9.50 \\
\hline Poa compressa & 5.20 & 7.30 \\
\hline Carex nebraskensis & 5.00 & 7.00 \\
\hline Cirsium arvense & & \\
\hline Poa pratensis & & \\
\hline
\end{tabular}

\begin{tabular}{|l|c|c|}
\hline Reclaimed Community & Foliar Cover (\%) & Relative Foliar Cover (\%) \\
\hline Sample Site & 36.20 & \\
\hline TR07 & 28.40 & 48.40 \\
\hline Bromus inermis & 3.20 & 38.00 \\
\hline Agropyron intermedium & 2.40 & 4.30 \\
\hline Melilotus officinalis & 1.20 & 3.20 \\
\hline Alyssum minus & 53.60 & 1.60 \\
\hline Agropyron smithii & 14.40 & 76.60 \\
\hline TR08 & 0.40 & 20.60 \\
\hline Bromus inermis & 0.40 & 0.60 \\
\hline Agropyron intermedium & 0.40 & 0.60 \\
\hline Cirsium arvense & $\ddots . .2$ & 0.60 \\
\hline Convolvulus arvensis & 47.20 & \\
\hline Melilotus alba & 44.20 & 49.50 \\
\hline TR09 & 2.40 & 46.10 \\
\hline Agropyron intermedium & 0.80 & 2.50 \\
\hline Bromus inermis & 0.60 & 0.84 \\
\hline Alyssum minus & & 0.63 \\
\hline Convolvulus arvensis & & \\
\hline Agropyron cristatum & & \\
\hline
\end{tabular}

Relative Foliar Cover $=$ mean cover value $(n=5)$ of a given species expressed as a proportion of the total coverage for all species.

Top five cover species listed only.

Frequency $=$ Probability of getting a hit for a given species $(n=5)$. 
Table B-11 (cont.). 1994 Foliar Cover Dominant Species by EcMP Site.

\begin{tabular}{|l|c|c|}
\hline Riparian Community & Shrub Cover (\%) & Relative Shrub Cover (\%) \\
\hline Sample Site & 24.80 & \\
\hline TR03 & 11.20 & 58.50 \\
\hline Amorpha fruticosa & 3.60 & 26.40 \\
\hline Salix exigua & 0.80 & 8.50 \\
\hline Symphoricarpos occidentalis & 0.80 & 0.20 \\
\hline Prunus virginiana & 15.20 & 0.20 \\
\hline Rosa woodsia & 6.40 & 47.50 \\
\hline TR05 & 5.80 & 20.00 \\
\hline Salix exigua & 3.80 & 18.10 \\
\hline Populus deltoides & 0.60 & 11.90 \\
\hline Amorpha fruticosa & & 0.20 \\
\hline Symphoricarpos occidentalis & 15.80 & 35.10 \\
\hline Salix amygdaloides & 15.40 & 34.20 \\
\hline TRio & 5.80 & 12.90 \\
\hline Salix exigua & 3.40 & 7.60 \\
\hline Amorpha fruticosa & 2.20 & 4.90 \\
\hline Symphoricarpos occidentalis & & \\
\hline Prunus virginiana & & \\
\hline Rosa arkansana & & \\
\hline
\end{tabular}

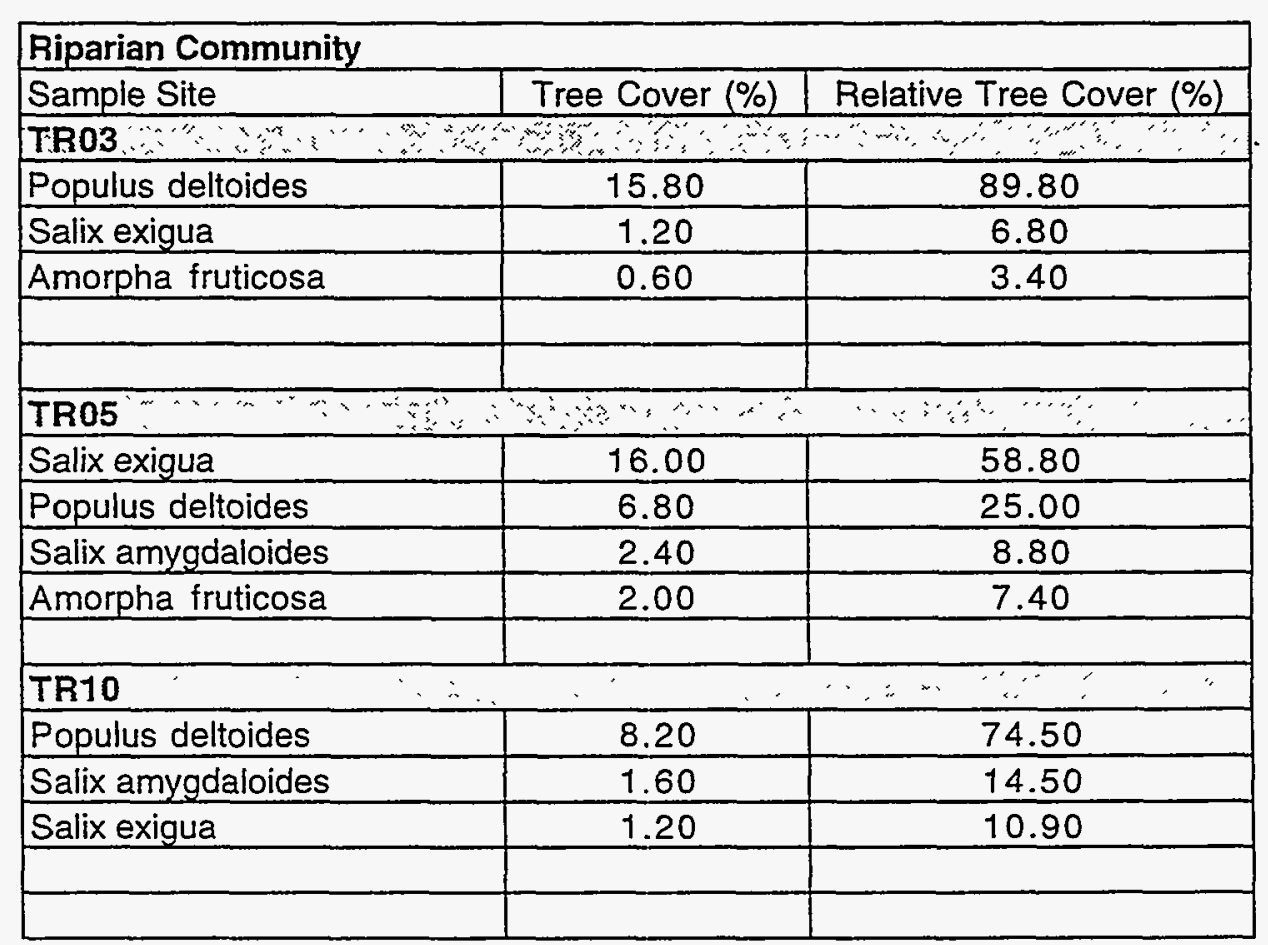

Relative Foliar Cover $=$ mean cover value $(n=5)$ of a given species expressed as a proportion of the total coverage for all species.

Top five cover species listed only.

Frequency $=$ Probability of getting a hit for a given species $(n=5)$. 
Table B-12. 1994 Native vs. Non-native Current Year Production Biomass at EcMP Sites and Communities.

\begin{tabular}{|c|c|c|c|}
\hline Sample Site & Native CYP $\left(\mathrm{g} / \mathrm{m}^{\wedge} 2\right)$ & Non-Native CYP $\left(\mathrm{g} / \mathrm{m}^{\wedge} 2\right)$ & $\%$ Native CYP \\
\hline Xeric Cómmúnity & $\therefore \because 99.54 \quad \because 3$ & 3704 & $\therefore 71 \div 19 \cdots$ \\
\hline TR01 & 93.28 & 9.18 & 91.04 \\
\hline TR06 & 72.68 & 85.01 & 46.09 \\
\hline TR12 . & 108.67 & 16.94 & 86.51 \\
\hline Mesic Commúnitity & $\because 75: 18$ & $\because \cdots 44.94 \therefore \because \cdots$ & $\therefore 62.58$ \\
\hline TR02 & 74.51 & 26.61 & 73.68 \\
\hline TR04 & 54.47 & 58.70 & 48.13 \\
\hline TR11 & 96.55 & 49.52 & 66.10 \\
\hline Reclaimed Community & $\because 0.32$ & 145,44 & $\because 0.22$ \\
\hline TR07 & 0.54 & 138.91 & 0.39 \\
\hline TR08 & 0.42 & 119.71 & 0.35 \\
\hline TR09 & 0.00 & 177.71 & 0.00 \\
\hline
\end{tabular}

CYP $=$ Current Year Production

Community means based on $n=75$

Site means based on $n=25$

$\%$ Native CYP = Native CYP/(Native CYP+Non-native CYP) 
Table B-13. 1994 Leading Biomass Producers by EcMP Site.

\begin{tabular}{|c|c|c|}
\hline \multicolumn{3}{|l|}{ Xeric Community } \\
\hline Sample Sile & Frequency & Total CYP $\left(\mathrm{g} / \mathrm{m}^{\wedge} 2\right)$ \\
\hline \multicolumn{3}{|l|}{ TR01 } \\
\hline Aster porteri & 0.84 & 12.78 \\
\hline Andropogon gerardii & 0.40 & 11.82 \\
\hline Chrysopsis villosa & 0.92 & 11.12 \\
\hline Liatris punctata & 0.80 & 8.43 \\
\hline Arenaria fendleri & 0.80 & 7.94 \\
\hline Stipa comala & 0.60 & 6.93 \\
\hline Andropogon scoparius & 0.32 & 5.94 \\
\hline Muhlenbergia montana & 0.40 & 5.46 \\
\hline Carex heliophila & 0.80 & 4.34 \\
\hline Poa compressa & 0.16 & 4.03 \\
\hline \multicolumn{3}{|c|}{ Th06 } \\
\hline Linaria dalmalica & 0.92 & 51.47 \\
\hline Slipa comata & 0.92 & 47.10 \\
\hline Poa compressa & 0.32 & 10.86 \\
\hline Alyssum minus & 0.08 & 9.84 \\
\hline Sisymbrium altissimum & 0.12 & 3.63 \\
\hline Bouteloua gracilis & 0.76 & 3.54 \\
\hline Agropyron smithii & 0.16 & 3.39 \\
\hline Stipa neomexicana & 0.12 & 3.25 \\
\hline Carex heliophila & 0.40 & 3.12 \\
\hline Carduus nutans & 0.08 & 2.88 \\
\hline \multicolumn{3}{|c|}{ TR12: } \\
\hline Stipa comata & 1.00 & 55.71 \\
\hline Liatris punctata & 0.60 & 14.54 \\
\hline Alyssum minus & 0.72 & 8.67 \\
\hline Carex heliophila & 0.96 & 5.30 \\
\hline Andropogon gerardii & 0.28 & 5.20 \\
\hline Bouteloua curtipendula & 0.68 & 4.88 \\
\hline Andropogon scoparius & 0.24 & 4.59 \\
\hline Poa compressa & 0.16 & 3.61 \\
\hline Psoralea tenuiflora & 0.40 & 3.29 \\
\hline Arenaria fendleri & 0.56 & 3.13 \\
\hline
\end{tabular}

\begin{tabular}{|c|c|c|}
\hline Mesic Cómimulnity & $\therefore$ & $\because 6$ \\
\hline Sample Sile & Frequency & Total CYP $\left(\mathrm{g} / \mathrm{m}^{\wedge} 2\right)$ \\
\hline 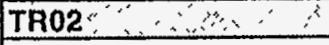 & $\therefore \cos$ & $\because n+\cdots, \ldots$ \\
\hline Agropyron smithii & 96.00 & 34.19 \\
\hline Bromus japonicus & 84.00 & 10.06 \\
\hline Bouteloua gracilis & 60.00 & 6.66 \\
\hline Scorzonera laciniata & 64.00 & 5.97 \\
\hline \begin{tabular}{|l|} 
Centaurea diffusa \\
\end{tabular} & 4.00 & 4.69 \\
\hline Bouteloua curtipendula & 28.00 & 4.56 \\
\hline Bouteloua hirsuta & 36.00 & 4.00 \\
\hline Alyssum minus & 32.00 & 3.78 \\
\hline Artemisla frigida & 16.00 & 3.57 \\
\hline Chrysopsis villosa & 20.00 & 3.15 \\
\hline TRO4 & 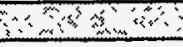 & 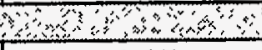 \\
\hline Bromus japonicus & 100.00 & 34.37 \\
\hline Agropyron smithil & 100.00 & 22.45 \\
\hline Carex eleocharis & 16.00 & 8.61 \\
\hline Bouteloua gracilis & 76.00 & 6.94 \\
\hline Scorzonera laciniata & 64.00 & 4.69 \\
\hline Poa compressa & 16.00 & 4.42 \\
\hline \begin{tabular}{|l} 
Linaria dalmatica \\
\end{tabular} & 20.00 & 4.26 \\
\hline Aster ericoides & 28.00 & 3.28 \\
\hline Poa pratensis & 20.00 & 2.59 \\
\hline Alyssum minus & 16.00 & 2.46 \\
\hline TRI1 & 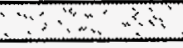 & 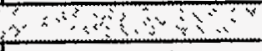 \\
\hline Agropyron smithii & 88.00 & 22.24 \\
\hline \begin{tabular}{|l} 
Bromus japonicus \\
\end{tabular} & 92.00 & 14.61 \\
\hline Carex heliophila & 68.00 & 13.26 \\
\hline Carduus nutans & 28.00 & 12.98 \\
\hline Stipa comata & 52.00 & 11.23 \\
\hline Artemisia ludiviciana & 52.00 & 10.51 \\
\hline Andropogon gerardil & 28.00 & 9.44 \\
\hline Grindelia squarrosa & 12.00 & 7.86 \\
\hline Poa compressa & 8.00 & 5.31 \\
\hline Bromus tectorum & 40.00 & 5.07 \\
\hline
\end{tabular}


Table B-13 (cont.). 1994 Leading Biomass Producers by EcMP Site.

\begin{tabular}{|c|c|c|}
\hline Réclaimed Cóminúnilty. & & $\therefore$ \\
\hline Sample Site & Frequency & Total CYP $\left(g / \mathrm{m}^{\wedge} 2\right)$ \\
\hline TROT & $\therefore \therefore, \cdots$ & $\because \vdots \because \cdots$ \\
\hline Bromus inermis & 80.00 & 81.81 \\
\hline Agropyron intermedium & 88.00 & 51.20 \\
\hline Alyssum minus & 56.00 & 2.91 \\
\hline Melilotus officinalis & 20.00 & 1.47 \\
\hline Poa pratensis & 4.00 & 0.48 \\
\hline Chrysopsis villosa & 8.00 & 0.45 \\
\hline Cirsium arvense & 20.00 & 0.43 \\
\hline Medicago lupulina & 52.00 & 0.32 \\
\hline Tragopogon dubius & 8.00 & 0.16 \\
\hline Camelina microcarpa & 16.00 & 0.08 \\
\hline 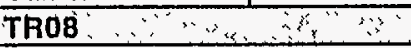 & & $\because$ \\
\hline Bromus inermis & 100.00 & 100.51 \\
\hline Agropyron intermedium & 100.00 & 16.86 \\
\hline Medicago lupulina & 48.00 & 0.96 \\
\hline Alyssum minus & 28.00 & 0.93 \\
\hline Vicla americana & 28.00 & 0.21 \\
\hline Aristida purpurea var.robusta & 4.00 & 0.18 \\
\hline Cirsium anvense & 8.00 & 0.14 \\
\hline Melilotus alba & 8.00 & 0.11 \\
\hline Convolvulus arvensis & 8.00 & 0.06 \\
\hline Linaria dalmatica & 4.00 & 0.06 \\
\hline TRO9 : & $\because 3$ & 3 \\
\hline Agropyron intermedium & 100.00 & 96.37 \\
\hline Bromus Inermis & 80.00 & 74.62 \\
\hline Convolvulus arvensis & 56.00 & 4.00 \\
\hline Cirsium arvense & 4.00 & 1.20 \\
\hline Alyssum minus & 44.00 & 1.02 \\
\hline Agropyron cristatum & 4.00 & 0.29 \\
\hline Tragopogon dubius & 4.00 & 0.11 \\
\hline Camelina microcarpa & 4.00 & 0.06 \\
\hline Bromus japonicus & 12.00 & 0.03 \\
\hline
\end{tabular}


Table B-14. Terrestrial Vegetation DECORANA Ordination by EcMP Transect - Based on Species Presence/Absence Data.

\begin{tabular}{|c|c|c|c|c|c|}
\hline Sample Site & Community & AXIS 1 & AXIS 2 & AXIS 3 & AXIS 4 \\
\hline TR01 T1 & Xeric & 12 & 14 & 20 & 54 \\
\hline \begin{tabular}{|ll} 
TR01 T2 \\
\end{tabular} & Xeric & 11 & 28 & 56 & 34 \\
\hline TR01 T3 & Xeric & 3 & 16 & 31 & 58 \\
\hline TR01 T4 & Xeric & 1 & 29 & 37 & 56 \\
\hline TR01 T5 & Xeric & 9 & 18 & 37 & 44 \\
\hline TR02 T1 & Mesic & 34 & 72 & 38 & 76 \\
\hline TR02 T2 & Mesic & 46 & 69 & 41 & 74 \\
\hline TR02 T3 & Mesic & 34 & 63 & 40 & 71 \\
\hline TR02 T4 & Mesic & 70 & 62 & 39 & 79 \\
\hline TR02 T5 & Mesic & 77 & 59 & 42 & 62 \\
\hline TR03 T1 & Riparian & 271 & 86 & 4 & 0 \\
\hline TRO3 T2 & Riparian & 253 & 34 & 50 & 33 \\
\hline TR03 T3 & Riparian & 278 & 4 & 49 & 51 \\
\hline TR03 T4 & Riparian & 263 & 30 & 72 & 128 \\
\hline TR03 T5 & Riparian & 324 & 7 & 59 & 164 \\
\hline TR04 T1 & Mesic & 79 & 61 & 46 & 72 \\
\hline TR04 T2 & Mesic & 48 & 69 & 56 & 67 \\
\hline \begin{tabular}{|l} 
TR04 T3 \\
\end{tabular} & Mesic & 77 & 85 & 77 & 49 \\
\hline TR04 T4 & Mesic & 92 & 61 & 83 & 49 \\
\hline TR04 T5 & Mesic & 73 & 75 & 87 & 54 \\
\hline TR05 T1 & Riparian & 231 & 146 & 16 & 52 \\
\hline TR05 T2 & Riparian & 329 & 93 & 0 & 16 \\
\hline TR05 T3 & Riparian & 264 & 189 & 24 & 77 \\
\hline TR05 T4 & Riparian & 312 & 181 & 57 & 44 \\
\hline TR05 T5 & Riparian & 341 & 152 & 60 & 20 \\
\hline TR06 T1 & Xeric & 49 & 58 & 103 & 54 \\
\hline TR06 T2 & Xeric & 26 & 64 & 112 & 46 \\
\hline \begin{tabular}{|l} 
TR06 T3 \\
\end{tabular} & Xeric & 28 & 65 & 99 & 41 \\
\hline \begin{tabular}{|ll} 
TR06 T4 \\
\end{tabular} & Xeric & 1 & 69 & 90 & 57 \\
\hline TR06 T5 & Xeric & 24 & 65 & 98 & 54 \\
\hline \begin{tabular}{|l} 
TR07 T1 \\
\end{tabular} & Reclaimed & 156 & 139 & 48 & 63 \\
\hline \begin{tabular}{|l} 
TR07 T2 \\
\end{tabular} & Reclaimed & 152 & 121 & 24 & 71 \\
\hline TR07 T3 & Reclaimed & 126 & 107 & 5 & 91 \\
\hline TR07 T4 & Reclaimed & 131 & 124 & 56 & 60 \\
\hline TR07 T5 & Reclaimed & 132 & 133 & 63 & 42 \\
\hline \begin{tabular}{|l} 
TR08 T1 \\
\end{tabular} & Reclaimed & 144 & 143 & 52 & 85 \\
\hline TR08 T2 & Reclaimed & 146 & 125 & 25 & 96 \\
\hline TR08 T3 & Reclaimed & 138 & 126 & 13 & 76 \\
\hline \begin{tabular}{|l|l|} 
TR08 T4 \\
\end{tabular} & Reciaimed & 168 & 165 & 1 & 105 \\
\hline \begin{tabular}{|l} 
TR08 T5 \\
\end{tabular} & Reclaimed & 147 & 126 & 27 & 80 \\
\hline TRO9 T1 & Reclaimed & 179 & 102 & 155 & 47 \\
\hline TR09 T2 & Reclaimed & 179 & 109 & 174 & 55 \\
\hline TRO09 T3 & Reclaimed & 152 & 68 & 135 & 51 \\
\hline
\end{tabular}


Table B-14 (cont.). Terrestrial Vegetation DECORANA Ordination by EcMP Transect - Based on Species Presence/Absence Data.

\begin{tabular}{|l|l|c|c|c|c|}
\hline TR09 T4 & Reclaimed & 141 & 77 & 171 & 53 \\
\hline TR09 T5 & Reclaimed & 162 & 89 & 147 & 43 \\
\hline TR10 T1 & Riparian & 314 & 0 & 28 & 61 \\
\hline TR10 T2 & Riparian & 276 & 36 & 26 & 11 \\
\hline TR10 T3 & Riparian & 279 & 82 & 63 & 91 \\
\hline TR10 T4 & Riparian & 295 & 23 & 78 & 57 \\
\hline TR10 T5 & Riparian & 194 & 60 & 52 & 79 \\
\hline TR11 T1 & Mesic & 34 & 75 & 62 & 63 \\
\hline TR11 T2 & Mesic & 60 & 65 & 39 & 64 \\
\hline TR11 T3 & Mesic & 43 & 61 & 40 & 58 \\
\hline TR11 T4 & Mesic & 79 & 48 & 80 & 51 \\
\hline TR11 T5 & Mesic & 43 & 73 & 78 & 49 \\
\hline TR12 T1 & Xeric & 13 & 32 & 26 & 76 \\
\hline TR12 T2 & Xeric & 5 & 41 & 33 & 67 \\
\hline TR12 T3 & Xeric & 0 & 48 & 42 & 64 \\
\hline TR12 T4 & Xeric & 13 & 33 & 23 & 76 \\
\hline TR12 T5 & Xeric & 17 & 44 & 36 & 70 \\
\hline
\end{tabular}


Table B-15. Terrestrial Vegetation Orclination by EcMP Transect Reciprocal Averaging Method - Species Presence/Absence Data.

\begin{tabular}{|c|c|c|c|c|c|}
\hline Sample Site & Community & AXIS 1 & AXIS 2 & AXIS 3 & AXIS 4 \\
\hline TR01 T1 & Xeric & -92 & -61 & 107 & 35 \\
\hline TR01 T2 & Xeric & -97 & -58 & 64 & 27 \\
\hline TR01 T3 & Xeric & -95 & -75 & 112 & 26 \\
\hline TR01 T4 & Xeric & -99 & -64 & 84 & 31 \\
\hline TR01 T5 & Xeric & -92 & -66 & 98 & 35 \\
\hline TR02 T1 & Mesic & -81 & -15 & -25 & 0 \\
\hline TR02 T2 & Mesic & -76 & -4 & -57 & -25 \\
\hline TR02 T3 & Mesic & -83 & -15 & -24 & -12 \\
\hline \begin{tabular}{|l} 
TR02 T4 \\
\end{tabular} & Mesic & -55 & 11 & -28 & -17 \\
\hline \begin{tabular}{|l} 
TR02 T5 \\
\end{tabular} & Mesic & -55 & 9 & -34 & -16 \\
\hline TR03 T1 & Riparian & 209 & -11 & -31 & 98 \\
\hline \begin{tabular}{|l} 
TR03 T2 \\
\end{tabular} & Riparian & 195 & -27 & 3 & -29 \\
\hline TR03 T3 & Riparian & 233 & -46 & 25 & -54 \\
\hline TR03 T4 & Riparian & 217 & -45 & 30 & -127 \\
\hline TR03 T5 & Riparian & 297 & -71 & 108 & -184 \\
\hline TR04 T1 & Mesic & -47 & 1 & -43 & -23 \\
\hline TR04 T2 & Mesic & -74 & -14 & -67 & -24 \\
\hline TR04 T3 & Mesic & -52 & 2 & -109 & -30 \\
\hline TR04 T4 & Mesic & -44 & -2 & -90 & -35 \\
\hline \begin{tabular}{|l} 
TR04 T5 \\
\end{tabular} & Mesic & -61 & 2 & -95 & -36 \\
\hline TR05 T1 & Riparian & 132 & 50 & -56 & 126 \\
\hline TR05 T2 & Riparian & 278 & -33 & -43 & 138 \\
\hline TR05 T3 & Riparian & 170 & 69 & -30 & 101 \\
\hline TR05 T4 & Riparian & 251 & 24 & -14 & 101 \\
\hline TR05 T5 & Riparian & 303 & -24 & -52 & 195 \\
\hline TR06 T1 & Xeric & -69 & -26 & -36 & -11 \\
\hline TR06 T2 & Xeric & -87 & -31 & -38 & -14 \\
\hline TR06 T3 & Xeric & -84 & -31 & -21 & -1 \\
\hline \begin{tabular}{|l} 
TR06 T4 \\
\end{tabular} & Xeric & -102 & -35 & -21 & -6 \\
\hline \begin{tabular}{|l} 
TR06 T5 \\
\end{tabular} & Xeric & -88 & -33 & -21 & -5 \\
\hline TR07 T1 & Reclaimed & -10 & 201 & 27 & -3 \\
\hline TR07 T2 & Reclaimed & -13 & 222 & 48 & -11 \\
\hline TR07 T3 & Reclaimed & -28 & 167 & 28 & -7 \\
\hline \begin{tabular}{|l} 
TR07 T4 \\
\end{tabular} & Reclaimed & -26 & 189 & 23 & -10 \\
\hline TR07 T5 & Reclaimed & -22 & 179 & 37 & 7 \\
\hline TR08 T1 & Reclaimed & -22 & 246 & 24 & -17 \\
\hline TR08 T2 & Reclaimed & -13 & 218 & 39 & -10 \\
\hline TR08 T3 & Reclaimed & -25 & 238 & 46 & -7 \\
\hline TR08 T4 & Reclaimed & -4 & 323 & 60 & 5 \\
\hline TR08 T5 & Reclaimed & -8 & 220 & 56 & 10 \\
\hline \begin{tabular}{|l|} 
TR09 T1 \\
\end{tabular} & Reclaimed & 2 & 246 & 55 & -29 \\
\hline TR09 T2 & Reclaimed & -5 & 342 & 91 & -23 \\
\hline TR09 T3 & Reclaimed & -15 & 240 & 33 & -43 \\
\hline
\end{tabular}


Table B-15 (cont.). Terrestrial Vegetation Ordination by EcMP Transect Reciprocal Averaging Method - Species Presence/Absence Data.

\begin{tabular}{|l|l|c|c|c|c|}
\hline TR09 T4 & Reclaimed & -24 & 179 & 13 & -28 \\
\hline TR09 T5 & Reclaimed & -8 & 228 & 48 & -20 \\
\hline TR10 T1 & Riparian & 274 & -50 & 28 & -36 \\
\hline TR10 T2 & Riparian & 224 & -24 & 5 & 54 \\
\hline TR10 T3 & Riparian & 196 & -11 & -25 & 28 \\
\hline TR10 T4 & Riparian & 253 & -48 & 0 & -38 \\
\hline TR10 T5 & Riparian & 84 & 18 & -34 & 12 \\
\hline TR11 T1 & Mesic & -79 & -26 & -50 & -6 \\
\hline TR11 T2 & Mesic & -64 & -7 & -46 & -16 \\
\hline TR11 T3 & Mesic & -78 & -20 & -33 & -9 \\
\hline TR11 T4 & Mesic & -52 & -18 & -55 & -20 \\
\hline TR11 T5 & Mesic & -78 & -22 & -53 & -19 \\
\hline TR12 T1 & Xeric & -92 & -48 & 59 & 24 \\
\hline TR12 T2 & Xeric & -99 & -52 & 50 & 28 \\
\hline TR12 T3 & Xeric & -103 & -48 & 50 & 25 \\
\hline TR12 T4 & Xeric & -93 & -46 & 58 & 22 \\
\hline TR12 T5 & Xeric & -91 & -44 & 41 & 21 \\
\hline
\end{tabular}


Table B-16. 1994 DECORANA Ordination by Species Presence/Absence Data.

\begin{tabular}{|c|c|c|c|c|}
\hline SPECOODE & AXIS1 & AXIS 2 & AXIS 3 & AXIS 4 \\
\hline ACMII & 248 & -42 & -59 & 0 \\
\hline AGCA1 & 369 & -62 & -158 & -450 \\
\hline AGCR1 & 183 & 100 & 236 & 127 \\
\hline AGIN1 & 172 & 127 & 192 & 53 \\
\hline AGRE 1 & 358 & 286 & -14 & -125 \\
\hline AGSM1 & 246 & 23 & -33 & 163 \\
\hline AGST1 & 386 & 205 & 16 & 26 \\
\hline ALMI1 & 127 & -4 & 124 & 1 \\
\hline ALTE1 & -55 & 26 & 45 & 80 \\
\hline AMFRI & 358 & 260 & -13 & -61 \\
\hline AMPS1 & 129 & 31 & -20 & 8 \\
\hline ANGE1 & -59 & 28 & 31 & 37 \\
\hline ANMI1 & -96 & -40 & -68 & 158 \\
\hline ANOC1 & -68 & 211 & 572 & 40 \\
\hline ANSC1 & -69 & 35 & 25 & 63 \\
\hline APCA1 & 401 & 281 & -95 & -395 \\
\hline ARCA1 & 97 & 0 & -271 & 184 \\
\hline ARDR1 & 131 & 186 & -31 & -3 \\
\hline ARFE1 & -36 & 131 & 93 & 74 \\
\hline ARFE2 & -96 & -38 & -45 & 50 \\
\hline ARFE3 & 45 & -39 & 350 & -86 \\
\hline ARFRI & 27 & 39 & 51 & -15 \\
\hline ARFU1 & 189 & 130 & 48 & 219 \\
\hline ARGL1 & 10 & 5 & 207 & -68 \\
\hline ARLO1 & 7 & 105 & -55 & 55 \\
\hline ARLU1 & 74 & 10 & 35 & -25 \\
\hline ASAG1 & 57 & -31 & 140 & -38 \\
\hline ASCR1 & -34 & 97 & -117 & 195 \\
\hline ASDR1 & -19 & 126 & -20 & -16 \\
\hline ASER1 & 242 & 168 & -17 & 129 \\
\hline ASFL1 & -5 & 196 & -76 & 208 \\
\hline ASIN1 & 382 & -115 & 141 & 348 \\
\hline ASMl1 & -91 & -71 & 14 & -118 \\
\hline ASOC1 & 400 & -262 & 306 & 569 \\
\hline ASOF1 & 397 & -187 & -166 & -287 \\
\hline ASPA1 & 169 & 219 & 12 & 211 \\
\hline ASPO1 & 27 & 182 & -95 & 148 \\
\hline ASPU1 & 52 & 188 & -118 & 207 \\
\hline ASSE1 & -10 & 47 & 319 & -23 \\
\hline ASSH1 & -64 & 126 & 106 & 88 \\
\hline ASSP1 & 376 & -47 & 102 & 193 \\
\hline ASVI1 & 232 & -100 & -119 & 192 \\
\hline BAOR1 & 403 & 181 & 45 & 71 \\
\hline BOCU1 & -53 & 35 & 47 & 45 \\
\hline BOGR1 & -3 & 5 & 64 & 10 \\
\hline $\mathrm{BOHI}$ & -39 & 46 & 73 & 33 \\
\hline BRIN1 & 238 & 242 & 152 & 162 \\
\hline BRJA1 & 187 & 120 & 138 & -6 \\
\hline BRTE1 & -12 & 63 & 166 & -29 \\
\hline BUDA1 & -32 & 33 & -18 & 51 \\
\hline $\mathrm{CACH} 1$ & 400 & -154 & 343 & -141 \\
\hline CAEL1 & -13 & 40 & -125 & 193 \\
\hline CAFI1 & -34 & 32 & 604 & 2 \\
\hline CAHE1 & -59 & 33 & 15 & 25 \\
\hline CAIN1 & -31 & 103 & 228 & -71 \\
\hline
\end{tabular}


Table B-16. 1994 DECORANA Ordination by Species

Presence/Absence Data.

\begin{tabular}{|c|c|c|c|c|}
\hline CALA1 & 322 & -36 & 235 & 369 \\
\hline CAMI1 & 65 & 14 & 143 & -22 \\
\hline CANE1 & 399 & -6 & 30 & -10 \\
\hline CANU1 & 246 & 24 & 191 & 120 \\
\hline CAOR1 & -73 & 165 & -113 & 193 \\
\hline CAPR1 & 356 & -174 & 436 & 533 \\
\hline CARO2 & 356 & -174 & 436 & 533 \\
\hline CASE2 & -97 & -36 & -29 & 12 \\
\hline CASE3 & -98 & -54 & -44 & 1 \\
\hline CASII & 443 & -350 & 175 & 605 \\
\hline CAST1 & 338 & -16 & 78 & 223 \\
\hline CEAR1 & 356 & -174 & 436 & 533 \\
\hline CEDI1 & 114 & -58 & .99 & 112 \\
\hline CHFU1 & 68 & -61 & -7 & 199 \\
\hline CHLE? & -31 & 183 & 176 & 65 \\
\hline CHVI1 & 64 & 31 & 43 & 32 \\
\hline CIAR1 & 271 & 173 & 0 & 55 \\
\hline CIIN1 & 246 & -117 & 315 & -22 \\
\hline CIMA1 & 388 & -261 & 173 & 252 \\
\hline ClUN1 & -32 & 111 & 90 & 81 \\
\hline COAR1 & 218 & 178 & 164 & 188 \\
\hline COCA1 & 385 & 279 & 288 & 274 \\
\hline COLII & -42 & 154 & -116 & -10 \\
\hline COMA1 & 418 & 734 & 212 & -172 \\
\hline COMl1 & 4 & 22 & 134 & -8 \\
\hline COUM1 & 33 & -42 & 55 & 171 \\
\hline CRERI & 359 & -202 & 260 & 228 \\
\hline CROC1 & 45 & -39 & 350 & -86 \\
\hline CYOF1 & 395 & 225 & 44 & -84 \\
\hline DACA1 & 68 & 223 & -306 & 238 \\
\hline DAGL1 & 374 & 327 & -44 & -217 \\
\hline DAPU1 & -68 & 36 & 84 & 41 \\
\hline DENU1 & 271 & -65 & -197 & 83 \\
\hline DEPI1 & 76 & -3 & 134 & 75 \\
\hline DERI1 & 4 & 51 & 192 & -38 \\
\hline DESO1 & -68 & 211 & 572 & 40 \\
\hline DRNE1 & 273 & -218 & 41 & 384 \\
\hline \begin{tabular}{|l} 
DRRE1 \\
\end{tabular} & -72 & 34 & 66 & 118 \\
\hline ECVII & -59 & 62 & 32 & 25 \\
\hline ELCA1 & 356 & 255 & -170 & -151 \\
\hline ELMA1 & 472 & 439 & 405 & -358 \\
\hline ELPA1 & 384 & 262 & 205 & 244 \\
\hline EPCl1 & 398 & -250 & 136 & 180 \\
\hline EPPA1 & 328 & 188 & -81 & -184 \\
\hline EQAR1 & 395 & -14 & 199 & -290 \\
\hline EQHY1 & 378 & -248 & 142 & -78 \\
\hline EQLA1 & 379 & -142 & -48 & -230 \\
\hline ERAL1 & -74 & 18 & 103 & 86 \\
\hline ERASI & -35 & 66 & 95 & -4 \\
\hline ERCl1 & 90 & -17 & -46 & -11 \\
\hline ERDI1 & 79 & -33 & 94 & 172 \\
\hline ERFL1 & 14 & -20 & -12 & 127 \\
\hline ERRE1 & 33 & 69 & 130 & 79 \\
\hline EUDE1 & -45 & 216 & 10 & -44 \\
\hline EURO1 & .56 & 39 & -147 & 202 \\
\hline EUSE1 & 271 & -65 & -197 & 83 \\
\hline
\end{tabular}


Table B-16. 1994 DECORANA Ordination by Species Presence/Absence Data.

\begin{tabular}{|c|c|c|c|c|}
\hline EUSP1 & 1 & 146 & .50 & 150 \\
\hline EVNU1 & -21 & 123 & -88 & 41 \\
\hline FEPR1 & 388 & 436 & -81 & -142 \\
\hline GAAR 1 & -96 & -38 & -45 & 50 \\
\hline GABO1 & 369 & -130 & 6 & 187 \\
\hline GACO1 & -22 & 130 & 144 & 6 \\
\hline GAPA1 & 351 & 498 & 7 & 323 \\
\hline GECA1 & 377 & -160 & 44 & -45 \\
\hline GEMA1 & 391 & -237 & 188 & 242 \\
\hline GLEE1 & 385 & 205 & -50 & 224 \\
\hline GRSQ1 & 207 & 165 & -56 & -11 \\
\hline GUSA1 & 59 & 179 & -14 & 140 \\
\hline HEAN1 & -31 & -9 & -174 & -27 \\
\hline HEPE1 & -100 & -30 & 139 & -109 \\
\hline HEPU1 & -34 & 45 & 6 & 50 \\
\hline HOJU1 & 289 & 477 & 18 & 1 \\
\hline HYPE1 & 167 & -26 & 2 & 170 \\
\hline HYVE1 & 4 & 38 & -160 & 185 \\
\hline IPSP1 & -93 & -67 & -7 & -83 \\
\hline JUBA1 & 386 & 205 & 16 & 26 \\
\hline JUDU1 & 369 & -65 & 135 & -84 \\
\hline JUTO1 & 374 & 190 & 80 & 289 \\
\hline KOPY1 & -16 & -14 & 25 & 29 \\
\hline KUCH1 & 178 & 221 & -304 & 242 \\
\hline KUEU1 & 84 & 179 & -139 & 179 \\
\hline LAEU1 & 346 & 362 & 185 & 378 \\
\hline LAOB1 & 443 & -350 & 175 & 605 \\
\hline LARE 1 & -24 & 168 & 284 & -7 \\
\hline LASE1 & 211 & 196 & 68 & -24 \\
\hline LEDE1 & 43 & 221 & 278 & -17 \\
\hline LEMI1 & 400 & -262 & 306 & 569 \\
\hline LEMO1 & -71 & 34 & 74 & 43 \\
\hline LEMO2 & -66 & 144 & 155 & 155 \\
\hline LICU1 & 271 & -65 & -197 & 83 \\
\hline LIDA1 & 33 & 115 & 182 & 60 \\
\hline LIIN1 & -55 & 188 & 223 & -6 \\
\hline LIPE1 & 55 & 60 & 187 & 187 \\
\hline LIPU1 & -28 & 85 & -8 & 51 \\
\hline LOOR1 & 83 & 10 & 54 & 84 \\
\hline LUAR1 & 356 & -174 & 436 & 533 \\
\hline LYAM1 & 425 & -311 & -173 & -124 \\
\hline MEAL1 & 268 & 375 & -213 & 253 \\
\hline MEAR1 & 364 & 68 & 0 & 48 \\
\hline MELA1 & 56 & -21 & 16 & 106 \\
\hline MELUT & 262 & 254 & -133 & -43 \\
\hline MEOF1 & 246 & 288 & -48 & 95 \\
\hline MESA1 & 204 & 17 & 626 & -81 \\
\hline MICU1 & -14 & 56 & -40 & 148 \\
\hline MIGR1 & 59 & 158 & 283 & -43 \\
\hline MILII & -46 & 37 & 60 & 34 \\
\hline MOFl1 & 374 & -196 & 62 & -41 \\
\hline MUDI1 & 15 & 111 & -57 & 167 \\
\hline MUMO1 & -82 & -35 & -55 & 87 \\
\hline MURA1 & 454 & 203 & -409 & -144 \\
\hline MUWR1 & -38 & 145 & .191 & 144 \\
\hline NAOF1 & 411 & -299 & 159 & 359 \\
\hline
\end{tabular}


Table B-16. 1994 DECORANA Ordination by Species

Presence/Absence Data.

\begin{tabular}{|c|c|c|c|c|}
\hline NECA1 & 370 & -157 & 82 & 216 \\
\hline OEBI1 & 394 & 198 & 184 & 212 \\
\hline OEBR1 & 6 & 86 & 334 & -6 \\
\hline OECO1 & -104 & 155 & -43 & 221 \\
\hline ONMO1 & 286 & -20 & -86 & 227 \\
\hline OPFR1 & 157 & -47 & 88 & -63 \\
\hline OPHU1 & 74 & -18 & 154 & -31 \\
\hline ORFA1 & -38 & 19 & -41 & 169 \\
\hline OXDI1 & 380 & -236 & 270 & 392 \\
\hline OXLA1 & -79 & 70 & 133 & 102 \\
\hline PAJA1 & -79 & -41 & 6 & -10 \\
\hline PAVI1 & 309 & 213 & -48 & 295 \\
\hline PEAN1 & -87 & 60 & -107 & 207 \\
\hline PESE1 & -45 & 177 & 164 & -20 \\
\hline PESI1 & -61 & 173 & 51 & 182 \\
\hline PEVI1 & -70 & 11 & -82 & 81 \\
\hline PHHE1 & -51 & 117 & 206 & -31 \\
\hline PHPRI & 325 & 271 & -217 & -147 \\
\hline PHVI2 & 248 & -38 & -196 & 192 \\
\hline PIOP1 & -31 & 103 & 228 & -71 \\
\hline PLLA1 & 393 & -101 & -302 & -251 \\
\hline PLMA1 & 226 & 53 & 811 & -145 \\
\hline PLPA1 & 0 & 166 & 364 & -4 \\
\hline POAC1 & 361 & 276 & -430 & -377 \\
\hline POCA1 & -11 & -12 & 556 & 16 \\
\hline POCO1 & 192 & 176 & 108 & 21 \\
\hline PODE1 & 373 & 228 & -91 & -193 \\
\hline POFI1 & -86 & -57 & -187 & 213 \\
\hline POGR1 & -93 & -25 & 230 & -207 \\
\hline POHI1 & 267 & -160 & 46 & 202 \\
\hline POLA1 & 431 & 306 & 194 & 332 \\
\hline POPR1 & 219 & 103 & 40 & 12 \\
\hline \begin{tabular}{|l|} 
POSA1 \\
\end{tabular} & 43 & 221 & 278 & -17 \\
\hline PRVI1 & 392 & -157 & -11 & 191 \\
\hline PRVU1 & 370 & -133 & 126 & -267 \\
\hline PSTE1 & 3 & 7 & 61 & 145 \\
\hline QULO1 & 164 & -169 & 830 & -61 \\
\hline RACO1 & 10 & 90 & -86 & 166 \\
\hline RHAR1 & 283 & -127 & -20 & -216 \\
\hline RIOD1 & 391 & -207 & -82 & -218 \\
\hline ROARI & 277 & 209 & 40 & 156 \\
\hline ROWO1 & 392 & -56 & 3 & -75 \\
\hline RuCR1 & 372 & 254 & -3 & -15 \\
\hline RUME1 & 376 & 380 & -4 & -147 \\
\hline RUOB1 & 397 & -273 & 56 & 211 \\
\hline SAAM1 & 377 & -124 & -74 & -95 \\
\hline SAEX1 & 390 & -117 & -100 & -218 \\
\hline SALU1 & 360 & -216 & 171 & -144 \\
\hline SCAM1 & 430 & 407 & 320 & -223 \\
\hline SCBR1 & 11 & 12 & -150 & 90 \\
\hline SCLA1 & 13 & 80 & 164 & 54 \\
\hline SCLA2 & 400 & -154 & 343 & -141 \\
\hline SCPAI & 397 & 170 & -20 & -139 \\
\hline SCVA1 & 444 & 350 & 264 & 207 \\
\hline SEDE1 & 378 & -192 & 307 & 241 \\
\hline SEIN1 & 41 & 47 & -132 & 161 \\
\hline
\end{tabular}


Tabie B-16. 1994 DECORANA Ordination by Species Presence/Absence Data.

\begin{tabular}{|c|c|c|c|c|}
\hline SEPL 1 & -4 & -31 & -76 & 21 \\
\hline SESP1 & -11 & 106 & -103 & 192 \\
\hline SEIR1 & 176 & 217 & -278 & 217 \\
\hline SIALI & 77 & 172 & 160 & 155 \\
\hline SIAN1 & -40 & -41 & -25 & -25 \\
\hline SIDR1 & -88 & -12 & 63 & 22 \\
\hline SIHYY & -22 & 3 & 148 & -31 \\
\hline SIMO1 & 271 & -65 & -197 & 83 \\
\hline SOMl1 & 275 & 98 & -78 & 28 \\
\hline SOMO1 & 248 & -42 & -58 & 207 \\
\hline SONE1 & -102 & 61 & .70 & 209 \\
\hline SONU1 & -96 & -20 & -39 & 84 \\
\hline SORl1 & -45 & 206 & -209 & 205 \\
\hline SPCO1 & 0 & 111 & 25 & 69 \\
\hline SPCR1 & 264 & 389 & -100 & 211 \\
\hline SPHE1 & -76 & -44 & -47 & -59 \\
\hline SPOB1 & 356 & -174 & 436 & 533 \\
\hline SPPE1 & 356 & -174 & 436 & 533 \\
\hline STCO1 & -62 & 33 & 96 & 11 \\
\hline STNE1 & -57 & 108 & 653 & -6 \\
\hline STPA2 & 401 & -248 & 185 & 283 \\
\hline STRO1 & 369 & -62 & -158 & -450 \\
\hline STVI1 & 30 & -13 & -77 & 202 \\
\hline SYOC1 & 382 & -67 & 24 & 188 \\
\hline TAOF1 & 240 & -25 & 266 & -24 \\
\hline TAPA1 & -96 & -61 & -4 & -68 \\
\hline THAR1 & 311 & 51 & 89 & 228 \\
\hline THME1 & 238 & 364 & 424 & -75 \\
\hline THRH1 & 392 & -79 & 1 & -248 \\
\hline TOGR1 & -57 & 108 & 653 & -6 \\
\hline TOHO1 & -106 & -86 & -50 & 46 \\
\hline TORY1 & 397 & -187 & -166 & -287 \\
\hline TRAE1 & -19 & -41 & -71 & -14 \\
\hline TRDU1 & 103 & 128 & 149 & -16 \\
\hline TRl1 & -45 & 216 & 10 & -44 \\
\hline TRI2 & -32 & 126 & -126 & 130 \\
\hline TROC1 & 14 & 175 & 165 & 4 \\
\hline TYLA1 & 352 & -14 & 145 & 213 \\
\hline VEAM1 & 402 & -52 & 76 & 237 \\
\hline VEAN1 & 380 & -97 & -31 & -199 \\
\hline VEBL 1 & 273 & -77 & 80 & 172 \\
\hline VEBR1 & 295 & 550 & 140 & -25 \\
\hline VEHA1 & 389 & -216 & 116 & -159 \\
\hline VETH1 & 266 & -76 & 156 & 99 \\
\hline VIAM1 & 185 & 9 & -73 & 107 \\
\hline \begin{tabular}{|l|} 
VINE1 \\
\end{tabular} & 397 & -176 & 22 & 249 \\
\hline VINU1 & -71 & 24 & 166 & 23 \\
\hline YUGL1 & 4 & 176 & 173 & 105 \\
\hline
\end{tabular}


Table B-17. 1994 Reciprocal Averaging Ordination by Species Presence/Absence Data.

\begin{tabular}{|c|c|c|c|c|}
\hline SPECCOOE & AXIS 1 & AXIS2 & AXIS 3 & AXIS 4 \\
\hline AC MI1 & 75 & -53 & -26 & 42 \\
\hline$A G$ CA1 & 358 & -61 & 26 & 261 \\
\hline AG CR1 & -24 & 586 & 180 & -76 \\
\hline AG IN1 & -27 & 538 & 160 & -63 \\
\hline AG REI & 318 & -1 & -111 & 351 \\
\hline AG SM1 & 70 & -18 & -113 & -25 \\
\hline AG ST1 & 369 & -44 & -15 & 127 \\
\hline AL MII & -29 & 121 & 26 & -28 \\
\hline $\mathrm{AL}$ TE1 & -134 & -81 & 31 & 15 \\
\hline AM FR1 & 317 & -11 & -90 & 240 \\
\hline AMPS1 & -17 & -56 & 4 & 37 \\
\hline AN GEI & -135 & .88 & 47 & 26 \\
\hline AN MII & -152 & -141 & 320 & 133 \\
\hline AN OC1 & -141 & -84 & -92 & -28 \\
\hline AN SC1 & -140 & -96 & 90 & 44 \\
\hline AP CAI & 392 & -49 & -112 & 555 \\
\hline AR CA1 & -63 & 354 & 250 & 10 \\
\hline AR DR1 & -27 & 122 & -117 & -13 \\
\hline AR FE1 & -125 & -34 & -50 & -15 \\
\hline ARFE2 & -152 & -141 & 316 & 133 \\
\hline AR FE3 & -83 & -46 & -241 & -96 \\
\hline ARFRI & -87 & -39 & -4 & 14 \\
\hline AR FU1 & 11 & -28 & -174 & -44 \\
\hline AR GL1 & -100 & -55 & -147 & -49 \\
\hline AR L01 & -105 & 87 & 84 & 14 \\
\hline AR LU1 & -54 & -58 & -53 & 17 \\
\hline AS AG1 & -67 & -72 & -60 & -49 \\
\hline AS CR1 & -123 & -16 & 67 & .34 \\
\hline AS DR1 & -118 & -35 & -292 & -116 \\
\hline AS ER1 & 58 & 60 & -41 & 0 \\
\hline AS FL1 & -114 & 97 & -24 & -42 \\
\hline AS IN1 & 366 & -89 & 49 & -217 \\
\hline AS MII & -147 & -166 & 427 & 168 \\
\hline AS OC1 & 411 & -146 & 301 & -746 \\
\hline AS OF1 & 398 & -93 & 75 & 43 \\
\hline AS PA1 & -35 & 615 & 107 & -82 \\
\hline AS PO1 & -89 & 10 & 79 & 77 \\
\hline AS PU1 & -84 & 201 & -41 & -55 \\
\hline AS SE1 & -110 & -40 & -133 & -47 \\
\hline AS SH1 & -138 & -89 & 5 & 17 \\
\hline AS SP1 & 355 & -59 & 23 & -34 \\
\hline AS VI1 & 49 & 4 & 268 & -17 \\
\hline BA ORI & 396 & -73 & 14 & 82 \\
\hline BO CU1 & -132 & -82 & 17 & 11 \\
\hline BO GR1 & -104 & -66 & -35 & -11 \\
\hline BO HII & -126 & -70 & -32 & -9 \\
\hline BR IN1 & 29 & 425 & 94 & 34 \\
\hline BR JA1 & 5 & 77 & -19 & -7 \\
\hline BR TE1 & -112 & -58 & -157 & -49 \\
\hline BU DA1 & -122 & -62 & -41 & -11 \\
\hline $\mathrm{CA} \mathrm{CH} 1$ & 405 & -122 & 2 & -183 \\
\hline CA EL1 & -110 & -61 & 2 & 21 \\
\hline CA FI1 & -124 & -72 & -163 & -63 \\
\hline CA HE1 & -135 & -91 & 52 & 28 \\
\hline$C A \mathbb{N} 1$ & -126 & -57 & -231 & -94 \\
\hline
\end{tabular}


Table B-17. 1994 Reciprocal Averaging Ordination by Species Presence/Absence Data.

\begin{tabular}{|c|c|c|c|c|}
\hline CA LA1 & 278 & 5 & -56 & -2 \\
\hline CAMI1 & -69 & 81 & -24 & -21 \\
\hline CANE1 & 390 & -77 & 13 & 57 \\
\hline CANU1 & 65 & 10 & -106 & -58 \\
\hline CA OR1 & -144 & -77 & 45 & 42 \\
\hline CA PR1 & 346 & -113 & 133 & -611 \\
\hline CARO2 & 346 & -113 & 133 & -611 \\
\hline CA SE? & -153 & -144 & 323 & 136 \\
\hline CA SE 3 & -153 & -160 & 394 & 149 \\
\hline CA SI1 & 475 & -179 & 469 & -880 \\
\hline CA ST1 & 284 & -35 & -85 & 3 \\
\hline CE AR1 & 346 & -113 & 133 & -611 \\
\hline CEDI1 & -24 & -86 & 127 & -5 \\
\hline CHFU1 & -57 & -31 & 233 & -22 \\
\hline CHLE2 & -123 & -44 & -199 & -70 \\
\hline CH VII & -71 & 125 & 79 & -13 \\
\hline CI AR1 & 129 & 177 & 9 & 21 \\
\hline Cl IN1 & 55 & 324 & -3 & -74 \\
\hline CI MAI & 386 & -121 & 198 & -428 \\
\hline CI UN1 & -123 & -58 & -104 & -33 \\
\hline CO AR1 & 8 & 414 & 102 & -62 \\
\hline CO CA1 & 366 & -50 & -9 & -44 \\
\hline COLII & -129 & -52 & -157 & -46 \\
\hline COMA1 & 402 & 62 & -63 & 484 \\
\hline COMl1 & -104 & -36 & -170 & -71 \\
\hline CO UMI & -78 & -96 & 115 & 1 \\
\hline CRER1 & 343 & -99 & 86 & -338 \\
\hline CROC1 & -83 & -46 & -241 & .96 \\
\hline CY OF1 & 383 & -55 & -4 & 104 \\
\hline DA CA1 & -78 & 246 & -27 & -32 \\
\hline DA GL1 & 343 & 12 & -203 & 670 \\
\hline \begin{tabular}{|l|} 
DA PU1 \\
\end{tabular} & -140 & -97 & 77 & 39 \\
\hline DE NU1 & 135 & 45 & -149 & 60 \\
\hline DEPI1 & -58 & 23 & -69 & -63 \\
\hline DERI1 & -105 & -42 & -248 & -92 \\
\hline DE SO1 & -141 & -84 & -92 & -28 \\
\hline DR NE1 & 161 & -183 & 480 & -375 \\
\hline DRRE1 & -141 & -99 & 90 & 41 \\
\hline EC VI1 & -136 & -85 & 22 & 17 \\
\hline EL CAI & 322 & 16 & -72 & 330 \\
\hline EL MA1 & 484 & -60 & -229 & 934 \\
\hline ELPA1 & 364 & -28 & -6 & 78 \\
\hline EP Cl1 & 400 & -122 & 144 & -328 \\
\hline EP PA1 & 284 & 32 & -109 & 433 \\
\hline EQ AR1 & 389 & -78 & -46 & 217 \\
\hline EQHY1 & 372 & -116 & 112 & -262 \\
\hline EQ LA1 & 370 & -87 & 23 & -4 \\
\hline ER AL 1 & -142 & -103 & 123 & 55 \\
\hline ER AS1 & -124 & -46 & -28 & -15 \\
\hline ERCl1 & -46 & -13 & -197 & -106 \\
\hline ERDI1 & -53 & -9 & -81 & -86 \\
\hline ERFL1 & -94 & -25 & -30 & -34 \\
\hline ERRE1 & -90 & -7 & -322 & -143 \\
\hline EUDEI & -127 & -67 & -220 & -33 \\
\hline \begin{tabular}{|l} 
EURO1 \\
\end{tabular} & -134 & -67 & 39 & 24 \\
\hline EUSE1 & 135 & 45 & -149 & 60 \\
\hline
\end{tabular}


Table B-17. 1994 Reciprocal Averaging Ordination by Species Presence/Absence Data.

\begin{tabular}{|c|c|c|c|c|}
\hline EUSP1 & -107 & -17 & -259 & -99 \\
\hline EVNU1 & -119 & -28 & -149 & -58 \\
\hline FEPR1 & 358 & 31 & -165 & 607 \\
\hline GA AR1 & -152 & -141 & 316 & 133 \\
\hline GA BO1 & 349 & -79 & 48 & -132 \\
\hline GACO1 & -118 & -45 & -155 & -58 \\
\hline GAPA1 & 293 & 72 & -120 & 310 \\
\hline GE CA1 & 368 & -96 & 41 & -150 \\
\hline GE MA1 & 391 & -121 & 142 & -375 \\
\hline GLLE1 & 360 & -44 & -24 & 120 \\
\hline GRSQ1 & 16 & 99 & -113 & -15 \\
\hline GUSA1 & -78 & 155 & -60 & -28 \\
\hline HE AN1 & -125 & -52 & -144 & -46 \\
\hline HEPE1 & -157 & -153 & 325 & 141 \\
\hline HEPU1 & -124 & -56 & -59 & -26 \\
\hline HO JU1 & 189 & 73 & -165 & 386 \\
\hline HYPE1 & 2 & -58 & 15 & -34 \\
\hline HYVE1 & -104 & 0 & -192 & -93 \\
\hline IP SP1 & -150 & -163 & 416 & 149 \\
\hline JUBA1 & 369 & -44 & -15 & 127 \\
\hline JUDU1 & 347 & -70 & -17 & 17 \\
\hline JU TO1 & 353 & -25 & 117 & -178 \\
\hline KOPY1 & -110 & -83 & 29 & 7 \\
\hline $\mathrm{KUCHI}$ & -29 & 599 & 181 & -36 \\
\hline KUEU1 & -68 & 275 & -24 & -59 \\
\hline LAEUI & 309 & 29 & 0 & -62 \\
\hline LA OB1 & 475 & -179 & 469 & -880 \\
\hline LARE1 & -120 & -47 & -232 & -84 \\
\hline LA SE1 & 23 & 0 & -88 & 31 \\
\hline LE DE1 & -83 & 6 & -476 & -145 \\
\hline LE Ml1 & 411 & -146 & 301 & -746 \\
\hline LEMO1 & -141 & -101 & 88 & 46 \\
\hline LE MO2 & -140 & -82 & -22 & 6 \\
\hline LICU1 & 135 & 45 & -149 & 60 \\
\hline ㄴI DAT & -88 & 24 & -104 & -14 \\
\hline LIINI & -135 & -66 & -151 & -40 \\
\hline LIPE1 & -69 & -35 & -168 & -101 \\
\hline LIPU1 & -121 & -18 & 35 & 13 \\
\hline LOOR1 & -49 & -68 & -35 & 1 \\
\hline LU AR1 & 346 & -113 & 133 & -611 \\
\hline LY AM1 & 438 & -126 & 124 & -173 \\
\hline ME AL1 & 115 & 414 & 33 & 292 \\
\hline ME AR1 & 338 & -34 & 13 & 9 \\
\hline ME LA1 & -66 & -111 & 215 & 116 \\
\hline MELU1 & 95 & 352 & 79 & 88 \\
\hline ME OF1 & 42 & 481 & 118 & 89 \\
\hline ME SA1 & -10 & 656 & 256 & -103 \\
\hline MI CU1 & -112 & -59 & -35 & 1 \\
\hline MIGR1 & -77 & 0 & -434 & -158 \\
\hline MI LII & -129 & -76 & 4 & 5 \\
\hline MOFI1 & 365 & -97 & 82 & -185 \\
\hline MU DI1 & -99 & 0 & -239 & -106 \\
\hline MUMO1 & -145 & -128 & 270 & 111 \\
\hline MU RA1 & 444 & -83 & -187 & 663 \\
\hline MUWR1 & -127 & -45 & -126 & -23 \\
\hline NA OF1 & 424 & -147 & 291 & -571 \\
\hline
\end{tabular}


Table B-17. 1994 Reciprocal Averaging Ordination by Species Presence/Absence Data.

\begin{tabular}{|l|c|c|c|c|}
\hline NE CA1 & 350 & -85 & 69 & -199 \\
\hline OEBI1 & 382 & -58 & 32 & -21 \\
\hline OEBR1 & -106 & -28 & -317 & -133 \\
\hline OE CO1 & -158 & -131 & 220 & 134 \\
\hline ON MO1 & 197 & -37 & -42 & -74 \\
\hline OPFR1 & -3 & -59 & -132 & -90 \\
\hline OP HU1 & -59 & 28 & 0 & -13 \\
\hline OR FA1 & -126 & -49 & 54 & 32 \\
\hline OXDI1 & 378 & -120 & 205 & -544 \\
\hline OX LA1 & -146 & -105 & 105 & 56 \\
\hline PA JA1 & -145 & -123 & 244 & 94 \\
\hline PA VI1 & 224 & 8 & -130 & 97 \\
\hline PE AN1 & -149 & -106 & 169 & 97 \\
\hline PE SE1 & -129 & -60 & -164 & -48 \\
\hline PE SI1 & -139 & -63 & -77 & -16 \\
\hline PEVI1 & -141 & -103 & 128 & 70 \\
\hline PHHE1 & -133 & -79 & -58 & -6 \\
\hline PHPR1 & 272 & 48 & -190 & 538 \\
\hline PH VI2 & 57 & 296 & 10 & 4 \\
\hline PIOP1 & -126 & -57 & -231 & -94 \\
\hline PL LA1 & 386 & -77 & -5 & 148 \\
\hline PL MA1 & 4 & 617 & 240 & -141 \\
\hline PL PA1 & -108 & -32 & -306 & -117 \\
\hline PO AC1 & 334 & -28 & -135 & 471 \\
\hline PO CA1 & -110 & -66 & -158 & -56 \\
\hline POCO1 & 13 & -32 & -13 & 37 \\
\hline PODE1 & 347 & -24 & -68 & 297 \\
\hline POF1 & -148 & -116 & 252 & 107 \\
\hline POGR1 & -155 & -145 & 282 & 132 \\
\hline PO HI1 & 145 & -137 & 260 & -139 \\
\hline PO LA1 & 439 & -58 & 203 & -198 \\
\hline POPR1 & 29 & 22 & -2 & 20 \\
\hline PO SA1 & -83 & 6 & -476 & -145 \\
\hline PR V11 & 393 & -105 & 103 & -186 \\
\hline PR VU1 & 358 & -84 & 14 & -21 \\
\hline PS TE1 & -100 & -49 & -25 & -26 \\
\hline QU LO1 & -25 & 602 & 143 & -208 \\
\hline RA CO1 & -99 & -19 & -80 & 1 \\
\hline RHAR1 & 194 & -114 & 188 & 55 \\
\hline RI OD1 & 389 & -101 & 87 & -58 \\
\hline ROAR1 & 161 & -28 & -166 & 101 \\
\hline ROWO1 & 381 & -81 & -25 & 109 \\
\hline RUCR1 & 341 & -18 & -81 & 227 \\
\hline RUME1 & 351 & 14 & -14 & 242 \\
\hline RUOB1 & 399 & -122 & 180 & -364 \\
\hline SA AM1 & 355 & -54 & -36 & 138 \\
\hline SA EX1 & 380 & -86 & -6 & 90 \\
\hline SA LU1 & 342 & -92 & 63 & -202 \\
\hline SC AM1 & 430 & -40 & -96 & 411 \\
\hline SCBR1 & -102 & -17 & -203 & -78 \\
\hline SCLA1 & -99 & 4 & -19 & -14 \\
\hline SC PA1 & 405 & -122 & 2 & -183 \\
\hline SC VA1 & 488 & -66 & -22 & 180 \\
\hline SEDE1 & 374 & -117 & 88 & 179 \\
\hline SE IN1 & -89 & 122 & -33 & -352 \\
\hline
\end{tabular}


Table B-17. 1994 Reciprocal Averaging Ordination by Species Presence/Absence Data.

\begin{tabular}{|l|c|c|c|c|}
\hline SE PL1 & -104 & -58 & 115 & 28 \\
\hline SE SP1 & -114 & 54 & 38 & 3 \\
\hline SE TR1 & -29 & 564 & 175 & -29 \\
\hline SI AL1 & -55 & -36 & -146 & -58 \\
\hline SI AN1 & -126 & -86 & 74 & 17 \\
\hline SI DR1 & -148 & -128 & 207 & 90 \\
\hline SI HY1 & -110 & -106 & 114 & 66 \\
\hline SI MO1 & 135 & 45 & -149 & 60 \\
\hline SO MI1 & 153 & 20 & 30 & 26 \\
\hline SOMO1 & 85 & -53 & 70 & 96 \\
\hline SONE1 & -157 & -123 & 230 & 121 \\
\hline SO NU1 & -154 & -134 & 284 & 131 \\
\hline SORI1 & -129 & -39 & -109 & 0 \\
\hline SP CO1 & -107 & -28 & -208 & -80 \\
\hline SP CR1 & 117 & 86 & -162 & 364 \\
\hline SP HE1 & -144 & -125 & 242 & 105 \\
\hline SP OB1 & 346 & -113 & 133 & -611 \\
\hline SP PE1 & 346 & -113 & 133 & -611 \\
\hline ST CO1 & -137 & -94 & 43 & 26 \\
\hline ST NE1 & -139 & -79 & -169 & -69 \\
\hline ST PA2 & 407 & -131 & 168 & -422 \\
\hline STRO1 & 358 & -61 & 26 & 261 \\
\hline ST VI1 & -82 & -57 & -53 & -81 \\
\hline SY OC1 & 364 & -72 & 33 & -59 \\
\hline TA OF1 & 55 & 54 & -38 & -8 \\
\hline TA PA1 & -152 & -163 & 407 & 149 \\
\hline TH AR1 & 244 & -38 & -29 & -108 \\
\hline TH ME1 & 52 & -27 & -105 & 140 \\
\hline THRH1 & 386 & -83 & -12 & 129 \\
\hline TO GR1 & -139 & -79 & -169 & -69 \\
\hline TO HO1 & -152 & -187 & 490 & 128 \\
\hline TORY1 & 398 & -93 & 75 & 43 \\
\hline TR AE1 & -111 & -81 & 118 & 28 \\
\hline TR DU1 & -44 & 114 & 10 & -3 \\
\hline TRI1 & -127 & -67 & -220 & -33 \\
\hline TR I2 & -125 & -29 & -216 & -98 \\
\hline TROC1 & -100 & -14 & -350 & -129 \\
\hline TY LA1 & 316 & -70 & 66 & -190 \\
\hline VE AM1 & 404 & -83 & 137 & -184 \\
\hline VE AN1 & 370 & -88 & -6 & 8 \\
\hline VE BL1 & 150 & -41 & -69 & -69 \\
\hline VE BR1 & 197 & 80 & -223 & 275 \\
\hline VE HA1 & 385 & -106 & 46 & -166 \\
\hline VE TH1 & 130 & -61 & -71 & -94 \\
\hline VI AM1 & -1 & 200 & -62 & -32 \\
\hline VI NE1 & 400 & -113 & 118 & -275 \\
\hline YI NU1 & -141 & -106 & 89 & 46 \\
\hline YU GL1 & -107 & 85 & -79 & -51 \\
\hline
\end{tabular}


Table B-18. 1993 and 1994 Biomass Comparisons by Community and EcMP Site.

\begin{tabular}{|c|c|c|c|c|}
\hline Site & 93CYP & 94CYP & 93Litter & 94Litter \\
\hline Xeric Commúnity & $124.16 \%$ & 128.59 & $115.77 \%$ & 262.92 \\
\hline TRO1 & 98.43 & 102.46 & 88.69 & 179.01 \\
\hline TR06 & 156.93 & 157.70 & 130.69 & 342.80 \\
\hline TR12 & 117.12 & 125.62 & 127.94 & 266.96 \\
\hline Mesic Community & $\therefore 177 \times 37 \div$ & $5=1200120$ & 15705 & 5225000 \\
\hline TR02 & 99.76 & 101.12 & 114.03 & 207.10 \\
\hline TR04 & 115.64 & 113.17 & 153.55 & 148.51 \\
\hline TA11 & 136.71 & 146.06 & 203.58 & 319.38 \\
\hline Réclaimed Cómmúnín & $\therefore 113,62$ & $145.77^{\prime \prime 8}$ & $\because 150,48$ & 22745 \\
\hline TR07 & 110.77 & 139.46 & 115.81 & 212.37 \\
\hline TR08 & 99.20 & 120.13 & 125.92 & 195.62 \\
\hline TRO9 & 130.90 & 177.71 & 209.70 & 274.37 \\
\hline
\end{tabular}

Community values based on $n=75$.

Site values based on $n=25$.

All values given in $\mathrm{g} / \mathrm{m}^{\wedge} 2$. 
APPENDIX C: SMALL MAMMALS

AUTHORS: ALISON DEANS MICHELLE FINK 


\section{TABLE OF CONTENTS}

LIST OF FIGURES $\ldots \ldots \ldots \ldots \ldots \ldots \ldots \ldots \ldots \ldots \ldots \ldots \ldots \ldots \ldots \ldots \ldots \ldots \ldots \ldots \ldots \ldots$

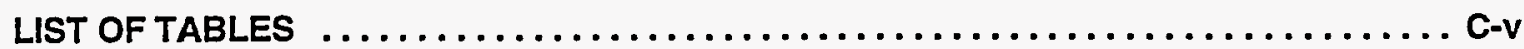

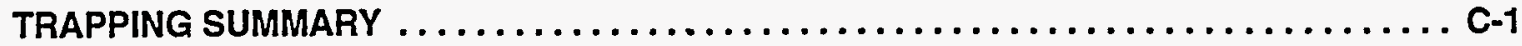

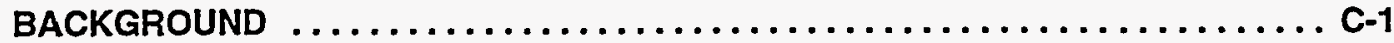

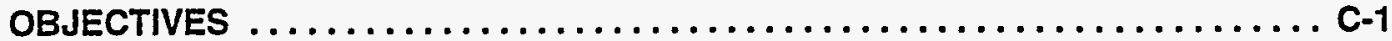

HYPOTHESES $\ldots \ldots \ldots \ldots \ldots \ldots \ldots \ldots \ldots \ldots \ldots \ldots \ldots \ldots \ldots \ldots \ldots \ldots \ldots \ldots \ldots \ldots \ldots \ldots$, C-1

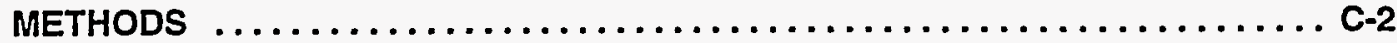

Field Methods $\ldots \ldots \ldots \ldots \ldots \ldots \ldots \ldots \ldots \ldots \ldots \ldots \ldots \ldots \ldots \ldots, \ldots \ldots \ldots, 2$

Analytical Methods ............................... C-2

DATABASE STATUS $\ldots \ldots \ldots \ldots \ldots \ldots \ldots \ldots \ldots \ldots \ldots \ldots \ldots \ldots \ldots \ldots \ldots \ldots \ldots$ C-2

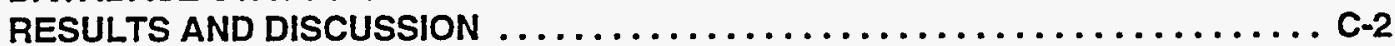

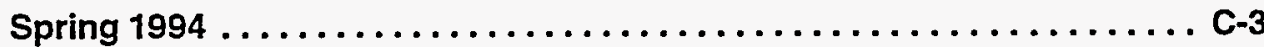

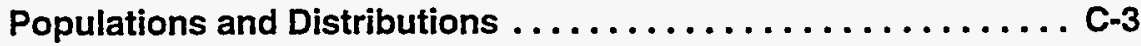

Habitat Preferences ........................... C-4

Age and Sex Distributions $\ldots \ldots \ldots \ldots \ldots \ldots \ldots \ldots \ldots \ldots \ldots \ldots \ldots \ldots \ldots \ldots \ldots \ldots \ldots \ldots \ldots \ldots \ldots \ldots \ldots \ldots \ldots \ldots \ldots \ldots \ldots$
Fall $1994 \ldots \ldots \ldots \ldots \ldots \ldots \ldots$

Populations and Distributions $\ldots \ldots \ldots \ldots \ldots \ldots \ldots \ldots \ldots \ldots \ldots \ldots \ldots \ldots \ldots$, C-4

Habitat Preferences ......................... C-5

Age and Sex Distributions . . . . . . . . . . . .

1993 and 1994 Comparisons . . . . . . . . . . . . . . . . . .

Populations and Distributions ................. C-6

Habitat Preferences ......................... C-6

Age and Sex Distributions $\ldots \ldots \ldots \ldots \ldots \ldots \ldots \ldots \ldots \ldots \ldots$ C-6

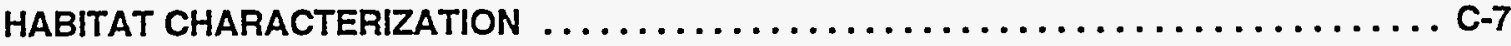

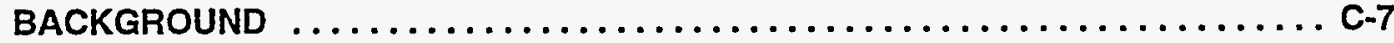

OBJECTIVES ...............................

HYPOTHESES $\ldots \ldots \ldots \ldots \ldots \ldots \ldots \ldots \ldots \ldots \ldots \ldots \ldots \ldots \ldots \ldots \ldots \ldots \ldots \ldots \ldots \ldots \ldots$ C-7

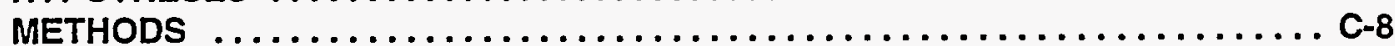

Field Methods $\ldots \ldots \ldots \ldots \ldots \ldots \ldots \ldots \ldots \ldots \ldots \ldots \ldots \ldots \ldots$ C-8

Analytical Methods ..........................

RESULTS AND DISCUSSION ............................ C-9

Association Between Vegetation Species and Trap Success ........ C-9

Association Between Canopy Species and Trap Success . . . . . . . . . C-9

Association Between Mammal Species Captured and Community Types

..................................... C

Comparison of Successful versus Unsuccessful Trapsite Physical

Characteristics ......................... C-10

Correlation of Physical Characteristics .................. C-10

Comparison of Shrub and Cactus Density at.Successful and Unsuccessful

Trap Stations . ........................... C-10

Comparison of Vegetation Species Richness at Successful and

Unsuccessful Trap Stations . ................... C-10

PREBLE'S MEADOW JUMPING MOUSE TRAPPING SUMMARY $\ldots \ldots \ldots \ldots \ldots \ldots \ldots$ C-10

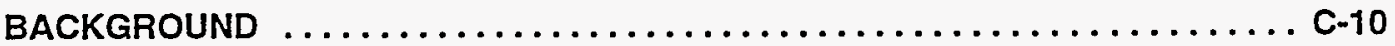

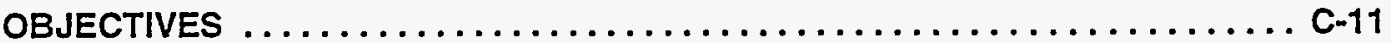

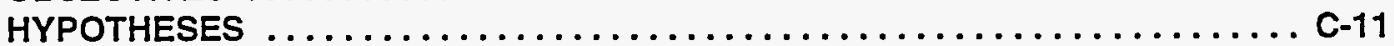




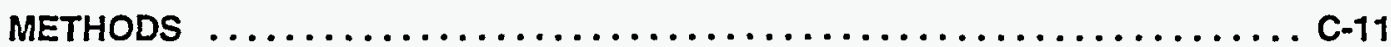

Field Methods $\ldots \ldots \ldots \ldots \ldots \ldots \ldots \ldots \ldots \ldots \ldots \ldots \ldots \ldots \ldots \ldots \ldots \ldots \ldots, 11$

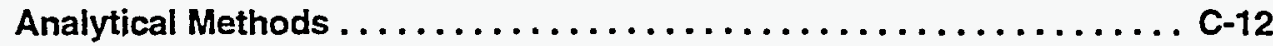

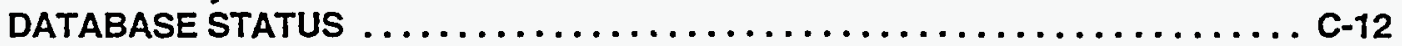

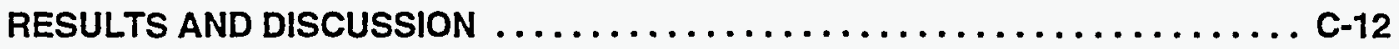

Populations and Distributions $\ldots \ldots \ldots \ldots \ldots \ldots \ldots \ldots \ldots \ldots \ldots, \mathrm{C}-12$

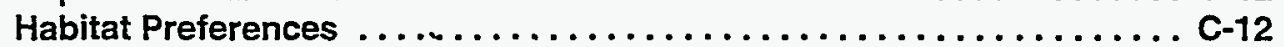

Age and Sex Distributions . . . . . . . . . . . . . . . . . .

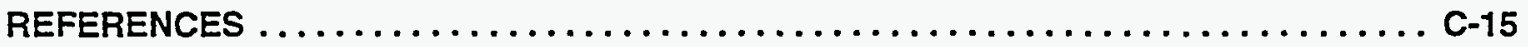




\section{LIST OF FIGURES}

Figure C-1. Spring Capture Summary, All Communities, 1994................ C-16

Figure C-2. Deer Mouse Sex Ratio, Spring 1994....................... C-17

Figure C-3. Deer Mouse Age Ratio, Spring 1994. ...................... C-18

Figure C-4. Fall Capture Summary, All Communities, $1994 . \ldots \ldots \ldots \ldots \ldots \ldots \ldots \ldots$ C-19

Figure C-5. Deer Mouse Sex Ratio, Fall 1994......................... C-20

Figure C-6. Deer Mouse Age Ratio, Fall 1994. . . . . . . . . . . . . . . . . . . . C-21

Figure C-7. Average Number of Individuals of All Species per Season and Year. . . . . . C-22

Figure C-8. Average Number of Individuals of All Species per Community (both years). . C-23

Figure C-9. Average Number of Individuals of All Species per Site. $\ldots \ldots \ldots \ldots \ldots \ldots \ldots$ C-24

Figure C-10. Average Success Rate per Community. $\ldots \ldots \ldots \ldots \ldots \ldots \ldots \ldots \ldots \ldots \ldots$ C-25

Figure C-11. Small Mammal Capture Comparison, Xeric Mixed Grassland Community, Spring. ..................... C-26

Figure C-12. Small Mammal Capture Comparison, Mesic Mixed Grassland Community, Spring. . . . . . . . . . . . . . . . . . C-27

Figure C-13. Small Mammal Capture Comparison, Reclaimed Grassland Community, Spring. . . . . . . . . . . . . . . . . C-28

Figure C-14. Small Mammal Capture Comparison, Riparian Community Complex, Spring. ....................... C-29

Figure C-15. Small Mammal Capture Comparison, All Communities, Spring.......... C-30

Figure C-16. Small Mammal Capture Comparison, Xeric Mixed Grassland Community, Fall. ...................... C-31

Figure C-17. Small Mammal Capture Comparison, Mesic Mixed Grassland Community, Fall. ...................... C-32

Figure C-18. Small Mammal Capture Comparison, Reclaimed Grassland Community, Fall. ...................... C-33

Figure C-19. Small Mammal Capture Comparison, Riparian Community Complex, Fall. ........................ C-34

Figure C-20. Small Mammal Capture Comparison, All Communities, Fall. ............35 Figure C-21. Deer Mouse Sex Ratio Comparison, Spring and Fall 1993 and 1994. ....... C-36 
Figure C-22. Deer Mouse Age Ratio Comparison, Spring and Fall 1993 and 1994. . . . . . C-37

Figure C-23. Capture Locations of Preble's Meadow Jumping Mouse $\ldots \ldots \ldots \ldots \ldots \ldots$. C-38

\section{LIST OF TABLES}

Table C-1. Small Mammal Capture Summary,

Xeric Mixed Grassland Community, Spring 1994................... C-39

Table C-2. Small Mammal Capture Summary,

Mesic Mixed Grassland Community, Spring 1994. . . . . . . . . . . . . C-40

Table C-3. Small Mammal Capture Summary,

Reclaimed Grassland Community, Spring 1994.................... C-41

Table C-4. Small Mammal Capture Summary,

Riparian Community Complex, Spring 1994..................... C-42

Table C-5. Small Mammal Capture Summary, All Communities, Spring 1994. . . . . . . C-43

Table C-6. Small Mammal Summary at the Rocky Mountain Arsenal, Spring 1987. . . . . . C-44

Table C-7. Small Mammal Age and Sex Data,

Xeric Mixed Grassland Community, Spring 1994................... C-45

Table C-8. Small Mammal Age and Sex Data,

Mesic Mixed Grassland Community, Spring 1994................... C-46

Table C-9. Small Mammal Age and Sex Data,

Reclaimed Grassiand Community, Spring 1994. . . . . . . . . . . . . . . . . . C-47

Table C-10. Small Mammal Age and Sex Data,

Riparian Community Complex, Spring 1994.................... C-48

Table C-11. Small Mammal Age and Sex Data, All Communities, Spring 1994. . . . . . . . C-49

Table C-12. Small Mammal Capture Summary,

Xeric Mixed Grassland Community, Fall 1994...................... C-50

Table C-13. Small Mammal Capture Summary,

Mesic Mixed Grassland Community, Fall 1994..................... C-51

Table C-14. Small Mammal Capture Summary,

Reclaimed Grassland Community, Fall 1994. . . . . . . . . . . . . . . . . . . C-52

Table C-15. Small Mammal Capture Summary,

Riparian Community Complex, Fall $1994 \ldots \ldots \ldots \ldots \ldots \ldots \ldots \ldots \ldots$. . . 53

Table C-16. Small Mammal Capture Summary, All Communities, Fall 1994. . . . . . . . . C C-54

Table C-17. Small Mammal Capture Summary at the Rocky Mountain Arsenal, Fall 1986. ..C-55 
Table C-18. Small Mammal Age and Sex Data,

Xeric Mixed Grassland Community, Fall 1994..................... C.56

Table C-19. Small Mammal Age and Sex Data,

Mesic Mixed Grassland Community, Fall 1994.................... C-57

Table C-20. Small Mammal Age and Sex Data,

Reclaimed Grassland Community, Fall 1994...................... C-58

Table C-21. Small Mammal Age and Sex Data,

Riparian Community Complex, Fall 1994......................... C-59

Table C-22. Small Mammal Age and Sex Data, All Communities, Fall 1994. . . . . . . . . C-60

Table C-23. Average Number of Individuals of All Species

and Average Trap Success Rates per Season and Year. ............... C-61

Table C-24. Average Number of Individuals of All Species

and Average Trap Success Rate by Site and Community. .............. C-62

Table C-25. Small Mammal Capture Summary, All Communities, 1993 and 1994. . . . . . C-63

Table C-26. Deer Mouse Age and Sex Ratios, Spring and Fall 1993 and 1994. . . . . . . . . C-64

Table C-27. Association Between Plant Species and Trap Success. . . . . . . . . . . . C-65

Table C-28. Correlation of Physical Characteristics. ......................66

Table C-29. Distance of the Trap Station to the Nearest Canopy Edge. . . . . . . . . . C-67

Table C-30. Distance of the Trap Station to the Nearest Embankment. . . . . . . . . C-68

Table C-31. Distance of the Trap Station to the Nearest Stream Channel. . . . . . . . . C-69

Table C-32. Soil Moisture, Burrowing Opportunities,

Litter Cover, and Trap Position. ......................... C-70

Table C-33. Primary Canopy Species. ................................

Table C-34. Frequency of Occurrence of All Plant Species. $\ldots \ldots \ldots \ldots \ldots \ldots \ldots \ldots \ldots$ C-72

Table C-35. Frequency and Cover of Community Types.................... 


\section{TRAPPING SUMMARY}

\section{BACKGROUND}

Small mammals are a valuable component of ecological investigations and contaminant pathways analyses because they are numerous and easily captured, they occupy small home ranges and so reflect habitat quality or contamination on a small scale, and they live in close contact with surface soils and thus are maximally exposed to surficial contaminants. Small mammal species at the Site consume a variety of food including leafy tissue, seeds, and invertebrates. Additionally, they are a primary prey species for many predators including raptors and coyotes and could be responsible for the spread of bioaccumulated contaminants through the food chain.

The 1994 trapping season was the second full season of data collection at 12 permanent sites. Comparisons across seasons and years are now possible.

\section{OBJECTIVES}

The primary objective of this study module is to assess the dynamics of small mammal populations at the Site and the relationship of these populations to specific habitat characteristics. This objective will be accomplished by collecting data for common and rare species of small mammals in order to gain an understanding of their population characteristics and movement patterns at the Site. Data on biotic, abiotic, and habitat preference variables were collected to assess their influence on these populations. There is also an interest in the extent to which anthropogenic disturbance, if any, of preferred habitat affects long-term health and success of these populations. As the relationships between habitat and populations become better defined, information will be available to managers who are interested in project impacts to natural environments, and this information will become the basis of mitigation strategies.

\section{HYPOTHESES}

All of the hypotheses discussed below were listed in the EcMP Program Plan (EcMP 1993).

1) $H_{0}$ : Populations of small mammals do not vary significantly year-to-year, on a seasonally adjusted basis, within a given study site.

$H_{A}$ : Populations of small mammals vary significantly year-to-year, on a seasonally adjusted basis, within a given study site.

Because only 2 years of data have been collected, long-term trends cannot be projected. However, some preliminary comparisons can be made.

2) $H_{0}$ : Recruitment levels do not vary significantly from year-to-year, on a seasonally adjusted basis, within a given study site.

$H_{A}$ : Recruitment levels vary significantly from year-to-year, on a seasonally adjusted basis, within a given study site.

As in Hypothesis 1, it would be difficult to project trends with only 2 years of data, but some preliminary comparisons can be made.

3) $\mathrm{H}_{0}$ : Small mammal populations do not correlate with proximity to water sources.

$H_{A}$ : Small mammal populations correlate with proximity to water sources.

Maps of all EcMP sites and transects (Terrestrial Vegetation and Small Mammal) are being updated. The Global Positioning System (GPS) used for mapping the EcMP sites uses more current technology than the system used to map the Site. As a result, they are not always compatible and accurate distances from trap sites to water sources cannot be determined via GIS methods. However, the Site has been re-mapped and the data are being verified. When these digitized data are received and the maps updated, this hypothesis may be tested. 
4) $\mathrm{H}_{0}$ : Small mammal populations do not correlate with proximity to human activities. $\mathrm{H}_{\mathrm{A}}$ : Small mammal populations correlate with proximity to human activities.

Testing this hypothesis is dependent upon the maps discussed in Hypothesis 3.

\section{METHODS}

\section{Field Methods}

The Spring sampling session occurred from April 19, 1994 to May 5, 1994 and the Fall sampling occurred from October 4,1994 to October 20,1994. Both sampling sessions followed the procedures presented in the EcMP Program Management/Technical Performance Report, 1993, Appendix 16 and occurred on all twelve permanent terrestrial sites using Longworth live traps so that all 1994 data are comparable to the Fall 1993 data. The Spring 1993 data were collected from nine of the twelve sites using Sherman live traps which do not capture as many species or as many individuals as the Longworth traps (EcMP 1994).

The same methods were used and the same information was collected from each capture during the 1994 and 1993 sampling sessions. This allows for direct comparisons between seasons and years. Each capture was identified to species (where possible), weighed, sexed, aged, marked, and measured for tail, ear, foot, and total body length. Reproductive condition was also noted. Any noteworthy comments, such as traps that were closed but empty and the dye color used that day, were recorded on the datasheet.

Field identifications of small mammals were made using Hall (1981) as the primary source. Secondary identification sources are Armstrong (1972) and Leichleitner (1969). The authority for nomenclature was Jones, et. al. (1992).

\section{Analytical Methods}

Recaptures were not included in any analyses conducted to estimate population sizes and recruitment levels. Some individuals were also found to be "trap happy;" sometimes the same individual would be trapped repeatedly in the same area. Occasionally animals would escape before they could be processed in the field. Animals that were not processed were noted and each field in the database for that record was flagged with "ND," " $\mathrm{Y}$, or "999" to designate missing data values, depending on the field type and width. These animals were not included in calculations of sex and age ratios.

Populations were inferred from trap-night success or the number of captures per 100 trap-nights. A trap-night is one trap set out for one night so 100 traps set out for three consecutive nights would result in 300 trap-nights. Calculation the number of captures per 100 trap-nights is done for convenience because the number resulting from the calculation can be directly converted to percent success. If there are 13.5 Deer Mice per 100 captures at a particular site, this is equal to $13.5 \%$ of the traps contained a Deer Mouse at that site.

\section{DATABASE STATUS}

A total of 718 records were entered into the EcMP database for the Spring trapping session and a total of 1097 records were entered into the EcMP database for the Fall trapping session. All records have been verified and edited according to EcMP data management procedures.

\section{RESULTS AND DISCUSSION}

Throughout this Appendix, common names of all small mammal species will be capitalized for emphasis. This practice does not necessarily follow any particular convention. 


\section{Spring 1994}

\section{Populations and Distrịbutions}

A total of 423 individuals (excluding recaptures) of nine species were captured in the course of the exercise (Tables C-1 to C-5; Figure C-1). Table C-5 shows a breakdown of captures by species and community types. The most individuals and fewest number of species were captured at riparian sites and the most species were captured at xeric grassland sites. The fewest individuals were captured at reclaimed grassland sites. At all sites, except one reclaimed grassland site, the Deer Mouse (Peromyscus maniculatus) was the most commonly trapped species (Tables C-1 to C-4) and occupied $8.5 \%$ of all traps (Table C-5 and Figure C-1). During the spring trapping session, one new species was documented for the Site, the Plains Pocket Mouse (Perognathus flavescens). One individual of this species was trapped once at a xeric grassland site. The other Perognathus species captured, $P$. flavus (Silky Pocket Mouse), was also unique to the same xeric grassland site.

The most common species caught was the Deer Mouse which comprised $72 \%$ of the total capture. The Deer Mouse was trapped in all community types and at all sites but one reclaimed grassland site. The Meadow Vole (Microtus pennsylvanicus) was captured in all community types but the reclaimed grassland and comprised $7.8 \%$ of the catch. In previous non-EcMP work at the Site (Baseline and Operable Unit reports), the Deer Mouse comprised $66 \%$ of the capture and the Meadow Vole comprised 27\% of the capture. At the Rocky Mountain Arsenal, located about 16 $\mathrm{km}$ northeast of Denver, the Deer Mouse was the most common species captured during the Spring of 1986 and comprised $57 \%$ of the capture (Shell 1989). The Deer Mouse was present in all community types sampled at the Rocky Mountain Arsenal and was the most common in all community types except streamside meadow sites, where the Western Harvest Mouse was the most common species, and cattail/rush sites, where the Meadow Vole was the most common species. A total of seven species were documented during the Shell (1989) study at the Rocky Mountain Arsenal, six of which are common at Rocky Flats. These data are summarized in Table C-6. The Rocky Mountain Arsenal is farther removed from the mountains than Rocky Flats and its flora and fauna show a stronger prairie influence. Its land use history is similar to that of Rocky Flats in that it has been removed from agricultural use for several decades. Use of the Rocky Mountain Arsenal has since changed to the manufacture of chemical and incendiary munitions; production, storage and demilitarization of chemical agents; production of pesticides and herbicides; and, finally, cleanup (Shell 1989).

At Rocky Flats, Thirteen-lined Ground Squirrels (Spermophilus tridecemlineatus) comprised $7.1 \%$ of the catch and were found only at the grassland sites and most frequently at the mesic grassland sites. Twenty-nine Prairie Vole (Microtus ochrogaster) individuals were captured $(6.9 \%$ of total captures), primarily in riparian and xeric grassland communities. The Western Harvest Mouse (Reithrodontomys megalotis) was captured in all community types ( $2.8 \%$ of total captures) and the Plains Harvest Mouse ( $R$. montanus) was captured in all grassland community types and comprised $1.9 \%$ of the catch. Four Hispid Pocket Mice (Chaetodipus hispidus) were captured $(0.9 \%$ of the catch): two in the xeric grassland community and two in the reclaimed grassland community. As mentioned above, one each of the Plains Pocket Mouse and the Silky Pocket Mouse were captured $(0.2 \%)$ at the same xeric grassland site. In previous non-EcMP work, the Prairie Vole and the Plains Harvest Mouse each contributed $3 \%$ to the catch and the Western Harvest Mouse, the Preble's Meadow Jumping Mouse (Zapus hudsonius preblel), the Mexican Woodrat (Neotoma mexicana) and the Thirteen-lined Ground Squirrel each contributed less than $1 \%$ to the catch. 


\section{Habitat Preferences}

Total small mammal populations, as inferred from trap-night success, were lowest at reclaimed grassland sites (4\%) and highest at riparian sites (15\%). However, riparian, mesic grassland $(14 \%)$ and xeric grassland (13\%) community population numbers were all very similar (Table C5). Trap-night success for deer mice was highest in riparian and mesic grassland communities at $11 \%$ and lowest at reclaimed sites at $3 \%$. Xeric grassland community trap success for the Deer Mouse was $10 \%$. Overall, trap success was $12 \%$ (423 individuals in 3600 trap-nights). These percentages are higher than the Spring capture percentages from 1993. The primary difference is in the type of trap used. Longworth live traps have been used by EcMP staff since Fall 1993 and have demonstrated the ability to capture not only more individuals but more species than the Sherman traps. This finding was documented in the 1994 EcMP Annual Report.

At the Rocky Mountain Arsenal (Shell 1989), the highest trap-night success was reported at the weedy forb sites where the Deer Mouse was the only species captured. Communities dominated by shrubs (sand sagebrush and rubber rabbitbrush) and yuccas, which most closely resemble the EcMP xeric community, had the greatest number of species captured (seven). Cattail/rush sites also had high small mammal populations and were dominated by the Meadow Vole. Four species of small mammals were captured at these sites (Table C-6).

\section{Age and Sex Distributions}

Age and sex distribution data for the Deer Mouse are presented in Tables $C-7$ to $C-11$. Figures C-2 and C-3 present the ratios calculated from those data for all communities. The Deer Mouse was the only species captured in sufficient numbers to compare age and sex distribution across community types, seasons, and years. However, these data are available for some additional species in some community types.

Sex ratios are expressed in number of males per 100 females. The ratio was highest in the reclaimed grassiand community at 150 males per 100 females and lowest in the xeric grassland community at 102.5 males per 100 females. For all communities combined, there were 109 males per 100 females.

Age ratios are expressed in terms of number of young per 100 females. The ratio ranged from 0 in mesic grassland and riparian communities to 37.5 in reclaimed grassland communities. For all communities combined, there were 4.35 young per 100 females.

\section{Fall 1994}

\section{Populations and Distributions}

A total of 661 individuals (excluding recaptures) of 11 species were captured during the fall trapping exercise (Tables $\mathrm{C}-12$ to $\mathrm{C}-16$; Figure $\mathrm{C}-4$ ). As in the spring trapping session, the most individuals were captured in the riparian community complex and the fewest individuals were captured in the reclaimed community. The fewest number of species (5) were captured in the riparian community complex and the reclaimed grassland community. The most number of species were captured in the xeric grassland community.

One new species was documented for the Site: the House Mouse (Mus musculus). The individual was captured at the reciaimed grassland site TR08. It is suspected that this species also occurs near buildings on plantsite, although to date, only the Deer Mouse has been documented in those areas. 
The Deer Mouse was the most commonly captured species in all community types and at all sites except one reclaimed grassland site, TR07, (Tables C-12 to C-15) where the Western Harvest Mouse was the most commonly captured species (Table C-14). The Deer Mouse constituted $73 \%$ of the individuals (484 of 661 ) captured and occupied $54 \%$ of all traps. The Western Harvest Mouse constituted $8.5 \%$ of the overall catch and was common at all community types. The Meadow Vole constituted $7.8 \%$ of the overall catch and occurred primarily in riparian complexes (49 of 254) but one capture was also recorded at a mesic site. The Prairie Vole comprised $7.3 \%$ of the catch and was captured in all community types but not all sites. Five Plains Pocket Mice were captured at TR06, a xeric site, and one Western Harvest Mouse was captured at the same site. Site TR06 differs floristically from the other two xeric sites, as well as in its fauna. One Silky Pocket Mouse died in the trap at a mesic site and was kept as a voucher. During the fall of 1993, four Silky Pocket Mice were captured at TR06.

At the Rocky Mountain Arsenal (Shell 1989), as at Rocky Flats, the Deer Mouse was the most common species captured during the Fall of 1986 and comprised $79 \%$ of the total capture. It was present in all community types sampled and was the most common species in all community types except native perennial grassland sites where the Northern Grasshopper Mouse was the most common species captured. The Northern Grasshopper Mouse has not been documented at Rocky Flats. Of the other species captured at the Rocky Mountain Arsenal during the Shell (1989) study, all are also common at Rocky Flats except Ord's Kangaroo Rat, which has not been documented (Table C-17).

\section{Habitat Preferences}

Total small mammal populations, as inferred from trap-night success, were highest in the riparian community complex $(28 \%)$, and the mesic grassland community $(25 \%)$, and lowest in the reclaimed grassland community $(5.7 \%)$. Success in xeric grasslands was $14 \%$. Success was higher in the Fall than in the Spring as expected but the ranking of success at the sites is the same.

As in the Spring, small mammal populations at the Rocky Mountain Arsenal (Shell 1989) were highest in areas dominated by weedy forbs and these populations were composed almost entirely of the Deer Mouse. Sites dominated by shrubs (sand sagebrush and rubber rabbitbrush) and yucca again showed the greatest species diversity (four species) and the highest small mammal populations next to the weedy forb sites (Table C-17). Like the EcMP studies, the highest diversity was found at the sites dominated by shrubs and yucca.

The Deer Mouse, the most ubiquitous small mammal species on the Site, was most common in the mesic community. In the riparian community complex, the Meadow Vole contributed to the trap success which was highest overall. Trap success for the Deer Mouse was lowest in the reclaimed grassland community (3.1\%). At the reclaimed site TR09, located in the southeast corner of the Site, only two Deer Mice were captured for a success rate of $0.7 \%$ but constituted $100 \%$ of the catch. The highest success rate $(24.3 \%)$ was at site TR03 $(71 \%$ of the catch), the Rock Creek riparian site and TRO2 (90\% of the catch), the Rock Creek mesic site.

\section{Age and Sex Distributions}

Age and sex data are shown in Tables C-18 to C-22. Ratios calculated from these data are presented in Figures C-5 and C-6.

As in spring, sex ratios are presented in terms of number of males per 100 females and only the Deer Mouse was captured in sufficient numbers to compare across community types. The number of males per 100 females averaged 97 . The highest ratio was found in the reclaimed 
grassland communities ( 320 males per 100 females) and the lowest in mesic grassland communities (93 males per 100 females).

Young per 100 females averaged 56 . The highest ratio was found in the reclaimed grassland communities (120 young per 100 females) and the lowest in the xeric grassland community (61 young per 100 females). The data suggest that young are dispersing out of the riparian and xeric areas to the mesic and reclaimed areas.

\section{3 and 1994 Comparisons}

\section{Populations and Distributions}

Comparison of means was conducted using one-way ANOVA $(\alpha=0.05)$ and mean separation was conducted using Tukey HSD.(Honestly Significant Differences) Intervals, a conservative test, unless otherwise noted. To test Hypothesis 1, the total number of captures of all species (excluding recaptures) for each year were compared (Table C-23; Figure C-7). Additionally, the number of captures for each season (Spring and Fall) of each year were compared. Overall, there was no significant difference in the mean total number of individuals captured in 1993 and the mean total number of individuals captured in 1994. The only significant difference in number of captures (excluding recaptures) occurred between Spring and Fall 1993 (Spring ave. $=21.13$, Fall ave. $=59.25, p=0.03$ ). Using the less conservative LSD (Least Significant Differences) Intervals for mean separation, there were significantly more captures in Fall 1993 and 1994 than in Spring $1993(p=0.03)$ but Spring 1994 did not differ significantly in terms of individuals captured than any of the other sampling sessions. These differences may be partially explained by the use of an inferior trap during the Spring 1993 sampling session. Therefore, there is not enough evidence to suggest that populations vary significantly from year to year.

For both seasons of both years, riparian and mesic sites had significantly higher numbers $(p<0.001)$ of captures than the reclaimed and xeric sites. There were no significant differences in the number of captures between reclaimed and xeric sites or between riparian and mesic sites. TR03, the Rock Creek riparian site had significantly more $(p<0.001)$ individuals captured than all the reclaimed sites (TR07, TR08, TR09) as well as the Woman Creek xeric site TR12. TR09 had significantly fewer individuals than TR02 (the Rock Creek mesic site), TR05 (the Walnut Creek mesic site), and TR03. These data are shown in Table C-24 and Figures C-7 to C-10.

\section{Habitat Preferences}

As inferred from trap-night success, habitat preferences were consistent for all trapping sessions. Riparian sites consistently had the highest success rate in terms of the percent of successful traps (23\% overall) and reclaimed grassland sites consistently had the lowest percent of successful traps ( $6 \%$ overall). Mesic and xeric grassland sites ranked second and third $(17 \%$ overall and $11 \%$ overall, respectively). Success rates at riparian sites were significantly higher $(p=0.0001)$ than at reclaimed grassland or xeric grassland sites. Success rates at mesic grassland and xeric grassland sites did not differ significantly. Reclaimed grassland sites had significantly $(p=0.001)$ lower success rates than mesic grassland and riparian community complex sites (Table C-24 and Figure C-8). Table C-25 summarizes small mammal captures by species at all communities for both years. Figures $\mathrm{C}-12$ through $\mathrm{C}-20$ summarize captures by species and community for both years and seasons.

\section{Age and Sex Distributions}

During both years, the Deer Mouse sex ratio (males per 100 females) was higher in the spring than in the Fall for all communities combined although the difference was small in 1994 (Table C26; Figures C-21 and C-22). The ratio was higher in the Fall than in the Spring for mesic 
grassland community in 1993; reclaimed grassland community in 1994, and; riparian community complex in 1994. The highest Deer Mouse sex ratio was 320 and was found in the reclaimed grassland during the Fall 1994 sampling session. The lowest Deer Mouse sex ratio was 88 and was found in the reclaimed grassland during the Fall 1993 sampling session.

In order to test Hypothesis 2, the number of juvenile Deer Mice per 100 females was compared across seasons and years. As expected, the Deer Mouse age ratio (young per 100 females) was higher in the Fall than in the Spring The one exception was during the 1993 sampling session on the mesic sites. These differences however, were not statistically significant. Recruitment levels did not differ significantly either between seasons or years. Riparian sites consistently have one of the lowest age ratios for all sampling suggesting that juveniles disperse out of these areas into adjacent grasslands. The data are presented in Table C-25 and Figure C-22.

\section{HABITAT CHARACTERIZATION}

\section{BACKGROUND}

The Small Mammal Habitat Characterization study was conducted to determine if there are any statistically significant differences in vegetation cover, shrub and succulent densities, and species richness between trap stations for which there were captures (successful) during the Small Mammal trapping exercise and those for which there were no captures (unsuccessful).

\section{OBJECTIVES}

The primary objective of characterizing small mammal habitats at the Site is to uncover patterns of habitat heterogeneity which may be due to topography, vegetation, or anthropogenic disturbance. This information may be used when restoring habitat disturbed by clean-up activities at the Site.

\section{HYPOTHESES}

Some of the hypotheses discussed below are different than those listed in the EcMP Plan.

1) $H_{0}$ : Vegetation species and trap success are not associated. $H_{A}$ : Vegetation species and trap success are associated.

2) $H_{0}$ : Canopy species and trap success are not associated. $\mathrm{H}_{\mathrm{A}}$ : Canopy species and trap success are associated.

3) $\mathrm{H}_{0}$ : Small mammals and plant community type are not associated. $H_{A}$ : Small mammals and plant community type are associated.

4) $H_{0}$ : Physical characteristics do not differ significantly between successful and unsuccessful trap stations.

$H_{A}:$ Physical characteristics differ significantly between successful and unsuccessful trap stations.

5) $H_{0}$ : Shrub and cactus densities do not differ significantly between successful and unsuccessful traps.

$H_{A}$ : Shrub and cactus densities differ significantly between successful and unsuccessful traps. 
6) $H_{0}$ : Vegetation species richness does not differ significantly between successful and unsuccessful traps.

$H_{A}$ : Vegetation species richness differs significantly between successful and unsuccessful traps.

\section{METHODS}

\section{Field Methods}

Ten successful and ten unsuccessful trap stations from each of the 12 sites sampled were chosen for habitat characterization. Because the Deer Mouse (Peromyscus maniculatus) was the only small mammal species present in high enough numbers to compare, successful sites were randomly chosen, where possible, from among trapsites where only the Deer Mouse was captured. Unsuccessful sites were randomly chosen from among trapsites which never had a capture over the 3-day trapping period and for which the trap was never closed and empty, where possible. During trapping, the two primary habitat types present in the immediate vicinity of the trap were recorded for every trapsite regardless of success or species captured.

At each of the 20 trapsites chosen as described above, slope angle (degrees) and slope aspect (degrees) were measured. The trapsite's position on the moisture gradient as indicated by the plant species present was recorded. Hydric sites are characterized by the presence of Juncus and Typha species and are in direct contact with water throughout the year. Humid sites are those that are in wet meadow or ecotonal situations. Mesic sites are characterized by sodforming grasses and xeric sites are characterized by bunch-forming grasses. Burrowing opportunities, low, medium or high, were estimated for each trap station based on the presence of burrows and on the soil texture. The distance to the edge of the nearest contiguous woodland or shrubland associated with a riparian complex was measured and the predominant species present in the canopy was recorded. Each plant species located within a 3-m radius of the trap station was recorded and the number of cactus individuals and woody stems by species were tallied.

\section{Analytical Methods}

Several statistical analyses were conducted on the 1994 habitat characterization data. Three were tests of association, between vegetation species and trap success, between canopy species and trap success, and between mammal species captured and plant community type. Another test compared the physical characteristics of successful versus unsuccessful trapsites. The last analysis looked at possible correlation between these same physical characteristics. Steel and Torrie (1980) was consulted for these statistical methods.

Association tests used a Chi square test on $2 \times 2$ contingency tables that express presence or absence of the two features of concern. A corrected Chi square equation is recommended for use on $2 \times 2$ contingency tables. However, this corrected equation is highly sensitive to low numbers. Only the tests of association between the vegetation species and trap success produced sufficient numbers to use the corrected equation. For this test, Spring and Fall 1994 were calculated separately and then compared to data from Fall of 1993. The other two association tests used the non-corrected equation. Caution is therefore given during interpretation of the results for canopy species with trap success, and mammal species with community type associations. For these two tests, Spring and Fall 1994 data were combined.

Comparison of the physical characteristics found at successful versus unsuccessful trapsites were done using Student's T-test on sample means. The exact equation used varied according to whether variances and/or sample sizes equalled. The characteristics tested were: distance to the nearest canopy edge, in meters (DCE), slope angle, in degrees (ANG), and slope aspect, in 
degrees (ASP). Comparisons were made of successful and unsuccessful trapsites within each sample site, and then within areas classified by soil moisture and burrowing opportunities (see field methods for definitions). No attempt was made to compare among sites or soil classifications because of the high degree of inherent heterogony from site to site. Spring and Fall 1994 were compared separately.

The three physical characteristics, DCE, ANG, and ASP, may provide redundant information. To test this hypothesis, Pearson's Correlation Coefficient was calculated on pair-wise combinations of the three characteristics. Data from both Spring and Fall 1994 were combined for this procedure.

Comparisons of shrub and cactus densities found at successful versus unsuccessful sites were conducted using a Student's T-test on sample means. Where the sample sizes were unequal, it was assumed that the variances were equal which determined the equation used for the comparison. The same tests were performed to compare the number of plant species present at successful versus unsuccessful sites.

\section{RESULTS AND DISCUSSION}

\section{Association Between Vegetation Species and Trap Success}

For Spring 1994, 4 out of 248 (1.6\%) plant species demonstrated significant associations with trap success (Table C-27). Two, Draba reptans and Salix exigua, were associated with successful trapsites $(p=0.05)$, while the other two, Artemisia ludoviciana and Lactuca serriola were significantly associated with unsuccessful trapsites $(p=0.05)$. The Fall 1994 data set produced 9 out of $224(4 \%)$ species with significant associations (Table C-27). Artemisia frigida, Erigeron flagellaris, Gutierrezia sarothrae, Nepeta cataria, and Senecio plattensis were associated with successful trapsites $(p=0.05)$. Convolvulus arvensis, Plantago lanceolata, Sporobolus cryptandrus, and Taraxacum officinale were associated with unsuccessful trapsites $(p=0.05)$.

For comparison, Fall 1993 data were also tested (Table C-27). Three out of 182 (1.6\%) species surfaced; Sisymbrium altissimum was significantly associated with successful trapsites $(p=0.05)$ and Agrostis hyemalis and Monarda fistulosa were associated with unsuccessful trapsites ( $p=$ 0.05).

Because the Deer Mouse has a varied diet and eats insects and other small invertebrates as well as various plant parts (Fitzgerald, et al. 1994), one would not expect to find many positive associations between particular plant species and successful trapsites. The plant species listed in Table C-27 have little in common and the associations appear to be stochastic. One purpose of the EcMP is to define a baseline and to attempt to define ranges of variation. Table C-27 clearly shows that considerable variation in plant species occurs in Deer Mouse habitat and that these mice are successful in a wide range of habitats as already indicated in the section of this appendix which discusses the capture information. These associations may prove more useful in studies of rare species or species with particular habitat affinities.

\section{Association Between Canopy Species and Trap Success}

No significant association emerged.

\section{Association Between Mammal Species Captured and Community Types}

Due to the low numbers involved, habitat types were pooled into general community types; grassland, shrubland, woodland, wetland, and disturbed. The only significant result found was that Microtus pennsylvanicus (Meadow Vole) captures were negatively associated with 
grasslands $\left(X^{2}=5.64, d f=1, p<0.025\right)$. In other words, given the great abundance of grassland habitat on the Site, Meadow Voles occurred significantly less in grasslands than would have been expected. These results are consistent with the capture results which show that the Meadow Vole, although the most common small mammal species at the site next to the Deer Mouse, occurred almost exclusively in riparian habitats (Tables C-5 and C-16).

\section{Comparison of Successful versus Unsuccessful Trapsite Physical Characteristics}

Four out of the 12 sample sites showed significant differences in physical characteristics. Mean slope angle at successful trapsites $\left(3^{\circ}\right)$ is significantly greater than at unsuccessful sites $\left(2^{\circ}\right)$ located at the reclaimed sites TR08 and TR09 which are located on gently sloping terrain and at TR11 which is on a south-facing slope. However, this small difference probably has little biological significance. Slope aspect is significantly lower at successful trapsites at TROT.

When trapsites were grouped by soil moisture and burrowing opportunity characteristics, only the combination of mesic soil and "medium" burrowing opportunities demonstrated a significant difference $(P=0.05)$, and then only with slope aspect. Aspect was lower in successful trapsites than in unsuccessful trapsites.

\section{Correlation of Physical Characteristics}

For both Spring and Fall, 1994, all three characteristics displayed significant correlations to each other (Table C-28). This would indicate that measuring all three characteristics may be redundant.

\section{Comparison of Shrub and Cactus Density at Successful and Unsuccessful Trap Stations}

There were no significant differences between shrub and cactus densities at successful and unsuccessful trap stations for the Deer Mouse.

\section{Comparison of Vegetation Species Richness at Successful and Unsuccessful Trap Stations}

There were no significant differences between vegetation species richness at successful and unsuccessful trap stations for the Deer Mouse.

\section{PREBLE'S MEADOW JUMPING MOUSE TRAPPING SUMMARY}

\section{BACKGROUND}

The Preble's Meadow Jumping Mouse (Zapus hudsonius preblei) (PMJM) is a state species of concern. A private party (Biodiversity Legal Foundation) has petitioned the U.S. Fish and Wildilie Service to federally list the PMJM as threatened or endangered under the Endangered Species Act. PMJM populations have declined precipitously over the past few decades throughout its range (Compton and Hugie 1993) and Rocky Flats is known to have a viable population. Surveys for PMJM were conducted at the Site in the summers of 1992 and 1993 by a subcontractor. Several captures were recorded and habitat was noted, however, individuals were not marked and there is no way to estimate population size from the data. Captures were made in each of the three major watersheds on plantsite. The subcontractor had identified some of the mice captured in the Rock Creek drainage as Zapus princeps (Stoecker 1992 and Stoecker 1993), a larger member of the genus that occurs commonly at higher elevations. The EcMP 1994 work set out to determine if the two species are sympatric and, if they are, the elevation and habitat of sympatry. After fairly extensive trapping of the Rock Creek drainage by EcMP personnel, only $Z$. $h$. preblei 
were found. The subcontractor had collected two specimens during trapping and assigned a specimen to each species. The EcMP mammalogist examined these specimens and determined that one had been misidentified and that both specimens were $Z$. h. preblei. Concurrence was obtained from Dr. David Armstrong, a University of Colorado mammalogist.

\section{OBJECTIVES}

As mentioned above, one of the objectives of the 1994 PMJM work was to confirm the capture of $Z$. princeps and the possible sympatry with $Z$. $h$. preblei. Secondly, the work was designed to confirm the occurrence of PMJM in all drainages at the plantsite and to determine the viability of those populations. Additionally, a sitewide survey of all areas containing known suitable habitat was conducted in order to increase the known range of PMJM at the Site.

\section{HYPOTHESES}

1) Zapus hudsonius preblei and $Z$. princeps have overlapping ranges.

2) Z.h. preblei populations occur on plantsite in the same locations as in previous years.

3) Z.h. preblei populations occur on plantsite in locations where they have not been previously captured but which contain suitable habitat.

\section{METHODS}

\section{Field Methods}

Because the objective of this exercise was to confirm previous captures and species identifications, trapping for the PMJM was conducted only in riparian areas. Future studies may include trapping seeps and hillsides between the riparian areas and the seeps.

Trapping began in the lower Walnut Creek drainage on July 12, 1994, in an area where PMJM had been previously captured. Twenty-five Sherman live traps were placed in each location for three days. Most, but not all, sites were pre-baited for four days using either a sweet horse feed or a mixture of peanuts, oatmeal, and raisins, or a combination of the two baits. The final area to be trapped was in lower Rock Creek and the final trapping day was September 20, 1994.

Each capture was identified to species, aged and sexed. For each PMJM, head and body length, tail length, hind foot length, ear length and weight were recorded. Each individual was marked and the reproductive condition and any unusual characteristics were noted. Each capture was released and no vouchers were collected.

Field identifications were made using Hall (1981). Specimens from the Front Range located at local museums were examined and the range of variation in size and pelage was noted.

The habitat in the vicinity of each capture site was characterized. Endpoints in addition to those measured for the EcMP small mammal habitat characterization were recorded in order to ascertain habitat preferences. Additional variables measured were the distance of the trap station to an embankment, litter cover, the position of the trap relative to the canopy edge (inside, outside, or the edge), and the primary community types in a 3-m radius of the trap station (up to four). 


\section{Analytical Methods}

Recaptures were not included in any analyses in order to estimate population sizes and recruitment levels, and to eliminate redundancy in morphological characteristics.

\section{DATABASE STATUS}

The database contains 34 records of 23 PMIM individuals captured in 1994. An additional 31 records are of captures from 1991, 1992, and 1993. The database is not part of the EcMP database; instead, the data were entered into a QuattroPro file. Future data will be entered into the EcMP database.

\section{RESULTS AND DISCUSSION}

\section{Populations and Distributions}

The majority of the captures during 1994 were in the Rock Creek drainage (18 out of 23 captures). Surveys were unable to confirm the occurrence of PMJM in Woman Creek but new sites were identified in Walnut Creek. In addition, three captures of two individuals occurred on the Pond A-1 margin and four captures of three individuals were recorded above Pond $A-1$. Capture locations are shown in Figure $\mathrm{C}-23$. There are fewer capture locations than capture sites.

All captures occurred in or very near riparian habitats. The two individuals captured on the Pond A-1 margin were the first captures recorded for a pond margin habitat type. It is believed that they occupy those areas where grass seed is plentiful late in the season. More intensive trapping of these areas throughout the PMJM active period may be done during 1995.

\section{Habitat Preferences}

In an effort to obtain an understanding of the PMJM's habitat needs, environmental and floristic characteristic related to successful trap stations were measured. Environmental characteristics measured included distance to the edge of the nearest canopy cover (Table C-29), distance to nearest embankment (Table C-30), distance to the nearest stream channel (Table C-31), and soil moisture, burrowing opportunities, litter cover, and the position of the trap station in relation to the canopy edge (Table C-32).

Canopy cover was defined in this exercise as a large, continuous patch of tree or shrub cover usually in association with a riparian area. Table C-29 shows that $89 \%$ of the sites where a PMJM was captured were within $5 \mathrm{~m}$ of canopy cover and that $93 \%$ were $10 \mathrm{~m}$ or less from canopy cover. There is one outlier on the table that is located on a side drainage $150 \mathrm{~m}$ away from canopy cover and this site has a high abundance of species of Juncus (rushes) and Carex (sedges). Symphoricarpos occidentalis (snowberry) and Amorpha fruticosa (leadplant) also occur in the vicinity of this site. These four plant species may provide cover or a food source for the PMJM and compensate for the lack of typical riparian canopy species.

This study was designed specifically to capture PMJM so traps were placed in riparian areas where the mouse is most likely to occur. Approximately 36,000 trap-nights in other habitat types onsite (from EcMP sampling) have resulted in no PMJM captures. The distance of the trap station to the edge of the nearest stream channel is shown in Table C-32. Seventy-three percent of successful trap stations were located less than $10 \mathrm{~m}$ from a stream channel and none were greater than $35 \mathrm{~m}$ away from a stream channel. The results of an analysis of the distance to an embankment are similar (Table C-30): 46 of the 55 successful sites (84\%) are located $5 \mathrm{~m}$ or less from an embankment and none are greater than $40 \mathrm{~m}$ away from an embankment. These 
embankments may provide hibernating or nesting sites for PMJM and may be important for its success.

Soil moisture, as indicated by the vegetation present, was humid at the majority of successful trap stations (49\%). Humid sites are dominated by marsh or riparian vegetation. PMJM were not captured at xeric sites, which are characterized by the predominance of bunchgrasses, and were rarely captured at hydric sites (sites with standing water throughout most of the year). Burrowing opportunities were estimated using soil texture and the presence or absence of burrows. All successful sites were located in areas where the burrowing opportunities were considered medium or high with the majority $(65 \%)$ located in areas of high burrowing opportunities. Litter cover may provide nesting sites for PMJM and the ground area it covered was visually estimated. Litter cover was considered low if less than $25 \%$, medium if from $25 \%$ to $50 \%$ and high if greater than $50 \%$. The position of the traps in relation to the canopy cover is somewhat subjective because the majority of the traps were located along the edge of the canopy as it is very difficult to place them within thick canopy cover. However, $64 \%$ of the successful trap stations were located along the edge of the canopy and only $5 \%$ were located within the canopy.

At each successful site, the primary plant species of the canopy cover was recorded. At $91 \%$ of the sites, either Salix exigua or Amorpha fruticosa were the primary canopy species (Table C-33). Other species which comprised the majority of the canopy cover were Prunus virginiana, Symphoricarpos occidentalis, and Salix amygdaloides.

As shown in Table C-34, two weedy species, Cirsium arvense and Bromus japonicus, were the most frequently occurring plant species at all sites. C. arvense occurred at $97 \%$ of the PM.JM sites and $B$. japonicus occurred at $77 \%$ of the sites. At a minimum, this information indicates that PMJM are not deterred by the presence of these two weedy plants.

At each PMJM site, the four main community types and the amount of foliar cover for each were recorded. Bottomland shrubland community (Salix spp. and $A$. fruticosa) was the primary community type at $68 \%$ of the sites with an average of $62 \%$ cover. The second most frequently occurring primary community type was mesic mixed grassland (Agropyron smithii and Poa pratensis) and the third most frequently occurring primary community type was short upland shrubland (S. occidentalis and associated). All four community types, their frequencies and their total percent cover are shown in Table C-35.

These data suggest that it is perhaps the juxtaposition of several community types which provide food and cover to the PMJM that is important to the mouse, and not necessarily the occurrence of a single habitat type. The presence of tall plant species which may provide cover for PMJM also appear to be important components of their habitat, as does the presence of soft soil or litter for nest-building. These are all important factors to consider in plans to create suitable habitat for PMJM recovery or for conducting a search for populations either across the plantsite or the state.

\section{Age and Sex Distributions}

Only data from 1994 were used to calculate age and sex ratios of the Mouse at the Site. Data from previous years were not used because recapture information was not collected. Because the sample size is rather small, it is imperative to use caution when interpreting these results. All that can be stated with certainty is that PMJM are reproducing and that the population at this time appears viable.

Of the 231994 captures, two escaped before they could be processed. These two individuals were adults but sex information was not obtained so they were not included in the calculations of the age and sex ratios. Of the 21 individuals processed, there were 6 juveniles, 12 males and 9 females to yield approximately 133 males per 100 females and 67 young per 100 females. These 
ratios are most similar to those for the Deer Mouse in riparian sites during the Fall of 1994 which were approximately 119 males per 100 females and 55 young per 100 females (Table C-21). 


\section{REFERENCES}

Armstrong, D.M. 1972. . Distribution of mammals in Colorado. Monograph of the Museum of Natural History, Univ. of Kansas. 3:1-415.

Ecological Monitoring Program. 1993. Ecological Monitoring Program Program Plan Draft Final. Rocky Flats Plant. U.S. Department of Energy, Golden, CO.

Ecological Monitoring Program. 1994. Ecological Monitoring Program Annùal Report. Rocky Flats Plant. U.S. Department of Energy, Golden, CO.

Compton, S.A. and R.D. Hugie. 1993. Status report on Zapus hudsonius preblei, a candidate endangered subspecies. Prepared by Pioneer Environmental Consulting Services, Inc., Logan, UT.

Fitzgerald, J.P., C.A. Meaney, and D.M. Armstrong. 1994. Mammals of Colorado. University Press of Colorado, Niwot, Colorado. 467 pp.

Hall, R.E. 1981. The mammals of North America, 2nd Edition, Vols I and II. John Wiley and Sons, New York. 1174 pp.

Jones, J.K., R.S. Hoffman, D.W. Rice, C. Jones, R.J. Baker, and M.D. Engstrom. 1992. Revised checklist of North American mammals north of Mexico, 1991. Occas. Papers Mus., Texas Tech. Univ. 146:1-23.

Leichleitner, R.L. 1969. Wild mammals of Colorado. Pruett Publishing Co., Boulder, CO. 239 pp.

Shell Oil Company. 1989. Wildlife resources of the Rocky Mountain Arsenal, Adams County, Colorado. Prepared by Morrison-Knudsen Environmental Services, Inc., Denver, Colorado.

Steel, R.G.D. and J.H. Torrie. 1980. Principles and procedures of statistics, a biometrical approach, 2nd Edition, McGraw-Hill Book Company, New York. 633 pp.

Stoecker, R.E. 1992. Report of Findings, Survey for Preble's jumping mouse. Prepared by Stoecker Ecological Consultants, Boulder, $\mathrm{CO}$.

Stoecker, R.E. 1993. Report of Findings, Second year Survey for Preble's jumping mouse. Prepared by Stoecker Ecological Consultants, Boulder, CO. 


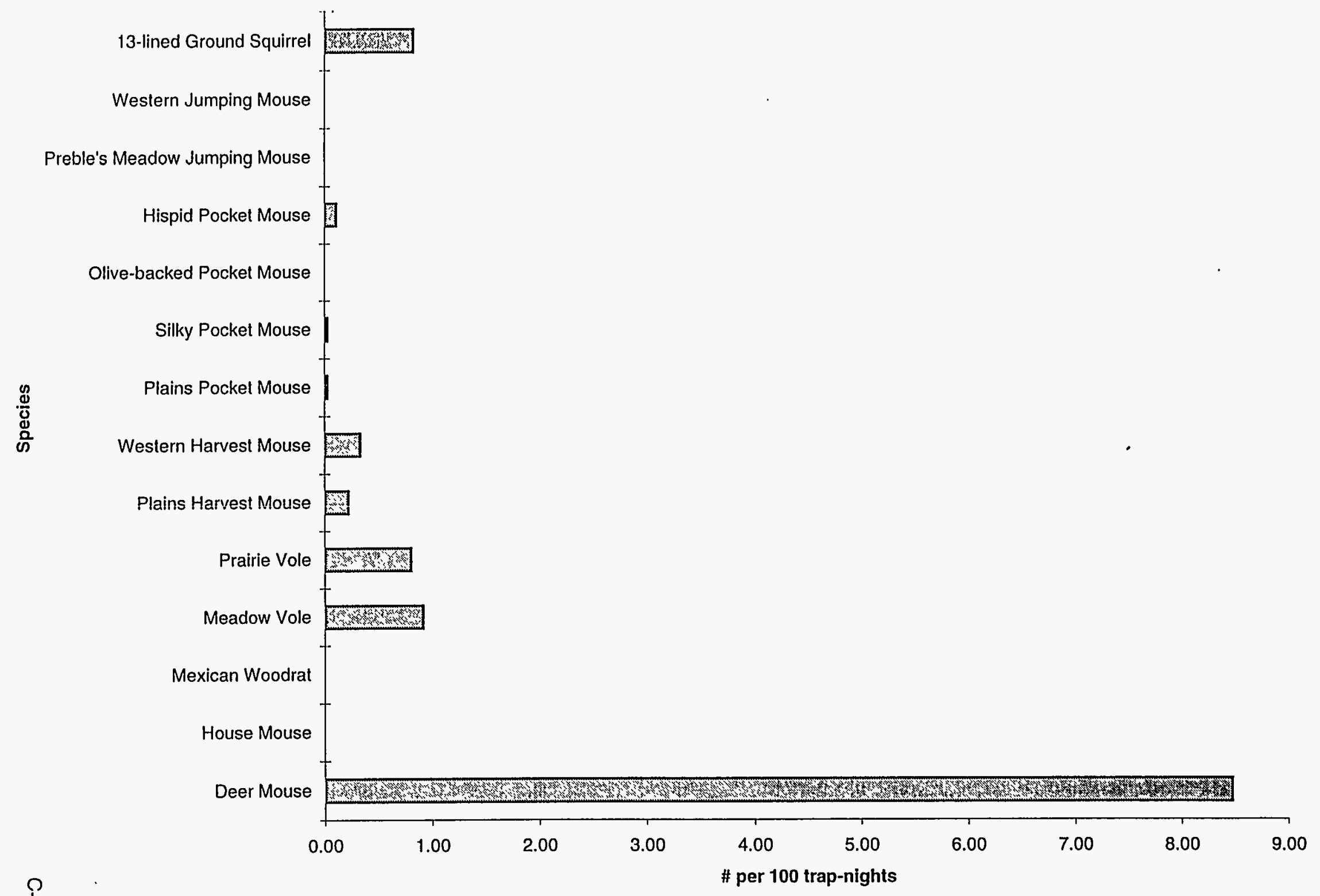

Figure C-1. Spring Capture - nmary, All Communities, 1994. 


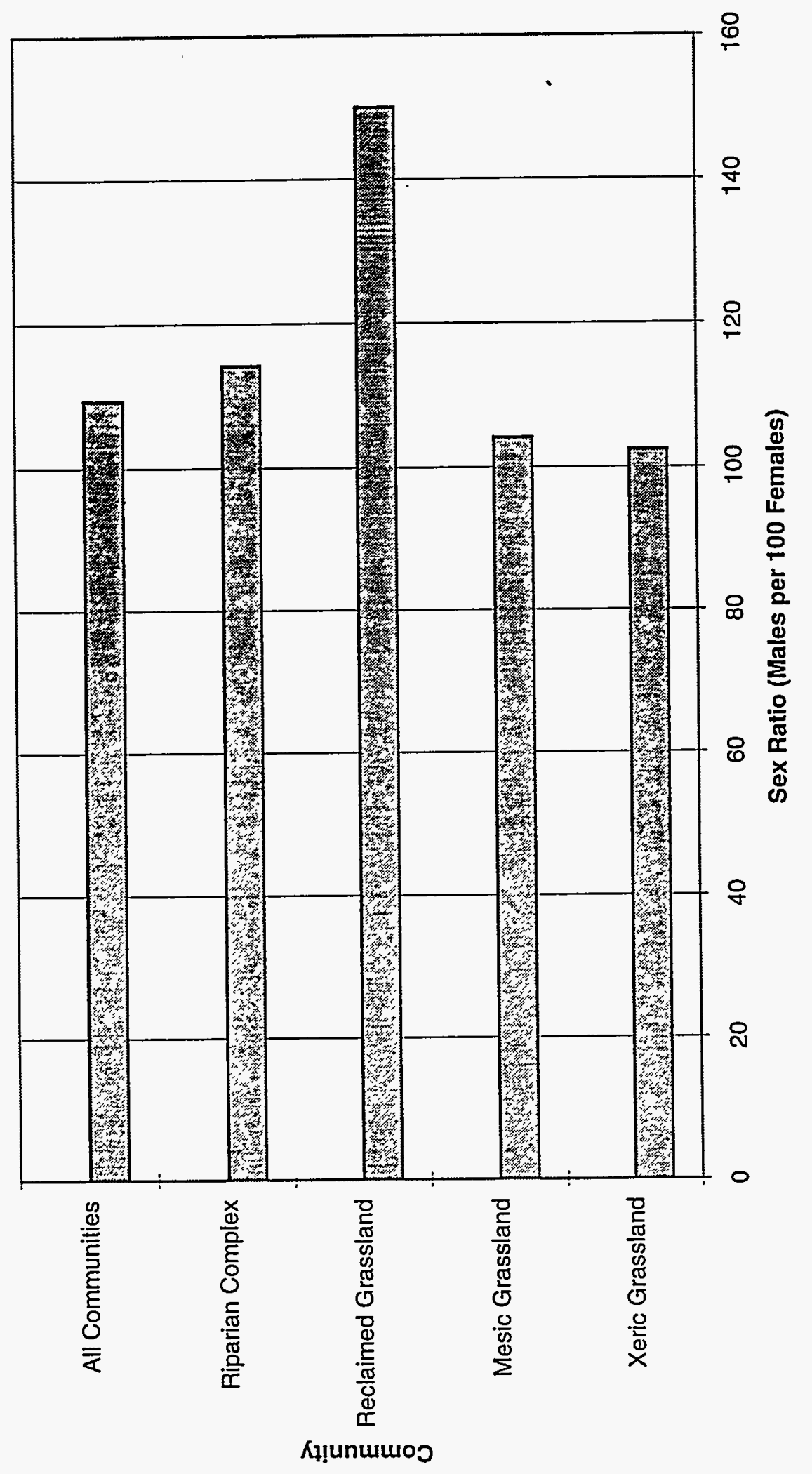

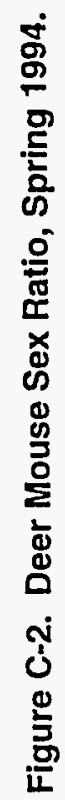




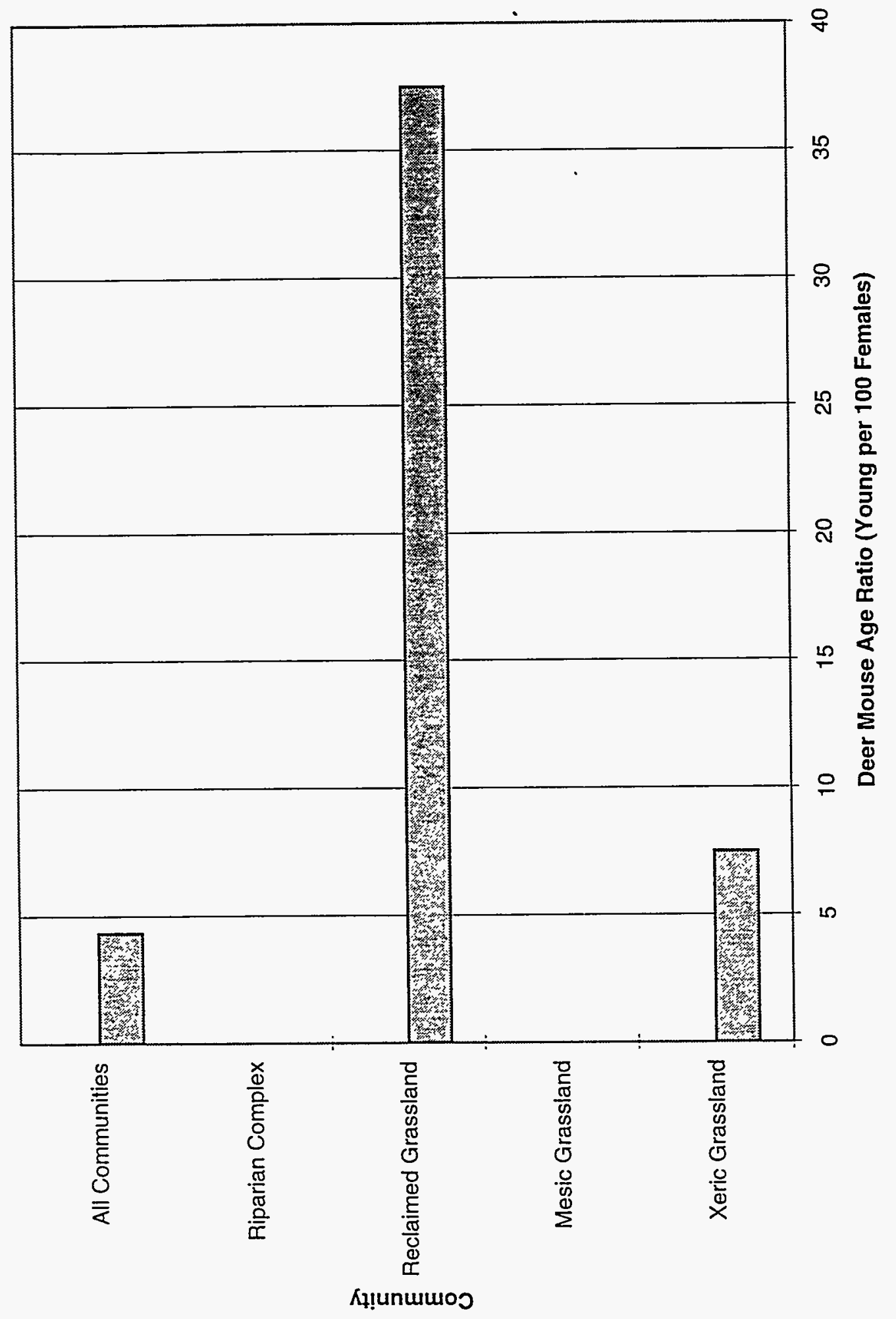

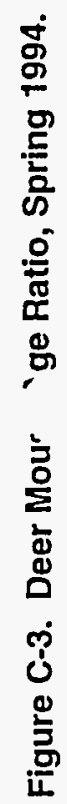
C-18 


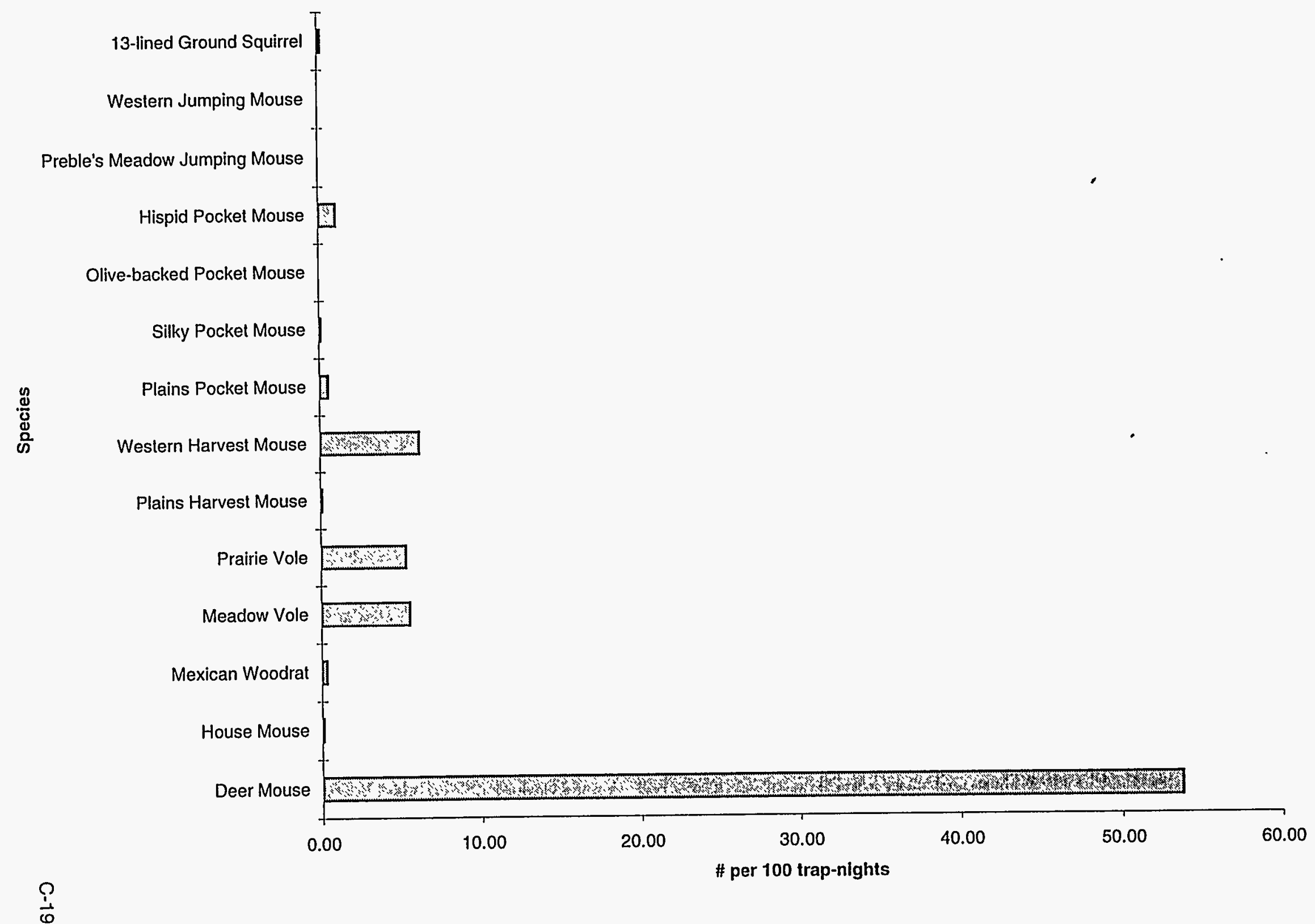

Figure C-4. Fall Capture Summary, All Communities, 1994. 


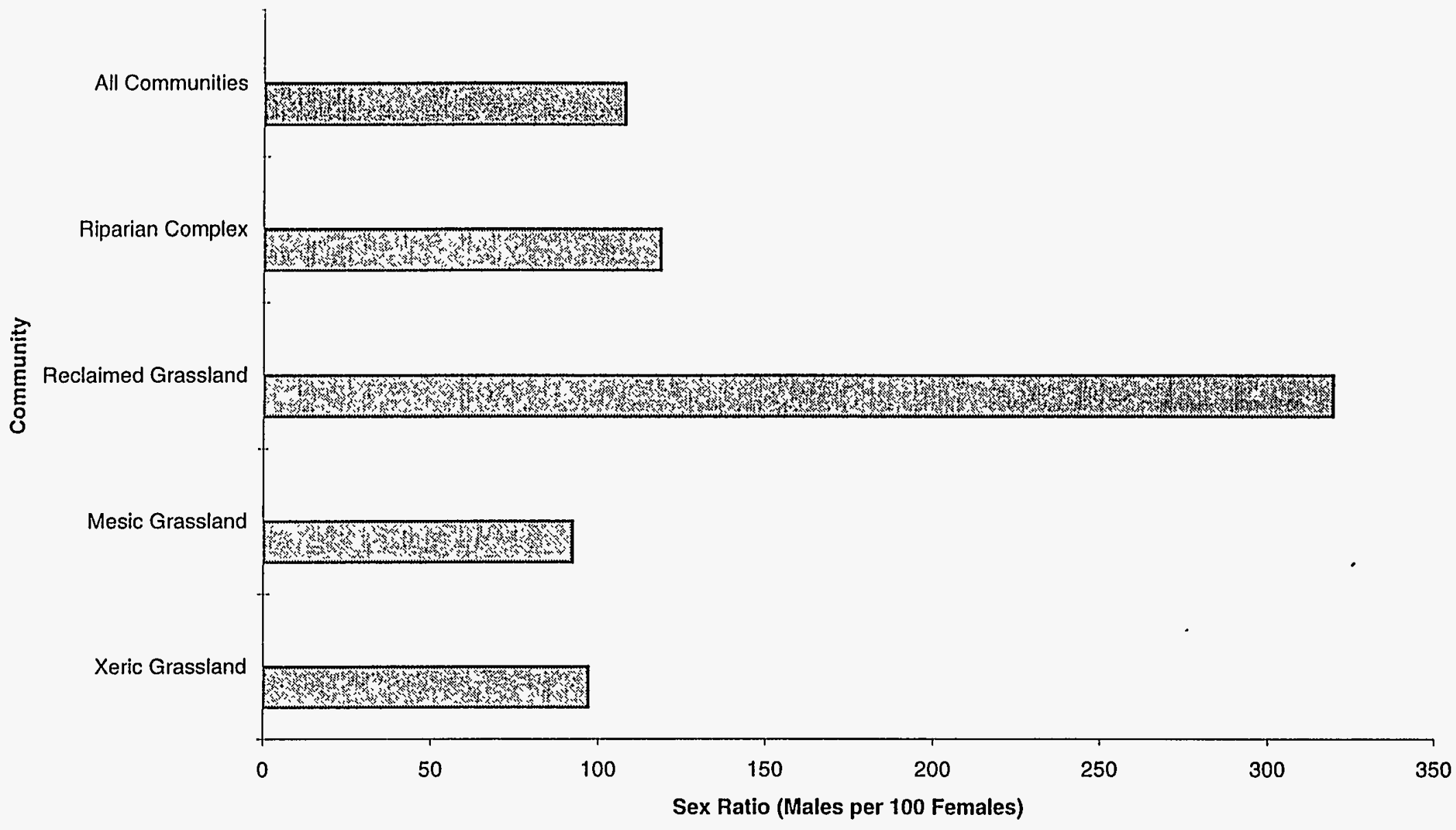

กิ

Figure C-5. Deer Mouse Sex Ratio, Fall 1994. 


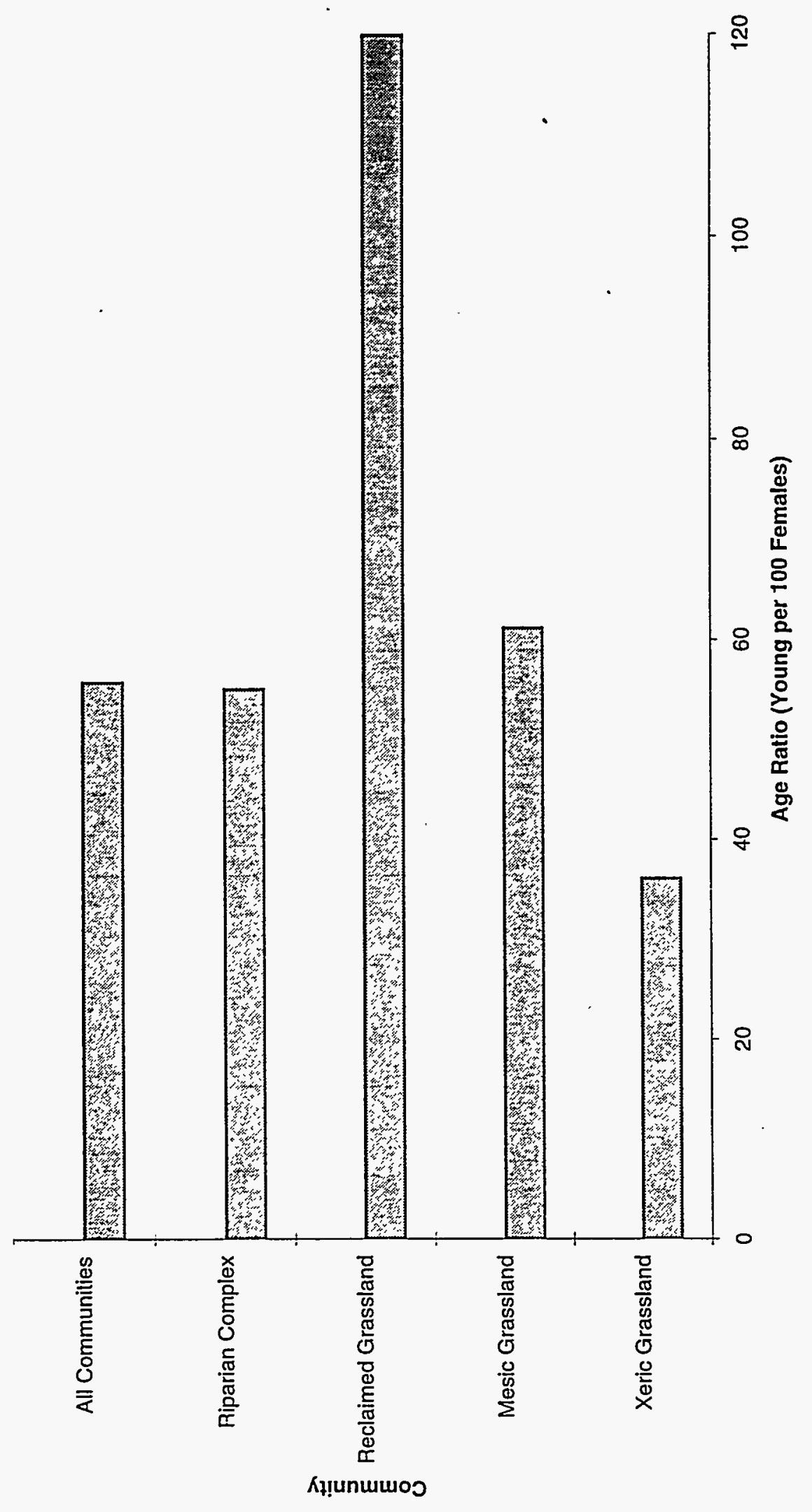

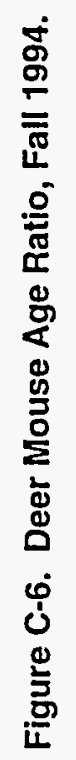




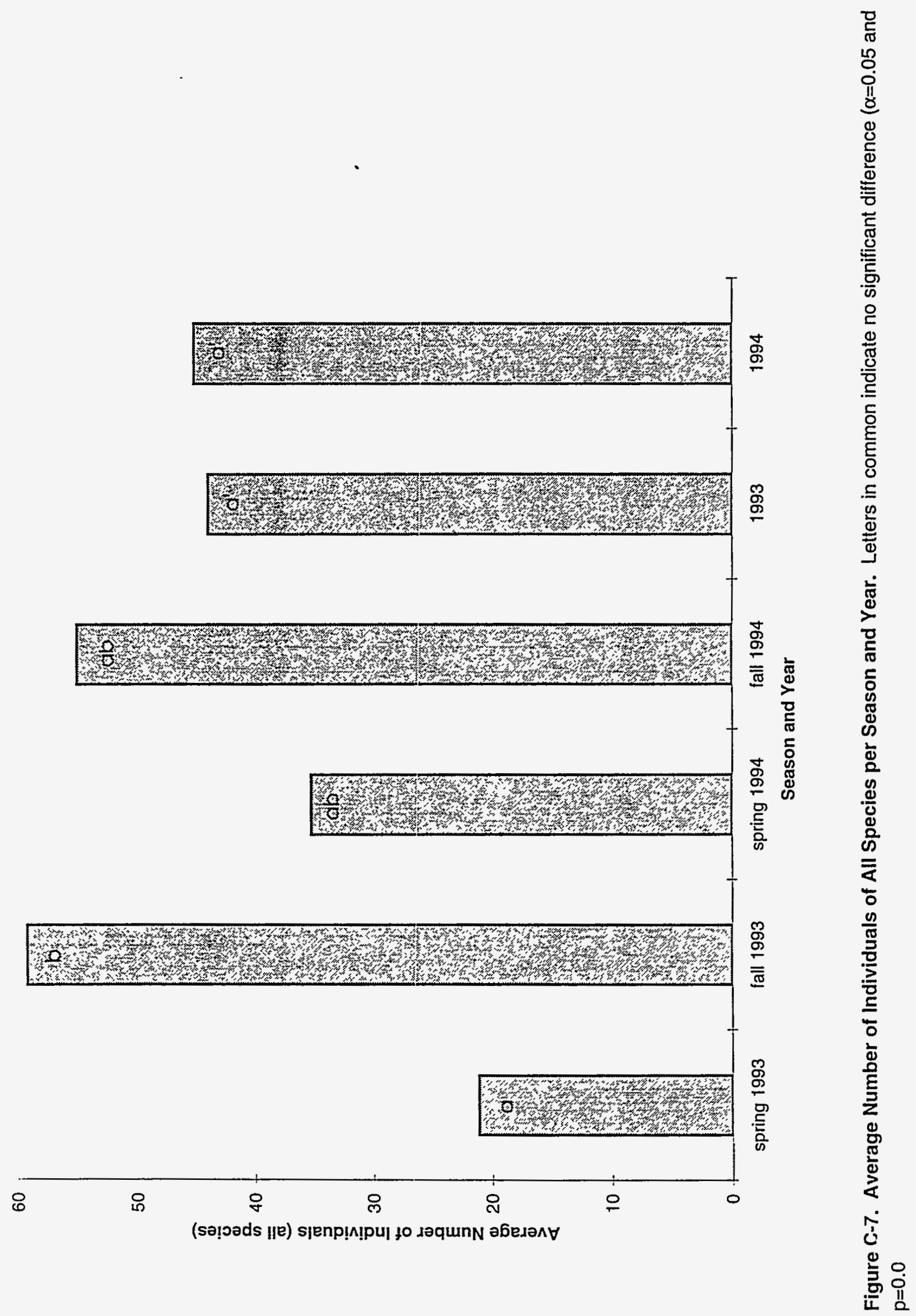




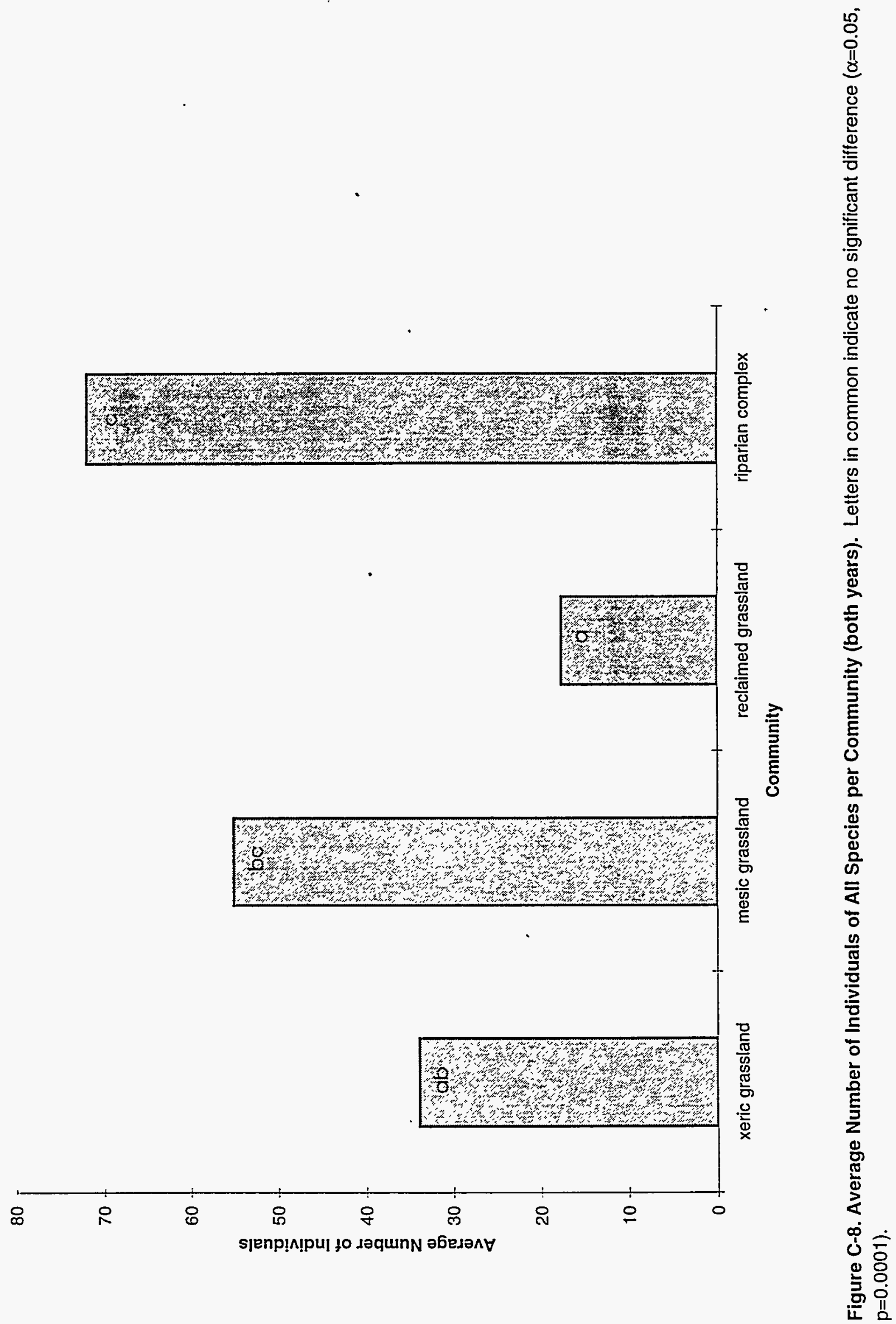


$\downarrow z-\supset$

$\frac{\pi}{5}$

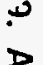

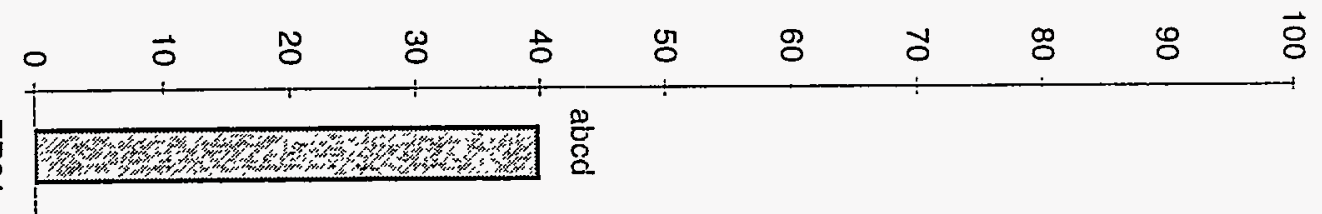

$z$

3

그

증

$\frac{5}{n}$

으

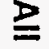

S

กั

\%

$\stackrel{0}{\overrightarrow{0}}$

$\stackrel{5}{=}$

5

8

亲

.

믕

$\stackrel{\vec{D}}{\mathbb{D}}$

ठ

$\stackrel{0}{2}$

三.

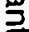

을

응

咞

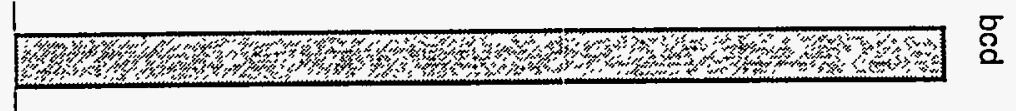

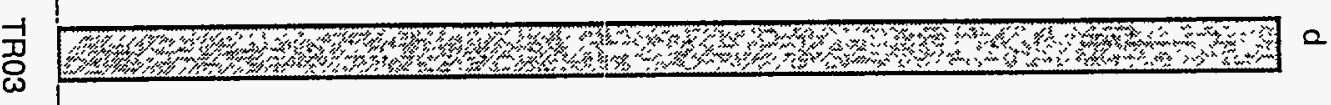

ษ

等,

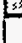

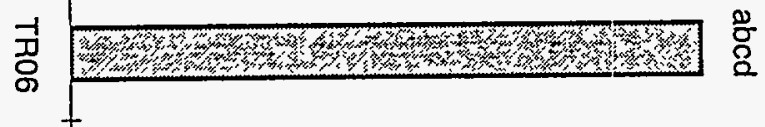

声

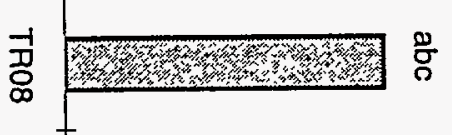

ग्रें

पूर

-1

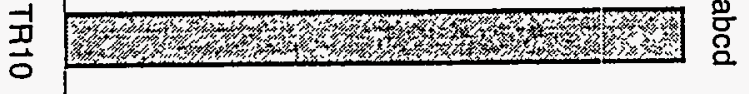

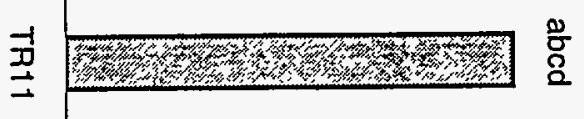

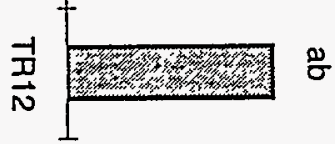


פट-ว

꿍

$\stackrel{?}{\circ}$

峦

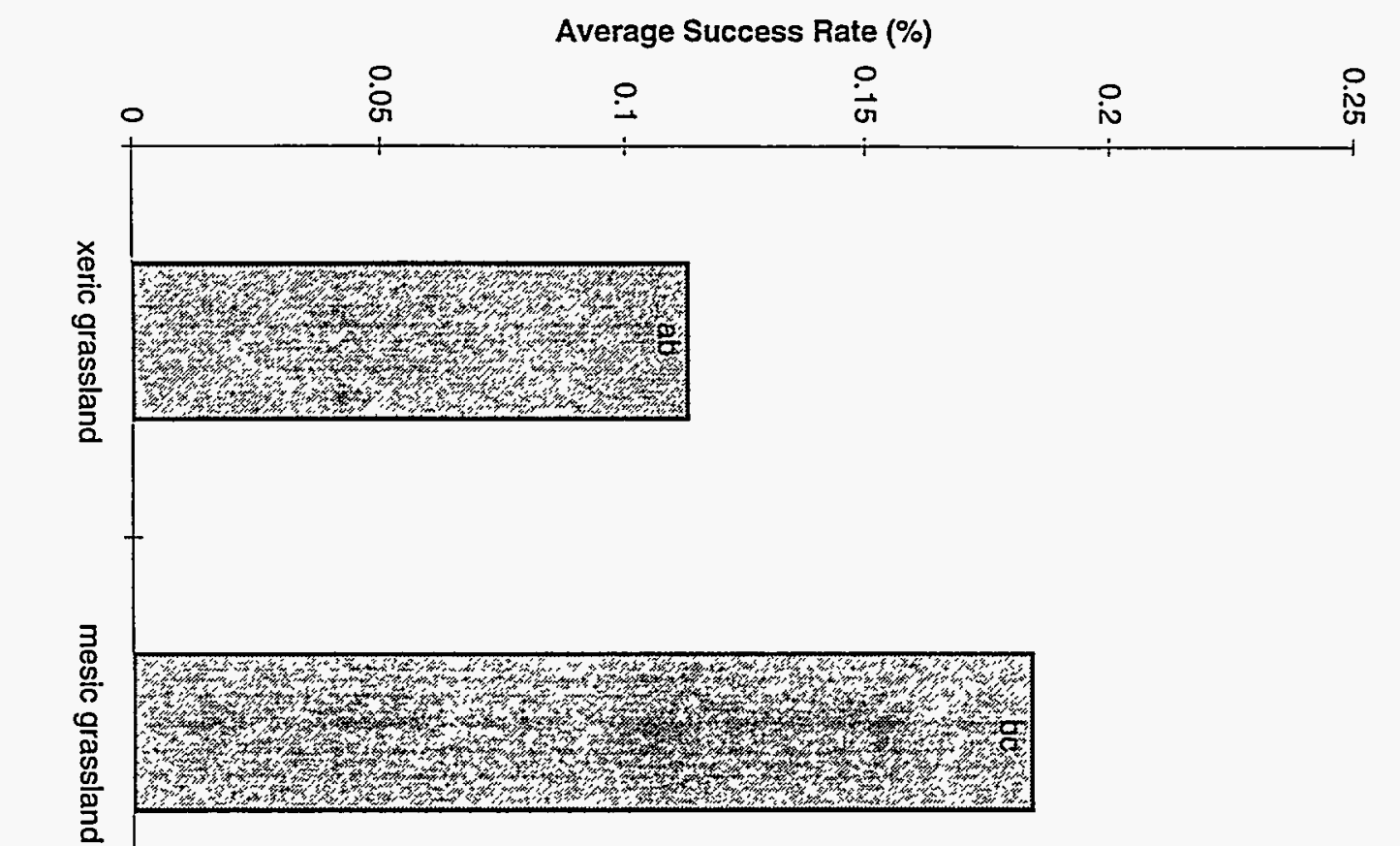

올

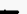

号

을 를

胥

$\frac{\text { D }}{\overline{\mathrm{D}}}$

$\frac{5}{5}$

ร

옥

옥

응

$\frac{\mathscr{Q}}{\bar{\sigma}}$

ठ

올

훙

$\stackrel{2}{2}$

읗

离

章 


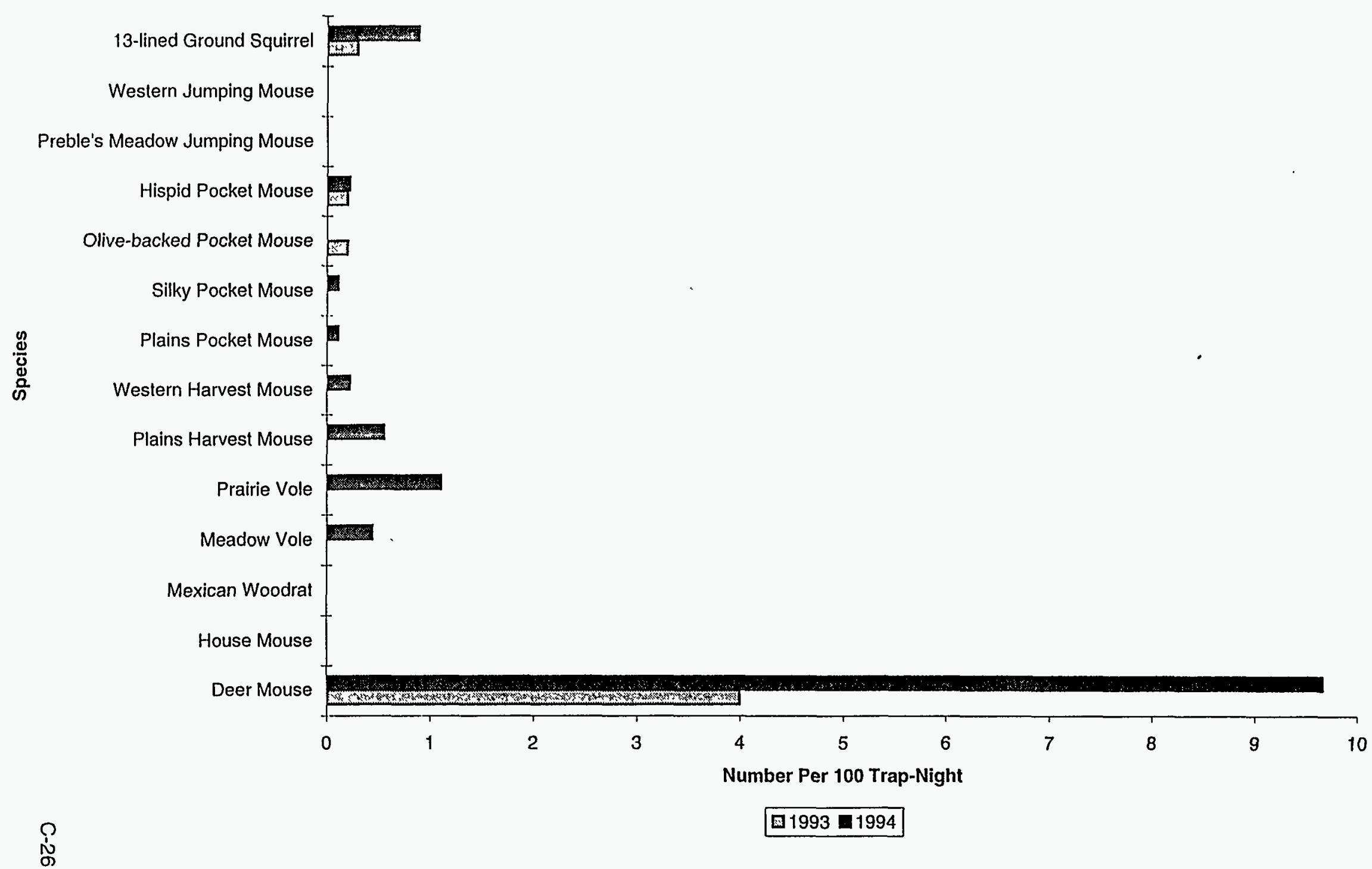

Figure C-11. Small Mammal Capture Compar $\quad\urcorner$, Xeric Mixed Grassland Community, Spring 


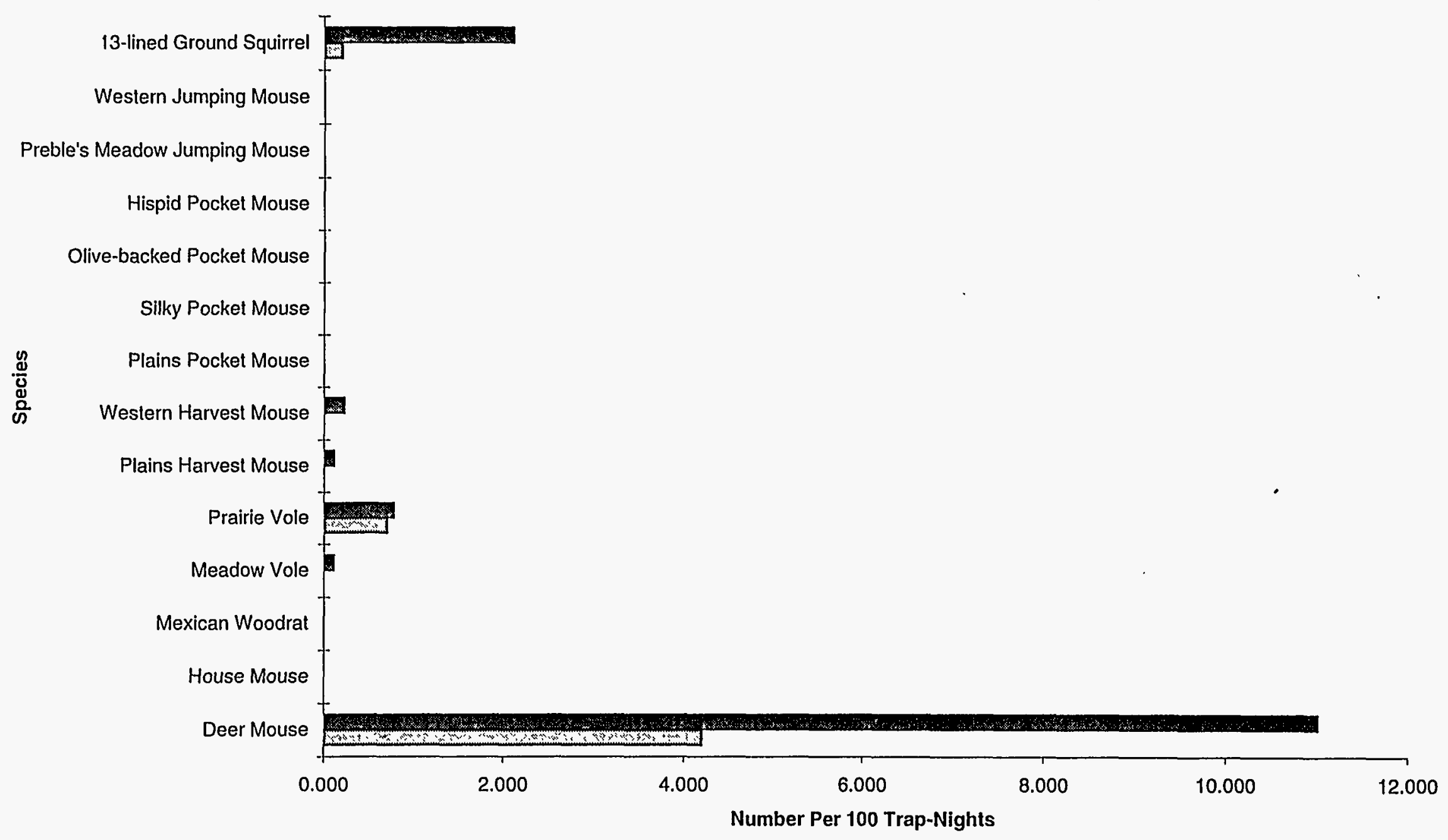

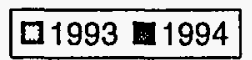




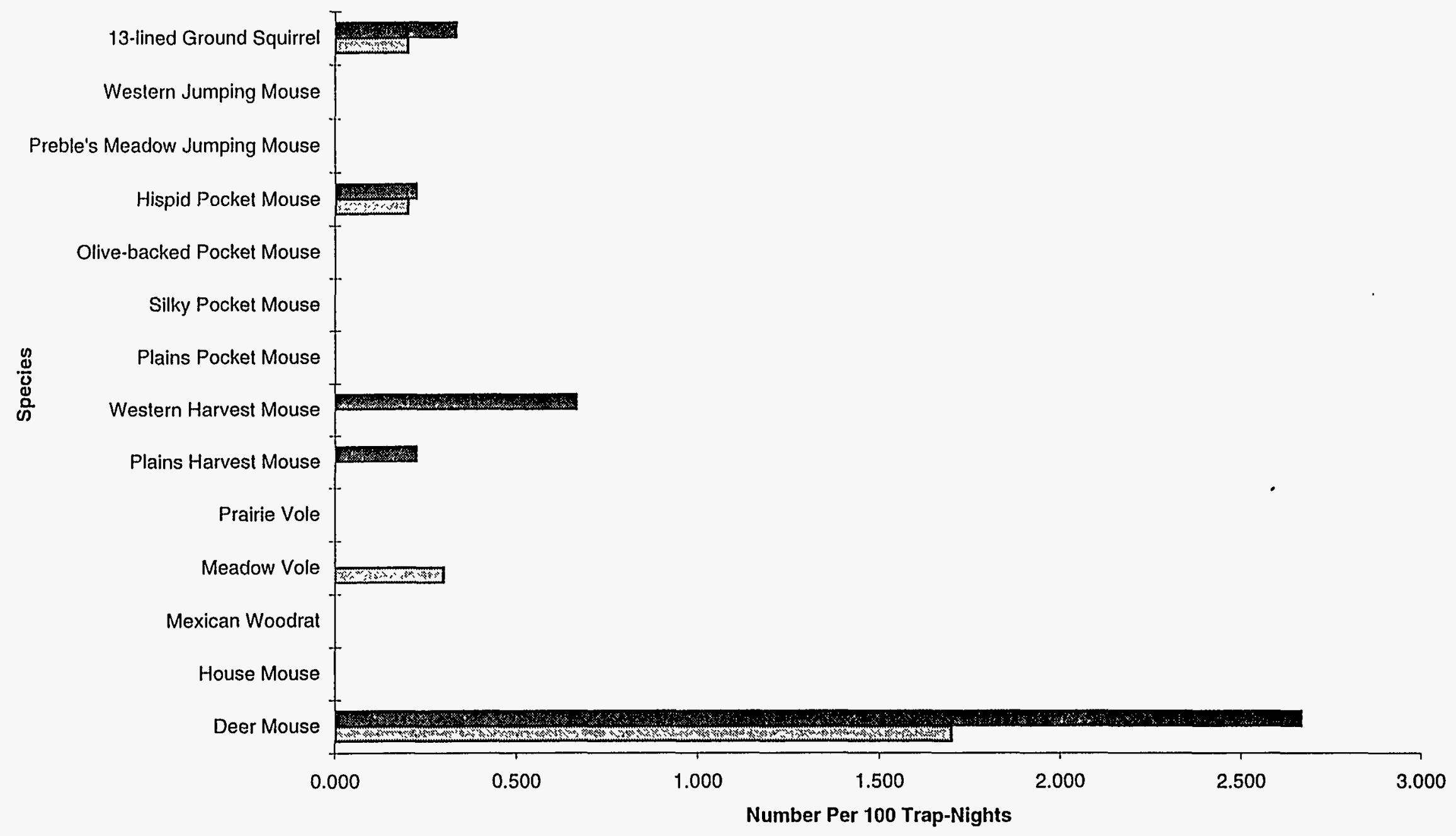

圆1993 1994

定

Figure C-13. Small Mammal Capture Compar:- n, Reclaimed Grassland Community, Spring 


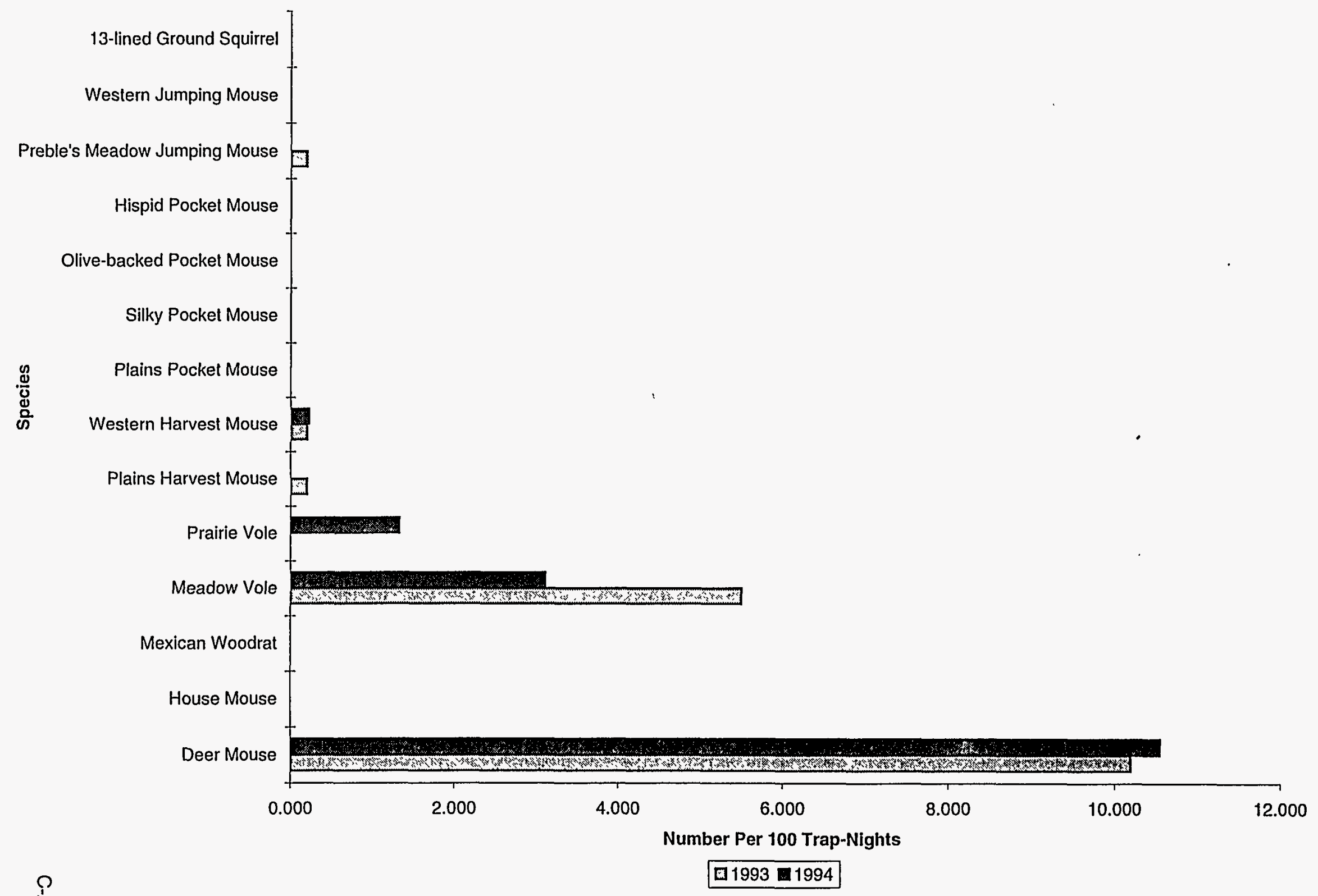

ปิ

Figure C-14. Small Mammal Capture Comparison, Riparian Community Complex, Spring 


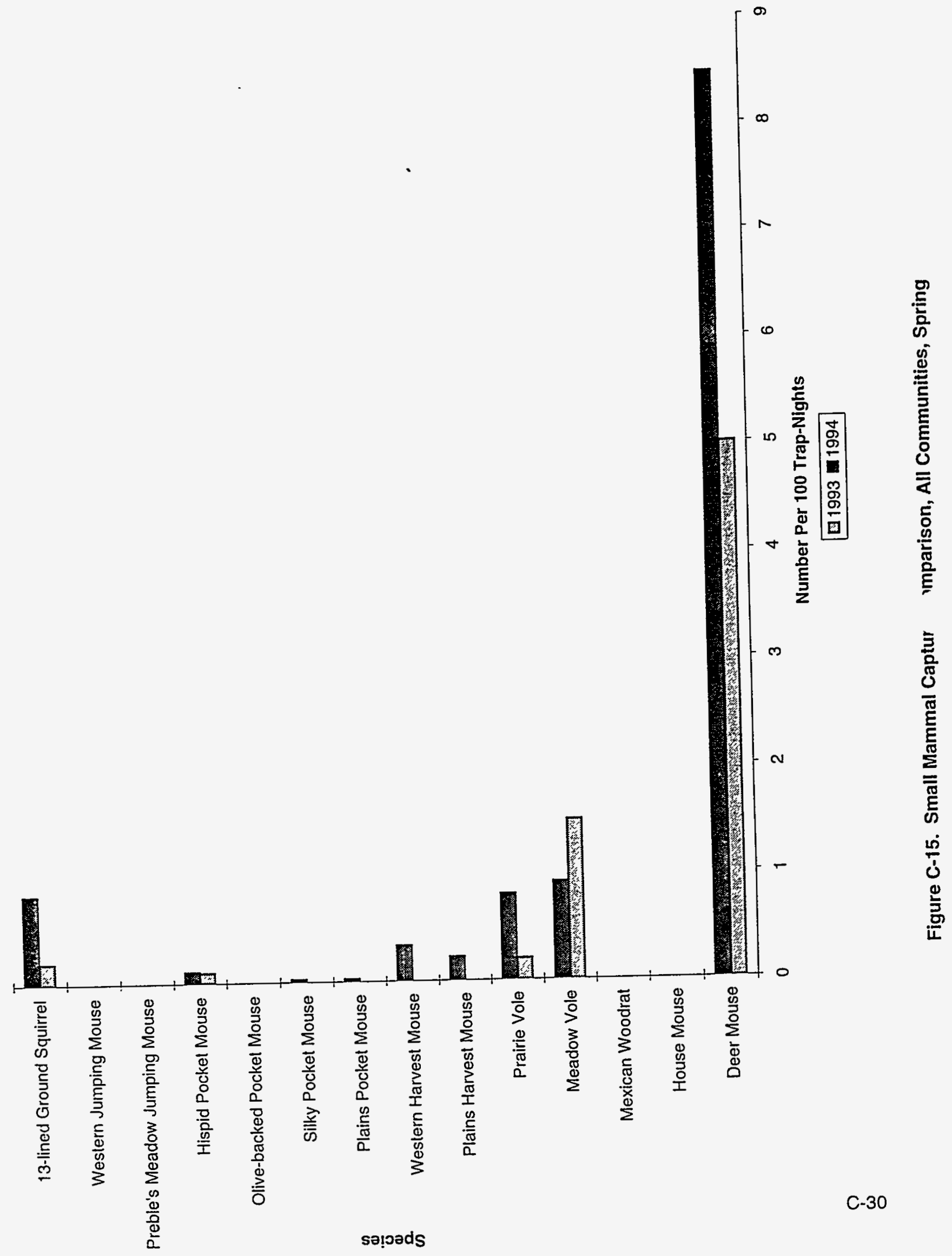




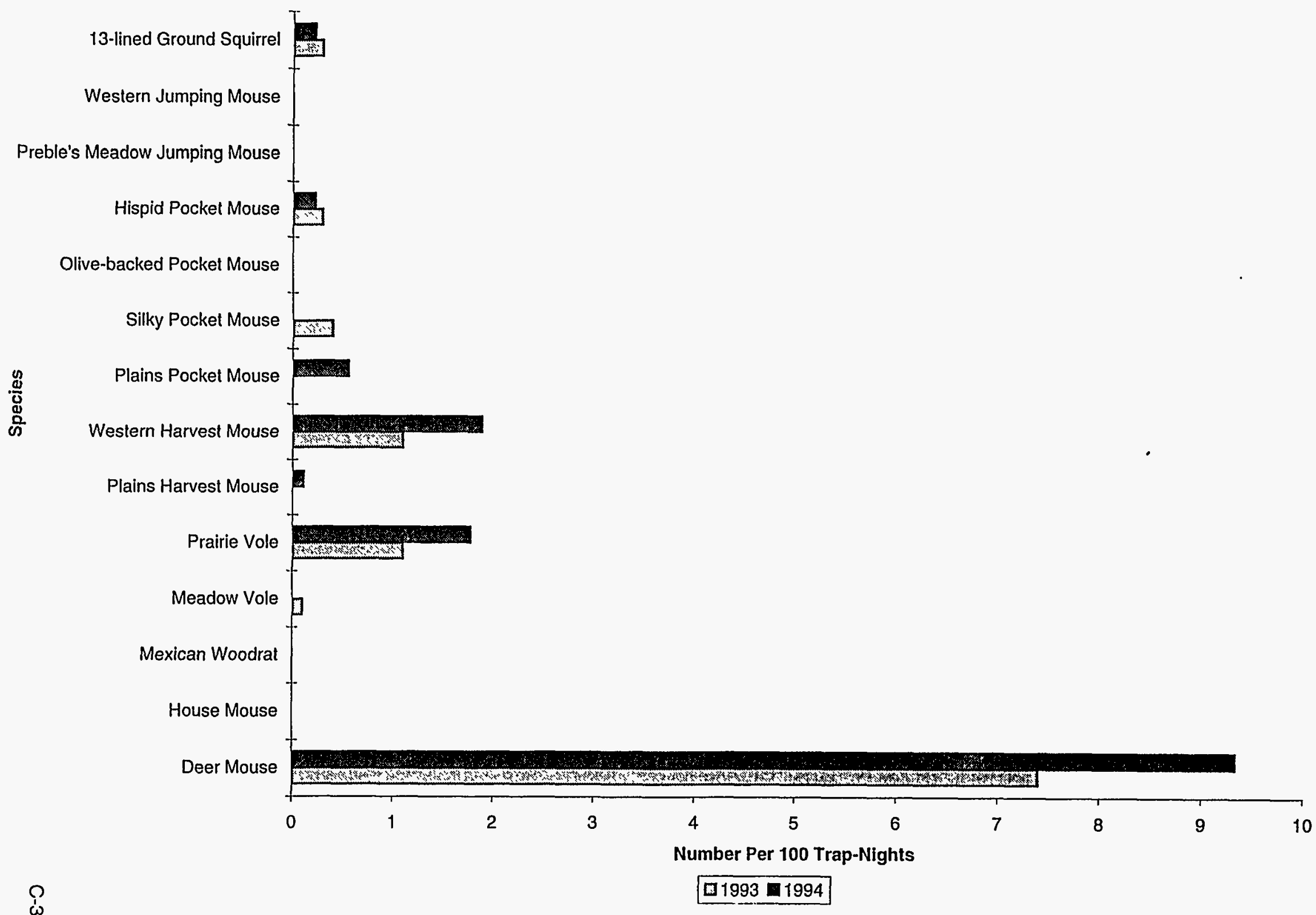

Figure C-16. Small Mammal Capture Comparison, Xeric Mixed Grassland Community, Fall 


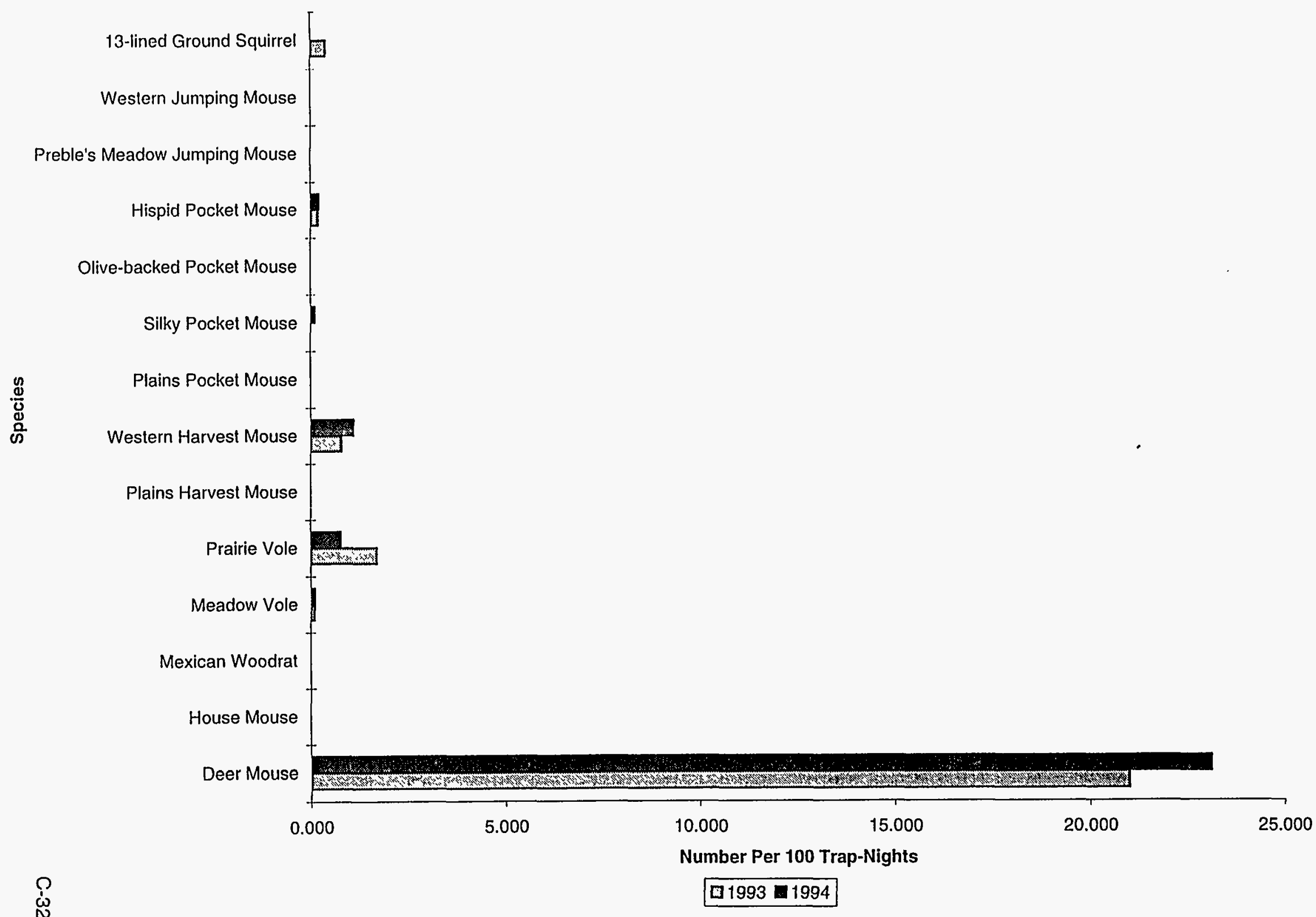

Figure C-17. Small Mammal Capture Comp

in, Mesic Mixed Grassland Community, Fall 


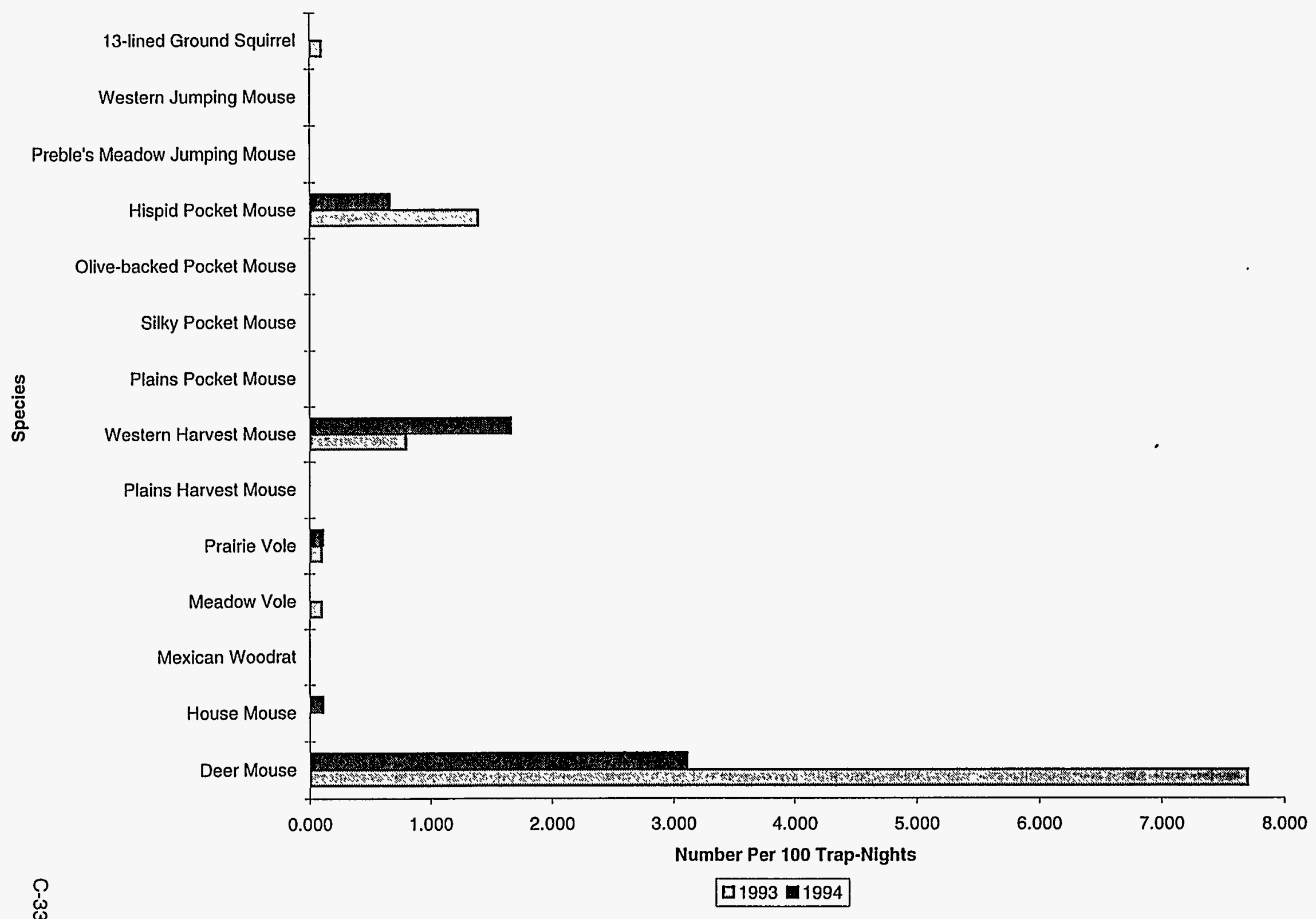

Figure C-18. Small Mammal Capture Comparison, Reclaimed Grassland Community, Fall 


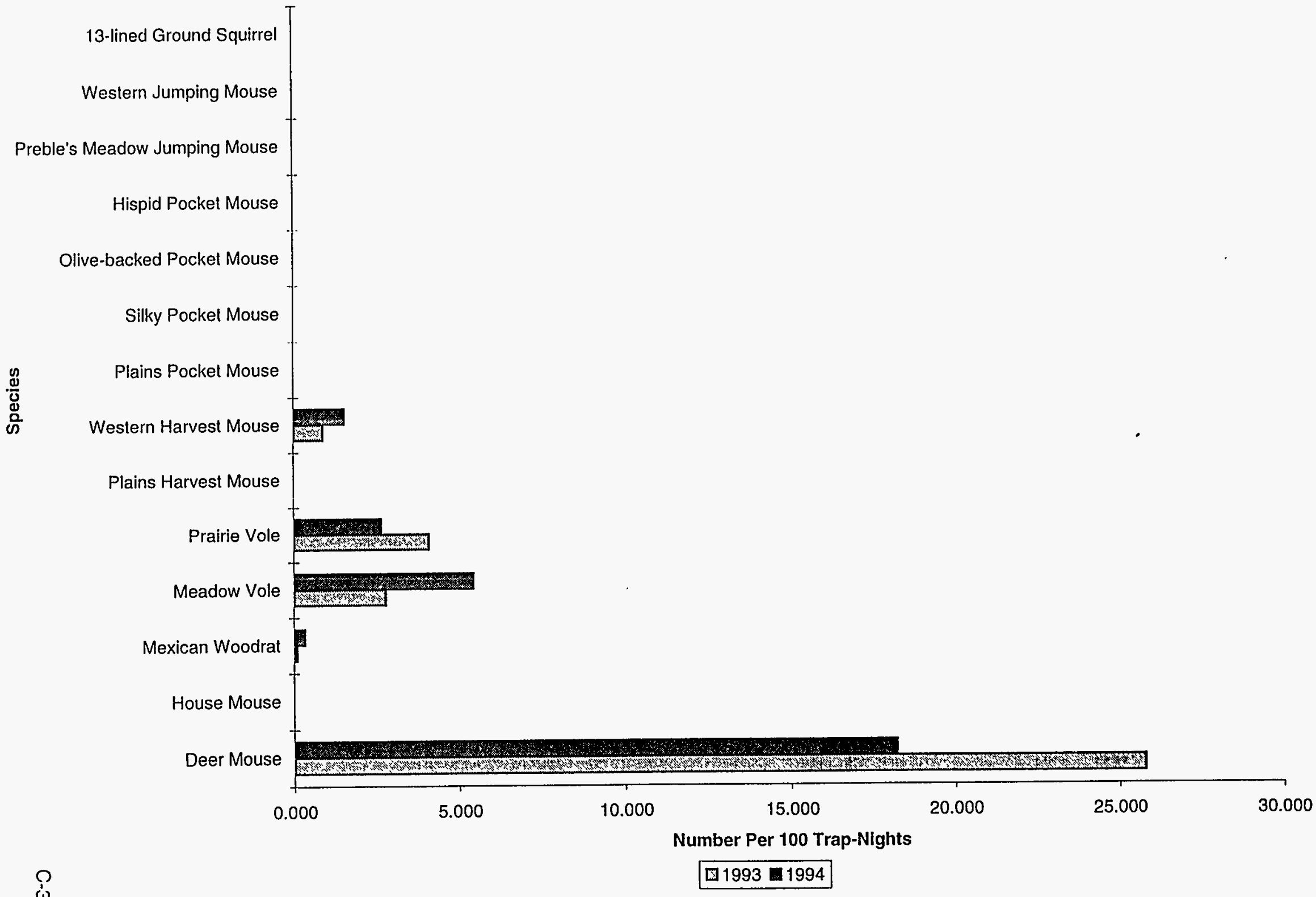

Figure C-19. Small Mammal Capture Cor rison, Riparian Community Complex, Fall 


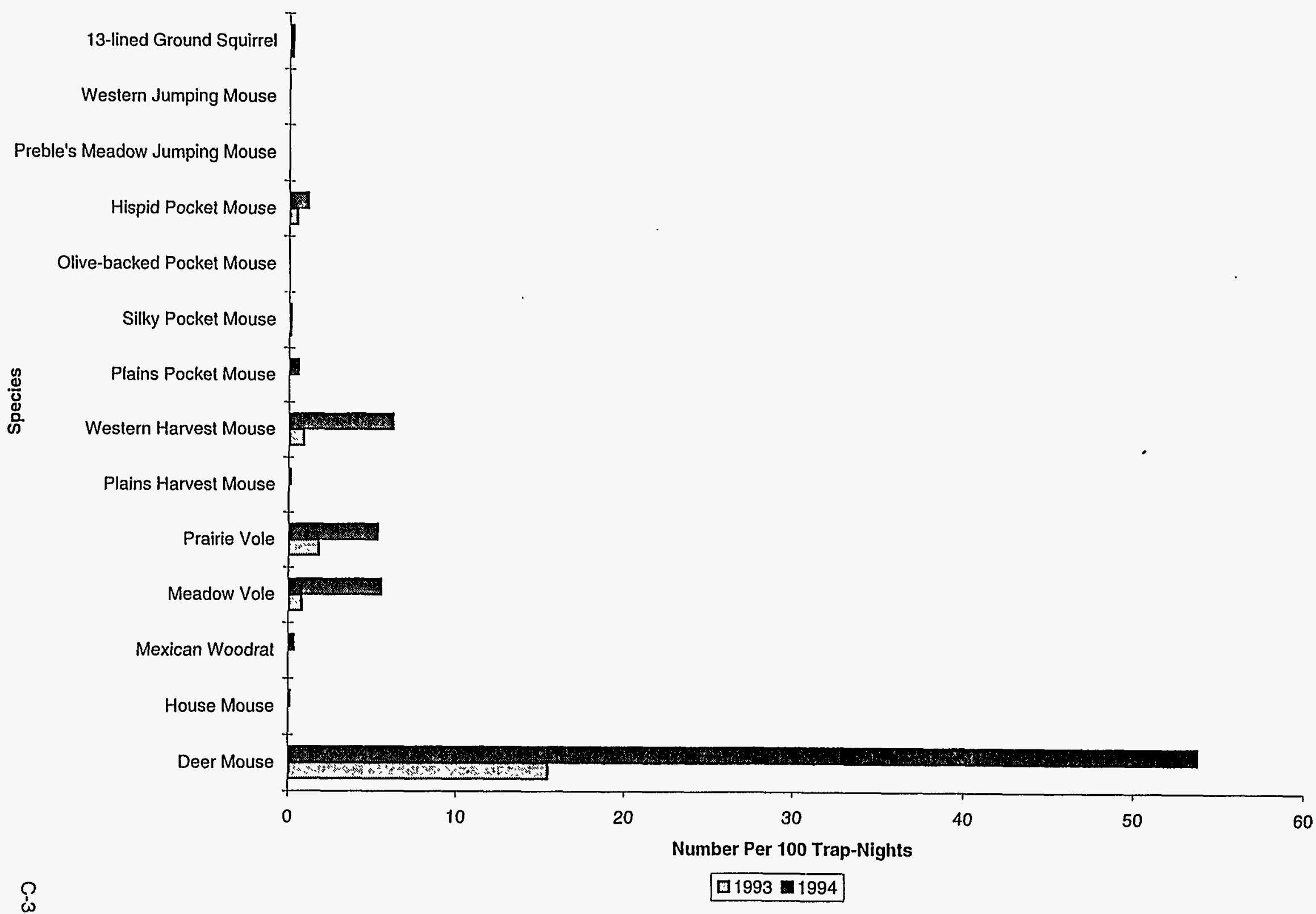

Figure C-20. Small Mammal Capture Comparison, All Communities, Fall 


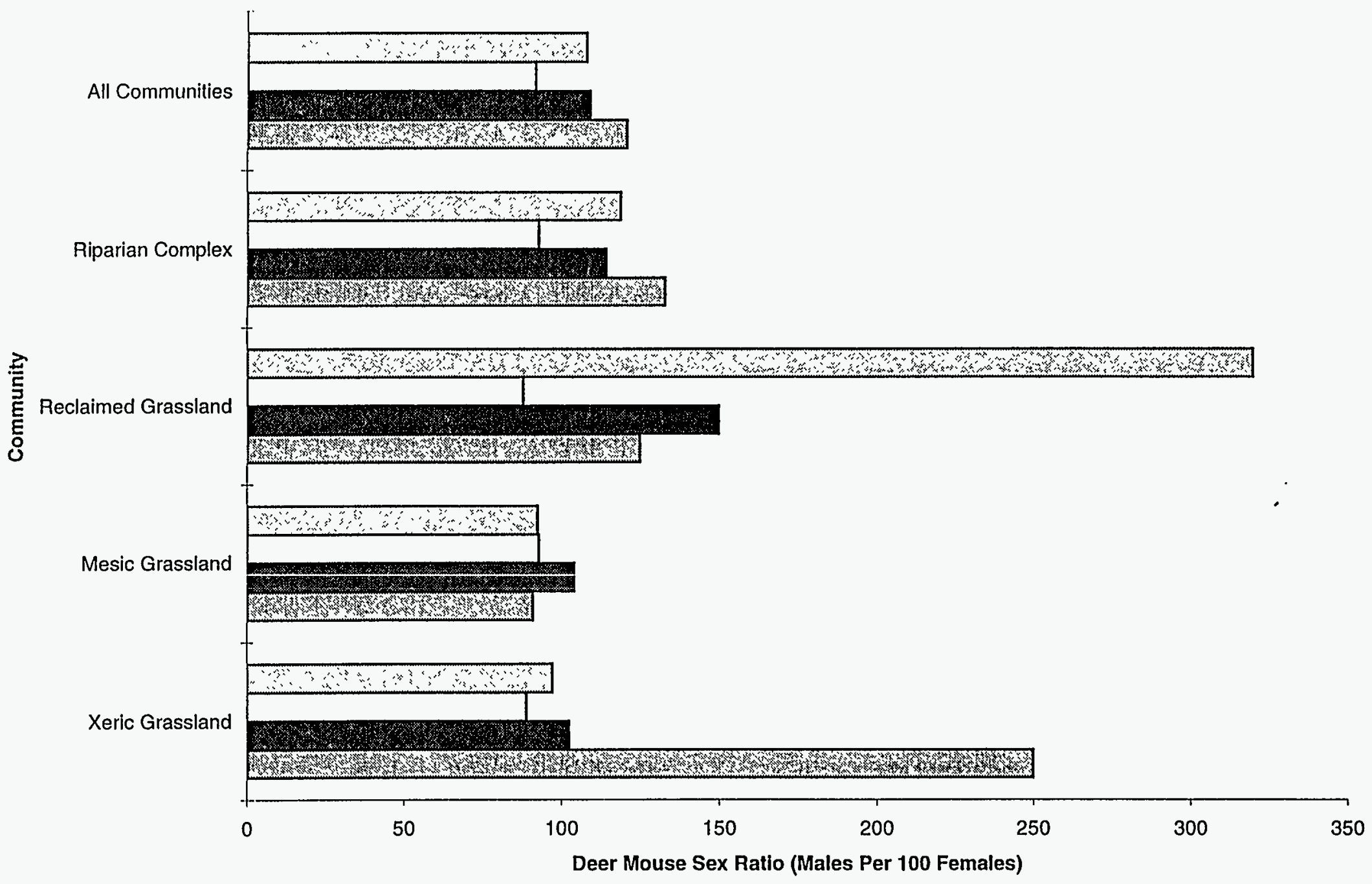

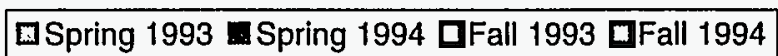

$\stackrel{\circ}{\omega}$

Figure C-21. Deer Mouse Sex Ratio Cr arison, Spring and Fall 1993 and 1994. 


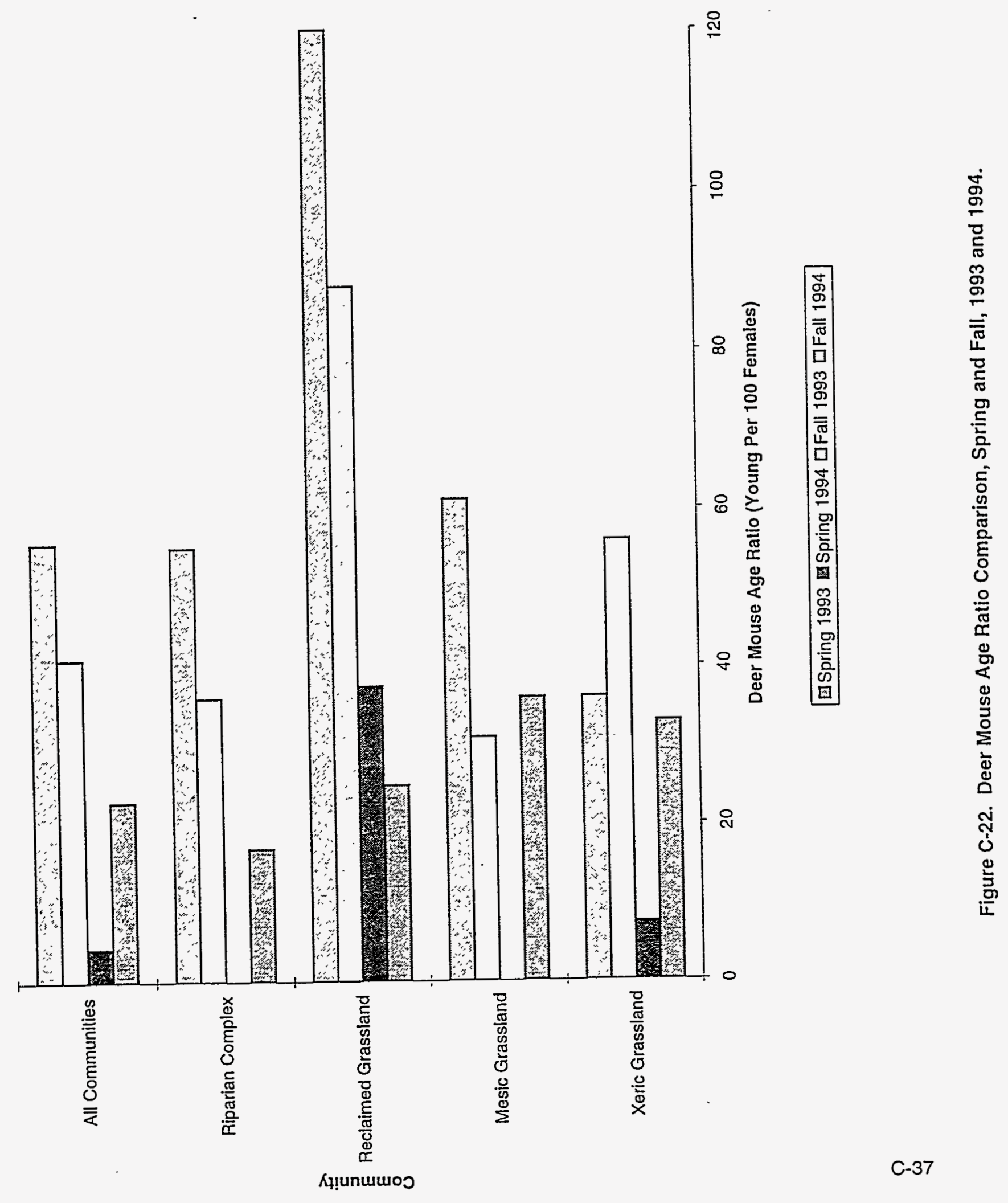




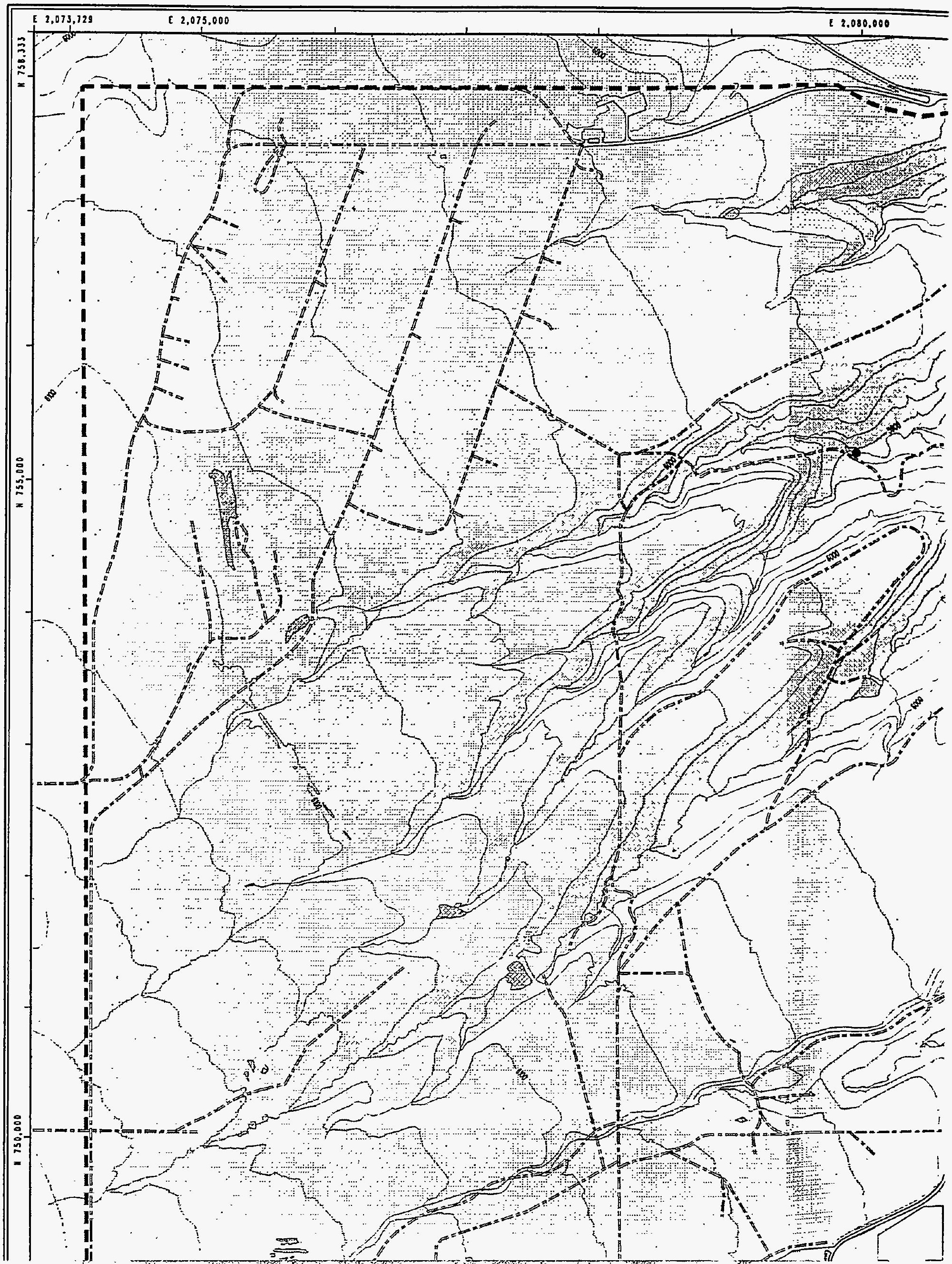




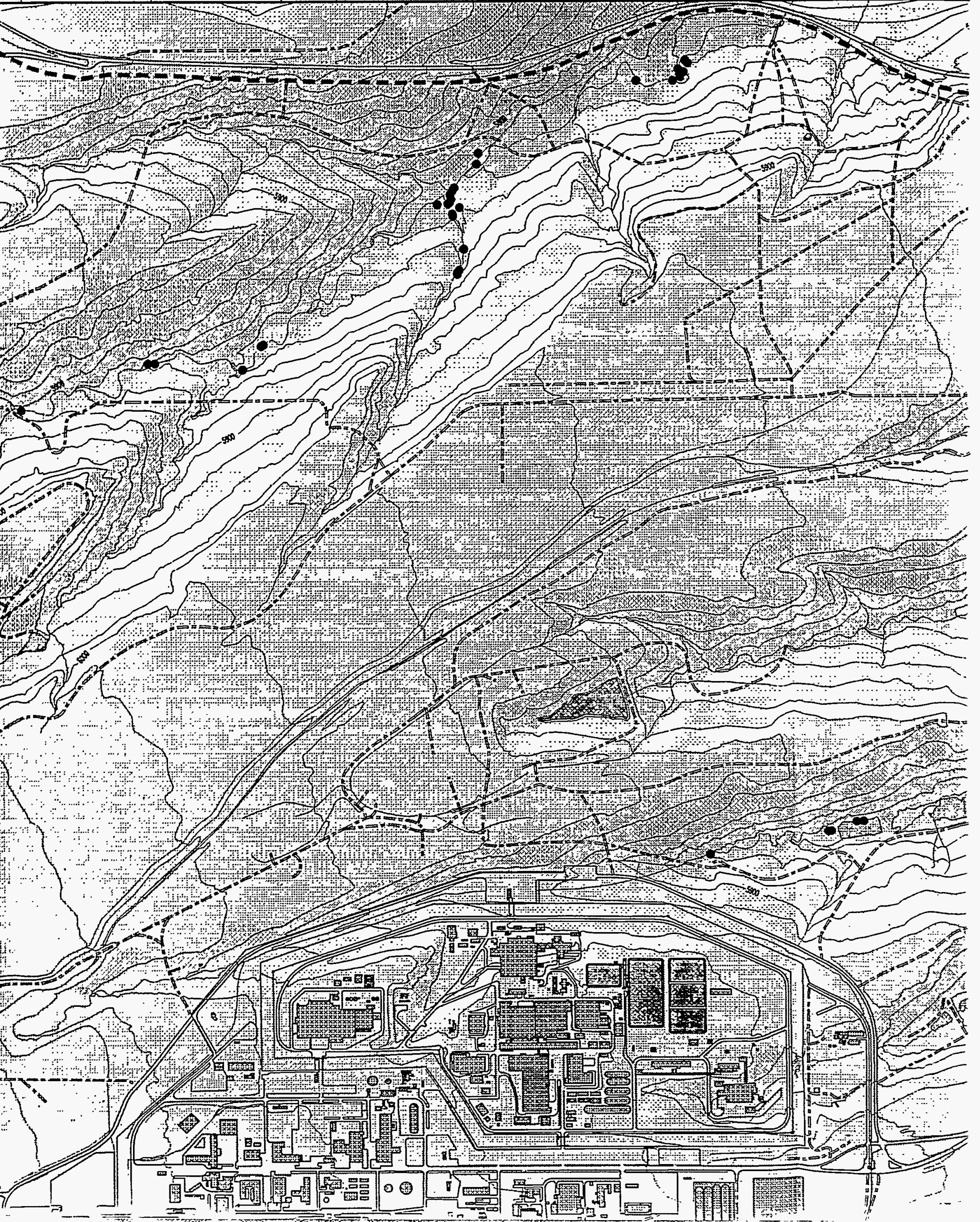




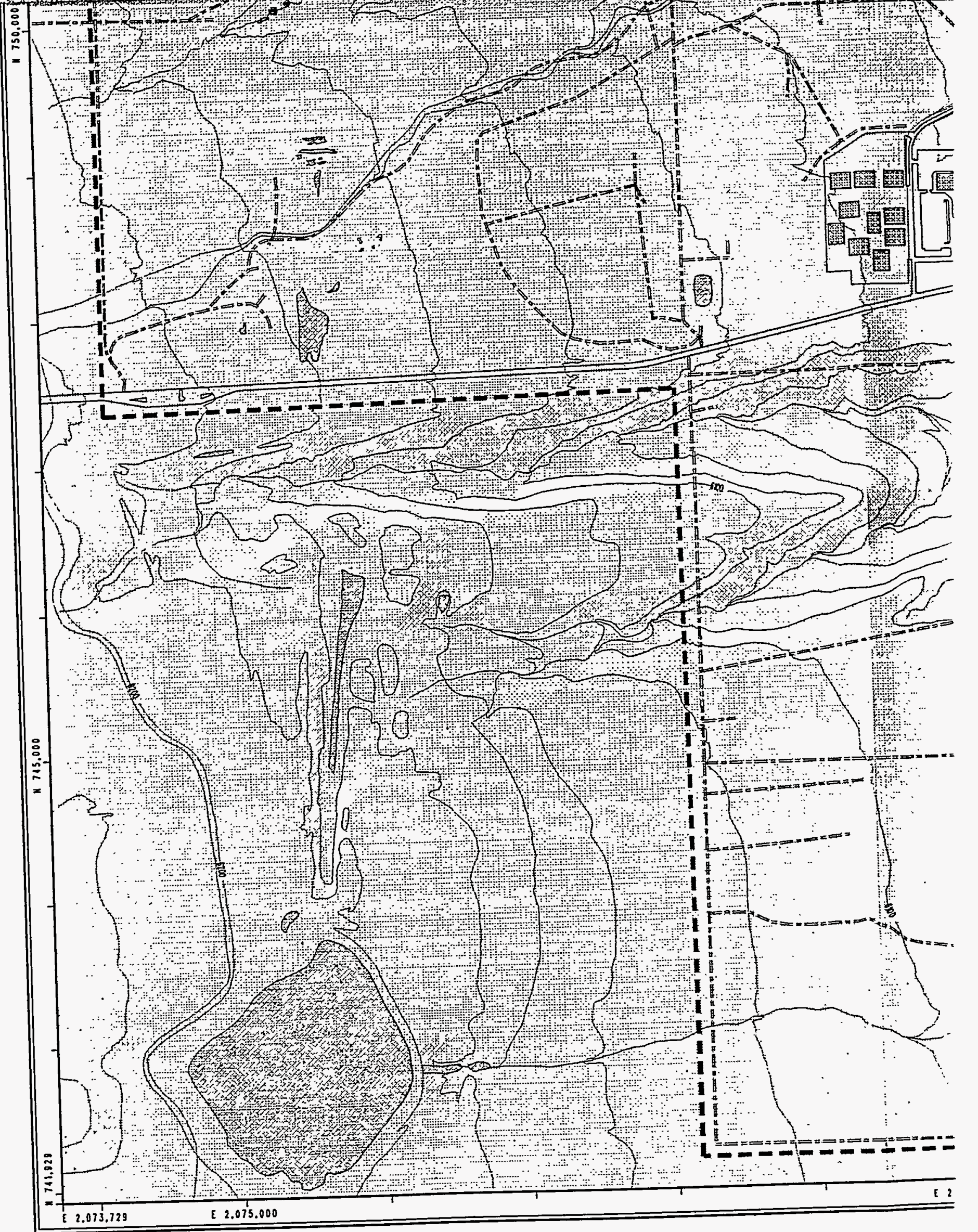




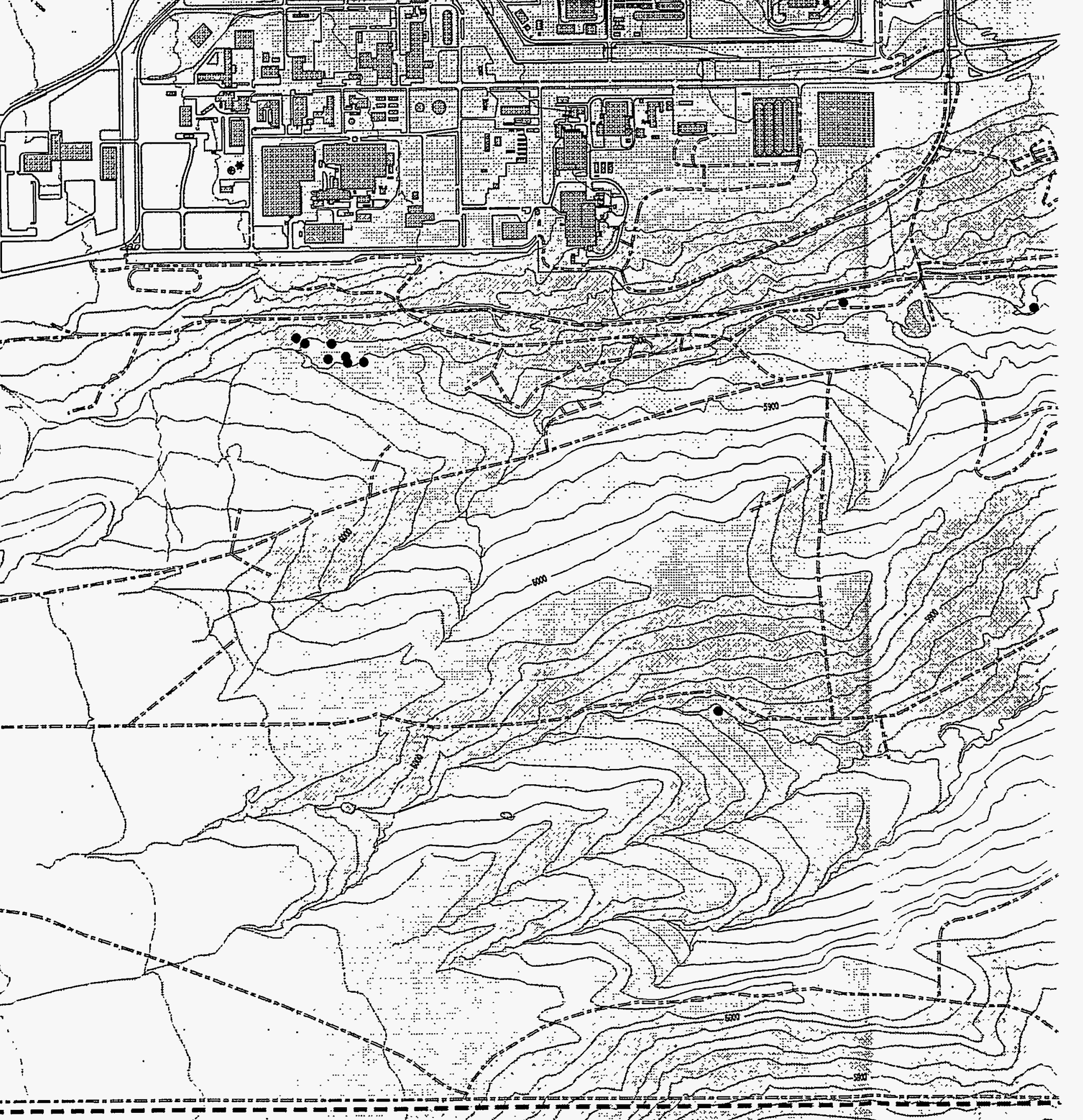




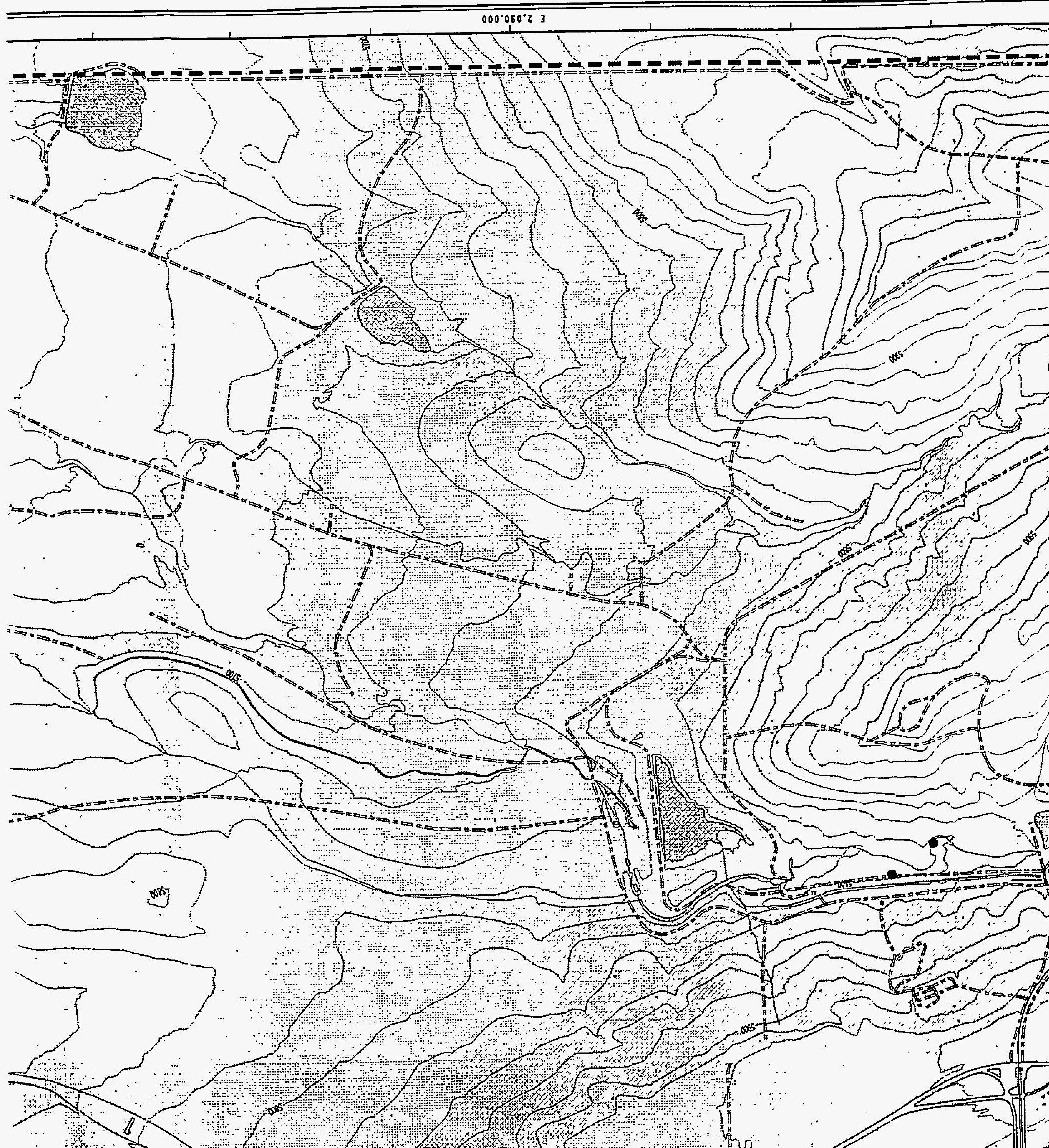




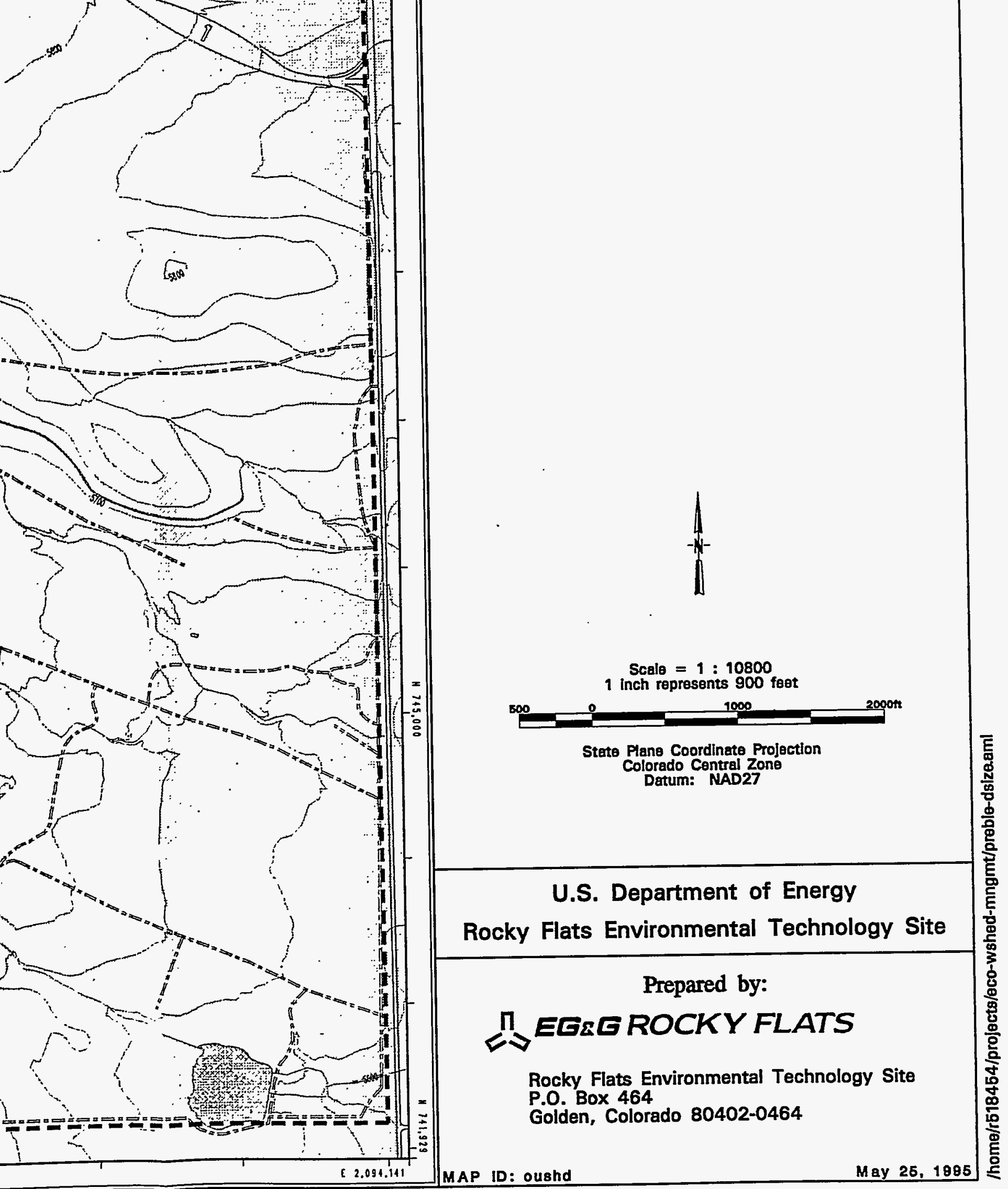


Table C-1. Small Mammal Capture Summary, Xeric Mixed Grassland Community, Spring 1994.

Species

Deer Mouse

House Mouse

Mexican Woodrat

Meadow Vole

Prairie Vole

Plains Harves! Mouse

Weslern Harvesl Mouse

Plains Pockel Mouse

Silky Pocket Mouse

Olive-backed Pockel Mouse

Hispid Pockel Mouse

Preble's Meadow Jumping Mouse

Weslern Jumping Mouse

13-lined Ground Squirrel

TOTAL

\begin{tabular}{|c|c|c|c|c|c|c|c|c|}
\hline \multirow[b]{2}{*}{ Code } & \multicolumn{2}{|c|}{ TR01 } & \multicolumn{2}{|c|}{ TR06 } & \multicolumn{2}{|c|}{ TR12 } & \multicolumn{2}{|c|}{ TOTAL } \\
\hline & $\#$ & $\# / 100 \mathrm{TN}$ & $\#$ & $\# / 100 \mathrm{TN}$ & $\#$ & $\$ / 100 \mathrm{TN}$ & $\#$ & $\# / 100 \mathrm{TN}$ \\
\hline PEMA1 & 51 & 17.00 & 26 & 8.67 & 10 & 3.33 & 87 & 9.67 \\
\hline MUMU1 & & 0 & & 0 & & 0 & 0 & 0 \\
\hline NEME1 & & 0 & & 0 & & 0 & 0 & 0 \\
\hline MIPE1 & & 0 & 4 & 1.33 & & 0 & 4 & 0.44 \\
\hline MIOC1 & 1 & 0.33 & 8 & 2.67 & 1 & 0.33 & 10 & 1.11 \\
\hline REMO1 & & 0 & 3 & 1.00 & 2 & 0.67 & 5 & 0.56 \\
\hline REME 1 & & 0 & 2 & 0.67 & & 0 & 2 & 0.22 \\
\hline PEFL2 & & 0 & 1 & 0.33 & & 으 & 1 & 0.11 \\
\hline PEFLY & & 0 & 1 & 0.33 & & 0 & 1 & 0.11 \\
\hline PEFA1 & & 0 & & 0 & & 0 & 요 & 0 \\
\hline $\mathrm{CHHII}$ & 1 & 0.33 & & 0 & 1 & 0.33 & 2 & 0.22 \\
\hline ZAHU1 & & 0 & & 0 & & 이 & of & 0 \\
\hline ZAPA1 & & 0 & & 0 & & 0 & 0 & 0 \\
\hline SPTR1 & 5 & 1.67 & 2 & 0.67 & 1 & 0.33 & 8 & 0.89 \\
\hline & 58 & 19.33 & 47 & 15.667 & 15 & 5.00 & 120 & 13.33 \\
\hline
\end{tabular}

$\#=$ tolal number of captures, excluding recaptures

$\# / 100 T N=$ number of captures per 100 trap-nights, excluding recaptures, based on 300 trap-nights per site 
Table C-2. Small Mammal Capture Summary, Mesic Mixed Grassland Community, Spring 1994.

Species

Deer Mouse

House Mouse

Mexican Woodrat

Meadow Vole

Prairie Vole

Plains Harvest Mouse

Western Harvest Mouse

Plains Pocket Mouse

Silky Pocket Mouse

Olive-backed Pocket Mouse

Hispid Pocket Mouse

Preble's Meadow Jumping Mouse

Western Jumping Mouse

13-lined Ground Squirrel

TOTAL

\begin{tabular}{|c|c|c|c|c|c|c|c|c|}
\hline & \multicolumn{2}{|c|}{ TR02 } & \multicolumn{2}{|c|}{ TR04 } & \multicolumn{2}{|c|}{ TR11 } & \multicolumn{2}{|c|}{ TOTAL } \\
\hline Code & $\#$ & $\# / 100 \mathrm{TN}$ & $\#$ & $\# / 100 \mathrm{TN}$ & $\#$ & $\# / 100 \mathrm{TN}$ & $\#$ & $\# / 100 \mathrm{TN}$ \\
\hline PEMA1 & 31 & 10.33 & 48 & 16.00 & 20 & 6.67 & 99 & 11.00 \\
\hline MUMU1 & & 0 & & of & & of & 0 & 0 \\
\hline NEME1 & & 0 & & of & & 0 & 0 & 0 \\
\hline MIPE1 & 1) & 0.33 & & 0 & & 0 & 1 & 0.11 \\
\hline MIOC1 & 1 & 0.33 & 5 & 1.67 & 1 & 0.33 & 7 & 0.78 \\
\hline REMO1 & & 0 & 1 & 0.33 & & 0 & 1 & 0.11 \\
\hline REME 1 & & of & & 0 & 2 & 0.67 & 2 & 0.22 \\
\hline PEFL2 & & 0 & & 0 & & 0 & 요 & 0 \\
\hline PEFL1 & & 0 & & 0 & & 이 & 0 & 0 \\
\hline PEFA1 & & 의 & & 의 & & 의 & 이 & 0 \\
\hline $\mathrm{CHHII}$ & & of & & 0 & & 0 & 0 & 0 \\
\hline ZAHU1 & & 0 & & of & & 0 & 0 & 0 \\
\hline ZAPR1 & & 0 & & of & & 이 & 요 & 0 \\
\hline SPTR1 & 12 & 4.00 & 4 & 1.33 & 3 & 1.00 & 19 & 2.11 \\
\hline & 45 & 15.00 & 58 & 19.33 & 26 & 8.67 & 129 & 14.33 \\
\hline
\end{tabular}

$\#$ = total number of captures, excluding recaptures

$\# / 100 T N=$ number of captures per 100 trap-nights, excluding recaptures, based on 300 trap-nights per site 
Table C-3. Small Mammal Capture Summary, Reclaimed Grassland Community, Spring 1994.

Deer Mouse

Species

House Mouse

Mexican Woodrat

Meadow Vole

Prairie Vole

Plains Harvest Mouse

Western Harvest Mouse

Plains Pocket Mouse

Silky Pocket Mouse

Olive-backed Pockel Mouse

Hispid Pocket Mouse

Preble's Meadow Jumping Mouse

Western Jumping Mouse

13-lined Ground Squirrel

TOTAL

\begin{tabular}{|c|c|c|c|c|c|c|c|c|}
\hline \multirow[b]{2}{*}{ Code } & \multicolumn{2}{|c|}{ TROT } & \multicolumn{2}{|c|}{ TR08 } & \multicolumn{2}{|c|}{ TROS } & \multicolumn{2}{|c|}{ TOTAL } \\
\hline & $\#$ & $\# / 100 \mathrm{TN}$ & $\#$ & $\# / 100 \mathrm{TN}$ & $\#$ & $\# / 100 \mathrm{TN}$ & $\#$ & $\# / 100 \mathrm{TN}$ \\
\hline PEMA1 & 11 & 3.67 & 13 & 4.33 & & 0 & 24 & 2.67 \\
\hline MUMU1 & & 0 & & 0 & & 0 & 0 & 0 \\
\hline NEME 1 & & 0 & & 0 & & 0 & 0 & 0 \\
\hline MIPE1 & & 0 & & 0 & & 0 & 0 & 0 \\
\hline MIOC1 & & 0 & & 0 & & 0 & 0 & 0 \\
\hline REMO1 & 2 & 0.67 & & 0 & & 0 & 2 & 0.22 \\
\hline REME1 & 2 & 0.67 & & 0 & 4 & 1.33 & 6 & 0.67 \\
\hline PEFL2 & & 0 & & 0 & & 0 & 0 & 0 \\
\hline PEFL1 & & 0 & & 0 & & 0 & 0 & $c$ \\
\hline PEFA1 & & 0 & & 0 & & 0 & 0 & 0 \\
\hline $\mathrm{CHHI1}$ & 1 & 0.33 & & 0 & 1 & 0.33 & 2 & 0.22 \\
\hline ZAHU1 & & 0 & & 0 & & 0 & 0 & 0 \\
\hline ZAPR1 & & 0 & & 0 & & 0 & 0 & 0 \\
\hline SPTR1 & & 0 & & 0 & 3 & 1.00 & 3 & 0.33 \\
\hline & 16 & 5.33 & 13 & 4.33 & 8 & 2.67 & 37 & 4.11 \\
\hline
\end{tabular}

$\#=$ total number of captures, excluding recaptures

$\# / 100 T N=$ number of captures per 100 trap-nights, excluding recaptures, based on 300 trap-nights per site 
Table C-4. Small Mammal Capture Summary, Riparian Community Complex, Spring 1994.

\begin{tabular}{l}
\multicolumn{1}{c}{ Species } \\
Deer Mouse \\
House Mouse \\
Mexican Woodrat \\
Meadow Vole \\
Prairie Vole \\
Plains Harvest Mouse \\
Western Harvest Mouse \\
Plains Pocket Mouse \\
Silky Pocket Mouse \\
Olive-backed Pocket Mouse \\
Hispid Pocket Mouse \\
Preble's Meadow Jumping Mouse \\
Western Jumping Mouse \\
13-lined Ground Squirrel
\end{tabular}

\begin{tabular}{|c|c|c|c|c|c|c|c|c|}
\hline & \multicolumn{2}{|c|}{ TRO3 } & \multicolumn{2}{|c|}{ TR05 } & \multicolumn{2}{|c|}{ TR10 } & \multicolumn{2}{|c|}{ TOTAL } \\
\hline Code & $\#$ & $\# / 100 \mathrm{TN}$ & $\#$ & $\# / 100 \mathrm{TN}$ & \# & $\# / 100 \mathrm{TN}$ & \# & $\# / 100 \mathrm{TN}$ \\
\hline PEMA1 & 26 & 8.67 & 32 & 10.67 & 37 & 12.33 & 95 & 10.56 \\
\hline MUMU1 & & 0 & & 0 & & 0 & of & $\underline{0}$ \\
\hline NEME1 & & 의 & & 0 & & of & 의 & 0 \\
\hline MIPE1 & 15 & 5 & 1 & 0.33 & 12 & 4.00 & 28 & 3.11 \\
\hline MIOC1 & 2 & 0.67 & 6 & 2.00 & 4 & 1.33 & 12 & 1.33 \\
\hline REMO1 & & 0 & & 0 & & 0 & 0 & 0 \\
\hline REME1 & 1 & 0.33 & & 0 & 1 & 0.33 & 2 & 0.22 \\
\hline PEFL2 & & 0 & & of & & 0 & 9 & 0 \\
\hline PEFL1 & & 0 & & 0 & & 0 & of & 0 \\
\hline PEFA1 & & of & & of & & 아 & of & 0 \\
\hline $\mathrm{CHHI1}$ & & 0 & & 0 & & 0 & 0 & 0 \\
\hline ZAHU1 & & 0 & & 0 & & 0 & 0 & 0 \\
\hline ZAPR1 & & 0 & & 0 & & 이 & 0 & 0 \\
\hline SPTA1 & & 0 & & 0 & & 0 & 0 & 0 \\
\hline & 44 & 14.67 & 39 & 13.00 & $\overline{54}$ & 18.00 & 137 & 15.22 \\
\hline
\end{tabular}

$\#=$ total number of captures, excluding recaptures

\#/100TN = number of captures per 100 trap-nights, excluding recaptures, based on 300 trap-nights per site 
Table C-5. Small Mammal Capture Summary, All Communities, Spring 1994.

Species

Deer Mouse

House Mouse

Mexican Woodrat

Meadow Vole

Prairie Vole

Plains Harvest Mouse

Western Harvest Mouse

Plains Pocket Mouse

Silky Pocket Mouse

Olive-backed Pocket Mouse

Hispid Pockel Mouse

Preble's Meadow Jumping Mouse

Western Jumping Mouse

13-lined Ground Squirre

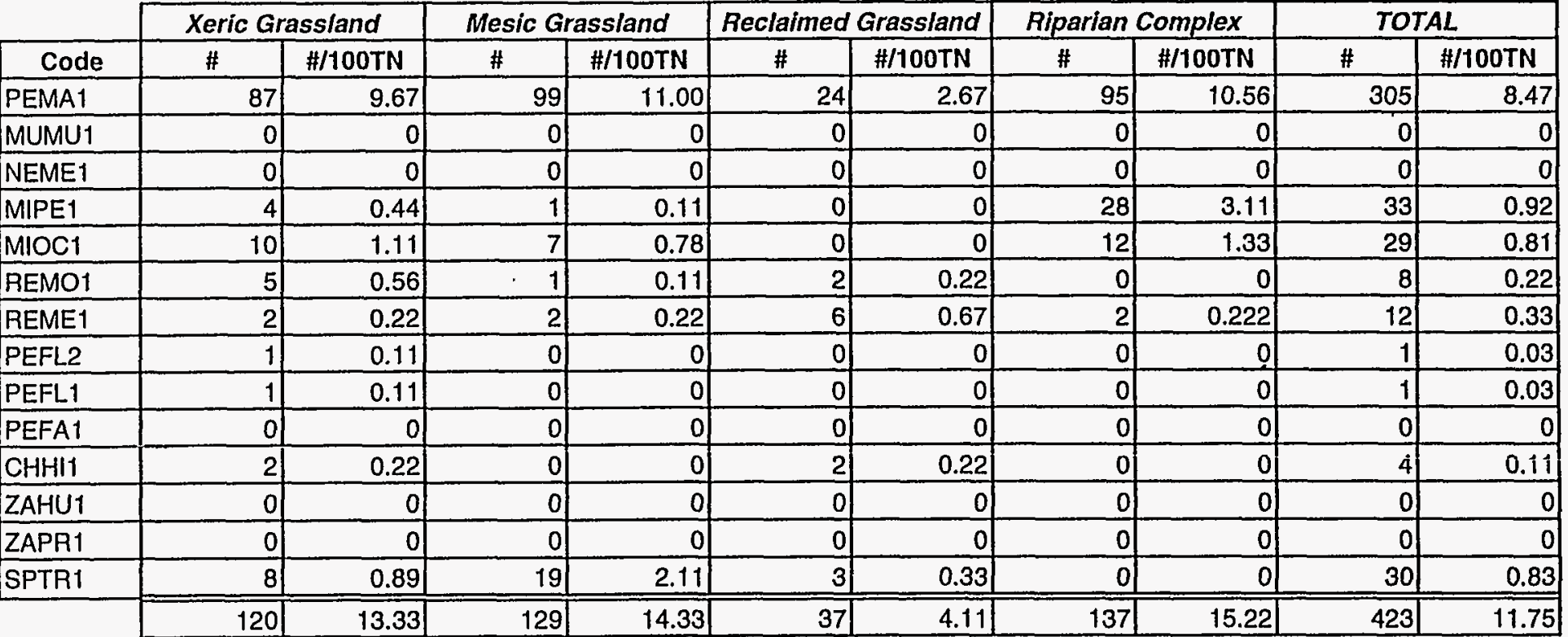

TOTAL

$\#=$ total number of captures, excluding recaptures

\#/100TN = number of captures per 100 trap-nights, excluding recaptures, based on 900 trap-nights per communily 
Table C-6. Small Mammal Capture Summary at the Rocky Mountain Arsenal, Spring 1987. Adapted from Shell 1989.

\begin{tabular}{|c|c|c|c|c|c|c|c|}
\hline & $\begin{array}{l}\text { Weedy } \\
\text { Forbs }\end{array}$ & Shrubs/Yucca' & Thickets $^{2}$ & $\begin{array}{l}\text { Cattails/ } \\
\text { Rushes }\end{array}$ & $\begin{array}{c}\text { Streamside } \\
\text { Meadows }\end{array}$ & Cottonwoods & TOTAL \\
\hline Species & $\# / 100 \mathrm{TN}$ & $\# / 100 \mathrm{TN}$ & $\# / 100 \mathrm{TN}$ & $\# / 100$ TN & $\# / 100 \mathrm{TN}$ & $\# / 100 \mathrm{TN}$ & $\# / 100 \mathrm{TN}$ \\
\hline Deer Mouse & 30.0 & 9.8 & 2.7 & 2.6 & 1.0 & 1.0 & 47.1 \\
\hline Western Harvest Mouse & & 2.2 & 2.2 & 3.1 & 1.5 & & 9.0 \\
\hline Meadow Vole & & 0.4 & & 11.7 & 1.0 & & 13.1 \\
\hline Prairie Vole & & 1.6 & 2.2 & 5.7 & & & 9.5 \\
\hline Silky Pocket Mouse & & 0.2 & & & & & 0.2 \\
\hline Hispid Pockel Mouse & & 0.8 & & & & & 0.8 \\
\hline Ord's Kangaroo Rat & & 2.5 & & & & & 2.5 \\
\hline TOTAL & 30.0 & 17.5 & 7.1 & 23.1 & 3.5 & 1.0 & 82.2 \\
\hline
\end{tabular}

$\# / 100 T N=$ number of captures per 100 trap-nights, from Shell (1989).

1 Shrubs include sand sagebrush and rubber rabbilbrush.

2 Thickets include New Mexico locust and American plum. 
Table C-7. Small Mammal Age and Sex Data, Xeric Mixed Grassland Community, Spring 1994.

Deer Mouse

House Mouse

Mexican Woodrat

Meadow Vole

Prairie Vole

Plains Harvest Mouse

Western Harvest Mouse

Plains Pocket Mouse

Silky Pocket Mouse

Olive-backed Pocket Mouse

Hispid Pocket Mouse

Preble's Meadow Jumping Mouse

Western Jumping Mouse

13-lined Ground Squirrel

\begin{tabular}{|c|c|c|c|c|c|c|c|c|c|c|c|c|}
\hline & \multicolumn{3}{|c|}{ TR01 } & \multicolumn{3}{|c|}{ TR06 } & \multicolumn{3}{|c|}{ TR12 } & \multicolumn{3}{|c|}{ TOTAL } \\
\hline Code & ADM & ADF & JUV & ADM & ADF & JUV & ADM & ADF & JUV & ADM & ADF & JUV \\
\hline PEMA1 & 25 & 23 & & 10 & 14 & 2 & 6 & 3 & 1 & 41 & 40 & 3 \\
\hline MUMU1 & & & & & & & & & & 0 & 0 & 0 \\
\hline NEME1 & & & & & & & & & & 0 & 이 & 0 \\
\hline MIPE1 & & & & & 1 & 3 & & & & 0 & 1 & 3 \\
\hline MlOC1 & & 1 & & 1 & 4 & 3 & & 1 & & 1 & 6 & 3 \\
\hline REMO1 & & & & 2 & 1 & & 1 & 1 & & 3 & 2 & 0 \\
\hline REME1 & & & & 1 & & & & & & 1 & 0 & 0 \\
\hline PEFL2 & & & & & 1 & & & & & 0 & 1 & 0 \\
\hline PEFL1 & & & & & 1 & & & & & of & 1 & 0 \\
\hline PEFA1 & & & & & & & & & & 0 & 요 & 0 \\
\hline $\mathrm{CHHII}$ & & 1 & & & & & & 1 & & 0 & 2 & 0 \\
\hline ZAHU1 & & & & & & & & & & 0 & 0 & $\underline{0}$ \\
\hline ZAPR1 & & & & & & & & & & 0 & 0 & 0 \\
\hline SPTR1 & 1 & 3 & & & 2 & & & 1 & & 1 & 6 & 0 \\
\hline
\end{tabular}

ADM = Adult Males

ADF $=$ Adult Females

JUV = Juveniles and Sub-Adults

Values based on 300 trap-nights per site.

o 
Table C-8. Small Mammal Age and Sex Data, Mesic Mixed Grassland Community, Spring 1994.

Deer Mouse

Species

House Mouse

Mexican Woodrat

Meadow Vole

Prairie Vole

Plains Harvest Mouse

Western Harvest Mouse

Plains Pocket Mouse

Silky Pocket Mouse

Olive-backed Pocket Mouse

Hispid Pocket Mouse

Preble's Meadow Jumping Mouse

Western Jumping Mouse

13-lined Ground Squirrel

\begin{tabular}{|c|c|c|c|c|c|c|c|c|c|c|c|c|}
\hline & \multicolumn{3}{|c|}{ TR02 } & \multicolumn{3}{|c|}{ TR04 } & \multicolumn{3}{|c|}{ TR11 } & \multicolumn{3}{|c|}{ TOTAL } \\
\hline Code & ADM & ADF & JUV & ADM & ADF & JUV & ADM & ADF & JUV & ADM & ADF & JUV \\
\hline PEMA1 & 16 & 15 & & 24 & 23 & & 10 & 10 & & 50 & 48 & 0 \\
\hline MUMU1 & & & & & & & & & & 0 & 0 & . \\
\hline NEME1 & & & & & & & & & & 0 & 0 & 0 \\
\hline MIPE 1 & & 1 & & & & & & & & 0 & 1 & 0 \\
\hline MIOC1 & 1 & & & 2 & 3 & & 1 & & & 4 & 3 & 0 \\
\hline REMO1 & & & & & 1 & & & & & of & 1 & 0 \\
\hline REME1 & & & & & & & 1 & 1 & & 1 & 1 & $\underline{0}$ \\
\hline PEFL2 & & & & & & & & & & 이 & 요 & 0 \\
\hline PEFL1 & & & & & & & & & & 요 & 요 & 0 \\
\hline PEFA1 & & & & & & & & & & 0 & 0 & 0 \\
\hline $\mathrm{CHHII}$ & & & & & & & & & & 0 & 0 & 0 \\
\hline ZAHU1 & & & & & & & & & & 요 & 0 & 0 \\
\hline ZAPR1 & & & & & & & & & & 의 & 의 & 0 \\
\hline SPTA1 & 5 & 7 & & 3 & 1) & & 2 & 1 & & 10 & 9 & 0 \\
\hline
\end{tabular}

ADM = Adult Males

ADF $=$ Adult Females

JUV = Juveniles and Sub-Adults

Values based on 300 trap-nights per site.

$\stackrel{8}{0}$ 
Table C-9. Small Mammal Age and Sex Data, Reclaimed Grassland Community, Spring 1994.

Species

Deer Mouse

House Mouse

Mexican Woodrat

Meadow Vole

Prairie Vole

Plains Harvest Mouse

Western Harvest Mouse

Plains Pocket Mouse

Silky Pocket Mouse

Olive-backed Pocket Mouse

Hispid Pocket Mouse

Preble's Meadow Jumping Mouse

Western Jumping Mouse

13-lined Ground Squirre

\begin{tabular}{|c|c|c|c|c|c|c|c|c|c|c|c|c|}
\hline & \multicolumn{3}{|c|}{ TROT } & \multicolumn{3}{|c|}{ TROB } & \multicolumn{3}{|c|}{ TR09 } & \multicolumn{3}{|c|}{ TOTAL } \\
\hline Code & ADM & ADF & JUV & ADM & ADF & JUV & ADM & ADF & JUV & ADM & ADF & JUV \\
\hline PEMA1 & 5 & 3 & 3 & 7 & 5) & & & & & 12 & 8 & 3 \\
\hline MUMU1 & & & & & & & & & & of & 0 & 의 \\
\hline NEME1 & & & & & & & & & & 의 & 0 & 0 \\
\hline MIPE1 & & & & & & & & & & 우 & 의 & 요 \\
\hline MIOC1 & & & & & & & & & & 0 & 0 & 0 \\
\hline AEMO1 & 1 & 1 & & & & & & & & 1 & 1 & 0 \\
\hline REME1 & 1 & 1 & & & & & 2 & 2 & & 3 & 3 & 0 \\
\hline PEFL2 & & & & & & & & & & of & 0 & 0 \\
\hline PEFL1 & & & & & & & & & & 0 & 이 & 0 \\
\hline PEFA1 & & & & & & & & & & 의 & 요 & 0 \\
\hline $\mathrm{CHHII}$ & $i$ & & & & & & 1 & & & 2 & 우 & 0 \\
\hline ZAHU1 & & & & & & & & & & 0 & 0) & 0 \\
\hline ZAPA1 & & & & & & & & & & 0 & 0 & 0 \\
\hline SPTA1 & & & & & & & 2 & 1 & & 2 & 11 & 0 \\
\hline
\end{tabular}

ADM = Adult Males

$\mathrm{ADF}=$ Adult Females

JUV $=$ Juveniles and Sub-Adults

Values based on 300 trap-nights per site. 
Table C-10. Small Mammal Age and Sex Data, Riparian Community Complex, Spring 1994.

Deer Mouse

House Mouse

Mexican Woodrat

Meadow Vole

Prairie Vole

Plains Harvest Mouse

Western Harvest Mouse

Plains Pocket Mouse

Silky Pocket Mouse

Olive-backed Pockel Mouse

Hispid Pocket Mouse

Preble's Meadow Jumping Mouse

Western Jumping Mouse

13-lined Ground Squirrel

\begin{tabular}{|c|c|c|c|c|c|c|c|c|c|c|c|c|}
\hline & \multicolumn{3}{|c|}{ TR03 } & \multicolumn{3}{|c|}{ TR05 } & \multicolumn{3}{|c|}{ TR10 } & \multicolumn{3}{|c|}{ TOTAL } \\
\hline Code & ADM & ADF & JUV & ADM & ADF & JUV & ADM & ADF & JUV & ADM & ADF & JUV \\
\hline PEMA1 & 10 & 13 & & 17 & 13 & & 21 & 16 & & 48 & 42 & 0 \\
\hline MUMU1 & & & & & & & & & & 0 & 0 & $\dot{5}$ \\
\hline NEME1 & & & & & & & & & & 0 & 0 & 0 \\
\hline MIPE 1 & 4 & 8 & 3 & & & 1 & 7 & 3 & 2 & 11 & 11 & 6 \\
\hline MIOC1 & & 2 & & 2 & 4 & & 3 & 1 & & 5 & 7 & 0 \\
\hline REMO1 & & & & & & & & & & 0 & 0 & 0 \\
\hline AEME1 & & 1 & & & & & & 1 & & 0 & 2 & 0 \\
\hline PEFL2 & & & & & & & & & & 0 & 0 & 0 \\
\hline PEFL1 & & & & & & & & & & 0 & 0 & 0 \\
\hline PEFA1 & & & & & & & & & & 0 & 0 & 0 \\
\hline $\mathrm{CHHII}$ & & & & & & & & & & 0 & 0 & 0 \\
\hline ZAHU1 & & & & & & & & & & 의 & 0 & 0 \\
\hline ZAPR1 & & & & & & & & & & 0 & 0 & 0 \\
\hline SPTR1 & & & & & & & & & & 0 & 0 & 0 \\
\hline
\end{tabular}

$\mathrm{ADM}=$ Adult Males

$\mathrm{ADF}=$ Adult Females

JUV = Juveniles and Sub-Adults

Values based on 300 trap-nights per site. 
Table C-11. Small Mammal Age and Sex Data, All Communities, Spring 1994.

Species

Deer Mouse

House Mouse

Mexican Woodrat

Meadow Vole

Prairie Vole

Plains Harvest Mouse

Western Harvest Mouse

Plains Pocket Mouse

Silky Pocket Mouse

Olive-backed Pocket Mouse

Hispid Pocket Mouse

Preble's Meadow Jumping Mouse

Western Jumping Mouse

13-lined Ground Squirrel

\begin{tabular}{|c|c|c|c|c|c|c|c|c|c|c|c|c|c|c|c|}
\hline & \multicolumn{3}{|c|}{ Xeric Grassland } & \multicolumn{3}{|c|}{ Mesic Grassland } & \multicolumn{3}{|c|}{ Reclaimed Grassland } & \multicolumn{3}{|c|}{ Riparian Complex } & \multicolumn{3}{|c|}{ TOTAL } \\
\hline Code & ADM & ADF & JUV & ADM & ADF & JUV & ADM & ADF & JUV & ADM & ADF & JUV & ADM & ADF & JUV \\
\hline PEMA1 & 41 & 40 & 3 & 50 & 48 & 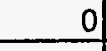 & 12 & 8 & 3 & 48 & 42 & 0 & 151 & 138 & 6 \\
\hline MUMU1 & 0 & 0 & 0 & 0 & 0 & 요 & 요 & 0 & 0 & 0 & 0 & 0 & 0 & 요 & 0 \\
\hline NEME1 & 0 & 0 & 0 & 0 & 0 & 0 & 0 & 요 & 0 & 0 & 0 & 0 & 0 & 0 & 0 \\
\hline MIPE1 & 아 & 1 & 3 & 0 & 1 & 0 & 0 & 0 & 0 & 11 & 11 & 6 & 11 & 13 & 9 \\
\hline MIOC1 & 1 & 6 & 3 & 4 & 3 & 0 & 0 & 0 & 0 & 5 & 7 & 0 & 10 & 16 & 3 \\
\hline REMO1 & 3 & 2 & 0 & 요 & 1 & 0 & 1 & 1 & 0 & 0 & 0 & 0 & 4 & 4 & 0 \\
\hline REME 1 & 1 & 요 & 0 & 1 & 1 & 0 & 3 & 3 & 0 & 0 & 2 & 0 & 5 & 6 & 0 \\
\hline PEFL2 & 0 & 1 & 0 & 0 & 0 & 0 & 0 & 0 & 0 & 0 & 이 & 0 & 아 & 1 & 0 \\
\hline PEFL1 & 0 & 1 & 0 & 0 & 0 & 0 & 0 & 0 & 0 & 0 & 0 & 0 & 아 & 1 & 0 \\
\hline PEFA1 & 0 & 0 & 0 & 0 & 0 & 0 & 0 & 0 & 0 & 0 & 0 & 0 & 0 & 0 & 0 \\
\hline $\mathrm{CHHII}$ & 0 & 2 & 0 & 0 & 0 & 0 & 2 & 0 & 0 & 0 & 0 & 0 & 2 & 2 & 0 \\
\hline ZAHU1 & 0 & 0 & 0 & 0 & 0 & 0 & 0 & 0 & 0 & 0 & 0 & 0 & 0 & 0 & 0 \\
\hline ZAPR1 & 0 & 0 & 0 & 0 & 0 & 0 & 0 & 0 & 0 & 0 & 0 & 0 & 0 & 0 & 0 \\
\hline SPTRI & 1 & 6 & 0 & 10 & 9 & 0 & 2 & 1 & 0 & 0 & 0 & 0 & 13 & 16 & 0 \\
\hline
\end{tabular}

$\mathrm{ADM}=$ Adult Males

ADF $=$ Adult Females

JUV = Juveniles and Sub-Adults

Values based on 900 trap-nights per community. 
Table C-12. Small Mammal Capture Summary, Xeric Mixed Grassland Community, Fall 1994.

Deer Mouse

House Mouse

Mexican Woodrat

Meadow Vole

Prairie Vole

Plains Harvest Mouse

Western Harvest Mouse

Plains Pocket Mouse

Silky Pocket Mouse

Olive-backed Pocket Mouse

Hispid Pocket Mouse

Preble's Meadow Jumping Mouse

Western Jumping Mouse

13-lined Ground Squirrel

TOTAL

\begin{tabular}{|c|c|c|c|c|c|c|c|c|}
\hline \multirow[b]{2}{*}{ Code } & \multicolumn{2}{|c|}{ TROT } & \multicolumn{2}{|c|}{ TR06 } & \multicolumn{2}{|c|}{ TR12 } & \multicolumn{2}{|c|}{ TOTAL } \\
\hline & $\#$ & $\# / 100 \mathrm{TN}$ & $\#$ & $\# / 100 \mathrm{TN}$ & $\#$ & $\# / 100 \mathrm{TN}$ & $\#$ & $\# / 100$ TN \\
\hline PEMA1 & 45 & 15.00 & 21 & 7.00 & 18 & 6.00 & 84 & 9.33 \\
\hline MUMU1 & & 0 & & 0 & & 0 & 이 & 0 \\
\hline NEME 1 & & 이 & & 0 & & 0 & 요 & 0 \\
\hline MIPE1 & & 요 & & 0 & & 이 & 0 & 0 \\
\hline MIOC1 & & 0 & 16 & 5.33 & & 0 & 16 & 1.78 \\
\hline REMO1 & & 0 & 1 & 0.33 & & 으 & 1 & 0.11 \\
\hline REME1 & & 0 & 13 & 4.33 & 4 & 1.33 & 17 & 1.89 \\
\hline PEFL2 & & 0 & 5 & 1.67 & & 이 & 5 & 0.56 \\
\hline PEFL1 & & 0 & & 요 & & 요 & 요 & 0 \\
\hline PEFA1 & & 요 & & 요 & & 요 & 요 & $\underline{0}$ \\
\hline $\mathrm{CHHII}$ & 1 & 0.33 & 1 & 0.33 & & 0 & 2 & 0.22 \\
\hline ZAHU1 & & 0 & & of & & 0 & 0 & 0 \\
\hline ZAPR1 & & 0 & & 이 & & 0 & 0 & 0 \\
\hline SPTR1 & 1 & 0.33 & 1 & 0.33 & & 이 & 2 & 0.22 \\
\hline & 47 & 15.67 & 58 & 19.33 & 22 & 7.33 & 127 & 14.11 \\
\hline
\end{tabular}

$\#=$ total number of captures, excluding recaptures

$\# / 100 \mathrm{TN}=$ number of captures per 100 trap-nights, excluding recaptures, based on 300 trap-nights per site 
Table C-13. Small Mammal Capture Summary, Mesic Mixed Grassland Community, Fall 1994.

Deer Mouse

House Mouse

Mexican Woodrat

Meadow Vole

Prairie Vole

Plains Harvest Mouse

Western Harvest Mouse

Plains Pocket Mouse

Silky Pocket Mouse

Olive-backed Pocket Mouse

Hispid Pocket Mouse

Preble's Meadow Jumping Mouse

Western Jumping Mouse

13-lined Ground Squirre

TOTAL

\begin{tabular}{|c|c|c|c|c|c|c|c|c|}
\hline & \multicolumn{2}{|c|}{ TRO2 } & \multicolumn{2}{|c|}{ TR04 } & \multicolumn{2}{|c|}{ TR11 } & \multicolumn{2}{|c|}{ TOTAL } \\
\hline Code & $\#$ & $\# / 100 \mathrm{TN}$ & $\#$ & $\# / 100 \mathrm{TN}$ & $\#$ & $\# / 100 \mathrm{TN}$ & $\#$ & $\# / 100$ TN \\
\hline PEMA1 & 73 & 24.33 & 101 & 33.67 & 34 & 11.33 & 208 & 23.11 \\
\hline MUMU1 & & 0 & & of & & o & 0 & 0 \\
\hline NEME1 & & 0 & & 요 & & 0 & 0 & 0 \\
\hline MIPE1 & 1 & 0.33 & & 의 & & 의 & 1 & 0.11 \\
\hline MIOC1 & 6 & 2.00 & & 여 & 1 & 0.33 & 7 & 0.78 \\
\hline REMO1 & & of & & of & & 0 & 이 & 0 \\
\hline REME1 & & 이 & 5 & 1.67 & 5 & 1.67 & 10 & 1.11 \\
\hline PEFL2 & & 0 & & 0 & & 0 & 0 & 0 \\
\hline PEFL1 & & 이 & 1 & 0.33 & & ㅇ․ & 1 & 0.11 \\
\hline PEFA1 & & 요 & & 요 & & 요 & 0 & 0 \\
\hline CHHII & 1 & 0.33 & 1 & 0.33 & & 의 & 2 & 0.22 \\
\hline ZAHU1 & & 요 & & 의 & & 의 & 요 & 0 \\
\hline ZAPR1 & & 0 & & 이 & & 우 & 의 & 은 \\
\hline SPTR1 & & 이 & & 0 & & 이 & 이 & 0 \\
\hline & 81 & 27.00 & 108 & 36.00 & 40 & 13.33 & 229 & 25.44 \\
\hline
\end{tabular}

$\#$ = total number of caplures, excluding recaplures

$\# / 100 T N=$ number of captures per 100 trap-nights, excluding recaptures, based on 300 trap-nights per site 
Table C-14. Small Mammal Capture Summary, Reclaimed Grassland Community, Fall 1994.

$\quad$ Species
Deer Mouse
House Mouse
Mexican Woodrat
Meadow Vole
Prairie Vole
Plains Harvest Mouse
Western Harvest Mouse
Plains Pocket Mouse
Silky Pocket Mouse
Olive-backed Pocket Mouse
Hispid Pocket Mouse
Preble's Meadow Jumping Mouse
Western Jumping Mouse
13-lined Ground Squirrel
TOTAL

\begin{tabular}{|c|c|c|c|c|c|c|c|c|}
\hline & \multicolumn{2}{|c|}{ TR07 } & \multicolumn{2}{|c|}{ TR08 } & \multicolumn{2}{|c|}{ TR09 } & \multicolumn{2}{|c|}{ TOTAL } \\
\hline Code & $\#$ & $\# / 100 \mathrm{TN}$ & $\#$ & $\# / 100 \mathrm{TN}$ & $\#$ & $\# / 100 \mathrm{TN}$ & $\#$ & $\# / 100 \mathrm{TN}$ \\
\hline PEMA1 & 10 & 3.33 & 16 & 5.33 & 2 & 0.67 & 28 & 3.11 \\
\hline MUMU1 & & 0 & 1 & 0.33 & & 0 & 1 & 0.11 \\
\hline NEME1 & & 0 & & 요 & & 0 & 0 & 0 \\
\hline MIPE1 & & 0 & & 0 & & 0 & 0 & 0 \\
\hline MIOC1 & 1 & 0.33 & & 0 & & 0 & 1 & 0.11 \\
\hline REMO1 & & 0 & & 0 & & 0 & $\underline{0}$ & 0 \\
\hline REME1 & 14 & 4.67 & 1 & 0.33 & & 0 & 15 & 1.67 \\
\hline PEFL2 & & 0 & & 0 & & 0 & 0 & 0 \\
\hline PEFL1 & & 0 & & 0 & & 0 & 0 & 0 \\
\hline PEFA1 & & 0 & & 0 & & 0 & 0 & 0 \\
\hline $\mathrm{CHHII}$ & 5 & 1.67 & 1 & 0.33 & & 0 & 6 & 0.67 \\
\hline ZAHU1 & & 0 & & 0 & & o & 0 & 0 \\
\hline ZAPR1 & & 0 & & 0 & & 0 & 0 & 0 \\
\hline \begin{tabular}{|l|} 
SPTR1 \\
\end{tabular} & & 0 & & 0 & & 0 & 0 & 0 \\
\hline & 30 & 10.00 & 19 & 6.33 & 2 & 0.67 & 51 & 5.67 \\
\hline
\end{tabular}

$\#=$ total number of captures, excluding recaptures

$\# / 100 \mathrm{TN}=$ number of captures per 100 trap-nights, excluding recaptures, based on 300 trap-nights per site 
Table C-15. Small Mammal Capture Summary, Riparian Community Complex, Fall 1994.

Deer Mouse

Species

House Mouse

Mexican Woodrat

Meadow Vole

Prairie Vole

Plains Harvest Mouse

Western Harvest Mouse

Plains Pocket Mouse

Silky Pockel Mouse

Olive-backed Pocket Mouse

Hispid Pocket Mouse

Preble's Meadow Jumping Mouse

Western Jumping Mouse

13-lined Ground Squirrel

TOTAL

\begin{tabular}{|c|c|c|c|c|c|c|c|c|}
\hline & \multicolumn{2}{|c|}{ TR03 } & \multicolumn{2}{|c|}{ TR05 } & \multicolumn{2}{|c|}{ TR10 } & \multicolumn{2}{|c|}{ TOTAL } \\
\hline Code & \# & $\# / 100$ TN & $\#$ & $\# / 100 \mathrm{TN}$ & $\#$ & $\# / 100 \mathrm{TN}$ & $\#$ & $\# / 100 \mathrm{TN}$ \\
\hline PEMA1 & 73 & 24.33 & 62 & 20.67 & 29 & 9.67 & 164 & 18.22 \\
\hline MUMU1 & & 0 & & 0 & & 0 & 0 & 0 \\
\hline NEME1 & 2 & 0.67 & 1 & 0.33 & & 0 & 3 & 0.33 \\
\hline MIPE1 & 26 & 8.67 & 9 & 3.00 & 14 & 4.67 & 49 & 5.44 \\
\hline MIOC1 & 2 & 0.67 & 16 & 5.33 & 6 & 2.00 & 24 & 2.67 \\
\hline REMO1 & & 0 & & 0 & & 0 & 0 & 0 \\
\hline REME1 & & 0 & 3 & 1.00 & 11 & 3.67 & 14 & 1.56 \\
\hline PEFL2 & & 0 & & 0 & & 0 & 0 & 0 \\
\hline PEFL1 & & 0 & & 0 & & 0 & 0 & 0 \\
\hline PEFA1 & & 0 & & 0 & & 0 & 0 & 0 \\
\hline $\mathrm{CHHI} 1$ & & 이 & & 0 & & 이 & 0 & 0 \\
\hline ZAHU1 & & 0 & & 0 & & 0 & 0 & 0 \\
\hline ZAPR1 & & 0 & & 0 & & 0 & 0 & 0 \\
\hline SPTR1 & & 0 & & 0 & & 0. & 0 & 0 \\
\hline & 103 & 34.33 & 91 & 30.33 & 60 & 20.00 & 254 & 28.22 \\
\hline
\end{tabular}

\# = total number of captures, excluding recaptures

\#/100TN = number of caplures per 100 trap-nights, excluding recaptures, based on 300 trap-nights per site 
Table C-16. Small Mammal Capture Summary, All Communities, Fall 1994.

Species

Deer Mouse

House Mouse

Mexican Woodrat

Meadow Vole

Prairie Vole

Plains Harvest Mouse

Western Harvest Mouse

Plains Pocket Mouse

Silky Pocket Mouse

Olive-backed Pockel Mouse

Hispid Pockel Mouse

Preble's Meadow Jumping Mouse

Western Jumping Mouse

13-lined Ground Squirrel

TOTAL

\begin{tabular}{|c|c|c|c|c|c|c|c|c|c|c|}
\hline & \multicolumn{2}{|c|}{ Xeric Grassland } & \multicolumn{2}{|c|}{ Mesic Grassland } & \multicolumn{2}{|c|}{ Reclaimed Grassland } & \multicolumn{2}{|c|}{ Riparian Complex } & \multicolumn{2}{|c|}{ TOTAL } \\
\hline Code & $\#$ & $\# / 100 T N$ & $\#$ & $\# / 100 T N$ & $\#$ & $\# / 100 \mathrm{TN}$ & $\#$ & $\# / 100 \mathrm{TN}$ & $\#$ & $\# / 100 \mathrm{TN}$ \\
\hline PEMA1 & 84 & 9.33 & 208 & 23.11 & 28 & 3.11 & 164 & 18.22 & 484 & 53.78 \\
\hline MUMU1 & 0 & 0 & 0 & 0 & 1 & 0.11 & 0 & 0 & 1 & 0.11 \\
\hline NEME1 & 0 & 0 & 0 & 0 & 의 & 0 & 3 & 0.33 & 3 & 0.33 \\
\hline MIPE1 & 0 & 0 & 1 & 0.11 & 0 & 0 & 49 & 5.44 & 50 & 5.56 \\
\hline MIOC1 & 16 & 1.78 & 7 & 0.78 & 1 & 0.11 & 24 & 2.67 & 48 & 5.33 \\
\hline REMO1 & 1 & 0.11 & 0 & 0 & 0 & 0 & 0 & 0 & 1 & 0.11 \\
\hline REME1 & 17 & 1.89 & 10 & 1.11 & 15 & 1.67 & 14 & 1.56 & 56 & 6.22 \\
\hline PEFL2 & 5 & 0.56 & 0 & 요 & of & 0 & 0 & 0 & 5 & 0.56 \\
\hline PEFL1 & $\underline{0}$ & 0 & 1 & 0.11 & 0 & 의 & 0 & 0 & 1 & 0.11 \\
\hline PEFA1 & 0 & 0 & 의 & 0 & 이 & 0 & 0 & 0 & 0 & 0 \\
\hline CHHII & 2 & 0.22 & 2 & 0.22 & 6 & 0.67 & 0 & 0 & 10 & 1.11 \\
\hline ZAHU1 & 0 & 0 & 0 & 요 & 의 & 0 & 0 & 0 & 0 & 0 \\
\hline ZAPR1 & 0 & 0 & of & 의 & 의 & 0 & 0 & 0 & 0 & 0 \\
\hline SPTR1 & 2 & 0.22 & 이 & 0 & 0 & 0 & 0 & 0 & 2 & 0.22 \\
\hline & 127 & 14.11 & 229 & 25.44 & 51 & 5.67 & 254 & 28.22 & 661 & 73.44 \\
\hline
\end{tabular}

\# = total number of captures, excluding recaptures

$\# / 100 T N=$ number of captures per 100 trap-nights, excluding recaptures, based on 900 trap-nights per community 
Table C-17. Small Mammal Capture Summary at the Rocky Mountain Arsenal, Fall 1986. Adapted from Shell 1989.

Deer Mouse

Plains Harvest Mouse

Western Harvest Mouse

Northern Grasshopper Mouse

Meadow Vole

Prairie Vole

Ord's Kangaroo Rat

TOTAL

\begin{tabular}{|c|c|c|c|c|c|c|c|}
\hline $\begin{array}{c}\text { Tall Weedy } \\
\text { Forbs }\end{array}$ & $\begin{array}{c}\text { Short Weedy } \\
\text { Forbs }\end{array}$ & Cheatgrass & $\begin{array}{c}\text { Crested } \\
\text { Wheatgrass }\end{array}$ & $\begin{array}{c}\text { Native } \\
\text { Grass }\end{array}$ & Shrubs/Yucca' & Cottonwoods & TOTAL \\
\hline$\# / 100 \mathrm{TN}$ & $\# / 100 \mathrm{TN}$ & $\# / 100 \mathrm{TN}$ & $\# / 100 \mathrm{TN}$ & $\# / 100 \mathrm{TN}$ & $\# / 100 \mathrm{TN}$ & $\# / 100 \mathrm{TN}$ & $\# / 100 \mathrm{TN}$ \\
\hline 31.9 & 15.6 & 8.3 & 2.5 & 0.3 & 13.9 & 1.1 & 73.6 \\
\hline 2.2 & & & & & & 1.1 & 3.3 \\
\hline & & & & & 2.2 & & 2.2 \\
\hline & & & & 0.6 & 3.3 & & 3.9 \\
\hline & & & & & & 7.8 & 7.8 \\
\hline 0.3 & & 0.3 & 0.3 & 0.3 & & & 1.2 \\
\hline & & & & & 1.1 & & 1.1 \\
\hline \hline 34.4 & 15.6 & 8.6 & 2.8 & 1.2 & 20.5 & 10.0 & 93.1 \\
\hline
\end{tabular}

$\# / 100 T N=$ number of caplures per 100 trap-nights, from Shell (1989).

1 Shrubs include sand sagebrush and rubber rabbitbrush. 
Table C-18. Small Mammal Age and Sex Data, Xeric Mixed Grassland Community, Fall 1994.

\begin{tabular}{l}
\multicolumn{1}{c}{ Species } \\
Deer Mouse \\
House Mouse \\
Mexican Woodrat \\
Meadow Vole \\
Prairie Vole \\
Plains Harvest Mouse \\
Western Harvest Mouse \\
Plains Pocket Mouse \\
Silky Pocket Mouse \\
Olive-backed Pocket Mouse \\
Hispid Pocket Mouse \\
Preble's Meadow Jumping Mouse \\
Western Jumping Mouse \\
13-lined Ground Squirrel
\end{tabular}

\begin{tabular}{|c|c|c|c|c|c|c|c|c|c|c|c|c|}
\hline & \multicolumn{3}{|c|}{ TRO1 } & \multicolumn{3}{|c|}{ TR06 } & \multicolumn{3}{|c|}{$T R 12$} & \multicolumn{3}{|c|}{ TOTAL } \\
\hline Code & ADM & ADF & JUV & ADM & ADF & JUV & ADM & ADF & JUV & ADM & ADF & JUV \\
\hline PEMA1 & 19 & 18 & 8 & 7 & 12 & 2 & 9 & 6 & 3 & 35 & 36 & 13 \\
\hline MUMU1 & & & & & & & & & & 0 & 0 & 0 \\
\hline NEME1 & & & & & & & & & & 0 & 0 & 0 \\
\hline MIPE1 & & & & & & & & & & 0 & 0 & 0 \\
\hline MIOCI & & & & 3 & 9 & 4 & & & & 3 & 9 & 4 \\
\hline REMO1 & & & & & & 1 & & & & 0 & 0 & 1 \\
\hline REMEI & & & & 4 & 8 & 1 & 4 & & & 8 & 8 & 1 \\
\hline PEFL2 & & & & & 5 & & & & & 0 & 5 & 0 \\
\hline PEFL1 & & & & & & & & & & $00^{\circ}$ & 0 & 0 \\
\hline PEFA1 & & & & & & & & & & 0 & 0 & 0 \\
\hline $\mathrm{CHHI1}$ & & 1 & & & 1 & & & & & 0 & 2 & 0 \\
\hline ZAHU1 & & & & & & & & & & 0 & 0 & 0 \\
\hline ZAPR1 & & & & & & & & & & 이 & 0 & 0 \\
\hline SPTR1 & 1 & & & & 1 & & & & & 1 & 1 & 0 \\
\hline
\end{tabular}

$\mathrm{ADM}=$ Adult Males

ADF $=$ Adult Females

JUV $=$ Juveniles and Sub-Adults

Values based on 300 trap-nights per site. 


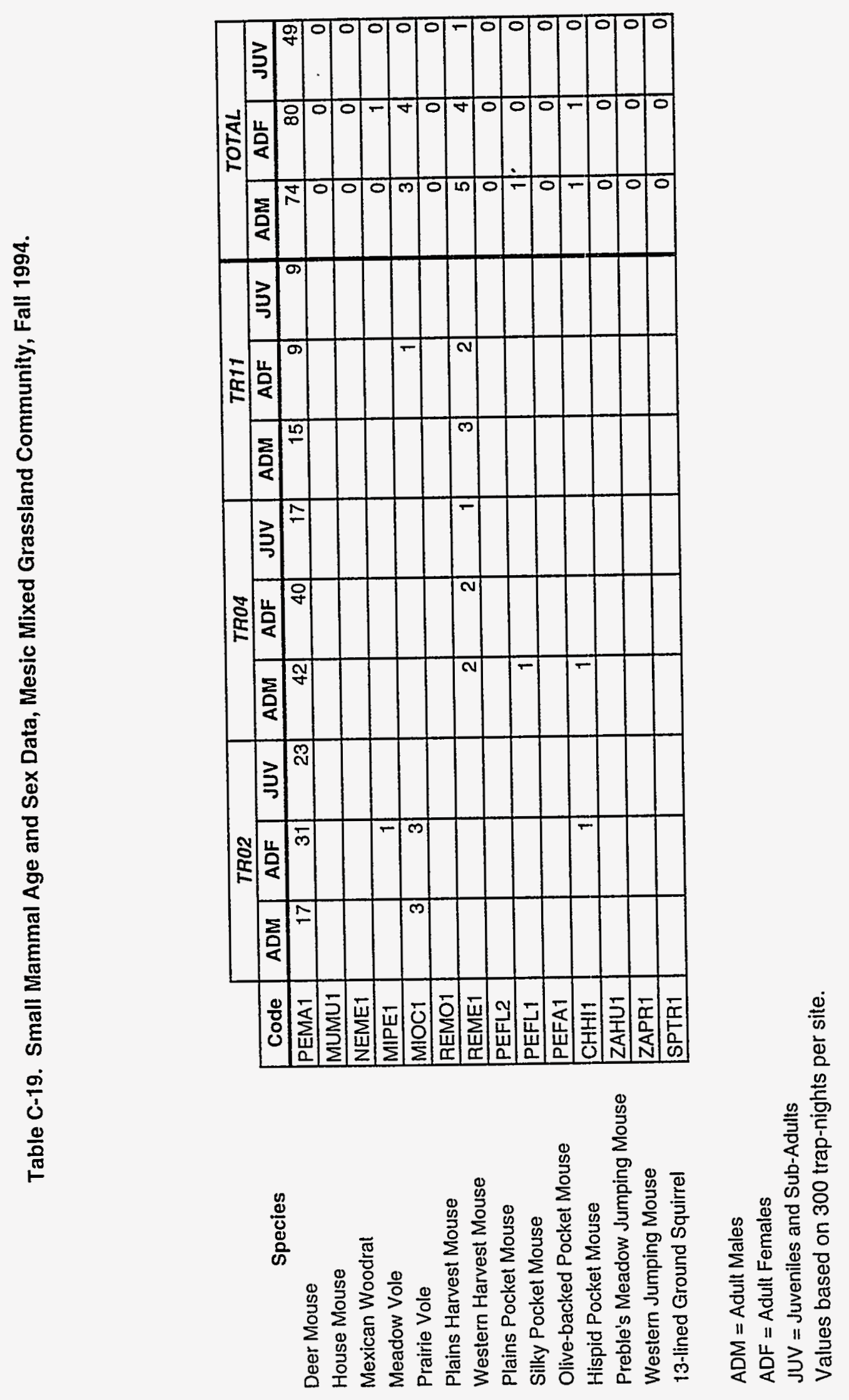


Table C-20. Small Mammal Age and Sex Data, Reclaimed Grassland Community, Fall 1994.

Deer Mouse

Species

House Mouse

Mexican Woodrat

Meadow Vole

Prairie Vole

Plains Harvest Mouse

Western Harvest Mouse

Plains Pocket Mouse

Silky Pocket Mouse

Olive-backed Pocket Mouse

Hispid Pocket Mouse

Preble's Meadow Jumping Mouse

Western Jumping Mouse

13-lined Ground Squirrel

\begin{tabular}{|l|r|r|r|r|r|r|r|r|r|r|r|r|}
\cline { 2 - 11 } \multicolumn{1}{c|}{} & \multicolumn{3}{c|}{ TR07 } & \multicolumn{3}{c|}{ TR08 } & \multicolumn{3}{c|}{ TR09 } & \multicolumn{3}{c|}{ TOTAL } \\
\hline Code & ADM & ADF & JUV & ADM & ADF & JUV & ADM & ADF & JUV & ADM & ADF & JUV \\
\hline PEMA1 & 8 & 2 & & 6 & 3 & 6 & 2 & & & 16 & 5 & 6 \\
\hline MUMU1 & & & & 1 & & & & & & 1 & 0 & 0 \\
\hline NEME1 & & & & & & & & & & 0 & 0 & 0 \\
\hline MIPE1 & & & & & & & & & & 0 & 0 & 0 \\
\hline MIOC1 & & & 1 & & & & & & & 0 & 0 & 1 \\
\hline REMO1 & & & & & & & & & & 0 & 0 & 0 \\
\hline REME1 & 7 & 6 & 1 & & & & & & & 7 & 6 & 2 \\
\hline PEFL2 & & & & & & & & & & 0 & 0 & 0 \\
\hline PEFL1 & & & & & & & & & & 0 & 0 & 0 \\
\hline PEFA1 & & & & & & & & & & 0 & 0 & 0 \\
\hline CHHI1 & 2 & 3 & & & & & & & & 3 & 3 & 0 \\
\hline ZAHU1 & & & & & & & & & & 0 & 0 & 0 \\
\hline ZAPR1 & & & & & & & & & & 0 & 0 & 0 \\
\hline SPTR1 & & & & & & & & & & 0 & 0 & 0 \\
\hline
\end{tabular}

\section{$A D M=$ Adult Males}

ADF $=$ Adult Females

JUV = Juveniles and Sub-Adults

Values based on 300 trap-nights per site. 
Table C-21. Small Mammal Age and Sex Data, Riparian Community Complex, Fall 1994.

Species

Deer Mouse

House Mouse

Mexican Woodrat

Meadow Vole

Prairie Vole

Plains Harvest Mouse

Western Harvest Mouse

Plains Pocket Mouse

Silky Pocket Mouse

Olive-backed Pocket Mouse

Hispid Pocket iviouse

Preble's Meadow Jumping Mouse

Western Jumping Mouse

13-lined Ground Squirrel

\begin{tabular}{|c|c|c|c|c|c|c|c|c|c|c|c|c|}
\hline & \multicolumn{3}{|c|}{ TR03 } & \multicolumn{3}{|c|}{ TRO5 } & \multicolumn{3}{|c|}{$T R 10$} & \multicolumn{3}{|c|}{ TOTAL } \\
\hline Code & ADM & ADF & JUV & ADM & ADF & JUV & ADM & ADF & JUV & ADM & ADF & JUV \\
\hline PEMA1 & 33 & 25 & 11 & 25 & 21 & 15 & 11 & 12 & 6 & 69 & 58 & 32 \\
\hline MUMU1 & & & & & & & & & & 0 & 0 & 0 \\
\hline NEME1 & & 1 & 1 & & 1 & & & & & 0 & 2 & 1 \\
\hline MIPE1 & 10 & 15 & & 2 & 3 & 4 & & 2 & 12 & 12 & 20 & 16 \\
\hline MIOC1 & 2 & & & 5 & 10 & 1 & 3 & 3 & & 10 & 13 & 1 \\
\hline REMO1 & & & & & & & & & & 의 & 0 & 0 \\
\hline REME1 & & & & 2 & & 1 & 5 & 3 & 3 & 7 & 3 & 4 \\
\hline PEFL2 & & & & & & & & & & 0 & 0 & 0 \\
\hline PEFL1 & & & & & & & & & & 0 & 0 & 0 \\
\hline PEFA1 & & & & & & & & & & 0 & 0 & 0 \\
\hline CHiHil & & & & & & & & & & 아 & 요 & 0 \\
\hline ZAHU1 & & & & & & & & & & 0 & 0 & 0 \\
\hline ZAPR1 & & & & & & & & & & 이 & 0 & 0 \\
\hline SPTR1 & & & & & & & & & & 0 & 0 & 0 \\
\hline
\end{tabular}

$\mathrm{ADM}=$ Adult Males

ADF $=$ Adult Females

JUV = Juveniles and Sub-Adults

Values based on 300 trap-nights per site. 
Table C-22. Small Mammal Age and Sex Data, All Communities, Fall 1994.

Species

Deer Mouse

House Mouse

Mexican Woodrat

Meadow Vole

Prairie Vole

Plains Harvest Mouse

Western Harvest Mouse

Plains Pocket Mouse

Silky Pocket Mouse

Olive-backed Pocket Mouse

Hispid Pockel Mouse

Preble's Meadow Jumping Mouse

Western Jumping Mouse

13-lined Ground Squirre

\begin{tabular}{|c|c|c|c|c|c|c|c|c|c|c|c|c|c|c|c|}
\hline & \multicolumn{3}{|c|}{ Xeric Grassland } & \multicolumn{3}{|c|}{ Mesic Grassland } & \multicolumn{3}{|c|}{ Reclaimed Grassland } & \multicolumn{3}{|c|}{ Riparian Complex } & \multicolumn{3}{|c|}{ TOTAL } \\
\hline Code & ADM & ADF & JUV & ADM & ADF & JUV & ADM & ADF & JUV & ADM & ADF & JUV & ADM & ADF & JUV \\
\hline PEMA1 & 35 & 36 & 13 & 74 & 80 & 49 & 16 & 5 & 6 & 69 & 58 & 32 & 194 & 179 & 100 \\
\hline MUMU1 & 0 & 0 & 0 & 0 & 0 & 0 & 1 & 0 & 0 & 이 & 0 & 0 & $\cdot 1$ & 0 & 0 \\
\hline NEME1 & 0 & 0 & 0 & 0 & 0 & 0 & 0 & 0 & 0 & 0 & 2 & 1 & 0 & 2 & 1 \\
\hline MIPE1 & 0 & 0 & 0 & 0 & 1 & 0 & 0 & 0 & 0 & 12 & 20 & 16 & 12 & 21 & 16 \\
\hline MIOC1 & 3 & 9 & 4 & 3 & 4 & 0 & 0 & 0 & 1 & 10 & 13 & 1 & 16 & 26 & 6 \\
\hline REMO1 & 0 & 0 & 1 & 0 & 0 & 0 & 0 & 0 & 0 & 0 & 0 & 0 & 0 & 0 & 1 \\
\hline REME1 & 8 & 8 & 1 & 5 & 4 & 1 & 7 & 6 & 2 & 7 & 3 & 4 & 27 & 21 & 8 \\
\hline PEFL2 & 0 & 5 & 0 & 0 & 0 & 0 & 0 & 0 & 0 & 0 & 0 & 0 & 0 & 5 & 0 \\
\hline PEFL1 & 0 & 0 & 0 & 1 & 0 & 0 & 0 & 0 & 0 & 의 & 0 & 0 & 1 & 0 & 0 \\
\hline PEFA1 & 0 & 0 & 0 & 0 & 0 & 0 & 0 & 0 & 0 & 0 & 0 & 0 & 0 & 0 & 0 \\
\hline $\mathrm{CHHII}$ & 0 & 2 & 0 & 1 & 1 & 0 & 3 & 3 & 0 & 0 & 0 & 0 & 4 & 6 & 0 \\
\hline ZAHU1 & 0 & 0 & 0 & 0 & 0 & 0 & 0 & 0 & 0 & 0 & 0 & 0 & 0 & 0 & 0 \\
\hline ZAPA1 & 0 & 0 & 0 & 0 & 0 & 0 & 0 & 0 & 0 & 0 & 0 & $\overline{0}$ & 0 & 0 & 0 \\
\hline SPTR1 & 1 & 1 & 0 & 0 & 0 & 0 & 0 & 0 & 0 & 0 & 0 & 0 & 1 & 1 & 0 \\
\hline
\end{tabular}

ADM $=$ Adult Males

$A D F=$ Adult Females

JUV = Juveniles and Sub-Adults

Values based on 900 trap-nights per community. 
Table C-23. Average Number of Individuals of All Species and Average Trap Success per Season and Year.

\begin{tabular}{l|lcc|lcc}
\multirow{2}{*}{ season and year } & \multicolumn{3}{|c|}{$\begin{array}{c}\text { number of individuals } \\
\text { (all species) }\end{array}$} & \multicolumn{3}{c}{$\begin{array}{c}\text { rate of successful traps } \\
\text { (captures per trap-night) }\end{array}$} \\
\cline { 2 - 7 } & average & maximum & minimum & average maximum & minimum \\
\hline \hline spring 1993 & $21.13^{\mathrm{a}}$ & 59 & 2 & $0.071^{\mathrm{a}}$ & 0.197 & 0.007 \\
fall 1993 & $59.25^{\mathrm{b}}$ & 144 & 16 & $0.198^{\mathrm{b}}$ & 0.480 & 0.053 \\
1993 & 44.00 & 144 & 2 & 0.147 & 0.480 & 0.007 \\
spring 1994 & $35.25^{\mathrm{ab}}$ & 58 & 8 & $0.118^{\mathrm{ab}}$ & 0.193 & 0.027 \\
fall 1994 & $55.08^{\mathrm{ab}}$ & 108 & 2 & $0.184^{\mathrm{ab}}$ & 0.360 & 0.007 \\
1994 & 45.17 & 108 & 2 & 0.151 & 0.360 & 0.007
\end{tabular}

Letters in common signily no significant difference $(\alpha=0.05)$. Year totals do not differ significantly from each other at the $\alpha=0.05$ level. 
Table C-24. Average Number of Individuals of All Species and Average Trap Success Rate by Site and Community.

\begin{tabular}{|c|c|c|c|c|}
\hline community & & $\begin{array}{l}\text { iverage number } \\
\text { of individuals }\end{array}$ & $\begin{array}{r}\text { aver } \\
\text { (\% tra }\end{array}$ & $\begin{array}{l}\text { e success rate } \\
\text { with a capture) }\end{array}$ \\
\hline xeric grassland & & & & \\
\hline & TR01 & 39.75 & & 0.133 \\
\hline & TR06 & 50.00 & & 0.167 \\
\hline & TR12 & 16.00 & & 0.053 \\
\hline & & $3.91^{\mathrm{ab}}$ & $0.113^{\mathrm{ab}}$ & \\
\hline mesic grassland & & & & \\
\hline & TRO2 & 73.67 & & 0.246 \\
\hline & TR04 & 61.00 & & 0.203 \\
\hline & TR11 & 35.25 & & 0.118 \\
\hline & & $5.09^{b c}$ & $0.184^{b c}$ & \\
\hline reclaimed grasst & and & & & \\
\hline & TR07 & 22.00 & & 0.073 \\
\hline & TR08 & 25.00 & & 0.083 \\
\hline & TROO & 7.00 & & 0.024 \\
\hline & & $7.64^{\mathrm{a}}$ & $0.059^{a}$ & \\
\hline riparian complex & & & & \\
\hline & TR03 & 97.00 & & 0.323 \\
\hline & TR05 & 76.00 & & 0.253 \\
\hline & TR10 & 49.00 & & 0.164 \\
\hline & All & $1.91^{\mathrm{c}}$ & $0.24^{c}$ & \\
\hline
\end{tabular}

Means with one or more letter in common are not significantly different at $\alpha=0.05$.

Compare means down columns. 
Table C-25. Small Mammal Capture Summary, All Communities, 1993 and 1994.

Species

Deer Mouse

House Mouse

Mexican Woodrat

Meadow Vole

Prairie Vole

Plains Harvest Mouse

Western Harvest Mouse

Plains Pocket Mouse

Silky Pocket Mouse

Olive-backed Pocket Mouse

Hispid Pocket Mouse

Preble's Meadow Jumping Mouse

Western Jumping Mouse

13-lined Ground Squirrel

\begin{tabular}{|c|c|c|c|c|c|c|c|c|c|c|c|c|c|c|c|c|c|c|c|}
\hline \multicolumn{4}{|c|}{ Xeric } & \multicolumn{4}{|c|}{ Mesic } & \multicolumn{4}{|c|}{ Reclaimed } & \multicolumn{4}{|c|}{ Riparian } & \multicolumn{4}{|c|}{ All Communities } \\
\hline \multicolumn{2}{|c|}{1993} & \multicolumn{2}{|c|}{1994} & \multicolumn{2}{|c|}{1993} & \multicolumn{2}{|c|}{1994} & \multicolumn{2}{|c|}{1993} & \multicolumn{2}{|c|}{1994} & \multicolumn{2}{|c|}{1993} & \multicolumn{2}{|c|}{1994} & \multicolumn{2}{|c|}{1993} & \multicolumn{2}{|c|}{1994} \\
\hline Spring & Fall & Spring & Fall & Spring & Fall & Spring & Fall & Spring & Fall & Spring & Fall & Spring & Fall & Spring & Fall & Spring & Fall & Spring & Fall \\
\hline 4 & 7.4 & 9.7 & 9.3 & 4.2 & 21.0 & 11.0 & 23.1 & 1.7 & 7.7 & 2.7 & 3.1 & 10.2 & 25.8 & 10.6 & 18.2 & 5.0 & 15.5 & 8.5 & 53.8 \\
\hline 0 & 0 & 0 & 0 & 0 & 0 & 아 & 0 & 0 & 0 & 요 & 0.1 & 요 & 요 & 요 & 요 & 0 & 아 & 와 & 0.1 \\
\hline 0 & 0 & 0 & 0 & 0 & 0 & 아 & 0 & 0 & 0 & 0 & 0 & 이 & 0.1 & 0 & 0.3 & 0 & 0 & 요 & 0.3 \\
\hline 0 & 0.1 & 0.4 & 0 & of & 0.1 & 0.1 & 0.1 & 0.3 & 0.1 & of & 0 & 5.5 & 2.8 & 3.1 & 5.4 & 1.5 & 0.5 & 0.9 & 5.6 \\
\hline 0 & 1.1 & 1.1 & 1.8 & 0.7 & 1.7 & 0.8 & 0.8 & 0 & 0.1 & 0 & 0.1 & 0 & 4.1 & 1.3 & 2.7 & 0.2 & 1.5 & 0.8 & 5.3 \\
\hline 0 & 0 & 0.6 & 0.1 & 0 & 0 & 0.1 & 0 & 이 & 0 & 0.2 & 0 & 0.2 & 0 & 0 & 0 & 0 & 의 & 0.2 & 0.1 \\
\hline 0 & 1.1 & 0.2 & 1.9 & 0 & 0.8 & 0.2 & 1.1 & 요 & 0.8 & 0.7 & 1.7 & 0.2 & 0.9 & 0.2 & 1.6 & 0 & 0.6 & 0.3 & 6.2 \\
\hline 0 & 0 & 0.1 & 0.6 & 0 & 0 & 0 & of & 0 & 0 & 0 & 0 & 0 & 아 & 0 & 0 & 0 & 0 & 이 & 0.6 \\
\hline 0 & 0.4 & 0.1 & 0 & 0 & 0 & 0 & 0.1 & of & 0 & 0 & 0 & 0 & 0 & 0 & 0 & 0 & 0.1 & 0 & 0.1 \\
\hline 0.2 & 0 & 0 & 0 & 0 & 0 & 0 & 0 & 0 & 0 & 아 & 0 & 0 & 요 & 아 & 0 & 우 & 0 & 0 & 0 \\
\hline 0.2 & 0.3 & 0.2 & 0.2 & 0 & 0.2 & 0 & 0.2 & 0.2 & 1.4 & 0.22 & 0.7 & 요 & 이 & 요 & 0 & 0.1 & 0.5 & 0.1 & 1.1 \\
\hline 0 & 0 & 0 & 0 & 0 & 0 & 0 & 0 & 0 & 0 & 0 & 0 & 0.2 & 0 & 0 & 0 & 0 & 0 & 요 & 0 \\
\hline 0 & 0 & 이 & 0 & 0 & 0 & 0 & 0 & 0 & o) & 0 & 0 & 0 & 요 & 0 & 0 & 0 & 0 & 0 & 0 \\
\hline 0.3 & 0.3 & 0.9 & 0.2 & 0.2 & 0.4 & 2.1 & 0 & 0.2 & 0.1 & 0.3 & 0 & 0 & 0 & 0 & 0 & 0.200 & 0.2 & 0.8 & 0.2 \\
\hline 4.7 & $\overline{10.7}$ & 0.0 & 14.1 & 5.1 & 24.2 & 14.3 & 25.4 & 2.3 & 10.2 & 4.11 & 5.7 & 16.2 & 33.7 & 15.2 & 28.2 & 7.0 & 18.9 & 11.8 & 73.4 \\
\hline
\end{tabular}

TOTAL

Values based on number captured per 100 trap-nights, excluding recaptures. 
Table C-26. Deer Mouse Age and Sex Ratios, Spring and Fall 1993 and 1994

\begin{tabular}{|c|c|c|c|c|c|c|c|c|}
\hline \multirow[b]{2}{*}{ Community } & \multicolumn{2}{|c|}{ Spring 1993} & \multicolumn{2}{|c|}{ Fall 1993} & \multicolumn{2}{|c|}{ Spring 1994} & \multicolumn{2}{|c|}{ Fall 1994} \\
\hline & $\mathrm{M} / \mathrm{CF}$ & Y/CF & $M / C F$ & Y/CF & $M / C F$ & Y/CF & $\mathrm{M} / \mathrm{CF}$ & Y/CF \\
\hline Xeric Grassland & 250 & 33 & 89 & 56 & 103 & 8 & 97 & 36 \\
\hline Mesic Grassland & 91 & 36 & 93 & 31 & 104 & 0 & 93 & 61 \\
\hline Reclaimed Grassland & 125 & 25 & 88 & 88 & 150 & 38 & 320 & 120 \\
\hline Riparian Complex & 133 & 17 & 93 & 36 & 114 & 0 & $\overline{119}$ & 55 \\
\hline All Communities & 121 & 23 & 92 & 41 & 109 & 4 & 108 & 56 \\
\hline
\end{tabular}

M/CF=Males per 100 Females

$Y / C F=$ Young per 100 Females 
Table C-27. Association Between Plant Species and Trap Success.

\begin{tabular}{|c|c|c|c|c|}
\hline Scientific Name & $\mathrm{x}^{2}$ & $P<$ & $\begin{array}{l}\text { Number of Occurrences } \\
\text { Associated with } \\
\text { Successful Trapsites }\end{array}$ & $\begin{array}{l}\text { Number of Occurrences } \\
\text { Associated with } \\
\text { Unsuccessful Trapsites }\end{array}$ \\
\hline \multicolumn{5}{|l|}{ Spring 1994} \\
\hline Artemisia ludoviciana & 5.12 & 0.05 & 27 & 44 \\
\hline Draba reptans & 5.22 & 0.05 & 19 & 7 \\
\hline Lacluca serriola & 4.40 & 0.05 & 22 & 37 \\
\hline Salix exigua & 4.42 & 0.05 & 15 & 5 \\
\hline \multicolumn{5}{|l|}{ Fall 1994} \\
\hline Artemisia frigida & 4.46 & 0.05 & 44 & 28 \\
\hline Convolvulus arvensis & 6.44 & 0.05 & 8 & 22 \\
\hline Erigeron flagellaris & 4.82 & 0.05 & 24 & 11 \\
\hline Gutierrezia sarothrae & 4.40 & 0.05 & 45 & 29 \\
\hline Nepeta calaria & 4.30 & 0.05 & 10 & 2 \\
\hline Plantago lanceolata & 4.27 & 0.05 & 0 & 6 \\
\hline Senecio plattensis & 5.22 & 0.05 & 16 & 5 \\
\hline Sporobolus cryptandrus & 4.05 & 0.05 & 4 & 13 \\
\hline Taraxacum officinale & 5.07 & 0.05 & 13 & 27 \\
\hline \multicolumn{5}{|l|}{ Fall 1993} \\
\hline Agrostis hyemalis & 6.33 & 0.05 & 3 & 14 \\
\hline Monarda fistulosa & 5.30 & 0.05 & 0 & 7 \\
\hline Sisymbrium altissimum & 5.22 & 0.05 & 16 & 5 \\
\hline
\end{tabular}


Table C-28. Correlation of Physical Characteristics

\begin{tabular}{lcc} 
Pair-wise Comparison & Pearson's $r$ & $P<$ \\
\hline Spring 1994 $(n=241)$ & & \\
DCE and ANG & 0.248 & 0.01 \\
DCE and ASP & 0.141 & 0.05 \\
ANG and ASP & 0.250 & 0.01 \\
& & \\
Fall 1994 $(n=233)$ & & \\
DCE and ANG & 0.272 & 0.01 \\
DCE and ASP & 0.162 & 0.05 \\
ANG and ASP & 0.469 & 0.01
\end{tabular}


Table C-29. Distance of the Trap Station to the Nearest Canopy Edge for 1994 Zapus hudsonius preblei Captures.

\begin{tabular}{rrrr} 
distance to canopy edge $(\boldsymbol{m})$ & number & frequency & $\%$ \\
\hline 0 & 35 & 35 & 63.64 \\
1 & 7 & 42 & 76.36 \\
2 & 3 & 45 & 81.82 \\
3 & 2 & 47 & 85.45 \\
5 & 2 & 49 & 89.09 \\
10 & 2 & 51 & 92.73 \\
30 & 1 & 52 & 94.55 \\
40 & 1 & 53 & 96.36 \\
45 & 1 & 54 & 98.18 \\
150 & 1 & 55 & 100.00
\end{tabular}


Table C-30. Distance of the Trap Station to the Nearest Embankment for Zapus hudsonius preblei Captures.

\begin{tabular}{crrr} 
distance to embankment $(\boldsymbol{m})$ & number & frequency & $\%$ \\
\hline 0 & 19 & 19 & 34.55 \\
1 & 13 & 32 & 58.18 \\
2 & 5 & 37 & 67.27 \\
3 & 6 & 43 & 78.18 \\
4 & 1 & 44 & 80.00 \\
5 & 2 & 46 & 83.64 \\
9 & 1 & 47 & 85.45 \\
10 & 3 & 50 & 90.91 \\
16 & 1 & 51 & 92.73 \\
20 & 1 & 52 & 94.55 \\
30 & 1 & 53 & 96.36 \\
40 & 2 & 55 & 100.00
\end{tabular}


造

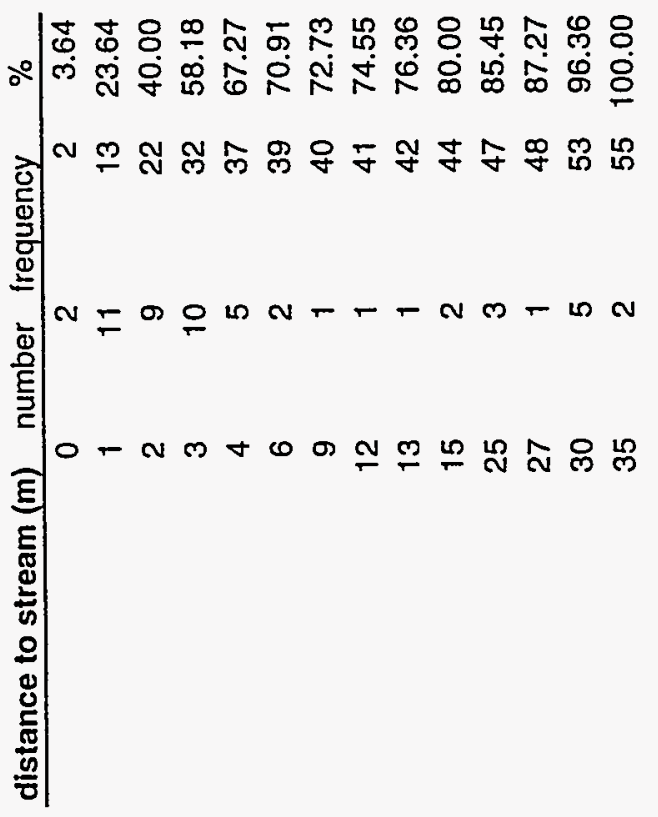


Table C-32. Soil Moisture, Burrowing Opportunities, Litter Cover, and Trap Position for Zapus hudsonius preblei Capture Locations.

\begin{tabular}{lrr} 
moisture & number & $\%$ \\
\hline xeric & 0 & 0.00 \\
mesic & 21 & 38.18 \\
humid & 27 & 49.09 \\
hydric & 7 & 12.73
\end{tabular}

\begin{tabular}{lrr} 
burrowing opportunities & number & $\%$ \\
\hline low & 0 & 0.00 \\
medium & 19 & 34.55 \\
high & 36 & 65.45
\end{tabular}

\begin{tabular}{lrr} 
litter & number & \multicolumn{1}{c}{$\%$} \\
\hline low & 2 & 3.64 \\
medium & 13 & 23.64 \\
high & 40 & 72.73
\end{tabular}

\begin{tabular}{lrr} 
trap canopy position & number & \multicolumn{1}{c}{$\%$} \\
\hline in & 3 & 5.45 \\
out & 17 & 30.91 \\
edge & 35 & 63.64
\end{tabular}


Table C-33. Primary Canopy Species for Zapus hudsonius preblei Capture Locations.

\begin{tabular}{llrr} 
Canopy Species & common name & number & $\%$ \\
\hline Salix exigua & coyote willow & 31 & 56 \\
Amorpha fruticosa & leadplant & 19 & 35 \\
Prunus virginiana & chokecherry & 3 & 5 \\
Symphoricarpos occidentalis & snowberry & 1 & 2 \\
Salix amygdaloides & peachleai willow & 1 & 2
\end{tabular}


Table C-34. Frequency of Occurrence of All Plant Species at Zapus hudsonius preblei Capture Locations.

\begin{tabular}{llrr} 
Species & Common Name & Number & Occurrence \\
\hline Cirsium arvense & Canadian thistle & 58 & 96.67 \\
Bromus japonicus & Japanese brome & 46 & 76.67 \\
Salix exigua & peachleaf willow & 43 & 71.67 \\
Agropyron smithii & western wheatgrass & 40 & 66.67 \\
Poa pratensis & Kentucky bluegrass & 39 & 65.00 \\
Juncus balticus & baltic rush & 36 & 60.00 \\
Barbarea orthoceras & northern winter cress & 36 & 60.00 \\
Amorpha fruticosa & leadplant & 35 & 58.33 \\
Hypericum perforatum & St. John's-wort & 34 & 56.67 \\
Symphoricarpos occidentalis & snowberry & 32 & 53.33
\end{tabular}


Table C-35. Frequency and Cover of Community Types at Zapus hudsonius preblei Capture Locations.

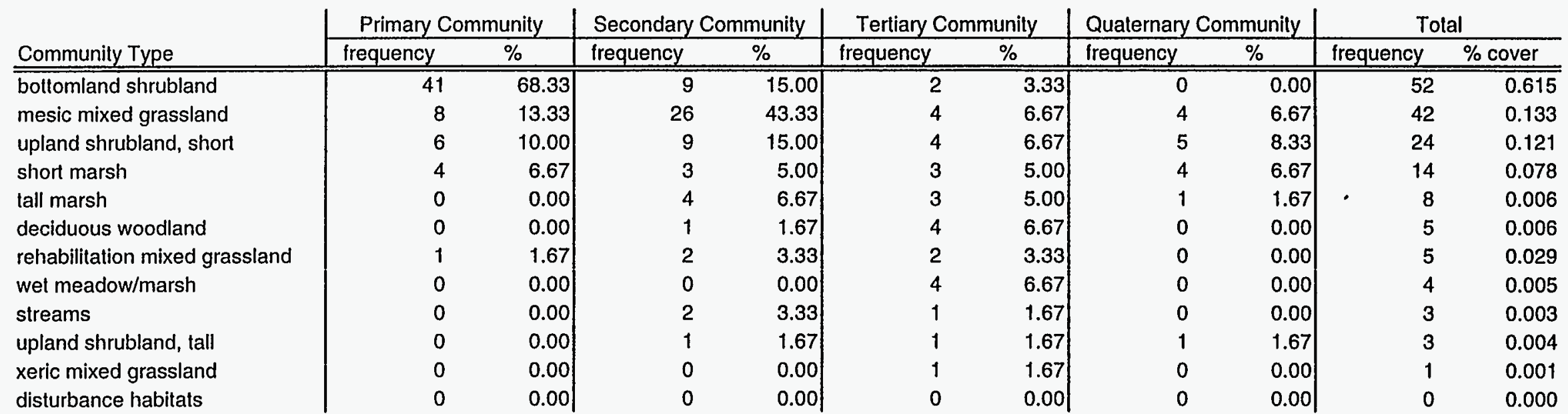




\section{APPENDIX D. AQUATIC ECOLOGY}

Authors: William J. Freeman

Michelle M. Fink

Mark D'Agostino 


\section{APPENDIX D. AQUATIC ECOLOGY}

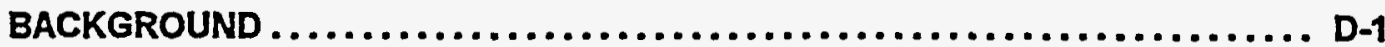

OBJECTIVES ............................................ D-1

Aquatic Ecological Monitoring Program.$\ldots \ldots \ldots \ldots \ldots \ldots \ldots \ldots \ldots$ D-1

Bioassessment of Walnut Creek ........................ D-1

Tissue Sampling for Woman and Walnut Creek Drainage and Offsite

Reservoirs ................................... D-2

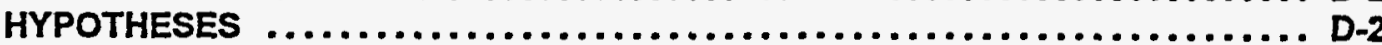

Aquatic Ecological Monitoring Program $\ldots \ldots \ldots \ldots \ldots \ldots \ldots \ldots \ldots \ldots$ D-2

Bioassessment of Walnut Creek $\ldots \ldots \ldots \ldots \ldots \ldots \ldots \ldots \ldots \ldots \ldots \ldots$ D-3

METHODS ........................................... D 3

Aquatic Ecological Monitoring Program $\ldots \ldots \ldots \ldots \ldots \ldots \ldots \ldots \ldots$ D-3

Field Methods ................................. D-3

Laboratory Methods ............................. D-3

Analytical Methods ............................. D-3

Macrobenthic Invertebrates .............. D-3

Phytoplankton ......................... D-4

Zooplankton ......................... D-4

Emergent Insects $\ldots \ldots \ldots \ldots \ldots \ldots \ldots \ldots \ldots \ldots$ D -4

Bioassessment of Walnut Creek .......................... D.4

Fields Methods .............................. D-4

Laboratory Methods ............................ D.5

Analytical Methods ................................. D 5

Tissue Sampling for Walnut and Woman creek Drainages and Offsite

Reservoirs ................................. D-6

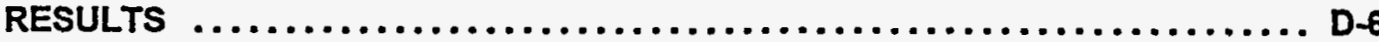

Aquatic Ecological Monitoring Program $\ldots \ldots \ldots \ldots \ldots \ldots \ldots \ldots \ldots$ D-6

Macrobenthic Invertebrates ...................... D-6

Phytoplankton ................................ D

Zooplankton ................................ D-8

Emergent Insects ............................. D-8

Bioassessment of Wainut Creek $\ldots \ldots \ldots \ldots \ldots \ldots \ldots \ldots \ldots \ldots \ldots$ D-8

INTERPRETATION ........................................ D-9

Aquatic Ecological Monitoring Program.$\ldots \ldots \ldots \ldots \ldots \ldots \ldots \ldots \ldots \ldots$ D-9

Bioassessment of Walnut Creek ....................... D-10

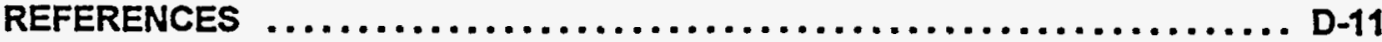

\section{LIST OF FIGURES}

Figure D-1. The Four Biotic Components of EcMP Aquatic Sampling $\ldots \ldots \ldots \ldots \ldots \ldots D-12$

Figure D-2. Diagram of Zooplankton Sampler $\ldots \ldots \ldots \ldots \ldots \ldots \ldots \ldots \ldots \ldots \ldots \ldots \ldots \ldots \ldots \ldots$

Figure D-3. Diagram of Multicore (Core) Macrobenthic Invertebrate Sampler ........ D-14

Figure D-4. Number of Macrobenthic Families Sampled, All Methods Combined ...... D-15

Figure D-5. Number of Families Versus Macrobenthic Sampling Method ........... D-16 
Figure D-6. Number of Macrobenthic Families Sampled With the Core Method ....... D-17

Figure D-7. Number of Macrobenthic Families Sampled With the Dip Net Method ...... D-18

Figure D-8. Number of Macrobenthic Families Sampled With the Drift Net Method ..... D-19

Figure D-9. Number of Phytoplankton Genera Sampled $\ldots \ldots \ldots \ldots \ldots \ldots \ldots \ldots \ldots \ldots$ D-20

Figure D-10. A-series Ponds Phytoplankton Comumunity Composition $\ldots \ldots \ldots \ldots \ldots$. D-21

Figure D-11. A-series Ponds Phytoplankton Community Composition, continued ..... D-22

Figure D-12. B-series Ponds Phytoplankton Community Composition ........... D-23

Figure D-13. B-series Ponds Phytoplankton Community Composition, continued ..... D-24

Figure D-14. B-series Ponds Phytoplankton Community Composition, continued ..... D-25

Figure D-15. D-series Ponds Phytoplankton Community Composition ........... D-26

Figure D-16. Lindsay and C2 Ponds Phytoplankton Community Composition ....... D-27

Figure D-17. Number of Zooplankton Families Sampled $\ldots \ldots \ldots \ldots \ldots \ldots \ldots \ldots \ldots \ldots$ D-28

Figure D-18. Number of Emergent Insect Families Sampled $\ldots \ldots \ldots \ldots \ldots \ldots \ldots \ldots$ D-29

Figure D-19. Percentage of Biotic Taxa Shared Among Ponds Sampled .......... D-30

Figure D-20. Graphical Site Summary of Ammonium Concentrations $\ldots \ldots \ldots \ldots \ldots$ D-31

Figure D-21. Graphical Site Summary of Macrobenthic Invertebrate and Emergent Insect

Richness ......................................... D 32

Figure D-22. Graphical Site Summary of Zooplankton and Phytoplankton Richness ... D-33

\section{LIST OF TABLES}

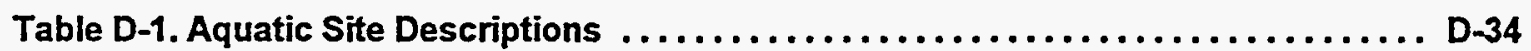

Table D-2. Jaccard Similarity Index and EPT/C Community Index Formulas . . . . . . . . . D-35

Table D-3. Analysis of Variances Tables for Macrobenthic Invertebrate Taxonomic Richness, 994 Data ........................................... D-36

Table D-4. Aquatic Site Summaries for $1994 \ldots \ldots \ldots \ldots \ldots \ldots \ldots \ldots \ldots \ldots \ldots \ldots \ldots \ldots$

Table D-5. EPT/C Index Values for all Macrobenthic Invertebrate Sites ........... D-40

Table D-6. Jaccard Index Matrices for Macrobenthic Invertebrates .............. D 41

Table D-7. Analysis of Variance Table for Phytoplankton Taxonomic Richness, 1994 Data .............................................. D 42 
Table D-8. Jaccard Index Matrix for Phytoplankton ..................... D-43

Table D-9. Analysis of Variance Table for Zooplankton Taxonomic Richness, 1994 Data D-44

Table D-10. Jaccard Index Matrix for Zooplankton $\ldots \ldots \ldots \ldots \ldots \ldots \ldots \ldots \ldots \ldots$ D-45

Table D-11. Analysis of Variance Table for Emergent Insect Taxonomic Richness, 1994 Data ............................................ D-46

Table D-12. Jaccard Index Matrix for Emergent Insects $\ldots \ldots \ldots \ldots \ldots \ldots \ldots \ldots \ldots$ D-47

Table D-13. Macrobenthic Invertebrate Taxonomic Composition Among Sites Sampled for

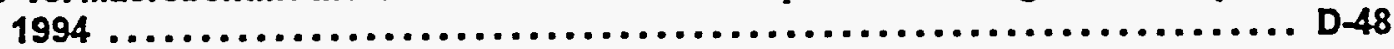

Table D-14. Bioassessment Values of Onsite Aquatic Systems, Based on the Calculated EPTIC Index .......................................... D 52 


\section{BACKGROUND}

The aquatic ecosystems associated with the Site range from natural springs and seeps to diversion ditches and containment ponds designed to hold "domestic" sewage outfall and accidental contaminant releases. The hydrology of onsite streams and ponds is highly regulated by both onsite activities and the needs of neighboring municipalities and individual ranchers. Subsequently, both streamflow and pond elevation vary with both the season and short-term anthropogenic manipulation. Transport of contaminants via'surface water to receptor ecosystems onsite; i.e:, Woman Creek, and possible transport offsite are major concerns of DOE-RFFO.

\section{OBJECTIVES}

The EcMP Aquatic Ecology Module had three main objectives for the 1994 season, corresponding to the three main projects of the module; 1) long-term ecological monitoring ,2) bioassessment of Walnut Creek, and 3) tissue sampling for the Woman and Walnut Creek Drainages and offsite reservoirs. This section is devoted primarily to the reporting and discussion of the aquatic ecological monitoring program. Results and discussion of the bioassessment are available in Wright Water Engineers, inc. (1995). Results and discussion of the tissue sampling study are available in EG\&G (1994).

Objectives specific to the monitoring program are a) to characterize the aquatic communities onsite, b) to determine sources of variation, both natural and anthropogenic, that affect seasonal, annual, and long-term fluctuations in the aquatic ecosystems, c) to compare the Rocky Flats aquatic ecosystems to offsite systems, and d) to determine if parameters associated with aquatic community structure can be correlated with the overall "health" (degree of disturbance or contamination) of individual systems.

\section{Aquatic Ecological Monitoring Program}

Due to budget constraints, sampling in 1994 was restricted to only onsite ponds. The objective of the program was to continue the long-term monitoring of the health and composition of Rocky Flats aquatic ecosystems. Four major biological components of aquatic systems were sampled; macrobenthic invertebrates (insect nymph and larvae), phytoplankton (algae), zooplankton (diatoms and other microscopic animals), and emergent insect (adult mayflies, mosquitoes, etc.) populations (Figure D-1). Abundance, taxonomic composition, and taxonomic richness were the main parameters measured from each. Some of the EcMP pond sampling results were used by the Environmental Restoration Program Division as reference data for the OU6 Remedial Investigation (RI).

\section{Bioassessment of Walnut Creek}

The main purpose of this study was to assess the overall ecologic health of Walnut Creek and to evaluate the potential causes of variations in the aquatic communities, in order to establish a relationship between the amount of ammonium $\left(\mathrm{NH}_{2}\right)$ in the water and the health of the biological community. A primary focus was on the potential effects on biota of ammonium effluent discharges from the Site wastewater treatment plant (WWTP) to the A- and B-series ponds and to the downstream reaches of Walnut Creek. EG\&G's Surface Water Division and EcMP staff collaborated on this study to provide supporting documentation for a DOE proposal to the Colorado Water Quality Control Commission (WQCC) to re-classify portions of Segments 4 and 5 of Walnut Creek, such that all of Walnut Creek east of Indiana Street would become Segment 5 and to remove the current ammonium standard for this revised segment. This requires a demonstration that the targeted stream area has different characteristics than the rest of the stream segment. These characteristics include water flow, water quality, habitat, and biological conditions. Based on Section 3.1.6 (4) of the State's Basic Standards for surface water (1993), "segments shall generally 
be delineated according to the points at which the use physical characteristics or water quality characteristics of a water course are determined to change significantly...." The assignment of standards is based on the nature of the pollutant, the need, effects on organisms, and other factors as described in Section 3.1.7(2) of the Basic Standards. Refer to Wright Water Engineers, Inc. (1995) for specific methods, results, and interpretation.

\section{Tissue Sampling for Woman and Walnut Creek Drainage and Offsite Reservoirs}

Results of sediment and tissue samples collected during the OU 6 RI (EG\&G, 1994) indicated elevated polychlorinated biphenyl (PCB) concentrations from some of the A-and B-series ponds. The A- and B-series ponds are located in the drainages of North and South Walnut creeks (Table D-1 and Figure 2, Technical Summary). Prior to 1989, Walnut Creek discharged into Great Western Reservoir (OU 3, IHSS 200). A diversion canal was constructed in 1989 that routed the flow coming from Walnut Creek around Great Western Reservoir and back into Walnut Creek below the dam. The potential exists for sediments and/or specific biota in Great Western Reservoir and Standley Lake Reservoir to have been impacted by PCB contaminants from the Site prior to 1989.

Therefore, a sediment and tissue PCB's sampling project was included as part of the Environmental Evaluation (EE) portion of the OU 6 RI. EcMP staff conducted all fish tissue sampling for this project. Fish samples were taken from the Walnut Creek terminal pond at Indiana Street (OU 6) and Great Western Resenoir to determine if any PCB'S have migrated downstream of the terminal ponds and bioaccumulated in fish species.

The study was expanded at the request of DOE (DOE, 1994b) to include fish tissue samples from Mower Reservoir, Standley Lake Reservoir, the C-series ponds, and the D-series ponds (Figure 2, Technical Summary). Refer to EG\&G (1994) for specific methods, results, and interpretation.

\section{HYPOTHESES}

\section{Aquatic Ecological Monitoring Program}

$H_{0}$ : There is no significant difference between the macrobenthic invertebrate communities of onsite aquatic systems.

$\mathrm{H}_{\mathrm{A}}$ : There is a significant difference between the macrobenthic invertebrate communities of onsite aquatic systems.

$\mathrm{H}_{\circ}: \quad$ There is no significant difference between the phytoplankton communities of onsite aquatic systems.

$H_{\wedge}$ : There is a significant difference between the phytoplankton communities of onsite aquatic systems.

$H_{0}$ : There is no significant difference between the zooplankton communities of onsite aquatic systems.

$H_{A}:$ There is a significant difference between the zooplankton communities of onsite aquatic systems.

$H_{0}$ : There is no significant difference between the emergent insect communities of onsite aquatic systems.

$H_{\Lambda}$ : There is a significant difference between the emergent insect communities of onsite aquatic systems. 


\section{Bioassessment of Walnut Creek}

$\mathrm{H}_{0}$ : There is no significant difference between the physical/chemical composition of onsite aquatic systems.

$H_{A}$ : There is a significant difference between the physical/chemical composition of onsite aquatic systems.

$\mathrm{H}_{\circ}$ : The calculated Ephemeroptera, Plec̀optera, Tricoptera.over Chironomidae (EPT/C) index is directly correlated with the ecosystem health of a site.

$H_{A}$ : The calculated EPT/C index is not directly correlated with the ecosystem health of a site.

\section{METHODS}

Various methods were used for collecting aquatic samples from ponds and streams. The techniques and tools used for obtaining aquatic samples depend on current velocity, substrate characteristics, and the objective of the sampling program.

\section{Aquatic Ecological Monitoring Program}

\section{Field Methods}

The sampling season was from April through September, 1994. A total of 346 biological samples were taken and used for the monitoring program (126 macrobenthic invertebrate samples, 68 phytoplankton samples, 69 zooplankton samples, and 83 emergent insect samples). Collection methods for aquatic samples are documented in the EcMP Program Plan (EG\&G, 1993). In addition to following "Aquatic invertebrate Sampling, Standard Operating Procedure" (SOP, 4-K49ENV-ECOL.02 REVISION 2) and "Fish Sampling SOP" (4-LO4-ENV-ECOL-04 REVISION 2), new sampling methods have been developed and implemented. A new water column zooplankton sampler, developed by subcontractor Ecosystem Testing Design Incorporated of Kansas (ETDI), was successfully used by aquatic technicians (Figure D-2). Both qualitative and quantitative results were obtained and time was saved by using this method. A different method, tested for the first time this year, was the new sediment core sampler (ETDI, manufacturer), for macrobenthic invertebrate sampling. Technicians were able to pull four core columns simultaneously, reducing effort and saving time (Figure D-3) over single core sampling. The core sampler was used from a boat only, due to the weight of the equipment.

\section{Laboratory Methods}

Quality assurance of taxonomic identification and enumeration procedures is accomplished by maintaining a voucher collection of aquatic organisms and the use of detailed Quality Assurance/Quality Control (QAQC) procedures used by the contract laboratory (ETDI). Methods and data handling procedures employed by ETDI meet EPA protocols for level 3 data.

\section{Analytical Methods}

\section{Macrobenthic Invertebrates}

The Jaccard coefficient of similarity, $J$ (Digby and Kempton, 1987), was calculated in a pair-wise manner (i.e., every possible combination of two sites paired) on the macrobenthic community composition for all sites sampled. The index was calculated at the level of family, the lowest taxonomic level to which individual organisms could be confidently and consistently identified. The Jaccard index is limited to comparing only the presence or absence of a taxa between two sites. The values range from 0 to 1 , with 1 being a perfect match in taxonomic composition between two sites (Table D-2). The Jaccard coefficient is the most widely used index of similarity between two 
objects and can be viewed in this instance as a percent value of taxa that two sites have in common (e.g., $\mathrm{J}=0.44$ for macrobenthic invertebrates in comparing ponds $\mathrm{A}-1$ to $\mathrm{A}-2$, then $\mathrm{A}-1$ and $\mathrm{A}-2$ share $44 \%$ of the same macrobenthic taxa).

Analyses of variance (ANOVA's) were calculated to determine differences between sites and differences between sampling methods using taxonomic richness (the number of distinguishably different taxa per sample) of macrobenthic invertebrates as the discriminating measure. Lindsay Pond (SW05) was removed from the data set because only one sample was taken at the pond. Each sampling method (drift net, dip net, core sampling, and surber sampling) was tested separately for differences among sites, with the exception of surber sampling, as there were no replicate samples using this method. Also, ANOVA was conducted on a composite macrobenthos richness value.

\section{Phytoplankton}

As with macrobenthic invertebrates, a Jaccard coefficient of similarity was calculated for each site sampled in a pair-wise fashion on phytoplankton community composition. Calculations were made at the genus level, as this was the lowest taxonomic level identified. Because similarity indices only deal with the presence or absence of a taxa, the phytoplankton community composition in terms of relative abundance was also examined for each pond sampled. Relative abundance was calculated at the taxonomic Division level to simplify visual comparison of sites.

ANOVA was used to determine differences between sites using taxonomic richness (number of genera per sample) of phytoplankton as the discriminating measure.

\section{Zooplankton}

A Jaccard coefficient of similarity was calculated for each site sampled in a pair-wise fashion on zooplankton community composition. Calculations were made at the genus level, as this was the lowest taxonomic level identified. ANOVA was used to determine differences between sites using taxonomic richness (number of genera per sample) of zooplankton as the discriminating measure.

\section{Emergent Insects}

A Jaccard coefficient of similarity was calculated for each site sampled in a pair-wise fashion on the emergent insect community composition. Calculations were made at the genus level, as this was the lowest taxonomic level identified. ANOVA was used to determine differences between sites using taxonomic richness (the number of distinguishably different taxa per sample) of emergent insects as the discriminating measure.

\section{Bioassessment of Walnut Creek}

\section{Fields Methods}

Three different sampling methods were chosen for the macrobenthic invertebrate sampling for the Bioassessment of Woman and Walnut Creeks. Dip net, surber sampler, and drift net methods were used according to the SOP, "Aquatic Invertebrate Sampling" (4-K49-ENV-ECOL.02 REVISION 2).

Flow and water quality characteristics of lower Walnut Creek below the Site ponds were compared to data from Woman Creek (the reference site). The bioassessment used data from a 1991 biological characterization study and new data collected by the Ecology Staff in July and September, 1994, which used procedures consistent with EPA's Rapid Bioassessment Protocols (EPA RBP III) for use in streams and rivers (EPA, 1989). These procedures assume that 
macrobenthic invertebrates are sensitive biological indicators of the physical and chemical characteristics of a stream, and therefore the stream's overall biological health.

Quantitative samples of aquatic biota were collected in June, 1994, primarily to support the Ecological Risk Assessment for OU 6. These data were also used to characterize the Segment 5 pond ecosystems. At each pond, A-1 through A-4, B-1 through B-5, D-1, D-2, and Lindsay Pond, five samples each were taken from multicore samplers, emergent insect traps, integrated water column zooplankton samplers, and surface $(0.25 \mathrm{~m}$ depth) phytoplankton samplers in order to quantify aquatic biota composition.

For water chemistry, two replicate samples were taken from eight sites, A-4, BD1, BD2, GW2, GW3, IW1, and W2 (Table D-1). See Figure 2, Technical Summary, for site locations.

\section{Laboratory Methods}

For biotic samples, the Ecology Staff maintain a voucher collection and detailed QAQC procedures used by the contract laboratory (ETDI). Methods and data handling procedures employed by ETDI meet EPA protocols for level 3 data. For water chemistry samples, completed chemical analysis results and extensive QAVC documentation for all of the 1994 samples were delivered by Global GeoChemistry (GGC) in hard copy and digital format. Laboratory methods and data handling procedures employed by GGC meet EPA protocols for level 3 data.

\section{Analytical Methods}

The sum of all individuals within the orders Ephemeroptera, Plecoptera, and Tricoptera was divided by the sum of individuals within the Chironomidae family to create the EPT/C index value for every sample (Table D-2). The EPT/C index was calculated for every sample taken as a representation of aquatic ecosystem health. The three orders in the numerator are considered to be sensitive to environmental pollutants, while Chironomids are generally pollution tolerant (EPA, 1989). Therefore, a low EPT/C index value indicates an unbalanced macrobenthic community and, presumably, a system in poor health. However, a zero value appears to represent insufficient data, rather than a highly polluted system. Therefore, only non-zero EPT/C index values were used in comparative calculations.

To explore the possibility that the EPT/C index is redundant to other measures of community health, correlations were performed on the index value and the corresponding taxonomic richness of collected samples. Pearson's Correlation Coefficient was used and results were initially significant $(P<0.05)$, but it was suspected that the high number of zero index values were skewing the results. The test was repeated with all samples containing a zero EPT/C index value removed and the correlation between the two parameters was no longer significant. Therefore, the EPT/C index is considered to be a measure of ecosystem health and it does not have a linear relationship to taxonomic richness. ANOVA's were calculated to determine differences between sites and differences between sampling methods using the EPT/C index.

Water chemistry samples were divided into "before" and "after" sewage release dates and analyzed with a paired Student's $T$-test for significant difference in major chemical parameters due to sewage releases. Parameters tested were $\mathrm{NH}_{4}, \mathrm{Cl}, \mathrm{PO}_{4}, \mathrm{Br}_{1} \mathrm{NO}_{3}, \mathrm{SO}_{4}, \mathrm{Na}, \mathrm{K}, \mathrm{Ca}, \mathrm{Mg}, \mathrm{Al}$, and $\mathrm{Fe}$. A significant effect indicates that the difference between before and after release values of a variable are significantly different than zero. 


\section{Tissue Sampling for Walnut and Woman creek Drainages and Offsite Reservoirs}

A gill net, seine net, and minnow traps were used for the sampling of fish tissue for the PCB sampling project. Methods cited in the SOP "Fish Sampling" (4-LO4-ENV-ECOL-04 REVISION 2) were followed.

Detailed methods, results, and discussion of the tissue sampling study are available in EG\&G (1994).

\section{RESULTS}

Aquatic Ecological Monitoring Program

\section{Macrobenthic Invertebrates}

Analyses used to make comparisons among sites included ANOVA tests, the EPT/C index and the Jaccard coefficient of similarity.

A one-way (one source of variance) ANOVA was used to test for significant difference in taxonomic richness between sites with a composite of all sampling methods (i.e., all taxa collected at a site, regardless of sampling method used. Table D-3). There is a highly significant difference in macrobenthic invertebrate richness between sites $(p=0.00)$. Pond $A-1$ to pond $A-4$ show a trend of declining richness (Figure $D-4)$. Pond A-1 had the highest mean macrobenthic invertebrate taxonomic richness of all the sites (18.4), which is significantly greater than the terminal pond in the series, $A-4$ (2.6). The sites that were most similar in their mean taxonomic richness values were BD1 (12.6) and W2 (12.8). Sites BD1 and W2 are streamsites in the Big Dry Creek drainage (Figure 2, Technical Summary). It is expected that sites BD1 and W2 would be most similar due to their close proximity $(50 \mathrm{~m})$ within the same drainage.

ANOVA's of taxonomic richness broken down by each sampling method indicate that there were significant differences between sampling methods. However, due to both variances and sample sizes being unequal, these were not reliable tests (Table D-3).

ANOVA'S were individually calculated for the core method, the drift net method and the hand picked dip net sampling method. Each result will be discussed separately by sampling method. The core method was used to sample pond and stream macrobenthos. There is a highly significant difference in macrobenthic invertebrate richness among sites ( $p=0.0000$, Table D-3). The trend of declining richness from Pond A-1 to Pond A-4 is clearly repeated here (Figure D-5). Pond $A-1$ had the highest mean macrobenthic invertebrate taxonomic richness of all the sites (18.4), which is significantly greater than the terminal pond in the series, $A-4$ (2.6). The sites that were most similar by the core method in their mean taxonomic richness values were A-3 (6.2) and D-1 (6.0).

The dip net method showed no significant difference in taxonomic richness among sites sampled (Figure D-6). However, the sample size for this technique was small ( $n=17$ for all sites sampled, approximately 3 observations per site), decreasing the reliability of the analysis. Dip net sampling will be repeated in the next season for comparison.

The results of the ANOVA for the drift net method (Table D-3) showed significant difference in taxonomic richness among sites $(p=0.048)$, despite a small sample size $(n=19$ for all sites sampled, approximately 4 observations per site). However the Tukey Honest Significant Difference (HSD) analysis (a more conservative test) did not show a significant difference (Figure D-7). The mean taxonomic richness for all five sites sampled with drift nets are streams were: BD1 (16.0), BD2 (9.3), W1 (8.0), and W2 (14.3) and GW3 (24.3). Streamsite GW3 stands out as clearly higher in macrobenthic richness than the other streams (Figure $D-7$ ). 
All macrobenthic invertebrate sampling methods were combined in a final analysis of taxonomic richness (Table $D-3$ ). Overall, sites differed in the number of macrobenthic families collected regardless of sampling method $(p=0.0001)$ and no sampling method stood out from the others in capturing distinctly more or less macrobenthic families (Figure D-8).

Pond A-1 has a mean macrobenthic invertebrate taxonomic richness of 18.4 (Table D-4), with 16 orders and 18 families represented in a total of six functional groups. The EPT/C index is low $(0.078$, Table D-5), with Chironomidae being well represented. The Jaccard coefficient indicated that Pond B-1 was most similar to $B-2(J=0.75$, Table $D-6)$. Eighty percent of all of the families in Pond A-1 are annelids (segmented worms). Pond B-1 is species rich with a mean taxonomic richness of 16.0 (Table D-4), with seven functional groups present. The mean EPT/C index is 1.876 with two representative taxonomic groups (Chironomidae, and Ephemeroptera). Forty percent of all of the families in Pond B-1 are annelids and 33\% are mollusks. Pond D-1 contained 15 orders but had only one representative family from both Chironomidae and Ephemeroptera. The EPT/C index is zero and Pond D-1 has a lower taxonomic richness (6.66) than Pond B-1. There were six functional groups represented.

Pond D-2 is a reference pond for aquatic ecological studies. It has the highest mean value for the EPT/C index (2.172) which is directly correlated to the presence of all four target taxa (Ephemeroptera, Plecoptera, and Tricoptera orders and the Chironomidae family). There are 21 orders represented in nine functional groups. Although D-2 does not show the highest value for family richness (12.8, Table $D-4)$, an analysis of the taxonomic composition of families reveals a comparatively well balanced ecosystem.

\section{Phytoplankton}

A one-way ANOVA was used to test for significant difference in phytoplankton taxonomic richness between sites (Table D-7, Figure D-9). There is a highly significant difference in richness between sites $(p=0.0000)$. Seven Divisions of algae are represented in Rocky Flats aquatic ecosystems; Bacillariophyceae (diatoms), Chlorophyta (green algae), Chrysophyta (golden brown algae), Cryptophyta (cryptophytes), Cyanophyta (blue green algae), Euglenophyta (flagellates), and Pyrrhophyta (dinoflagelates). A total of 72 phytoplankton taxa have been identified and logged in the reference collection for the Site to date.

Community composition and relative abundance of algae varies widely between ponds, even those closely in series to one another. The Jaccard index shows that no two ponds are more than $65 \%$ alike in the composition of algal genera (A-3 and B-3, Table D-8). In an overall comparison against all other sites, both Pond $B-4$ and Pond $C-2$ are the most unlike any of the other ponds in their phytoplankton taxonomic composition.

Figures D-10 through D-16 represent the phytoplankton relative abundance for each site sampled. Overall, Cyanophytes were the most abundant algae on the Site, making up $47.1 \%$ of the algae sampled (sample standard deviation, $s,=27.3$ ). Next abundant were the Chlorophytes, at $31.3 \%$ $(s=18.1)$. The rarest taxa were the Chrysophytes, $1 \%(s=1.3)$, and the Pyrrhophytes, $<1 \%$ of the algae sampled.

Ponds that were sampled for phytoplankton in both 1993 and 1994 are A4, B5, C2, D1, D2, and Lindsay Pond. Comparing the relative abundance from year to year, Lindsay and $D 2$ ponds have remained the same, Cyanophytes have decreased in ponds A4, B5, and D1 (from $52.9 \%$ to $6.8 \%$; $73.1 \%$ to $25.3 \%$; and $81.2 \%$ to $45.9 \%$, respectively). Chlorophytes increased in D1 (from $15 \%$ to $40.5 \%$ ), Cryptophytes increased an order of magnitude in B5 (from $4.7 \%$ to $40.1 \%$ ), and Euglenophytes increased nearly an order of magnitude in A4 (from $2.5 \%$ to $18 \%$ ). The degree of variation in relative abundance of algae for the C2 Pond was too high in 1993 to allow a comparison with 1994 results. 


\section{Zooplankton}

A one-way ANOVA was used to test for significant difference in zooplankton taxonomic richness between sites (Table D-9). There is a highly significant difference in richness between sites $(p=0.0000)$. Pond B-2 was significantly greater in taxonomic richness than most other sites (Figure $D-17)$. The greatest differences were between B-2 (19 taxa, $s=3.32)$ and $B-4(6 \operatorname{taxa}, s=1.00)$. The least amount of difference was between B-3 (10 taxa, $s=2.79)$ and B-5 ( 11 taxa, $s=4.37$, Table $D$ 4). Ponds B-3 through B-5, C-2, and D-1 show similarity in zooplankton taxonomic richness (Figure D-17). Pond $B-2$ is the most taxonomically rich.

The Jaccard coefficient of similarity indicates that ponds B-5 and A-3 are the most similar in their zooplankton community composition ( $\mathrm{J}=0.636$, Table $\mathrm{D}-10$ ). Ponds $\mathrm{B}-4$ and $\mathrm{C}-2$ apparently have no zooplankton in common $(\mathrm{J}=0.00)$. Reference poind $\mathrm{D}-2$ is most similar to Pond $\mathrm{B}-2$ in zooplankton taxa $(\mathrm{J}=0.515)$.

\section{Emergent Insects}

A one-way ANOVA was used to test for significant difference in emergent insect taxonomic richness between sites (Table D-11). There is a highly significant difference in richness between sites $(p=0.0000)$. Pond $A-2$ has the highest number of emergent insect taxa (18.8). The greatest amount of difference was between A-2 (18.8 taxa, $s=3.90)$ and $A-4$ (3.0 taxa, $s=2.12)$. Ponds $A-1$ and $B-5$ had identical numbers of insect taxa (8.4).

Woman Creek (SW03) and Pond $\mathrm{C}-2$ share the most emergent insect taxa $(\mathrm{J}=0.478)$ and ponds $\mathrm{A}-$ 1 and $A-3$ are the least similar $(J=0.080$, Table $D-12)$. Reference pond $D-2$ is most similar to Pond $A-2$ in emergent insect communities $(\mathrm{J}=0.396)$ and the two ponds are not significantly different in taxonomic richness (Figure D-18). The taxonomic representation for Pond A-2 is 5 orders and 10 families. Pond D-2 also had 5 orders but there are ? less families present.

\section{Bioassessment of Walnut Creek}

An EPT/C index value was calculated for all reference and impacted sites in Woman and Walnut Creek drainages, respectively; only non-zero values of the index were used. This reduced the number of sites compared. In addition, sites A-3, B-3, B-4 were removed from analysis because of a lack of non-zero replicates. As expected, ponds $A-1, A-2$, and $B-2$ all had low mean EPT/C index values $(0.078,0.003$, and 0.220 , respectively). Table $D-13$ displays the macrobenthic invertebrate community of each site to the family level. All sites contain individuals from the Chironomidae family, a ubiquitous taxon. Ponds A-1, A-2, and B-2 apparently contain no individuals from the Plecoptera or Tricoptera order, and few Ephemeroptera, thereby resulting in low EPT/C index values (Table D-5). However, a high number of sampled Chironomidae can produce a low EPT/C index value even if the numerator taxa are well represented, as is the case for Pond D-2. The highest mean EPT/C value (7.035) was for Walnut Creek (W2), approximately 50 meters from the confluence with Big Dry Creek. Chironomidae total 20 for this site but Ephemeroptera $=4$, Plecoptera $=0$ and Tricoptera $=3$.

ANOVA comparisons of the EPT/C index were to be calculated to detect differences in the index value among sites and among macrobenthic sampling methods. However, the calculations could not be performed because the small sample sizes and unequal variances involved violated basic assumptions of the ANOVA technique.

The paired T-test resulted in significant differences for only three of the 13 analytes tested. Ammonium $\left(\mathrm{NH}_{4}\right)$ and potassium $(K)$ increased significantly after sewage releases $(p=0.01$ and $p=0.05$, respectively). Nitrate $\left(\mathrm{NO}_{3}\right)$ decreased significantly after a release $(p=0.05)$. Amounts by which these analytes increased or decreased were very small; $\mathrm{NH}_{4}$ increased an average of 
$0.02 \mathrm{mg} /(s=0.01 \mathrm{mg} / \mathrm{h}), \mathrm{K}$ increased an average of $1.44 \mathrm{mg} /(\mathrm{s}=1.64 \mathrm{mg} / \mathrm{h})$, and $\mathrm{NO}_{3}$ decreased an average of $0.37 \mathrm{mg} /(s=0.36 \mathrm{mg} / \mathrm{h})$. Other analytes had larger differences, for example, $\mathrm{SO}_{4}$ decreased an average of $70.56 \mathrm{mgh}$, but the differences varied too greatily from site to site to achieve a significant difference $\left(\mathrm{SO}_{4} \mathrm{~s}=153.84 \mathrm{mg} / \mathrm{)}\right)$. A summary of ammonium concentrations is given in Figure D-20.

Graphical summaries of macrobenthos and emergent insect richness are given in Figure D-21 and zooplankton and phytoplankton in D-22.

\section{INTERPRETATION}

\section{Aquatic Ecological Monitoring Program}

Pond $A-1$ to Pond A-4 (Figure D-4) show a trend of declining macrobenthic invertebrate richness. This trend was not observed in any other. pond series or with any other biotic community. The observable decline was detected by the core sampling method. The 1994 core method sampling schedule resulted in the largest number of replicates per site of any of the sampling methods $(n=53)$. With the corresponding effect of higher precision (less variation), the core method was the only 1994 macrobenthic invertebrate field method that could detect the subtle decline (Figure D-5). The surber and the drift net method are both dependent on flowing water and would therefore be limited to sampling in streams. The hand-picked dip net method is designed to be a surface sweeper and would not accurately sample the mud and gravel bottoms. There could be any number of reasons for the decline of macrobenthic invertebrates in the A-series ponds. Pond A-1 is partly fed by a seep that could account for a healthier aquatic environment. During high water conditions, the ponds fiow into one another (Figure 2, Technical Summary). A limiting factor to macrobenthic invertebrate taxonomic richness may be industrial practices that progressively degrade the ponds. One approach would be to compare facultative anaerobic macrobenthic invertebrates (organism normally growing anaerobically but able to tolerate aerobic conditions) to those with a continuously high oxygen demand in some of the deeper ponds such as A-4 and B-5. Sampling with the core may not be possible due the depth and may lead to the use of other methods such as an Ekman grabber. A plot of both thermoclines and oxygen isopleths may reveal new ecological relationships both spatially and temporally.

Using the Jaccard Similarity Index tables (Tables D-6, D-8, D-10, and D-12), overall biotic similarities between groups of sites can be examined (Figure D-19). Sites of interest are reference ponds (Ponds D-1, D-2, and SW05), and impacted ponds (the A- and B-series). Out of the four biotic populations sampled (macrobenthic invertebrates, emergent insects, zooplankton, and phytoplankton), the taxonomic composition of reference ponds were compared to each other, as were the composition of impacted ponds to each other, and the composition of reference ponds compared to impacted ponds. No group of ponds shared more than $45 \%$ of any of the biota sampled, indicating that Rocky Flats aquatic systems show considerable diversity in their biotic composition. For macrobenthic invertebrate, emergent insect, and phytoplankton community compositions, reference ponds shared more taxa with each other $(29 \%, 29 \%$, and $42 \%$, respectively) and impacted ponds shared more taxa with each other $(28 \%, 29 \%$, and $45 \%$, respectively) than reference and impacted ponds shared $(25 \%, 24 \%$, and $40 \%$, respectively), but only by a few percent. This does not hold true for zooplankton community composition (reference ponds were $25 \%$ alike, impacted ponds were $40 \%$ alike, and impacted ponds had $30 \%$ of the same taxa as reference ponds).

The most diverse OU site for overall biotic community composition is Pond A-2 (mean of 57.4 biotic taxa sampled). The most diverse reference site is Pond D-2 (53 biotic taxa). The least diverse OU site is $\mathrm{B}-4$ (25.2 taxa). The fact that an OU site is slightly more diverse than a reference site would seem to indicate that the effects of contamination in the OU ponds are not a major consideration. However, contaminant concentrations are known to be higher in OU ponds than in reference ponds 
(Wright Water Engineers, 1995 and EG\&G, 1994). This question will be addressed again during the 1995 field season. Some data are available for biota and contaminants that were sampled concurrently. Future analysis will determine if a relationship exists between these variables.

Cyanophytes decreased in A-4, B-5, and D-1 from 1993 to 1994, while Chlorophytes increased in D-1, Chrysophytes increased in B-5, and Euglenophytes increased in A-4. Chlorophytes replaced Cyanophytes in D-1. Seasonal algal fiuctuations called blooms are dependent upon nutrient availability (nitrates, phosphates) and other limiting factors such as $\mathrm{pH}$, temperature and available sunlight. An increase in the frequency of sampling at different times of the growth season is necessary to understand what limiting factors are primary in seasonal taxonomic richness.

Zooplankton feed on phytoplankton. The fathead minnow (Pimephales promelas) is a predator of the larger zooplankton species, such as Cladocera and some copopods. Ponds found to have a fathead minnow population include C-2, D-1, and D-2. Seining methods used in Pond D-1 for collecting fish for tissue analysis revealed a high population of fathead minnows near the north shore. There is an inverse relationship between the mean taxonomic richness (20.2) of phytoplankton to zooplankton (9.0) in Pond D-1, whereas, for Pond D-2, phytoplankton mean taxonomic richness (8.6) in less than the zooplankton richness (14, Figure D-2). Therefore, ponds with minnows have fewer taxa zooplankton due to predation, resulting in more phytoplankton diversity.

\section{Bioassessment of Walnut Creek}

A survey of the macrobenthic invertebrate taxa sampled from Pond D-2 showed that approximately $60 \%$ were pollution intolerant and only $30 \%$ were facultatively intolerant (EPA, 1973). A survey of the macrobenthic taxa sampled from Pond A-2 showed that equal numbers ( $33 \%$ each of the total taxa collected) were pollution intolerant and facultatively intolerant (EPA, 1973). A facultatively intolerant organism has inherent characteristics or demonstrates a facility for tolerance to pollutants under certain conditions e.g., water temperature, dissolved oxygen level or the presence of the pollutant at a particular point in the life cycle. An intolerant organism is sensitive to pollution and shows no facility to tolerate contamination under most circumstances.

EcMP's use of the EPT/C index is for the purpose of comparing this metric with other indicators and performing analyses of a composite of the Site's aquatic profile (Table D-4, Figures D-20 through $D$-23). A ranking can be derived from the ratio of the target site EPT/C index value to a reference site EPT/C value and then multiplying the ratio by 100 (EPA, 1989). To receive a top score of six the result must be $>90 \%$. To receive a minimum score of three the result must be between $70 \%$ $90 \%$. Any result $<70 \%$ is scored 0 . When using Pond D-2 as the reference site, Pond $B-1$ was the only pond to receive the minimum score of three with a ratio of $86.37 \%$ (Table D-14). Pond B-2 was only $10.13 \%$, followed by A-1 $(3.6 \%), B-3(0.46 \%), B-4(0.32 \%), A-2(0.14 \%)$ and A-3 $(0.09 \%)$. To test the integrity of this method, the ratios were re-calculated by alternately using ponds $A-2, B-$ 1 , and streamsite BD1 as the designated reference site (Table D-14). With Pond A-2 (the most diverse pond onsite) and Pond $B-1$ as the reference sites, all scoring results were either 0 or nonapplicable. A-3 (with a $66.7 \%$ ratio) came the closest to a non-zero score when compared with A2. BD2 as the reference site gave streamsite GW3 a score of 3 , other streamsites scored 0 . This calculated ratio method was used in Wright Water Engineers (1995) bioassessment study. Results from that paper and from the above ratio calculations indicate that this ratio method is most effective as a bioassessment value when used strictly on streamsites, and not ponds. The EPT/C index value by itself seems to be a good overall indicator of aquatic ecosystem health when used in conjunction with other analyses, such as ANOVA's, T-tests, Jaccard coefficient of similarity, and Pearson's correlation coefficient.

For remediation purposes, EcMP staff can provide DOE and regulatory agencies with information on the spatial and temporal variability of Rocky Flats aquatic systems and how these resources will 
respond to present or future stressors, either natural or anthropogenic. Following remediation, monitoring efforts could focus on the aquatic community successional changes of the pond ecosystems.

\section{REFERENCES}

Aquatic invertebrate Sampling, Standard Opęrating Procedure. 4-K49-ENV-ECOL.02 REVISION 2.

Digby, P.G.N. and R.A. Kempton. 1987. Multivariate Analysis of Ecological Communities. Chapman and Hall, NY. 206 pp.

DOE. 1994b. Correspondence from Jessie Roberson of DOE to Sue Stiger of EG\&G, Rocky Flats, Environmental Restoration Management (ER:JP:09005), PCB Sampling in the Woman Creek Drainage and Offsite, dated August 25, 1994.

EG\&G Rocky Flats, Inc. 1993. Rocky Flats Plant Ecological Monitoring Program, Program Plan. U.S. Department of Energy, Rocky Flats Plant, Golden, CO.

EG\&G Rocky Flats, Inc. 1994. Results of PCB Sediment and Tissue Sampling for Walnut and Woman Creek Drainages and Offsite Resenoirs. U.S. Department of Energy, Rocky Flats Plant, Golden, CO.

EPA. 1973. Biological Field and Laboratory Methods for Measuring the Quality of Surface Waters and Effluents. U.S. Environmental Protection Agency, Office of Research and Development. EPA-670/4-73-001.

EPA. 1989. Rapid Bioassessment Protocols for Use in Streams and Rivers; Benthic Macroinvertebrates and Fish. U.S. Environmental Protection Agency, Office of Water (WH-553). EPA 444/4-89-001.

Fish Sampling, Standard Operating Procedure. 4-LO4-ENV-ECOL-04 REVISION 2.

State of Colorado Water Quality Control Commission. 1993. The Basic Standards and Methodologies for Surface Water. CCR 1002-8. Sections 3.1.6(4) and 3.1.7(2).

Wright Water Engineers, Inc. 1995. Bioassessment and Physical/Chemical Characterization of Walnut Creek and Woman Creek. U.S. Department of Energy, Rocky Flats Plant, Golden, co. 


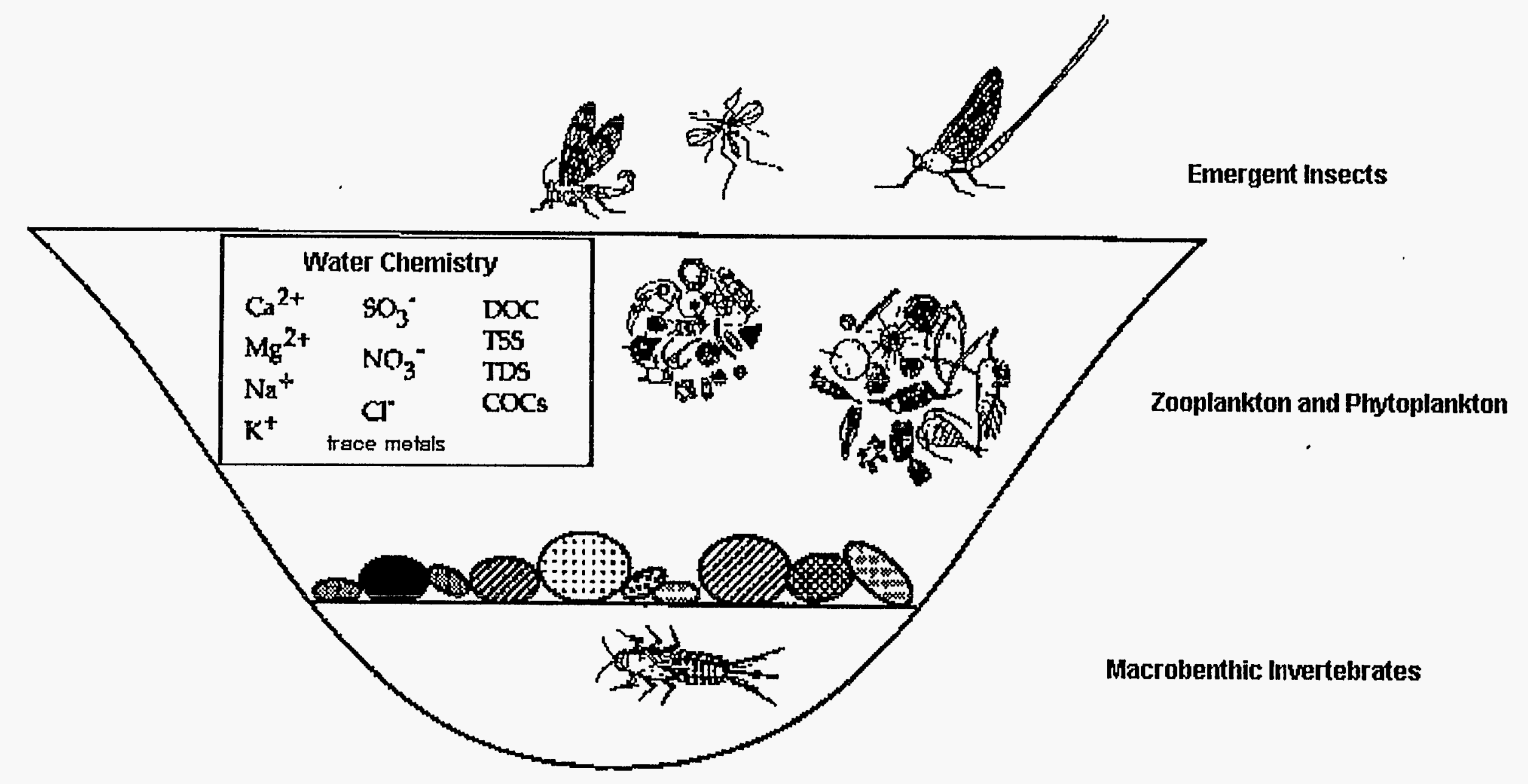

Figure D-1. The Four Botic Componenta of EcMP Aquatic Sampling. 


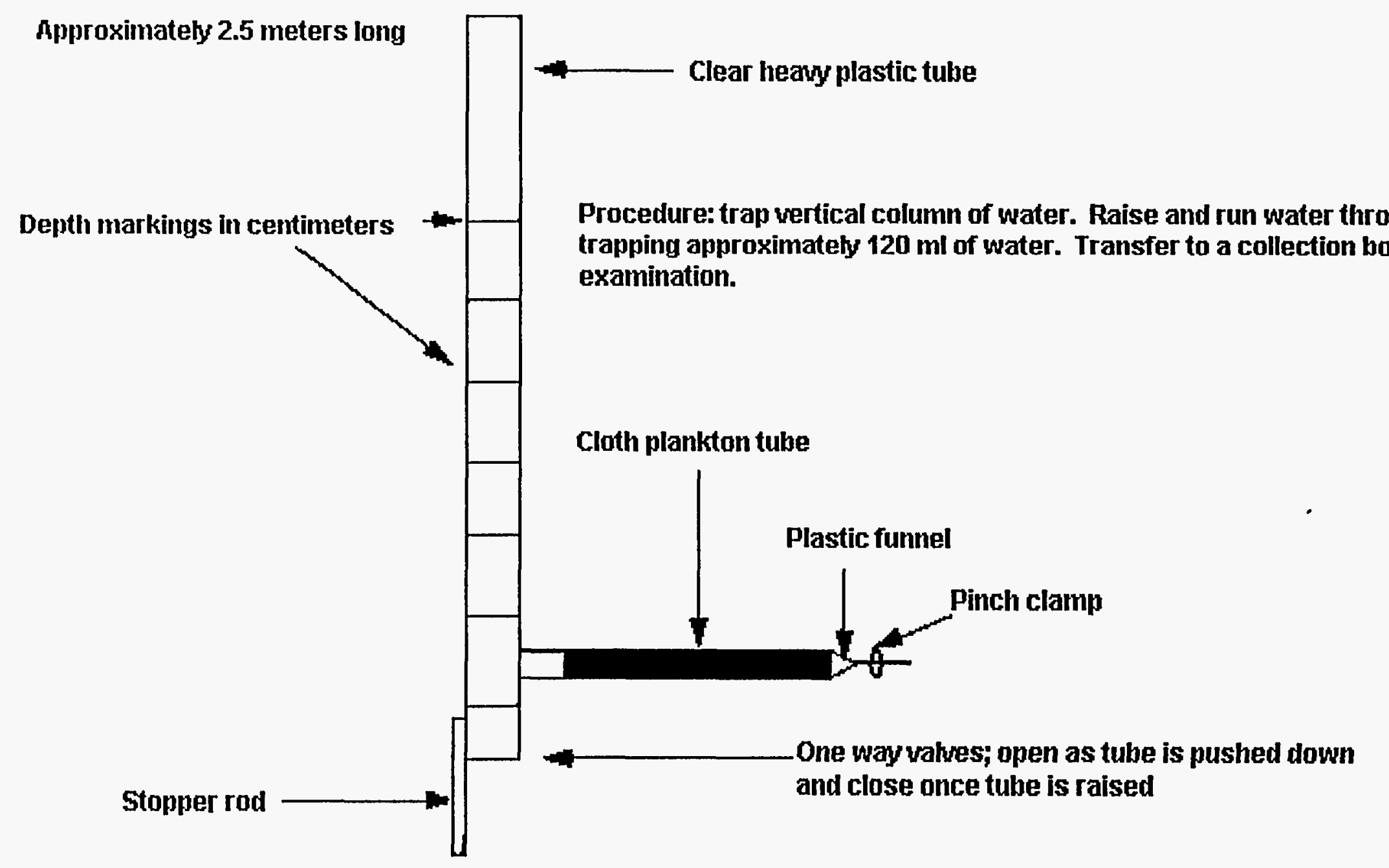

Figure D-2. Diagram of Zooplankton Gampler. 


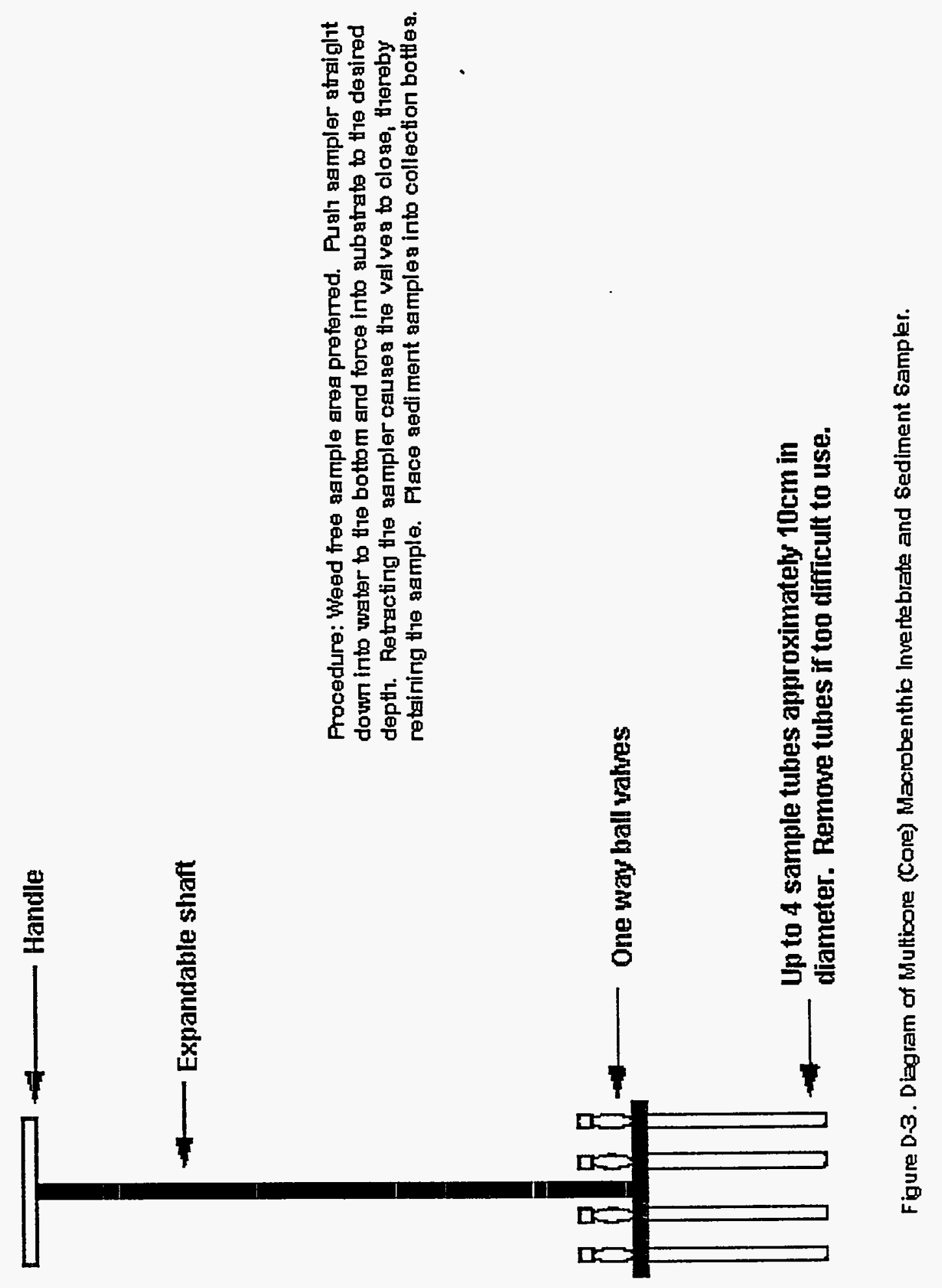



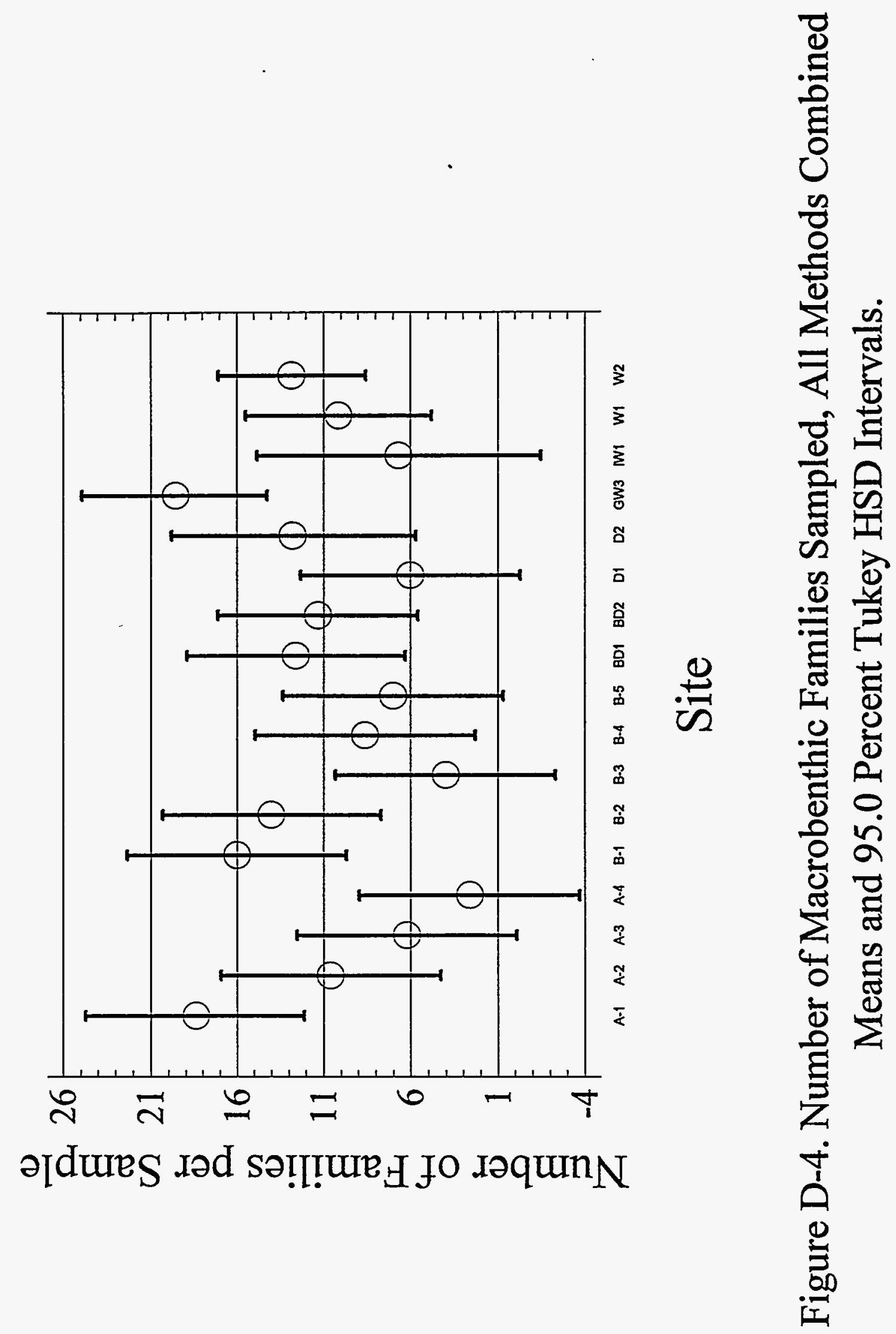


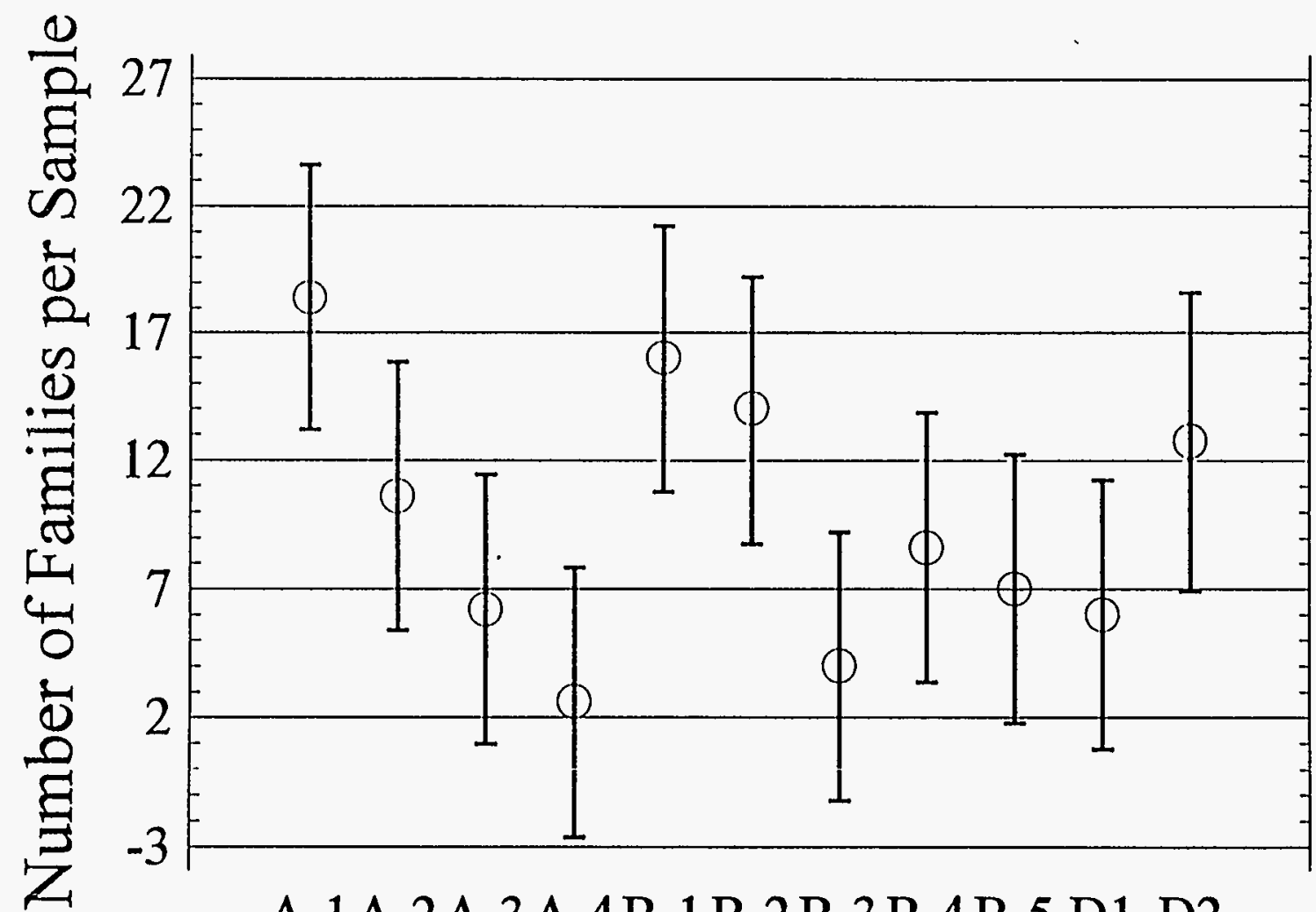

A-1 A-2A-3 A-4B-1 B-2B-3 B-4 B-5 D1 D2

Site

Figure D-5. Number of Macrobenthic Families Sampled With the Core Method Means and 95.0 Percent Tukey HSD Intervals. 


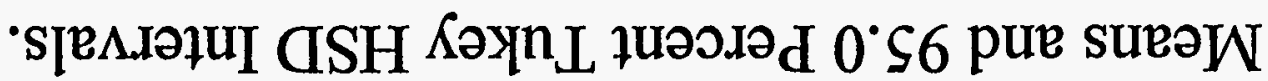

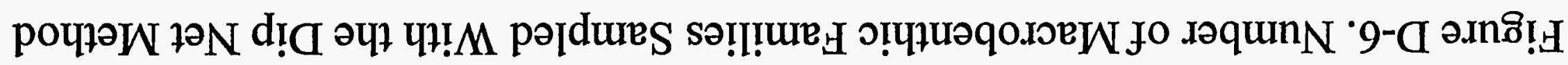

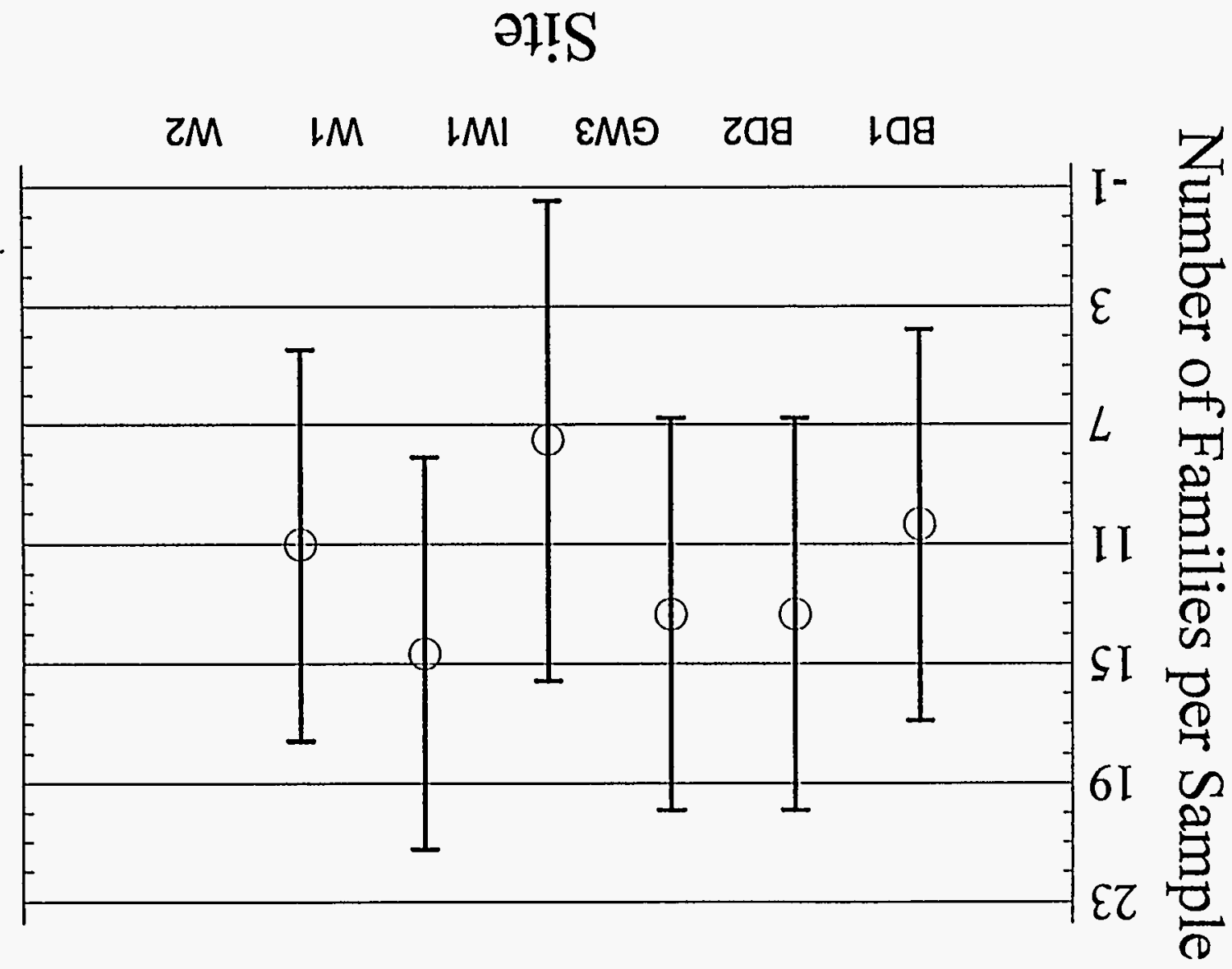




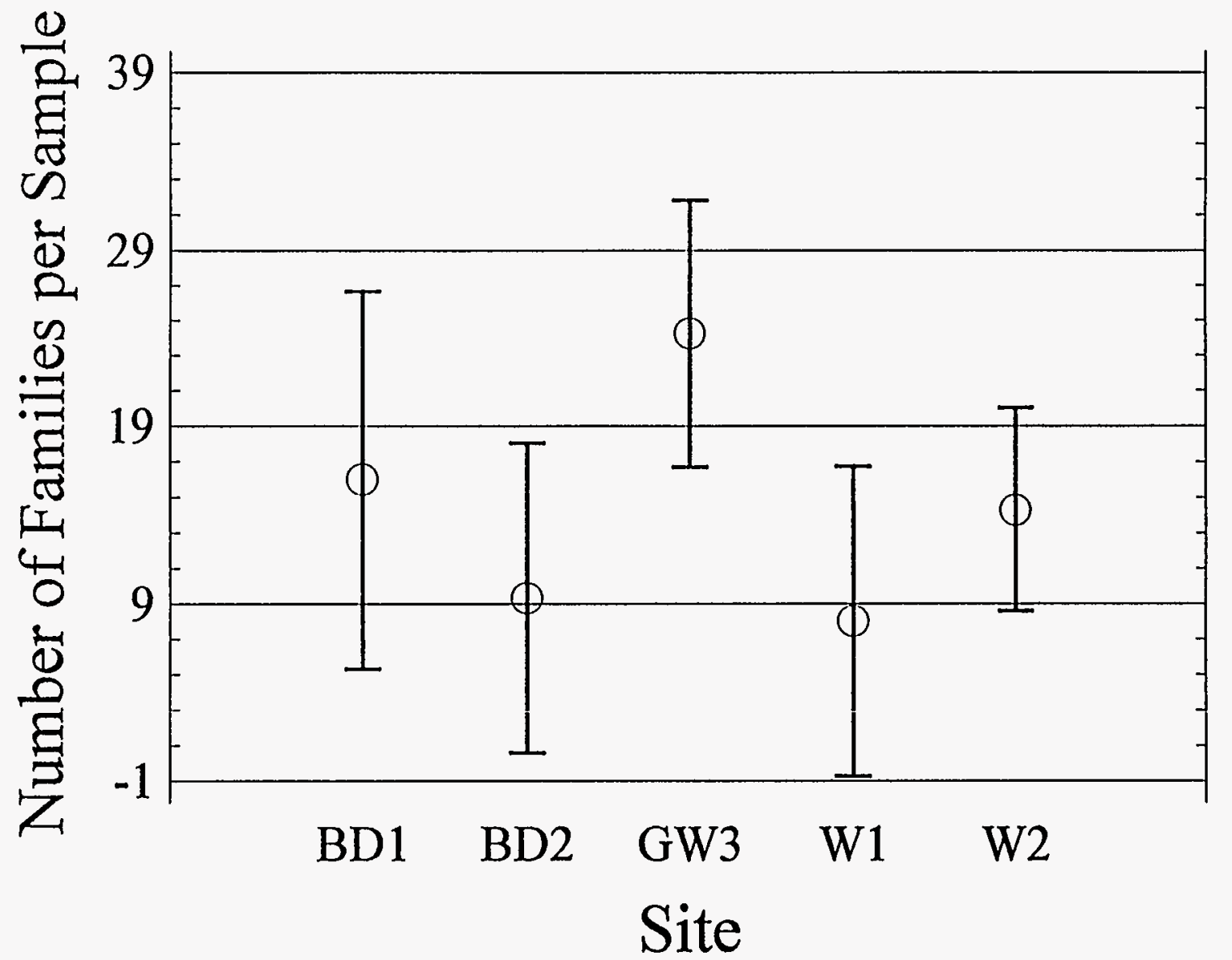

Figure D-7. Number of Macrobenthic Families Sampled With the Drift Net Method Means and 95.0 Percent Tukey HSD Intervals. 


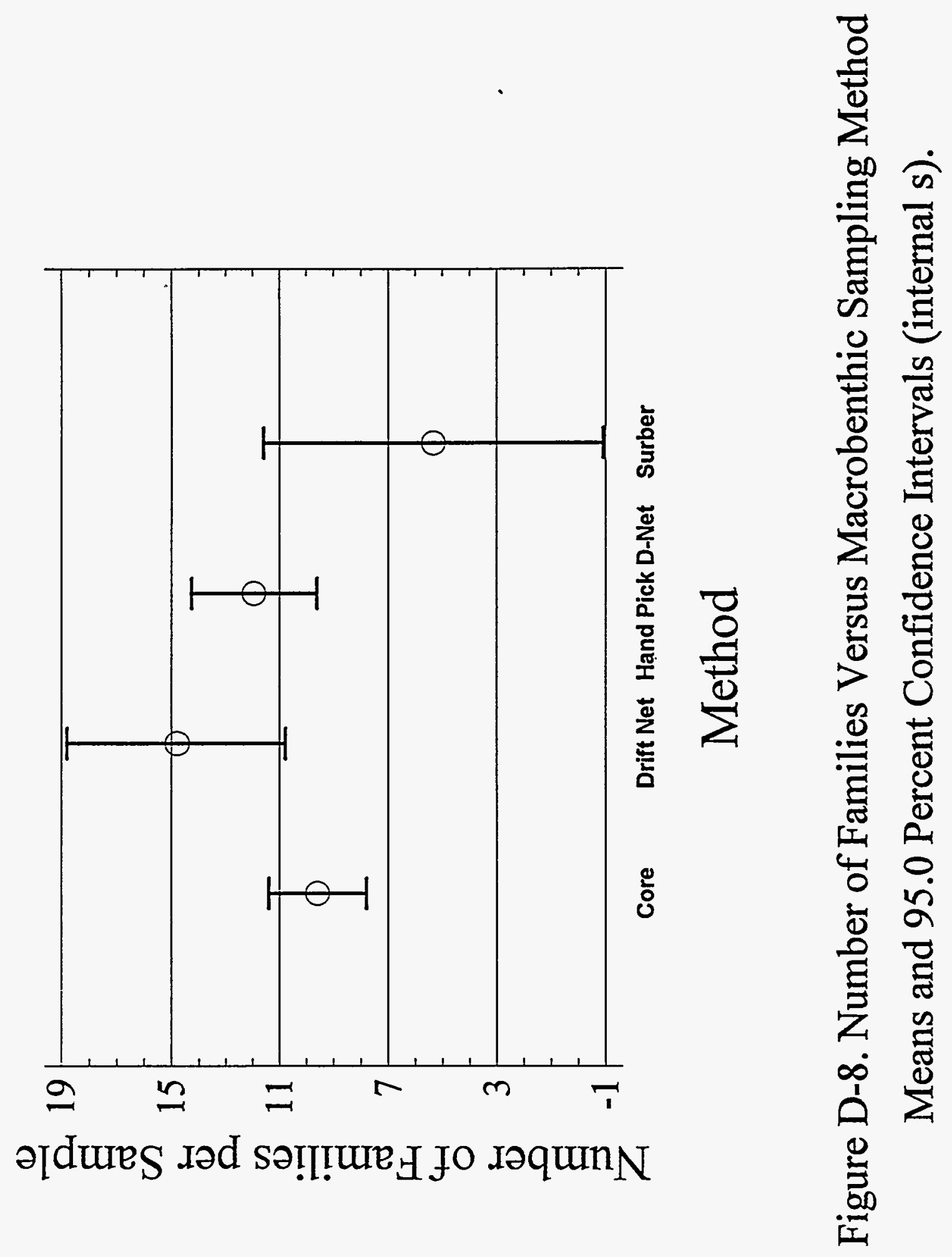

D-19 


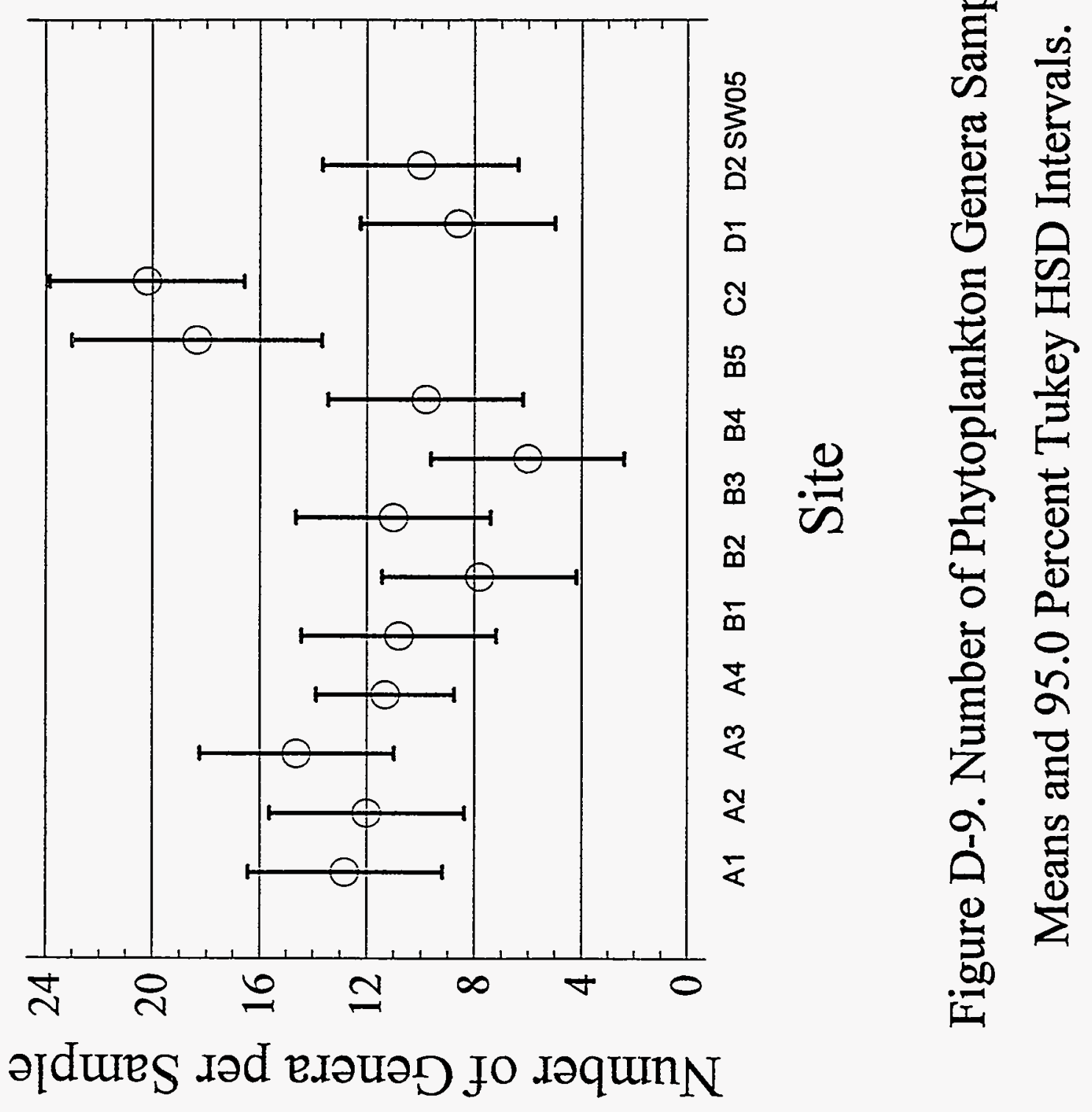




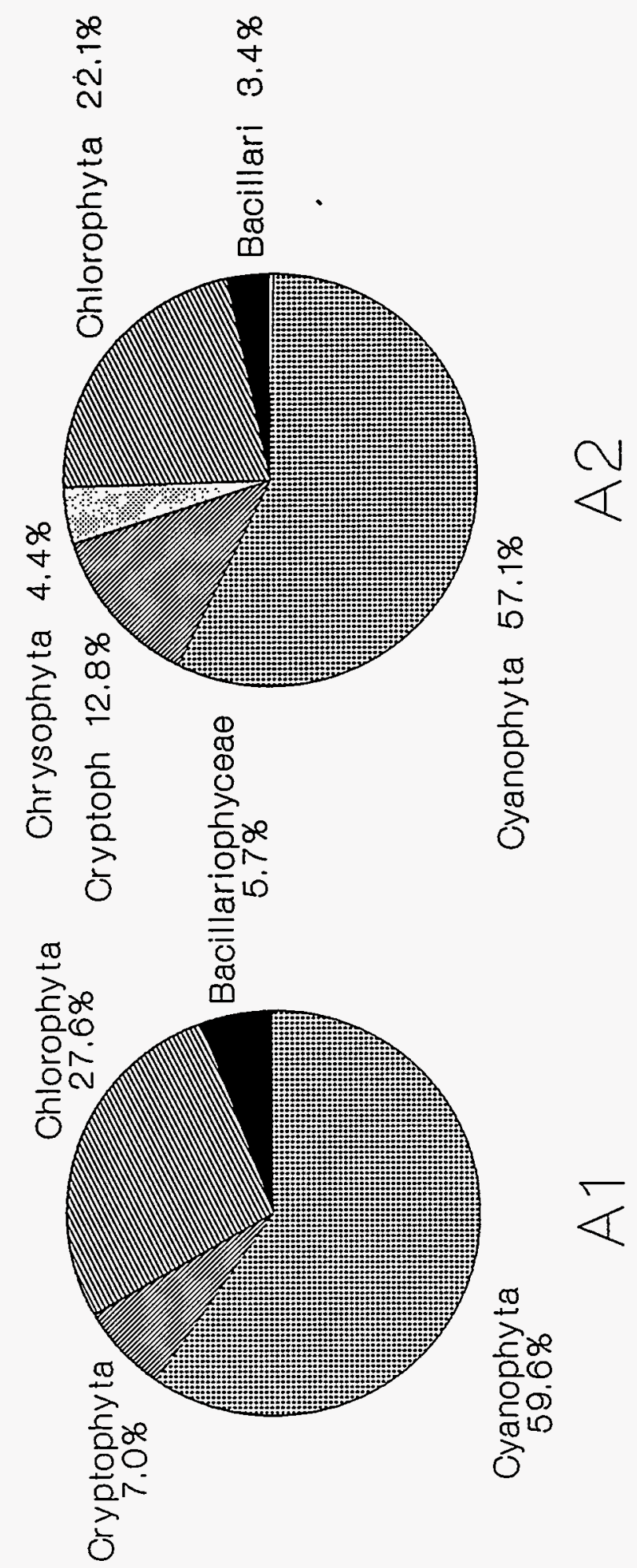

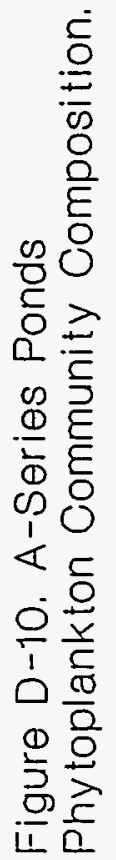




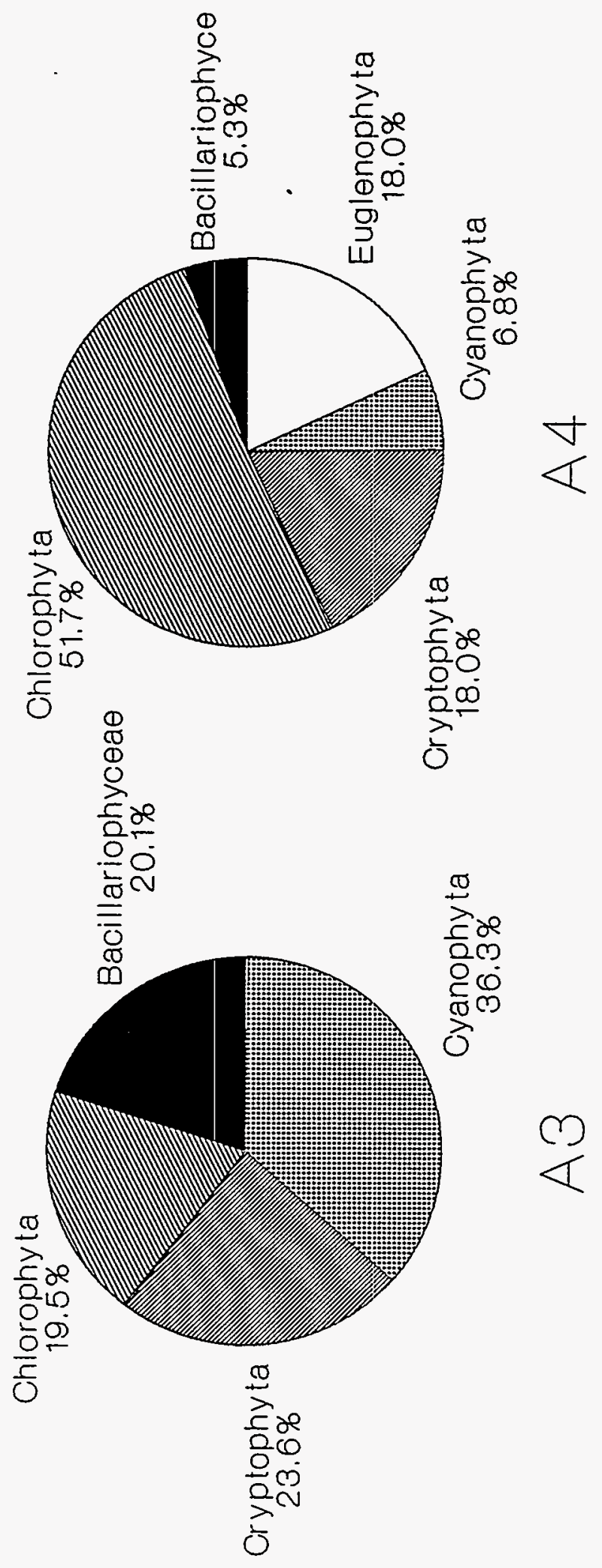

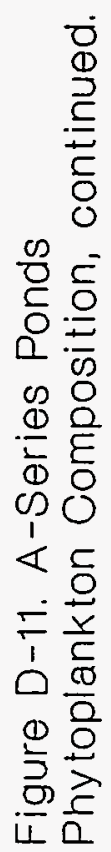




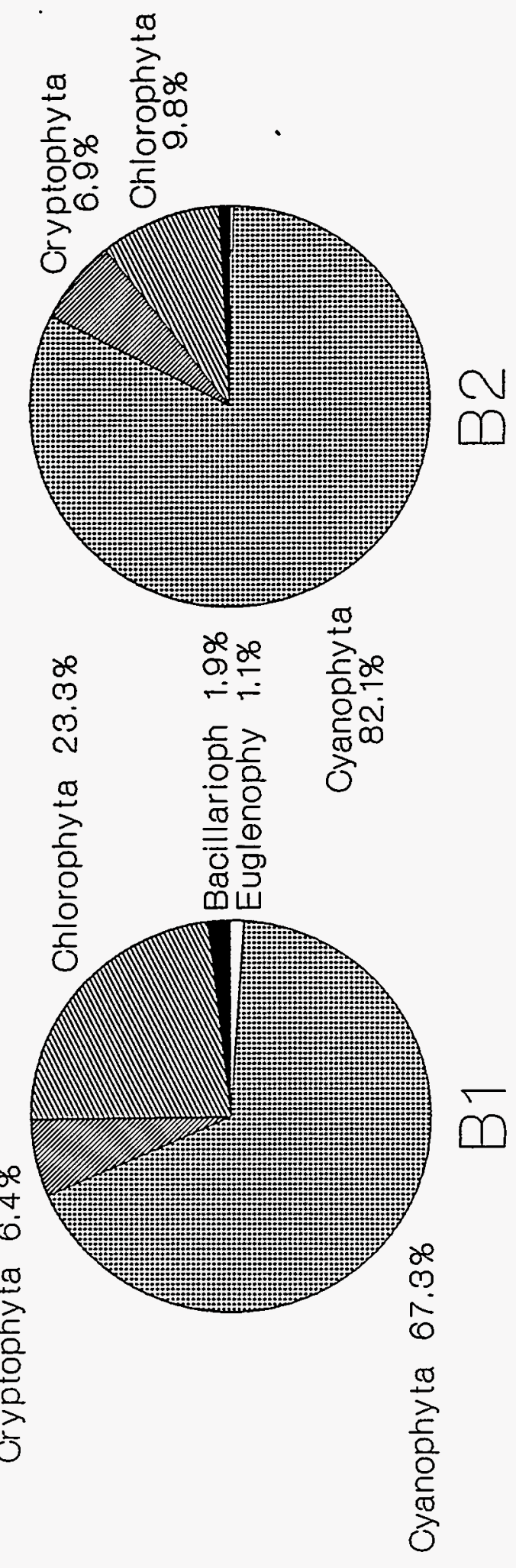

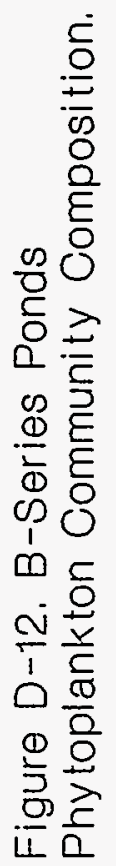



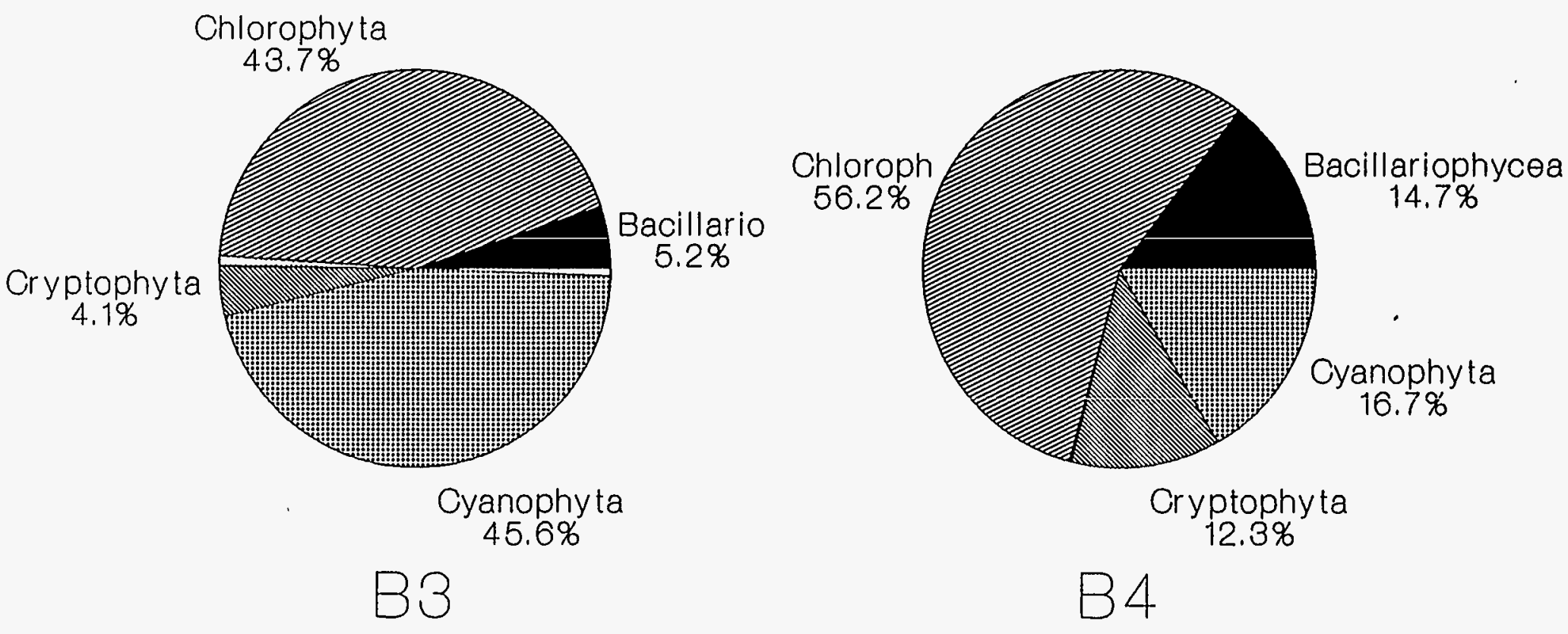

Figure D-13. B-Series Ponds

Phytoplankton Composition, continued. 


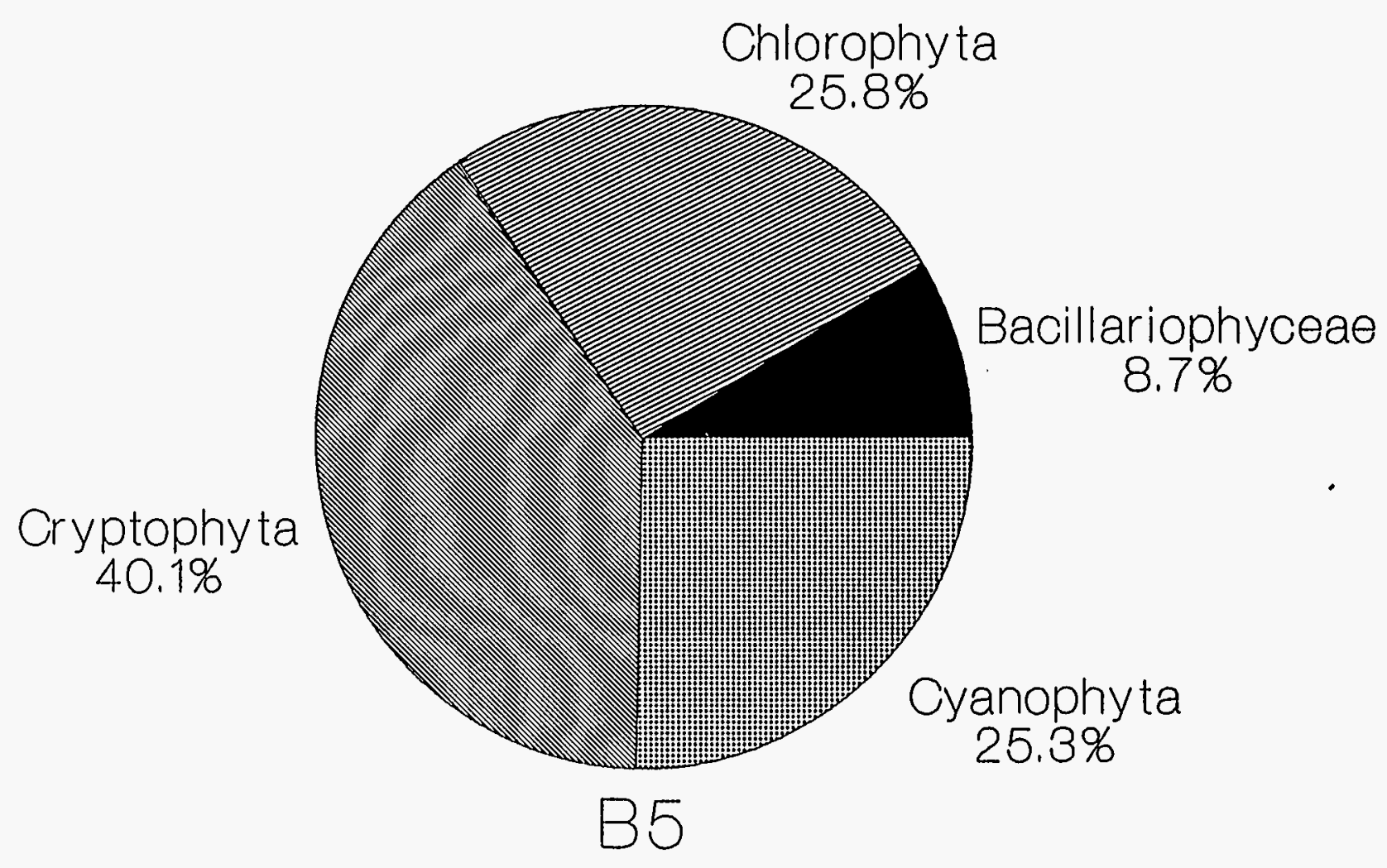

芯

Figure D-14. B-Series Ponds

Phytoplankton Composition, continued. 


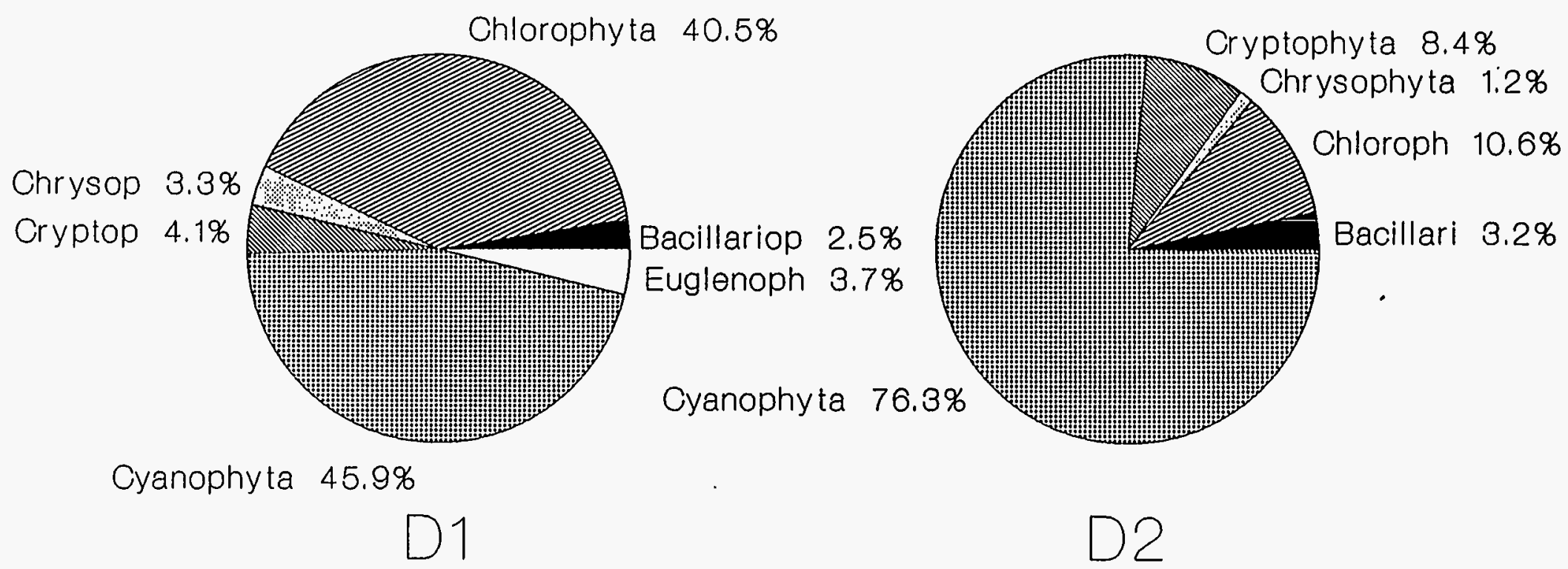

号

Figure D-15. D-Series Ponds

Phytoplankton Community Composition. 


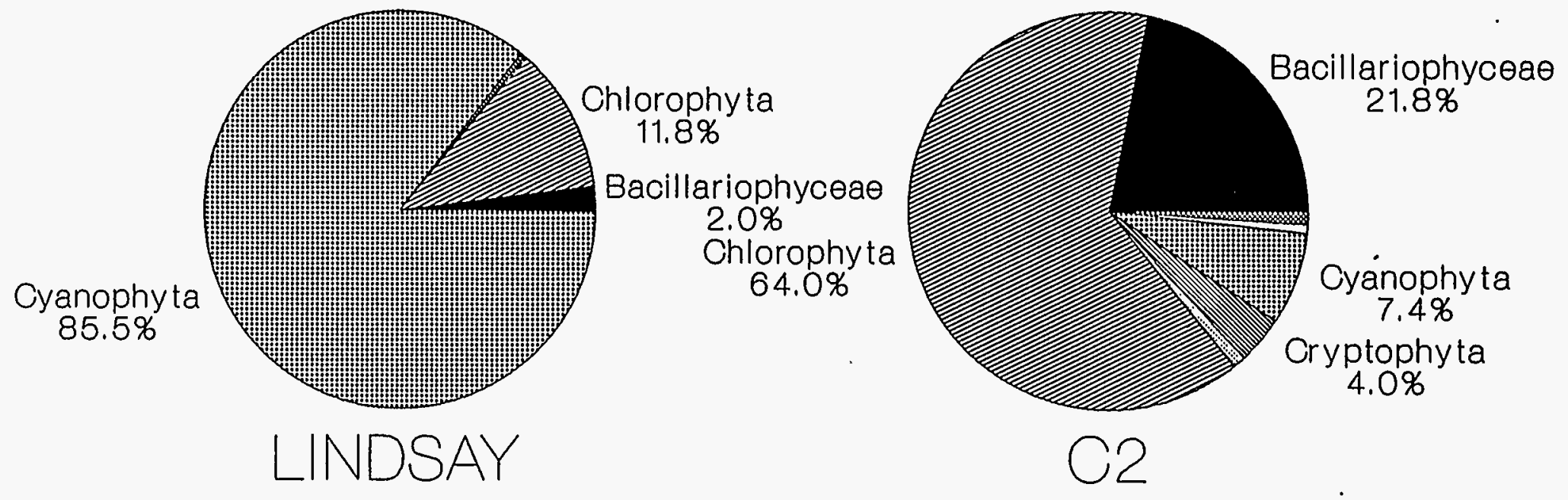

Figure D-16. Lindsay and C2 Ponds

ن Phytoplankton Community Composition. 

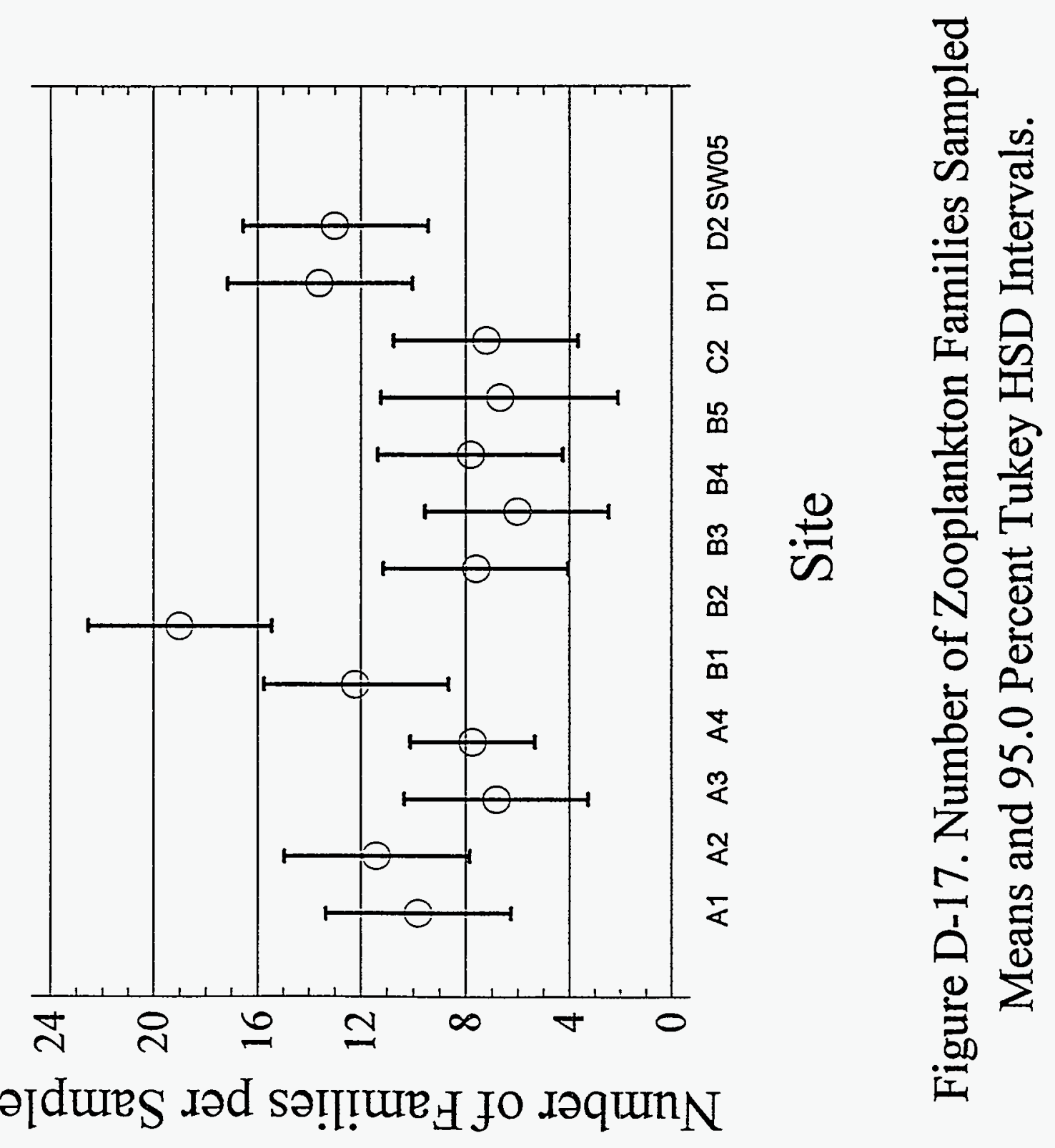


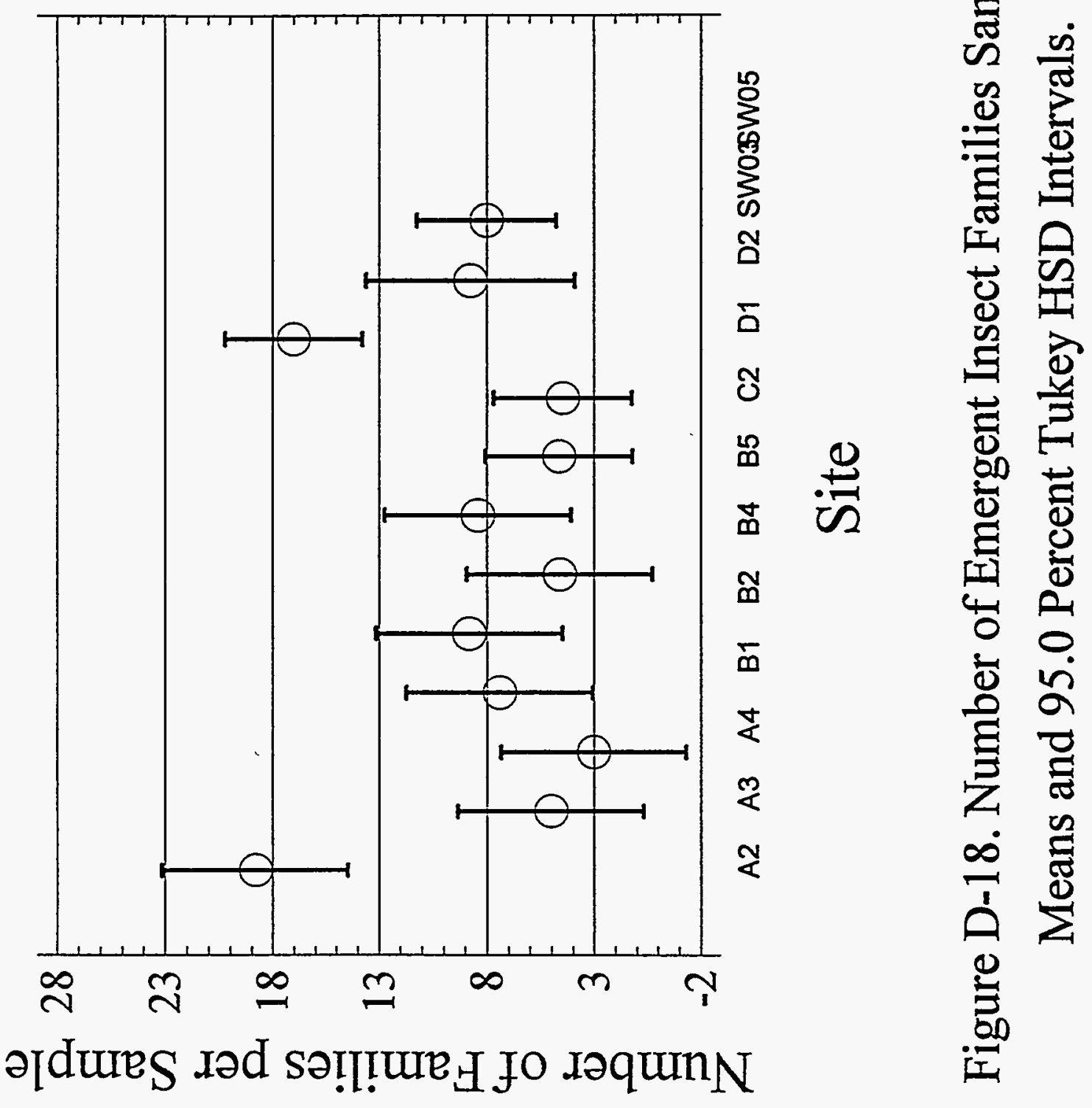




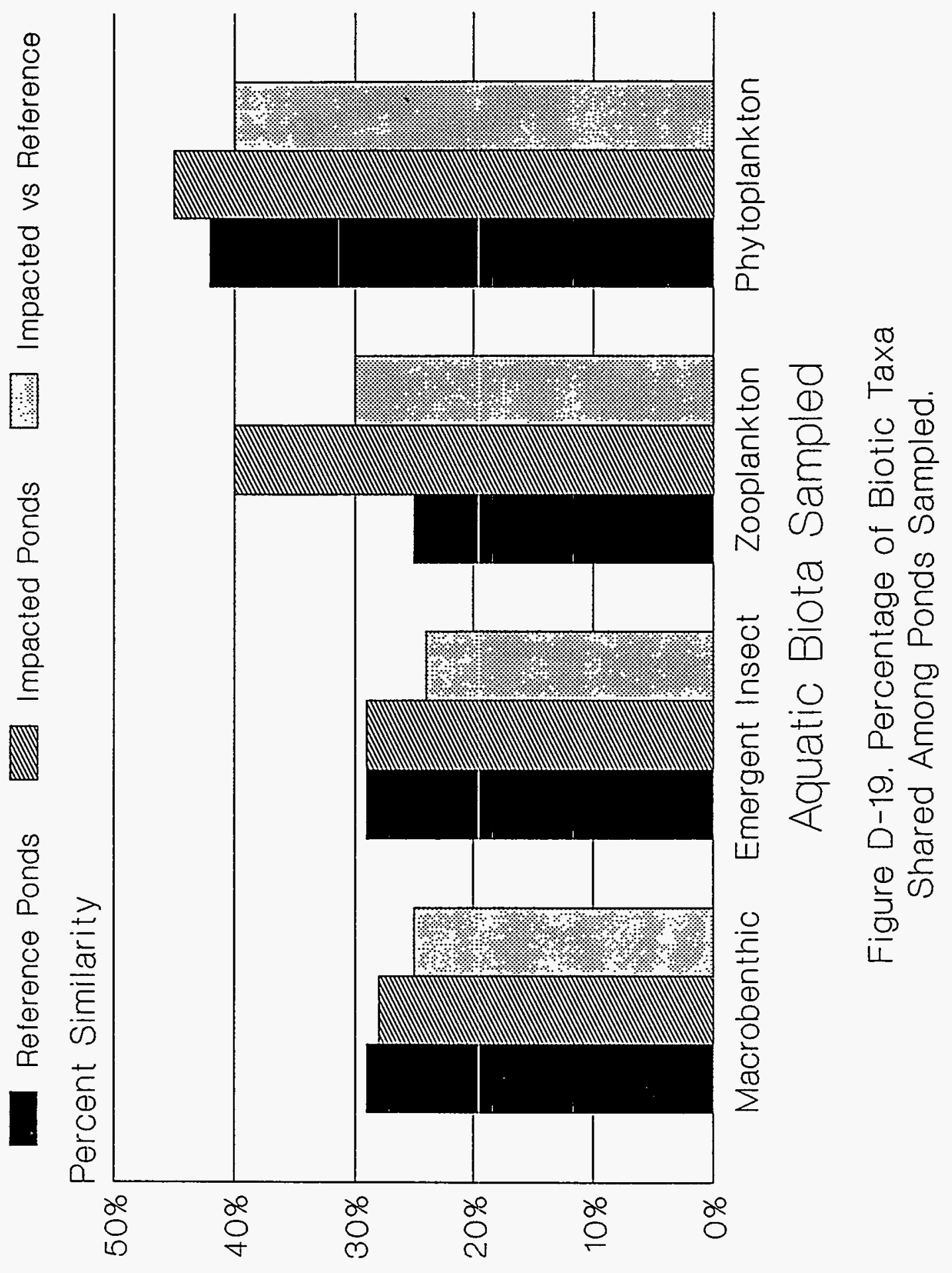




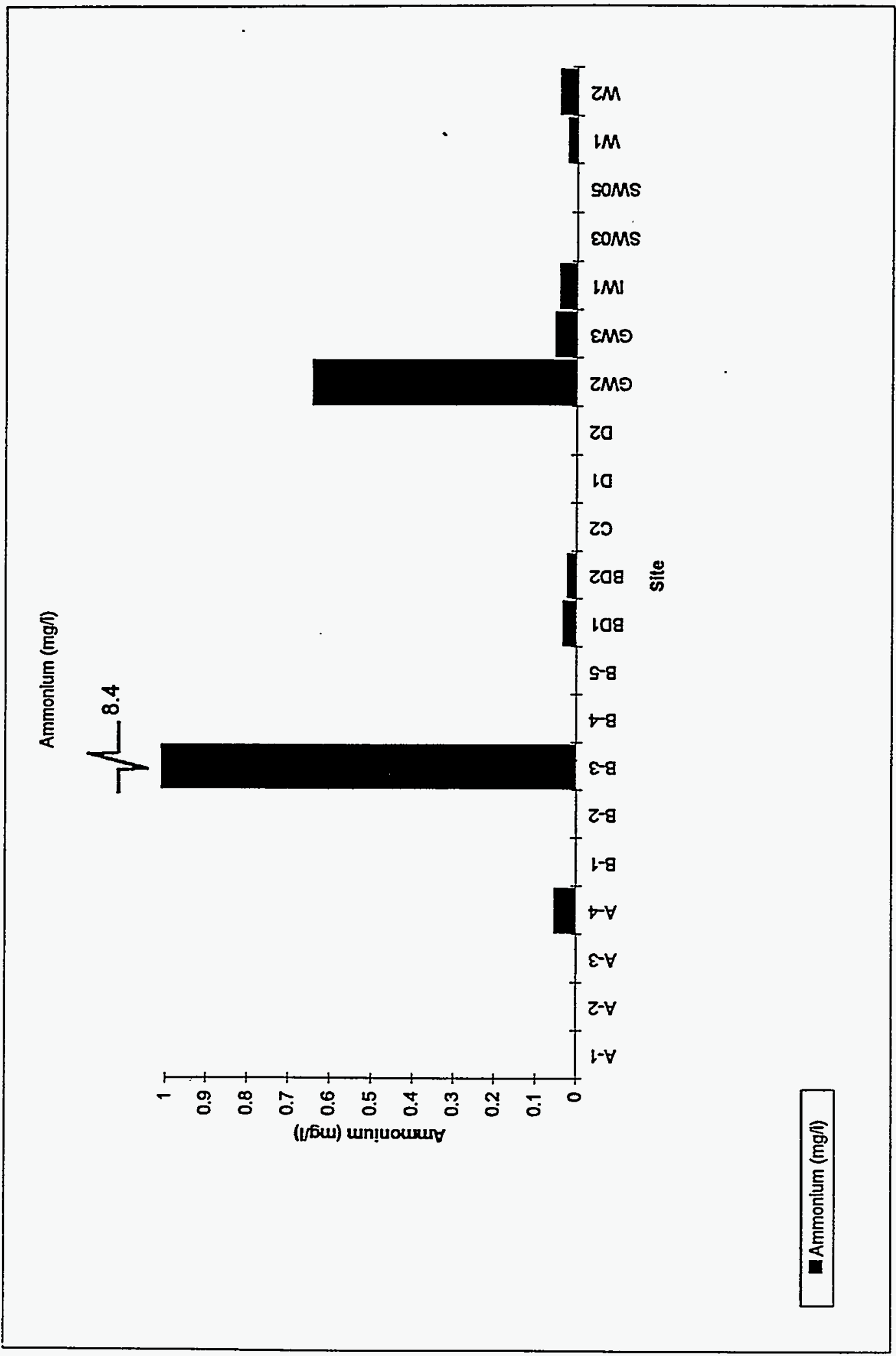

告 

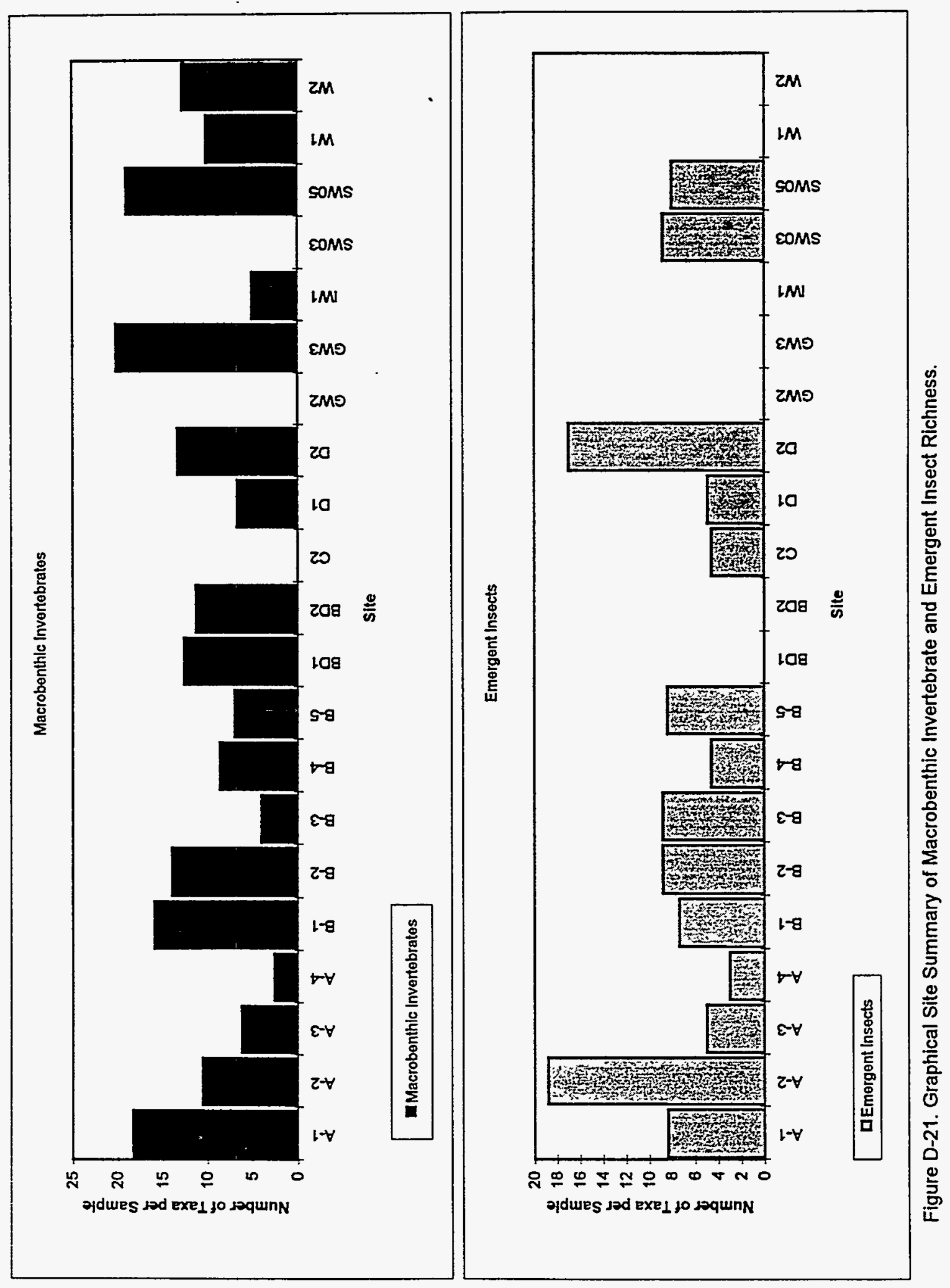

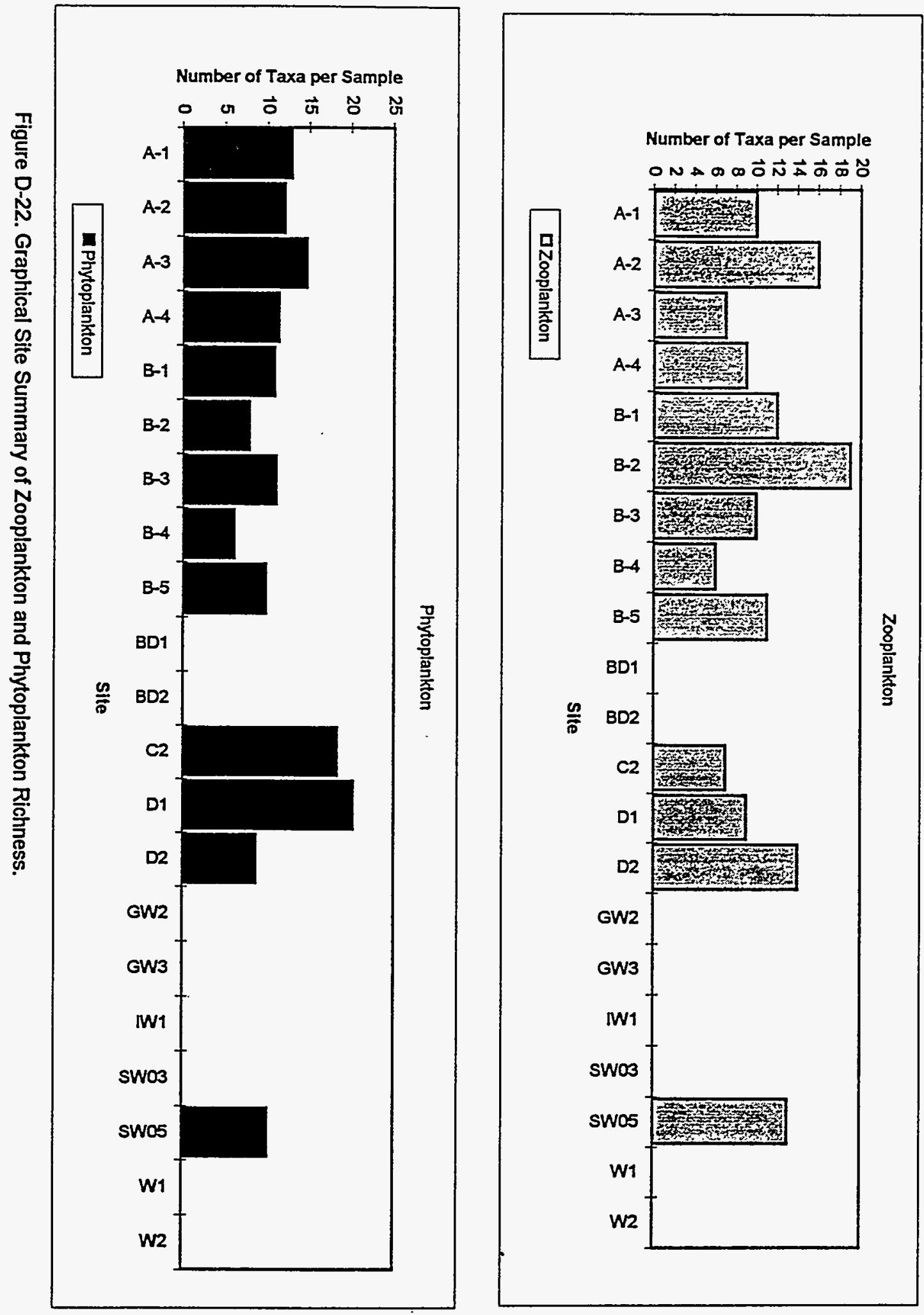


\section{Table D-1. Aquatic Site Descriptions.}
A-1
A-1 pond, North Wainut Creek drainage
A-2
A-2 pond, North Walnut Creek drainage
A-3
A-3 pond, North Walnut Creek drainage
A-4
A-4 pond, North Walnut Creek drainage
B-1
B-1 pond, South Walnut Creek drainage
B-2
B-2 pond, South Walnut Creek drainage
B-3
B-3 pond, South Wainut Creek drainage
B-4
B-4 pond, South Wainut Creek drainage
B-5
B-5 pond, South Walnut Creek drainage
BD1
Big Dry Creek downstream of Walnut Creek confluence
BD2
Big Dry Creek upstream of Walnut Creek confluence
C-1
C-1 pond, Woman Creek drainage
C-2
C-2 pond, Woman Creek drainage
D-1
D-2
D-1 pond, Smart ditch drainage
D3
D-2 pond, Smart ditch drainage
D4
Walnut Creek downstream of Mckay confluence
D5
Walnut Creek upstream of Mckay confluence
GW1
GW2
Walnut Creek downstream of A-4 pond dam
GW3
Runoff stream from GWR located east of GWR at the service road culvert
Overflow pipe emptying into Walnut Creek east of GWR
Walnut Creek east of Great Western Reservoir (GWR), downstream of diversion ditch, upstream of GWR overflow pipe
GW4 Downstream or at the end of Walnut diversion ditch at 2 small culverts
IW1
SW039
Wainut Creek west of Indiana at the culvert just inside Rocky Flats fence boundaries
SW033
Woman Creek, surface water site
SW026
Woman Creek, surface water site
SW05
W1
Woman Creek, east of $\mathrm{C}-2$ pond, surface water site
W2
Lindsay Pond
Wainut Creek west of culvert at 105 th St. and Old Wadsworth intersection
Walnut Creek upstream of confluence with Big Dry Creek 
Table D-2. Jaccard Similarity Index and EPT/C Community Index Formulas.

Jaccard Index, $J=\frac{a}{a+b+c}$

\begin{tabular}{|l|c|c|}
\cline { 2 - 3 } \multicolumn{1}{c|}{ where: } & $\begin{array}{l}\text { Factor A, } \\
\text { present }\end{array}$ & $\begin{array}{l}\text { Factor A, } \\
\text { absent }\end{array}$ \\
\hline Factor B, present & a & b \\
\hline Factor B, absent & c & d \\
\hline
\end{tabular}

from Digby and Kempton, 1987.

EPT/C Index =

from EPA, 1989. 
Table D-3. Analysis of Variance Tables for Macrobenthic Invertebrate Taxonomic Richness, 1994 Data.

Analysis of Variance; Macrobenthic Taxonomic Richness, all methods across all sites.

\begin{tabular}{lrrrrr}
\hline Source & Sum of Squares & Df & Mean Square & F-Ratio & P-Value \\
\hline Between Sites & 2028.97 & 16 & 126.811 & 4.08 & 0.0000 \\
Within Sites & 2363.76 & 76 & 31.1021 & & \\
\hline & & & & & \\
Total (Corr.) & 4392.73 & 92 & & &
\end{tabular}

Analysis of Variance; Macrobenthic Taxonomic Richness by sampling method.

\begin{tabular}{llllll}
\hline Source & Sum of Squares & Df & Mean Square & F-Ratio & P-Value \\
\hline Between Methods & 490.928 & 3 & 163.643 & 3.73 & 0.0141 \\
Within Methods & 3901.8 & 89 & 43.8405 & & \\
\hline
\end{tabular}

Total (Corr.) $\quad 4392.73 \quad 92$

Analysis of Variance; Macrobenthic Taxonomic Richness, Core sampling method across all sites.

\begin{tabular}{lrrrrrr} 
Source & Sum of Squares & Df & Mean Square & F-Ratio & P-Value \\
\hline Between Sites & 1296.69 & 10 & 129.669 & 5.48 & 0.0000 \\
Within Sites & 1018.35 & 43 & 23.6826 & &
\end{tabular}

Total (Corr) $\quad 2315.04 \quad 53$


Table D-3. Analysis of Variances Tables for Macrobenthic Invertebrate Taxonomic Richness, 1994 Data, continued.

Analysis of Variance; Macrobenthic Taxonomic Richness, Drift Net sampling method across all sites.

\begin{tabular}{lrllll}
\hline Source & Sum of Squares & Df & Mean Square & F-Ratio & P-Value \\
\hline Between Sites & 590.313 & 4 & 147.578 & 3.16 & 0.0481 \\
Within Sites & 654.845 & 14 & 46.7747 & & \\
\hline Total (Corr.) & 1245.16 & 18 & & &
\end{tabular}

Analysis of Variance; Macrobenthic Taxonomic Richness, Hand Picked Dip Net sampling method across all sites.

\begin{tabular}{lrllll} 
Source & Sum of Squares & Df & Mean Square & F-Ratio & P-Value \\
\hline Between Sites & 83.7745 & 5 & 16.7549 & 0.75 & 0.6019 \\
Within Sites & 245.167 & 11 & 22.2879 & & \\
\hline Total (Corr.) & 328.941 & 16 & & &
\end{tabular}




\begin{tabular}{|c|c|c|c|c|c|c|c|c|}
\hline \multirow{2}{*}{\multicolumn{9}{|c|}{ 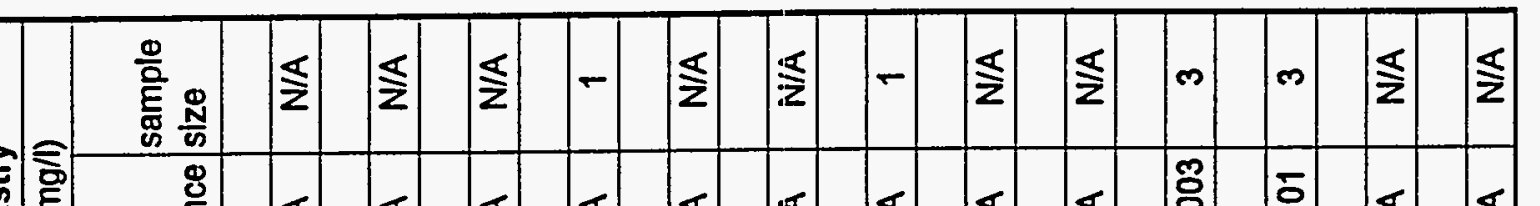 }} \\
\hline & & & & & & & & \\
\hline & \begin{tabular}{|l|l|l|}
$\mathbf{z}$ & \multicolumn{1}{|c|}{} \\
\end{tabular} & \begin{tabular}{l|l}
$:$ & $\frac{1}{2}$
\end{tabular} & $\frac{\pi}{2}$ & & & & & \\
\hline & .10 & 0 & & & & & & \\
\hline & $\approx \tilde{0}$ & 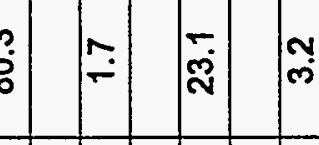 & $y=$ & & & 童 & & \\
\hline & $=\because$ & $=|-| \cdot \mid \approx$ & $=$ & & & & & \\
\hline & 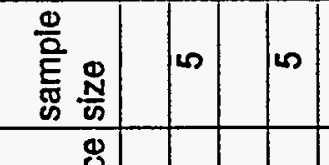 & 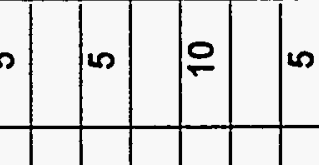 & 0 & & & 1 & & \\
\hline & $=0$ & 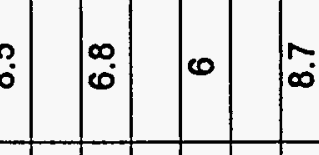 & 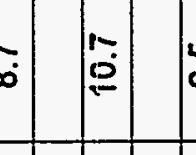 & & & 歨 & & \\
\hline & $\approx$ & 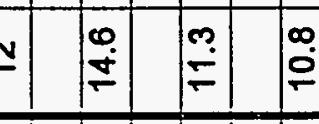 & $=0$ & & 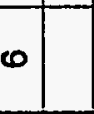 & & & \\
\hline & 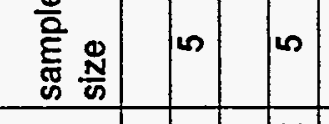 & $0.10 \mid-10$ & 010 & & & & & \\
\hline & 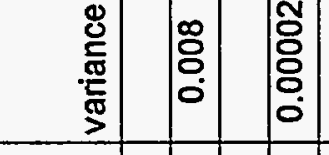 & 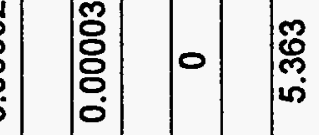 & 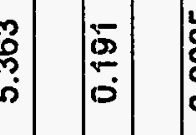 & & & $\mid \frac{2}{8}$ & & \\
\hline & 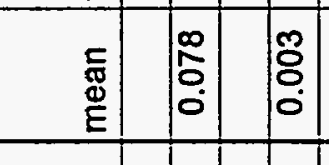 & \begin{tabular}{|c|c|c|c|c}
\multirow{2}{*}{} & 0 & 0 \\
\end{tabular} & $:$ & & ڤ & & & \\
\hline & 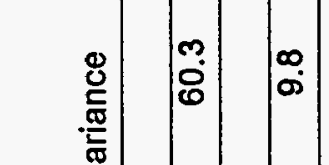 & 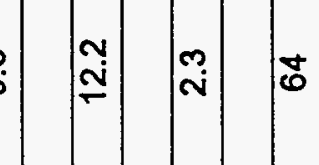 & 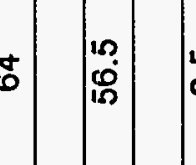 & & & & & \\
\hline & $:$ & 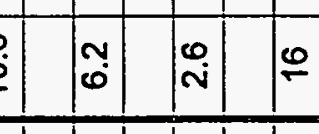 & $= \pm 1$ & & $\stackrel{\infty}{\infty}$ & $\approx$ & & \\
\hline & 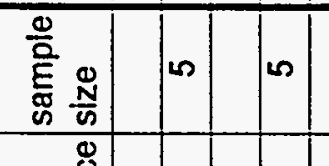 & 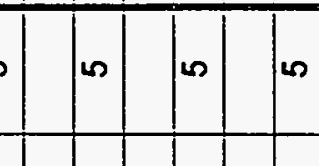 & .10 & & & $\frac{\hat{x}}{2}$ & & \\
\hline & 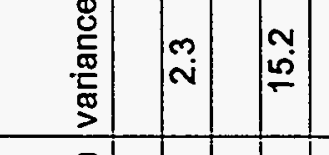 & $=\infty$ & $\approx=1$ & & & & & \\
\hline & $|=|$ & & & & & & & \\
\hline & 1 & & & & & & & \\
\hline
\end{tabular}


Table D-4. Aquatic Site Summaries for 1994.

\begin{tabular}{|c|c|c|c|c|c|c|c|c|c|c|c|c|c|c|c|c|c|}
\hline \multirow{4}{*}{ Site } & \multirow{2}{*}{\multicolumn{3}{|c|}{ Emergent Insects }} & \multirow{2}{*}{\multicolumn{3}{|c|}{ Macrobenthic Invertebrates }} & & & \multirow{2}{*}{\multicolumn{3}{|c|}{ Phytoplankton }} & \multirow{2}{*}{\multicolumn{2}{|c|}{ Zooplankton }} & & \multirow{2}{*}{\multicolumn{3}{|c|}{ Water Chemistry }} \\
\hline & & & & & & & & & & & & & & & & & \\
\hline & \multicolumn{3}{|c|}{ Taxonomic Richness } & \multicolumn{2}{|c|}{ Taxonomic Richness } & \multicolumn{2}{|c|}{ EPT/C Index } & & \multicolumn{3}{|c|}{ Taxonomic Richness } & \multicolumn{3}{|c|}{ Taxonomic Richness } & \multicolumn{3}{|c|}{ Ammonium (ppm) } \\
\hline & mean & |variance & $\begin{array}{l}\text { sample } \\
\text { size }\end{array}$ & mean & variance & mean & variance & $\begin{array}{l}\text { sample } \\
\text { size }\end{array}$ & mean & variance & $\begin{array}{l}\text { sample } \\
\text { size }\end{array}$ & mean & variance & $\begin{array}{l}\text { sample } \\
\text { size }\end{array}$ & mean & variance & $\begin{array}{l}\text { sample } \\
\text { size }\end{array}$ \\
\hline$\overline{\mathbf{D 2}}$ & 17 & 64.3 & 9 & 12.8 & 40.9 & 2.172 & 21.677 & 4 & 8.6 & 30.3 & 5 & $\overline{14}$ & $\overline{6.3}$ & 5 & N/A & N/A & N/A \\
\hline$\overline{\text { GW2 }}$ & $\overline{N / A}$ & $\widehat{N / A}$ & N/A & N/A & $\mathrm{N} / \mathrm{A}$ & $\bar{N} / \mathrm{A}$ & N/A & N/A & $\overline{N / A}$ & $\bar{N} / \mathrm{A}$ & $\bar{N} / \mathrm{A}$ & $\overline{\text { N/A }}$ & $\overline{N / A}$ & N/A & 0.64 & 0.00005 & 2 \\
\hline$\overline{\text { GW3 }}$ & $\overline{N / A}$ & N/A & N/A & 19.6 & 53 & 4.205 & 18.791 & 7 & N/A & $\bar{N} / A$ & $\overline{\mathrm{N} / \mathrm{A}}$ & $\bar{N} / A$ & $\bar{N} / A$ & $\bar{N} / A$ & 0.05 & 0.0002 & 2 \\
\hline IW1 & N/A & $\mathrm{N} / \mathrm{A}$ & N/A & 6.7 & 8.3 & 0 & 0 & 3 & N/A & N/A & $\overline{\mathrm{N} / \mathrm{A}}$ & $\bar{N} / A$ & N/A & N/A & 0.04 & 0.0002 & 2 \\
\hline$\overline{\text { SW03 }}$ & 8.8 & 12.9 & 4 & N/A & N/A & N/A & N/A & N/A & N/A & N/A & N/A & N/A & N/A & N/A & N/A & N/A & N/A \\
\hline SW05 & 8 & $\overline{9.8}$ & 9 & 19 & N/A & 0.04 & N/A & 1 & 10 & 3.5 & 5 & 13 & 43 & 5 & N/A & N/A & N/A \\
\hline$\overline{\mathrm{W1}}$ & N/A & $\bar{N} / \mathrm{A}$ & N/A & 10.1 & 37.5 & 0.712 & 1.133 & 7 & N/A & N/A & N/A & N/A & N/A & N/A & 0.02 & 0.0002 & 2 \\
\hline$\overline{W 2}$ & $\overline{N / A}$ & $\bar{N} / A$ & N/A & 12.8 & 59 & 7.035 & 116.548 & 11 & N/A & N/A & N/A & N/A & N/A & N/A & 0.04 & 0.0001 & 3 \\
\hline
\end{tabular}


Table D-5. EPT/C Index Values For All Macrobenthic Invertebrate Sites.

\begin{tabular}{|l|l|l|l|}
\hline Site & EPT/C index (mean) & Standard Deviation & Sample Size \\
\hline A1 & 0.078 & 0.088 & 5 \\
\hline A2 & 0.003 & 0.005 & 5 \\
\hline A3 & 0.002 & 0.005 & 5 \\
\hline A4 & 0.000 & 0.000 & 5 \\
\hline B1 & 1.876 & 2.316 & 5 \\
\hline B2 & 0.220 & 0.437 & 5 \\
\hline B3 & 0.010 & 0.021 & 5 \\
\hline B4 & 0.007 & 0.016 & 5 \\
\hline B5 & 0.000 & 0.000 & 5 \\
\hline BD1 & 1.923 & 0.724 & 5 \\
\hline BD2 & 5.484 & 5.406 & 6 \\
\hline D1 & 0.000 & 0.000 & 6 \\
\hline D2 & 2.172 & 4.656 & 5 \\
\hline GW3 & 4.205 & 4.335 & 6 \\
\hline IW1 & 0.000 & 0.000 & 2 \\
\hline SW05 & 0.040 & N/A & 1 \\
\hline W1 & 0.712 & 1.065 & 7 \\
\hline W2 & 7.035 & 10.796 & 11 \\
\hline
\end{tabular}


Table D-6. Jaccard Index Matrices For Macrobenthic Invertebrates.

Macrobenthic Invertebrate Families Other Than Chironomidae.

\begin{tabular}{|c|c|c|c|c|c|c|c|c|c|c|c|c|c|c|c|c|}
\hline $\begin{array}{c}\text { Sites } \\
\text { A1 }\end{array}$ & $\begin{array}{c}\text { A1 } \\
1.000\end{array}$ & $\begin{array}{c}\text { A2 } \\
0.444\end{array}$ & $\begin{array}{c}\text { A3 } \\
0.259\end{array}$ & $\begin{array}{c}\text { A4 } \\
0.111\end{array}$ & $\begin{array}{c}\text { B1 } \\
0.576\end{array}$ & $\begin{array}{c}\text { B2 } \\
0.594\end{array}$ & $\begin{array}{c}\text { B3 } \\
0.200\end{array}$ & $\begin{array}{c}\text { B4 } \\
0.407\end{array}$ & $\begin{array}{c}\text { B5 } \\
0.167\end{array}$ & $\begin{array}{c}\text { BD1 } \\
0.231\end{array}$ & $\begin{array}{l}\text { BD2 } \\
0.277\end{array}$ & $\begin{array}{c}\text { D1 } \\
0.293\end{array}$ & $\begin{array}{c}\text { D2 } \\
0.262\end{array}$ & $\begin{array}{l}\text { SW05 } \\
0.455\end{array}$ & $\begin{array}{c}\text { W1 } \\
\mathbf{0 . 2 3 3}\end{array}$ & $\begin{array}{c}\text { W2 } \\
0.353\end{array}$ \\
\hline A2 & & 1.000 & 0.357 & 0.154 & 0.423 & 0.440 & 0.167 & 0.353 & 0.176 & 0.114 & 0.125 & 0.154 & 0.136 & 0.375 & 0.086 & 0.200 \\
\hline A3 & & & 1.000 & 0.429 & 0.231 & 0.292 & 0.231 & 0.286 & 0.364 & 0.100 & 0.053 & 0.100 & 0.088 & 0.217 & 0.100 & 0.140 \\
\hline A4 & & & & 1.000 & 0.120 & 0.125 & 0.200 & 0.273 & 0.222 & 0.053 & 0.059 & 0.063 & 0.036 & 0.043 & 0.074 & 0.071 \\
\hline B1 & & & & & 1.000 & 0.750 & 0.259 & 0.440 & 0.222 & 0.216 & 0.261 & 0.304 & 0.290 & 0.484 & 0.244 & 0.340 \\
\hline B2 & & & & & & 1.000 & 0.222 & 0.458 & 0.185 & 0.245 & 0.239 & 0.309 & 0.254 & 0.552 & 0.220 & 0.347 \\
\hline B3 & & & & & & & 1.000 & 0.333 & 0.308 & 0.070 & 0.135 & 0.140 & 0.085 & 0.154 & 0.129 & 0.133 \\
\hline B4 & & & & & & & & 1.000 & 0.188 & 0.171 & 0.222 & 0.157 & 0.138 & 0.280 & 0.156 & 0.205 \\
\hline B5 & & & & & & & & & 1.000 & 0.098 & 0.079 & 0.120 & 0.105 & 0.160 & 0.133 & 0.163 \\
\hline BD1 & & & & & & & & & & 1.000 & 0.429 & 0.250 & 0.394 & 0.184 & 0.340 & 0.386 \\
\hline BD2 & & & & & & & & & & & 1.000 & 0.286 & 0.375 & 0.200 & 0.341 & 0.442 \\
\hline D1 & & & & & & & & & & & & 1.000 & 0.288 & 0.211 & 0.254 & 0.475 \\
\hline D2 & & & & & & & & & & & & & 1.000 & 0.206 & 0.286 & 0.448 \\
\hline SW05 & & & & & & & & & & & & & & 1.000 & 0.146 & 0.235 \\
\hline W1 & & & & & & & & & & & & & & & 1.000 & 0.333 \\
\hline W2 & & & & & & & & & & & & & & & & 1.000 \\
\hline
\end{tabular}

Macrobenthic Invertebrate Chironomidae Family Only.

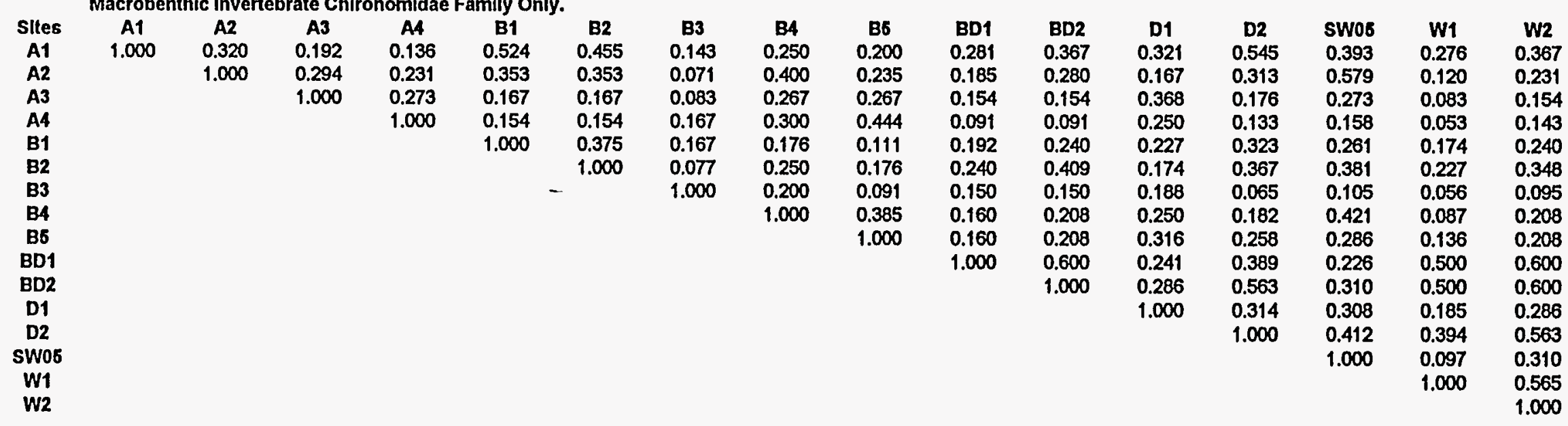


Table D-7. Analysis of Variance Table for Phytoplankton Richness, 1994 Data.

Analysis of Variance; Phytoplankton Taxonomic Richness across all sites sampled.

\begin{tabular}{lrrrrr}
\hline Source & Sum of Squares & Df & Mean Square & F-Ratio & P-Value \\
\hline Between Sites & 867.598 & 12 & 72.2998 & 6.59 & 0.0000 \\
Within Sites & 603.167 & 55 & 10.9667 & & \\
\hline & & & & & \\
Total (Corr.) & 1470.76 & 67 & &
\end{tabular}


Table D-8. Jaccard Index Matrix For Phytoplankton.

\begin{tabular}{|c|c|c|c|c|c|c|c|c|c|c|c|c|c|}
\hline $\begin{array}{l}\text { Sites } \\
\text { A1 }\end{array}$ & $\begin{array}{l}\text { A1 } \\
1.000\end{array}$ & $\begin{array}{l}\text { A2 } \\
0.629\end{array}$ & $\begin{array}{l}\text { A3 } \\
0.463\end{array}$ & $\begin{array}{l}\text { Á4 } \\
0.500\end{array}$ & $\begin{array}{l}\text { B1 } \\
0.486\end{array}$ & $\begin{array}{l}\text { B2 } \\
0.351\end{array}$ & $\begin{array}{l}\text { B3 } \\
0.486\end{array}$ & $\begin{array}{l}\text { B4 } \\
0.414\end{array}$ & $\begin{array}{l}\text { B5 } \\
0.471\end{array}$ & $\begin{array}{l}\text { D1 } \\
0.375\end{array}$ & $\begin{array}{l}\text { D2 } \\
0.457\end{array}$ & $\begin{array}{r}\text { Lindsay } \\
0.405\end{array}$ & $\begin{array}{l}\text { C2 } \\
0.333\end{array}$ \\
\hline A2 & & 1.000 & 0.525 & 0.486 & 0.559 & 0.457 & 0.432 & 0.448 & 0.457 & 0.367 & 0.444 & 0.395 & 0.262 \\
\hline A3 & & & 1.000 & 0.568 & 0.474 & 0.350 & 0.647 & 0.286 & 0.588 & 0.522 & 0.486 & 0.436 & 0.302 \\
\hline A4 & & & & 1.000 & 0.429 & 0.412 & 0.515 & 0.258 & 0.455 & 0.455 & 0.400 & 0.351 & 0.389 \\
\hline B1 & & & & & 1.000 & 0.394 & 0.500 & 0.370 & 0.533 & 0.319 & 0.424 & 0.412 & 0.231 \\
\hline B2 & & & & & & 1.000 & 0.394 & 0.296 & 0.294 & 0.364 & 0.324 & 0.278 & 0.243 \\
\hline B3 & & & & & & & 1.000 & 0.423 & 0.586 & 0.442 & 0.516 & 0.412 & 0.297 \\
\hline B4 & & & & & & & & 1.000 & 0.346 & 0.214 & 0.286 & 0.276 & 0.194 \\
\hline B5 & & & & & & & & & 1.000 & 0.364 & 0.452 & 0.394 & 0.278 \\
\hline D1 & & & & & & & & & & 1.000 & 0.419 & 0.378 & 0.476 \\
\hline D2 & & & & & & & & & & & 1.000 & 0.469 & 0.270 \\
\hline LIND & & & & & & & & & & & & 1.000 & 0.333 \\
\hline $\mathrm{C} 2$ & & & & & & & & & & & & & 1.000 \\
\hline
\end{tabular}


Table D-9. Analysis of Variance Table for Zooplankton Taxonomic Richness, 1994 Data.

Analysis of Variance; Zooplankton Taxonomic Richness across all sites sampled.

\begin{tabular}{lrrrrr}
\hline Source & Sum of Squares & Df & Mean Square & F-Ratio & P-Value \\
\hline Between Sites & 860.102 & 12 & 71.6752 & 6.80 & 0.0000 \\
Within Sites & 590.448 & 56 & 10.5437 & & \\
\hline & & & & & \\
Total (Corr.) & 1450.55 & 68 & &
\end{tabular}


Table D-10. Jaccard Index Matrix For Zooplankton.

\begin{tabular}{|c|c|c|c|c|c|c|c|c|c|c|c|c|c|}
\hline Sites & A1 & $A 2$ & $A 3$ & A4 & B1 & B2 & B3 & B4 & B5 & $\mathrm{C} 2$ & D1 & D2 & SW05 \\
\hline$A 1$ & 1.000 & 0.333 & 0.316 & 0.429 & 0.478 & 0.467 & 0.526 & 0.500 & 0.389 & 0.042 & 0.174 & 0.407 & 0.345 \\
\hline $\mathrm{A} 2$ & & 1.000 & 0.450 & 0.308 & 0.462 & 0.500 & 0.320 & 0.292 & 0.381 & 0.160 & 0.348 & 0.355 & 0.303 \\
\hline A3 & & & 1.000 & 0.353 & 0.286 & 0.276 & 0.294 & 0.250 & 0.636 & 0.125 & 0.333 & 0.192 & 0.185 \\
\hline A4 & & & & 1.000 & 0.391 & 0.355 & 0.350 & 0.316 & 0.438 & 0.211 & 0.316 & 0.286 & 0.233 \\
\hline B1 & & & & & 1.000 & 0.533 & 0.550 & 0.381 & 0.350 & 0.125 & 0.318 & 0.429 & 0.367 \\
\hline B2 & & & & & & 1.000 & 0.414 & 0.300 & 0.321 & 0.121 & 0.219 & 0.515 & 0.545 \\
\hline B3 & & & & & & & 1.000 & 0.412 & 0.294 & 0.048 & 0.143 & 0.458 & 0.385 \\
\hline B4 & & & & & & & & 1.000 & 0.333 & 0.000 & 0.100 & 0.320 & 0.259 \\
\hline B5 & & & & & & & & & 1.000 & 0.125 & 0.333 & 0.192 & 0.143 \\
\hline $\mathrm{C2}$ & & & & & & & & & & 1.000 & 0.538 & 0.069 & 0.000 \\
\hline D1 & & & & & & & & & & & 1.000 & 0.138 & 0.097 \\
\hline D2 & & & & & & & & & & & & 1.000 & 0.500 \\
\hline SW05 & & & & & & & & & & & & & 1.000 \\
\hline
\end{tabular}


Table D-11. Analysis of Variance Table for Emergent Insect Taxonomic Richness, 1994 Data.

Analysis of Variance; Emergent Insect Taxonomic Richness across all sites sampled.

\begin{tabular}{llllll}
\hline Source & Sum of Squares & Df & Mean Square & F-Ratio & P-Value \\
\hline & & & & & \\
Between Sites & 1745.51 & 13 & 134.27 & 8.64 & 0.0000 \\
Within Sites & 1088.05 & 70 & 15.5435 & & \\
\hline
\end{tabular}

Total (Corr) $\quad 2833.56 \quad 83$ 
Table D-12. Jaccard Index Matrix For Emergent Insects.

\begin{tabular}{|c|c|c|c|c|c|c|c|c|c|c|c|c|c|c|}
\hline Sites & A1 & A2 & A3 & A4 & B1 & B2 & B3 & B4 & B5 & C2 & D1 & D2 & SW03 & sW05 \\
\hline A1 & 1.000 & 0.405 & 0.080 & 0.304 & 0.346 & 0.462 & 0.357 & 0.208 & 0.242 & 0.241 & 0.281 & 0.289 & 0.214 & 0.333 \\
\hline A2 & & 1.000 & 0.194 & 0.278 & 0.308 & 0.385 & 0.317 & 0.250 & 0.390 & 0.300 & 0.295 & 0.396 & 0.282 & 0.429 \\
\hline A3 & & & 1.000 & 0.167 & 0.182 & 0.115 & 0.115 & 0.176 & 0.333 & 0.174 & 0.185 & 0.114 & 0.190 & 0.129 \\
\hline A4 & & & & 1.000 & 0.261 & 0.455 & 0.391 & 0.278 & 0.207 & 0.250 & 0.250 & 0.209 & 0.217 & 0.267 \\
\hline B1 & & & & & 1.000 & 0.423 & 0.194 & 0.217 & 0.212 & 0.207 & 0.250 & 0.267 & 0.222 & 0.303 \\
\hline B2 & & & & & & 1.000 & 0.333 & 0.240 & 0.303 & 0.267 & 0.265 & 0.304 & 0.241 & 0.278 \\
\hline B3 & & & & & & & 1.000 & 0.292 & 0.194 & 0.310 & 0.303 & 0.250 & 0.200 & 0.278 \\
\hline B4 & & & & & & & & 1.000 & 0.259 & 0.381 & 0.308 & 0.133 & 0.421 & 0.194 \\
\hline B5 & & & & & & & & & 1.000 & 0.367 & 0.438 & 0.260 & 0.345 & 0.225 \\
\hline C2 & & & & & & & & & & 1.000 & 0.414 & 0.234 & 0.478 & 0.257 \\
\hline D1 & & & & & & & & & & & 1.000 & 0.235 & 0.393 & 0.256 \\
\hline D2 & & & & & & & & & & & & 1.000 & 0.191 & 0.375 \\
\hline SW03 & & & & & & & & & & & & & 1.000 & 0.313 \\
\hline SW05 & & & & & & & & & & & & & & 1.000 \\
\hline
\end{tabular}




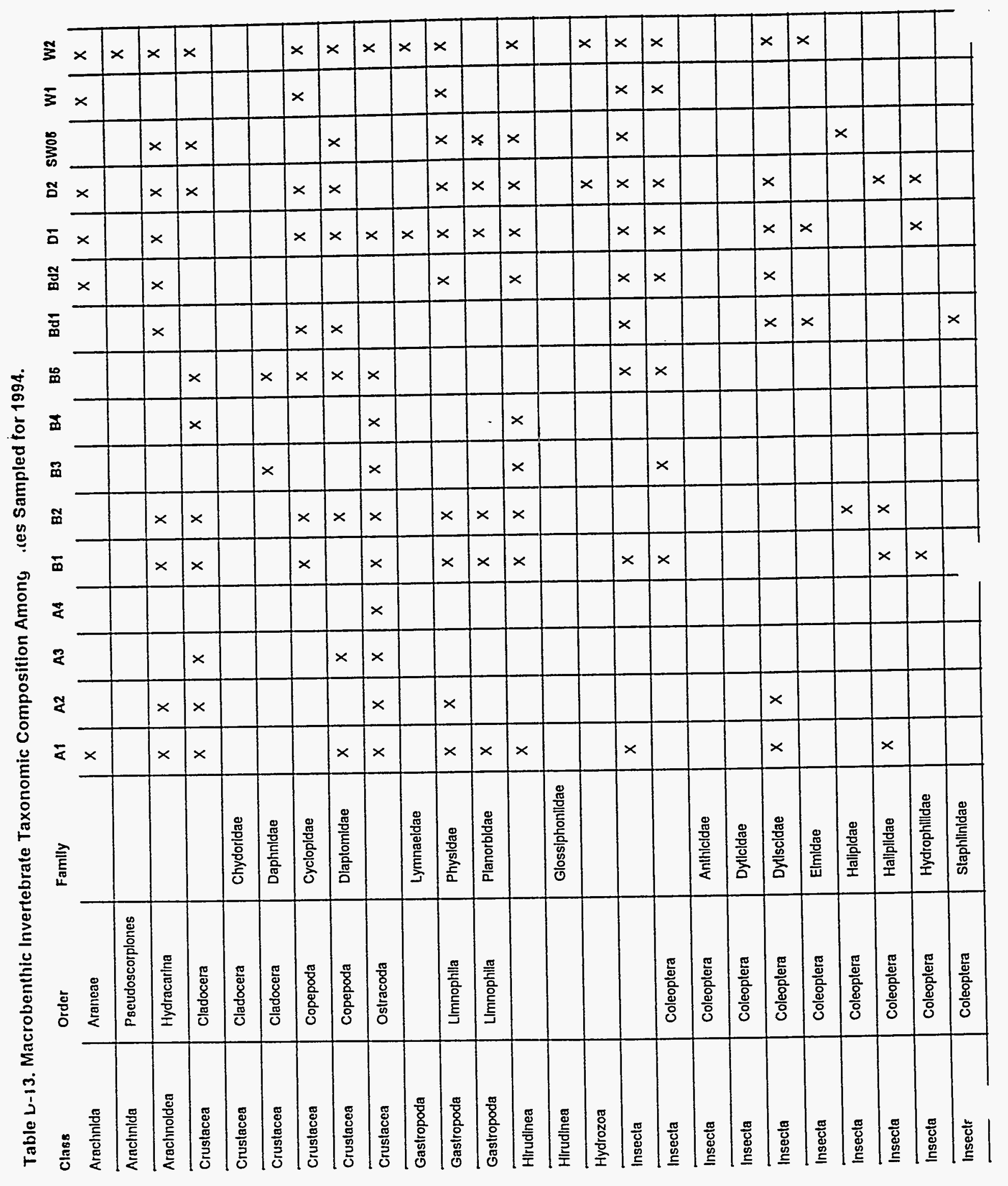


Table D-13. Macrobenthic Invertebrate Taxonomic Composition Among Sites Sampled for 1994, continued.

\begin{tabular}{|c|c|c|c|c|c|c|c|c|c|c|c|c|c|c|c|c|c|c|}
\hline $\begin{array}{l}\text { Class } \\
\text { Insecla }\end{array}$ & $\begin{array}{l}\text { Order } \\
\text { Coleoplera }\end{array}$ & $\begin{array}{l}\text { Family } \\
\text { Hydrophlilidae }\end{array}$ & A1 & A2 & A3 & A4 & $\begin{array}{l}B 1 \\
x\end{array}$ & B2 & B3 & B4 & B6 & Bd1 & Bd2 & $\begin{array}{l}\text { D1 } \\
X\end{array}$ & $\begin{array}{l}\mathrm{D2} \\
\mathrm{X}\end{array}$ & SWos & W1 & $W_{2}$ \\
\hline Insecla & Coleoplera & Slaphilinldae & & & & & & & & & & $x$ & & & & & & \\
\hline Insocla & Coleoplera & Staphyllnldae & & & & & & & & & & & & & & & & \\
\hline Insecta & Collembola & & & & & & & & & & & $x$ & & $x$ & $x$ & & $x$ & $x$ \\
\hline Insecla & Dlplera & & & & & & & & & & & . & & $x$ & $x$ & & & $x$ \\
\hline Insecta & Dlplera & Ceratopogonldae & $x$ & $x$ & & & $x$ & $\mathrm{x}$ & & $x$ & & $x$ & $x$ & $x$ & & $x$ & & $x$ \\
\hline Insecla & Diptera & Chaoborldae & $x$ & $x$ & $x$ & & $x$ & $x$ & $x$ & & & & & $x$ & & $x$ & & \\
\hline Insecta & Diptera & Chlronomldae & $x$ & $x$ & $x$ & $x$ & $x$ & $x$ & $x$ & $x$ & $x$ & $x$ & $x$ & $x$ & $x$ & $x$ & $x$ & $x$ \\
\hline Insecta & Dlplera & Cullcldae & & & & & & & & & & & & $x$ & & & & \\
\hline Insecla & Dlplera & Dlxldae & & & & & & & & & & & & & & & & \\
\hline Insecla & Diptera & Dolichopodidae & & & & & & & & & & & & $x$ & & & & \\
\hline Insecla & Diptera & Empldldae & & & & & & & & & & $x$ & & & $x$ & & & \\
\hline Insecla & Diptera & Ephydridae & & & & & & & & & & $x$ & & & & & & . \\
\hline Insecla & Diplera & Muscldae & & & & & & & & & & $x$ & $x$ & $x$ & $x$ & & & $x$ \\
\hline Insecla & Dlplera & Psychodidae & & & & & & & & & & & & & & & & \\
\hline Insecta & Dlplera & Ptychoplerldae & & & & & & & & & & & & & & & & \\
\hline Insecla & Dlplera & Simullidae & & & & & & & & & & $x$ & $x$ & $x$ & $x$ & & $x$ & $x$ \\
\hline Insecla & Dlplera & Strallomyldae & & & & & & & & & & $x$ & & & $x$ & & & \\
\hline Insecla & DIplera & Tabanldae & & & & & & & & & & & & $x$ & & & & \\
\hline Insecta & Diptera & Tipulidae & & & & & & & & & & $x$ & $x$ & $x$ & $x$ & & $x$ & $x$ \\
\hline Insecta & Dlplera & famlly $A$ & & & & & & & & & & & & $x$ & & & & $x$ \\
\hline Insecla & Diptera & family $B$ & & & & & & & & & & & & & & & $x$ & \\
\hline Insecla & Ephemeroptera & & & & & & & & & & & & & & $x$ & & & \\
\hline
\end{tabular}


Talin D-13. Macrobenthic Invertebrate Taxonomic Composition Among sites Sampled for 1994, continued.

\begin{tabular}{|c|c|c|c|c|c|c|c|c|c|c|c|c|c|c|c|c|c|c|}
\hline Class & Order & Family & A1 & A2 & A3 & A4 & B1 & B2 & B3 & BA & B5 & Bdf & $B d 2$ & D1 & D2 & 8W08 & w1 & w2 \\
\hline Insecla & Ephemeroptera & Baellidae & $x$ & $x$ & & & $x$ & $x$ & $x$ & $x$ & & $x$ & $x$ & & $x$ & $x$ & $x$ & $\mathrm{x}$ \\
\hline Insecta & Ephemeroplera & Caenldae & $x$ & $x$ & $x$ & & $x$ & $x$ & & & & $x$ & & & $x$ & $x$ & $x$ & $x$ \\
\hline Insecla & Ephemeroplera & Ephemerellldae & & & & & & & & & & & & & & & & \\
\hline Insecla & Ephemeroplera & Heptagenlldae & & & & & & & & & & $x$ & $x$ & & $x$ & & & \\
\hline Insecla & Ephemeroptera & Leptophebildae & & & & & & & & & & & & & $x$ & & & \\
\hline Insecla & Ephemeroplera & Leplophleblldae & & & & & & & & & & & & & & & & \\
\hline Insecta & Ephemeroptera & Triconthldae & & & & & & $x$ & & & & $x$ & $x$ & $x$ & & & $x$ & $x$ \\
\hline Insecta & Hemiplera & & $x$ & & & & & & & & & $x$ & $x$ & $x$ & $x$ & & $x$ & $x$ \\
\hline Insecla & Hemiptera & Corlyldae & $x$ & $x$ & & & $x$ & $x$ & $x$ & $x$ & & $x$ & & $x$ & $x$ & & & $x$ \\
\hline Insecta & Hemlplera & Gerridae & & & & & & & & & & & & $x$ & & & $x$ & $x$ \\
\hline Insecta & Hemiplera & Nepldae & & & & & & & & & & & & . & & & & \\
\hline Insecta & Hemlptera & Notonectldae & & & & & & & & & & & & & & & & \\
\hline Insecla & Hemlptera & Vellildae & & & & & & & & & & & & & & & & \\
\hline Insecla & Lepldoptera & & & & & & & & & & & & & $x$ & & & & \\
\hline Insecla & Lepldoplera & Nocluidae & & & & & & & & & & & & $x$ & & & & \\
\hline Insecla & Lepldoplera & Pyralldae & & & & & & & & & & & & & & $x$ & & \\
\hline Insecla & Odonala & & & & & & & & & & & & & & & & & \\
\hline Insecla & Odonala & Aeshınldae & & & & & & & & & & & & & & & & \\
\hline Insecla & Odonala & Coenagrionldae & $x$ & $x$ & & & $x$ & $x$ & & & & & $x$ & $x$ & $x$ & $x$ & $x$ & $x$ \\
\hline Insecla & Odonata & Gomphldae & & & & & & & & & & $x$ & $x$ & & & & & \\
\hline Insecla & Odonata & Lestldae & & & & & $x$ & & & & & & & & & & & \\
\hline Insecla & Odonata & Libellulldae & $x$ & & & & & & & & & & & & & & & \\
\hline Insecla & Plecoplera & & & & & & & & & & & & & & $x$ & & & \\
\hline
\end{tabular}


Table U-13. Macrobenthic Invertebrate Taxonomic Composition Amony Sites Sampled for 1994, continued.

\begin{tabular}{|c|c|c|c|c|c|c|c|c|c|c|c|c|c|c|c|c|c|c|}
\hline $\begin{array}{l}\text { Class } \\
\text { Insecla }\end{array}$ & $\begin{array}{l}\text { Order } \\
\text { Ephemeroplera }\end{array}$ & $\begin{array}{l}\text { Family } \\
\text { Baelldae }\end{array}$ & $\begin{array}{l}A 1 \\
X\end{array}$ & $\begin{array}{l}\mathbf{A 2} \\
X\end{array}$ & A3 & A4 & $\begin{array}{l}\mathbf{8 1} \\
\mathrm{X}\end{array}$ & $\begin{array}{l}\mathbf{B 2} \\
\mathrm{X}\end{array}$ & $\begin{array}{l}\mathbf{8 3} \\
\mathrm{x}\end{array}$ & $\begin{array}{l}B 4 \\
X\end{array}$ & B6 & $\begin{array}{l}\text { Bd1 } \\
X\end{array}$ & $\begin{array}{l}\text { Bd2 } \\
X\end{array}$ & D1 & $\begin{array}{l}\mathrm{D2} \\
\mathrm{X}\end{array}$ & $\left.\right|_{x} ^{\text {swor }}$ & $\begin{array}{l}\text { w1 } \\
x\end{array}$ & $\begin{array}{l}w 2 \\
x\end{array}$ \\
\hline Insecla & Ephemeroplera & Caenldae & $x$ & $x$ & $x$ & & $x$ & $x$ & & & & $x$ & & & $x$ & $x$ & $x$ & $x$ \\
\hline Insecla & Ephemeroplera & Ephemerellidae & & & & & & & & & & & & & & & & \\
\hline Insecla & Ephemeroplera & Heplagenlldae & & & & & & & & & & $x$ & $x$ & & $x$ & & & \\
\hline Insecta & Ephemeroplera & Leplopheblldae & & & & & & & & & & & & & $x$ & & & \\
\hline Insecla & Ephemeroplera & Leplophleblidae & & & & & & & & & & & & & & & & \\
\hline Insecla & Ephemeroplera & Tricorythidae & & & & & & $x$ & & & & $\mathrm{x}$ & $x$ & $x$ & & & $x$ & $x$ \\
\hline Insecla & Hemiplera & & $x$ & & & & & & & & & $x$ & $x$ & $x$ & $x$ & & $x$ & $x$ \\
\hline Insecla & Hemiplera & Corixidae & $x$ & $x$ & & & $x$ & $\mathrm{x}$ & $x$ & $x$ & & $x$ & & $x$ & $x$ & & & $x$ \\
\hline Insecla & Hemiptera & Gerridae & & & & & & & & & & & & $x$ & & & $x$ & $x$ \\
\hline Insecla & Hemlptera & Nepldae & & & & & & 1 & & & & & & & & & & \\
\hline Insecla & Hemlplera & Notonectldae & & & & & & 1 & & & & & & & & & & \\
\hline Insecta & Hemlptera & Velllldae & & & & & & & & & & & & & & & & \\
\hline Insecla & Lepldoplera & & & & & & & e & & & & & & $x$ & & & & \\
\hline Insecla & Lepldoplera & Noctuldae & & & & & & & & & & & & $x$ & & & & \\
\hline Insecta & Lepldoptera & Pyralldae & & & & & & & & & & & & & & $x$ & & \\
\hline Insecla & Odonala & & & & & & & & & & & & & & & & & \\
\hline Insecla & Odonala & Aeshnldae & & & & & & & & & & & & & & & & \\
\hline Insecla & Odonala & Coenagrionldae & $x$ & $x$ & & & $X$ & $x$ & & & & & $x$ & $x$ & $x$ & $x$ & $x$ & $x$ \\
\hline Insecla & Odonala & Gomphldae & & & & & & & & & & $x$ & $x$ & & & & & \\
\hline Insecta & Odonala & Lestldae & & & & & $x$ & & & & & & & & & & & \\
\hline Insecta & Odonala & Llbellulldae & $x$ & & & & & & & & & & & & & & & \\
\hline Insecta & Plecoptera & & & & & & & & & & & & & & $x$ & & & \\
\hline
\end{tabular}


Table D-14. Bioassessment Values of Onsite Aquatic Systems, Based on the Calculated EPT/C Index.

D-2 as reference site (2.172)

\begin{tabular}{|l|r|r|c|}
\hline Pond & $\begin{array}{c}\text { EPT/C } \\
\text { index } \\
\text { mean }\end{array}$ & $\begin{array}{c}\text { Target } \\
\text { Index by } \\
\text { reference } \\
\text { index ratio }\end{array}$ & $\begin{array}{c}\text { Bloassessment } \\
\text { Value }\end{array}$ \\
\hline $\mathrm{A}-1$ & 0.078 & $3.59 \%$ & 0 \\
\hline $\mathrm{A}-2$ & 0.003 & $0.14 \%$ & 0 \\
\hline $\mathrm{A}-3$ & 0.002 & $0.09 \%$ & 0 \\
\hline $\mathrm{A}-4$ & 0.000 & $0.00 \%$ & 0 \\
\hline $\mathrm{B}-1$ & 1.876 & $86.37 \%$ & 3 \\
\hline $\mathrm{B}-2$ & 0.220 & $10.13 \%$ & 0 \\
\hline $\mathrm{B}-3$ & 0.010 & $0.46 \%$ & 0 \\
\hline $\mathrm{B}-4$ & 0.007 & $0.32 \%$ & 0 \\
\hline $\mathrm{B}-5$ & 0.000 & $0.00 \%$ & 0 \\
\hline $\mathrm{D}-1$ & 0.000 & $0.00 \%$ & 0 \\
\hline
\end{tabular}

\section{B-1 as reference site (1.876)}

\begin{tabular}{|l|r|r|c|}
\hline Pond & $\begin{array}{r}\text { EPT/C } \\
\text { Index } \\
\text { mean }\end{array}$ & $\begin{array}{r}\text { Target } \\
\text { Index by } \\
\text { reference } \\
\text { Index ratio }\end{array}$ & $\begin{array}{c}\text { Bioassessment } \\
\text { Value }\end{array}$ \\
\hline $\mathrm{A}-1$ & 0.078 & $4.16 \%$ & 0 \\
\hline $\mathrm{A}-2$ & 0.003 & $0.16 \%$ & 0 \\
\hline $\mathrm{A}-3$ & 0.002 & $0.11 \%$ & 0 \\
\hline $\mathrm{A}-4$ & 0 & $0.00 \%$ & 0 \\
\hline $\mathrm{B}-1$ & 1.876 & $100.00 \%$ & $\mathrm{~N} / \mathrm{A}$ \\
\hline $\mathrm{B}-2$ & 0.22 & $11.73 \%$ & 0 \\
\hline $\mathrm{B}-3$ & 0.01 & $0.53 \%$ & 0 \\
\hline $\mathrm{B}-4$ & 0.007 & $0.37 \%$ & 0 \\
\hline $\mathrm{B}-5$ & 0 & $0.00 \%$ & 0 \\
\hline $\mathrm{D}-1$ & 0 & $0.00 \%$ & 0 \\
\hline
\end{tabular}

A-2 as reference site $(0.003)$, based on A-2 being hlghly diverse.

\begin{tabular}{|l|r|r|c|}
\hline & $\begin{array}{r}\text { EPT/C } \\
\text { Index } \\
\text { mean }\end{array}$ & $\begin{array}{r}\text { Target Index } \\
\text { by reference } \\
\text { Index ratlo }\end{array}$ & $\begin{array}{c}\text { Bloassessment } \\
\text { Value }\end{array}$ \\
\hline $\mathrm{A}-1$ & 0.078 & $2600.00 \%$ & N/A \\
\hline $\mathrm{A}-2$ & 0.003 & $100.00 \%$ & N/A \\
\hline $\mathrm{A}-3$ & 0.002 & $66.67 \%$ & 0 \\
\hline $\mathrm{A}-4$ & 0.000 & $0.00 \%$ & 0 \\
\hline $\mathrm{B}-1$ & 1.876 & $62533.33 \%$ & N/A \\
\hline $\mathrm{B}-2$ & 0.220 & $7333.33 \%$ & N/A \\
\hline $\mathrm{B}-3$ & 0.010 & $333.33 \%$ & N/A \\
\hline $\mathrm{B}-4$ & 0.007 & $233.33 \%$ & N/A \\
\hline $\mathrm{B}-5$ & 0.000 & $0.00 \%$ & 0 \\
\hline $\mathrm{D}-1$ & 0.000 & $0.00 \%$ & 0 \\
\hline
\end{tabular}

$\mathrm{BD2}$ as a reference site $(5.484)$

\begin{tabular}{|l|r|r|c|}
\hline & $\begin{array}{c}\text { EPT/C } \\
\text { index } \\
\text { mean }\end{array}$ & $\begin{array}{c}\text { Target index } \\
\text { by reference } \\
\text { index ratlo }\end{array}$ & $\begin{array}{c}\text { Bloassessment } \\
\text { Value }\end{array}$ \\
\hline BD1 & 1.923 & $35.07 \%$ & 0 \\
\hline GW3 & 4.205 & $76.68 \%$ & 0 \\
\hline IW1 & 0 & $0.00 \%$ & 0 \\
\hline
\end{tabular}


APPENDIX E. SOIL INVERTEBRATES

Author: M. E. Bakeman 


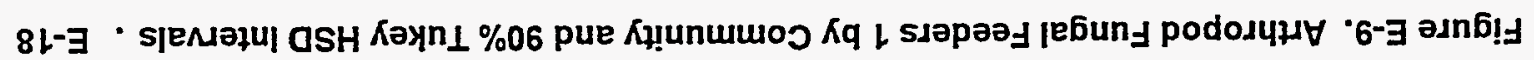

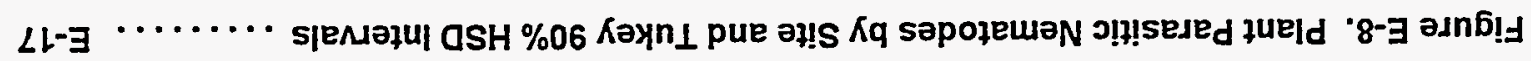

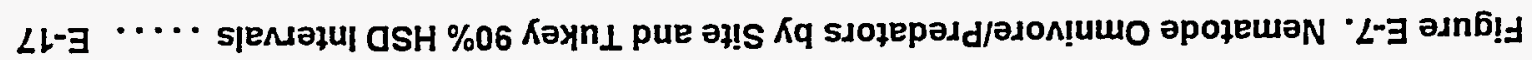

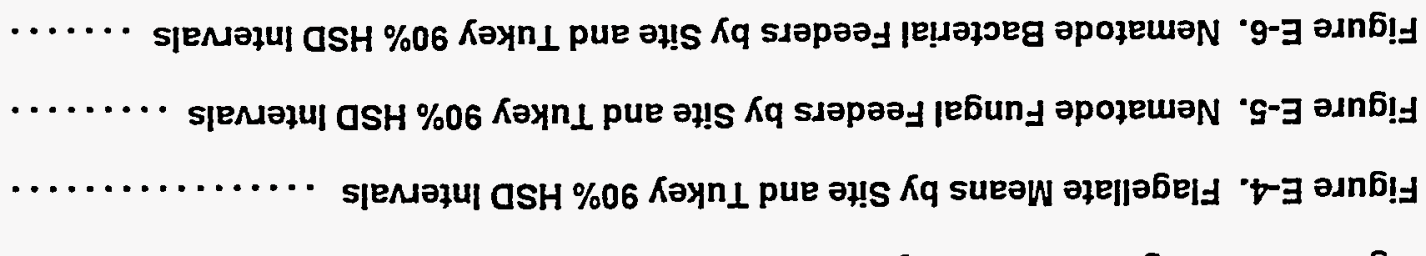

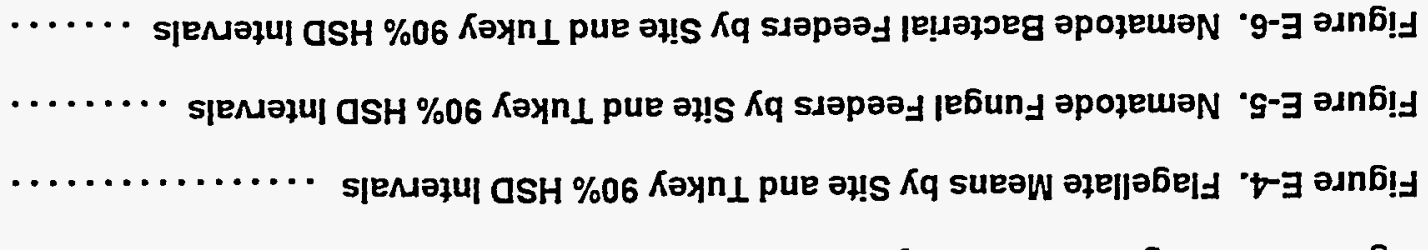

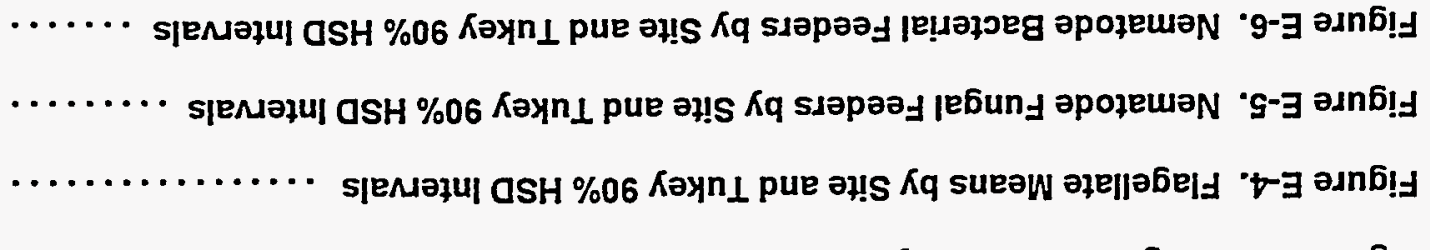

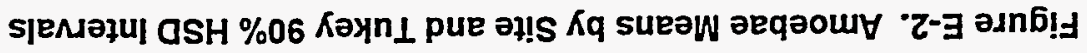
ฤレーヨ

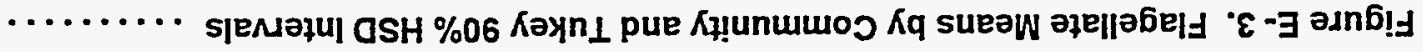
.

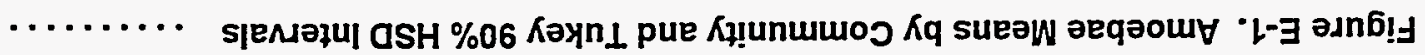

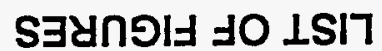

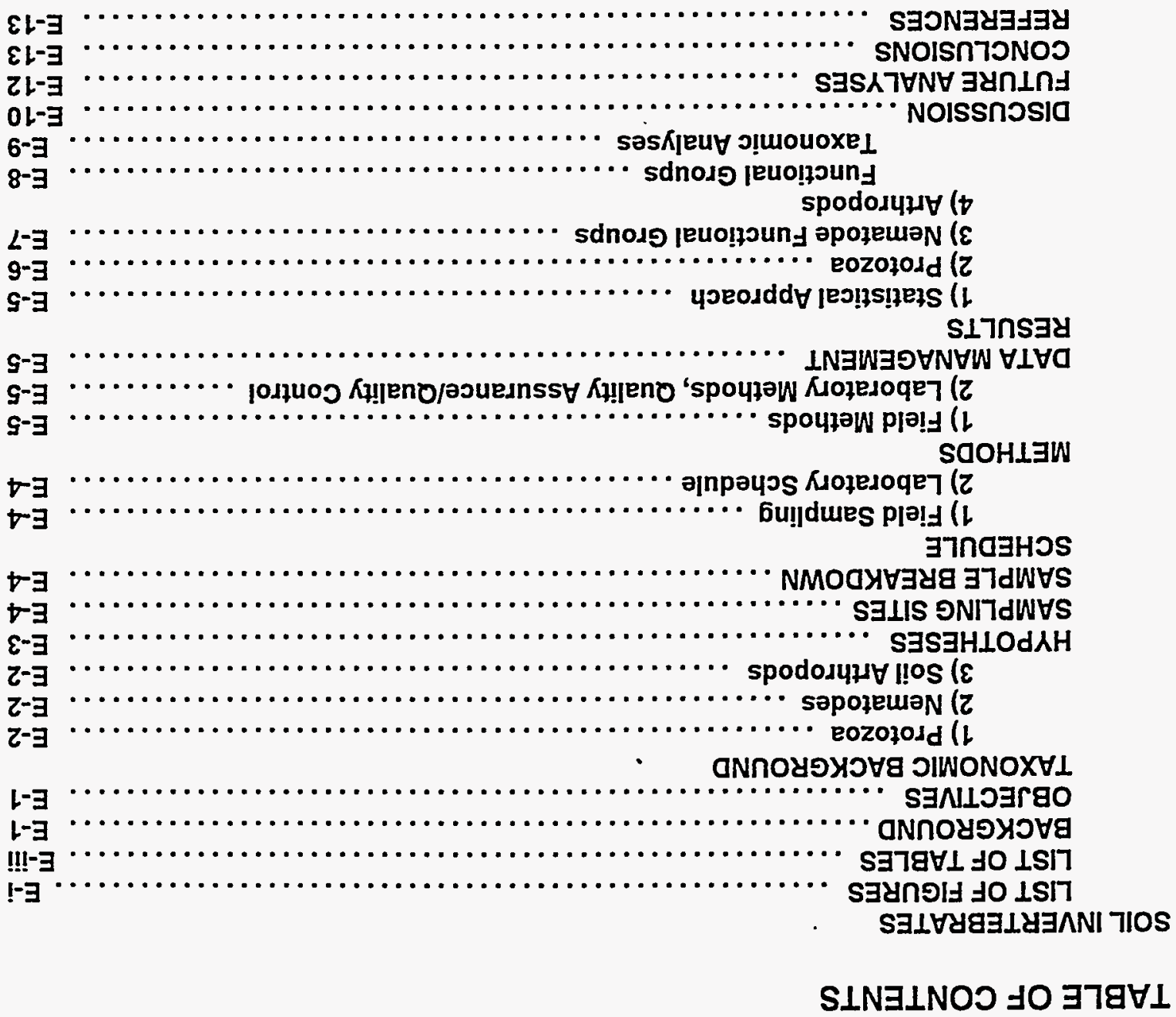


Figure E-10. Arthropod Fungal Feeders 1 by Site and 90\% Tukey HSD Intervals ..... E-18

Figure E-11. Arthropod Fungal Feeders 2 by Depth and 90\% Tukey HSD Intervals .... E-19

Figure E-12. Arthropod Detritivore 1 Means by Community and 90\% Tukey HSD Intervals

............................ E-19

Figure E-13. Arthropod Detritivore 1 Means by Site and 90\% Tukey HSD Intervals .... E-20

Figure E-14. Arthropod Detritivore 2 Means by Community and $90 \%$ Tukey HSD Intervals

Figure E-15. Arthropod Total Detritivore Means by Community and $90 \%$ Tukey HSD Intervais .......................... E-21

Figure E-16. Arthropod Total Detritivore Means by Site and $90 \%$ Tukey HSD Intervals . E-21

Figure E-17. Arthropod General Predators by Site and 90\% Tukey HSD Intervals ..... E-22

Figure E-18. Arthropod Predator Means by Community and $90 \%$ Tukey HSD Intervals . E-22

Figure E-19. Arthropod Predator Means by Site and 90\% Tukey HSD Intervals ...... E-23

Figure E-20. Arthropod Total Predators by Community and $90 \%$ Tukey HSD Intervals . E-23

Figure E-21. Arthropod Total Predators by Site and $90 \%$ Tukey HSD Intervals . . . . E E-24

Figure E-22. Arthropod Herbivore Means by Community and 90\% Tukey HSD Intervals E-24 


\section{LIST OF TABLES}

Table E-1. Analysis of Variance, EcMP Soil Amoebae by Community and Depth $\ldots \ldots$ E-25

Table E-2. Analysis of Variance, EcMP Soil Amoebae by Site $\ldots \ldots \ldots \ldots \ldots \ldots \ldots$ E-25

Table E-3. Analysis of Variance, EcMP Soil Flagellates by Community and Depth .... E-26

Table E-4. Analysis of Variance, EcMP Soil Flagellates by Site .............. E-26

Table E-5. Analysis of Variance, EcMP Soil Ciliates by Community and Depth ...... E-27

Table E-6. Analysis of Variance, EcMP Soil Ciliates by Site $\ldots \ldots \ldots \ldots \ldots \ldots \ldots \ldots$ E-27

Table E-7. Analysis of Variance, EcMP Soil Nematode Fungal Feeders by Community and Depth . . . . . . . . . . . . . . .

Table E-8. Analysis of Variance, EcMP Soil Nematode Fungal Feeders by Site ...... E-28

Table E-9. Analysis of Variance, EcMP Soil Nematode Bacterial Feeders by Community and

Depth .......................................... E-29

Table E-10. Analysis of Variance, EcMP Soil Nematode Bacterial Feeders by Site . . . E-29

Table E-11. Analysis of Variance, EcMP Soil Nematode Omnivore/Predators by Community

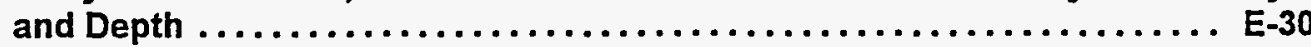

Table E-12. Analysis of Variance, EcMP Soil Nematode Omnivore/Predators by Site ... E-30

Table E-13. Analysis of Variance, EcMP Soil Plant Parasitic Nematodes by Community and

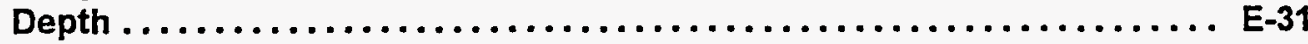

Table E-14. Analysis of Variance, EcMP Soil Plant Parasitic Nematodes by Site ...... E-31

Table E-15. Analysis of Variance, EcMP Soil Arthropod Fungal Feeders 1 by Community and

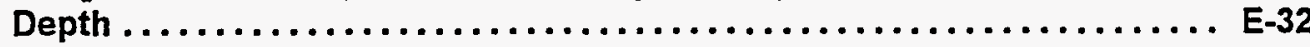

Table E-16. Analysis of Variance, EcMP Soil Arthropod Fungal Feeders 1 by Site .... E-32

Table E-17. Analysis of Variance, EcMP Soil Arthropod Fungal Feeders 2 by Community and

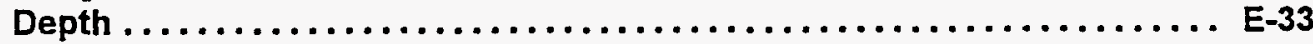

Table E-18. Analysis of Variance, EcMP Soil Arthropod Fungal Feeders 2 by Site .... E-33

Table E-19. Analysis of Variance, EcMP Arthropod Detritivores 1 by Community and Depth ..................................................

Table E-20. Analysis of Variance, EcMP Soil Arthropod Detritivores 1 by Site ....... E-34

Table E-21. Analysis of Variance, EcMP Arthropod Detritivores 2 by Community and Depth .................................... E-35

Table E-22. Analysis of Variance, EcMP Soil Arthropod Detritivores 2 by Site ....... E-35 
Table E-23. Analysis of Variance, EcMP Arthropod Total Detritivores by Community and

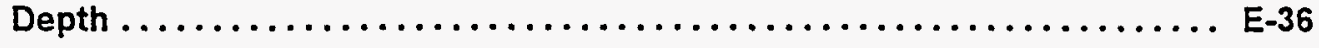

Table E-24. Analysis of Variance, EcMP Soil Arthropod Total Detritivores by Site .... E-36

Table E-25. Analysis of Variance, EcMP Arthropod Total Fungivores by Community and

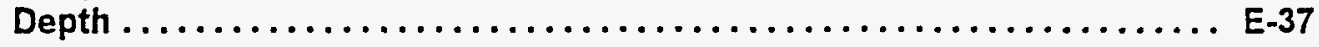

Table E-26. Analysis of Variance, EcMP Soil Arthropod Total Fungivores by Site ..... E-37

Table E-27. Analysis of Variance, EcMP Arthropod General Predators by Community and

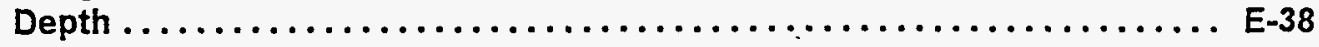

Table E-28. Analysis of Variance, EcMP Soil Arthropod General Predators by Site ... E-38

Table E-29. Analysis of Variance, EcMP Arthropod Predators by Community and Depth

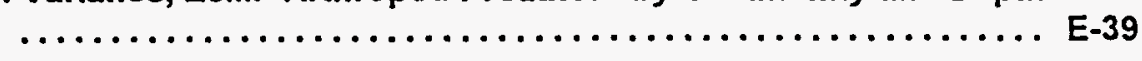

Table E-30. Analysis of Variance, EcMP Soil Arthropod Predators by Site ........ E-39

Table E-31. Analysis of Variance, EcMP Soil invertebrate Total Arthropod Predators by

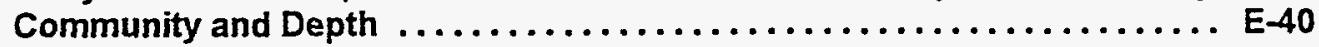

Table E-32. Analysis of Variance, EcMP Soil Invertebrate Total Arthropod Predators by Site ................................... E-40

Table E-33. Analysis of Variance, EcMP Soil Arthropod Herbivores by Community and Depth ........................................ E.

Table E-34. Analysis of Variance, EcMP Soil Arthropod Herbivores by Site . ....... E-41

Table E-35. Analysis of Variance, EcMP Soil Cryptostigmata Mite Richness by Community

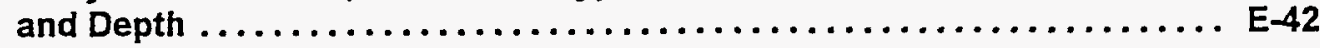

Table E-36. Analysis of Variance, EcMP Soil Cryptostigmata Mite Richness by Site ... E-42

Table E-37. Analysis of Variance, EcMP Soil Prostigmata Mite Richness by Community and Depth .......................................... E-43

Table E-38. Analysis of Variance, EcMP Soil Prostigmata Mite Richness by Site ..... E-43

Table E-39. Summary Findings and Ranked Community, Depth and Site Soil Invertebrate

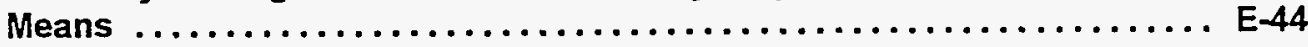




\section{BACKGROUND}

Soil invertebrates are common, numerous, and massive components of terrestrial ecosystems, and play several important roles. They affect biological, chemical, and physical soil properties, primarily by their relationships with bacterial and fungal communities, litter comminution, and maintenance of soil structure (Dindal, 1990). Soil invertebrates include earthworms, mites, insects, protozoa, nematodes, flatworms, and several other forms. They range in size from microns to centimeters in length, and numbers may run from a few to millions per gram of soil. They are particularly useful organisms for biological monitoring purposes because their abundances are relatively easy to measure, they are in intimate contact with soil particles, soil water and contaminants, and they exhibit a wide range of trophic groups that are affected by soil perturbations (EA Engineering, 1991). Invertebrate analysis has several potential applications at a Superfund site in a monitoring context. Since they are relatively more sensitive to anthropogenic disturbances than many other organisms, changes in invertebrate community structure or functional groups can be used to document effects of disturbances, or just as importantly, lack of effects. Such changes may be of interest in themselves (documentation of injury for NRDA under geological resources category), or serve as an early warning signal that additional biological effects will be forthcoming. However, since there are no soil invertebrate data for the Site, initial data are needed to establish baseline conditions.

Soil samples for invertebrate analysis are relatively easy to collect. Samples are transported to a laboratory, where the living organisms are extracted into preserving fluid and then counted and identified. There is such a variety of organisms that it is impossible to extract and identify all taxa. The taxa chosen in the EcMP are protozoa, arthropods, and nematodes. Subject matter experts in these taxa supervised the identification and counting of the organisms. Invertebrates were analyzed at two levels of resolution: (a) organisms were identified and counted at the appropriate taxonomic level (family, order, species, etc.), and (b) organisms were classified into functiona! groups. Functional groups are based on food source, feeding mode, life history, and distribution in the soil profile.

Samples were initially collected in August-September 1993 from EcMP sites and OU 11. These data have only recently become available, because the initial taxonomic identification work from sites that have no previous records is considerable. OU 11 data are reported separately under Appendix I. The program now has an established contract with Dr. John Moore, a soil invertebrate expert at the University of Northern Colorado at Greeley. Dr. Moore has completed the initial identifications of site organisms and has also compiled a reference collection that will aid in future identifications.

\section{OBJECTIVES}

1) Characterize the taxa and functional groups of soil invertebrates from several terrestrial vegetation communities and determine sources of variation that affect seasonal, annual, and long term changes in each community. This information can be used to describe the structure of invertebrate communities associated with native vegetation and anthropogenically disturbed sites. At this time, data are only available to assess differences in community structure.

2) Determine if the Rocky Flats Plant has a unique soil fauna when compared to other offsite areas. It is anticipated that offsite data will not be collected until summer 1995, at the earliest.

3) Determine if soil faunal community structure can be correlated with other biological indices, such as ecosystem functional measurements and vegetation species diversity. In this way a conceptual model of the Rocky Flats ecosystem can be refined, and the relationships between populations, communities, and ecosystem processes clarified. 


\section{TAXONOMIC BACKGROUND}

Brief descriptions of the sample taxa are given below.

\section{1) Protozoa}

Protozoa are single-celled organisms that are commonly found in terrestrial and freshwater habitats. Soil protozoa belong primarily to two phyla: Sarcomastigophora, and Ciliophora (Lousier and Bamforth, 1990). The former phylum contains the flagellates (subphylum Mastigophora) and the naked amoebae (subphylum Sarcodina). The latter phylum contains the ciliate protozoans. Flagellates are typically $5-20 \mathrm{um}$ in length, amoebae $<50 \mathrm{um}$, and ciliates $<100 \mathrm{um}$. Protozoa physiology is controlled to a great extent by available water, since the maintenance of proper osmotic conditions is critical to a unicellar organism. Protozoa are thought to be important predators of soil bacteria, and in this way they affect the cycling of important soil nutrients (Lousier and Bamforth, 1990).

Protozoa in this study were identified to the phylum or subphylum level. Most probable number counts were expressed for flagellates, ciliates, and amoebae as number of organisms $\mathrm{g}^{-1} \mathrm{dry}_{\text {soil. }}$

\section{2) Nematodes}

Nematodes, also called roundworms, are a group of ubiquitous soil organisms that move through the soil via water films. As with protozoa, soil water is a critical factor in their distribution. The taxonomy of free-living nematodes is not well documented (Freckman and Baldwin, 1990), primarily because much of the available work has been targeted at crop pests. Nematodes occupy a great variety of niches in the soil, acting as predators of soil arthropods, bacteria and other nematodes, fungal feeders, plant root feeders, and parasites of invertebrate and vertebrate hosts.

For this study, nematodes were classified into four functional groups:

a) Bacterial Feeders;

b) Fungal Feeders;

c) Ominivore/Predators, and

d) Plant Feeders.

Functional group determination is based on body morphology and mouth parts.

All nematode functional group data were expressed as counts of organisms $\mathrm{g}^{-1} \mathrm{dry}$ soil.

\section{3) Soil Arthropods}

Soil arthropods comprise a vast array of invertebrate groups and species. Some of the representative taxa encountered in this study are insects, crustaceans, arachnids (soil mites and spiders), and myriopods (centipedes, millipedes). Arthropods were analyzed both taxonomically and by functional groups for this study. Taxonomy resolution depended on class of organisms analyzed, from family/genus for most of the collembola and mites, to order for many of the remaining groups. All organisms were classified into the following functional groups:

a) Fungivore 1 - this was a count of all the collembola in the sample - this insect class was determined separately from other fungivores because of their predominance in this functional group;

b) Fungivore 2 - all other fungivores;

c) Total Fungivores - Count of fungivore 1 + fungivore 2; 
d) Detritivore 1 - small detritivores;

e) Detritivore 2 - large detritivores;

f) Total Detritivores - Count of Detritivore 1 + Detritivore 2;

g) Arthropod predators;

h) General predators;

i) Total predators - arthropod predators + general predators; and

j) Herbivores - Root Feeders.

Total counts were made of the various mite genera because finer taxonomic resolution was possible for these groups.

All arthropod counts were expressed as number of organisms $\mathrm{m}^{-2}$. However, counts on an area basis are rough approximations, because sample areas are very difficult to define in the rocky soils of the Site.

\section{HYPOTHESES}

$\mathrm{H} 1$ Soil invertebrate community structure is not related to above-ground plant community structure.

$\mathrm{H1}_{\mathrm{A}}$ Soil invertebrate community structure is related to above-ground plant community structure.

Soil microhabitats are related to the type and quantity of vegetation and litter cover on a site. Soil invertebrate communities would be expected to reflect vegetation communities, although the relationship may not be simple or direct.

$\mathrm{H} 2_{0} \quad$ Soil invertebrate functional groups are related to plant community type.

$\mathrm{H} 2_{\mathrm{A}} \quad$ Soil invertebrate functional groups are not related to plant community type.

Invertebrate functional groups would be expected to be related to the type and quantity of vegetation carbon substrate available (foliage, litter and roots) for herbivores and detritivores. Fungivores and bacterial feeders are related to soil microbial communities, which are correlated with soil carbon and root activity. Omnivores and predators then feed on taxa in these lower trophic levels.

$\mathrm{H} 3$ Invertebrate functional groups will not be related to levels of soil carbon, nitrogen, phosphorus, available moisture and depth.

$H 3_{A}$ Invertebrate functional groups will be related to levels of soil carbon, nitrogen, phosphorus, available moisture and depth.

Functional groups are related not only to carbon source, but also to availability of mineral nutrients and available water. Although soil invertebrates are often adapted to dry soil conditions, numbers and activity increase considerably in surface horizons with increases in soil moisture. This hypothesis will be explored in future data analysis activities.

$\mathrm{H}_{\mathrm{o}} \quad$ Variation in soil invertebrate populations will be greater within-a-season (on average) than between seasons, within the same year.

$\mathrm{H}_{\mathrm{A}} \quad$ Variation in soil invertebrate populations will be greater between seasons (on average) 
than within-a-season, within the same year.

At this time, data are not available to evaluate within or between season trends, but the proposed 1995 sampling program will provide the necessary data for these comparisons.

$\mathrm{H5}_{0} \quad$ The distribution of soil invertebrate taxa will not differ by soil depth.

$H 5_{\mathrm{A}} \quad$ The distribution of soil taxa will differ by soil depth.

Soil invertebrate activities are very moisture dependent; this is often reflected in their distribution in the profile. Organisms adapted to drier conditions are often found closer to the surface, while more intolerant organisms utilize deeper, wetter areas, or migrate to such areas as the profile dries out.

\section{SAMPLING SITES}

Soil samples from 0-5 and 5-10 cm depths were collected from 12 EcMP terrestrial sites (TR01TR12) in the Buffer Zone (see Figure 1, Technical Summary) and from 12 plots (5 samples/plot) in OU 11. The twelve EcMP sites are broken into five community types: mesic mixed grasslands, xeric mixed grasslands, reclaimed grasslands, riparian north (north side of stream), and riparian south (south side of stream). Sites were sampled in random order within a community type. That is, a single site within each community type was randomly selected (yielding five sites), and the process was repeated (once a site was selected, it was not replaced in the potential sampling pool) until all potential sample areas were selected. Sample selection was conducted in this way to prevent confounding time and community location effects

\section{SAMPLE BREAKDOWN}

Three-hundred and forty soil invertebrate samples were collected from the 12 EcMP sites. The sampling at a single site consisted of a separate arthropod sample at both depths and a protozoa + nematode sample at both depths; samples were composited from five transect locations on the ECMP TR sites. The north and south sides of riparian areas were sampled separately because all variables measured were expected to have greater variation than grassland sites. A total of 85 ECMP TR transects were sampled, including QA sarnples.

Two hundred and sixty-four samples were also collected from 12 OU 11 sites to support the Environmental Evaluation being conducted there by Ecology staff. The results of that study are reported in Appendix I. OU 11 Ecological Effects.

\section{SCHEDULE}

\section{1) Field Sampling}

Soil samples for invertebrate analysis were collected from mid-August 1993 until the end of September. Samples were collected by EcMP staff and subcontractors under EcMP supervision. All invertebrate samples were collocated with ecosystem function and soil physical and chemical samples.

\section{2) Laboratory Schedule}

All samples were delivered to the University of Northern Colorado Biology Laboratory by September 30,1993 . This laboratory is under the direction of Dr. John Moore, a prominent soil invertebrate ecologist. Protozoa and nematode data were delivered in 1994. Arthropod 
identifications took much longer, and the final data were not delivered until March, 1995.

\section{METHODS}

\section{1) Field Methods}

At grassland sites, soil samples were collected on a transect basis; a single sample was a composite of five subsamples from randomly located quadrats along the transect. In riparian areas, a single soil sample was a composite of three subsamples collected randomly along the transect. All random locations were determined from randomly generated $X$ and $Y$ coordinates, with the field transect serving as the $X$ axis. All samples were collected with hand tools after coring tools proved futile in the stony soils at the Site. Samples were placed in labeled plastic bags and transferred to coolers with blue ice. Coolers were stored in the locked EG\&G Biota trailer (T891G) until information was logged onto chain-of-custody forms and samples shipped to the laboratory. Detailed procedures can be found in the September 29, 1993 EG\&G report entitled: Ecological Monitoring Program Program Management/Technical Performance Report (93-RF-11615).

\section{2) Laboratory Methods, Quality Assurance/Quality Control}

After soil samples were delivered to the laboratory, they were immediately extracted or plated. Dynamic extraction was used for nematodes and arthropods; the sample was slowly dried out and the living organisms were forced to migrate either freely or in water films into an extraction vial. Organisms were then viewed under a binocular microscope, where they were counted and identified. Protozoa were plated out in a series of dilutions, and then identified and numbers estimated by most probable number counts. Quality assurance was provided by the use of standard published methods, collection of duplicate field samples and the use of a reference collection for the arthropods.

\section{DATA MANAGEMENT}

All qualifying field data, such as dates, locations and technician names, were recorded on field forms and chain-of-custody forms. These data were entered electronically and then merged with laboratory results using the common observation number (obsnum) identifier. Data are undergoing final proofreading steps before inclusion into the EcMP and Sitewide Ecological databases.

\section{RESULTS}

\section{1) Statistical Approach}

A two factor Analysis of Variance (ANOVA) model was used to evaluate the effect of community and depth on soil invertebrates. A significant community effect indicates that at least two of the community means are significantly different. A significant depth effect indicates that the means of the $0-5$ and the $5-10 \mathrm{~cm}$ depths are significantly different. This model detected if there were significant differences in invertebrates among communities (five levels: xeric grassland, mesic grassland, reclaimed grassland, riparian north side of stream, and riparian south side of stream), and by depth (two levels, $0-5 \mathrm{~cm}$ [surface] and $5-10 \mathrm{~cm}$ [subsurface]). The model also detected if there was a significant community-by-depth interaction. Variables analyzed in this model included the three protozoan phyla counts, the nematode functional group counts, and the arthropod functional counts.

In addition to the above model, a one-way ANOVA was run with Site as the factor (site means are 
calculated from values from both depths). A significant site effect indicates that at least two of the fourteen or fifteen sites are significantly different. There are eight or nine grassland sites, and three riparian sites, each with a north and south side (protozoa data are not available for site TR07, a reclaimed grassland site). Caution must be used in the interpretation of a significant site effect, because differences may simply reflect sampling time. It was impossible to collect all samples from all sites at the same time, and differences may reflect varying site conditions of vegetation phenology and soil moisture over the 1-month sampling period.

The assumptions of an ANOVA model do not always hold for count data because of the large variability in these data. Numbers of individuals in the same factor level may range from 0 to values in the thousands. Variances among group means are often not equal; although this does not necessarily disqualify the robust ANOVA model. Also, as sample sizes of each factor level mean increase, the sample tends to become normally distributed. Community level means had sample sizes of $20-30$ observations, depth means had 70 observations, and site means had 10 observations; these sample sizes are generally considered to be moderate to large. Most of the residuals that were examined in the analyses were normally distributed, lending credence to this model. If a significant main effect was found, means were separated by the conservative Tukey honestly significant difference (HSD) method, which produces wide confidence intervals, making it more difficult to detect statistically significant differences than other means separation procedures, such as Duncan's or LSD.

An alpha level ( $\alpha$ ) of 0.10 was generally used to consider if an effect was statistically significant; this is appropriate for such variable data.

Results are presented for protozoa phyla, and nematode and arthropod functional groups. Initial taxonomic analyses were performed for two arthropod groups.

\section{2) Protozoa}

Surface horizons are dominated by amoebae and flagellates, with mean values of 6799 and 6776 organisms $\mathrm{g}^{-1}$ soil respectively, all samples. Ciliates are much less abundant, with a mean of 34 ciliates $\mathrm{g}^{-1}$ soil. These data are extremely variable, especially the amoebae and flagellate data, with count values ranging from a few dozen to tens of thousands. These same general relationships hold for the subsurface horizon, except that all counts are less than the surface horizon (5126 amoebae $\mathrm{g}^{-1}$ soil, 5269 flagellates $\mathrm{g}^{-1}$ soil, and 14 ciliates $\mathrm{g}^{-1}$ soil, all samples).

The two factor ANOVA for amoebae, flagellates, and ciliates are presented in Tables E-1, E-3, and E-5. Site effects are presented in Tables E-2, E-4 and E-6. Summary statistics are also presented in these tables by community type, depth and site, respectively. The number of observations within factor levels was often not equal, because the plating technique failed for some samples. No data are available for site TR07.

Amoebae numbers showed a significant community effect at the $\alpha=0.1$ level $(p=0.0954$, Table $E$ 1). The north side of the riparian community type (riparian north) had the highest mean numbers of amoebae, (mean 9865 amoebae $\mathrm{g}^{-1}$ dry soii), followed closely by riparian south (6533) and xeric types 5999), while the mesic and reclaimed community types had the lowest means (3194 and 3310 respectively)[Figure E-1]. The riparian north and mesic community types were significantly different at the $\alpha=0.1$ level. Although there were more amoebae in the $0-5 \mathrm{~cm}$ layer than the $5-10$ (means 6799 vs. 5126), the difference was not statistically significant.

Amoebae numbers also showed a significant site effect $(p=0.0546)$. The north side of TR05 had a significantly higher mean count (15444 amoebae) than TR09 $($ mean $=369)$ at an $\alpha$ of 0.1 (Table E-2, Figure E-2). 
Flagellate numbers showed a highly significant community effect $(p=0.0113)$, with the riparian north community showing the highest mean count $\left(13,239\right.$ flagellates $\mathrm{g}^{-1} \mathrm{dry}$ soil), followed by riparian south, reclaimed, xeric and mesic communities (Table E-3 and Figure E-3). As with amoebae, there were more flagellates in the $0-5 \mathrm{~cm}$ layer than the $5-10$ although the difference was not significant.

Flagellate counts also showed a highly significant site effect $(p=0.0007$, Table $E-4)$, with the north side of TR05 (TR05N) being significantly higher than most of the other sites (Figure E-4).

Neither community, depth, or site effects were significant for soil ciliate numbers, although the pattern of community counts was similar to those for amoebae and flagellates (Tables E-5 and E6). The patterns of residuals on these analyses did not appear to be normally distributed in some cases (community), and the model may not be appropriate for ciliate data.

\section{3) Nematode Functional Groups}

Bacterial and fungal feeding nematodes dominated other functional groups in the surface $0-5 \mathrm{~cm}$ (4846 and 4264 nematodes $\mathrm{g}^{-1}$ soil, respectively, all samples). Mean plant feeder counts were ranked next ( $988 \mathrm{~g} \mathrm{~g}^{-1}$ soil ), followed by omnivore/predators ( $803 \mathrm{~g} \mathrm{~g}^{-1}$ soil ). On the average, a single $\mathrm{g}$ of dry soil $(0-5 \mathrm{~cm})$ harbors approximately 10,901 nematodes. Average subsurface nematode functional group distribution follows the same general trend, except that bacterial feeder, fungal feeder, and plant feeder numbers all diminish with depth; omnivore/predator counts are relatively insensitive to depth. Subsurface means are: 3848 bacterial feeders; 3147 fungal feeders; 485 omnivore/predators, and 982 plant feeders $\mathrm{g}^{-1}$ soil.

Four nematode functional groups were analyzed using the same ANOVA model used for protozoa. As before, treatment means are not always balanced because of extraction failures. Sites TR05 north and south had only 5 observations each, rather than the normal 10 .

In general, bacterial feeding nematodes had the highest average count (4351 nematodes $\mathrm{g}^{-1} \mathrm{dry}$ soil, $0-10 \mathrm{~cm}$ ), followed by fungal feeders (mean 3710 ), plant parasitic (mean 985 ) and omnivore/predators (mean 645). If all functional groups are summed, an average gram of dry soil contains 9691 nematodes $(0-10 \mathrm{~cm}$ depth).

None of the functional group populations had a significant community effect at an $\alpha$ of 0.1 (Tables $E-7, E-9, E-11$, and $E-13$ ), although fungal feeders, bacterial feeders, and omnivore/predator functional groups were all significant at $p$-values slightly higher than $\alpha=0.1$ (fungal feeders $[p=.1136]$, bacterial feeders [ $p=.12]$, and omnivores/predators $[p=0.12])$. Omivores/predators showed a significant depth effect, with significantly more in the $0-5 \mathrm{~cm}$ layer (mean count $=803$ ) than the $5-10 \mathrm{~cm}$ layer (mean $485, p=0.0197$ ). All functional groups had higher $0-5 \mathrm{~cm}$ layer means.

All four nematode functional groups showed a significant site effect at an $\alpha$ of 0.1 (Tables E-8, E$10, E-12$, and $E-14$ ). For fungal feeders, site means ranged from a high of 8649 (TR11) to a low of 616 (TR01, Figure E-5). Most of the 15 site means from 2000 to 6000 fungal feeders per $g$ soil and were not significantly different.

For bacterial feeders, two sites, TR06 and TR11, had significantly more nematodes (means 10,649 and 8358 respectively, Figure E-6) than most of the other sites.

The omnivore/predator group generally had the lowest counts and highest variability of all the functional groups. Abundance values ranged from mean site counts of 1401 (TR10S) to 124 nematodes $\mathrm{g}^{-1}$ soil (TR03S). This large variability increased the site confidence intervals, and most of the site means were not significantly different from each other (Figure E-7). 
Plant feeder nematode counts ranged from 1693 nematodes in site TR05N to 173 in site TR09. Site means for TR05N and TR07 were significantly different than many of the other sites (Figure E8).

Nematode functional group numbers showed a much more individual affinity for community types that did the protozoa. That is, a community type might have very high numbers of one functional group and very low numbers of another. For example, xeric communities had the lowest mean number of plant parasitic nematodes, but the highest mean number of bacterial feeders. Community ranking seems to be related to the functional group studied, and multivariate techniques will be used to further explore these relationships in the future.

\section{4) Arthropods}

\section{Functional Groups}

Arthropod numbers were dominated by the total fungivore functional group in the surface $0-5 \mathrm{~cm}$, with 3645 fungivores $\mathrm{m}^{-2}$, all samples. Small detritivores (detritivore 1) were the fewest in number (mean $140 \mathrm{~m}^{-2}$ ), but total detritivores were numerous (mean, $1704 \mathrm{~m}^{-2}$ ). Total predators were the fewest of these three functional groups (mean $\left.874 \mathrm{~m}^{-2}\right)$, as expected. Within surface horizon mite taxa, the Prostigmata were the most numerous (mean $3209 \mathrm{~m}^{-2}$ ), and the Astigmata the least (207 $\left.\mathrm{m}^{-2}\right)$. These same relative relationships hold for the subsurface horizon, but all functional group and taxa counts were fewer than the surface horizon.

Arthropod numbers were analyzed on both a taxonomic and functional group basis, although the two are often closely related (a functional group is often dominated by a particular taxon). A total of ten functional groups were analyzed, including the calculated variables of total fungivores, total detritivores, and total predators. Two families of mites were also analyzed for richness (number of families represented in a sample); all analyses used the same ANOVA models previously discussed.

Fungal feeder group 1 is comprised exclusively of seven families of collembolan insects. Community, depth, and community $x$ depth interactions were all significant at $p=0.1$ (Table $E-15$, Figure E-9). A significant interaction indicates that only simple effects, such as the comparison of two communities at a single depth can be evaluated. In general, the examination of simple effects were not explored because the more general questions stated in the hypotheses were of greater ecological significance.

Differences in site fungal feeder 1 means were highly significant ( $p=0.00$, Table $E-16$, Figure $E-1$ ). Four sites had mean values of 0 and 7 out of the 15 sites had mean counts less than 100 . Site TR05S had the highest mean count of 3213 fungal feeders 1 .

Fungal feeder group 2 included all other fungal feeders, primarily prostigmatid mites. The community effect was not significant $(p=0.2919)$, but the difference in distribution by depth was highly significant $(p=0.0003$, Table $E-17$, Figure $E-11)$. These feeders were more than two times more abundant in surface than subsurface soil.

The site effect was also not significant for this functional group $(p=0.4255$, Table $E-18)$.

Total fungivores (Table E-25) showed the same pattern as fungal feeders 1, with community, depth, and community $x$ depth interactions all significant $(p=0.0339,0.0001$, and 0.0587 , respectively). Again, the significant interaction confounds the interpretation of main effects.

Detritivore group 1 was a mixed group of small invertebrates from insecta, crustacea, and myriopoda taxa. They were few in number, but showed a highly significant community effect 
( $p=0.0001$, Table $E-19)$. The southern riparian site was significantly greater in mean detritivore 1 abundance than the grassland sites (Figure E-12), although the northern riparian areas were not.

Detritivore group 1 also showed a significant site effect (Table E-20, Figure E-13). Site TR10S had a significantly higher mean abundance of detritivores than all other sites.

Detritivore group 2 was primarily cryptostigmatid mites; this group generally exceeded group 1 detritivores. The ANOVA produced similar results to the analysis of detritivore group 1 , with a significant community effect (Table $E-21, p=0.0454$ ), and a similar ordination of communities (Figure E-14).

This functional group did not show a significant site effect $(p=.1925$, Table E-22). Site mean counts varied considerably, from 49 to 4605 , but variances were also high and shadowed significant effects.

Total detritivore (the sum of groups 1 and 2 ) abundance also had a significant community effect (Table $E-23, p=0.0208)$, and the depth effect was nearly significant at the $\alpha=1$ level $(p=0.1095)$. Again, the riparian south community type was significantly higher than three of the other communities (Figure E-15).

Total detritivore counts showed a significant site effect $(p=0.077$, Table E-24). Site TR10S was significantly different than all other sites (Figure E-16), similar to the results of the detritivore 1 analysis.

The three functional predator groups, general predators, arthropod predators, and total predators, showed significant community and depth effects (Tables E-27, E-29, and E-31). General predators also showed a significant community by depth interaction $(p=0.0762)$ and main effects were not further investigated. All surface soils had higher predator counts than subsurface soils. Community means typically showed that riparian areas had higher counts than grassland areas, but arthropod predators in reclaimed communities were significantly greater than riparian and most grassland communities (see Figures E-18 and E-20).

All three of the predator functional groups showed significant site effects (Tables E-28, E-30, and E-32). General predator mean counts were higher in both TR05 sites than most other sites (Figure E-17); arthropod predators were more numerous in TR07 and TR10S than most other sites (Figure E-19), and total predators were higher in sites TR05S and TR06 than other sites, but most mean comparisons were not significantly different at.

Arthropod herbivores showed both significant community and depth effects (Table $E-33, p=0.0031$ and 0.0309 respectively). As with arthropod predators, herbivores were also greater in the reclaimed community type, with the other communities showing similar means (Figure E-22). Site differences were also highly significant ( $p=0.00$, Table $E-34$ ), with site TR07 being significantly greater than all other sites (Figure E-23).

\section{Taxonomic Analyses}

Preliminary taxonomic analyses were conducted on two mite taxa that had sufficient resolution. The Cryptosigmatid mites were identified to 10 superfamily groups, and the Prostigmatid mites were identified to 12 family groups. The total number of superfamilies (Cryptostigmata) or families (Prostigmata) present in each sample were then calculated; this sum is referred to as richness.

Cryptostigmata richness showed significant depth and community $x$ depth interaction effects. Richness was higher in the $0-5 \mathrm{~cm}$ layer, but community types showed relatively small differences, ranging from 1.60 to 2.0 superfamily groups (Table $E-35$ ). Differences among sites were significant $(p=0.0002$, Table $E-36)$, and richness values ranged from 0.4 to 3.1 . 
Prostigmatid mite richness was not different by community type, but the $0-5 \mathrm{~cm}$ layer mean richness was greater than the $5-10 \mathrm{~cm}$ layer (mean 4.9 versus 4.1 families, $p=0: 0392$, Table $E-37$ ). Richness differences in the site factor were highly significant $(p=0.000$, Table $E-38)$, with sites TR02, TR06 and TR07 having the highest values. Interestingly, these sites represent mesic, xeric and reclaimed grassland community types.

\section{DISCUSSION}

The results presented investigate the effects of three major factors on distributions of soil invertebrate populations: community type, depth, and site differences.

Analysis of community differences was conducted on the three major groups of soil invertebrates: protozoa, nematodes, and arthropods. Community analysis can provide several levels of information that will answer questions such as:

1) Do community populations differ (that is, are at least two community means significantly different)? If they do, then general statements can be attributed to average values and variances associated with community types; if no community types differ, such statements cannot be made;

2) If some communities differ (a significant community effect), then how different are they? Are the relatively undisturbed xeric grassland types significantly different than the more disturbed reclaimed and mesic grassland types? Are riparian types different than grassland types? If significant differences are apparent between several community types and patterns of differences emerge, statements regarding community differences can then be further refined;

3) Are some of the variables analyzed more sensitive to the community effect than others?; and

4) If differences occur, what causes them?

Seventeen functional group variables were analyzed for community differences, and the significance of community effects are summarized in Table E-39. Eleven of the 17 variables showed a significant community effect; 3 of the 11 significant variables also showed a significant depth by community interaction, so that statements regarding the main effect of community must be made with caution. The remaining community discussion will deal only with the 8 variables that showed a statistically significant community effect $(\alpha=0.10)$ and no significant interaction term. These include amoebae, flagellates, and 6 arthropod functional groups (none of the nematode functional groups showed a significant community effect). Although there was an overall community effect in these cases, many of the means of the five community types were not statistically significantly different from each other. For instance, $90 \%$ confidence intervals for xeric and mesic grassland community types overlapped for all eight variables, indicating that these community types cannot be differentiated by the data here. The xeric community type had higher protozoa counts than the mesic type (up to 2 times greater) and four of the six xeric mean arthropod variables were higher than mesic types, yet means could not be differentiated because of high variability in these data.

The remaining grassland community, reclaimed grassland, showed surprisingly high arthropod predator and herbivore means, being statistically different at $\alpha=0.10$ than almost all other community types (see Figures E-18 and E-22). It appears that this community type can be distinguished from all others by these variables.

The riparian north community type had the highest rnean protozoa counts; the flagellate population in the riparian north type was significantly different than mesic and xeric grassland types, and the amoebae population in the riparian north type was significantly different than the mesic grassland type. Riparian community types were also higher for all arthropod detritivore functional group means than the other community types. The riparian south type could be distinguished from all grassland types by detritivore group 1 and total detritivore functional groups. Several other 
arthropod functional groups that did not show a statistically significant community effect also had the highest mean counts in these types (fungal feeder 1 , total fungivore, and general predators groups). Thus, it appears that in general, riparian community types often have the highest protozoa and arthropod populations, which are statistically different in some cases from all grassland community types. It is interesting to note that riparian north and south community types were not significantly different for any of the variables analyzed. However, for some variables, only the north or the south side (but not both) showed significant differences from grassland community types.

None of the nematode functional groups showed significant community differences, and no trends in ranking of community means was apparent.

Depth was evaluated as a factor at two levels: $0-5 \mathrm{~cm}$ and $5-10 \mathrm{~cm}$. The surface layer was sampled with intact vegetation and also included litter, so it would be expected to have a greater diversity of microhabitats for the various taxa, which might translate to a greater diversity of functional group members. All surface layers had higher mean counts for all functional groups and mite richness values, but differences were only statistically significant for soil arthropods. Of those functional groups that had statistically significant depth differences, only four did not have significant depth $x$ community interactions (fungal feeders 2 , arthropod predators, total predators, and total herbivore groups, Table E-39). In those cases, the surface soil had approximately two times more organisms than the subsurface horizon.

Site was explored as a factor to see if the $12 \mathrm{EcMP}$ sites could be distinguished from one another through several functional variables. Many of the questions regarding this factor are similar to the analysis of community effects. Ideally, the "natural" or noncontaminated (in the CERCLA sense) distributions of soil invertebrates can be discerned from site-to-site. It would be expected that contaminated sites have very different distributions than these natural sites, although this can only be evaluated through contaminant treatments. And if sites are significantly different, how different are they? It would be expected that sites from the same community types to be more similar than sites from other community types; does this relationship hold?

As previously discussed, significant site differences must be interpreted with caution because of the possible confounding effect of sample timing on the results.

As with community analysis, three major taxa (protozoa, nematodes and arthropods) were analyzed by functional groups and two mite taxa richness classes for site effects. Seventeen functional group analyses were conducted for these taxa; thirteen showed a significant site effect at an $\alpha=0.10$ level (Table E-39). This included two of the three protozoa, four of four nematode functional groups, and seven of the ten arthropod functional groups. Both Cryptosigmatid and Prostigmatid mite richness values also showed significant site differences (Table E-36 and E-38).

Protozoa showed a general site trend, with highest mean counts of amoebae and flagella in the TR05 sites (Walnut Creek), and the remaining sites clustered together (Figure E-2 and E-4). The TR05N site was significantly higher in flagellate counts than all grassland sites.

Nematode population site means generally fell into two site groupings; group one consisted of a few sites that were significantly greater than all other sites, which constituted group 2 (Figure E-5 through E-8). A riparian site functional group mean was always ranked as one of the greatest three of fifteen possible site means for the four functional groups, and was also ranked as one of the lowest three mean values for 3 functional groups. Omnivore/predators were the only functional group that did not have any significant differences between any of the grassland sites. For fungal feeders, the TR11 mean abundance (a mesic community type) was significantly greater than TR01, TR02, TR03N and S, TR07, TR10N and S, and TR12. A very similar relationship existed between TR11 and the other site means for bacterial feeders. Site TR07 mean plant parasitic nematode counts were significantly greater than most other grassland sites and two of the riparian 
sites as well. These data illustrate that sites within a particular community type can have significant differences in functional group counts, and that varialion between sites within a community type may exceed site variation between community types.

Arthropod functional groups had more consistent site differences than did nematode functional groups. Site differences were often due to one or more riparian sites having higher mean populations than all other sites. Arthropod predators were the only functional group that had a significant difference between grassland sites (the TR07 mean count was significantly greater than four other grassland sites).

These data have applicability for activities at the Site in several ways. The most obvious application is to determine if adverse ecological effects have occurred as a result of Site activities, be they construction, remediation, or accidental contamination. In the injury definition section of Natural Resource Damage Assessment guidelines (43 CFR 11.62), "concentrations in the soil of substances sufficient to cause a toxic response to soil invertebrates" are specifically mentioned. These data are the beginning of the baseline information that is necessary to determine if injury has occurred.

Soil invertebrate means and $90 \%$ confidence intervals are available for some community types, as measured by several soil invertebrate functional group variables. For other community types where this resolution is not yet available, ranges and variabilities have been established that can guide interpretation of potential injury. For instance, if an area is damaged in some way where injury to ecological receptors is suspected (or claimed by Natural Resource Trustees), soil invertebrate measurements of the area may be taken. If the appropriate organism counts are below the known range of values for the Site, then injury may have occurred. If values fall within the Site range, ecologists may determine if comparisons to appropriate sites are available.

The above scenario assumes that soil invertebrate measurements are collected following the potentially damaging action. However, if injury is suspected as a result of a planned activity, these measurements can be collected both before and after the activity, and information is available to guide these sampling efforts to determine if real differences have occurred.

It is important to realize that the above scenarios are quantitative data exercises, where means and confidence intervals are generated. Therefore, the approach is both defensible and repeatable.

Finally, these data will contribute towards the description and understanding of the Rocky Flats ecosystem. The future use of the Site is becoming an increasingly important topic, and biodiversity values are important factors in land use planning and conservation. Two of Rocky Flats' major neighbors, Jefferson and Boulder Counties, are very interested in the natural value of landscapes, and data reported here can have region-wide applications. Recently, arthropod inventories and assemblages are being used more in such efforts to categorize and prioritize areas for conservation efforts.

\section{FUTURE ANALYSES}

The data presented here deal almost exclusively with soil invertebrate populations, and many relationships remain unexplored at this time. Multivariate community analysis may provide insights into better ways to classify communities and new ways to analyze data. For example, ordinations may show new relationships among sample units that will better distinguish mixed mesic and xeric grassland communities. Soil invertebrate data also must be analyzed relative to many of the other collocated data that were gathered, such as soil physical/chemical properties, ecosystem functions, and vegetation production and composition. Finally, these measurements represent data from a single year and single season, and annual and seasonal variation are unknown. Sampling efforts 
in 1995 will provide new data to answer those questions.

\section{CONCLUSIONS}

Protozoa, nematode, and arthropod data collected in 1993 were analyzed for community, depth, and site effects to assign mean values and confidence intervals from selected variables to particular areas by community classification or other classification means. Eight of seventeen functional group variables (all taxa) showed à significant community effect; riparian community types were significantly different than some or all grassland types when measured by amoebae, flagellate, or arthropod detritivore functional groups.

\section{REFERENCES}

Dindal, D.L., 1990. Introduction, pp 1-14. Soil Biology Guide. Ed. by D.L. Dindal. John Wiley \& Sons. 1349 pp.

EA Engineering, 1991. Terrestrial soil fauna in environmental assessment and environmental management. E.A. Engineering, Science and Technology Division. Sparks, MD.

Freckman, D.W. and J.G. Baldwin. 1990. Nematoda, pp 155-200. In: Soil Biology Guide. Ed. by D.L. Dindal. John Wiley \& Sons. 1349 pp.

Lousier, J.D. and S.S. Bamforth. 1990. Soil Protozoa, pp 97-136. In: Soil Biology Guide. Ed. by D.L. Dindal. John Wiley \& Sons. 1349 pp. 

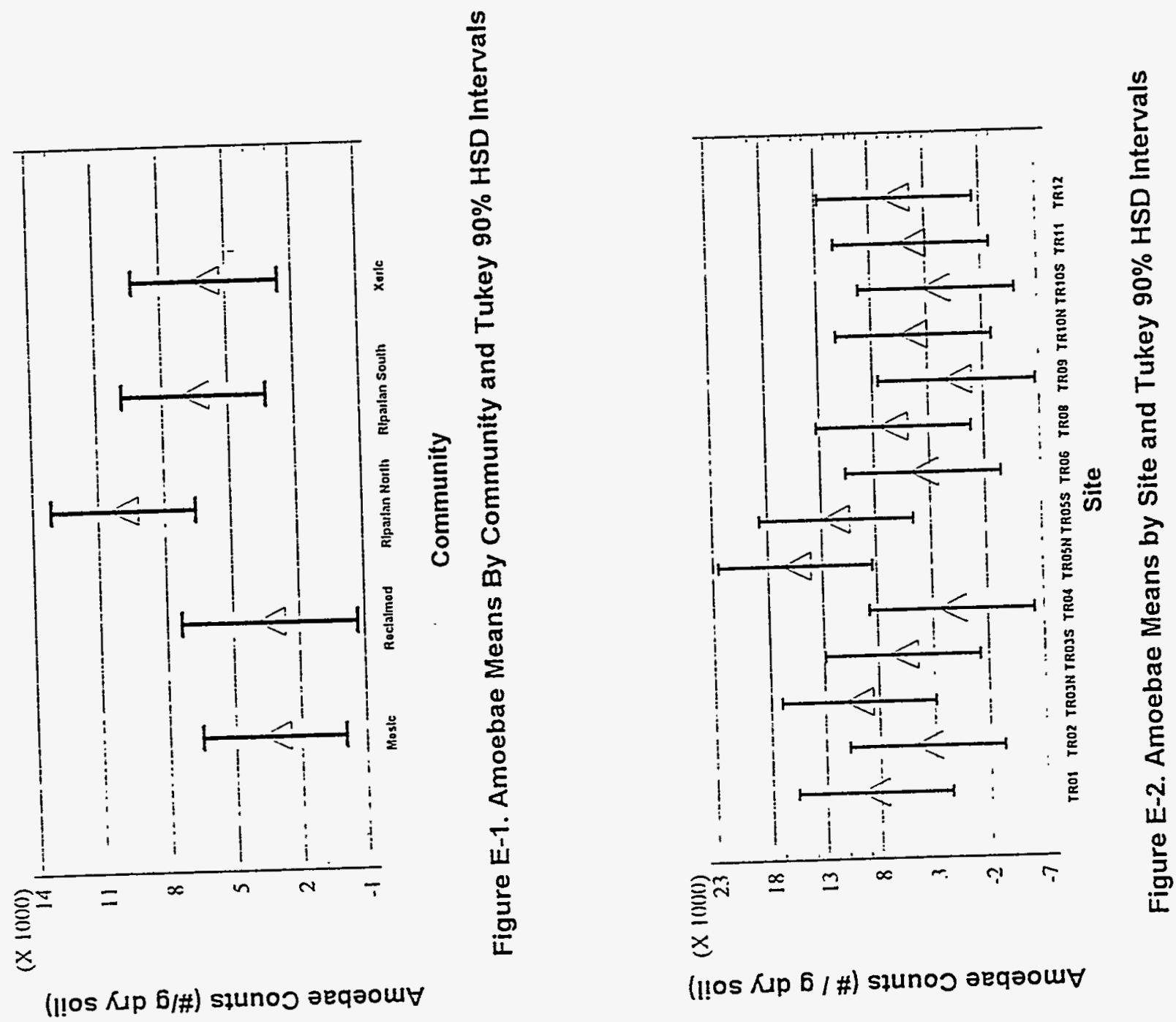


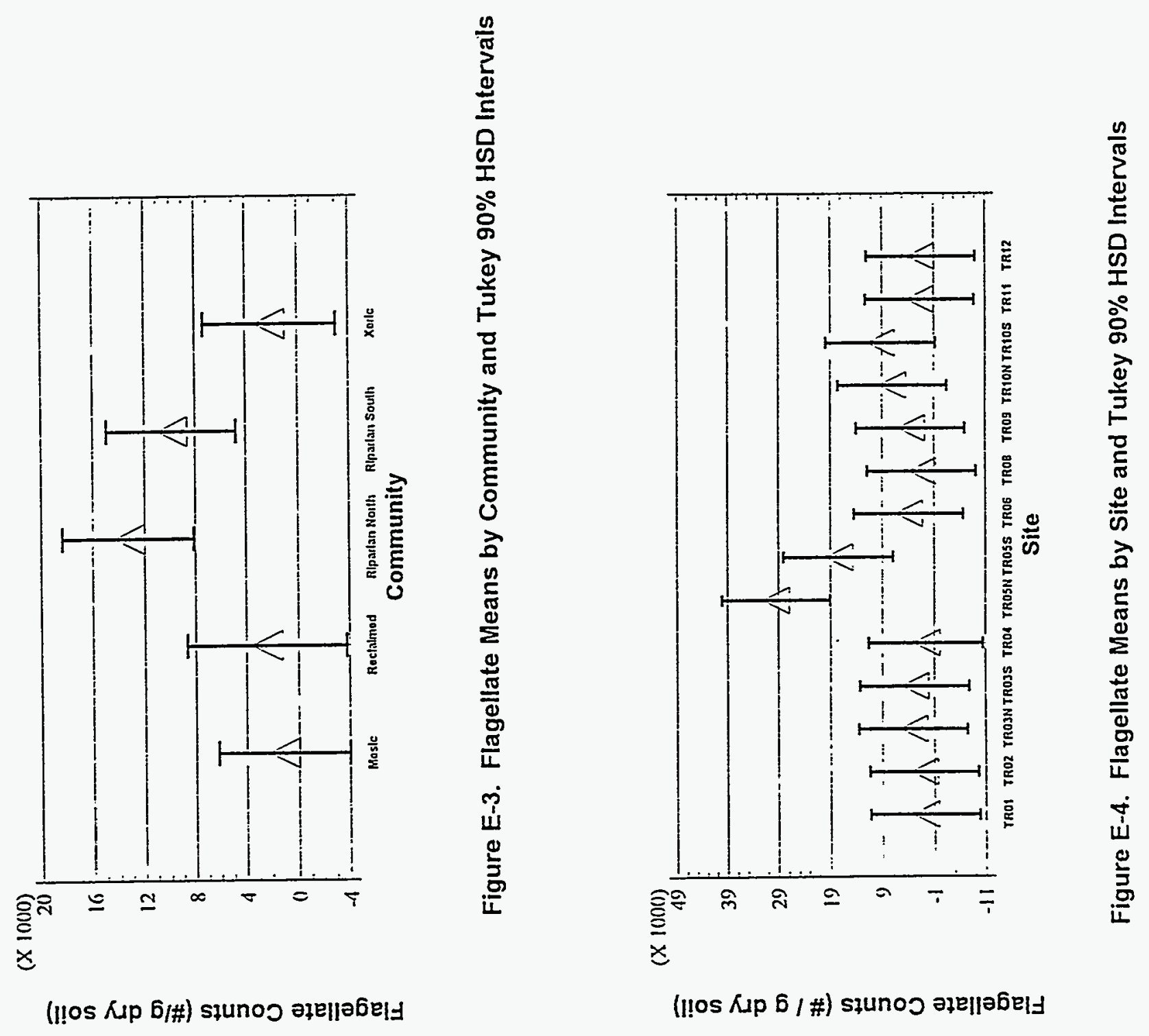



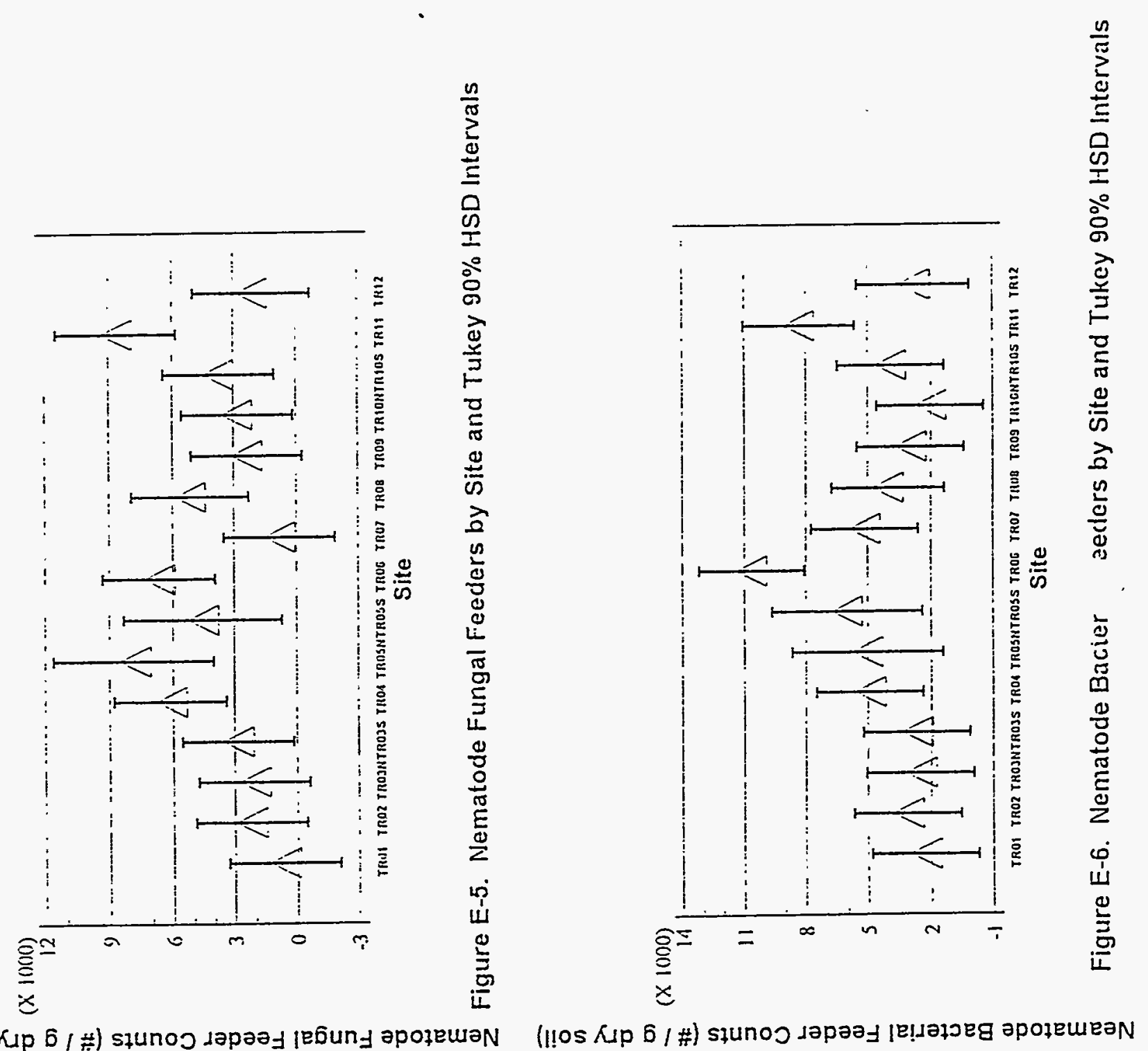


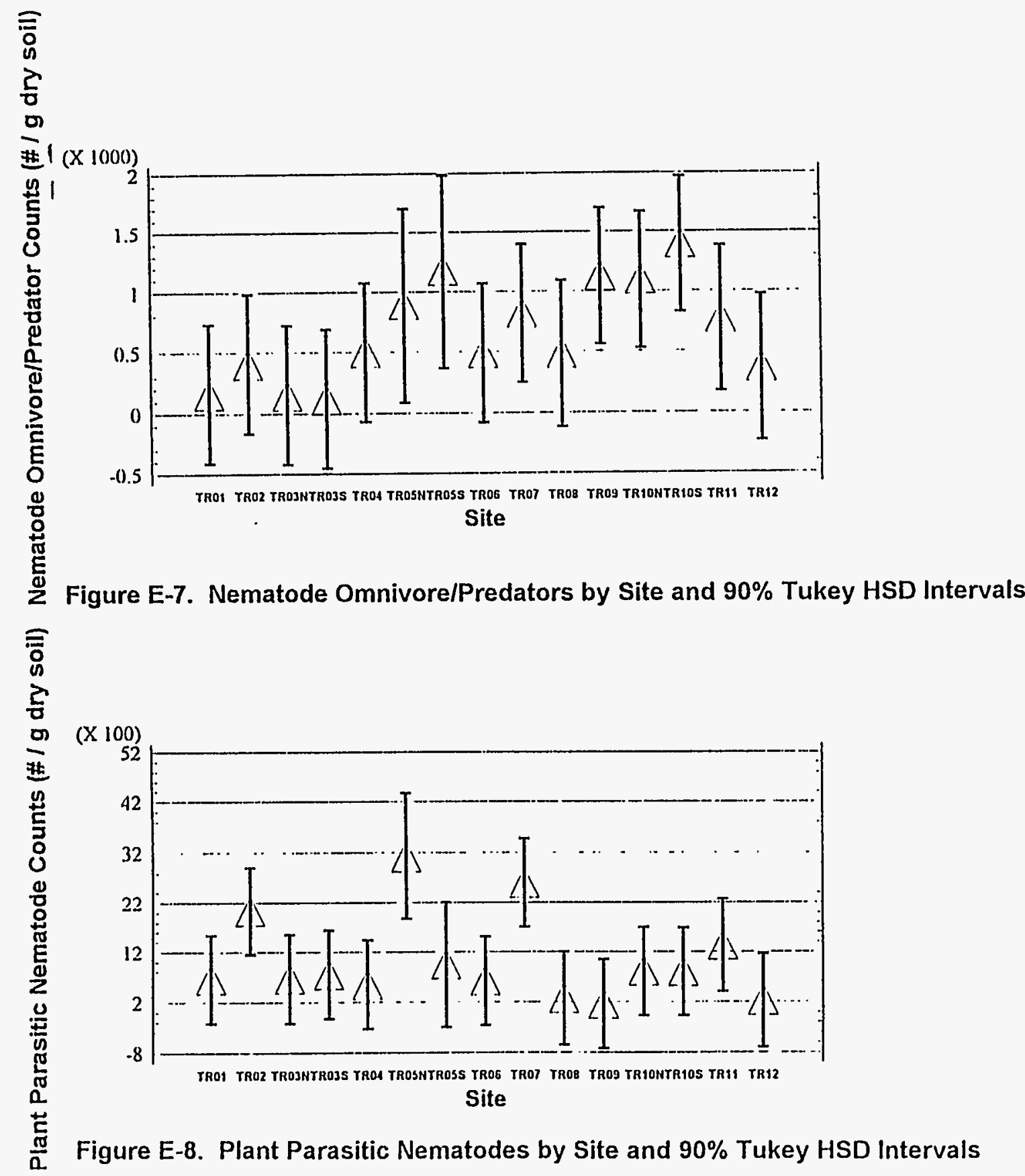




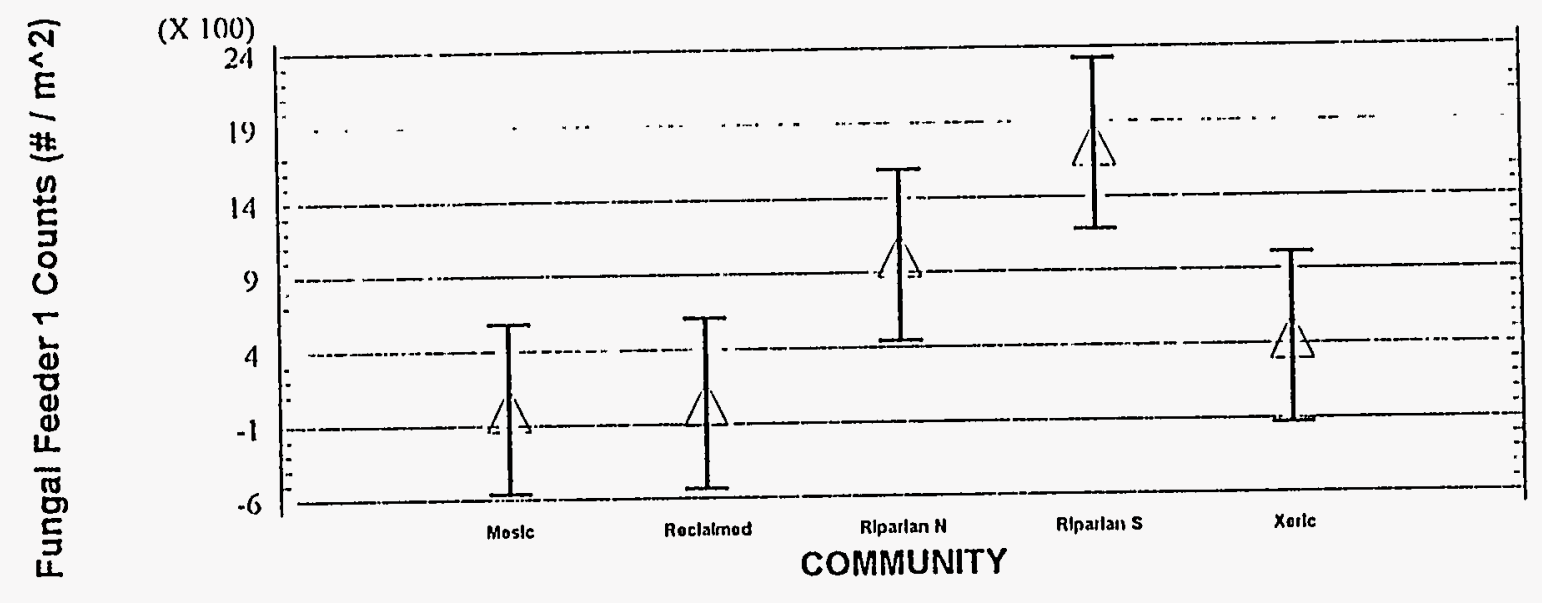

Figure E-9. Arthropod Fungal Feeders 1 Means by Community \& 90\% Tukey HSDIntervals

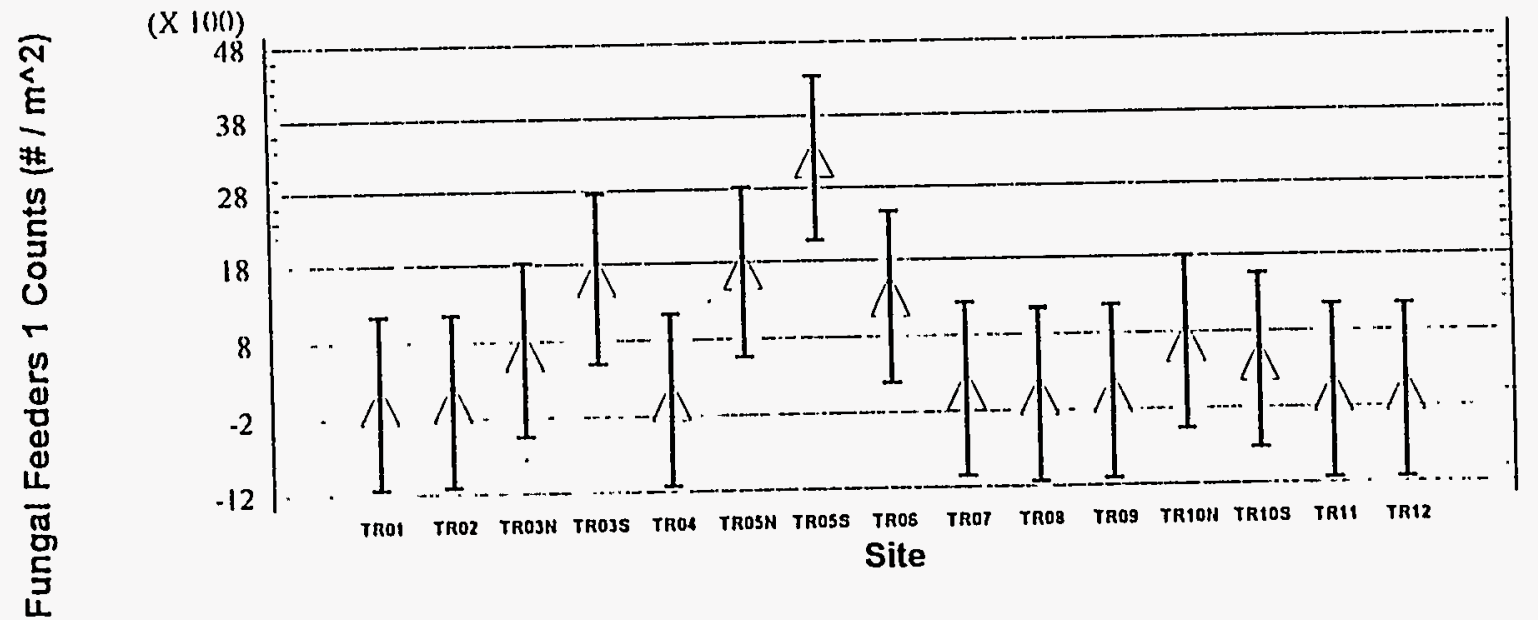




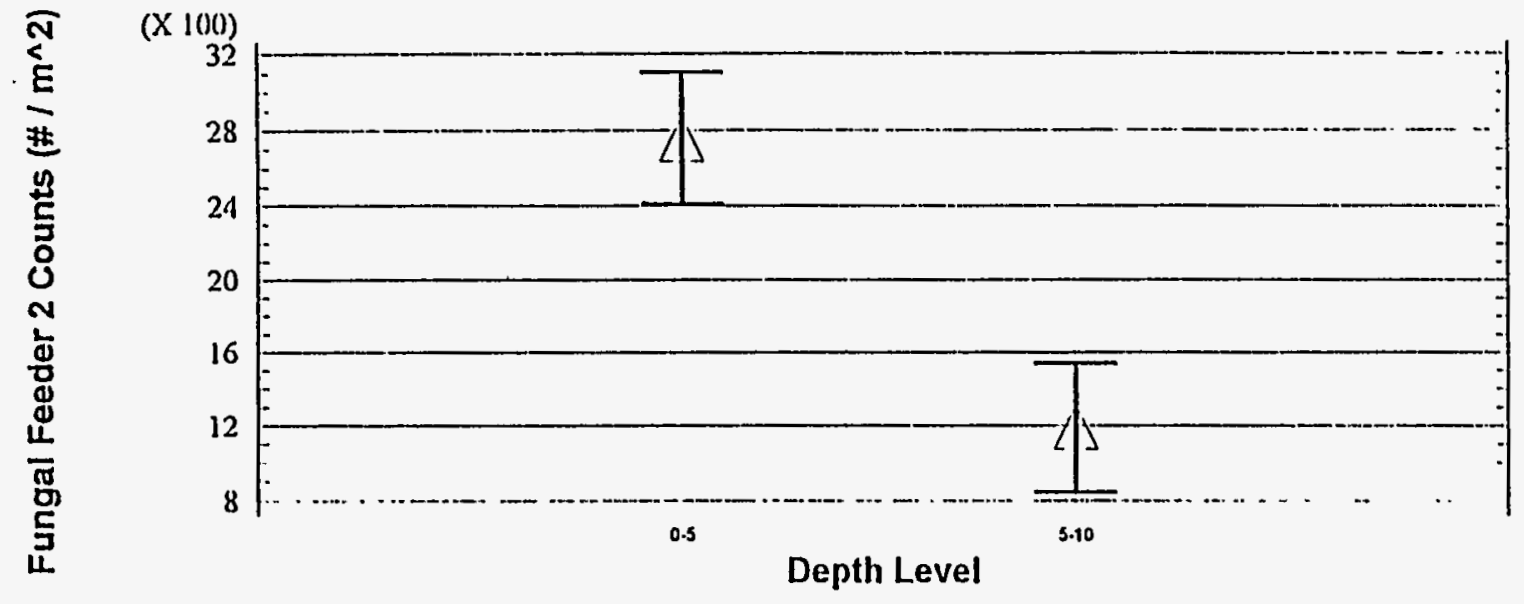

Figure E-11. Arthropod Fungal Feeders 2 by Depth and $90 \%$ Tukey HSD Intervals

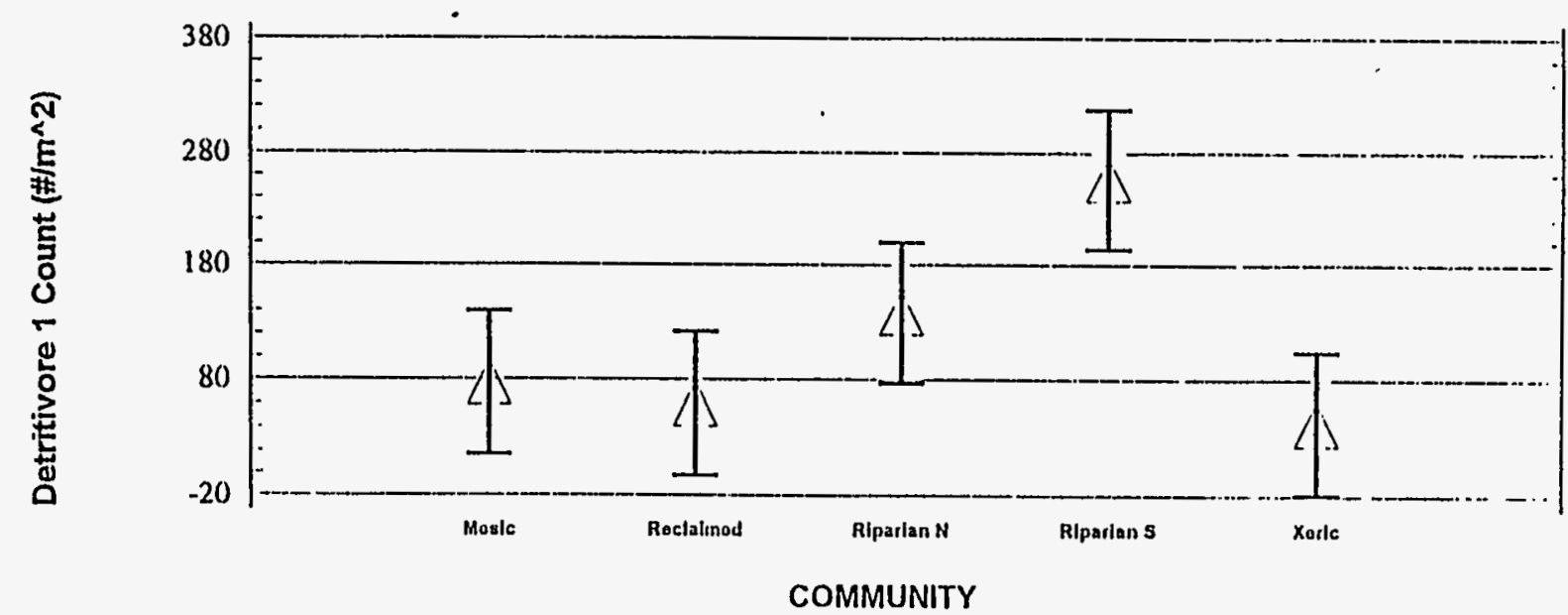

Figure E-12. Arthropod Detritivore 1 Means by Community and Tukey $90 \%$ HSC-Intervals 


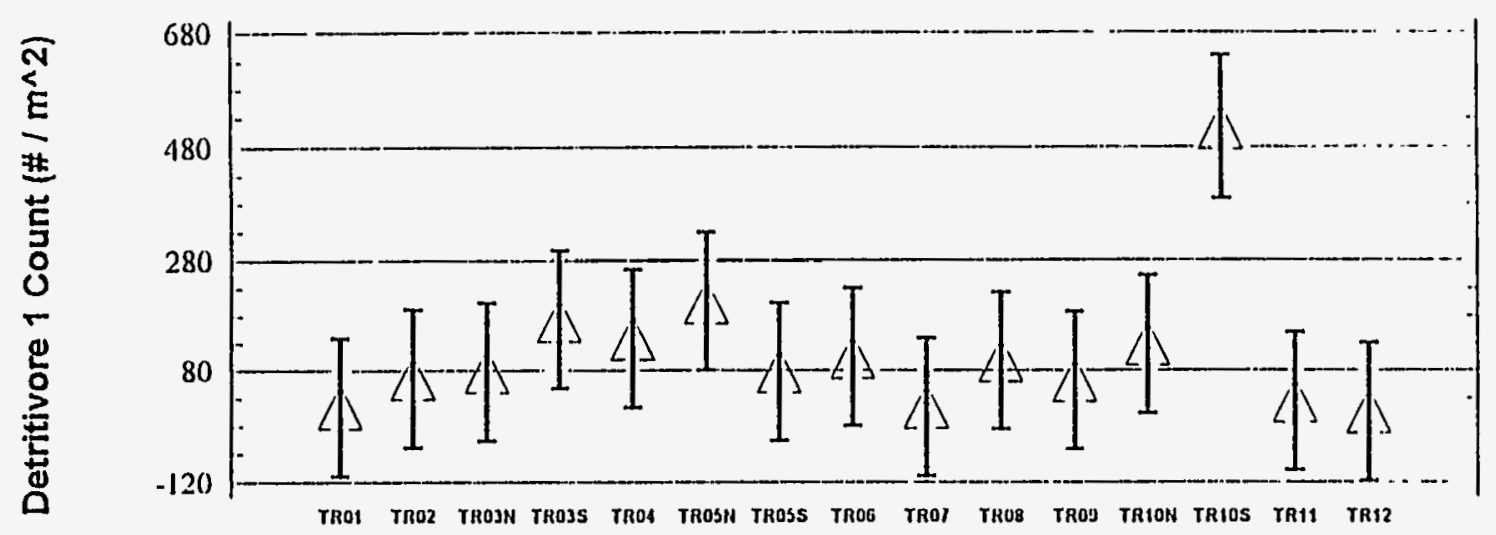

Site

Figure E-13. Arthropod Detritivore 1 Means by Site and 90\% Tukey HSD Intervals

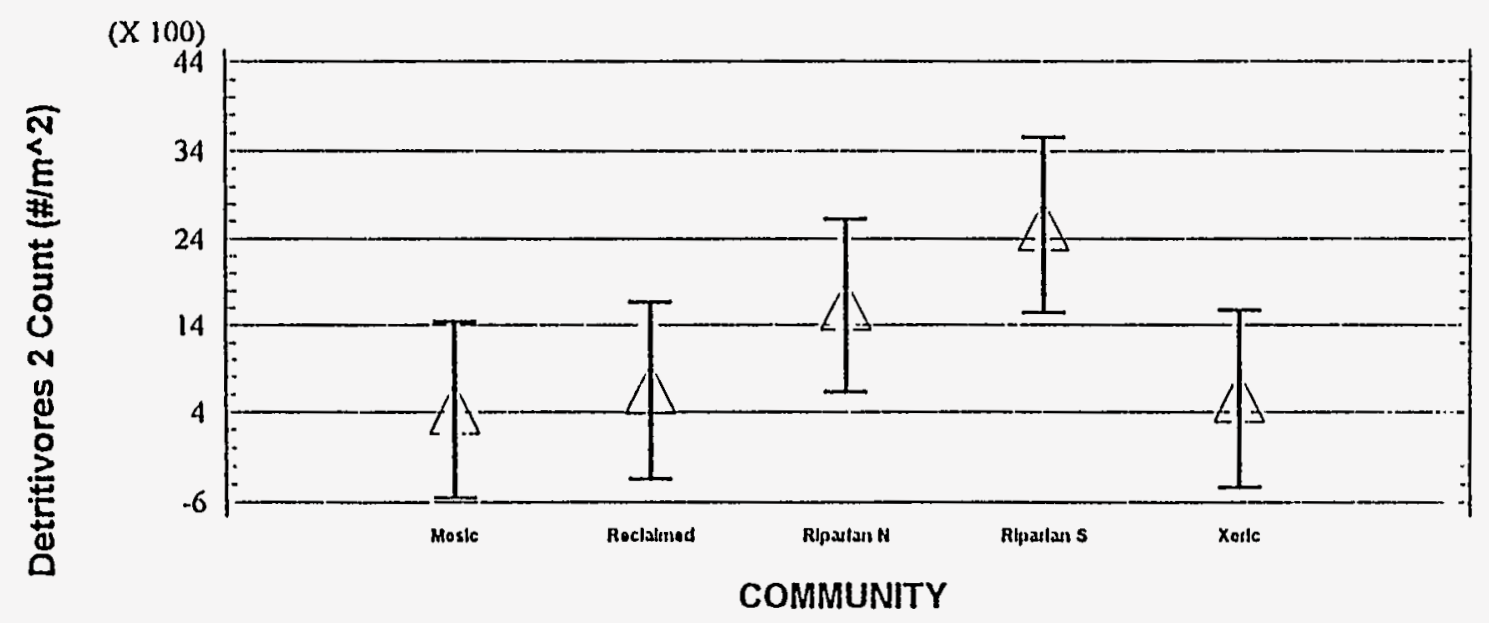

Figure E-14. Arthropod Detritivore 2 Means by Community and Tukey $90 \%$ HSD Intervals 


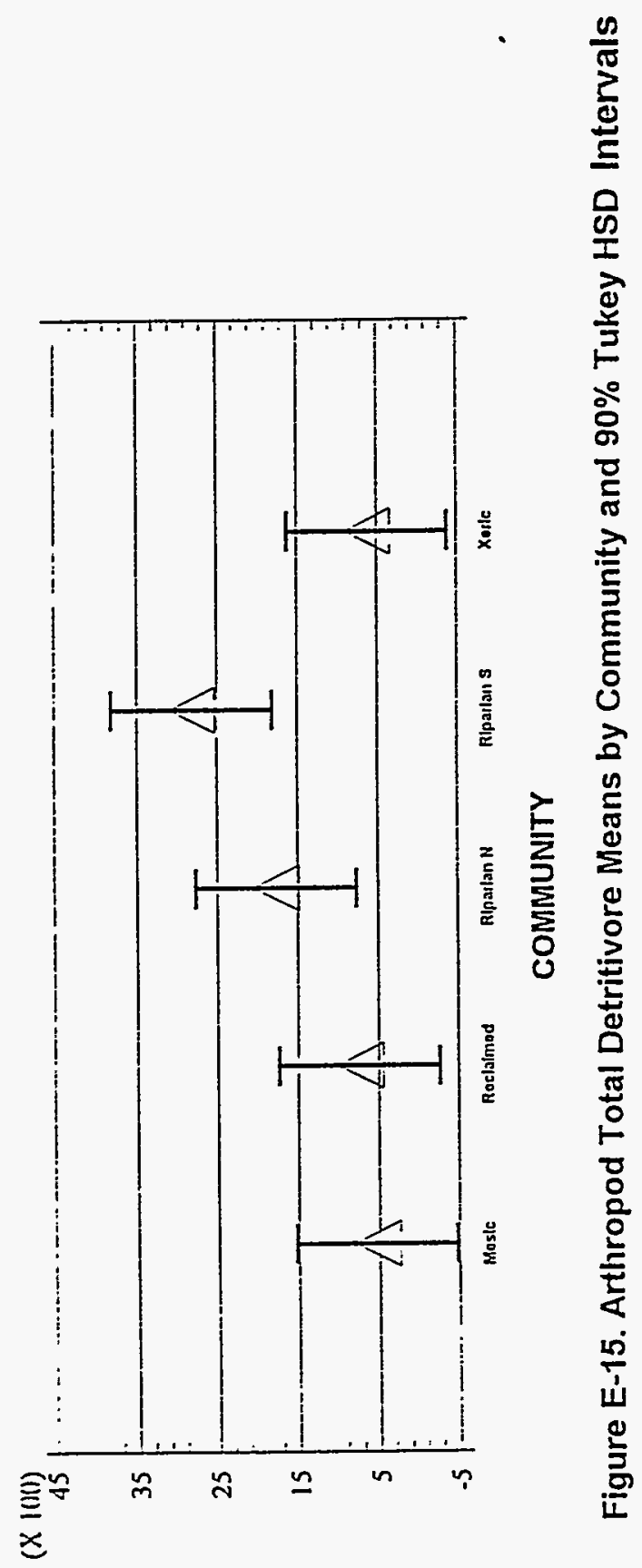

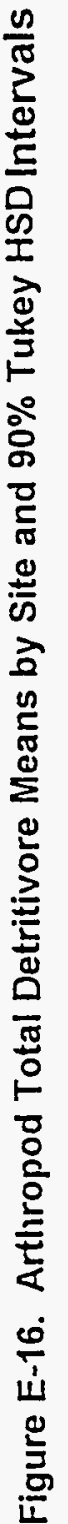

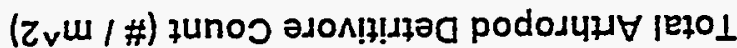

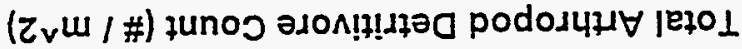




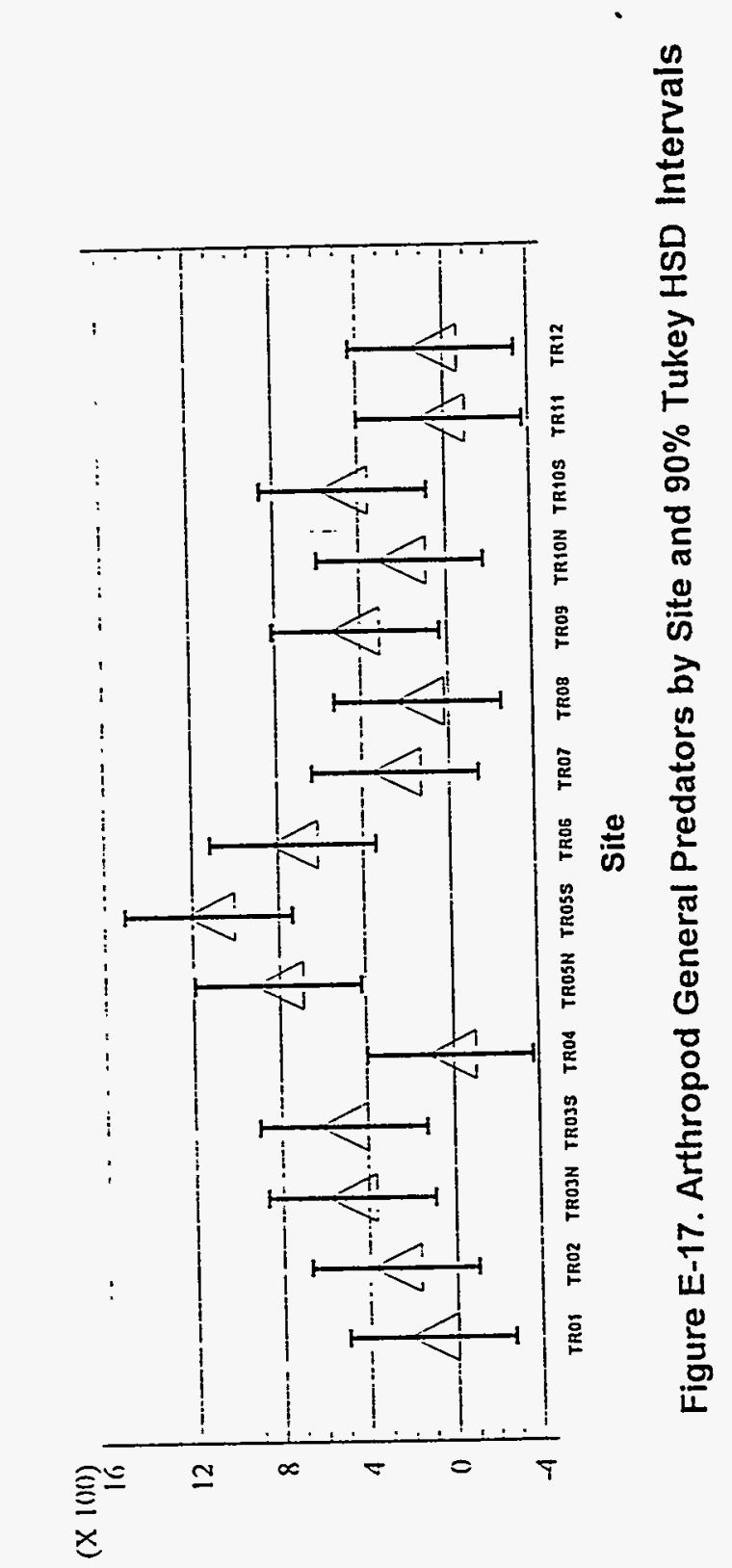

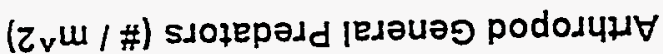

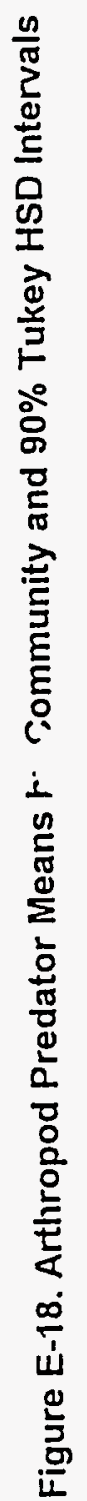

(Zvw/\#) squnos ssozepasd pododuдy 


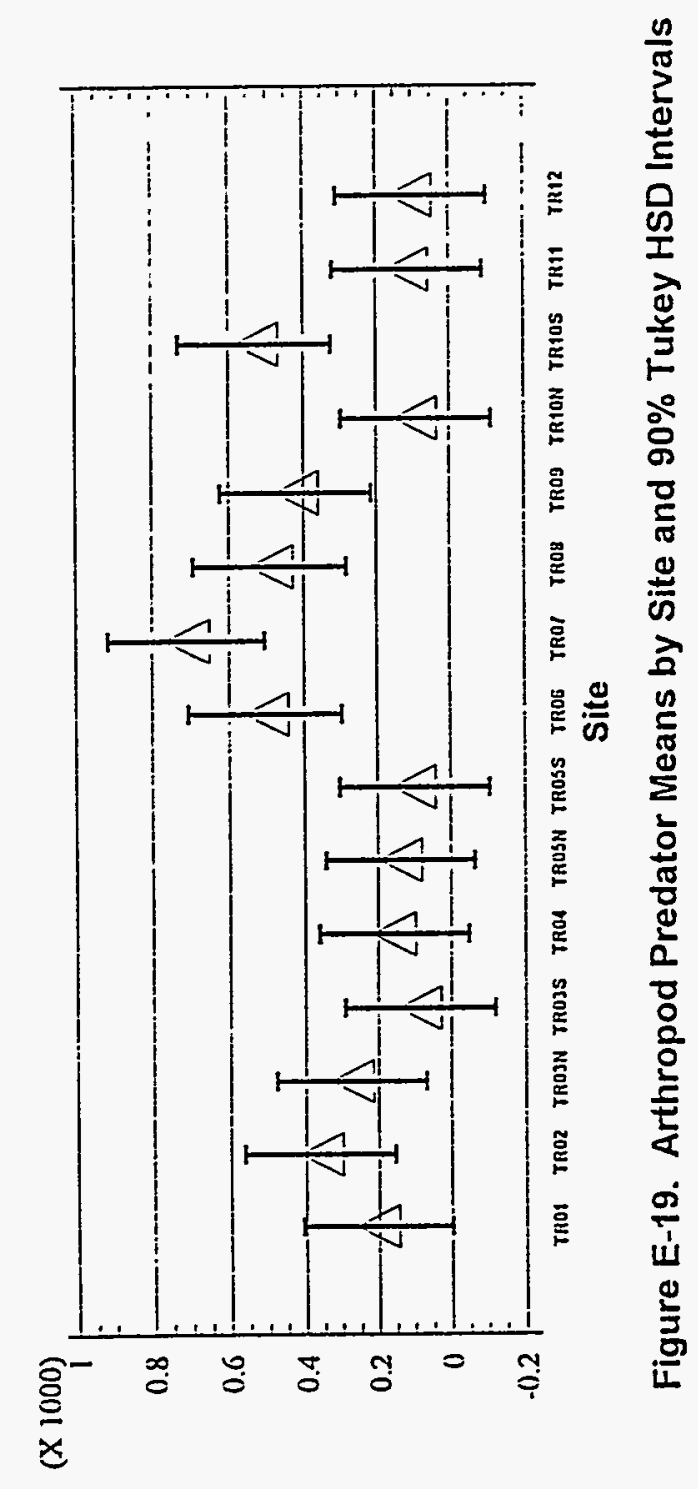

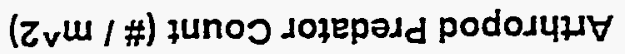

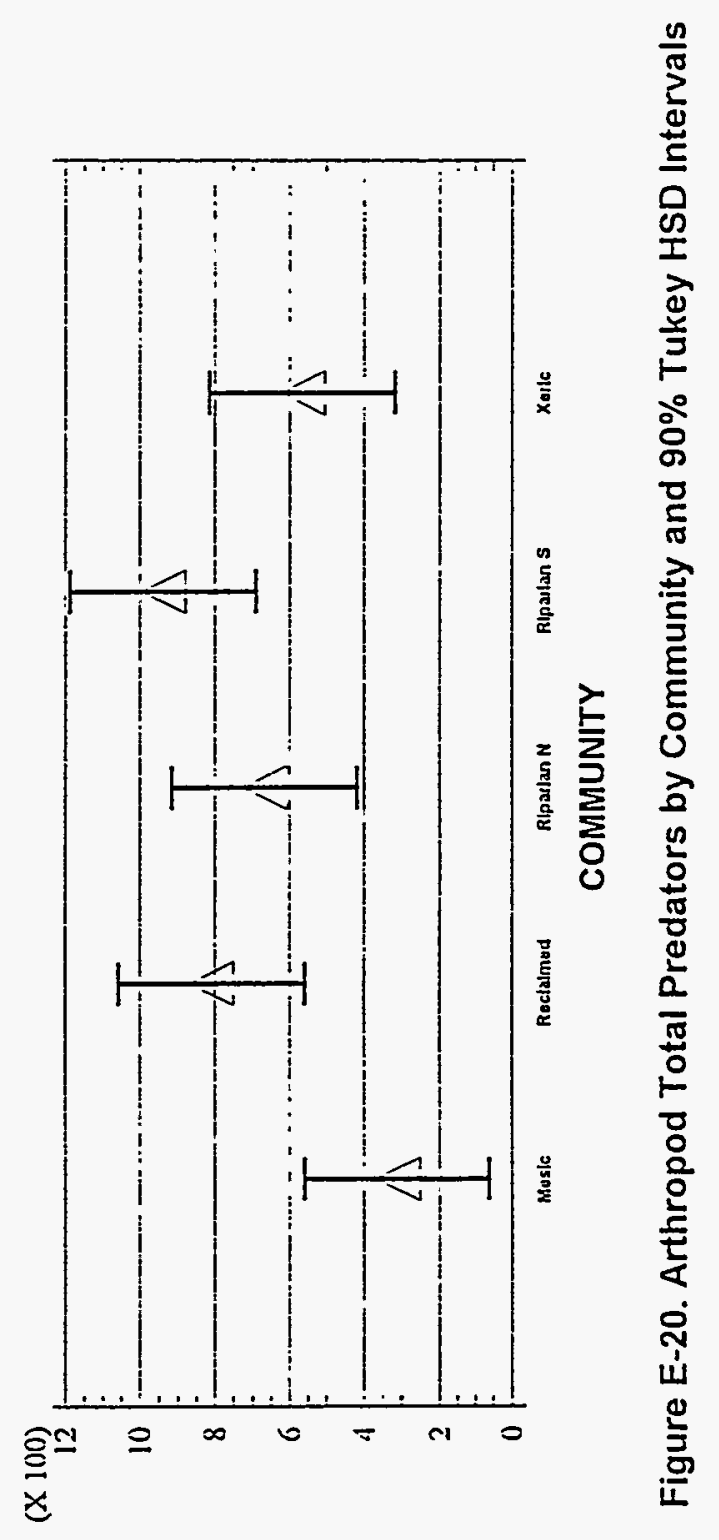

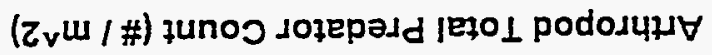



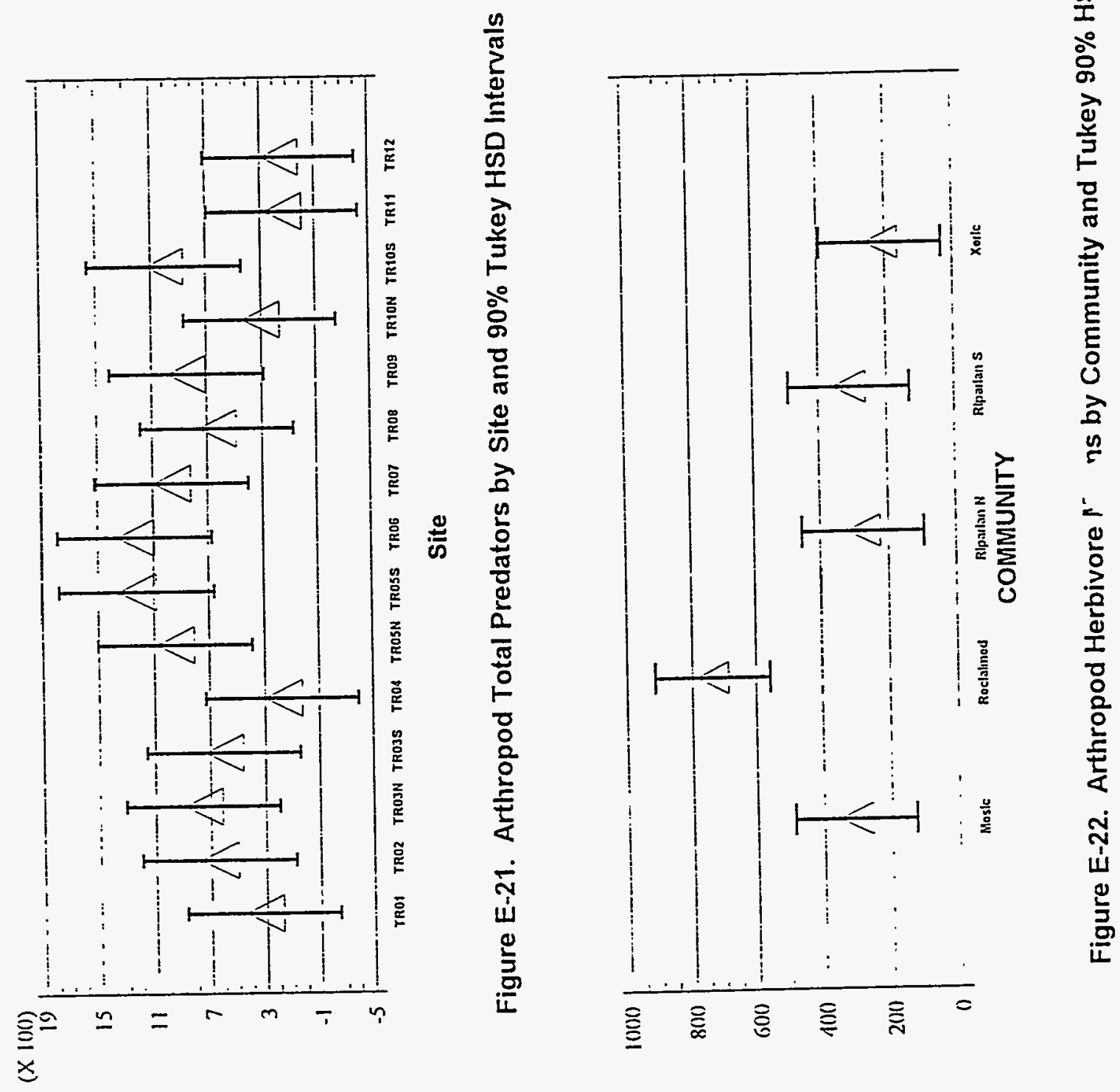

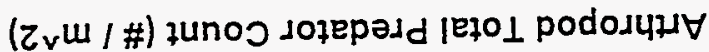

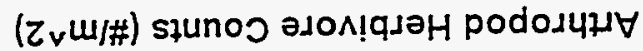


Table E-1. Analysis of Variance, EcMP Soil Amoebae By Community and Depth

\begin{tabular}{lcccccc} 
& Sum of Squares & df & Mean Square & F-ratlo & p-value \\
& & & & & & \\
& Community & 837328000 & 4 & 209332000 & 2.02 & 0.0954 \\
& Depth & 96353400 & 1 & 96353400 & 0.93 & 0.347 \\
Cosidual & 368498000 & 4 & 9712400 & 0.94 & 0.4447 \\
\hline Total & 13368300000 & 129 & 103630000 & &
\end{tabular}

Amoebae

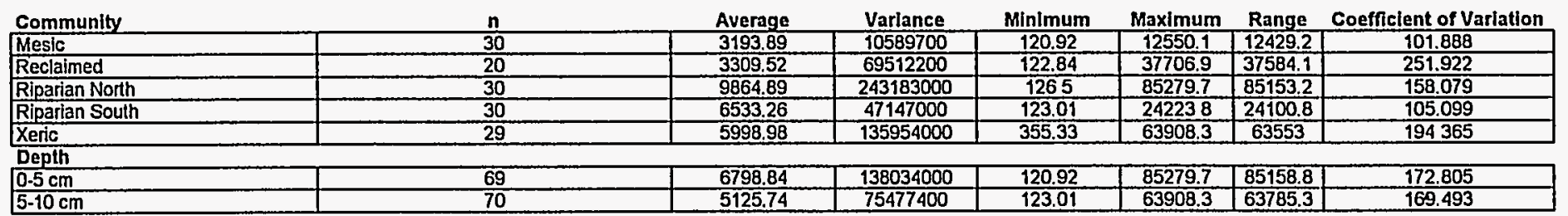

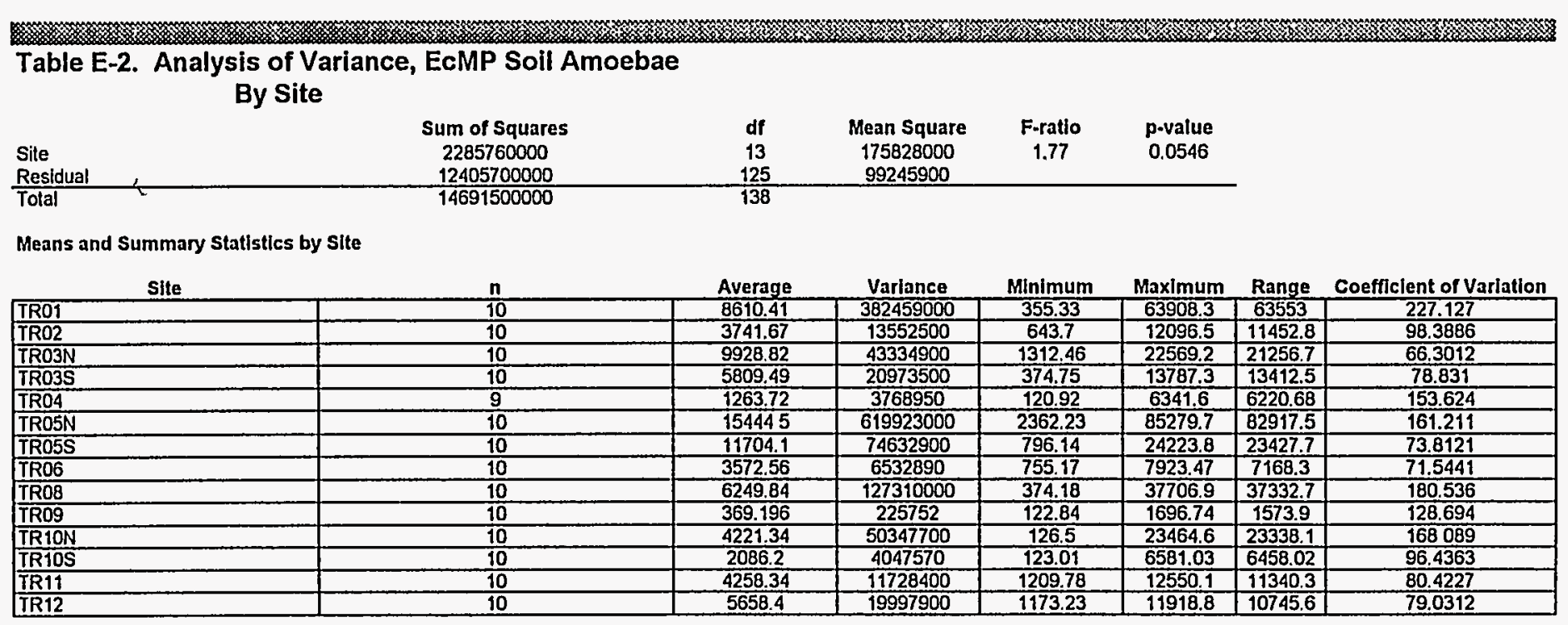


Table E-3. Analysis of Variance, EcMP Soil Flagellates

Source By Community and Depth

\begin{tabular}{|c|c|c|c|c|c|c|c|}
\hline $\begin{array}{l}\text { Source } \\
\text { Treatment }\end{array}$ & $\begin{array}{l}\text { Community } \\
\text { Depth } \\
\text { Community x Depth }\end{array}$ & $\begin{array}{c}\text { Sum of Squares } \\
3422380000 \\
66145500 \\
239770000 \\
32571900000\end{array}$ & $\begin{array}{c}\text { df } \\
4 \\
1 \\
4 \\
129 \\
\end{array}$ & $\begin{array}{c}\text { Mean Square } \\
855596000 \\
66145500 \\
59942600 \\
252496000 \\
\end{array}$ & $\begin{array}{c}\text { F-ratio } \\
3.39 \\
026 \\
024\end{array}$ & $\begin{array}{l}\text { p-value } \\
0.0113 \\
0.6151 \\
0.9168\end{array}$ & \\
\hline Total & & 36314900000 & 138 & & & & \\
\hline Means by Community and Depth & Flagellates & & & & & & \\
\hline Community & n & Average & Variance & Minimum & Maximum & Range & Coefficient of Variation \\
\hline Mesic & 30 & 1102.8 & 860798 & 119.3 & 3602.75 & 3483.45 & 84.1309 \\
\hline Reclaimed & 20 & 2436.04 & 14262100 & 36.56 & 12509.4 & 12472.8 & 155.027 \\
\hline Riparian North & 30 & 13238.9 & 771519000 & 124.06 & 108520 & 108396 & 209.807 \\
\hline Riparian South & 30 & 9864.3 & 330918000 & 74.89 & 77941.3 & 777866.4 & 184.414 \\
\hline Xeric & 29 & 2120.79 & 22082900 & 118.07 & 25632.9 & 25514.8 & 221.58 \\
\hline \multicolumn{8}{|l|}{ Depth } \\
\hline $0.5 \mathrm{~cm}$ & 69 & 6776.49 & 266497000 & 3656 & 85279.7 & 85243.1 & 240.903 \\
\hline $5.10 \mathrm{~cm}$ & 70 & 5268.96 & 262523000 & 74.89 & 108520 & 108445 & 307.51 \\
\hline
\end{tabular}

Tа.

Tabie E-4. Analysis of Variance, EcMP Soi! Flage!lates

By Site

\begin{tabular}{lccccc} 
& Sum of Squares & df & Mean Square & F-ratio & p-value \\
Site & 8681640000 & 13 & 667818000 & 3.02 & 0.0007 \\
\hline Residual & 27633200000 & & 125 & 221066000 & \\
\hline Total & 36314900000 & 138 & &
\end{tabular}

Means and Summary Statistics by Site

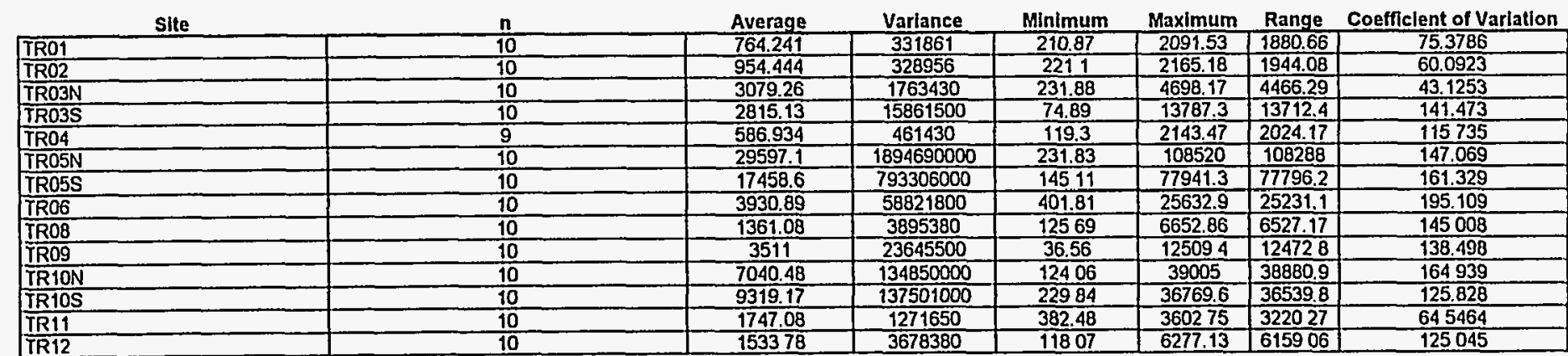


Table E-5. Analysis of Variance, EcMP Soil Ciliates

\begin{tabular}{llccccc}
\multicolumn{2}{c}{ By Community. and Depth } & & & & \\
Source & & & & & \\
Treatment & Communily & Sum of Squares & df & Mean Square & F-ratio & p-value \\
& Depth & 18198.5 & 4 & 459.61 & 0.86 & 0.4896 \\
& Community xDepth & 11035.4 & 1 & 11035.4 & 2.09 & 0.151 \\
Residual & & 19992.9 & 4 & 4998.24 & 0.95 & 0.44 \\
\hline Total & & 682007 & 129 & 5286.87 & \\
\hline
\end{tabular}

\section{Means by Community and Depth Flagellates}

\begin{tabular}{|c|c|c|c|c|c|c|c|}
\hline Community & $\mathbf{n}$ & Average & Variance & Minimum & Maximum & Range & Coefficlent of Varlation \\
\hline Mesic & 30 & 16.0337 & 251.103 & 0 & 63.91 & 63.91 & 98.831 \\
\hline Reclaimed & 20 & 10.109 & 81.0553 & 0 & 37.7 & 37.7 & 89.06 \\
\hline Riparian South & 30 & 20.2427 & 568.345 & 0 & 121.91 & 121.91 & 117.771 \\
\hline Xeric & 29 & 26.6703 & 344.359 & 0 & 63.07 & 63.07 & 69.5788 \\
\hline $0.5 \mathrm{~cm}$ & 69 & 33.9361 & 10389 & 0 & 851.6 & 851.6 & 300.348 \\
\hline $5.10 \mathrm{~cm}$ & 70 & 14.815 & 199.512 & 0 & 63.91 & 63.91 & 953418 \\
\hline
\end{tabular}

\section{All means are in \#lg dry soil}

Anall of

Table E-6. Analysis of Variance, EcMP Soil Ciliates By Site

\begin{tabular}{lccccc} 
& Sum of Squares & df & Mean Square & F-ratto & p-value \\
Site & 76703.1 & 13 & 5900.24 & 1.12 & 0.3453 \\
Residual & 656219.0 & 125 & 5249.75 & & \\
\hline Total & 732922.0 & 138 &
\end{tabular}

Means and Summany Statistics by SIte

\begin{tabular}{|c|c|c|c|c|c|c|c|}
\hline Site & $\mathbf{n}$ & Average & Variance & Minimum & Maximum & Range & Coefficient of Variation \\
\hline TRO1 & 10 & 17.785 & 110.52 & 5.2 & 35.94 & 30.74 & 59.1109 \\
\hline TR02 & 10 & 8.449 & 36.7333 & 0 & 21.53 & 21.53 & 71.734 \\
\hline TRO3S & 10 & 15968 & 202.253 & $\overline{0}$ & 41.17 & 41.17 & 89063 \\
\hline TRO4 & 9 & 8.29889 & 12.9418 & 5.19 & 12.41 & 7.22 & 43.3488 \\
\hline TR05S & 10 & 17.727 & 334.147 & 0 & 61.19 & 61.19 & 103.118 \\
\hline TRO6 & 10 & 17.729 & 177.105 & 0 & 4569 & 45.69 & 750638 \\
\hline TROB & 10 & 11.841 & 110.262 & $\mathbf{0}$ & 37.7 & 37.7 & 88.6796 \\
\hline TRO9 & 10 & 8.377 & 54.1889 & 0 & 21.89 & 21.89 & 878753 \\
\hline TR10N & 10 & 12.818 & 123.032 & 0 & 38.83 & 3883 & 86.5345 \\
\hline TR12 & 10 & 44.463 & 255.42 & 20.95 & 63.07 & 42.12 & 359442 \\
\hline
\end{tabular}


Table E-7. Analysis of Variance, EcMP Soil Nematode Fungal Feeders

\begin{tabular}{llccccc}
\multicolumn{2}{c}{ By Community and Depth } & Sum of Squares & df & Mean Square & F-ratio & p-value \\
Source & & & & & \\
Treatment & Community & 131656000 & 4 & 32914100 & 1.9 & 0.1136 \\
& Depth & 38321600 & 1 & 38321600 & 2.22 & 0.1389 \\
& Community x Depth & 79169700 & 4 & 19792400 & 1.15 & 0.3383 \\
\hline Residual & & 2194620000 & 127 & 17280500 & \\
\hline Total & 2453210000 & 136 &
\end{tabular}

\begin{tabular}{|c|c|c|c|c|c|c|c|}
\hline Means by Community and Depth & Fungal Feeders & & & & & & \\
\hline Community & $n$ & Average & Variance & Minimum & Maximum & Range & Coelficient of Variation \\
\hline Mesic & 29 & 5548.56 & 28583100 & 0 & 16797.2 & 16797.2 & 96.355 \\
\hline Reclaimed & 29 & 2706.51 & 12374000 & 125.678 & 18172.9 & 18047.2 & 129.971 \\
\hline Riparian North & 25 & 3533.95 & 22507700 & 102.711 & 15436 & 15333.3 & 134.247 \\
\hline Riparian South & 25 & 3547.8 & 11560200 & 0 & 17268.4 & 17268.4 & 95,8348 \\
\hline Xeric & $\frac{29}{29}$ & 3164.55 & 12553300 & 0 & 13491 & 13491 & 111.961 \\
\hline \multicolumn{8}{|l|}{ Depth } \\
\hline $0.5 \mathrm{~cm}$ & 69 & 4264.27 & 24079200 & 0 & 18172.9 & 18172.9 & $\overline{115.074}$ \\
\hline $5-10 \mathrm{~cm}$ & $\frac{28}{68}$ & 3146.74 & 11538200 & 0 & 14243.1 & 14243.1 & 107.946 \\
\hline
\end{tabular}

Table E-8. Analysis of Variance, EcMP Soil Nematode Fungal Feeders

By Site

\begin{tabular}{lccccc} 
& Sum of Squares & df & Mean Square & F-ratio & p-value \\
Sile & 749042000 & 14 & 53503000 & 3.83 & 0.00 \\
\hline Residual & 1704170000 & 122 & 13968600 & \\
\hline Total & 2453210000 & 136 &
\end{tabular}

Means and Summary Statistics by site

\begin{tabular}{|c|c|c|c|c|c|c|c|}
\hline Site & $n$ & Average & Varlance & Minimum & Maximum & Range & Coefficient of Variation \\
\hline TR01 & 10 & 616.872 & 119668 & 258.931 & 1207.76 & 948.625 & 56.0783 \\
\hline TRO2 & 10 & 2219.27 & 2067330 & 534.737 & 4657.83 & 4123.09 & 647882 \\
\hline TROON & 10 & 2065.31 & 7084940 & 102.711 & 8852.44 & 8749.73 & 128879 \\
\hline TR03S & 10 & 2850.16 & 3481690 & 0 & 6042.81 & 6042.81 & 65.4674 \\
\hline TROA & 10 & 6087,43 & 36371900 & 0 & 15919.8 & 15919.8 & 990716 \\
\hline TROSN & 5 & 7816.53 & 42971700 & 723.044 & 14243.1 & 13520 & 838642 \\
\hline TROSS & 5 & 4519.03 & 4106880 & 2144.8 & 7368.12 & 5223.33 & 448446 \\
\hline TR06 & 10 & 6630.35 & 11673900 & 2109.93 & 13491 & 11381.1 & 51.5314 \\
\hline TR07 & 10 & 832.549 & 330864 & 125.678 & 1873.29 & 1747.61 & 690899 \\
\hline TR08 & 9 & 5137.06 & 26560400 & 256.113 & 18172.9 & 17916.7 & 100324 \\
\hline TR09 & 10 & 2392.99 & 4638100 & 222.316 & 6993.64 & 6771.33 & 899973 \\
\hline TR1ON & 10 & 2861.29 & 20748600 & 157.792 & 15436 & 152782 & 159.196 \\
\hline TR1OS & 10 & 3759.83 & 24405500 & 499.287 & 172684 & 16769.1 & 131.394 \\
\hline TR11 & 9 & 8649.03 & 31763900 & 2479.86 & 16797.2 & 14317.3 & 65.1628 \\
\hline TR12 & 9 & 2144.41 & 6369780 & & 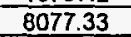 & 5 & a \\
\hline
\end{tabular}


Table E-9. Analysis of Variance, EcMP Soil Nematode Bacterial Feeders By Community and Depth

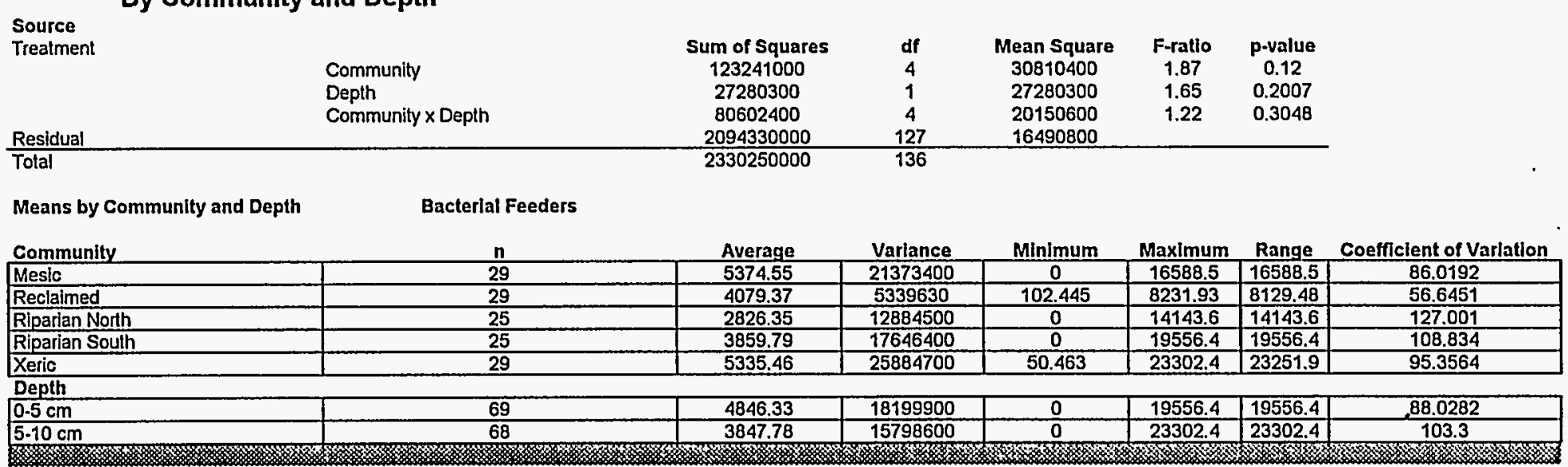

Table E-10. Analysis of Variance, EcMP Soil Nematode Bacterial Feeders

By Site

\begin{tabular}{lccccc} 
& Sum of Squares & df & Mean Square & F-ratlo & $p$-value \\
Slte & 784027000 & 14 & 56001900 & 4.42 & 0.00 \\
\hline Residual & 1546220000 & 122 & 12674000 & & \\
\hline Total & 2330250000 & 136 & &
\end{tabular}

Means and Summary Statlstics by Site

\begin{tabular}{|c|c|c|c|c|c|c|c|}
\hline Site & $n$ & Average & Varlance & Minimum & Maximum & Range & Coefficient of Variation \\
\hline TR01 & 10 & 2268.74 & 735870 & 992.569 & 3957.12 & 2964.55 & 37.8108 \\
\hline TR02 & 10 & 3126.11 & 2041850 & 109481 & 5094.5 & 3999.7 & 45.7096 \\
\hline TR03N & 10 & 2509.54 & 18546000 & 0 & 14143.6 & 14143.6 & 171.605 \\
\hline TR03S & 10 & 2688.4 & 4171990 & 0 & 5483.7 & 5483.7 & 75.9762 \\
\hline TR04 & 10 & 4937.66 & 25587700 & 0 & 13542.2 & 13542.2 & 102.446 \\
\hline TRO5N & 5 & 5060.51 & 18981800 & 276.458 & 10504.2 & 10227.7 & 86.0943 \\
\hline TR05S & 5 & 6036.6 & 14182700 & 2359.49 & 11769.9 & 9410.37 & 62.386 \\
\hline TR06 & 10 & 10648.7 & 26698800 & 6548.89 & 23302.4 & 16753.5 & 48.5234 \\
\hline TR07 & 10 & 5182.04 & 5085370 & 1849.82 & 8231.93 & 6382.1 & 435172 \\
\hline TR08 & 9 & 4083.44 & 5230340 & 102.445 & 7215.42 & 7112.98 & 560065 \\
\hline TRO9 & 10 & 2973.04 & 4166670 & 689.18 & 6950.21 & 6261.03 & 68.6584 \\
\hline TR10N & 10 & 2026.07 & 3780030 & 112.708 & 6473.18 & 6360.47 & 95.9604 \\
\hline TR10S & 10 & 3942.77 & 32416900 & 612.87 & 19556.4 & 18943.6 & 144.406 \\
\hline TR11 & 9 & 8358.23 & 27150700 & 3547.34 & 16588.5 & 13041.2 & 62.3414 \\
\hline TR12 & 9 & 2839.36 & 5679620 & 50.463 & 7875.4 & 7824.93 & 839341 \\
\hline
\end{tabular}


Table E-11. Analysis of Variance, EcMP Soil Nematode Omnivore/Predators

\begin{tabular}{llccccc}
\multicolumn{2}{c}{ By Community and Depth } & Sum of Squares & df & Mean Square & F-ratio & p-value \\
Source & & & & & \\
Treatment & Community & 5115760 & 4 & 1278940 & 1.86 & 01217 \\
& Depth & 3838710 & 1 & 3838710 & 558 & 0.0197 \\
& Community $x$ Depth & 3115830 & 4 & 778958 & 1.13 & 0.3443 \\
\hline Residual & & 87366700 & 127 & 687926 & \\
\hline Total & 98940700 & 136 &
\end{tabular}

Means by Community and Depth

Ominlvore/Predators

\begin{tabular}{|c|c|c|c|c|c|c|c|}
\hline Community & $n$ & Average & Variance & Minimum & Maximum & Range & Coefficient of Variation \\
\hline Mesic & 29 & 559.174 & 392428 & 0 & 2086.61 & 2086.61 & 112.03 \\
\hline Reclaimed & 29 & 828.151 & 354762 & 0 & 2519.45 & 2519.45 & 71.9216 \\
\hline Riparlan North & 25 & 681.991 & 643249 & 0 & 2499.23 & 2499.23 & 117.601 \\
\hline Rlparian South & 25 & 845.961 & 2124260 & $\frac{5}{0}$ & 6346.13 & 6346.13 & 172.288 \\
\hline Xeric & 29 & 343.586 & 240507 & 0 & 2423.2 & 2423.2 & 142.734 \\
\hline \multicolumn{8}{|l|}{ Depth } \\
\hline $0.5 \mathrm{~cm}$ & 69 & 802.687 & 1091630 & 0 & 6346.13 & 6346.13 & 130.164 \\
\hline $5-10 \mathrm{~cm}$ & 68 & 485.438 & 317359 & 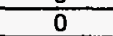 & 2519.45 & 2519.45 & 116.049 \\
\hline
\end{tabular}

等

Table E-12. Analysis of Variance, EcMP Soil Nematode Omnivore/Preditors By Site

\begin{tabular}{lccccc} 
& Sum of Squares & df & Mean Square & F-ratio & p-value \\
Site & 21726600 & 14 & 155100 & 2.45 & 0.0044 \\
\hline Residual & 77214200 & 122 & 632903 & & \\
\hline Total & 98940700 & 136 &
\end{tabular}

Means and Summary Statlstics by Site

\begin{tabular}{|c|c|c|c|c|c|c|c|}
\hline Site & n & Average & Varlance & Minimum & Maximum & Range & Coefficlent of Variation \\
\hline TR01 & 10 & 164299 & 4417.25 & 22.528 & 251.109 & 228.581 & 40.4522 \\
\hline TR02 & 10 & 414253 & 49271.8 & 128.337 & 846.179 & 717.842 & 53.5839 \\
\hline TRO3N & 10 & 152.815 & 39011.5 & 0 & 603.148 & 603.148 & 129.25 \\
\hline TR03S & 10 & 123.636 & 14692 & $\overline{0}$ & 328.243 & 328.243 & 98.0382 \\
\hline TR04 & 10 & 506.624 & 446595 & 0 & 1759.11 & 1759.11 & 131.908 \\
\hline TR05N & 5 & 898.873 & 628642 & 22049 & 1848.03 & 1825.99 & 88.2071 \\
\hline TR05S & 5 & 1180.34 & 2549740 & 136.902 & 3900.38 & 3763.48 & 135283 \\
\hline TR06 & 10 & 495387 & 150160 & 47.223 & 1165.12 & 1117.9 & 782227 \\
\hline TR07 & 10 & 826.303 & 163657 & 110.108 & 1485.71 & 13756 & 48.9585 \\
\hline TROB & 9 & 490.012 & 237594 & 0 & 1690.95 & 1690.95 & 99.4743 \\
\hline TR09 & 10 & 113432 & 510354 & 298.815 & 2519.45 & 2220.63 & 62.9794 \\
\hline TR1ON & 10 & 1102.73 & 862962 & 45083 & 2499.23 & 2454.15 & 842418 \\
\hline TR10S & 10 & 1401.1 & 3532530 & 181.591 & 6346.13 & 6164.54 & 134145 \\
\hline TR11 & 9 & 778.586 & 731786 & 0 & 2086.61 & 2086.61 & 109872 \\
\hline TR12 & 9 & 374.127 & 597840 & 0 & 2423.2 & 2423.2 & 206668 \\
\hline
\end{tabular}


Table E-13. Analysis of Variance, EcMP Soil Nematode Plant Feeders By Community and Depth

Source
Treatme

\begin{tabular}{|c|c|c|c|c|c|c|}
\hline Treatment & $\begin{array}{l}\text { Community } \\
\text { Depth } \\
\text { Community } \times \text { Depth }\end{array}$ & $\begin{array}{c}\text { Sum of Squares } \\
10985200 \\
13962.9 \\
10781400 \\
245155000\end{array}$ & $\begin{array}{c}\text { df } \\
4 \\
1 \\
4 \\
127\end{array}$ & $\begin{array}{c}\text { Mean Square } \\
2746300 \\
13962.9 \\
2695340 \\
1930360\end{array}$ & $\begin{array}{c}\text { F-ratio } \\
1.42 \\
0.01 \\
1.4\end{array}$ & $\begin{array}{c}\text { p-value } \\
0.2302 \\
0.9333 \\
0.239\end{array}$ \\
\hline Residual & & $\begin{array}{r}245155000 \\
267518000\end{array}$ & $\frac{127}{136}$ & 1930360 & & \\
\hline
\end{tabular}

Total

Plant Parasitic

\begin{tabular}{|c|c|c|c|c|c|c|c|}
\hline Communlty & $\mathbf{n}$ & Average & Varlance & Minimum & Maximum & Range & Coefficlent of Variation \\
\hline Mesic & 29 & 1315.27 & 3463030 & 0 & 9253.93 & 9253.93 & 141.486 \\
\hline Reclaimed & 29 & 1045.33 & 1747290 & 0 & 4386.04 & \begin{tabular}{|l|l|}
43866.04 \\
\end{tabular} & 126.452 \\
\hline Riparian North & 25 & 1227.61 & 3503090 & 0 & 6595.78 & 6595.78 & 152.463 \\
\hline Riparian South & 25 & 823.377 & 798239 & 0 & 3919.97 & \begin{tabular}{|l|}
3919.97 \\
\end{tabular} & 108.51 \\
\hline Xeric & 29 & 523.146 & 243497 & $\overline{0}$ & 1757.63 & \begin{tabular}{|l|}
1757.63 \\
\end{tabular} & 94.3244 \\
\hline \multicolumn{8}{|l|}{ Depth } \\
\hline $0-5 \mathrm{~cm}$ & 69 & 987.575 & 2391100 & 0 & 9253.93 & 9253.93 & .156 .577 \\
\hline $5-10 \mathrm{~cm}$ & 68 & 981.776 & 1566010 & 0 & 6595.78 & 6595.78 & 127.463 \\
\hline
\end{tabular}

Table E-14. Analysis of Variance, EcMP Soil Nematode Plant Feeders

By Site

\begin{tabular}{lccccc} 
& Sum of Squares & df & Mean Square & F-ratlo & p-value \\
Site & 83554700 & 14 & 5968190 & 3.96 & 0.00 \\
\hline Residual & 183963000 & 122 & 1507900 & & \\
\hline Total & 267518000 & 136 & &
\end{tabular}

Means and Summary Statistics by Site

\begin{tabular}{|c|c|c|c|c|c|c|c|}
\hline Site & $\mathbf{n}$ & Average & Varlance & Minimum & Maximum & Range & Coefficlent of Varlation \\
\hline TRO1 & 10 & 670.811 & 130599 & 334.812 & 1368.23 & 1033.42 & 53.8727 \\
\hline TR02 & 10 & 2041.3 & 1153660 & 770.021 & 4142.07 & 3372.05 & 526177 \\
\hline TRO3N & 10 & 677.808 & 1163390 & 0 & 3306.95 & 3306.95 & 159.131 \\
\hline TR03S & 10 & 763.165 & 1517140 & $\overline{0}$ & 3919.97 & 3919.97 & 161.397 \\
\hline TRO4 & 10 & 561.773 & 403347 & 0 & 2067.5 & 2067.5 & 113.052 \\
\hline TRO5N & 5 & 3134.28 & 9491880 & 198.444 & 6595.78 & 6397.34 & 98.2967 \\
\hline TRO5S & 5 & 959.867 & 451700 & 216688 & 1843.66 & 1626.97 & 70.0187 \\
\hline TRO6 & 10 & 630.708 & 417833 & 28.903 & 1757.63 & 1728.73 & 102.488 \\
\hline TR07 & 10 & 2601.09 & 1218020 & 814.802 & 4386.04 & 3571.24 & 42.4298 \\
\hline TR08 & 9 & 285.829 & 76384.2 & 0 & 845.249 & 845.249 & 966932 \\
\hline TRO9 & 10 & 173.136 & 38689.4 & 0 & 564.704 & 564.704 & 113.608 \\
\hline TR1ON & 10 & 824.089 & 1423140 & 45.553 & 3983.49 & 3937.94 & 144.76 \\
\hline TR10S & 10 & 815.342 & 396286 & 113.121 & 1795.43 & 1682.31 & 77.2084 \\
\hline TR11 & 9 & 1345.78 & 8999330 & 0 & 9253.93 & 9253.93 & 222.911 \\
\hline TR12 & 9 & 239.56 & 103062 & 0 & 1009.67 & 100967 & 13401 \\
\hline
\end{tabular}


Table E-15. Analysis of Variance, EcMP Soil Arthropod Fungal Feeders 1

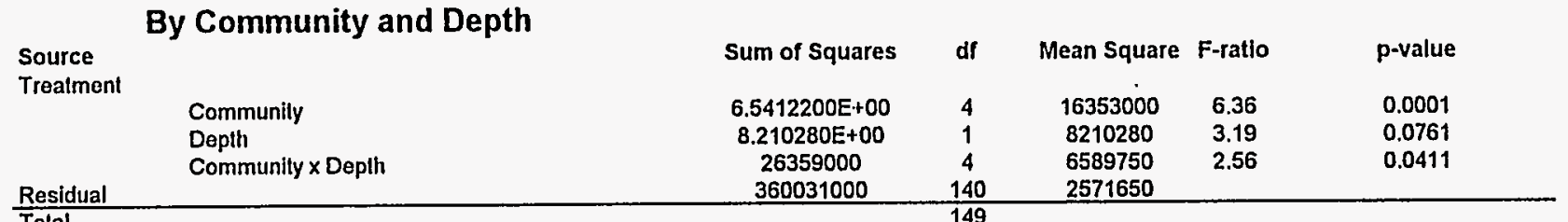

Tola

Means by Communlty and Depth

Community
\begin{tabular}{|l|c|c|}
\hline Mesic & Fungal Feeders $1\left(t / \mathrm{m}^{\wedge} 2\right)$ & $n$ \\
\hline Reclaimed & 8.889 & 30 \\
\hline Riparian North & 36.889 & 30 \\
\hline Riparian South & 1017.33 & 30 \\
\hline Xeric & 1752.45 & 30 \\
\hline Depth & 442.222 & 30 \\
\hline $0-5 \mathrm{~cm}$ & 885.511 & 75 \\
\hline $5-10 \mathrm{~cm}$ & 417.6 & 75 \\
\hline
\end{tabular}

Table E-16. Analysis of Variance, EcMP Soil Arthropod Fungal Feeders 1

By Site

\begin{tabular}{lccccc} 
& Sum of Squares & df & Mean Square & F-ratio & p-value \\
Site & 123366000 & 14 & 8811840 & 3.53 & 0.0001 \\
Residual & 336647000 & 135 & 2493680 & & \\
\hline Tolal & 460013000 & 149 & & &
\end{tabular}

Means and Summary Statistics by Site

\begin{tabular}{|c|c|c|c|c|c|c|c|}
\hline Site & $n$ & Average & Variance & Minimum & Maximum & Range & Coefficient of Variation \\
\hline TR01 & 10 & 0 & 0 & 0 & 0 & 0 & \\
\hline TR02 & 10 & 20 & 800 & 0 & 80 & 80 & 141.421 \\
\hline TR03N & 10 & 686.666 & 514615 & 0 & 2333.33 & 2333.3 & 104.471 \\
\hline TR03S & 10 & 1626.67 & 9279210 & 66.67 & 10200 & 10133 & 187.265 \\
\hline TR04 & 10 & 6.667 & 444.489 & 0 & 66.67 & 66.67 & 316.228 \\
\hline TR05N & 10 & 1693.33 & 3575510 & 0 & 5733.33 & 5733.3 & 111.667 \\
\hline TR05S & 10 & 3213.33 & 17883200 & 0 & 13933.3 & 13933 & 131.603 \\
\hline TR06 & 10 & 1326.67 & 3632050 & 0 & 6600 & 6600 & 143.653 \\
\hline TR07 & 10 & 84 & 20071.1 & 0 & 440 & 440 & 168.658 \\
\hline TROB & 10 & 0 & 0 & 0 & 0 & 0 & \\
\hline TRO9 & 10 & 26.667 & 4148.18 & 0 & 200 & 200 & 241.521 \\
\hline TR10N & 10 & 672 & 2383930 & 0 & 5000 & 5000 & 229.762 \\
\hline TR10S & 10 & 417.334 & 111172 & 66.67 & 933.33 & 866.66 & 79.8941 \\
\hline TR11 & 10 & 0 & 0 & 0 & 0 & 0 & \\
\hline TR12 & 10 & 0 & 0 & 0 & 0 & 0 & \\
\hline
\end{tabular}


Table E-17. Analysis of Variance, EcMP Arthropod Fungal Feeders 2 By Community and Depth

\begin{tabular}{llccccc} 
Source & & Sum of Squares & df & Mean Square & F-ratio & p-value \\
Treatment & Cornmunity & 32821700 & 4 & 8205430 & 1.25 & 0.2919 \\
& Depth & 91885100 & 1 & 91885100 & 14.02 & 0.0003 \\
& Communily $x$ Depth & 24605900 & 4 & 6151480 & 0.94 & 0.4436 \\
\hline Residual & & 917465000 & 140 & 6553320 & & \\
\hline Total & 1066780000 & 149 & & &
\end{tabular}

1066780000

149

Means by Community and Depth

\begin{tabular}{|c|c|c|}
\hline Community & Fungal Feeders $2\left(\sharp / m^{\wedge} 2\right)$ & $\mathbf{n}$ \\
\hline Mesic & 1740.89 & 30 \\
\hline Reclaimed & 2687.33 & 30 \\
\hline Riparian North & 1585.78 & 30 \\
\hline Riparian South & 2368.89 & 30 \\
\hline Xeric & 1500.44 & 30 \\
\hline \multicolumn{3}{|l|}{ Depth } \\
\hline $0.5 \mathrm{~cm}$ & 2759.33 & 75 \\
\hline $5-10 \mathrm{~cm}$ & 1194 & 75 \\
\hline
\end{tabular}

Table E-18. Analysis of Variance, EcMP Soil Arthropod Fungal Feeders 2

By Site

\begin{tabular}{lccccc} 
& Sum of Squares & df & Mean Square & F-ratio & p-value \\
Site & 103154000 & 14 & 7368170 & 1.03 & 0.4255 \\
\hline Residual & 963623000 & 135 & 7137950 & & \\
\hline Tolal & 1066780000 & 149 & & &
\end{tabular}

Means and Summary Statistics by Site

\begin{tabular}{|c|c|c|c|c|c|c|c|}
\hline Site & $\mathbf{n}$ & Average & Variance & Minimum & Maximum & Range & Coefflcient of Variation \\
\hline TR01 & 10 & 1000 & 446933 & 120 & 1960 & 1840 & 66.8531 \\
\hline TRO2 & 10 & 3076 & 16474800 & 0 & 13880 & 13880 & 131.954 \\
\hline TRO3N & 10 & 1420 & 1769930 & 0 & 4066.67 & \begin{tabular}{|l|}
4066.7 \\
\end{tabular} & 93.6893 \\
\hline TR03S & 10 & 1226.67 & 1898460 & 66.67 & 3933.33 & 3866.7 & 112.324 \\
\hline TR04 & 10 & 550 & 548210 & 0 & 2300 & 2300 & 134.62 \\
\hline TR05N & 10 & 1006.67 & 3004890 & 133.33 & 5866.67 & 5733.3 & 172.198 \\
\hline TR05S & 10 & 2600 & 10614300 & 0 & 11400 & 11400 & 125.306 \\
\hline TR06 & 10 & 2143.33 & 1923470 & 0 & 4200 & 4200 & 64.7072 \\
\hline TR07 & 10 & 2792 & 4931840 & 0 & 7240 & 7240 & 79.5406 \\
\hline TROB & 10 & 2583.33 & 14506700 & 0 & 11900 & 11900 & 147.436 \\
\hline TRO9 & 10 & 2686.67 & 7532140 & 333.33 & 7800 & 7466.7 & 102.152 \\
\hline TR10N & 10 & 2330.67 & 5115130 & 133.33 & 6933.33 & 6800 & 97.0395 \\
\hline TR10S & 10 & 3280 & 24571700 & 200 & 15866.7 & 15667 & 151.127 \\
\hline TR11 & 10 & 1596.67 & 10910400 & 0 & 10900 & 10900 & 206.874 \\
\hline TR12 & 10 & 1358 & 2820290 & $\overline{0}$ & 4600 & 4600 & 123.665 \\
\hline
\end{tabular}


Table E-19. Analysis of Variance, EcMP Arthropod Detritivores 1

By Community and Depth

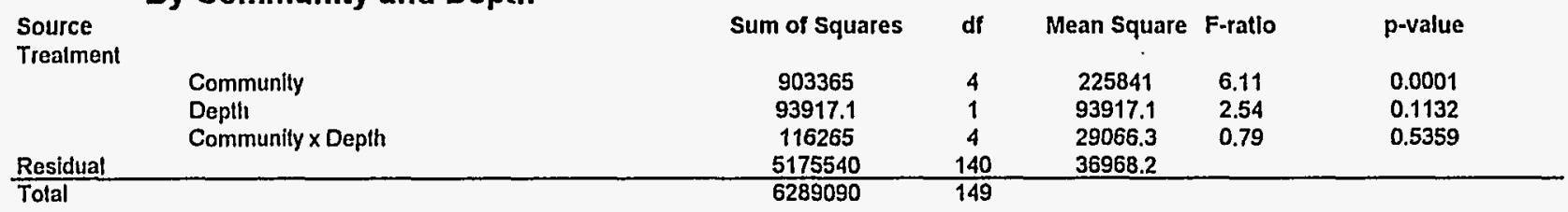

Means by Community and Depth

\begin{tabular}{|c|c|c|}
\hline Community & Detritlivores $1\left(\# / m^{\wedge} 2\right)$ & $\mathbf{n}$ \\
\hline Mesic & 78.2227 & 30 \\
\hline Reclaimed & 60 & 30 \\
\hline Riparian North & 138.667 & 30 \\
\hline Riparian South & 256.446 & 30 \\
\hline Xeric & 43.111 & 30 \\
\hline \multicolumn{3}{|l|}{ Depth } \\
\hline $0.5 \mathrm{~cm}$ & 140.311 & 75 \\
\hline $5-10 \mathrm{~cm}$ & 90.2669 & 75 \\
\hline
\end{tabular}

Table E-20. Analysis of Variance, EcMP Soil Arthropod Detritivores 1 By Site

\begin{tabular}{lccccc} 
& Sum of Squares & df & Mean Square & F-ratlo & p-value \\
Site & 2201320 & 14 & 157237 & 5.19 & 0.00 \\
Residual & 4087770 & 135 & 30279.8 & & \\
\hline Total & 6289090 & 149 & & &
\end{tabular}

Means and Summary Statistics by Site

\begin{tabular}{|c|c|c|c|c|c|c|c|}
\hline Site & $\mathrm{n}$ & Average & Varlance & Minimum & Maximum & Range & Coefficient of Varlation \\
\hline TR01 & 10 & 16 & 782.222 & 0 & 80 & 80 & 174.801 \\
\hline TRO2 & 10 & 68 & 6062.22 & 0 & 200 & 200 & 114.5 \\
\hline TR03N & 10 & 80.001 & 8691.43 & $\mathbf{0}$ & 266.67 & 266.67 & 116.533 \\
\hline TR03S & 10 & 173.335 & 32790 & 0 & 600 & 600 & 104.468 \\
\hline TR04 & 10 & 140.001 & 75259.1 & 0 & 900 & 900 & 195.951 \\
\hline TR05N & 10 & 206.666 & 84394.3 & 0 & 933.33 & 933.33 & 140.568 \\
\hline TR05S & 10 & 80.001 & 10666.8 & 0 & 266.67 & 266.67 & 129.099 \\
\hline TR06 & 10 & 106.666 & 15999.9 & 0 & 333.33 & 333.33 & 118.586 \\
\hline TR07 & 10 & 16 & 782.222 & 0 & 80 & 80 & 174.801 \\
\hline TR08 & 10 & 100 & 33580.2 & 0 & 600 & 600 & 183.249 \\
\hline TR09 & 10 & 64 & 2787.06 & 0 & 133.33 & 133.33 & 82.4885 \\
\hline TR10N & 10 & 129.333 & 22717.8 & 0 & 440 & 440 & 116.54 \\
\hline TR10S & 10 & 516.001 & 157869 & 66.67 & 1266.67 & 1200 & 77.0012 \\
\hline TR11 & 10 & 26.667 & 1370.4 & 0 & 100 & 100 & 138.819 \\
\hline TR12 & 10 & 6.667 & 444.489 & 0 & 66.67 & 66.67 & 316.228 \\
\hline
\end{tabular}


Table E-21. Analysis of Variance, EcMP Arthropod Detritivores 2

By Community and Depth

\begin{tabular}{llrrrrr} 
Source & Sum of Squares & df & Mean Square & F-ratio & p-value \\
Trealment & Community & & & & & \\
& Depth & 97587600 & 4 & 24396900 & 2.5 & 0.0454 \\
& Community $\times$ Depth & 222285100 & 1 & 22285100 & 2.28 & 0.1332 \\
Residual & & 49333200 & 4 & 12333300 & 1.26 & 0.2875 \\
\hline
\end{tabular}

Tolal

Means by Community and Depth

\begin{tabular}{l|l|c|}
\multicolumn{1}{l|}{ Communily } & Detriltivores $2\left(\# / \mathrm{m}^{\wedge} 2\right)$ & $\mathbf{n}$ \\
\hline Mesic & 451.222 & 30 \\
\hline Reclaimed & 672.667 & 30 \\
\hline Riparian North & 1633.33 & 30 \\
\hline Riparian Soulh & 2557.33 & 30 \\
\hline Xeric & 578.444 & 30 \\
\hline Deplh & \multicolumn{3}{|c|}{} \\
\hline $0-5 \mathrm{~cm}$ & 1564.04 & 75 \\
\hline $5-10 \mathrm{~cm}$ & 793.155 & 75 \\
\hline
\end{tabular}

(1)

Table E-22. Analysis of Variance, EcMP Soil Arthropod Detritivores 2

\section{By Site}

\begin{tabular}{lccccc} 
& Sum of Squares & df & Mean Square & F-ratio & p-value \\
Sito & 187378000 & 14 & 13384200 & 1.34 & 0.1925 \\
Residual & 1349120000 & 135 & 9993470 & & \\
\hline Total & 1536500000 & 149 & &
\end{tabular}

Means and Summary Statlstics by Site

\begin{tabular}{|c|c|c|c|c|c|c|c|}
\hline Slte & $\mathbf{n}$ & Average & Varlance & Minimum & Maximum & Range & Coefficient of Variation \\
\hline TR01 & 10 & 156 & 10115.6 & 40 & 320 & 280 & 64.4719 \\
\hline TRO2 & 10 & 512 & 100196 & 0 & 1160 & 1160 & 61.8236 \\
\hline TRO3N & 10 & 1073.33 & 941678 & 66.67 & 2800 & 2733.3 & 90.41 \\
\hline TRO3S & 10 & 1780 & 2510670 & 0 & 4600 & 4600 & 89.0174 \\
\hline TR04 & 10 & 140 & 28839.3 & 0 & 533.33 & 533.33 & 121.301 \\
\hline TR05N & 10 & 2126.67 & 17645900 & 0 & 13266.7 & 13267 & 197.525 \\
\hline TRO5S & 10 & 1286.67 & 2797090 & 0 & 4533.33 & 4533.3 & 129.983 \\
\hline TRRo6 & 10 & 1530 & 1923570 & 0 & 3733.33 & 3733.3 & 90.6489 \\
\hline TR07 & 10 & 1236 & 788427 & 360 & 3080 & 2720 & 71.8393 \\
\hline TR08 & 10 & 416.667 & 176358 & 0 & 1300 & 1300 & 100.788 \\
\hline TRO9 & 10 & 365.333 & 222714 & 0 & 1400 & 1400 & 129.177 \\
\hline TR1ON & 10 & 1700 & 4860770 & 0 & 7133.33 & 7133.3 & 129.689 \\
\hline TR10S & 10 & 4605.33 & 117286000 & 160 & 35266.7 & \begin{tabular}{|l|}
5107 \\
\end{tabular} & 235.159 \\
\hline TR11 & 10 & 701.666 & 605150 & 0 & 2200 & 2200 & 110.867 \\
\hline TR12 & 10 & 49.334 & 4505.7 & $\frac{5}{0}$ & 200 & 200 & 136.061 \\
\hline
\end{tabular}


Table E-23. Analysis of Variance, EcMP Arthropod Total Detritivores

By Community and Depth

\begin{tabular}{llccccc} 
Source & & Sum of Squares & df & Mean Square & F-ratlo & p-value \\
Trealment & & & & & & 0.0208 \\
& Communily & 116701000 & 4 & 29175200 & 3 & 0.1095 \\
& Depth & 25272500 & 1 & 25272500 & 2.59 & 0.2596 \\
\hline & Communily x Depth & 52054100 & 4 & 13013500 & 1.34 & \\
\hline Residual & & 1363630000 & 140 & 9740220 & & \\
\hline Total & & 1557660000 & 149 & & &
\end{tabular}

Means by Community and Depth

\begin{tabular}{|c|c|c|}
\hline Community & Total Detritlvores $\left(\# / \mathrm{m}^{\wedge} \mathbf{2}\right)$ & $\mathbf{n}$ \\
\hline Mesic & 529.444 & 30 \\
\hline Reclaimed & 732.667 & 30 \\
\hline Riparian North & 1772 & 30 \\
\hline Riparian South & 2813.78 & 30 \\
\hline Xeric & 621.555 & 30 \\
\hline \multicolumn{3}{|l|}{ Depth } \\
\hline $0-5 \mathrm{~cm}$ & 1704.36 & 75 \\
\hline $5-10 \mathrm{~cm}$ & 883.422 & 75 \\
\hline
\end{tabular}

Table E-24. Analysis of Variance, EcMP Soil Arthropod Total Detritivores By Site

\begin{tabular}{lccccc} 
& Sum of Squares & df & Mean Square & F-ratio & p-value \\
Sile & 225956000 & 14 & 16139700 & 1.64 & 0.077 \\
Residual & 1331700000 & 135 & 9864460 & & \\
\hline Total & 1557660000 & 149 & & &
\end{tabular}

Means and Summary Statistics by Site

\begin{tabular}{|l|c|c|c|c|c|c|c|} 
Sile & $n$ & Average & Variance & Minimum & Maximum & \multicolumn{2}{c}{ Range Coefficlent of Variation } \\
\hline TR01 & 10 & 172 & 14951.1 & 40 & 400 & 360 & 71.09 \\
\hline TR02 & 10 & 580 & 137333 & 40 & 1360 & 1320 & 63.894 \\
\hline TR03N & 10 & 1153.33 & 1015360 & 66.67 & 2866.67 & 2800 & 87.3684 \\
\hline TR03S & 10 & 1953.33 & 2441530 & 0 & 4666.67 & 4666.7 & 79.9935 \\
\hline TR04 & 10 & 280 & 92394.9 & 0 & 1000 & 1000 & 108.559 \\
\hline TR05N & 10 & 2333.33 & 18323000 & 0 & 13666.7 & 13667 & 183.451 \\
\hline TR05S & 10 & 1366.67 & 3059010 & 0 & 4733.33 & 4733.3 & 127.976 \\
\hline TR06 & 10 & 1636.67 & 2024800 & 0 & 4000 & 4000 & 86.9423 \\
\hline TR07 & 10 & 1252 & 798951 & 360 & 3080 & 2720 & 71.393 \\
\hline TR08 & 10 & 516.667 & 270185 & 0 & 1600 & 1600 & 100.605 \\
\hline TR09 & 10 & 429.333 & 228228 & 0 & 1533.33 & 1533.3 & 111.273 \\
\hline TR10N & 10 & 1829.33 & 4880820 & 120 & 7200 & 7080 & 120.769 \\
\hline TR10S & 10 & 5121.33 & 114030000 & 320 & 35333.3 & 35013 & 208.509 \\
\hline TR11 & 10 & 728.333 & 645620 & 0 & 2300 & 2300 & 110.321 \\
\hline TR12 & 10 & 56 & 5206.86 & 0 & 200 & 200 & 128.855 \\
\hline
\end{tabular}


Table E-25 . Analysis of Variance, EcMP Soil Arthropod Total Fungivores By Community and Depth

\begin{tabular}{llccccc} 
Source & & Sum of Squares & df & Mean Square & F-ratio & p-value \\
Treatment & & & & & & \\
& Communily & 104426000 & 4 & 26106600 & 2.69 & 0.0339 \\
& Depth & 155028000 & 1 & 155028000 & 15.95 & 0.0001 \\
& Communily $\times$ Depth & 90723900 & 4 & 22681000 & 2.33 & 0.0587 \\
\hline Residual & & 1361040000 & 140 & 9721740 & & \\
\hline Total & & 1711220000 & 149 & &
\end{tabular}

Means by Community and Depth

Community
\begin{tabular}{|l|c|c|}
\hline Mesic & Total Funglvores $\left(\# / \mathrm{m}^{\wedge} 2\right)$ & $\mathrm{n}$ \\
\hline Reclaimed & 1749.78 & 30 \\
\hline Riparian North & 2724.22 & 30 \\
\hline Riparian South & 2603.11 & 30 \\
\hline Xeric & 4121.33 & 30 \\
\hline Depth & 1942.67 & 30 \\
\hline $0.5 \mathrm{~cm}$ & 3644.84 & 75 \\
\hline $5-10 \mathrm{~cm}$ & 1611.6 & 75 \\
\hline
\end{tabular}

Table E-26. Analysis of Variance, EcMP Soil Arthropod Total Fungivores

\begin{tabular}{lccccc} 
& By Site & & & & \\
Sill & Sum of Squares & df & Mean Square & F-ratio & p-value \\
Residual & 223741000 & 14 & 15981500 & 1.45 & 0.1386 \\
\hline Tolal & 1487480000 & 135 & 11018400 & & \\
\hline
\end{tabular}

Means and Summary Statistics by Site

\begin{tabular}{|c|c|c|c|c|c|c|c|}
\hline Site & $n$ & Average & Varlance & Minimum & Maximum & Range & Coefficient of Variatlon \\
\hline TR01 & 10 & 1000 & 446933 & 120 & 1960 & 1840 & 66.8531 \\
\hline TR02 & 10 & 3096 & 16526300 & 0 & 13920 & 13920 & 131.307 \\
\hline TR03N & 10 & 2106.67 & 3655510 & 133.33 & 5200 & 5066.7 & 90.7566 \\
\hline TRO3S & 10 & 2853.33 & 16881800 & 400 & 14133.3 & 13733 & 143.998 \\
\hline TR04 & 10 & 556.666 & 553346 & 0 & 2300 & 2300 & 133.63 \\
\hline TR05N & 10 & 2700 & 8082220 & 266.67 & 8866.67 & 8600 & 105.293 \\
\hline TR05S & 10 & 5813.33 & 35916800 & 0 & 17600 & 17600 & 103.092 \\
\hline TROG & 10 & 3470 & 8052950 & 0 & 10100 & 10100 & 81.7802 \\
\hline TR07 & 10 & 2876 & 5177050 & 0 & 7240 & 7240 & 79.1138 \\
\hline TROB & 10 & 2583.33 & 14506700 & 0 & 11900 & 11900 & 147.436 \\
\hline TRO9 & 10 & 2713.33 & 7794860 & 333.33 & 8000 & 7666.7 & 102.897 \\
\hline TR10N & 10 & 3002.67 & 7780850 & 133.33 & 7733.33 & 7600 & 92.898 \\
\hline TR10S & 10 & 3697.33 & 26169700 & 280 & 16533.3 & 16253 & 138.36 \\
\hline TR11 & 10 & 1596.67 & 10910400 & 0 & 10900 & 10900 & 206.874 \\
\hline TR12 & 10 & 1358 & 2820290 & 0 & 4600 & 4600 & 123.665 \\
\hline
\end{tabular}


Table E-27. Analysis of Variance, EcMP Soil Arthropod General Predators

\begin{tabular}{llccccc}
\multicolumn{1}{l}{ Source } & By Community and Depth & Sum of Squares & df & Mean Square F-ratio & p-value \\
Treatment & & & & & & \\
& Communily & 6418920 & 4 & 1604730 & 5.24 & 0.0006 \\
& Depth & 1904810 & 1 & 1904810 & 6.22 & 0.0138 \\
Residual & Communily $x$ Depth & 2648250 & 4 & 662064 & 2.16 & 0.0762 \\
\hline Total & & 42845200 & 140 & 306037 & & \\
\hline
\end{tabular}

Means by Community and Depth

\begin{tabular}{|c|c|c|}
\hline Community & General Predators $\left(\# / \mathrm{m}^{\wedge} 2\right)$ & $\mathbf{n}$ \\
\hline Mesic & 101.667 & 30 \\
\hline Reclaimed & 270.223 & 30 \\
\hline Riparian North & 498.667 & 30 \\
\hline Riparian South & 701.777 & 30 \\
\hline \begin{tabular}{|l|} 
Xeric \\
\end{tabular} & 296.222 & 30 \\
\hline \multicolumn{3}{|l|}{ Depth } \\
\hline $0-5 \mathrm{~cm}$ & 486.4 & 75 \\
\hline $5.10 \mathrm{~cm}$ & 261.022 & 75 \\
\hline
\end{tabular}

Table E-28. Analysis of Variance, EcMP Soi! Arthropod General Predators By Site

\begin{tabular}{lccccc} 
& Sum of Squares & df & Mean Square & F-ratio & p-value \\
Site & 14542000 & 14 & 1038710 & 3.57 & 0.0001 \\
Residual & 39275200 & 135 & 290928 & & \\
\hline Total & 53817200 & 149 & & &
\end{tabular}

Means and Summary Statistics by Site

\begin{tabular}{|c|c|c|c|c|c|c|c|}
\hline Site & $\mathbf{n}$ & Average & Varlance & Minimum & Maximum & Range & Coefficlent of Varlation \\
\hline TRO1 & 10 & 112 & 16284.4 & 0 & 440 & 440 & 113.938 \\
\hline TR02 & 10 & 280 & 33066.7 & 80 & 680 & 600 & 64.9437 \\
\hline TROBN & 10 & 479.999 & 198321 & 0 & 1400 & 1400 & 92.7777 \\
\hline TR03S & 10 & 513.333 & 269679 & 0 & 1466.67 & 1466.7 & 101.164 \\
\hline TR04 & 10 & 10 & 1000 & 0 & 100 & 100 & 316.228 \\
\hline TRO5N & 10 & 806.667 & 320446 & 133.33 & 1600 & \begin{tabular}{|l|}
1466.7 \\
\end{tabular} & 70.1751 \\
\hline TR05S & 10 & 1120 & 2143020 & 0 & 4800 & 4800 & 130.706 \\
\hline TR06 & 10 & 726.666 & 634518 & 0 & 2800 & 2800 & 109.619 \\
\hline TR07 & 10 & 248 & 74595.6 & 0 & 720 & 720 & 110.13 \\
\hline TR08 & 10 & 136.667 & 31962.9 & 0 & 500 & 500 & 130.816 \\
\hline TR09 & 10 & 426.001 & 266770 & 66.67 & 1600 & 1533.3 & 121.243 \\
\hline \begin{tabular}{|l|} 
TR1ON \\
\end{tabular} & 10 & 209.334 & 118915 & 0 & 1133.33 & 1133.3 & 164.732 \\
\hline TR10S & 10 & 472 & 244512 & 0 & 1466.67 & 1466.7 & 104.763 \\
\hline TR11 & 10 & 15 & 1138.89 & 0 & 100 & 100 & 224.983 \\
\hline TR12 & 10 & 50 & 9691.31 & 0 & 300 & 300 & 196.889 \\
\hline
\end{tabular}


Table E-29. Analysis of Variance, EcMP Soil Invertebrate Arthropod Predators

By Community and Depth

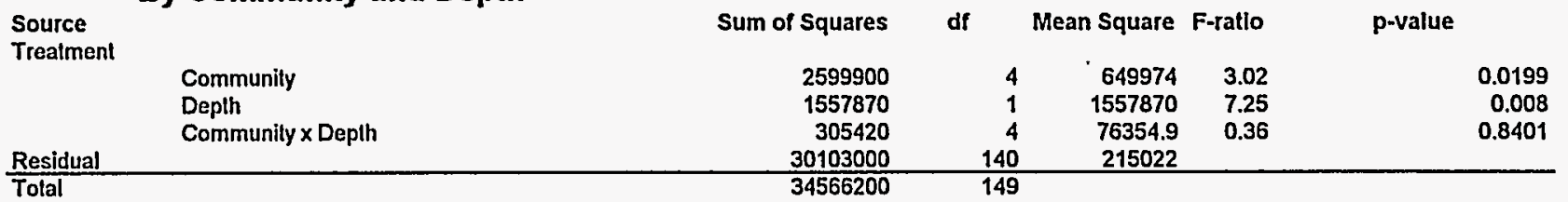

Means by Community and Depth

Community
\begin{tabular}{|l|c|c|}
\hline Mesic & Arthropod Predators(\#/m^2) & $\mathrm{n}$ \\
\hline Reclaimed & 211.111 & 30 \\
\hline Riparian North & 540.889 & 30 \\
\hline Riparian South & 169.333 & 30 \\
\hline Xeric & 238.667 & 30 \\
\hline Depth & 270.667 & 30 \\
\hline $0.5 \mathrm{~cm}$ & 388.044 & 75 \\
\hline $5-10 \mathrm{~cm}$ & 184.223 & 75 \\
\hline
\end{tabular}

Table E-30. Analysis of Variance, EcMP Soil Invertebrate Arthropod Predators

\section{By Site}

\begin{tabular}{lccccc} 
& Sum of Squares & df & Mean Square & F-ratlo & p-value \\
Sile & 5705680 & 14 & $\mathbf{4 0 7 5 4 8}$ & 1.91 & 0.0307 \\
Residual & 28860500 & 135 & 213782 & & \\
\hline Tolal & 34566200 & 149 & & &
\end{tabular}

Means and Summary Statistics by Site

\begin{tabular}{|c|c|c|c|c|c|c|c|}
\hline Site & $\mathbf{n}$ & Average & Variance & Minimum & Maximum & Range & Coefficlent of Variation \\
\hline TR01 & 10 & 204 & 46382.2 & 40. & 760 & 720 & 105.571 \\
\hline TRO2 & 10 & 360 & 79288.9 & 0 & 880 & 880 & 78.2175 \\
\hline TRO3N & 10 & 273.333 & 82419.5 & 0 & 800 & 800 & 105.032 \\
\hline TRO3S & 10 & 86.668 & 15851.8 & 0 & 400 & 400 & 145.271 \\
\hline TR04 & 10 & 156.667 & 24209.9 & 0 & 500 & 500 & 99.316 \\
\hline TR05N & 10 & 140 & 25135.8 & $\overline{0}$ & 400 & 400 & 113.245 \\
\hline TR05S & 10 & 100.001 & 12098.5 & 0 & 333.33 & 333.33 & 109.992 \\
\hline TR06 & 10 & 503.333 & 580850 & 0 & 2533.33 & 2533.3 & 151.418 \\
\hline TR07 & 10 & 712 & 1002240 & 0 & 3400 & 3400 & 140.607 \\
\hline TR0B & 10 & 490 & 534580 & 0 & 1900 & 1900 & 149.214 \\
\hline TRO9 & 10 & 420.667 & 160637 & 0 & 1200 & 1200 & 95.2761 \\
\hline TRION & 10 & 94.667 & 15938.7 & D & 400 & 400 & 133.361 \\
\hline TR10S & 10 & 529.333 & 585840 & 0 & 2400 & 2400 & 144.597 \\
\hline TR11 & 10 & 116.667 & 15555.7 & 0 & 300 & 300 & 106.905 \\
\hline TR12 & 10 & 104.667 & 25699.2 & 0 & 400 & 400 & 153.162 \\
\hline
\end{tabular}


Table E-31. Analysis of Variance, EcMP Soil Invertebrate Total Arthropod Predators By Community and Depth

\begin{tabular}{|c|c|c|}
\hline $\begin{array}{l}\text { Source } \\
\text { Treatment }\end{array}$ & $\begin{array}{l}\text { Communily } \\
\text { Depth } \\
\text { Community x Depth }\end{array}$ & \\
\hline \multicolumn{3}{|l|}{ Residual } \\
\hline \multicolumn{3}{|c|}{ Means by Community and Depth } \\
\hline Community & Total Arthropod Predators $\left(\# / \mathrm{m}^{\wedge} \mathbf{2}\right)$ & $\mathbf{n}$ \\
\hline Mesic & 312.778 & 30 \\
\hline Reclaimed & 811.111 & 30 \\
\hline Riparian North & 668 & 30 \\
\hline Riparian South & 940.444 & 30 \\
\hline Xeric & 566.889 & 30 \\
\hline \multicolumn{3}{|l|}{ Depth } \\
\hline $0.5 \mathrm{~cm}$ & 874.445 & 75 \\
\hline $5-10 \mathrm{~cm}$ & 445.245 & 75 \\
\hline
\end{tabular}

\begin{tabular}{ccccc} 
Sum of Squares & df & Mean Square & F-ratio & p-value \\
6923410 & 4 & 1730850 & 2.89 & 0.0246 \\
6907970 & 1 & 6907970 & 11.53 & 0.0009 \\
4256790 & 4 & 1064200 & 1.78 & 0.1369 \\
83860000 & 140 & 599000 & & \\
\hline 101948000 & 149 & & &
\end{tabular}

149

Table E-32. Analysis of Variance, EciviF Soil invertebrate Total Arthropod Predators

By Site

\begin{tabular}{lccccc} 
& Sum of Squares & df & Mean Square & F-ratlo & p-value \\
Site & 19988000 & 14 & 1427710 & 2.35 & 0.006 \\
\hline Residual & 81960100 & 135 & 607112 & & \\
\hline Total & 101948000 & 149 & & &
\end{tabular}

Means and Summary Statlstics by Site

\begin{tabular}{|c|c|c|c|c|c|c|c|}
\hline Site & $\mathbf{n}$ & Average & Variance & Minimum & Maximum & Range & Coefficient of Varlation \\
\hline TR01 & 10 & 316 & 77315.6 & 10 & 316 & 77315.6 & 87.9926 \\
\hline TR02 & 10 & 640 & 84977.8 & 10 & 640 & 84977.8 & 45.5484 \\
\hline TR03N & 10 & 753.333 & 305233 & 10 & 753.333 & 305233 & 73.338 \\
\hline TR03S & 10 & 600 & 328888 & 10 & 600 & 328888 & 95.5812 \\
\hline TR04 & 10 & 166.667 & 23950.6 & 10 & 166.667 & 23950.6 & 92.8558 \\
\hline TR05N & 10 & 946.667 & 389928 & 10 & 946.667 & 389928 & 65.9622 \\
\hline TR05S & 10 & 1220 & 2342770 & 10 & 1220 & 2342770 & 125.46 \\
\hline TR06 & 10 & 1230 & 1248510 & 10 & 1230 & 1248510 & 90.8429 \\
\hline TR07 & 10 & 960 & 1334760 & 10 & 960 & 1334760 & 120.345 \\
\hline TROB & 10 & 626.667 & 548839 & 10 & 626.667 & 548839 & 118.219 \\
\hline TRO9 & 10 & 846.667 & 770381 & 10 & 846.667 & 770381 & 103.667 \\
\hline TR10N & 10 & 304 & 161455 & 10 & 304 & 161455 & 132.176 \\
\hline TR10S & 10 & 1001.33 & 1409600 & 10 & 1001.33 & 1409600 & 118.568 \\
\hline TR11 & 10 & 131.667 & 17805.7 & 10 & 131.667 & 17805.7 & 101.345 \\
\hline TR12 & 10 & 154.667 & 62279.1 & 10 & 154.667 & 62279.1 & 161.352 \\
\hline
\end{tabular}


Table E-33. Analysis of Variance, EcMP Soil Arthropod Herbivores

\begin{tabular}{llccccc}
\multicolumn{1}{c}{ Source } & By Community and Depth & Sum of Squares & df & Mean Square F-ratio & p-value \\
Treatment & & & & 1309700 & 4.18 & 0.0031 \\
& Community & 5238810 & 4 & 1490020 & 4.76 & 0.0309 \\
& Depth & 1490020 & 1 & 377285 & 1.2 & 0.3118 \\
Residual & Communily x Depth & 1509140 & 4 & 313293 & & \\
\hline Tolal & & 43861000 & 140 & 149 & &
\end{tabular}

Means by Community and Depth

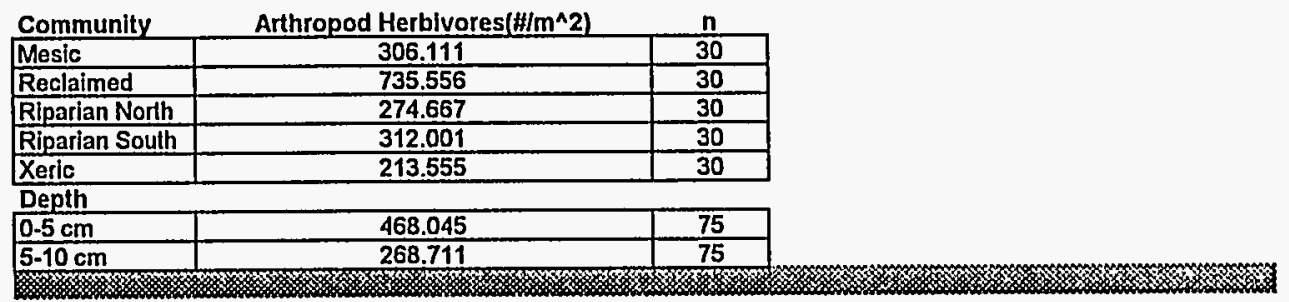

Table E-34. Analysis of Variance, EcMP Soil Arthropod Herbivores

By Site

\begin{tabular}{lccccc} 
& Sum of Squares & df & Mean Square & F-ratio & p-value \\
Sile & 16259000 & 14 & 1161360 & 4.37 & 0.00 \\
\hline Residual & 35840000 & 135 & 265481 & & \\
\hline Total & 52099000 & 149 & & &
\end{tabular}

Means and Summary Statistics by Site

\begin{tabular}{|c|c|c|c|c|c|c|c|}
\hline Slte & $n$ & Average & Variance & Minimum & Maximum & Range & Coefficlent of Variation \\
\hline TR01 & 10 & 164 & 117138 & 0 & 1120 & 1120 & 208.691 \\
\hline TR02 & 10 & 580 & 215556 & 0 & 1160 & 1160 & 80.0482 \\
\hline TR03N & 10 & 80 & 15604.8 & 0 & 400 & 400 & 156.149 \\
\hline TR03S & 10 & 93.335 & 13036.9 & 0 & 333.33 & 333.33 & 122.333 \\
\hline TR04 & 10 & 256.667 & 103470 & 0 & 900 & 900 & 125.325 \\
\hline TR05N & 10 & 520.001 & 863014 & 0 & 3066.67 & 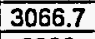 & 178.651 \\
\hline TRO5S & 10 & 473.333 & 947605 & 0 & 3200 & 3200 & 205.659 \\
\hline TR06 & 10 & 386.666 & 316838 & 0 & 1933.33 & 1933.3 & 145.574 \\
\hline TR07 & 10 & 1440 & 583111 & 280 & 2160 & 1880 & 53.029 \\
\hline TR0B & 10 & 336.667 & 115172 & 0 & 1000 & 1000 & 100.803 \\
\hline TR09 & 10 & 430.001 & 193335 & 0 & 1133.33 & 1133.3 & 102.255 \\
\hline TR10N & 10 & 224 & 116417 & 0 & 1066.67 & 1066.7 & 152.321 \\
\hline TR10S & 10 & 369.334 & 336635 & 0 & 1866.67 & 1866.7 & 157.094 \\
\hline TR11 & 10 & 81.667 & 8731.54 & 0 & 250 & 250 & 114.419 \\
\hline TR12 & 10 & 90 & 36555.6 & 0 & 600 & 600 & 212.439 \\
\hline
\end{tabular}


Table E-35. Analysis of Variance, EcMP Soil Cryptostigmatid Mite Richness By Community and Depth

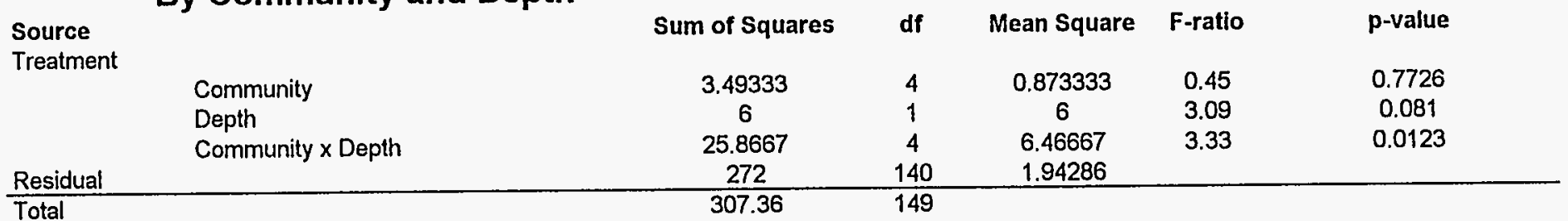

Means by Community and Depth

\begin{tabular}{|c|c|c|}
\hline Community & Mean Richness & $\mathbf{n}$ \\
\hline Mesic & 1.6 & 30 \\
\hline Reclaimed & 1.76667 & 30 \\
\hline Riparian North & 2.03333 & 30 \\
\hline Riparian South & 1.76667 & 30 \\
\hline Xeric & 1.63333 & 30 \\
\hline \multicolumn{3}{|l|}{ Depth } \\
\hline $0-5 \mathrm{~cm}$ & 1.96 & 75 \\
\hline $5-10 \mathrm{~cm}$ & 1.56 & 75 \\
\hline
\end{tabular}

Table E-36. Analysis of Variance, EcMP Soil Cryptostigmatid Mite Richness

\section{By Site}

\begin{tabular}{lcccrr} 
& Sum of Squares & df & Mean Square & F-ratio & p-value \\
Site & 77.36 & 14 & $5.5257 i$ & 3.24 & 0.0002 \\
Residual & 230.0 & 135 & 1.7037 & & \\
\hline Total & 307.36 & 149 &
\end{tabular}

Means and Summary Statistics by Site

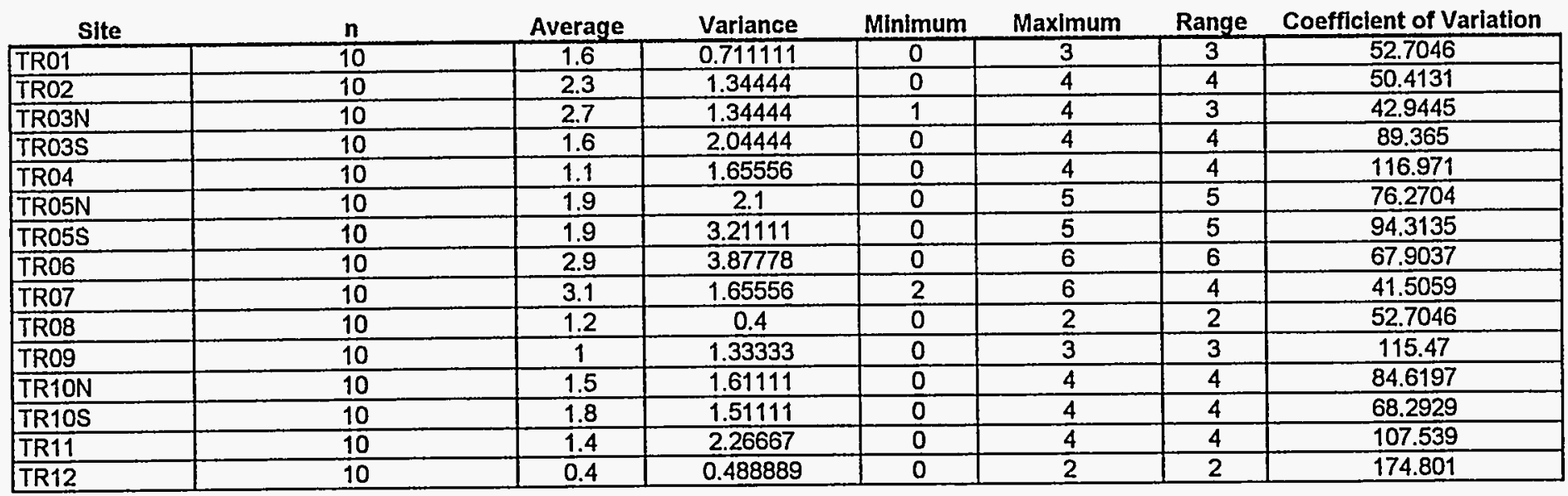


Table E-37. Analysis of Variance, EcMP Soil Prostigmatid Mite Richness By Community and Depth

Source

Treatment

Sum of Squares

Depth

Residual

Community $\times$ Depth

Total

Means by Community and Depth

\begin{tabular}{|c|c|c|}
\hline Community & Mean Richness & $\mathbf{n}$ \\
\hline Mesic & 8.34483 & 30 \\
\hline Reclaimed & 7.8954 & 30 \\
\hline Riparian North & 4.65402 & 30 \\
\hline Riparian South & 4.07931 & 30 \\
\hline Xeric & 7.63678 & 30 \\
\hline
\end{tabular}

Xeric

Depth

$0-5 \mathrm{~cm}$

$5-10 \mathrm{~cm}$

493333

\begin{tabular}{l}
4.93333 \\
4.06667 \\
\hline
\end{tabular}

$$
19.8
$$

28.1667

Mean Square F-ratio

p-value

7.66667

965.5

$\begin{array}{cc}4.95 & 0.76 \\ 28.1667 & 4.33 \\ 1.91667 & 0.29 \\ 6.49905 & \end{array}$

0.5519

0.0392

0.8809

Table E-38. Analysis of Variance, EcMP Soil Prostigmatid Mite Richness

\section{By Site}

\begin{tabular}{lccccc} 
& Sum of Squares & df & Mean Square & F-ratio & p-value \\
Site & 346.4 & 14 & 24.7429 & 5.40 & 0.0000 \\
Residual & 619.1 & 135 & 4.58593 & & \\
\hline Total & 965.5 & 149 & &
\end{tabular}

\section{Means and Summary Statistics by Site}

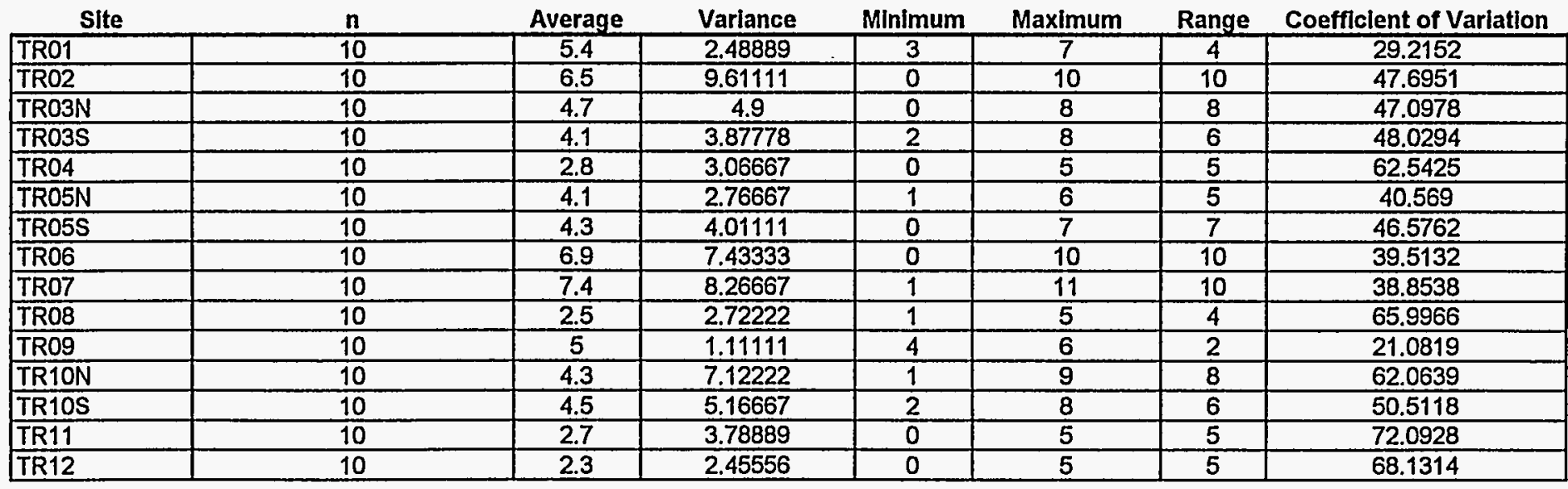


Table E-39. Summary Findings and Ranked Community, Depth and Site Soil Invertebrate Means

\begin{tabular}{|c|c|c|c|c|c|c|c|}
\hline Variable & $\begin{array}{c}\text { Community Effect } \\
\text { Slgnificant at atpha=0.1? }\end{array}$ & Ranked Community Means & $\begin{array}{c}\text { Depth Effect } \\
\text { Signiflcant at alpha=0.1? }\end{array}$ & Ranked Depth Means & $\begin{array}{l}\text { Community } \times \text { Depth Interaction } \\
\text { Slgniflcant at alpha }=0.1 \text { ? }\end{array}$ & $\begin{array}{c}\text { Site Eifect } \\
\text { Significant at alpha }=0.1 ?\end{array}$ & Ranked Site Means \\
\hline $\begin{array}{l}\text { Protozoa } \\
\text { Amoebae }\end{array}$ & Yes & RipN $>$ RipS $>$ Xeric $>$ Reclaimed $>$ Mesic $\mid$ & No & $0.5>5-10$ & No & Yes & $\begin{array}{c}T R 05 N>T R 05 S>T R 03 N>T R 01>T R 0 B>T R 03 S>T R 12> \\
T R 11>T R 10 N>T R 02>T R 06>T R 10 S>T R 04>T R 09\end{array}$ \\
\hline Flagellates & Yes & RipN>RipS $>$ Reclaimed $>$ Xeric>Mesic & No & $0.5 \times 5.10$ & No & Yes & 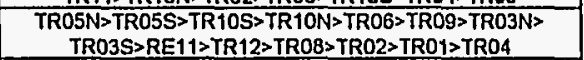 \\
\hline Ciliates & No & RipN $>$ Xeric $>$ RipS $>$ Mesic $>$ Reclaimed & No & $0.5 \times 5-10$ & No & No & $\begin{array}{l}T R 05 N>T R 12>T R 11>T R 10 S>T R 01>T R 0>T R 05 S> \\
T R 03 N>T R 03 S>T R 10 N>T R O B>T R 02>T R O 9>T R 04 \\
\end{array}$ \\
\hline \begin{tabular}{|l|} 
Nematodes \\
Ominivore/Predator
\end{tabular} & No & RipS $>$ Reclaimed $>$ RipN $>$ Mesic $>$ Xeric & No & $0.5>5-10$ & No & Yes & $\begin{array}{c}T R 10 S>T R 05 S>T R 09>T R 10 N>T R 05 N>T R 07>T R 11>T R 04>T \\
T R 06>T R 08>T R 02>T R 12>T R O 1>T R 03 N>T R 03 S\end{array}$ \\
\hline Fungal feeders & No & Mes|c>RipS>RipN>Xeric>Reclaimed & No & $0.5 \times 5-10$ & No & $\overline{\text { Yes }}$ & 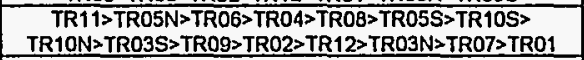 \\
\hline Bacterial Fceders & No & Mesic $>$ Xeric>Reclaimed $>$ RipS $>$ RipN & No & $0.5>5 \cdot 10$ & No & Yes & $\begin{array}{l}T R 06>T R 11>T R 05>T R 07>T R 05 N>T R 04>T R 08> \\
T R 10 S>T R 02>T R 09>T R 12>T R 03 S>T R 03 N>T R 01>T R 10 N \\
\end{array}$ \\
\hline Plant Parasites & No & Mesic $>$ RipN $>$ Reclaimed>RipS $>$ Xerlc & No & $0.5>5.10$ & No & Yes & $\begin{array}{l}\text { TR05N>TR07>TR02>TR } 11>\text { TR05S }>\text { TR } 10 N>\text { TR } 105> \\
T R 03 S>T R 03 N>T R 01>T R 06>T R 04>T R 0 B>T R+2>T R 09 \\
\end{array}$ \\
\hline $\begin{array}{l}\text { Arthropods } \\
\text { Fungal Feeders } 1\end{array}$ & Yes & RipS $>$ RipN $>$ Xeric $>$ Reclaimed $>$ Mesic & Yes & $0.5>5.10$ & Yes & Yes & $\begin{array}{c}\text { TR05S>TR05N }>T R 03 S>T R 06>T R 03 N>T R 10 N>T R 10 S> \\
T R 07>T R 09>T R 02>T R 11=T R 12=T R 01=T R 08\end{array}$ \\
\hline Fungal Feeders 2 & No & Reclaimed $>$ RipS $>$ Mesic $>$ RipN $>$ Xeric & Yes & $0.5 \times 5 \cdot 10$ & No & No & 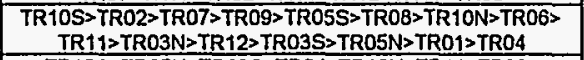 \\
\hline Detritivores 1 & Yes & RipS>RipN>Meslc>Reclaimed>Xeric & No & $0.5 \times 5.10$ & No & Yes & 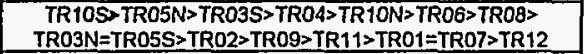 \\
\hline$\overline{\text { Detritivores } 2}$ & Yes & RipS>RipN>Reclaimed>Xeric>Mesic & No & $0.5 \times 5 \cdot 10$ & No & No & $\begin{array}{l}\text { TR10S>TRO5N>TR03S>TR } 10 N>T R 06>T R 05 S>T R 07> \\
T R 03 N>T R 11>T R 02>T R 08>T R 09>T R 01>T R 04>T R 12 \\
T\end{array}$ \\
\hline Detritivores Total & Yos & RipS>RipN>Reclaimed>Xeric>Mesic| & No & $0.5>5-10$ & No & Yes & \begin{tabular}{|c|c|} 
TR10S $>$ TROSN $>$ TROOSS $>$ TR $10 N>T R O 6>T R O 5 S>T R O 7>T R 03 N$ \\
TR $11>T R 02>T R 08>T R 09>T R 04>T R 01>T R 12$
\end{tabular} \\
\hline \begin{tabular}{|l|l} 
Fungivores Total \\
\end{tabular} & Yes & $\mid$ RipS>Reclalmed>RipN>Xeric>Mesic & Yos & $0.5>5 \cdot 10$ & Yes & No & 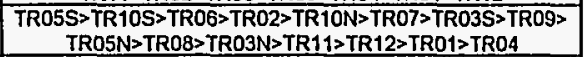 \\
\hline General Predalors & Yes & RipS $>$ RipN>Xeric>Reclaimed>Mesic & Yes & $0.5>5 \cdot 10$ & Yes & Yes & 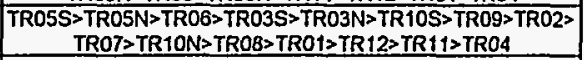 \\
\hline \begin{tabular}{|l} 
Arthropod Predators \\
\end{tabular} & Yes & $\mid$ Reclaimed $>$ Xeric $>$ RipS $>$ Mesic $>$ RipN & Yes & $0.5>5 \cdot 10$ & No & Yes & $\begin{array}{l}T R 07>T R 10 S>T R 06>T R 08>T R 09>T R 02>T R 03 N>T R 01> \\
T R O 4>T R 05 N>T R 11>T R 12>T R 05 S>T R 10 N>T R 03 S\end{array}$ \\
\hline Total Predators & Yes & $\mid$ Reclaimed $>$ Xeric $>$ RipS $>$ Mesic $>$ RipN & Yes & $0.5 \times 5 \cdot 10$ & No & Yes & 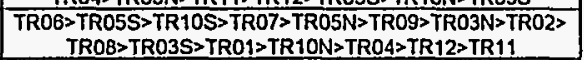 \\
\hline Total Herbivores & Yes & Reclaimed>RipS>Mesic>RipN>Xeric| & $\overline{\text { Yes }}$ & $0.5 \times 5 \cdot 10$ & No & Yes & 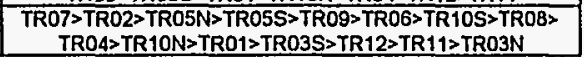 \\
\hline
\end{tabular}

$\stackrel{m}{\$}$

RipN=Riparian North, RipS= Riparian South, $\leqslant \quad$ Appendix B for Site and Community Descriptions 
APPENDIX F) RECLAMATION MONITORING

AUTHORS:

JODY K. NELSON

ALISON DEANS 


\section{TABLE OF CONTENTS}

\section{APPENDIX F) RECLAMATION MONITORING}

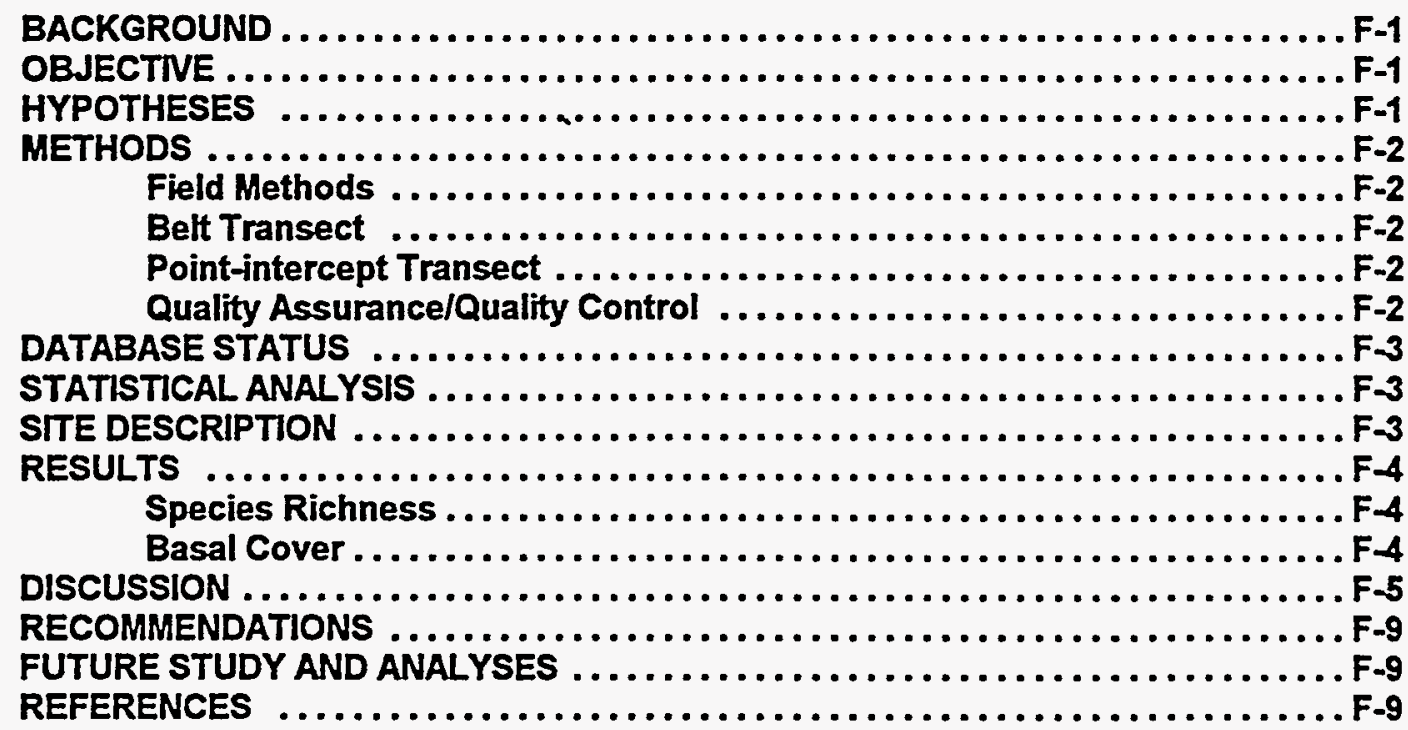

\section{LIST OF FIGURES}

Figure F-1. Comparison of $\mathbf{8 8 1}$ Hillside Reclamation Monitoring Data (1993 \& 1994) with Mesic Community (1994)

\section{LIST OF TABLES}

Table F-1. 1994 Reclamation Monitoring (881 Hillside)

Species Richness.

Table F-2. 1994 Reclamation Monitoring (881 Hillside) Species Richness - Summary and Comparison to Mesic Community and Sites.

Table F-3. $\quad 1993 \& 1994881$ Hillside Reclamation Monitoring Basal Cover Data.

Table F-4. \% Native and \% Annual Species Comparisons Between the 881 Hillside and Mesic Community.

Table F-5. Comparison of $\mathbf{8 8 1}$ Hillside Reclamation Monitoring Data with the Mesic Community 


\section{BACKGROUND}

Human disturbance of the landscape often results in removal of the native vegetation which may leave the soil exposed to erosion. Additionally, the native vegetation is often replaced by nonnative, exotic species. This has resulted in large scale alterations to the native ecosystems which were once present and often lead to the extinction of some components of localized floras. Environmental regulations and laws have become necessary to provide for revegetation of areas disturbed by mining, logging, and other activities which result in the loss of vegetation from the land. At the Rocky Flats Environmental Technology Site (Site), a variety of activities occur which require remediation for disturbance and loss of native vegetation.

\section{OBJECTIVE}

The objective of this module is to monitor the revegetation of the 881 Hillside (Hillside) since the area was disturbed by the construction of the French Drain.

\section{HYPOTHESES}

1) $H_{0}:$ Species richness will not differ from similar undisturbed habitats.

$H_{A}$ : $\quad$ Species richness will differ from similar undisturbed habitats.

2) $H_{0}: \quad$ Vegetation cover will not differ from similar undisturbed habitats.

$\mathrm{H}_{A}$ : Vegetation cover will differ from similar undisturbed habitats.

3) $\quad H_{0}: 1994$ species richness will not differ from 1993.

$H_{A}$ : 1994 species richness will differ from 1993.

4) $\quad H_{0}: 1994$ vegetation cover will not differ from 1993.

$H_{\mathrm{A}}: \quad 1994$ vegetation cover will differ from 1993.

5) $H_{0}:$ The percentage of native species richness on the Hillside will not differ from similar undisturbed habitats.

$H_{A}: \quad$ The percentage of native species richness on the Hillside will differ from similar undisturbed habitats.

6) $H_{0}:$ The percentage of basal cover from native species on the Hillside will not differ from similar undisturbed habitats.

$H_{A}$ : The percentage of basal cover from native species on the Hillside will differ from similar undisturbed habitats.

7) $H_{0}:$ The percentage of basal cover from annual species on the Hillside will not differ from similar undisturbed habitats.

$H_{A}:$ The percentage of basal cover from annual species on the Hillside will differ from similar undisturbed habitats. 


\section{METHODS}

\section{Field Methods}

The field sampling methodology used for the reclamation monitoring sampling is described in the Vegetation Sampling Standard Operating Procedures (4-H64-ENV-ECOL.10, Revision 0). In addition, more specific, detailed field instructions (though following the SOP methods) can be found in field training manuals which were written for the belt transect and point-intercept transect methods used for the terrestrial vegetation sampling in late summer 1994.

During the 1994 field season, data were collected by Ecolgical Monitoring Program (EcMP) personnel from the Hillside from November 30 through December 22, 1994. Twenty-five, 50-m long transects placed end to end were sampled across the Hillside in an east-west direction with the transects located generally perpendicular to the slope angle. Two different types of measurements were taken at the 25 transects: species richness and basal cover. A short description of the measurement methods follows, however, for more details, refer to the Terrestrial Vegetation SOP and field training manuals mentioned above.

\section{Belt Transect}

Species richness was determined in a $2-m$ belt centered along each $50-m$ transect. Each plant species observed within this $100 \mathrm{~m}^{2}$ area was recorded. A total of 25 belt transects were sampled on the Hillside during the sampling session.

\section{Point-intercept Transect}

Twenty-five transects (the same ones used for belt transects) were sampled by the point-intercept method on the Hillside. Basal cover was determined at 50- $\mathrm{cm}$ increments along each transect for a total of 100 "hits" per transect. A 2-m long rod with 0.25 inch diameter, was dropped along the right side of a tape measure stretched along the 50-m length of the transect. Material at ground level was recorded for the basal hit. A basal hit could be vegetation (live plant), litter (fallen dead material), rock (greater than the diameter of the point-intercept rod), bare ground, or water in that order of importance. Importance was determined by a cover type's potential to protect the soil from erosion.

\section{Quality Assurance/Quality Control}

Data were collected onsite by EcMP personnel. Nomenclature was standardized using the Flora of the Great Plains (Great Plains Flora Association, 1991) as the primary reference, and data were recorded on field sheets in the form of unique site and species codes. If a plant species could not be identified with confidence in the field, plant species were recorded as unknowns on the field data sheets. Voucher specimens were made of unknown species and later identified by keying, comparison with known specimens in the reference collection or herbarium collection, or by trips to the University of Colorado Herbarium in Boulder. In some cases, due to lack of key characteristics, specimens were identified only to the family or genus level. If a specimen could not even be identified to that level, it was ignored. Taxa identified to the family or genus level were included in calculations only when there were no verified species from the same family or genus present at the site. 
Prior to data entry, all unknown specimens were identified and corrections made to the field data sheets. Data entry and QA of the database files were done by EcMP personnel. The QA process used for data entry was as follows:

- data entry,

- printout hardcopy of electronic file for proofreading,

- initial $100 \%$ proofreading of hardcopy,

- corrections made to the database from the corrected hardcopy proofreading pages,

- second hardcopy printout after corrections made to database,

- second proofreading consisting of checking corrections made to database,

- if errors were still found another round of correcting and proofreading followed,

- if no errors were found, then a spot check of two random records from each page of the

final proofreading printout were made.

Each stage of the QA process was documented by a signature on a Quality Assurance Form.

\section{DATABASE STATUS}

Data from the 1994 Hillside sampling were entered into dBase files on an IBM compatible computer. The name of the file for the belt transect data was RMBEL942.dbf, and for the pointintercept data, RMPIT942.dbf. The RMBEL942.dbf contained 623 records and the RMPIT942.dbf contained 162 records.

\section{STATISTICAL ANALYSIS}

A one-way ANOVA was used to compare 1994 Hillside basal cover data with both 1994 Hillside and 1994 ECMP mesic community basal cover data to determine if significant differences were present between years and from the Hillside to the mesic community. The ANOVA was done on an IBM compatible computer using the Statgraphics statistical program. A Tukey means separation was used and checks were made of the variances and residual distributions. In order to have a balanced analysis, 15 of the 25 transects from each of the 1993 and 1994 Hillside transects were randomly chosen to represent each year. This balanced the analysis because the mesic community data consisted of 15 total transects.

\section{SITE DESCRIPTION}

The Hillside is a south facing slope in the Woman Creek watershed on the south side of the industrial complex at the Site. During 1991-1992, much of the Hillside was disturbed during the construction of the French Drain. As a result, a revegetation program was initiated to provide ground cover to stabilize the soil on the Hillside. A brief description of the revegetation history follows (Woods, 1993).

After the completion of construction, the site was prepared by ripping the area to a depth of 12 inches, applying $\mathrm{N}$ and $\mathrm{P}_{2} \mathrm{O}_{5}$ at 60 pounds per acre, and then disking. After this, stockpiled topsoil was spread over the surface of the disturbed area. A commercial compost was spread over remaining areas after topsoil had run out. A rangeland drill was used to plant spring barley (Hordeum vulgare, Otis variety), as an initial plant cover, on May 12 and 13, 1992. On May 13, 1992 a "hydroseeder" was used to spray on mulch. This initial plant cover was to provide a starter ground cover for the spring and summer of 1992. In November of 1992, a second seeding of native grass, forb, and shrub seeds was planted to provide a native, perennial cover. This seed was planted with a no-fill drill. The following species comprised the seed mix for this planting: 


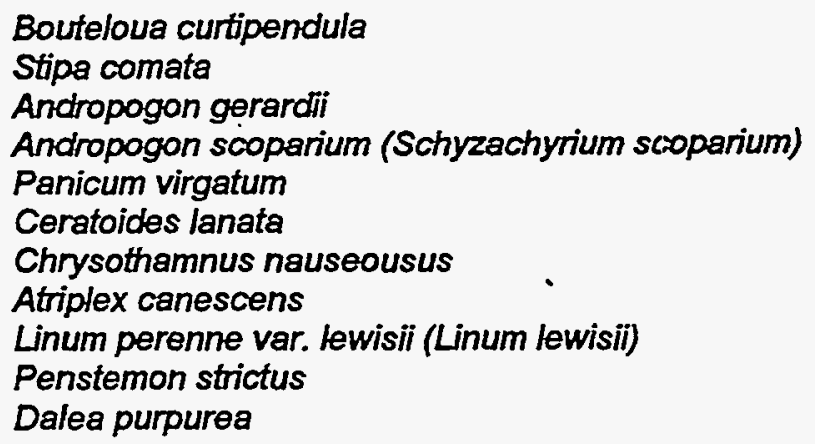

The August-September 1993 sampling of the Hillside revealed that the success of the seeded species was low. The Hillside was reseeded in the fall of 1993 using a pure mix of Agropyron smithii.

The surrounding vegetation and physical characteristics of the area make it most similar to the mesic mixed grassland sites monitored by the EcMP. The mesic mixed grassland sites monitored by the ECMP are all on southfacing hillsides at the Site and the areas around the disturbed hillside area have the same type of vegetation as the ECMP sites. Data from the OU1 study area which encompasses the Hillside revegetation project area reports vegetation cover to have been $29.2 \%$ and species richness to have been 117 species prior to the disturbance (DOE, 1992). Although none of the transects used for the OU1 study were in exactly the locations of those done for this monitoring, they are on the same general Hillside area.

\section{RESULTS}

Note: Species with no native or annual status (due to identification only to genus or family) were not included in calculations concerning these categories.

\section{Species Richness}

Species richness for the Hillside was determined by combining the belt transect and point-intercept data. A complete species list of the 1994 Hillside sampling is found in Table F-1. A summary of the species richness from the 1994 Hillside and a comparison with 1994 ECMP mesic sites and community is found in Table F-2. A total of 68 species in 19 families were recorded, with only $48 \%$ of the species being native. Annual species represented $29 \%$ of the total flora.

\section{Basal Cover}

Vegetation cover on the Hillside was only $14 \%$ based on basal cover from point-intercept sampling (Table F-3). The largest amount of ground cover was provided by litter (58.9\%). Bare ground accounted for $19.4 \%$ of the hits and rock for $7.8 \%$. Native species only accounted for $4.3 \%$ (Table $\mathrm{F}-4$ ) of the total vegetation cover of the transects sampled. Annual species (all of which were nonnative species in 1994) represented $91.6 \%$ of the total vegetation cover (Table F-4). Vegetation basal cover was dominated by Bromus tectorum and Aylssum minus, both non-native, annual species, which together made up over $77 \%$ of the vegetation cover $(56 \%$ and $21.1 \%$ respectively, Table F-3). 


\section{DISCUSSION}

To determine the success of the revegetation effort on the Hillside, the results from the 1994 sampling must be put into some context. In addition to examining the success of the seeded species by comparison to previous years' data, comparisons can also be made to similar, undisturbed communities.

It is important to mention some of the differences concerning the sampling exercises which may affect interpretation of 1993 to 1994 comparisons. First, different personnel conducted the sampling in 1993 and 1994 . This could affect the data because some species may have been identified as different species by the different personnel. Second, sampling was conducted at different times of year. In 1993, sampling was conducted in August and September. In 1994, sampling was done in November and December. The late 1994 sampling could account for some of the differences found in species richness and basal cover species values because some of the species may have died and blown away before sampling took place and therefore would not be accounted for. For example, the lack of Melilotus officinalis from the 1994 basal cover could be in part due to this because it is unlikely that it would have been absent in 1994 after having been so dominant (Table F-3) in 1993. In addition, during the 1994 sampling some of the higher litter value may be due in part to snow which fell during the sampling period which by matting down some of the dead plant stems may have increased the number of litter hits. Third, the transects are not permanent, so the transects sampled were not in exactly the same location during the two years. All of these concerns must be considered for the interpretation of the results. A suggestion for future sampling of the Hillside would be to attempt to limit the effect of these factors by using the same personnel for sampling, sampling at the same time of year, and possibly setting up permanent transects to sample on a yearly basis.

A general statement concerning the success of the species which were seeded on the Hillside in 1992 and 1993 would be that it has been rather poor. Of the 13 species seeded, only six were recorded as present in the 1994 sampling (Table F-1 and the list of species seeded from the site description section). This is up from three species recorded in 1993. Only Agropyron smithii, Bouteloua gracilis, Bouteloua curtipendula, Andropogon scoparius, Atriplex canescens, and Linum perenne var.lewisii were recorded in 1994. Of these, the amount of cover they provide totals to only $3.5 \%$ of the total vegetation cover on the hillside (Table F-3). This is a slight improvement over the $0.9 \%$ vegetation cover the seeded species provided on the Hillside in 1993.

A comparison of the 1994 Hillside data with the 1993 data shows species richness to be nearly the same -68 and 69 species, respectively. This supports hypothesis three, so the null hypothesis is retained that states, 1994 species richness would not differ from 1993. However, using the Sorenson similarity index $\left(S_{V}\right)$,

$$
S_{i}=\frac{2(C)}{A+B}
$$

where $C=$ the number of species in common between two sites, $A=$ the number of species at the first site, and $B=$ the number of species at the second site (Brower and Zar, 1977), the similarity between the 1993 and 1994 sampling is only $62 \%$. This indicates that although the number of species is essentially the same, species composition has changed from the first year to the second year. This change in species composition is further supported by the fact that in $1993,36 \%$ of the species recorded were natives, while in 1994, the percentage increased to $48 \%$ (Table F-2). The number of annual species recorded declined, from 30 species to 20 species from 1993 to 1994. The percentage of annuals making up the flora decreased from $45 \%$ to $29 \%$ from 1993 to 1994 . An interesting change however, took place in the ratio of graminoids to forbs from 1993 to 1994. In 1993 , the ratio was 0.31 , while in 1994 , the ratio increased to 0.52 , indicating that a large increase 
in the number of new graminoid species $(9$, Table $F-2)$ had occurred during the year. Whether this is a real change or due to the differences mentioned in sampling methods is not known, however the new graminoid species recorded for 1994 are mostly native Boutleoua, Aristida, Stipa, and Agropyron species. (Agropyron smithii was one of the seeded species). This would indicate that some native species are beginning to establish.

Comparison of the Hillside data with the mesic mixed grassland community (mesic community) data from the EcMP sites shows that some characteristics of overall species richness on the Hillside seem to be approaching that of the mesic community. Although the actual values are far short of the mesic community, the increase in the percent native species and decrease in the percent annuals from 1993 to 1994 are approaching that of the mesic community (Table F-2). Other comparisons however, show that the number of families and species represented on the Hillside are just over half what is found in the mesic community (Table F-2). Data from OU1 reported 117 species for the Hillside area, which although is less than that reported from the mesic community in 1994, is still considerably higher than that found on the Hillside at present (DOE, 1992). The data also show that the type of species most lacking on the hillside are perennial, herbaceous dicots. Each of the categories listed show the hiliside to be less than half what is found in the mesic community (Table F-2). For hypotheses number one and five, these data show the null hypotheses to be rejected, because species richness and the percentage of native species richness differs between the Hillside and similar undisturbed habitats.

Forty-three of the 68 species present on the Hiliside (63\%) are listed as weeds in the books, Weeds of the West (Whitson, 1991) and Weeds of Colorado (Zimdahl,1990). Four species, Carduus nutans, Centaurea diffusa, Cirsium arvense, and Convolvulus arvensis are considered prohibited noxious weed seed producers by Colorado law (Zimdahl, 1990). Seeds of these species are defined as "the seed of a perennial, biennial, or annual weeds which are highly detrimental and especially difficult to control, and the presence of which prohibits the sale of seeds for planting purposes." Two species, Agropyron repens and Rumex crispus, are considered restricted noxious weed seed producers by Colorado law (Zimdahl, 1990). The restricted noxious weed seed category differs from the former in that these seeds are from "weeds which are very objectionable in fields, lawns, and gardens of the state, but which can be controlled by good cultural practices." In addition, 11 of the species listed on the Hillside are weeds which are controlled by spraying, biological control, or mechanical methods on the Site (Department of Energy, 1993).

A comparison of basal cover data from the Hillside in 1993 and 1994 with the mesic community shows that 1) overall vegetation cover is far less than that of the mesic community (Table F-4, Figure $F-1$ ), and 2) the species providing the dominant vegetation cover on the Hillside are nonnative, annual species (Table F-3). Vegetation cover on the Hillside in 1994 (14\%) although up $10 \%$ from $1993(4.7 \%)$, is less than half that found mesic community in general $(29 \%$, Table F-5) and the $29.2 \%$ reported in the general area on the Hiliside during the OU1 characterization (DOE, 1992). A one-way ANOVA (Tukey means separation) for vegetation cover between the 1993 and 1994 Hillside data and the 1994 mesic community data found significant differences ( $\alpha=0.05$ level) between 1993 and 1994 Hillside vegetation cover (Figure F-1). Although the variances were not equal in the analysis, the residuals were evenly distributed. In addition, significant differences $(\alpha=0.05$ level) were found between both years' of Hillside vegetation cover and that of the mesic community also. A discussion follows below which examines the species composition of these differences. Based on these data the null hypotheses for both hypotheses number two and number four are rejected. These stated that vegetation cover would not differ from undisturbed habitats and last year, respectively. Although a significant increase in the amount of vegetation cover has taken place between 1993 and 1994 on the Hillside, at present, the amount on the Hillside is still far less than that of the mesic community reference area.

Although the amount of bare ground was much less in 1994 (19.4\%), than in 1993 (78.4\%, Table $F-5)$, the 1994 value still remains 11 times greater than that found in the mesic community $(1.7 \%$, 
Table F-4). A one-way ANOVA (Tukey means separation) for bare ground cover between the 1993 and 1994 Hillside data and the 1994 mesic community data found significant differences ( $\alpha=0.05$ level) between 1993 and 1994 Hillside bare ground cover (Figure F-1). Although the variances were not equal in the analysis, the residuals were evenly distributed. In addition, significant differences were found between both years' of Hillside bare ground cover and that of the mesic community. The high amount of bare ground on the Hillside is of special concern at the Site since the chief mechanism for potential plutonium movement in contaminated soils is from wind erosion (Little, 1980). So it is important to maintain a good vegetation cover on the soils to limit the amount of bare ground exposed. Most of the reduction in bare ground from 1993 to 1994 on the Hillside is due to an increase in litter and vegetation cover.

Litter cover on the Hillside increased approximately seven times from 1993 to 1994 (Table F-5). The increase in litter cover was significant between years ( $\alpha=0.05$ level), however, no significant differences ( $\alpha=0.05$ level) were found for the 1994 Hillside litter as compared with the 1994 litter cover in the mesic community. Much of the increase in litter cover is probably attributable to the increase in vegetation cover which then turned into litter.

Rock cover was found to be significant ( $\alpha=0.05$ level) only between the 1993 Hillside data and the 1994 mesic community data. No significant change was found between 1993 and 1994 sampling on the Hillside. A large part of the difference between the Hillside and mesic community may be due to the disturbance that took place on the Hillside during construction of the French Drain. The respreading of top soil and mulch over the surface may have buried many of the rocks which may have previously been present. Why the 1994 Hillside rock cover was not significantly different than the mesic community may have been due to the difference in transect locations from year to year.

The plant species providing the various amounts of vegetation cover on the Hillside are of special interest because although species richness can tell us what is present, it does not give any indication of amounts for each species. Based on 1994 species richness data, $48 \%$ of the species represented are native (an improvement from the $36 \%$ native species in 1993). In looking at cover however, in 1993, Melilotus officinalis, Bromus tectorum, Cirsium arvense, Lactuca semiola, and Centaurea diffusa, provided $65 \%$ of the vegetative cover on the Hillside (Tabie F-3). All of these are non-natives, with two of them, Cirsium anvense and Centaurea diffusa, considered prohibited noxious weed seed producers under Colorado law (Zimdahl, 1990). in 1994, the top five cover species were Bromus tectorum, Alyssum minus, Erodium cicutarium, Bromus japonicus, and Agropyron smithii. Together these five species accounted for $90.3 \%$ of the total vegetation cover on the Hillside (Table F-3). The first four listed are all non-native, annual species, and account for $87.4 \%$ of the total vegetation cover. These data show a drastic shift in the species providing the most cover from 1993 to 1994 . Bromus tectorum showed a seven-fold increase in cover, while Alyssum minus increased in cover by a factor of 12 . The other top three species increased by a factors of approximately three. Bromus tectorum was the only species present in the top five cover species for both years.

In 1993, native vegetation cover accounted for $7.9 \%$ of the total vegetation cover and annuals provided $83.3 \%$ of vegetation cover (Table F-4). In 1994 , native cover decreased to only $4.3 \%$ while at the same time annuals increased their dominance to $91.6 \%$ of the vegetation cover (Table F-4). Data from the mesic community in 1994 show that native plants provide $50.5 \%$ of the vegetation cover while annuals contribute $43.8 \%$ to the vegetation cover (Table $F-4$ ). The mesic community data provide reference area values for the Hillside and show at this point how different the Hillside is in many respects and how far it has to go in order to be comparable in quality. These data comparisons show the null hypotheses for hypotheses six and seven to be rejected. They stated that the percentage of basal cover from native species and annual species, respectively would not differ between the Hillside and similar undisturbed habitats. 
Using basal vegetation cover data from 1993 and 1994 Hillside sampling, separate similarity indices were determined for species richness by basal cover species and basal cover amounts by specific species. The similarity index using species richness by basal cover species was done using the Sorenson similarity index mentioned previously. The results showed a similarity of $53 \%$ for the species recorded in 1993 as compared with 1994 from the Hillside. This is not that different from the 61\% similarity found for the overall species richness results from 1993 and 1994.

The similarity index used for the species specific basal cover amounts was the Motyka's version of Sorenson's similiarity index $\left(S_{m l}\right.$ Chambers and Brolvn, 1983). The index is as follows:

$$
S_{m l}=\frac{2 M W}{M A+M B}
$$

$M W=$ The sum of the smaller values of the species common to both areas.

$M A=$ The sum of the values of all species from the first area.

$M B=$ The sum of the values of all species from the second area.

The results of this index show the similarity between the 1993 and 1994 cover values by species to be $19 \%$. This indicates that a large difference exists between the species providing cover in 1993 as compared to 1994 and agrees with what the other results have shown to be the case.

The shift in the top five cover species can be explained by a number of factors. First, the late sampling in 1994 would favor those species which have stems that remain attached to the ground after senescence. This could explain why no cover was found in 1994 for Melilotus officinale and the cover value for Centaurea diffusa was lower in 1994, than in 1993. Once these species senesce, the dead stems tend to break off and blow away. Most Centaurea diffusa hits in 1994 were basal rosettes which result from the fact that it is a winter annual which had already germinated and produced some basal rosettes at the time of the late fall sampling. Secondly, due to the very dry summer which occurred during 1994) (Balint, 1995), many of the late season species such as Cirsium arvense and Lactuca semiola were stunted in their growth and died. As a result, some of their stems were problably broken off and no longer attached, possibly accounting for their lower 1994 values: Thus the lack of summer precipitation has favored the spread of annuals which often germinate the previous fall and then grow rapidly with favorable spring conditions such as were present in 1994. Third, the shift to Bromus tectorum, Alyssum minus, Erodium cicutarium, and Bromus japonicus, in 1994, can be explained by the fact that these species are all winter annuals. Their seeds usually germinate under favorable fall conditions, such as existed during the fall of 1994, producing basal leaves and root systems which then overwinter until the following spring (Haferkamp et al.,1994; Monsen, 1994). Thus the high cover values for these species in 1994 may be due to the late fall sampling time when the 1994 sampling was done. Favorable conditions existed for the germination of these species in the fall and so they provided a high amount of vegetation cover at that time. Even though this may explain much of the shift in species composition, the fact however remains, that Bromus tectorum. Alyssum minus, Erodium cicutarium, and Bromus japonicus, have greatly expanded their cover values on the Hillside (providing $87 \%$ of the total vegetation cover in late 1994, Table F-3) and because of the high amount of cover present in late 1994, they will become even more dominant during the spring of 1995.

The Hillside data show that from 1993 to 1994 vegetation cover has increased, but a shift has occurred in the dominant species on the Hillside. Unfortunately that shift in species composition has increased the vegetation cover by non-native, annual species. The significance of this situation cannot be underestimated. The near total domination of the Hillside by these non-native, annuals could pose a problem to the rest of the Woman Creek drainage downstream and downwind on the Site. With no remediation of this situation, the Hillside will act as a weed seed source, spreading seed potentially downstream and downwind. Studies have shown (Monsen, 1994; Rosentreter, 1994), that left unattended, the competitive influences of weedy annuals such as are present on the Hillside will prevent the natural recovery of native species. Extensive controls and management will 
be necessary to allow the establishment of other species on the Hillside. In addition, dominance by annual weeds has been shown to alter the ecosytem functions on rangeland throughout the western United States (Rosentreter, 1994). The conversion of sites to annual species results in the lowering of genetic, species, and structural diversity, lowers the quality of watersheds by increasing the potential for soil erosion, and typically increases the frequency of wildfires (Pellant, 1994; Tausch et al., 1994; Rosentreter, 1994). All of these are detrimental and were certainly not present to the the extent found presently on the Hillside prior to the distubance for the construction of the French Drain.

\section{RECOMMENDATIONS}

Reseeding of the Hillside is necessary. It should be done soon with a mix of perennial and native grass and forb species. The original seed mix would be fine. The addition of other species common to the mesic community on Site (such as Stipa viridula, Artemesia frigida, Amica fulgens, and Aster ericoides) is also recommended. At some point further measures may be necessary to eliminate and control the non-native, adventive species which are presently dominant on the Hillside.

\section{FUTURE STUDY AND ANALYSES}

Potential future study and analyses might involve dividing the 881 Hillside area into different units and applying different remediation treatments in an attempt to determine the success of different seed mixes, seeding methods, mulches, and other variables, for reclamation work in the mesic mixed grassland type communities on the Site. Soil analyses on samples from the Hillside and other revegetated locations on Site would allow comparison to similar sites monitored by EcMP and give a better understanding as to what is occurring underground. This may help explain the poor response of the Hillside to revegetation efforts.

\section{REFERENCES}

Balint, S.J. Personal Communication. 1994. Rocky Flats Environmental Technology Site weather data for 1993-1994.

Brower, J.E. and J.H. Zar. 1977. Field and laboratory methods for general ecology. Wm. C. Brown Company Publishers, Dubuque, IA. 194 p.

Chambers, J.C. and R.W. Brown. 1983. Methods for vegetation sampling and analysis on revegetated mined lands. U.S. Department of Agriculture, Forest Service, Intermountain Forest and Range Experiment Station, General Technical Report INT-151. 57 p.

Department of Energy. 1992. Draft. Phase III/RI Report. Appendix E. Environmental evaluation. Rocky Flats Plant, 881 Hillside area, OU1. U. S. DOE, Rocky Flats Plant, Golden, CO.

Department of Energy. 1993. Watershed Management Plan for Rocky Flats. U. S. DOE, Rocky Flats Plant, Golden, CO.

Great Plains Flora Association. 1991. Flora of the Great Plains. University Press of Kansas. Lawrence, KS. 
Haferkamp, M.R., Young, J.A., Grings, E.E., Karl, M.G., Heitschmidt, R.K., and M.D. MacNeil. 1994. Japanese Brome in the the nothern Great Plains. In: Proceedings - Ecology and management of annual rangelands. Eds. Monsen, S.B. and S.G. Kitchen. U.S. Dept. of Agriculture, Forest Service, Intermountain Research Station, General Technical Report INT-GTR313. p.396-401.

Little, C.A., Whicker, F.W., and T.F. Winsor. 1980. Plutonium in a grassland ecosystem at Rocky Flats. Journal of Environmental Quality. 9(1):350-354.

Monsen, S.B. 1994. The competitive influences of cheatgrass (Bromus tectorum) on site restoration. In: Proceedings - Ecology and management of annual rangelands. Eds. Monsen, S.B. and S.G. Kitchen. U.S. Dept. of Agriculture, Forest Service, Intermountain Research Station, General Technical Report INT-GTR-313. p. 43-50.

Pellant, M. and C. Hall. 1994. Distribution of two exotic grasses on intermountain rangelands: status in 1992. In: Proceedings - Ecology and management of annual rangelands. Eds. Monsen, S.B. and S.G. Kitchen. U.S. Dept. of Agriculture, Forest Service, Intermountain Research Station, General Technical Report INT-GTR-313. p. 109-112.

Rosentreter, R. 1994. Displacement of rare plants by exotic grasses. In: Proceedings - Ecology and management of annual rangelands. Eds. Monsen, S.B. and S.G. Kitchen. U.S. Dept. of Agriculture, Forest Service, Intermountain Research Station, General Technical Report INT-GTR313. p. 170-175.

Tausch, R.J., Nowak, R.S., Bruner, A.D., and J. Smithson. 1994. Effects of simulated fall and early spring grazing on cheatgrass and perennial grass in western Nevada. In: Proceedings Ecology and management of annual rangelands. E:ds. Monsen, S.B. and S.G. Kitchen. U.S. Dept. of Agriculture, Forest Service, Intermountain Research Station, General Technical Report INTGTR-313. p. 113-119.

Whitson, T. D., Ed. 1991. Weeds of the West. Western Society for Weed Science. Pioneers of Jackson Hole, Jackson Hole, WY.

Woods, L.E. 1993. Interoffice correspondence regarding 881 hillside remediation efforts. Rocky Flats Environmental Technology Site, Golden, CO. LEW-361-93.

Zimdahl, R.L. 1990. Weeds of Colorado. Cooperative Extension, Colorado State University, Ft. Collins, CO. Bulletin 521A. $218 \mathrm{p}$. 


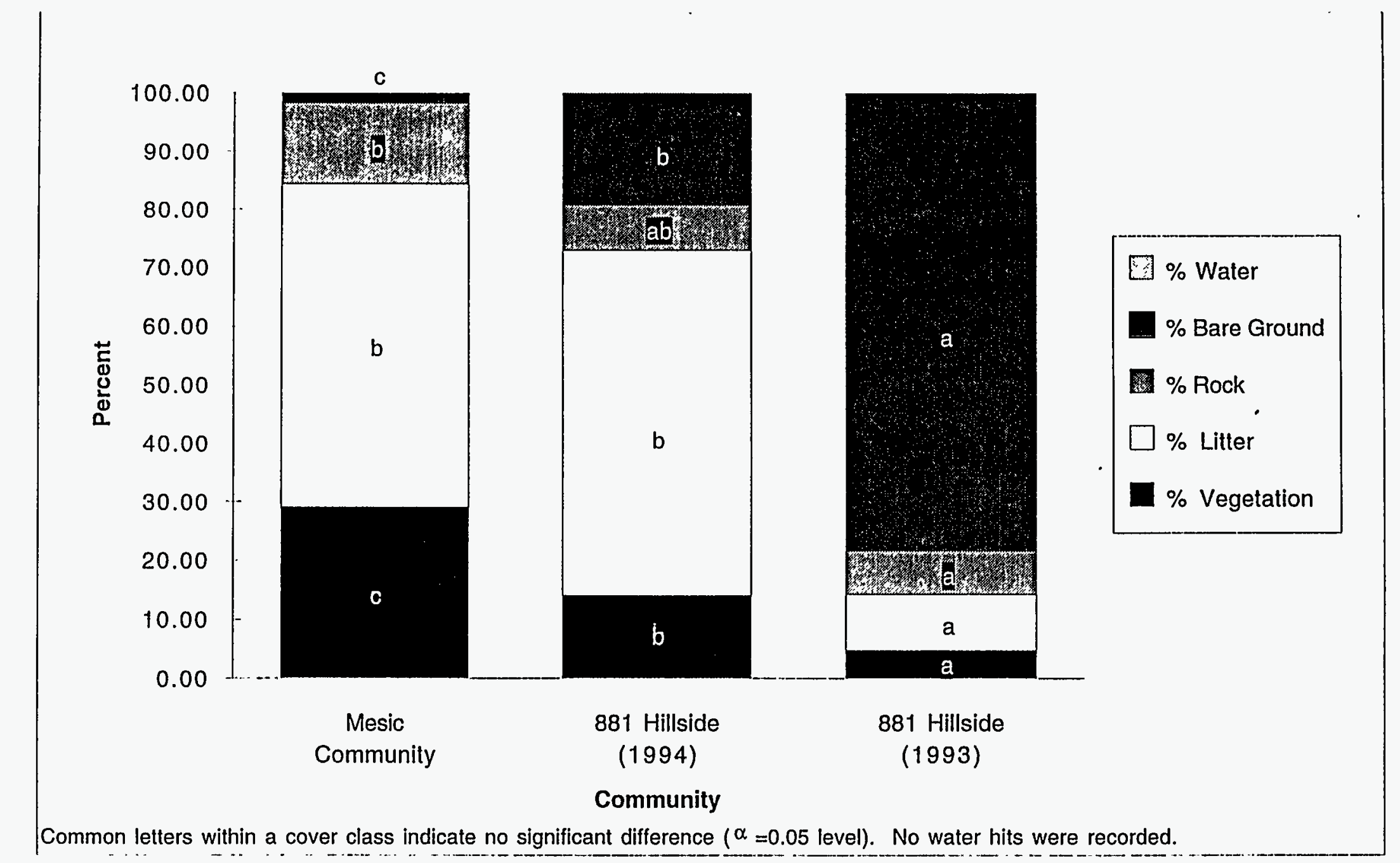
the Mesic Community (1994). 
Table F-1. 1994 Reclamation Monitoring (881 Hillside) Species Richness.

Scientific Name

Speccode Native

AGAVACEAE

Yucca glauca Nutt.

YUGL1 Y

ASTERACEAE

Achillea millefolium L. ssp. lanulosa (Nutt.) Piper

ACMI1 $Y$

Ambrosia artemisiifolia $L$.

Ambrosia psilostachya DC.

Arctium minus (Hill) Bernh.

AMAR1 $Y$

AMPS1 $Y$

ARMI1 $Y$

Artemisia dracunculus $L$.

ARDR1

Aster ericoides L.

Aster porteri Gray

ASER

ASPO1

CANU1 $N$

Carduus nutans $L$.

Centaurea diffusa Lam.

CEDIT N

Cirsium arvense (L.) Scop.

CIAR1 N

Cirsium vulgare (Savi) Ten.

CIVU1 N

Grindelia squarrosa (Pursh.) Dun.

Gutierrezia sarothrae (Pursh.) Britt. \& Rusby

GRSQ1 $Y$

GUSA1 $Y$

HEAN1 $Y$

Helianthus annuus $L$.

LASE1 N

Lactuca serriola $L$.

SCLA1 N

TAOF1 $N$

TRDU1 N

XAST1 $Y$

Xanthium strumarium $L$.

BRASSICACEAE

Alyssum alyssoides $\mathrm{L}$.

ALAL1 N

Alyssum minus (L.) Rothmaler

ALMI1 N

Camelina microcarpa Andrz.

Descurainia pinnata (Walt.) Britt.

Descurainia richardsonii (Sweet) Schultz

Sisymbrium altissimum $L$.

CHENOPODIACEAE

Atriplex canescens (Pursh.) Nutt.

CAMI1 N

DEPI1 $Y$

DERI1 $Y$

SIAL.1 N

Kochia scoparia (L.) Schrad.

Salsola iberica Senn. \& Pau.

CONVOLVULACEAE

Convolvulus arvensis $L$.

ATCA1 $Y$

KOSC1 N

SAIB1 N

CYPERACEAE

Carex sp.

COAR1 N

ELAEAGNACEAE

Elaeagnus angustifolia $L$.

FABACEAE

Melilotus sp.

GERANIACEAE

Erodium cicutarium (L.) L'Her.

CAR1

ELAN1 N

MEL1

ERCl1 $N$ 
Table F-1(cont.). 1994 Reclamation Monitoring (881 Hillside) Species Richness.

Scientific Name

Speccode Native

JUNCACEAE

Juncus torreyi Cov.

LAMIACEAE

Marrubium vulgare $L$.

JUTO1 $Y$

LINACEAE

Linum perenne L. var. lewisii (Pursh.) Eat. \& Wright LIPE1 Y

MALVACEAE

Malva neglecta Wallr.

Sphaeralcea coccinea (Pursh.) Rydb.

ONAGRACEAE

Oenothera biennis $L$.

POACEAE

Agropyron cristatum (L.) Gaertn.

MAVU1 N

Agropyron intermedium (Host) Beauv.

Agropyron repens (L.) Beauv.

Agropyron smithii Rydb.

Agropyron spicatum (Pursh) Schrib. and Sm.

Agrostis sp.

Andropogon scoparius Michx.

Aristida sp.

MANE1 N

SPCO1 $Y$

Bouteloua curtipendula (Michx.) Torr.

Bouteloua gracilis (H. B. K.) Lag ex Griffiths

OEBl1 $Y$

Bromus inermis Leyss.

Bromus japonicus Thunb. ex Murr.

Bromus tectorum L.

Dactylis glomerata $L$.

Festuca pratensis Huds.

Hordeum jubatum L.

AGCR1 N

AGIN1 N

AGRE1 N

AGSM1 $Y$

AGSP1 $Y$

AGR2

ANSC1 $Y$

ARI1

BOCU1 $Y$

BOGR1 $Y$

BRIN1 N

BRJA1 N

BRTE1 N

DAGL1 N

FEPR1 $Y$

HOJU1 $Y$

POCO1 N

POPR1 N

Poa pratensis $L$.

SECE1 N

Secale cereale $L$.

Sporobolus cryptandrus (Torr.) A. Gray

SPCR1 $Y$

Stipa viridula Trin.

STVI1 $Y$

POLYGONACEAE

Rumex crispus $L$.

RUCR1 N

Rumex mexicanus Meisn.

RUME1 $Y$

SALICACEAE

Salix exigua Nutt. ssp. interior (Rowlee) Cronq. SAEX1 $Y$

SCROPHULARIACEAE

Linaria dalmatica (L.) Mill.

LIDA1 N

Verbascum blattaria $L$.

VEBL1 N

Verbascum thapsus $L$.

VETH1 N

VERBENACEAE

Verbena bracteata Lag. \& Rodr.

VEBR1 $Y$ 
Table F-2. 1994 Reclamation Monitoring (881 Hillside) Species Richness Summary and Comparison to Mesic Community and Sites.

\begin{tabular}{|c|c|c|c|c|c|c|}
\hline Sample Site & \# Families & \# Species & $\%$ Native & \# Annuals & \# Biennials & \# Perennials \\
\hline Mesic Community & 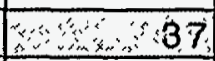 & 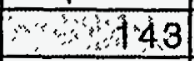 & $6 \times 8,1$ & 3027 & 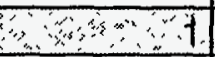 & 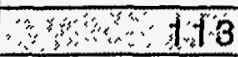 \\
\hline TR02 & 30 & 107 & 81 & 17 & 0 & 90 \\
\hline TR04 & 30 & 95 & 76 & 23 & 1 & 70 \\
\hline TR11 & 28 & 106 & 83 & 17 & 1 & 86 \\
\hline Mean & 29.33 & 102.67 & 80.00 & 19.00 & 0.67 & 82.00 \\
\hline Reclamation Cómínúnity 1994 & $\therefore<19$ & 68 & 48 & $22^{6}, 20$ & 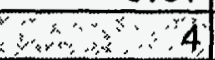 & $\therefore 6,44$ \\
\hline Reclamation Cómínúnity 1993 & 19 & (n) & 36 & 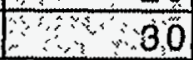 & 2 & 34 \\
\hline
\end{tabular}

\begin{tabular}{|c|c|c|c|c|c|c|c|c|c|c|c|}
\hline & \multicolumn{6}{|c|}{ Growth Form (\#'s) } & \multicolumn{2}{|c|}{ Type (\#'s) } & \multicolumn{3}{|c|}{ Form (\#'s) } \\
\hline Sample Site & Forb & Graminoid & Cactus & Shrub & Vine & Tree & Dicots & Monocots & Herbaceous & Succulent & Woody \\
\hline Mesic Comminnity & 1.06 & $\therefore, 30$ & 5 & $\because .82$ & 0 & 80 & 109 & $23 \times 34$ & 136 & 5 & \\
\hline TR02 & 78 & 22 & 5 & 2 & 0 & 0 & 81 & 26 & 100 & 5 & 2 \\
\hline TR04 & 70 & 20 & $4 \mid$ & 1 & 0 & 0 & 73 & 22 & 90 & 4 & 1 \\
\hline TR1 & 79 & 21 & 4 & 2 & 0 & 0 & 81 & 25 & 100 & 4 & 2 \\
\hline Mea & .67 & 21.00 & 4.33 & 67 & 0.00 & 0.00 & 78.33 & 24.33 & 96.67 & 4.33 & 1.67 \\
\hline Rec & 42 & $\therefore 22$ & 0 & 3 & 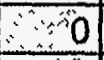 & $8+1$ & 44 & 24 & $\quad 64$ & 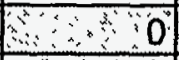 & 4 \\
\hline Reclamation Community 93 & 49 & $\therefore \because \div 15$ & $\therefore 0$ & 3 & 30 & & 51 & 1.5 & 64 & 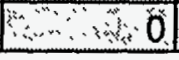 & 2 \\
\hline
\end{tabular}

\begin{tabular}{|l|r|r|r|r|r|r|}
\hline Community & \# Families & \# Species & \% Native & \% Annuals & Graminoids/Forbs & Monocots/Dicots \\
\hline Mesic & 37 & 143 & 81 & 19 & 0.28 & 0.31 \\
\hline Reclamation 1994 & 19 & 68 & 48 & 29 & 0.52 & 0.55 \\
\hline Reclamation 1993 & 19 & 69 & 36 & 45 & 0.31 & 0.29 \\
\hline
\end{tabular}


Table F-3. 1993 \& 1994881 Hillside Reclamation Monitoring Basal Cover Data.

\begin{tabular}{|c|c|c|c|c|c|c|c|c|c|c|}
\hline & & & & & 93 & 93 & 93 & 94 & 94 & 94 \\
\hline \multirow[t]{5}{*}{ Family } & Scientific Name & Speccode & Native & Annual & \# Hils & $\%$ Cover & Frequency & \# Hits & $\%$ Cover & Frequency \\
\hline & Litter & LITT & & & 238 & 9.50 & & 1472 & 58.90 & \\
\hline & Bare Ground & BARE & & & 1959 & 78.40 & & 484 & 19.40 & \\
\hline & Vegetation & & & & 117 & 4.70 & & 350 & 14.00 & \\
\hline & Rock & ROCK & & & 186 & 7.40 & & 194 & 7.80 & \\
\hline \multicolumn{11}{|l|}{ Graminoids } \\
\hline POACEAE & Agropyron cristatum (L.) Gaerln. & AGCR1 & $\mathrm{N}$ & FALSE & & & & 3 & 0.90 & 8.00 \\
\hline POACEAE & Agropyron smithii Rydb. & AGSM1 & $Y$ & FALSE & & & & 10 & 2.90 & 36.00 \\
\hline POACEAE & Agropyron intermedium (Host.) Beauv. & AGIN1 & $\mathrm{N}$ & FALSE & 3 & 2.60 & 12.00 & & & \\
\hline POACEAE & Agrostis sp. & AGR2 & & & & & & 2 & 0.60 & 4.00 \\
\hline POACEAE & Bouteloua gracilis (H. B. K.) Lag ex Griffiths & BOGR1 & $Y$ & FALSE & & & & 2 & 0.60 & 8.00 \\
\hline POACEAE & Bromus inermis Leyss. & BRIN1 & $\mathrm{N}$ & FALSE & 1 & 0.90 & 4.00 & 2 & 0.60 & 8.00 \\
\hline POACEAE & Bromus japonicus Thunb. ex Murr. & BRJA1 & $\mathrm{N}$ & TRUE & 2 & 1.70 & 8.00 & 13 & 3.70 & 28.00 \\
\hline POACEAE & Bromus tectorum L. & BRTE1 & $N$ & TRUE & 9 & 7.70 & 24.00 & 196 & 56.00 & 76.00 \\
\hline POACEAE & Echinochloa crusgallii (L.) Beauv. & ECCR1 & $\mathrm{N}$ & TRUE & 2 & 1.70 & 8.00 & & & \\
\hline POACEAE & Eragrostis cilanensis (All.) E. Mosher & ERCl2 & $\mathrm{N}$ & TRUE & 1 & 0.90 & 4.00 & & & \\
\hline POACEAE & Festuca pratensis Huds. & FEPR1 & $\bar{Y}$ & FALSE & & & & 1 & 0.30 & 4.00 \\
\hline POACEAE & Hordeum jubatum L. & HOJU1 & $Y$ & FALSE & 1 & 0.90 & 4.00 & 1 & 0.30 & 4.00 \\
\hline POACEAE & Hordeum sp. & HOR1 & & & 2 & 1.70 & 8.00 & & & \\
\hline POACEAE & Poaceae & P01 & & & & & & 1 & 0.30 & 4.00 \\
\hline POACEAE & Poa compressa L. & POCO1 & $\mathrm{N}$ & FALSE & & & & 5 & 1.40 & 16.00 \\
\hline \multicolumn{11}{|l|}{ Forbs } \\
\hline ASTERACEAE & Ambrosia psilostachya DC. & AMPS1 & $\mathrm{Y}$ & FALSE & 4 & 3.40 & 16.00 & & & \\
\hline ASTERACEAE & Carduus nutans $L$. & CANU1 & $\mathrm{N}$ & TRUE & 3 & 2.60 & 12.00 & 1 & 0.30 & 4.00 \\
\hline ASTERACEAE & Centaurea diffusa Lam. & CEDI1 & $\mathrm{N}$ & TRUE & 5 & 4.30 & 20.00 & 6 & 1.70 & 2.00 \\
\hline ASTERACEAE & Cirsium arvense (L.) Scop. & CIAR1 & $\bar{N}$ & FALSE & 6 & 5.10 & 20.00 & 3 & 0.90 & 12.00 \\
\hline ASTERACEAE & Helianthus annuus $\mathrm{L}$. & HEAN1 & $Y$ & TRUE & 2 & 1.70 & 4.00 & & & \\
\hline ASTERACEAE & Lactuca serriola $L$. & LASE1 & $\mathrm{N}$ & THUE & 6 & 5.10 & 20.00 & 1 & 0.30 & 4.00 \\
\hline ASTERACEAE & Scorzonera laciniata $L$. & SCLA1 & $\mathrm{N}$ & TRUE & 1 & 0.90 & 4.00 & 1 & 0.30 & 4.00 \\
\hline ASTERACEAE & Sonchus arvense $L$. & SOAR1 & $\mathrm{N}$ & FALSE & 1 & 0.90 & 4.00 & & & \\
\hline ASTERACEAE & Tragopogon dubius Scop. & TRDU1 & $\mathrm{N}$ & FALSE & 2 & 1.70 & 8.00 & 1 & 0.30 & 4.00 \\
\hline BRASSICACEAE & Alyssum minus (L.) Rothmaler & ALMI1 & $\mathrm{N}$ & TRUE & 2 & 1.70 & 8.00 & 74 & 21.10 & 56.00 \\
\hline BRASSICACEAE & Camelina microcarpa Andrz. & CAMI1 & $\mathrm{N}$ & TRUE & & & & 1 & 0.30 & 4.00 \\
\hline
\end{tabular}


Table F-3. 1993 \& 1994881 Hillside Reclamation Monitoring Basal Cover Data.

\begin{tabular}{|c|c|c|c|c|c|c|c|c|c|c|}
\hline CHENOPODIACEAE & Chenopodium leptophyllum Nut. ex. Mog. & CHLE2 & $Y$ & TRUE & 1 & 0.90 & 4.00 & & & \\
\hline CHENOPODIACEAE & Kochia scoparia (L.) Schrad. & KOSC1 & $\mathrm{N}$ & TRUE & 1 & 0.90 & 4.00 & 2 & 0.60 & 8.00 \\
\hline CHENOPODIACEAE & Salsola iberica Senn. and Pau. & SAIB1 & $N$ & TRUE & 2 & 1.70 & 8.00 & & & \\
\hline FABACEAE & Melilotus officinis $L$. & MEOF1 & $\mathrm{N}$ & TRUE & 50 & 42.70 & 72.00 & & & \\
\hline GERANIACEAE & Erodium cicularium (L.) L'Her. & ERCl1 & $N$ & TRUE & 3 & 2.60 & 12.00 & 23 & 6.60 & 32.00 \\
\hline LINACEAE & Linum perenne L. var. lewisil (Pursh) Eat. \& Wright & LIPE1 & $Y$ & FALSE & 1 & 0.90 & 4.00 & & & \\
\hline POLYGONACEAE & Polygonum aviculare $\mathrm{L}$. & POAV1 & $\mathrm{N}$ & TRUE & 4 & 3.40 & 8.00 & & & \\
\hline POLYGONACEAE & Rumex mexicanus Meisn. & RUME1 & $Y$ & FALSE & & & & 1 & 0.30 & 4.00 \\
\hline \multirow[t]{3}{*}{ VERBENACEAE } & Verbena bracteata Lag. \& Rodr. & VEBR1 & $\mathrm{N}$ & TRUE & 1. & 0.90 & 4.00 & & & \\
\hline & unknown forb & $?$ & & & 1 & 0.90 & 4.00 & & & \\
\hline & & Totals & & & 117 & 100,40 & & 350 & 100.30 & \\
\hline
\end{tabular}

NOTE: \% Cover value is \% Relative Cover. \% Cover sums are greater than $100 \%$ due to rounding.

MEOF1 is considered an annual for this exercise, although sometimes it is considered a biennial.

Frequency = Probability of getting a hit for a given species. 
Table F-4. \% Native and \% Annual Species Comparisons Between the $\mathbf{8 8 1}$ Hillside and Mesic Community.

\begin{tabular}{|l|r|r|r|}
\cline { 2 - 4 } \multicolumn{1}{c|}{} & 1993 Hillside & 1994 Hillside & Mesic Community \\
\hline$\%$ Native Cover & 7.9 & 4.3 & 50.5 \\
\hline$\%$ Annual Cover & 83.3 & 91.6 & 43.8 \\
\hline
\end{tabular}

Table F-5. Comparison of $\mathbf{8 8 1}$ Hillside Reclamation Monitoring Data with Mesic Community.

\begin{tabular}{|l|r|r|r|r|r|}
\hline Sample Site & $\%$ Vegetation & $\%$ Litter & $\%$ Rock & $\%$ Bare Ground & $\%$ Water \\
\hline Mesic Commühity & 29.00 & 55.30 & 14.00 & 0.70 & 0.0 \\
\hline TR02 & 21.40 & 56.00 & 21.00 & 1.60 & 0.00 \\
\hline TR04 & 40.40 & 51.00 & 6.20 & 2.60 & 0.00 \\
\hline TR11 & 25.40 & 59.00 & 14.80 & 0.80 & 0.00 \\
\hline 881 Hillside (1994) & 14.00 & 58.90 & 7.80 & 19.40 & 0.00 \\
\hline 881 Hiliside (1993) & 4.70 & 9.50 & 7.40 & 7.40 & 0.00 \\
\hline
\end{tabular}


APPENDIX G). TERRESTRIAL ARTHROPODS

AUTHOR: T.R. RYON 


\section{TABLE OF CONTENTS}

APPENDIX G). TERRESTRIAL ARTHROPODS

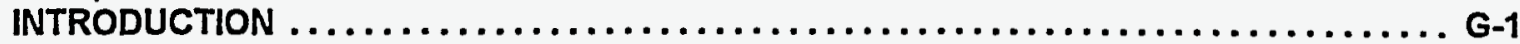

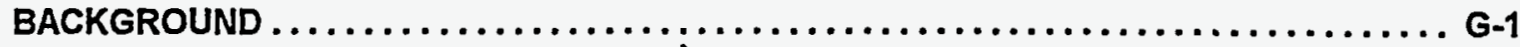

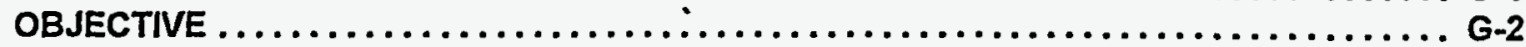

HYPOTHESIS $\ldots \ldots \ldots \ldots \ldots \ldots \ldots \ldots \ldots \ldots \ldots \ldots \ldots \ldots \ldots \ldots \ldots \ldots \ldots \ldots \ldots \ldots \ldots \ldots \ldots, \mathbf{G}, 2$

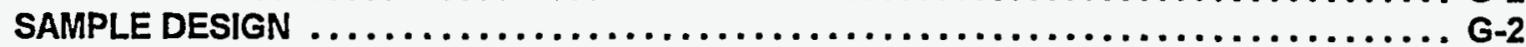

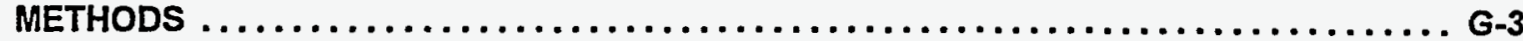

Sweep Net Methodology.$\ldots \ldots \ldots \ldots \ldots \ldots \ldots \ldots \ldots \ldots \ldots \ldots \ldots \ldots \ldots$, G-3

Pitfall Trap Methodology ...................................... G-3

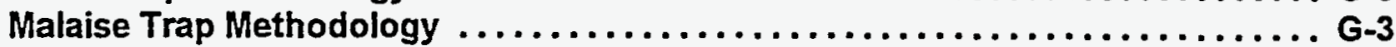

Beating Tray Methodology ................................ G-4

Sorting and Finalizing Taxonomic Samples ....................... G-4

Biomass Sampling Methodology $\ldots \ldots \ldots \ldots \ldots \ldots \ldots \ldots \ldots \ldots \ldots \ldots \ldots, G, 4$

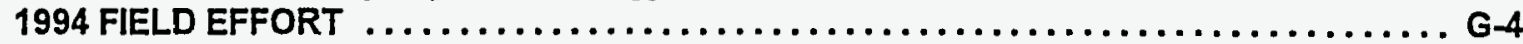

Schedule $\ldots \ldots \ldots \ldots \ldots \ldots \ldots \ldots \ldots \ldots \ldots \ldots \ldots \ldots \ldots \ldots \ldots \ldots \ldots, G, 4$

Sample Collection ...................................... G-4

1994 DATA MANAGEMENT AND ADMINISTRATIVE EFFORTS $\ldots \ldots \ldots \ldots \ldots \ldots \ldots \ldots$ G.5

Database ......................................... G.5

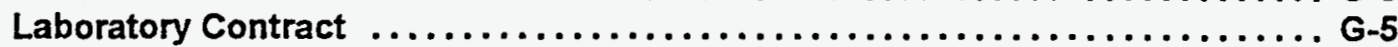

1995 FUTURE IMPROVEMENTS AND PLANNING $\ldots \ldots \ldots \ldots \ldots \ldots \ldots \ldots \ldots \ldots \ldots \ldots \ldots \ldots$

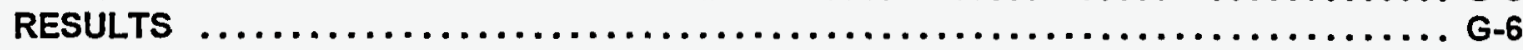

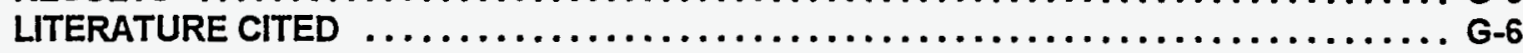

\section{LIST OF TABLES}

Table G-1. Terrestrial Arthropod Sampling Summary, $1994 \ldots \ldots \ldots \ldots \ldots \ldots \ldots \ldots$ G.7

Table G-2. Proposed Schedule for Terrestrial Arthropod Sampling, $1995 \ldots \ldots \ldots \ldots$ G-8 


\section{INTRODUCTION}

The Terrestrial Arthropod Module was established in June, 1994 with the delivery of the Ecological Monitoring Program Final Terrestrial Arthropod Field Procedure, DOE (deliverable \#61405206-E). The first sample collections were conducted in August and September of 1994. A laboratory contract with Colorado State University was established in January, 1995 to provide expertise in identifying arthropods in an efficient manner.

The following outlines the background, study objectives, methods, results, and discussion from activities conducted during 1994. Additionally, future plans for 1995 are discussed.

\section{BACKGROUND}

Insects, and therefore arthropods, make up more that half of all living things on earth (Borror and White,1970). Their overwhelming abundance and richness merit study. Arthropods tend to be localized in nature and are closely tied to soil and vegetative communities (Gilbert,1980). Therefore, arthropods may be sensitive to changes in soils, such as contaminant pollution, physical disturbance, or changes in vegetative communities.

Arthropods are important agents of pollination; important components in the diets of fish, reptiles, mammals, and birds; or may be beneficial in the control of noxious weeds and insect pests. Arthropods are probably the primary herbivores in terrestrial ecosystems at RFP. Therefore, the absence, presence, or abundance of specific arthropod species or groups can provide an assessment of the health of that ecosystem.

The large biomass represented by terrestrial arthropods represents large nutrient pools and possibly a significant pool for environmental contaminants. This biomass therefore, represents a foundation for RFP foodchains and possibly a contaminant pathway to top carnivores.

Colorado State University (CSU) researchers, Bly and Whicker (1979), measured potential contaminants in arthropod tissue collected from grasslands on the RFP. Researchers documented the relatively large biomass represented by terrestrial arthropods and recognized the potential for contaminant transfer from soils to arthropods. The study also documented a close correlation between soil contaminants and contaminants found in arthropods.

The Baseline Biological Characterization at RFP (DOE,1992) documented arthropod diversity found in the RFP buffer zone. The dominant groups were herbivores, mainly of the order Homoptera.

The Ecological Evaluation for Operable Unit One (DOE,1993) included a comparison of arthropod richness by habitat type. Sweep netting was used to gather samples, which were identified by the CSU Entomology Laboratory. Grasshopper tissue samples were collected on OU1 to determine contaminant levels in tissue. The results of tissue analysis were used to calculate a dose to insect predators and therefore reveal the potential risk to predators from contaminants found at OU1.

\section{OBJECTIVE}

The objective of this study is to characterize the diversity and biomass of insects, spiders, and other above ground terrestrial arthropods, collectively called terrestrial arthropods. Characterization will be conducted within and among vegetation communities. Data will be used to establish the natural variation in arthropod diversity and biomass among vegetation communities, document taxon richness by community types, develop a listing of arthropod taxa present at Rocky Flats and 
categorize the taxa by trophic groups.

\section{HYPOTHESIS}

H1: Arthropod taxon richness does not differ significantly among or within vegetation communities.

$\mathrm{H}_{\mathrm{A}}$ : $\quad$ Arthropod taxon richness differ significantly among or within vegetation communities.

Basis for hypothesis: If arthropod communities are closely tied to vegetation communities in which they live, differences in arthropod taxon richness should be detected between vegetation types. Differences noted within a terrestrial site reveal natural variation of arthropod taxon richness and document uncertainty of measurements.

H2: Arthropod biomass does not differ significantly among or within vegetation communities.

$\mathrm{H} 2_{\mathrm{A}}$ : Arthropod biomass measurements differ significantly among or within vegetation communities.

Basis for hypothesis: Vegetation production varies among vegetation types. Arthropod biomass may be a reflection of plant production and should vary accordingly.

$H 3_{\mathrm{o}}$ : The ratio of primary consumers to higher consumers is approximately equal among and within vegetation types.

$\mathrm{H}_{\mathrm{A}}$ : The ratio of primary consumers to higher consumers is not equal among and within vegetation types.

Basis for hypothesis: Trophic groups within the arthropod communities should have a ratio reflecting a large number of primary consumers which are fed upon by a smaller number of insect predators. This ratio should hold true regardless of vegetation communities. Changes in the documented ratios may indicate stressed communities or communities in transition.

H4: Arthropod taxon richness and biomass does not change significantly from year to year.

$\mathrm{H}_{\mathrm{A}}$ : $\quad$ Arthropod taxon richness and biomass does change significantly from year to year.

Basis for hypothesis: Arthropod taxon richness and biomass should reflect the variability of annual weather conditions and the annual variability of vegetation production.

\section{SAMPLE DESIGN}

This sampling design was intended to test the four hypotheses, monitor changes through space and time, and establish the natural variability associated with the selected arthropod communities. These data can then be used to help document a picture of Buffer Zone ecological resources, and serve as reference data for comparison to Operable Units and other impacted areas.

Long-term monitoring requires the establishment of permanent sampling transects to insure repeatability of data collection year after year. During 1994 sampling, sweep nets, malaise traps, and pitfall traps were used to collect samples. Each site was sampled for biomass and taxonomy at each of the 12 terrestrial sampling locations. All the sampling was conducted along the permanent vegetation transects. Each community type, which contain three site replicates, had one site sampled simply by collecting a sample for biomass and a sample for taxonomy. A second site was sampled by replicating four times for biomass. The remaining site was sampled by replicating four times for taxonomy. The replicates were conducted along a different vegetation transect within the same site. This replicated sampling documents variation within a site. The sampling session, conducted during August and September collected 24 sweep net samples, 4 
pitfall trap samples, and 4 Malaise trap samples (Table G-1).

\section{METHODS}

Many methods can be used to capture and study terrestrial arthropods. In fact, a number of methods and equipment must be used to sample all the arthropod groups that may be present in a community type. The methods employed by entomologists are semi-quantitative at best. One goal of the 1994 sampling, therefore, will be to compare methods and equipment to decide which combinations will provide the best sampling methodology for the testing of the stated hypotheses.

Grassland communities including mesic, xeric, and reclaimed grasslands, were sampled using sweep nets, pit fall traps, and malaise traps. Riparian communities were sampled using sweep nets, beating trays, pit fall traps, and malaise traps.

\section{Sweep Net Methodology}

Sweep netting was used to collect insects clinging to vegetation, such as grasshoppers, beetles, and spiders. The area that is swept is standardized between grassland sites. A sweep net sample consisted of a $50 \mathrm{~m}$ by $2 \mathrm{~m}$ transect which is located parallel to the chosen vegetation transect, offset 1 meter to the outside edge of the vegetation belt. Sweep net samples were also standardized among riparian sites, consisting of two $25 \mathrm{~m}$ by $2 \mathrm{~m}$ transects on both sides of the stream channel. Care was taken not to walk in the area to be swept prior to sampling. The Terrestrial Arthropod Sampling Standard Operating Procedure (SOP 4-K23-EVN-ECOL.09, revision 2, draft B) was followed for sweep net sampling.

Once the sweep net sample was collected, the material aggregate (plants and arthropods) was placed in a kill jar. A label with the site number, transect number, date, time, and method was placed in the kill jar.

\section{Pitfall Trap Methodology}

Pitfall traps were used to collect ground-dwelling arthropods that may have been missed during sweep netting. Pitfall traps were installed on either side of two randomly chosen vegetation transects. Traps were located $10 \mathrm{~m}$ in from the zero end on the left side of the transect and $40 \mathrm{~m}$ from the zero end on the right side of the vegetation transect. The traps were opened for one week during sweep net sampling and checked daily. The arthropods were transferred from the trap chamber to a sample jar using ethyl alcohol as a preservative. Labels with the site number, date, time, and method on the sample jar. Taxa were collected as a separate sample and included as a taxonomic sample for the site. Pitfall trap samples were not be included for biomass measurements. The Terrestrial Arthropod Sampling Standard Operating Procedure (SOP 4-K23EVN-ECOL.09, revision 2, draft B) was foliowed for pitfall trap sampling. The traps were closed at the end of the sampling session.

\section{Malaise Trap Methodology}

Malaise traps were used to collect flying and or emerging arthropods, such as wasps, flies, and moths. These traps are designed to intercept arthropods flying from any direction. They are tentlike structures made of netting which funnels flying insects into a collection jar located at the top of the tent.

One of three sites for each community type were chosen at random. Once the site was chosen, the trap was placed along stream beds or ridge tops, but within the EcMP site boundaries. The trap was checked once after 24 hours. A sample was collected after 72 hours. Organisms were 
collected from both the collection jar and from the netting. The sample was transferred from the trap chamber to a sample jar using ethyl alcohol as a preservative. Labels with the site number, date, time, and method on the sample jar. The Terrestrial Arthropod Sampling Standard Operating Procedure (SOP 4-K23-EVN-ECOL.09, revision 2, draft B) was followed for Malaise traps.

\section{Beating Tray Methodology}

For riparian locations, a combination of beating trays and sweep nets were employed to collect samples. Five points along the $25 \mathrm{~m}$ transect were established every $5 \mathrm{~m}$ starting at the beginning of the transect. Five trays were placed on either side of the transect line and all surrounding vegetation was "beat" with a sweep net for approximately 30 seconds. The samples from riparian locations consisted of arthropods collected from sweep nets and beating trays. The Terrestrial Arthropod Sampling Standard Operating Procedure (SOP 4-K23-EVN-ECOL.09, revision 2, draft B) was followed for beating trays.

\section{Sorting and Finalizing Taxonomic Samples}

Once samples were collected for the day (probably two sites), field personnel returned to the lab and sorted all samples (sweep net and beating tray) when necessary. For the sweep net samples, arthropods were sorted from plant material in a plastic or metal tray. The sample was then transferred to a $1 / 2$ pint sample jar containing a $70 \%$ solution of ethyl alcohol for taxonomic samples. Sample jars were labeled with the sample number, chain-of-custody number, and type of preservative. A chain-of-custody (COC) form for the sample was completed. Samples were secured until shipment to the Colorado State University Entomology lab.

\section{Biomass Sampling Methodology}

Biomass sampling was achieved by sweep netting a $50 \mathrm{~m}$ by $2 \mathrm{~m}$ area adjacent to a permanent vegetation transect. Sample materials were placed in a kill jar with a label containing information on sample number, site id, transect, date, and time. Once at the laboratory, the arthropod biomass sample was sorted from the vegetative material and placed in a labeled plastic bag and frozen.

Once sufficient numbers of biomass samples were collected, an initial weighing trial was conducted. The results of this trial are discussed in the Future Needs and the Planning sections.

\section{FIELD EFFORT}

\section{Schedule}

Field trials for testing methodologies were conducted during the last week of July to experiment with methods from a logistical view point. A training session was held 1 August after trial methods were determined. Sampling methods were explained and all EcMP staff present had the opportunity to practice methods prior to sampling. Arthropod sampling was conducted during a four week period from August 1 to September 1, 1994.

\section{Sample Collection}

Table G-1 summarizes taxonomic and biomass samples collected. These numbers may change annually, depending on new methods and past results. The general trend was to take one taxonomic and one biomass sample from one of the three terrestrial site in each community type. The remaining sites were replicated sites, where either four taxonomic samples or four biomass samples were taken. Biomass samples and taxonomic samples were not replicated at the same site. 


\section{DATA MANAGEMENT AND ADMINISTRATIVE EFFORTS}

The field sampling plan and.the technical field guide have been updated. Changes inciuded removal of the beating tray method and addition of instructions for determining personnel's individual sweep net sample area. Refined sample design for pitfall traps was incorporated based on sampling one watershed per sample session. Additionally, biomass sampling will be limited to the last sampling session to match activities last year. The results of this effort will be used to determine if the biomass study should continue.

The results of the initial weighing trials revealed biomass samples with insufficient mass to register on the scales provided. At this time, further efforts for determining biomass for 1994 samples were discontinued. Three samples from the Baseline Biological Characterization (DOE,1992) study were air dried and weighed for comparison. These samples contained a greater number of arthropods and weighed between 0.10 and 0.02 grams.

\section{Database}

The design of the arthropod database was completed. It consists of a sample tracking file, a dictionary of scientific names, a raw data file that will be uploaded from the laboratory, and a summary file that will contain ecological endpoint information including biomass and taxon richness.

Chain-of-custody forms were designed and used in the sample shipment. Information from these forms was entered into the tracking database. A quality assurance plan was adopted for data entry and a location for a QA file was determined.

\section{Laboratory Contract}

A laboratory subcontract was awarded on January 5, 1995 for taxonomic analysis of terrestrial arthropods with the Colorado State University Entomology Department. The contract covers four sampling sessions, one in 1994 and three in 1995. One sampling session equates to 32 samples.

The taxonomic analysis will list all taxa present and the abundance of each taxon identified. The identification will be to the lowest taxonomic level possible; probably to family for both insects and spiders.

The subcontractor is obligated to provide taxonomic data within 6 months of sample receipt. The current sample batch is due to the CRT on June 16, 1995. Results have been received for some sites, and are undergoing data entry and quality assurance requirements.

\section{FUTURE IMPROVEMENTS AND PLANNING}

The biomass study has been postponed until late summer due to the insufficient mass obtained via the sweep net method. The scales available cannot weigh these small samples. Hopefully, more sensitive scales from one of the RFETS analytic laboratories can be used in the future. Due to the dryness of the 1994 field season, another sampling session should be conducted to determine if biomass is a viable measurement for arthropods under more normal moisture conditions.

The D-vac method will be explored to supplement or replace sweep netting for the biomass sampling and possibly the taxonomic sampling. It is considered a superior method to sweep netting in that it samples a well-defined area, is easily replicated, and captures arthropods more completely when used properly. The deterring factor may be cost, however. Sweep netting is considerably less expensive and may be a sufficient method for monitoring purposes, especially for taxonomic sampling. 


\section{RESULTS}

As mentioned above, only partial information on taxonomic data has been provided to date. This includes thirteen samples that represent 5 of the 12 EcMP sample sites for sweep netting, one malaise trap sample, and 3 out of four pitfall sites. Partial results under going quality assurance do not provide data for hypothesis testing. Analysis must be delayed until all results are received and undergo quality assurance requirements. •

\section{LITERATURE CITED}

Bly, J.A., and F.W. Whicker. 1979. Plutonium Concentrations in Arthropods at a Nuclear Facility. Health Physics 37, 331-336.

Borror, D.J., and R.E. White. 1970. A Field Guide to the Insects of America, North of Mexico. Haughton Mifflin Co., Boston.

DOE (U.S. Department of Energy) 1992. Baseline Biological Characterization of the Terrestrial and Aquatic Habitats at RFP.

DOE (U.S. Department of Energy) 1993. Operable Unit One, 881 Hillside Area, Phase III RFI/RI Report, Appendix E, Ecological Evaluation.

EG\&G Rocky Flats, Inc. 1991. Standard Operating Procedures: Ecology 5-21200-Ecology 5.9, $\operatorname{Rev} 1.0$

Gilbert, L.E., 1980. Food Web Organization and Conservation of Neotropical Diversity: in Conservation Biology : An Evolutionary - Ecological Prospective. M.E. Soule and B.A. Wilcox, eds., Sinauer Associates, Inc., Sunderland, MA. 


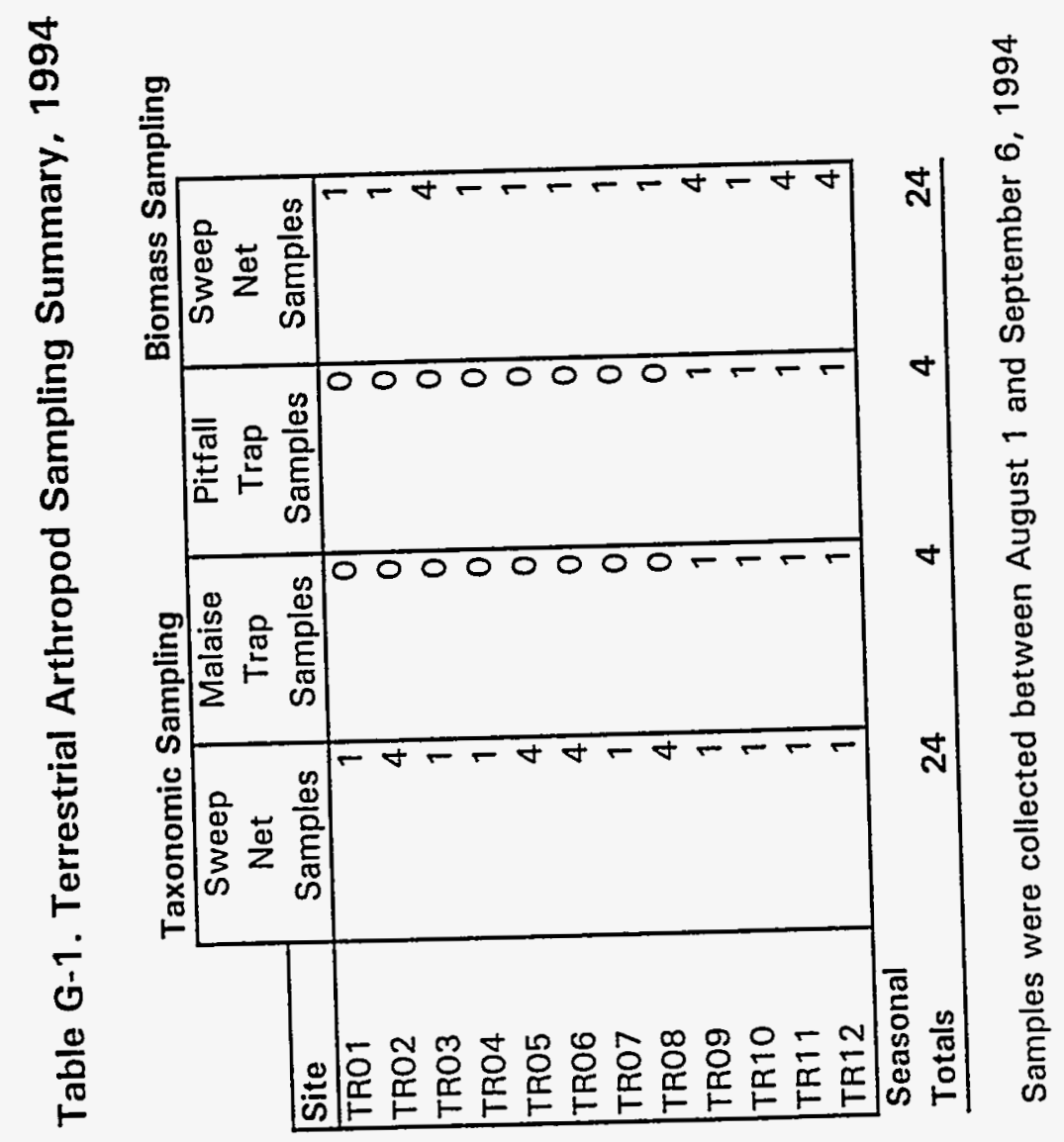


Table G-2. Proposed Schedule for Terrestrial Arthropod Sampling, 1995.

Sweep Netting Schedule

\begin{tabular}{|c|c|c|c|c|}
\hline Site & Session 1 & Session 2 & Session 3 & Total \\
\hline TRO1 & 4 & 1 & 1 & 6 \\
\hline TRO2 & 1 & 4 & 1 & 6 \\
\hline TRO3 & 1 & 1 & 4 & 6 \\
\hline TRO4 & 4 & 1 & 1 & 6 \\
\hline TRO5 & 1 & 4 & 1 & 6 \\
\hline TRO6 & 1 & 4 & 1 & 6 \\
\hline TRO7 & 4 & 1 & 1 & 6 \\
\hline TR08 & 1 & 4 & 1 & 6 \\
\hline TRO9 & 1 & 1 & 4 & 6 \\
\hline TR10 & 4 & 1 & 1 & 6 \\
\hline TR11 & 1 & 1 & 4 & 6 \\
\hline TR12 & 1 & 1 & 4 & 6 \\
\hline Sitewide & & & 1 & 1 \\
\hline \multicolumn{5}{|l|}{ Seasonal } \\
\hline Totals & 24 & 24 & 25 & 73 \\
\hline
\end{tabular}

* Sessions defined: Session 1 - May/June, Session 2 - July/August, Session 3 - September Notes: Samples will be collected during one week during each session.

\begin{tabular}{|l|r|r|r|r|}
\hline Site & Session 1 & Session 2 & Session 3 & Total \\
\hline TR01 & 0 & 0 & 1 & 1 \\
TR02 & 1 & 0 & 0 & 1 \\
TR03 & 0 & 0 & 1 & 1 \\
TR04 & 0 & 0 & 1 & 1 \\
TR05 & 1 & 0 & 0 & 1 \\
TR06 & 1 & 0 & 0 & 1 \\
TR07 & 0 & 0 & 1 & 1 \\
TR08 & 1 & 0 & 0 & 1 \\
TR09 & 0 & 1 & 0 & 1 \\
TR10 & 0 & 1 & 0 & 1 \\
TR11 & 0 & 1 & 0 & 1 \\
TR12 & 0 & 1 & 0 & 1 \\
\hline Seasonal & \multicolumn{4}{|c}{} \\
Totals & 4 & 4 & 4 \\
\hline
\end{tabular}

Malaise Trapping

Pitfall Traps will be checked daily during each session and added to the sweep net samples. 
Table G-2. Proposed Schedule for Terrestrial Arthropod Sampling, 1995.

Pitfall Trapping

\begin{tabular}{|l|r|r|r|r|}
\hline Site & Session 1 & Session 2 & Session 3 & Total \\
\hline TR01 & 0 & 0 & 1 & 1 \\
TR02 & 1 & 0 & 0 & 1 \\
TR03 & 0 & 0 & 1 & 1 \\
TR04 & 0 & 0 & 1 & 1 \\
TR05 & 1 & 0 & 0 & 1 \\
TR06 & 1 & 0 & 0 & 1 \\
TR07 & 0 & 0 & 1 & 1 \\
TR08 & 1 & 0 & 0 & 1 \\
TR09 & 0 & 1 & 0 & 1 \\
TR10 & 0 & 1 & 0 & 1 \\
TR11 & 0 & 1 & 0 & 1 \\
TR12 & 0 & 1 & 0 & 1 \\
\hline Seasonal & & & & \\
Totals & 4 & 4 & 4 & 12 \\
\hline
\end{tabular}

Biomass Sampling

\begin{tabular}{l|r|}
\hline Site & Session 3 \\
\hline TR01 & 1 \\
TR02 & 1 \\
TR03 & 4 \\
TR04 & 1 \\
TR05 & 1 \\
TR06 & 1 \\
TR07 & 1 \\
TR08 & 1 \\
TR09 & 4 \\
TR10 & 1 \\
TR11 & 4 \\
TR12 & 4 \\
Sitewide & \\
Seasonal \\
Totals
\end{tabular}

*Sessions defined: Session 1 - May/June, Session 2 - July/August, Session 3 - September Notes: Samples will be collected during one week during each session.

Pitfall Traps will be checked daily during each session and added to the sweep net samples. 


\section{H. EcMP DATABASE}

This section was summarized in the Technical Summary. 
1) OPERABLE UNIT 11 ECOLOGICAL EFFECTS

Authors: M.E. Bakeman and L.E. Woods 


\section{Table of Contents}

1) OPERABLE UNIT 11 ECOLOGICAL EFFECTS

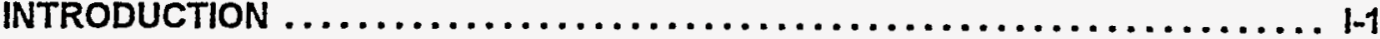

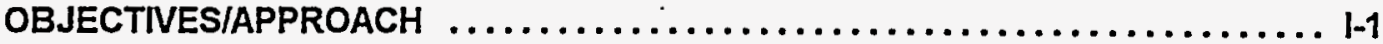

A) Soil Physical and Chemical Properties $\ldots \ldots \ldots \ldots \ldots \ldots \ldots \ldots \ldots$.-2

B) Vegetation and Litter $\ldots \ldots \ldots \ldots \ldots \ldots \ldots \ldots \ldots \ldots \ldots \ldots, \ldots \ldots \ldots, 2$

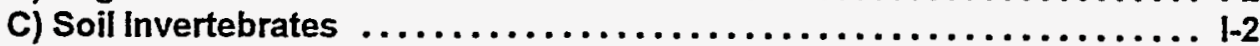

D) Ecosystem Functions $\ldots \ldots \ldots \ldots \ldots \ldots \ldots \ldots \ldots \ldots \ldots \ldots \ldots, 1-2$

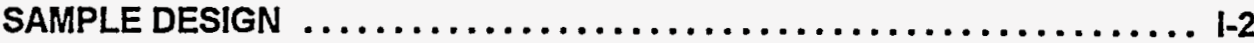

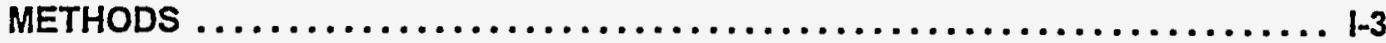

Field Methods

A) Field Methods, Soil Physical and Chemical Properties: ..... I-3

B) Field Methods, Vegetation and litter mass: $\ldots \ldots \ldots \ldots \ldots \ldots 1-3$

C) Plant and litter tissue nutrient analysis: $\ldots \ldots \ldots \ldots \ldots \ldots \ldots, \mid-3$

D) Field Methods, Soil Invertebrates: $\ldots \ldots \ldots \ldots \ldots \ldots \ldots \ldots \ldots$ I-3

E) Field Methods, Ecosystem Functions: .............. 1-3

Laboratory Methods

A) Laboratory Methods, Soil Physical and Chemical Properties: .. 1-4

B) Laboratory Methods, Vegetation and Litter: $\ldots \ldots \ldots \ldots \ldots \ldots$ l-4

C) Laboratory Methods, Soil Invertebrates: ............... 1-4

RESULTS

D) Laboratory Methods, Ecosystem Functions: ........... 1-4

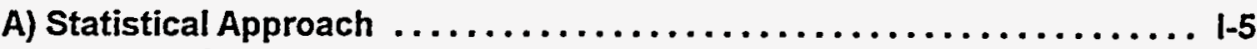

B) Soil Physical/Chemical Properties .....................

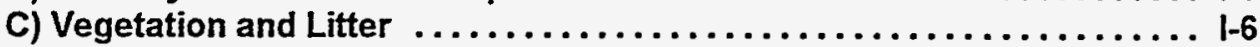

D) Soil Invertebrates

Nematodes ................................ $1-7$

Soil Arthropods ............................

E) Ecosystem Functions $\ldots \ldots \ldots \ldots \ldots \ldots \ldots \ldots \ldots \ldots \ldots \ldots \ldots, 1-9$ DISCUSSION

A) Soil Physical Chemical Properties . ..................... $1-11$

B) Vegetation and Litter Biomass and Nutrient Concentrations and Contents

C) Soil Invertebrates

Nematodes $\ldots \ldots \ldots \ldots \ldots \ldots \ldots \ldots \ldots \ldots \ldots \ldots \ldots \ldots \ldots \ldots, 1-12$

Arthropods ...............................13

General soil invertebrate discussion $\ldots \ldots \ldots \ldots \ldots \ldots \ldots \ldots \ldots \mid-13$

D) Ecosystem Functions $\ldots \ldots \ldots \ldots \ldots \ldots \ldots \ldots \ldots \ldots \ldots \ldots \ldots, 13$

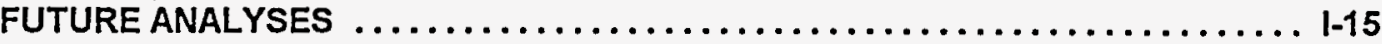

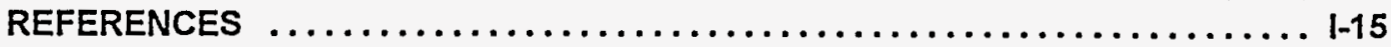




\section{LIST OF FIGURES}

Figure $1-1$. Soil Sampling Scheme, ou $11 \ldots \ldots \ldots \ldots \ldots \ldots \ldots \ldots \ldots \ldots \ldots \ldots \ldots \ldots$

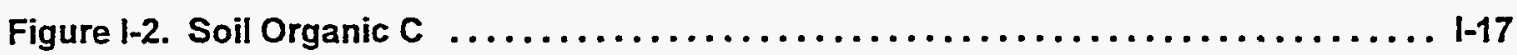

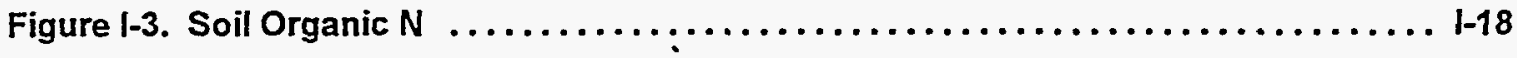

Figure 1-4. Nitrate-N Concentrations $\ldots \ldots \ldots \ldots \ldots \ldots \ldots \ldots \ldots \ldots \ldots \ldots \ldots \ldots \ldots \ldots \ldots \ldots \ldots \ldots$

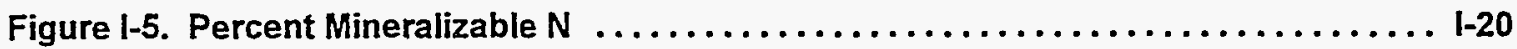

\section{LIST OF TABLES}

Table 1-1. Summary Statistics and ANOVA, Soil Potassium Concentrations, OU $11 \ldots \ldots$ 1-21

Table 1-2..Summary Statistics and ANOVA, Soil Phosphorus Concentrations, OU $11 \ldots$ I-21

Table 1-3. Summary Statistics and ANOVA, Soil Calcium Concentrations, OU $11 \ldots \ldots$ I-22

Table 1-4. Analysis of Variance, ou 11 Total Vegetation Production $\ldots \ldots \ldots \ldots \ldots \ldots$ 1-23

Table 1-5. Analysis of Variance, ou 11 Total Litter Mass $\ldots \ldots \ldots \ldots \ldots \ldots \ldots \ldots \ldots$

Table 1-6. Summary Statistics and ANOVA, Plant Carbon Concentration, OU $11 \ldots \ldots$ 1-24

Table 1-7. Summary Statistics and ANOVA, Plant Total Carbon, ou $11 \ldots \ldots \ldots \ldots \ldots$ 1-25

Table 1-8. Summary Statistics and ANOVA, Total Litter Carbon, OU $11 \ldots \ldots \ldots \ldots \ldots$

Table 1-9. Summary Statistics and ANOVA, Plant Nitrogen Concentration, OU $11 \ldots \ldots$ 1-26

Table 1-10. Summary Statistics and ANOVA, Litter Nitrogen Concentration, OU $11 \ldots$ 1-26

Table 1-11. Summary Statistics and ANOVA, Plant Nitrogen Content, OU $11 \ldots \ldots \ldots$ I-27

Table 1-12. Summary Statistics and ANOVA, Litter Nitrogen Content, OU $11 \ldots \ldots \ldots$ I-27

Table 1-13. Summary Statistics and ANOVA, Plant Potassium Concentration, OU $11 \ldots$ I-28

Table l-14. Summary Statistics and ANOVA, Litter Potassium Concentration, OU $11 \ldots$ I-28

Table 1-15. Summary Statistics and ANOVA, Plant Potassium Content, OU $11 \ldots \ldots$ I-29

Table 1-16. Summary Statistics and ANOVA, Litter Potassium Content, oU $11 \ldots \ldots$ 1-29

Table 1-17. Summary Statistics and ANOVA, Plant Phosphorus Concentration, OU 11 .. 1-30

Table 1-18. Summary Statistics and ANOVA, Litter Phosphorus Concentration, OU 11 . 1 1-30

Table 1-19. Summary Statistics and ANOVA, Plant Phosphorus Content, OU $11 \ldots \ldots$ I-31 
Table 1-20. Summary Statistics and ANOVA, Litter Phosphorus Content, OU $11 \ldots \ldots .$. I-31

Table 1-21. Analysis of Variance, OU 11 Soil Nematode Fungal Feeders, 0-5 cm Depth .. 1-32

Table 1-22. Analysis of Variance, OU 11 Soil Nematode Bacterial Feeders, 0-5 cm Depth I-32

Table 1-23. Analysis of Variance, OU 11 Soil Nematode Plant Feeders, 0-5 cm Depth .... I-33

Table 1-24. Analysis of Variance, OU 11 Soil Nematode Omnivore/Predators, 0-5 cm Depth ..

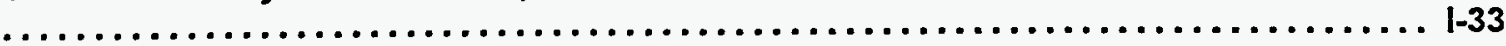
Table 1-25. Analysis of Variance, OU 11 Soil Nematode Fungal Feeders, 5-10 cm Depth . 1-34

Table 1-26. Analysis of Variance, OU 11 Soil Nematode Bacterial Feeders, 5-10 cm Depth 1-34 Table 1-27. Analysis of Variance, OU 11 Soil Nematode Plant Feeders, 5-10 cm Depth ... I-35

Table 1-28. Analysis of Variance, OU 11 Soil Nematode Omnivore/Predators, 5-10 cm Depth

Table 1-29. Analysis of Variance, OU 11 Soil Invertebrate Arthropod General Predators,

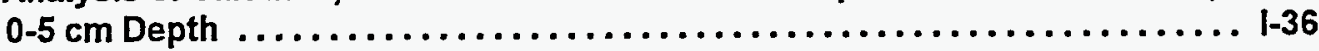

Table I-30. Analysis of Variance, OU 11 Soil Invertebrate Arthropod Predators, 0-5 cm Depth ...........................................................

Table I-31. Analysis of Variance, OU 11 Soil Invertebrate Total Arthropod Predators,

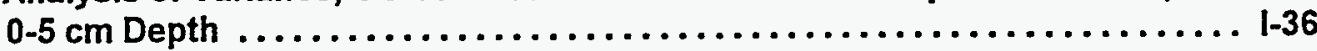

Table 1-32. Analysis of Variance, OU 11 Soil Invertebrate Arthropod Herbivores,

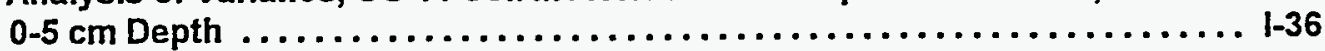

Table 1-33. Analysis of Variance, OU 11 Soil Invertebrate Arthropod Detritivores 1,

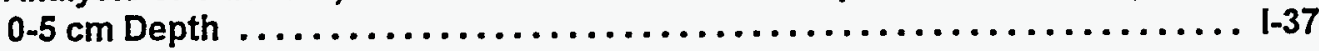

Table 1-34. Analysis of Variance, OU 11 Soil Invertebrate Arthropod Detritivores 2,

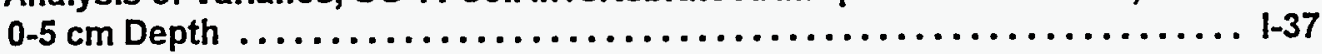

Table 1-35. Analysis of Variance, OU 11 Total Soil Invertebrate Arthropod Detritivores,

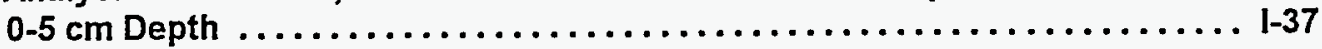

Table 1-36. Analysis of Variance, oU 11 Soil Invertebrate Arthropod Fungal Feeders 1,

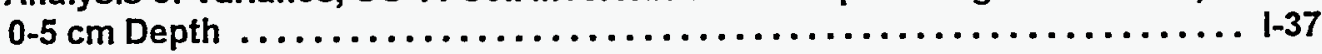

Table 1-37. Analysis of Variance, OU 11 Soil Invertebrate Arthropod Fungal Feeders 2,

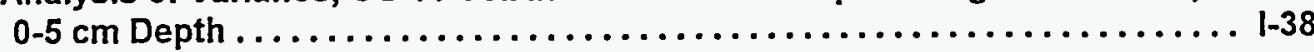

Table 1-38. Analysis of Variance, OU 11 Total Soil Invertebrate Arthropod Fungal Feeder,

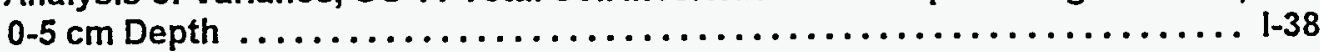

Table 1-39. Analysis of Variance, OU 11 Soil Invertebrate Mesostigmata, 0-5 cm Depth .. I-38 Table 1-40. Analysis of Variance, oU 11 Soil Invertebrate Prostigmata, 0-5 cm Depth .. 1-38 
Table 1-41. Analysis of Variance, oU 11 Soil Invertebrate Cryptostigmata, $0.5 \mathrm{~cm}$ Depth

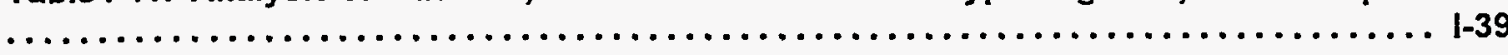

Table 1-42. Analysis of Variance, OU 11 Soil Invertebrate Astigmata, 0-5 cm Depth $\ldots . .1-39$

Table 1-43. Analysis of Variance, OU 11 Soil Invertebrate Arthropod General Predators,

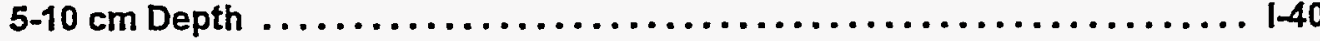

Table 1-44. Analysis of Variance, OU 11 Soil Invertebrate Arthropod Predators,

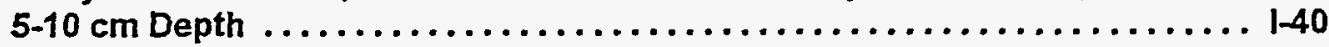

Table 1-45. Analysis of Variance, oU 11 Soil Invertebrate Total Arthropod Predators,

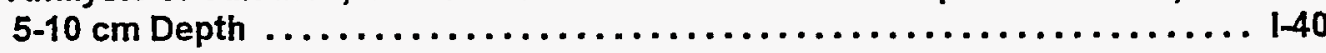

Table 1-46. Analysis of Variance, OU 11 Soil Invertebrate Arthropod Herbivores,

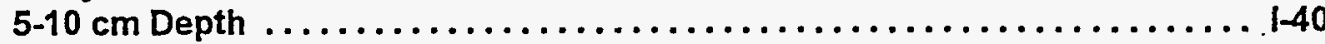

Table 1-47. Analysis of Variance, OU 11 Soil Invertebrate Arthropod Detritivores 1,

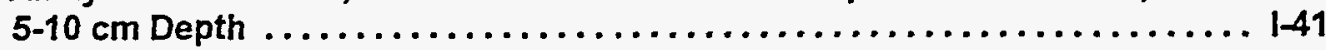

Table 1-48. Analysis of Variance, oU 11 Soil inveltebrate Arthropod Detritivores 2,

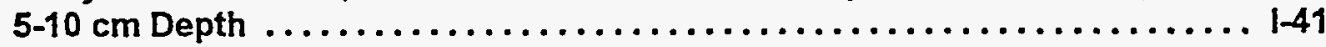

Table 1-49. Analysis of Variance, oU 11 Total Soil Invertebrate Arthropod Detritivores,

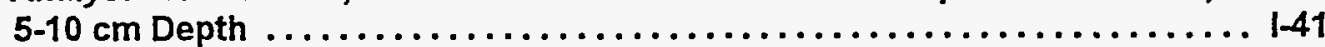

Table 1-50. Analysis of Variance, OU 11 Soil Invertebrate Arthropod Fungal Feeders 1, $5-10 \mathrm{~cm}$ Depth ...................................... 14

Table 1-51. Analysis of Variance, OU 11 Soil invertebrate Arthropod Fungal Feeders 2,

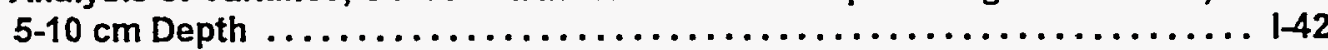

Table 1-52. Analysis of Variance, OU 11 Total Soil Invertebrate Arthropod Fungal Feeder,

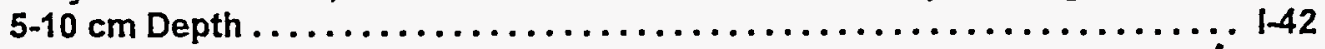

Table I-53. Analysis of Variance, oU 11 Soil Invertebrate Mesostigmata, 5-10 cm Depth ........................................................

Table 1-54. Analysis of Variance, OU 11 Soil Invertebrate Prostigmata, 5-10 cm Depth .................................................... $14 . \ldots$

Table 1-55. Analysis of Variance, oU 11 Soil Invertebrate Cryptostigmata, 5-10 cm Depth ........................................................ 14 


\section{INTRODUCTION}

Between April 1982 and October 1985, three areas in the Rocky Flats Buffer Zone were sprayed with water from the Solar Ponds. This was done to remove excess water when the ponds became full. Because the water was contaminated, the site was identified as a hazardous waste management unit under the Resource Conservation and Recovery Act (RCRA) in 1986. Through a series of regulatory actions, the three areas were combined to create Operable Unit (OU) 11 of the Rocky Flats interagency Agreement (IAG). Designation as an OU under the IAG required a RCRA Facility Investigation/Remedial Investigation (RFI/RI) to be carried out. an ecological Risk Assessment (ERA) is part of that investigation.

Ungrazed unplowed virgin native grassland comprises OU 11. Relict tallgrass species grow in association with shortgrass species that are common farther east. The Flatirons very cobbly sandy loam soil series covers the entire area. This soil is classified as a clayey-skeletal, montmorillonitic, mesic Aridic Paleustoll. Rock fragments make up 35 to $80 \%$ of its volume.

The sprayed area, originally reported to cover 14.1 acres (5.7 ha) (EG\&G, 1992), is now known to be somewhat larger. One location recieived 190 inches $(4.8 \mathrm{~m})$ of irrigation water. Exact amounts of $\mathrm{N}$ applied in irrigation water are not known, but amounts were large. In a single spraying, on April 17 and 18,1982, 89,445 gallons per acre containing $55.8 \mathrm{mg}$ per liter of nitrate as $\mathrm{N}$ added about $7.6 \mathrm{~kg} / \mathrm{ha}(6.8 \mathrm{lbs} / \mathrm{ac})$. Setlock (1985) estimated that 40,638 pounds of $N$ were applied in total. If added evenly to 14 acres, $4,838 \mathrm{lbs} / \mathrm{ac}(3251 \mathrm{~kg} / \mathrm{ha}$ ) were added in four years. Even if added to a somewhat larger area, this is more $\mathrm{N}$ than would be added to any agricultural crop. If any nitrate addition would alter $\mathrm{N}$ cycling in an ecosystem, this one should.

Most organic $\mathrm{N}$ in an ecosystem is in soil organic matter. The next largest amount is in plant tissue and litter. Another large and important amount of $\mathrm{N}$ is dinitrogen (or $\mathrm{N}_{2}$ ) in the atmosphere. All other ecosystem functions depend on the transfers between these constituents. These transfers are biologically-mediated processes of decomposition, plant uptake, denitrification and nitrogen fixation.

Measures of microbial biomass and potential microbial activity reflect basic ecosystem processes. If ecosystem functions changed when large excesses of water and $\mathrm{N}$ were applied, measurements of the amount of microbial biomass and its potential activity ought to reflect the changes, even if other aspects of the ecosystem do not. If they do not, other changes may not be important.

In late summer of 1993, staff from the Ecological Monitoring Program were asked by the OU 11 manager to investigate the possibility of conducting the ERA for this site. Ecology staff had contracts with several laboratories at that time whose analytical work might contribute to the assessment of ecological effects. Staff then devised a sampling program to determine ecological effects of several potential receptors.

\section{OBJECTIVESIAPPROACH}

The approach taken was to conduct a quantitative effects assessment on several potential ecological receptors, and to provide evidence from population, community, and ecosystem levels of organization as to whether an effect(s) was present eight years following the treatment application. If differences did persist, which ones demonstrated the clearest differences? A related purpose was to determine if these relatively inexpensive and quick tests could provide a sensitive measurement of contaminant effects. If similar trends were to emerge from this wide array of receptors, it might be possible to draw conclusions regarding the presence or absence of significant effects. 
The receptors measured include:

A) Soil Physical and Chemical Properties

1) Total soil organic carbon

2) Total soil nitrogen

3) Soil exchangeable potassium

4) Soil extractable phosphorus

5) Soil calcium concentration

6) Soil particle size (texture)

7) Soil cation exchange capacity

Some of these properties ( $C$ and $N$ ) and other soil properties (particle size) were also measured under the ecosystem function section of this report.

\section{B) Vegetation and Litter}

1) Vegetation biomass.

2) Vegetation carbon, nitrogen, potassium and phosphorus concentrations (mg element $\mathrm{kg}^{-1}$ vegetation) and element contents ( $\mathrm{mg}$ element $\mathrm{m}^{-2}$ ).

3) Litter mass.

4) Litter carbon, nitrogen, potassium and phosphorus concentrations (mg element $\mathrm{kg}^{-1}$ vegetation) and element contents (mg element $\mathrm{m}^{-2}$ ).

C) Soil Invertebrates

1) Soil invertebrate nematodes from the $0-5$ and the $5-10 \mathrm{~cm}$ depths, classified into several functional groups.

2) Soil invertebrate arthropods from the $0-5$ and the $5-10 \mathrm{~cm}$ depth, analyzed both taxonomically and by functional groups.

D) Ecosystem Functions

1) Extractable soil nitrate $\left(\mathrm{NO}_{3}\right)$

2) Extractable soil ammonium $\left(\mathrm{NH}_{4}\right)$

3) Total soil nitrogen

4) Total soil carbon

5) Fine Particulate Soil Organic Carbon

6) Fine Particulate Soil Organic Nitrogen

7) Microbial carbon concentration (direct exiraction)

8)Potentially mineralizable nitrogen (10 day incubation at field capacity water content at $25^{\circ}$

$\mathrm{C}$ followed by $\mathrm{NO}_{3}$ and $\mathrm{NH}_{4}$ analysis)

9)Potentially respirable carbon ( $\mathrm{CO}_{2}$ analysis during a 10 day incubation at field capacity water content and $25^{\circ} \mathrm{C}$ )

10)Nitrogen fixation rate (ethylene production)

11)Denitrification rate (nitrous oxide production under $10 \%$ acetylene)

All hypotheses tested were related to significant differences between treatment means. The null hypothesis was that the treatment means of the variable in question were equal, and the alternative hypothesis was that at least two of the treatment means were significantly different at the stated alpha level.

\section{SAMPLE DESIGN}

Twelve sites from Operable Unit (OU) 11 were sampled: three treatments (Sprayed, Nonsprayed and Reference), four replicate sites within each treatment, and five plots per site. Sprayed plots 
were exposed to high levels of nitrate. Non-sprayed plots were not initially thought to have been exposed to nitrates; but were subsequently found to have received some spray. Reference sites were outside the spray area, just north of the McKay ditch, but were in the same soil series and vegetation community (Xeric mixed grassland).

\section{METHODS}

\section{Field Methods}

A) Field Methods, Soil Physical and Chemical Properties:

Soil samples for invertebrate, ecosystem function, and physical chemical analyses were collocated in space and time for comparability. Five plots (P1-P5), in each of the four sites (MG1-MG4), in each of the three treatments (Sprayed, Nonsprayed, and Reference) were sampled, for a total of 60 sample units. Samples were not composited. Twelve additional quality assurance samples were taken. Soil invertebrate samples were taken from $0-5$ and $5-10 \mathrm{~cm}$ depths, but physical/chemical and ecosystem function samples were taken from 1 depth, 0-10 cm. Larger rock and cobbles were removed from samples by hand. All samples were taken with hand tools (shovels, trowels, knives) and transferred to pre-labeled ziplock plastic bags, which also had labels inside the bags. Samples were then placed on blue ice in coolers, sealed, and transferred to a locked room in T891 $\mathrm{G}$ at the end of the day. Samples were logged onto chain-of custody sheets within 24 hours of collection by M. Bakeman. Samples were delivered to laboratories within 48 hours, because of the relatively short holding time of the soil functional and invertebrate samples. These methods became the basis for the biological portion of the EMAD Operating Procedures, 4E07-ECOL.12 Soil Sampling. Figure 1 illustrates the field sampling scheme.

B) Field Methods, Vegetation and litter mass:

Vegetation was collected, dried and weighed by species by $0.25 \mathrm{~m}^{2}$ plot. Litter was dried and weighed by plot. All vegetation rooted within the plot was clipped by species, placed in labeled paper bags, and then transported to T891G. Samples were collected at the rate of 5 samples per site $\times 4$ sites per treatment $\times 3$ treatments $=60$ samples total.

C) Plant and litter tissue nutrient analysis:

Subsets of plant tissue were composited after drying (all species within the same quadrat) for nutrient analysis; it was felt that species nutrient data would be less useful information than average above-ground nutrient data on an area basis. Analyses was apportioned as follows: 3 (of 5) plots $x$ 2 (of 4) sites $\times 3$ treatments $=18$ sample units. Subsets of litter (corresponding to plant tissue) were analyzed for the same nutrient elements as plant tissue, with the exception that lignin analysis was performed on all litter samples.

D) Field Methods, Soil Invertebrates: See Field methods, Soil Physical Chemical Properties above. Above-ground vegetation was not removed from soil inveretbrate samples.

E) Field Methods, Ecosystem Functions:

Detailed descriptions of the soil sampling procedures have been provided in "Procedures for Sampling Soil Invertebrates and Ecosystem Function Measurements, Appendix 11 of the Ecological Monitoring Program Management/Technical Performance Report-GHS-462-93 (93-RF11615)." These procedures are also found in the Ecology Procedures: Volume $V$ of EG\&G Rocky Flats EMAD Operating Procedures, 4-E07-ECOL.12 Soil Sampling. Samples were collected by excavating a $10 \times 10 \times 10 \mathrm{~cm}$ cube of soil from the selected location. All samples represented the surface $10 \mathrm{~cm}$. Samples were collected adjacent to each vegetation production plot for ecosystem function measurements. Sample collection was complicated by the presence of cobbles and stones. Large rocks were removed and weighed separately. Samples were immediately 
transferred to coolers containing ice (Blue lce or its equivalent). They were maintained in coolers until they were transported to the laboratory. In the laboratory they were maintained in a $4^{\circ} \mathrm{C}$ cold room until analysis.

\section{Laboratory Methods}

A) Laboratory Methods, Soil Physical and Chemical Properties:

Soil samples were shipped to the University of Idaho Analytical Laboratory in plastic lined sample bags provided by the laboratory. Each sample consisted of approximately $1 \mathrm{~kg}$ of soil, fresh weight. Soil samples were passed through a $2 \mathrm{~mm}$ sieve and moisture content determined.

Microelements, such as $\mathrm{Zn}, \mathrm{Mn}, \mathrm{Cu}, \mathrm{Fe}, \mathrm{Pb}$, and $\mathrm{Cd}$ were extracted by DTPA at $\mathrm{pH} 7.3$, and then analyzed on an ICP-AES. Exchangeable elements such as $\mathrm{Ca}, \mathrm{Mg}, \mathrm{Na}$, and $\mathrm{K}$ were extracted with $1.0 \mathrm{~N}$ ammonium acetate and analyzed on the ICP. Phosphorus was extracted with $0.5 \mathrm{M}$ sodium bicarbonate and then analyzed on a spectrophotometer. Soil sulfate was determined by shaking the sample with deionized water with 1 drop of concentrated $\mathrm{HCL}$, filtered, and $\mathrm{BaCl}_{2}$ was added to form $\mathrm{Ba} \mathrm{SO}_{4}$, which was then measured on a Turbidometer. Cation exchange capacity was determined by extraction with ammonium acetate at $\mathrm{pH} 7$, followed by measurement of extractable cations by ICP. Total carbon and nitrogen concentrations were determined using an automated CHN Analyzer (McGeehan and Naylor, 1988). Quality control was ensured by the use of laboratory blanks, spikes, and certified standard materials. All laboratory procedures are on file with EcMP staff.

B) Laboratory Methods, Vegetation and Litter:

All vegetation samples were dried at $65^{\circ} \mathrm{C}$ in a forced air drying oven until they had reached constant weight, and then weighed on a top loading balance to the nearest $0.1 \mathrm{~g}$. Samples were then shipped to the University of Idaho Analytical Laboratory in paper bags for elemental analysis. Dried samples were first ground in a Wiley mill, weighed $(0.25-0.50 \mathrm{~g}$ of tissue), and digested in $3.0 \mathrm{ml}$ of reagent grade nitric acid. Samples were centrifuged and the resulting solutions were analyzed on a Perkin Elmer P-40 ICP for cation elements, phosphorus, and sulfur. Total carbon and nitrogen concentrations were determined using an automated CHN Analyzer (McGeehan and Naylor, 1988). Quality control was ensured by the use of laboratory blanks, spikes, and certified standard materials. All laboratory procedures are on file with EcMP staff.

C) Laboratory Methods, Soil Invertebrates:

After soil samples were delivered to the laboratory, they were immediately extracted. Dynamic extraction is used for nematodes and arthropods, where the sample is slowly dried out and the living organisms are forced to migrate either freely or via water films into an extraction vial. Organisms were then viewed under a binocular microscope, where they were counted and identified. Quality assurance was provided by the collection of duplicate samples and the use of a reference collection for the arthropods.

D) Laboratory Methods, Ecosystem Functions:

Detailed procedures for the analyses performed by the Natural Resource Ecology Laboratory are on file with EWM personnel. For initial processing at the laboratory, samples were sorted and laboratory identification numbers assigned. A separate field bag held each sample. The contents of these bags were mixed and coarse mineral and organic matter fragments were removed. These coarse fragments were later weighed. The soil was then sieved through a $2 \mathrm{~mm}$ sieve. Water content of the sieved soil at field capacity was measured.

Incubations were then initiated using sieved soil. Field nitrate and ammonium concentrations were measured. Three subsamples were prepared for each sample date. All extractions and incubations were carried out for each soil sample and for selected duplicates and three blanks. Fifty grams of soil was weighed into appropriate containers. Water was added to bring the soil to the water content at field capacity. The cups were placed into respiration chambers with several $\mathrm{ml}$ 
of water to prevent desiccation of the soil. A vial containing a known volume of $3 \mathrm{M} \mathrm{NaOH}$ (usually $1.275 \mathrm{ml}$ ) was place in each chamber. The chambers were sealed and incubated at $25^{\circ} \mathrm{C}$. On the third, sixth and tenth days, the vials of $\mathrm{NaOH}$ were titrated with $1 \mathrm{M} \mathrm{HCl}$ in the presence of $\mathrm{BaCl}_{2}$. The vials were replaced on the third and sixth days. On the tenth day, the soil was removed and subsampled for water content, mineralized $\mathrm{N}$, and microbial biomass $\mathrm{C}$ and $\mathrm{N}$.

Water content was measured gravimetrically. Mineralized $\mathrm{N}$ was measured by analyzing for ammonium and nitrate+nitrite on an auto-analyzer. Microbial biomass $\mathrm{C}$ and $\mathrm{N}$ were estimated by measuring the differences in soluble $\mathrm{C}$ and $\mathrm{N}$ between a control and a chloroform fumigated subsample of each sample. In this report, microbial biomass is presented as the difference between these subsamples. No correction was made for the efficiency of extraction. It is more common in scientific reporting to divided the difference in extractable carbon between chloroformed and unchloroformed soil by 0.41 or some other factor. That is to say, exposure to chloroform renders $41 \%$ of the microbial carbon extractable. Nitrogen is calculated by various formulae, because the extractability of nitrogen is not straightforward. Details of these corrections are not explored for this report.

Texture and Particulate Organic Carbon and Nitrogen were measured by suspending soil samples in $5 \%$ sodium hexametaphosphate. Sand sized particles are collected on a $53 \mu \mathrm{m}$ sieve. The remaining sample is placed in 1 I sedimentation cylinders and measured by hydrometer. Particulate organic carbon and nitrogen are then measured on the sand fraction collected on the sieve.

Statistical analyses were by nested Analysis of Variance. Three treatments were sampled: Sprayed, Non-sprayed and Reference Areas. Replicates were nested within treatments and plots were nested within replicates within treatments. Treatment mean squares were tested against replicate within treatment mean squares. Replicate mean squares were tested against plot within replicate within treatment, or residual, mean squares. Where the $\mathrm{F}$ statistic was significant at the 0.05 level, Honestly Significant Differences (HSDs) were calculated.

\section{RESULTS}

\section{A) Statistical Approach}

A nested Analysis of Variance (ANOVA) model was used to determine the significance of the treatment and replicate within treatment effects. If a treatment effect was significant, it indicated that at least two of the three treatment means (sprayed, nonsprayed, and reference) were significantly different. If the replicate within treatment effect was significant, it indicated that there was a significant difference in the sites within treatments. This approach tends to be more conservative than a simple one-way analysis of variance (there are fewer significant treatment effects). However, after analyzing data with both models and often finding significant replicate within treatment effects, it was decided that the nested model was the most appropriate for these data. In cases where the replicate within treatment effect was not significant in the nested model, some of the data were reanalyzed with the one-way ANOVA model to test for treatment effects. Variables analyzed in this model included vegetation and litter mass, soil invertebrate functional group and mite taxa counts, soil physical/chemical data, and ecosystem function analyses. Soil invertebrate data were analyzed separately for $0-5 \mathrm{~cm}$ and $5-10 \mathrm{~cm}$ depths. Vegetation and litter nutrient analyses were analyzed with a simple one-way ANOVA model because the reduced level of replication did not allow for use of the nested design.

The assumptions of an ANOVA model do not always hold for soil invertebrate count data; this is often due to the large variability in these data sets. Variances among group means are often not equal, and this was encountered in some of the data, although this does not in itself disqualify the 
robust ANOVA model. Most of the residuals that were examined in the analyses were normally distributed, lending credence to this model. Also, most treatment means had sample sizes of 20 observations, and the model is more robust at moderate ( $>10$ observations) to large sample sizes.

An alpha level of 0.10 was generally used to consider if an effect was statistically significant; this is applicable for such variable data.

\section{B) Soil Physical/Chemical Properties}

Soil carbon, nitrogen, potassium, phosphorus, and calcium concentrations, texture, and cation exchange capacity were measured and analyzed for significant treatment effects using the nested ANOVA model. Carbon, nitrogen, texture, and cation exchange capacity results are presented in the next section because of their particular relevance to ecosystem function properties.

Mean soil potassium concentrations were ranked in the order Sprayed $>$ Nonsprayed $>$ Reference $\left(306.15,298.3,235.25 \mathrm{mg} \mathrm{kg}^{-1}\right.$ respectively, Table $\left.\mathrm{l}-1\right)$. The overall treatment effect was not significant $(p=0.1774)$, but the replicate within treatment effect was highly significant $(p=0.0003)$. This illustrates the considerable variability within the replicate sites used for each treatment.

Phosphorus soil concentration means ranged from $6.935 \mathrm{mg} \mathrm{kg}^{-1}$ (Reference) to 9.485 (Nonsprayed). The treatment effect was not statistically significant $(p=0.1626)$, but the replicate within treatment effect was $(p=0.0002$, Table $1-2)$.

Mean soil calcium concentrations were very similar, and again the treatment effect was not statistically significant $(p=0.4684$ ), but the replicate within treatment effect was ( $p=0.0017$, Table (-3).

\section{C) Vegetation and Litter}

Results of vegetation biomass were reported previously, but are repeated again for completeness. Total vegetation production was greatest on the Sprayed treatment area (mean $166 \mathrm{~g} \mathrm{~m}^{-2}$ ), followed by Nonsprayed (146.8 $\left.\mathrm{g} \mathrm{m}^{-2}\right)$, and Reference (142.9 $\mathrm{g} \mathrm{m}^{-2}$, Table $\left.\mathrm{l}-4\right)$. None of these differences were significant $(p=.2311)$ at the 0.10 level.

Litter values followed a similar trend, with the exception that the Reference treatment mean was greater than the Nonsprayed mean (Sprayed, $233.3 \mathrm{~g} \mathrm{~m}^{-2}>$ Reference, $205.3 \mathrm{~g} \mathrm{~m}^{-2}>$ Nonsprayed, $195.2 \mathrm{~g} \mathrm{~m}^{-2}$, Table $\left.1-5\right)$. Again, these differences were not significant $(p=.4265)$.

All plant and litter nutrient concentrations and contents were corrected for ash content.

Plant carbon concentrations were significantly different $(p=0.0375)$ despite the extremely tight range of values encountered ( 47.7 to $46.6 \%$, Table $1-6$ ). The reference treatment had significantly lower plant tissue carbon values than the nonsprayed treatment.

Litter carbon concentration could not be analyzed using this model, because of inequality of variances among the treatment means.

Both plant and litter total carbon $\left(\mathrm{g} \mathrm{C} \mathrm{m}^{-2}\right)$ were not significant (p-values were 0.1613 and 0.3718 respectively, Tables $1-7$ and $1-8)$.

Plant and litter nitrogen concentrations and contents also did not show statistically significant differences among treatments (Tables I-9 through I-12). There was also no consistent ranking of the treatment means, with plant nitrogen concentration highest in the nonsprayed treatment, but nitrogen content highest in the sprayed treatment. Litter nitrogen concentrations and contents were 
highest in the sprayed treatment, but again, none of the nitrogen differences were statistically significant.

Plant potassium concentrations and contents showed unusual significant effects. Concentrations and contents were ranked Nonsprayed $>$ Reference $>$ Sprayed ( $P$-values $=0.0189$ and 0.0551 respectively, Tables $1-13$ and $(-15)$. Litter potassium concentrations and contents showed no statistically significant differences among treatments (Tables $1-14$ and I-16).

Plant phosphorus concentration showed a significant treatment effect $(p=0.0129$, Table $1-17)$, being highest in the Nonsprayed treatment. Litter $P$ concentration was also highest in the Nonsprayed treatment, but was not statistically significant $(p=0.2242$, Table $1-18)$. Plant and litter $P$ contents also showed higher contents in the Nonsprayed treatment, but neither were statistically significant (Tables $1-19$ and $1-20$ ).

\section{D) Soil Invertebrates}

Data are presented on the basis of the two gross taxonomic groups: nematodes, and arthropods. Brief descriptions of each group follow, including comments on life history, classification, units of analysis, and data variables.

Nematodes

Nematodes, also called roundworms, are a group of ubiquitous soil organisms that move throughout the profile via soil water films. Soil moisture is a critical factor affecting their distribution. The taxonomy of free-living nematodes is not well documented (Freckman and Baldwin, 1990), primarily because much of the available work has been targeted at crop pests. Nematodes occupy a great variety of niches in the soil, acting as predators of soil arthropods, bacteria and other nematodes, fungal feeders, plant root feeders, and parasites of invertebrate and vertebrate hosts.

For this study, nematodes were classified into four functional groups:

Bacterial Feeders;

Fungal Feeders;

Ominivore/Predator; and

Plant Feeders.

Functional group determination is based on body morphology and mouth part.

All nematode functional groups were expressed as counts of organisms $\mathrm{g}^{-1} \mathrm{dry}$ soil.

Nematodes functional groups were dominated by fungal and bacterial feeders ( $93 \%$ of total nematodes in both the $0-5$ and $5-10 \mathrm{~cm}$ depths), followed by omnivore/predators ( $4 \%$ surface, $3 \%$ subsurface) and plant parasites ( $2 \%$ surface, $3 \%$ subsurface). Surface soils $(0-5 \mathrm{~cm}$ depth) had higher functional group counts than subsurface soil $(5-10 \mathrm{~cm})$, with the exception of omnivore/predators which showed the opposite relationship. Surface soil had an average of 12,410 nematodes $\mathrm{g}^{-1}$ soil (all functional groups, all sites), and subsurface soil had an average of 11,858 nematodes $\mathrm{g}^{-1}$ soil (all functional groups, all sites).

In the $0-5 \mathrm{~cm}$ depth, most of the functional groups (omnivore/predator, plant feeders, and bacterial feeders) displayed the trend of treatment means being ranked in the order Sprayed $>$ Reference $>$ Nonsprayed Tables !-21 through $1-24$ ). In these cases, the Sprayed treatment often had an average number of nematodes that was 1.5 to 2 times greater than the next highest mean. However, the treatment effect was only statistically significant for the omnivore/predator functional group $(p=0.0853$, Tables $1-24)$. The fungal feeder functional group 
had the highest mean number of nematodes in the Nonsprayed treatment, followed by Reference and Sprayed treatments, but none of these differences were significantly different. Only one of the four functional groups had a significant replicate within treatment effect (plant feeders). The two remaining functional groups that did not show a signinicant treatment effect (fungal and bacterial feeders) were reanalyzed with the one-way ANOVA model; differences were not statistically significant.

In the 5-10 cm depth, functional group treatment means were often ranked in the same order as the surface horizon, with Sprayed means > either Reference or Nonsprayed means (Tables $1-25$ through (-28). Mean plant feeders nematode counts in the Sprayed treatment were significantly greater than in the Nonsprayed, with Reference treatment intermediate $(p=.0753$, Table 1-27). Again, the fungal feeder functional group had higher mean counts in the Nonsprayed treatment than Sprayed or Reference treatments. None of the functional groups had a significant replicate within treatment effect, so the three groups that had nonsignificant treatment effects were reanalyzed with the with the one-way ANOVA model; none had significant treatment effects.

\section{Soil Arthropods}

Soil arthropods are comprised of a vast array of invertebrate groups and species. Some of the representative taxa in this study are insects, crustaceans, arachnids (soil mites and spiders), and myriopods (centipedes, millipedes). Arthropods were analyzed both taxonomically and by functional groups for this study. Taxonomy resolution depended on class of organisms analyzed, from family/genus for most of the collembola and mites, to order for many of the remaining groups.

All organisms were classified into the following functional groups:

Fungivore 1 - this was a count of all the Collembola in the sample - this insect class was determined separately from other fungivores because of their predominance in this functional group;

Fungivore 2 - all other fungivores;

Total Fungivores - Count of fungivore $1+$ fungivore 2;

Detritivore 1 - small detritivores;

Detritivore 2 - large detritivores;

Arthropod predators;

General Predators;

Total Predators - Arthropod predators + general predators; and

Herbivores - Root Feeders.

Total counts were also made of the various mite genera because of the finer taxonomic resolution for these groups.

Arthropod counts were expressed as \# organisms $\mathrm{m}^{-2}$. However, these counts on an area basis are rough approximations, because defining a sample area in the rocky soils of the Site is extremely difficult.

Soil arthropod functional and mite groups were analyzed in the same manner as nematodes 
except that arthropods had more functional groups (10) and 3 to 4 mite taxa groups, all from surface $(0-5 \mathrm{~cm})$ and subsurface $(5-10 \mathrm{~cm})$ horizons.

For surface functional groups, total fungivores had the highest mean organism count (2102 total fungivores $\mathrm{m}^{-2}$ ) of all functional groups, all treatments, and arthropod predators the lowest mean count $\left(255 \mathrm{~m}^{-2}\right)$. Mite families were dominated by the Meșostigmata $\left(281 \mathrm{~m}^{-2}\right)$, and the Astigmata were relatively scarce $\left(7 \mathrm{~m}^{-2}\right)$.

Statistical analyses and treatment means for functional group counts and mite taxa counts from the surface horizon are summarized in Tables $1-29$ through 1-42. Two major patterns emerged in ranking functional group treatment means: Sprayed treatments had either the highest of the three treatment means (all 3 predator functional groups, total and detritivore 2 groups), or the lowest mean counts (all 3 fungivore groups, detritivore 1, and herbivores). However, none of the 10 surface horizon functional groups showed a significant treatment effect at an alpha level of 0.10 , and most were highly nonsignificant. Seven of the ten functional groups showed significant replicate within treatment effects, indicating a high degree of variability within sites in a treatment. Sites that did not show a significant replicate within treatment effect were reanalyzed with the oneway ANOVA model, and none showed a statistically significant treatment effect.

Mite counts from the four taxa groups in surface horizons showed both increases in the Sprayed treatment (mesostigmata and cryptostgmata) and decreases (prostgmata). Mesostigmatid mite counts from the surface horizon showed a significant treatment effect $(p=.0939)$, with the Sprayed treatment having the highest count ( 505 mites $\mathrm{m}^{-2}$ ) and the Nonsprayed treatment the lowest count (150). However, the conservative Tukey means separation procedure did not find the difference in these means statistically significant.

Subsurface arthropod functional groups were once again dominated by the total fungivore group (mean 1211 fungivores $\mathrm{m}^{-2}$, all samples), and the detritivore 1 functional group having the lowest average count $\left(14 \mathrm{~m}^{-2}\right)$. The cryptostigmatid mites dominated the mite taxa (mean 622 mites $\mathrm{m}^{-2}$ ), and the astigmata were again fewest $\left(2 \mathrm{~m}^{-2}\right)$.

Statistical analyses of functional group data found that 3 of the 10 functional groups showed a significant treatment effect (Tables $1-43$ through $1-52$ ). This included the functional groups herbivores $(p=0.0623)$, detritivores $2(p=0.0798)$, and total detritivores $(p=0.082)$. For these 3 functional groups, the Sprayed treatment had the highest organism counts and was significantly greater than the nonsprayed treatment, but not the reference treatment. As with the surface horizon, a majority of the functional groups $(6 / 10)$ had significant replicate within treatment effects, indicating considerable variation with sites within a treatment. Six functional groups had highest mean organism counts in the Reference treatment, and the Sprayed treatment was the lowest in those cases, but none of those differences were statistically significant.

Analyses of mite subsurface taxa counts were also conducted (Tables I-53 through I-55), except for astigmatid mites because of failures in the assumptions of the model. Cryptostigmatid mites showed the only statistically significant treatment effect, with the Sprayed treatment having a significantly greater mean count (906 mites $\left.\mathrm{m}^{-2}\right)$ than the Nonsprayed treatment (mean $=257$ mites $m^{-2}$ ).

\section{E) Ecosystem Functions}

The particle size distributions of particles that passed through a two-mm sieve from the surface 10 $\mathrm{cm}$ in all treatments were identical: $61.6 \%$ sand (standard deviation $=3.4$ ), $14.5 \%$ silt (standard deviation $=4.3$ ) and $23.9 \%$ clay (standard deviation $=4.0$ ). The soil texture is sandy clay loam. This soil has been classified as very cobbly or very stony sandy loams. Surface horizons are $20 \%$ cobbles, $40 \%$ gravel. The large fraction of coarse fragments precluded reliable estimates of bulk 
density.

Mean soil cation exchange capacity varied little among the treatments, from $18.09 \mathrm{cmol} \mathrm{kg}^{-1}$ in the Nonsprayed treatment, to 20.49 in the Sprayed treatment. These differences were not statistically significant $(p=0.1694)$.

Total soil organic $C$ concentrations were highest in the Sprayed plots; differences were statistically significant at $0.072(F=3.57)$. Sprayed plots àveraged $39 \mathrm{~g} / \mathrm{kg}$, reference plots averaged 32 and non-sprayed plots averaged $33 \mathrm{~g} / \mathrm{kg}$ (Fig. 2). If a significance level of 0.072 is accepted, apparently the difference between sprayed and the other two treatments is the only difference.

Soil Organic $\mathrm{N}$ concentrations were also greatest in sprayed plots. Differences were statistically significant at the 0.039 confidence level ( $F=4.75$ ). Sprayed plots averaged $3.08 \mathrm{~g} / \mathrm{kg}$ (Fig. 3 ). Nonsprayed plots averaged $2.67 \mathrm{~g} / \mathrm{kg}$. Reference plots averaged $2.60 \mathrm{~g} / \mathrm{kg}$. Means can be separated by an HSD of 0.47 . Thus the sprayed treatment hacl significantly more total $N$ than non-sprayed or reference areas.

Field nitrate concentrations were significantly higher in sprayed than in reference or non-sprayed plots $(F=9.21$; Significance of $F=0.007\rangle$. Figure 4 shows this relationship. Nitrate concentrations, expressed as $\mathrm{N}$, were more than twice as high in the sprayed plots.

Field ammonium concentrations were less than $5 \mathrm{mg} / \mathrm{kg}$ ammonium- $\mathrm{N}$. A treatment effect significant at $0.076(F=3.48)$ existed. Ammonium-N concentrations were $1.7 \mathrm{mg} / \mathrm{kg}$ in sprayed plots, 4.7 in reference plots and 4.9 in non-sprayed plot.

Potentially respirable $\mathrm{C}$ and mineralizable $\mathrm{N}$ concentrations exhibited no statistically significant differences.

Microbial biomass $\mathrm{C}$ concentrations were not statistically significantly different between treatments, but Microbial biomass $N$ revealed a treatment effect significant at $0.014(F=7.21)$. Mean concentrations of biomass $N$ were $68 \mathrm{mg} / \mathrm{kg}$ in sprayed plots, $45 \mathrm{mg} / \mathrm{kg}$ in reference plots and 53 $\mathrm{mg} / \mathrm{kg}$ in non-sprayed plots. Honestly Significant Differences were at least $15 \mathrm{mg} / \mathrm{kg}$. Therefore, Sprayed plots had significantly higher concentrations of micrabial biomass $N$ than reference, but not than non-sprayed plots.

Fine particulate organic $\mathrm{C}$ and $\mathrm{N}$ concentrations were higher in sprayed than in reference or nonsprayed plots. Sprayed plots averaged $12 \mathrm{~g} / \mathrm{kg}$ of fine particulate organic C compared to $9.4 \mathrm{~g} / \mathrm{kg}$ in reference and $9.5 \mathrm{~g} / \mathrm{kg}$ in non-sprayed plots. Sprayed plots averaged $0.752 \mathrm{~g} / \mathrm{kg}$ of fine particulate organic $\mathrm{N}$ compared to $0.567 \mathrm{~g} / \mathrm{kg}$ in reference and $0.576 \mathrm{~g} / \mathrm{kg}$ in non-sprayed plots. However, the significance level for fine particulate organic $C$ was $0.080(F=3.38)$ and for fine particulate organic $\mathrm{N}$ was $0.054(\mathrm{~F}=4.10)$.

The fraction of total organic $C$ that was microbial biomass $C$ had no significant treatment effects $(F=0.29)$. Similarly, the fraction of total soil $N$ that was microbial biomass $N$ had not significant treatment effects $(F=1.99)$. On average, 1.13 percent of the $C$ and 1.95 percent of the $N$ occurs in the fraction made soluble by chloroform fumigation. This fraction is called microbial biomass in this report. The trends of the means in these two variables, however, suggest that sprayed plots have a higher average fraction of their organic $\mathrm{C}$ and $\mathrm{N}$ in microbial biomass.

The fraction of the soil organic $C$ that was respirable in 10 days did not show any statistically significant treatment effects $(F=2.58)$. The fraction of the total soil $N$ that was mineralizable was, however, significant $(F=6.01$; significance of $F=0.022)$. The HSD for separating treatments is 0.177 percent. Figure 5 indicates that the sprayed treatment has the lowest fraction of $\mathrm{N}$ in mineralizable forms. Reference and Non-sprayed treatments were not different from each other. 
The fractions of organic $C$ and $N$ in fine particulate organic matter had no significant treatment effects. For $C$, the treatment was 0.24 and for $N$, the treatment $F$ was 1.38 .

\section{DISCUSSION}

\section{A) Soil Physical Chemical Properties}

Some of the physico-chemical soil variables measured, such as texture, and to a lesser extent soil cation exchange capacity, are basic ecosystem properties that affect many of the subsequent measurements. They are also much less sensitive to changes induced by the spray treatment than are many of the subsequent variables, and significant changes due to the treatment would not be expected. If significant differences are found, this could indicate that there were inherent, measurable differences in the three treatment sites before the application of the spray.

Soil sand, silt and clay mean contents were remarkably similar among the three treatments, as were mean cation exchange capacity values. Thus, it appears that there are not inherent treatment site differences as measured by these variables.

Soil chemical properties were considerably more variable, and most had a statistically significant replicate within treatment effect. Soil carbon and nitrogen concentrations at $0-10 \mathrm{~cm}$ were the only elements that showed a significant elevated response to the Spray treatment. The implications of these increases are further discussed below under ecosystem functions. All other soil element concentrations measured did not show a significant treatment effect. This is not unusual, given that the physical soil properties of this area are similar among treatments, and that the vegetation community type is the same for all treatments (xeric mixed grassland).

\section{B) Vegetation and Litter Biomass and Nutrient Concentrations and Contents}

These results include information on biomass $\left(\mathrm{g}\right.$ dry tissue $\left.\mathrm{m}^{-2}\right)$, nutrient concentrations ( $\mathrm{g}$ element $\mathrm{g}^{-1}$ biomass), and nutrient contents ( $\mathrm{g}$ element $\mathrm{m}^{-2}$ ). Biomass production is a fundamental property of all ecosystems, and if differences were found among the treatments, several other effects might be expected. Plant and litter nutrient concentration and content data are related to soil available nutrient pools, vegetation production, species composition, and decomposition rate, to name a few.

If a nutrient is added to a site and a growth effect is anticipated, then the effect can often be measured in both increased biomass production, and increased tissue concentration and content of the added element. Tissue concentration, content, and biomass data are often all related to one another, because of potential element dilution effects as biomass increases. A real biological effect often finds increases in all three of these variables.

For vegetation carbon, the Spray treatment had greater biomass, intermediate carbon concentration, and a moderate increase in total vegetation $C$ over the Reference treatment (but not the Nonsprayed). Only the increase in carbon concentration was statistically significant. It is clear that although there was a slight (statistically nonsignificant) increase in vegetation biomass production, carbon concentrations and contents were unaffected.

Sprayed mean litter mass also was higher than the other 2 treatments, but litter $C$ concentration was lower (a possible dilution effect), and litter $C$ content was higher. None of these differences were statistically significant (concentration was not analyzed), and there is no clear effect of the Spray treatment on litter carbon pools.

Vegetation and litter nitrogen data showed varied effects. Vegetation $N$ concentration was lowest in the Sprayed treatment (again, a possible dilution effect since biomass was greater), but $N$ content was highest; these differences were not statistically significant. Litter biomass, $N$ concentration and 
was highest; these differences were not statistically significant. Litter biomass, $N$ concentration and content means were all highest in the Sprayed treatment, although none were statistically significant. However, the trend of all 3 variables greater than the other 2 treatment means may indicate that a real biological effect occurred, and that the sampling intensity ( 6 observations/treatment for element data) was not adequate to detect statistical significance.

Both plant potassium concentration and content analyses showed a statistically significant treatment effect, although differences among treatments are not consistent. Nonsprayed treatment mean $\mathrm{K}$ concentrations were significantly greater than Sprayed, and Nonsprayed K contents were significantly greater than the Reference treatment. Mean Nonsprayed and Sprayed soil $\mathrm{K}$ concentrations were not different (298.3 and $306.15 \mathrm{mg} \mathrm{kg}^{-1}$ respectively). Litter potassium concentrations and contents showed this same trend (although statistically insignificant); it is not known why Nonsprayed treatments were higher than other treatments for this element. Plant and litter phosphorus concentrations and contents also displayed the trend of being highest in the Nonsprayed treatment.

Nutrient and biomass data show two general trends: 1) Sprayed plots increased in litter mass, nitrogen concentration, and nitrogen content, and 2) Nonsprayed plots had greater plant and litter $K$ and $P$ concentrations and contents. It appears that litter nitrogen may be the most biologically sensitive receptor (of those evaluated for biomass and nutrients) to the $\mathrm{N}$-spray treatment, although effects were not statistically significant. The elevated levels of $K$ and $P$ in plant tissue in the Nonsprayed treatment are not easily explained. This trend was also observed in the analysis of other receptors and will be further discussed.

\section{C) Soil Invertebrates}

Nematodes

Nematode functional group mean counts were greatest in the Sprayed treatment for omnivore/predator, plant feeders, and bacterial feeder functional groups at both depths. Mean counts were often at least 1.5 to two times greater than the next highest treatment mean. However, the effect was only statistically significant for two functional groups at an alpha of 0.10 : omnivore/predators increased at 0-5 cm, and plant feeders increased at 5-10 cm. It does appear that Sprayed plots have more total nematodes (Sprayed mean all functional groups 13,822 ; Nonsprayed 11,417, and Reference 11,087), but again, these differences are not statistically significant. This may be a response to increased total substrates or increase in available substrates. The Sprayed treatment was also higher in litter mass and litter nitrogen concentrations and content than the other treatments, although many of these comparisons were not statistically significant. There were also substantial differences in ratios of functional groups: mean (fungal feeders +1$) /($ bacterial feeders +1 ) was substantially lower in the Sprayed treatment than the two other treatments, (Sprayed $=1.10$, Nonsprayed $=1.73$, Reference $=4.59$ ), and the mean ratios of (omnivore-predator+1/plant feeders +1 ) were: Sprayed, 24.61, Reference, 69.32, and Nonsprayed, 104.60) (When ratios were determined, the value 1 was added to all functional group counts to eliminate all count values of 0 \}. However, none of these differences were statistically significant.

It appears that total numbers of nematodes in three functional groups increased in the spray plots, and the selected ratios of functional groups also changed in the Sprayed treatment. A few of these changes were statistically significant, but most were not. When OU 11 nematode means were compared to nematode Xeric mixed grassland community means from non-impacted (reference) sites at RFETS, counts in OU 11 usually exceeded reference sites, especially Sprayed treatment means (see Appendix E. Soil Invertebrates). It is possible that differences in Sprayed treatment areas are biologically relevant to changes in invertebrate biomass distribution and nutrient cycling pathways; the bacterial feeder functional group has increased at the expense of fungal feeders and omnivore/predators have decreased relative to plant feeders. The consequences of such changes 
statistically significant or perhaps biologically relevant, most soil nematode functional group populations (and total numbers) increased on Sprayed areas (with the exception of fungal feeders), and it is highly unlikely that this would have a deleterious effect on this ecosystem.

\section{Arthropods}

As with the nematode data, arthropod data were statistically analyzed for a significant treatment effect, but data were also scrutinized for trends that might emerge from ranking of treatment means. None of the organism counts in surface functional groups showed a statistically significant treatment effect, and only 3 of 10 subsurface functional groups were significant ( herbivores, detritivores 2, and total detritivores). In the cases of the significant functional groups, Sprayed treatment means were higher than Nonsprayed means, but not Reference means. Analysis of mite taxa found that one surface mite taxum (Mesostigmata) and one subsurface taxum (Cryptosigmata) were also significantly greater in the Sprayed treatment. Thus, the only statistically significant effects were an increase in a few functional group or mite taxa counts due to the Spray treatment.

The reverse trend, where Sprayed treatment means were lower than the other two treatments, was also evident, but none of the differences were significantly different. Ratios of predators to herbivores were also not significantly different by treatment at either depth.

It appears that although the Spray treatment may have caused both increases and decreases in soil arthropod functional group and mite taxa counts, most of the changes were not statistically significant, and significant effects were ususually found where there were organism increases on Sprayed treatment areas. The effect of these increases on other ecosystem properties is unknown, but the influence of the Spray treatment on most soil arthropods has been to increase their numbers.

General soil invertebrate discussion

Changes in both arthropod and nematode functional groups were generally not evident as a result of the Sprayed treatment. Detectable changes were only found where organisms in the Sprayed treatment were significantly greater than either Nonsprayed or Reference treatments. It was stated earlier that Nonsprayed treatment areas were found to have received treatment spray, although it was believed to have been at a lesser rate than the Sprayed treatment. However, there was not a consistent ranking of treatment means in the expected order (Sprayed > Nonsprayed > Reference, or the reverse). Many of the analyses showed a significant replicate within treatment effect in the nested ANOVA model used, indicating considerable variation within treatment areas, which made it difficult to detect treatment differences. This variation could be due to inconsistent spray application to different areas, or the inability to designate accurate treatment boundaries on the ground ten years later. Many additional analyses can be conducted on these data, including analyses of transformed data and multivariate classification and ordination techniques. The latter analyses may show better groupings of sample units than the current scheme, and data can be reanalyzed using new treatment designations. However, it can be stated that preliminary analyses have not shown any statistically significant or dramatic (more than 10x) nematode or arthropod functional group declines in areas where the Spray treatment was though to be heaviest.

\section{D) Ecosystem Functions}

Eight years after spraying ceased, soil $\mathrm{C}$ and $\mathrm{N}$ concentrations are greater in Sprayed than in unsprayed treatments (Figures. 2 and 3). Assuming that an acre of soil six inches deep has a mass of two million pounds, and that $0-10 \mathrm{~cm}$ has two-thirds of the mass found from $0-15 \mathrm{~cm}(0-6 \mathrm{in})$, we can calculate, even if crudely, that sprayed soil contains 650 pounds more $\mathrm{N}$ per acre than unsprayed soil in the top ten $\mathrm{cm}$ (four in). This amount is $13 \%$ of the total $\mathrm{N}$ applied, as estimated by Setlock (1985, unpublished internal letter, Rockwell International). Because assumptions and 
estimates are so crude, we do not emphasize specific values here. The salient point is that a substantial amount of applied $N$ remains in the soil organic matter. Soil organic $C$ concentrations probably increased because increased $\mathrm{N}$ caused greater plant growth, litter production, and greater microbial biomass and microbial metabolic products.

Nitrate- $\mathrm{N}$ concentrations were also greater eight years after spraying $(14.0 \mu \mathrm{g} / \mathrm{g})$ than in reference soil $(6.4 \mu \mathrm{g} / \mathrm{g})$. Concentrations of nitrate- $\mathrm{N}$ greater than ten $\mu \mathrm{g} / \mathrm{g}$ are unusually high for grassland soils, although they are common in agricultural soils.

Although potentially mineralizable $N$ concentrations were not different at $p=0.05$, they were significantly different at $p=0.10$. Sprayed soils mineralized the least $N(8.9 \mu \mathrm{g} / \mathrm{g})$ and reference soils the most $N(13.7 \mathrm{ug} / \mathrm{g})$. There are $7.6 \mathrm{ug} / \mathrm{g}$ more nitrate and $4.8 \mathrm{ug} / \mathrm{g}$ less mineralizable $\mathrm{N}$. Possibly $N$ that was mineralizable $N$ in reference soil was already mineralized in sprayed soil. The sum of mineral and mineralizable $\mathrm{N}$ is $23 \mathrm{ug} / \mathrm{g}$ for sprayed and $17 \mathrm{ug} / \mathrm{g}$ for reference soil. Together these fractions represent the most active part of the soil organic $N$. The rapidity of nitrogen transformations suggests that the combination of mineral and mineralizable $\mathrm{N}$ can be conceived as a unique part of the soil organic $N$. The concentration of this pool does not reflect the spraying treatment $(p=0.40)$. The fraction of the total $N$ represented by this active part, $0.9 \%$ on average, also does not reflect the spraying treatment $(p=0.28)$.

Microbial biomass $\mathrm{C}$ and $\mathrm{N}$ concentrations presented in this paper are simply the additional $\mathrm{C}$ and $\mathrm{N}$ made soluble by chloroform vapors. More commonly in the scientific literature, these values will be corrected for the extractability of the $C$ and $N$. Typically, microbial $C$ is assumed to be between $41 \%$ and $45 \%$ extractable. Microbial $N$ is corrected by various factors. It is beyond our scope to evaluate the differences in this manuscript. Comparisons should not be made to corrected microbial biomass from other sources. Essentially, the true microbial biomass concentration is a little more than double the values presented here. Comparisons between treatments in this report are not affected, however.

Microbial biomass $\mathrm{C}$ was not significantly different in sprayed soils, but microbial biomass $\mathrm{N}$ was significantly greater. At first, this suggested that microbial populations changed, changing the microbial $\mathrm{C}: \mathrm{N}$ ratio. For example, fungi have wider $\mathrm{C}: \mathrm{N}$ ratios than bacteria and as fungi become relatively more abundant, microbial $\mathrm{C}: \mathrm{N}$ ratios increase. There were, however, no statistical differences between treatments in microbial $\mathrm{C}: \mathrm{N}$ ratio.

Another part of the total soil organic matter that might be expected to change with large additions of $\mathrm{N}$ is fine particulate soil organic matter. This is the organic matter retained on a 54- $\mu \mathrm{m}$ sieve after dispersion in sodium hexametaphosphate (as standard soil particle size measurement method). This fraction is thought to be a very active part of the soil organic matter. Because soil organic matter is the largest reservoir of organic matter in any ecosystem and because the main function of ecosystem functions is to move organic matter into and out of this reservoir, the active portion should be the first to reflect changes brought on by large additions of $\mathrm{N}$. Concentrations of fine particulate organic $\mathrm{C}$ and $\mathrm{N}$ were greater in Sprayed than in Reference treatment soils.

In contrast to the concentrations, the fractions of the total soil organic $C$ and $N$ represented by fine particulate organic matter had no significant treatment effects. It is possible that changes were so small that they were lost in measurement error. It is also possible that the eight years between the application of $\mathrm{N}$ and the sample collection were long enough to convert the active to inactive organic matter and to reestablish the original ratio. It is also possible that this fraction of the soil organic matter was not changed by the spraying. In any case, fine particulate soil organic matter was not affected differently than total soil organic matter.

The only fraction of soil organic matter that showed a significant treatment effect was the fraction of the total $\mathrm{N}$ mineralized. Surprisingly, sprayed soil had less of its organic matter in mineralizable 
forms than the unsprayed soil. The meaning of this difference is not clear.

What is clear is that total organic $\mathrm{C}$ and $\mathrm{N}$ can be increased by a heavy addition of water and $\mathrm{N}$. Furthermore, it appears that a substantial fraction of the added $\mathrm{N}$ can be retained as soil organic matter. None of the measurements reported here show significant risks to the ecosystem from spraying, although some responses are measurable. It is not surprising that concentrations of substances (nitrate- $N$ ) did not "impede soil microbial respiration to an extent that plant and microbial growth have been inhibited, or inhibit carbon mineralization resulting from a reduction in soil microbial populations," as stated in the Natural Resource Damage Assessments - Final Rule (43 CFR Part 11). Nitrogen additions normally increase microbial activity. Other contaminants can either increase or decrease respiration, $\mathrm{N}$ mineralization or other microbial activity.

\section{CONCLUSIONS}

The effects of a nitrogen spray treatment on a xeric mixed grassland community were evaluated on several potential ecological receptors. Receptors measured included several soil physical and chemical variables, plant and litter biomass and nutrient analysis, soil invertebrate functional groups, and ecosystem functions. These measurements represent a variety of ecological variables at population, community, and ecosystem level s of organization, with varying levels of sensativity. Sprayed, Nonsprayed, and Reference treatment levels were evaluated for effects; Nonsprayed treatments were found to have received some spray, and treatment means were not always ranked in the expected order of Spray > Nonspray > Reference (or the reverse). A total of 74 variables were analyzed (Table 1-56), and 18 variables showed statistically significant differences at the $\alpha=$ 0.10 level of significance. The most biologically significant effects were the increase in soil $\mathrm{C}$ and $\mathrm{N}$ in the Sprayed treatment. This effect was also seen in elevated amounts of nitrate in the Sprayed treatment. Of seven soil invertebrate variables that were found to have a significant treatment effect, six functional or taxa groups showed increases in the Sprayed treatment areas. Variables that showed statistically significant decreases in the Sprayed treatment were not thought to have deleterious ecological effects. Although the spray treatment has altered some of the nutrient pools and cycling processes, the result has not caused any ecosystem damage.

\section{FUTURE ANALYSES}

The number of data variables analyzed for this report were considerable, and many other analyses are possible. Analysis of transformed invertebrate and gaseous functional data are not complete, as previously mentioned. Consideration will also be given to ordinating and classifying the sample units by several variables to see if patterns emerge among groups of sample units. Reclassifying the sample units may reduce some of the considerable variation that was often encountered when the replicate within treatment effect was evaluated, and make it easier to detect treatment effects.

\section{REFERENCES .}

McGeehan, S.L. and D.V. Naylor. 1988. Automated Instrumental Analysis of Carbon and Nitrogen in Plant and Soil Samples. Commun. In Soil Sci. Plant Anal., 19(4), 493-505. 


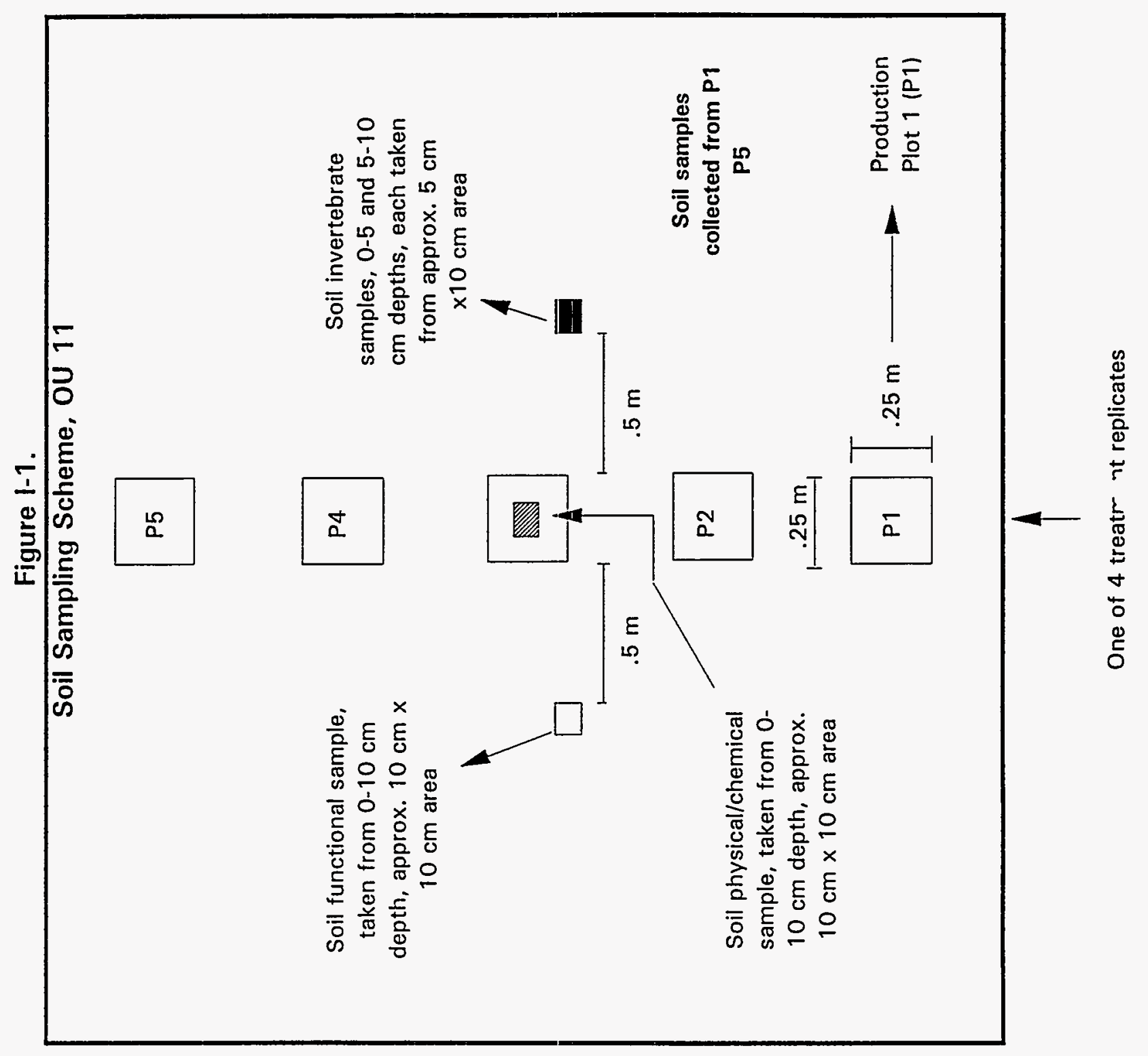


Figure I-2. Soil organic C.

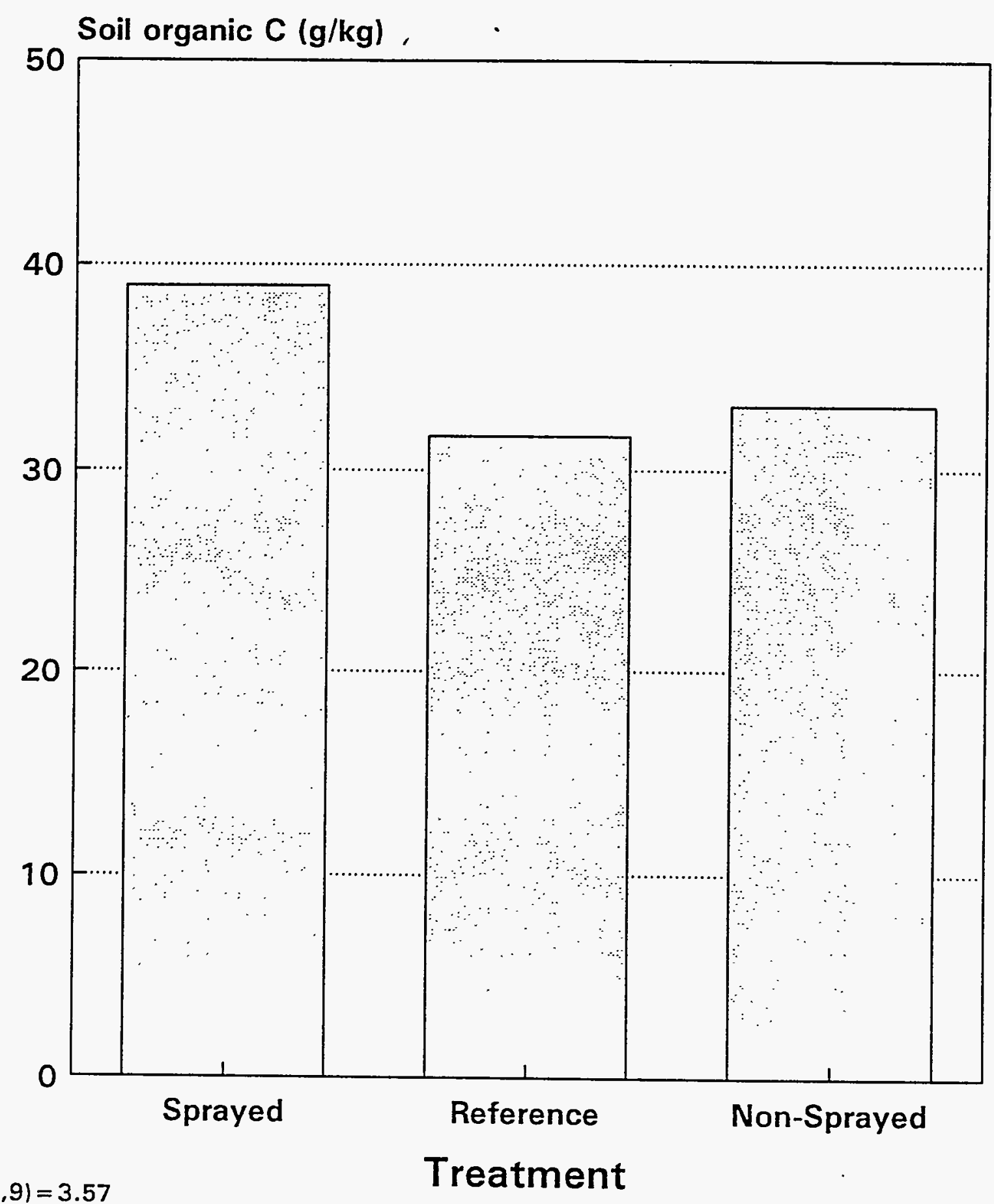

Sig. of $F=0.07$ 
Figure I-3. Soil Organic N

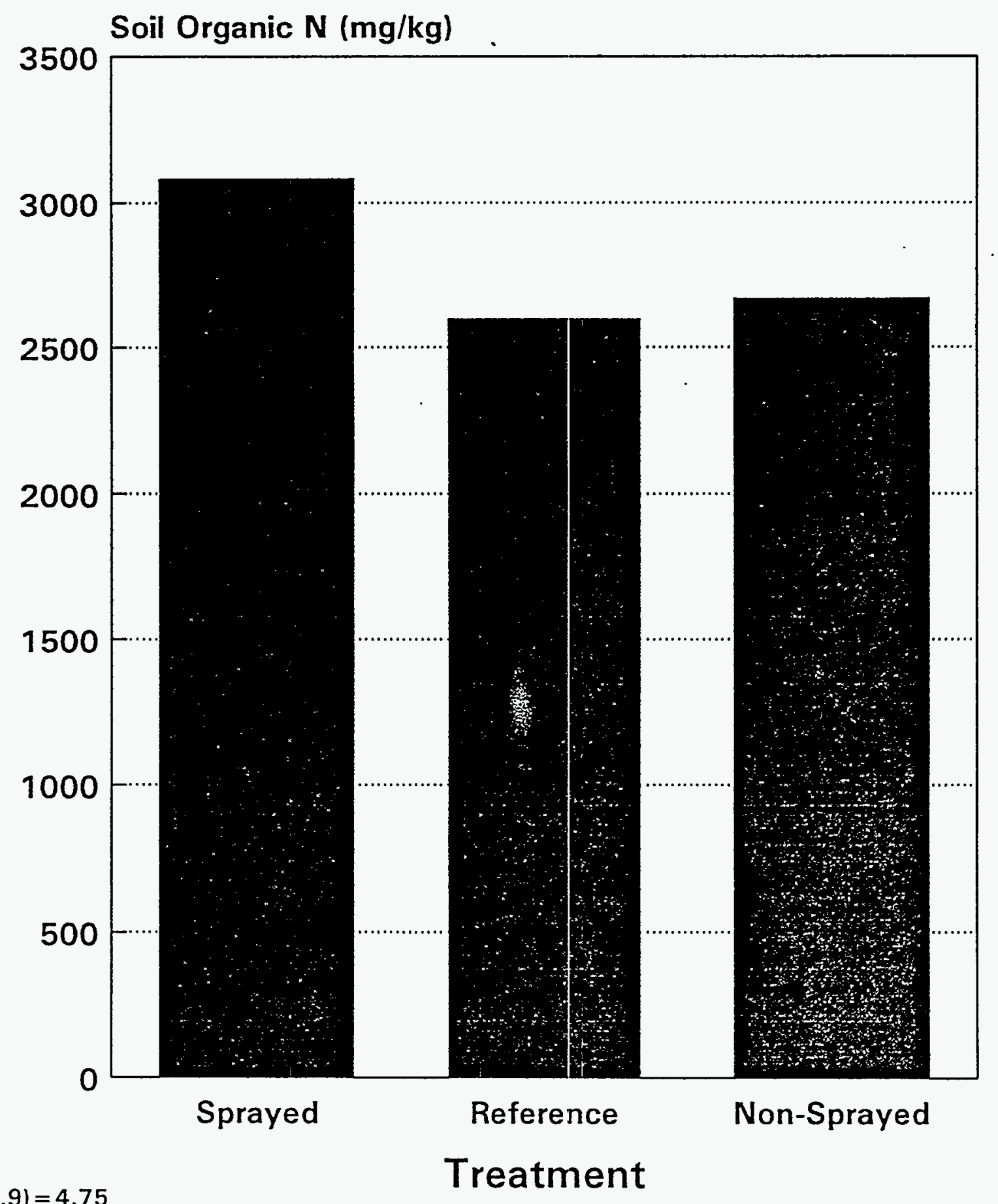

$F(2,9)=4.75$

Sig. of $F=0.04$

$\operatorname{HSD}(3,9)=473$ 
Figure I-4. Nitrate- $\mathrm{N}$ concentrations

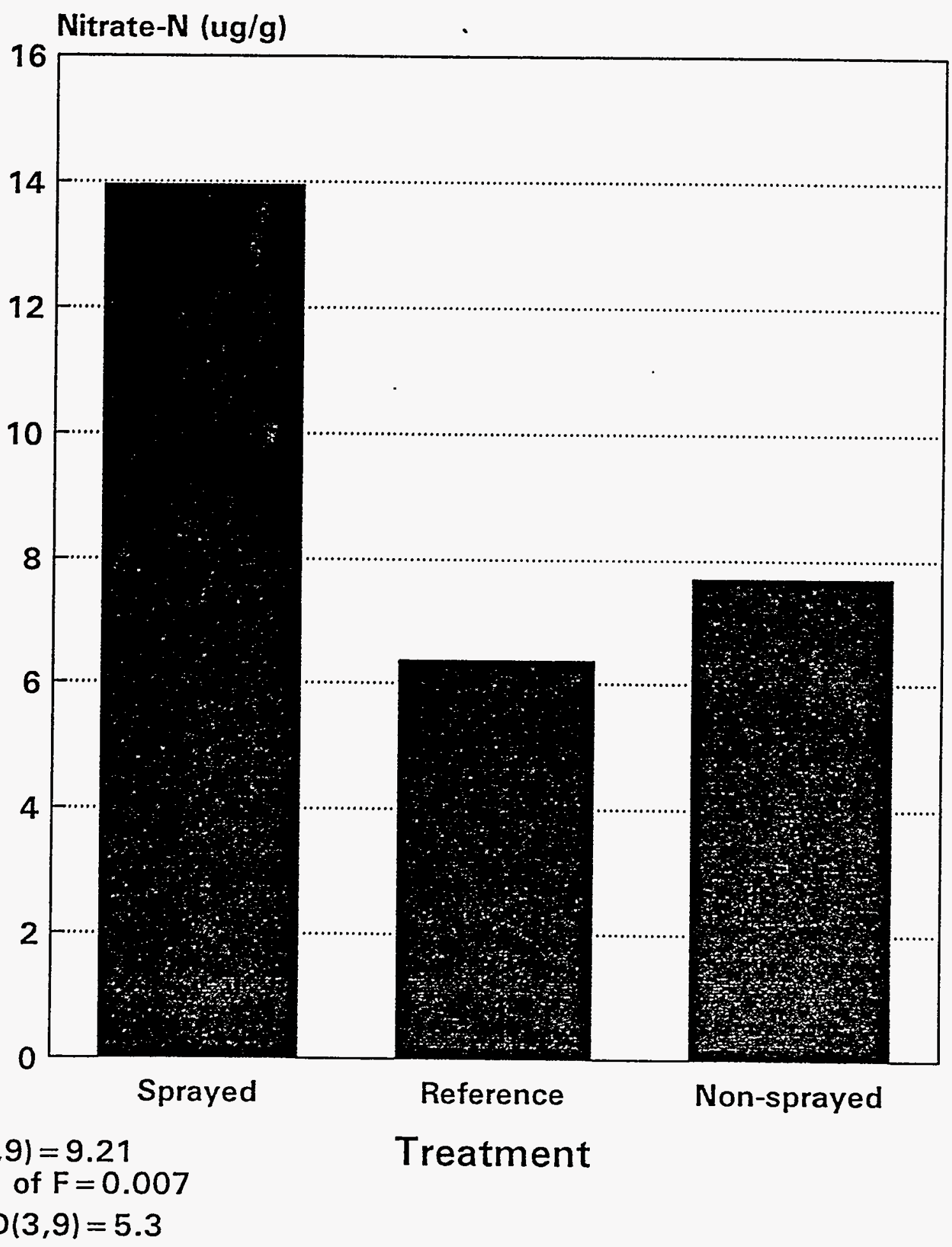




\section{Figure 1-5. Percent Mineralizable N}

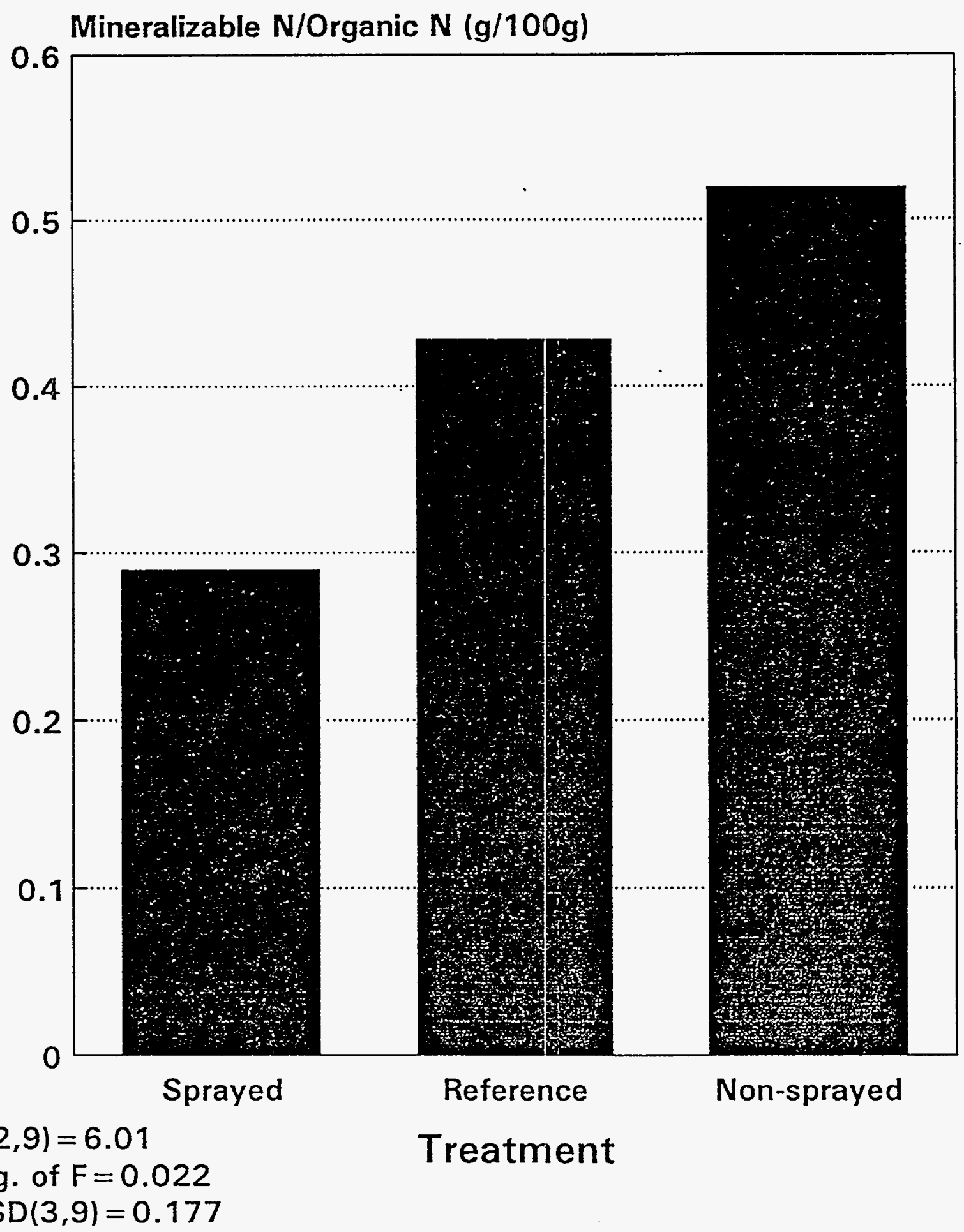


Table 1-1. Summary Statistics and ANOVA, Soil Potassium Concentrations, OU 11

Summary Statistics

\begin{tabular}{|c|c|c|c|c|c|c|c|}
\hline Treatment & Count & Average & Variance & Coefficient of Variation & Minimum & Maximum & Range \\
\hline Nonsprayed & 20 & 298.3 & 12358.0 & 37.2667 & 0.0 & 483.0 \\
\hline Reference & 20 & 235.25 & 2722.93 & 483.0 & 22.1814 & 162.0 & 385.0 \\
\hline Sprayed & 20 & 306.15 & 3945.29 & 223.0 & 20.5166 & 194.0 & 272.0 \\
\hline
\end{tabular}

Analysis of Variance

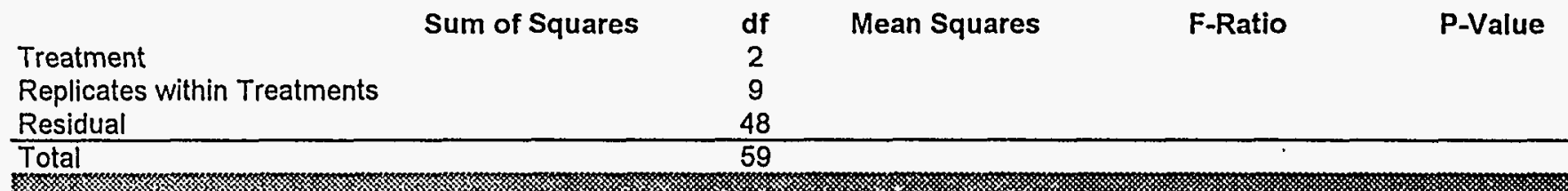

Table 1-2. Summary Statistics and ANOVA, Soil Phosphorus Concentrations, OU 11

Summary Statistics

\begin{tabular}{|c|c|c|c|c|c|c|c|}
\hline Treatment & Count & Average & Variance & Coefficient of Variation & Minimum & Maximum & Range \\
\hline Nonsprayed & 20 & 9.485 & 10.8624 & 34.7477 & 6.7 & 21.3 & 14.6 \\
\hline Reference & 20 & 6.935 & 1.05818 & 14.8332 & 5.5 & 8.8 & 3.3 \\
\hline Sprayed & 20 & 8.34 & 2.93305 & 20.535 & 6.6 & 12.2 & 5.6 \\
\hline
\end{tabular}

Analysis of Variance

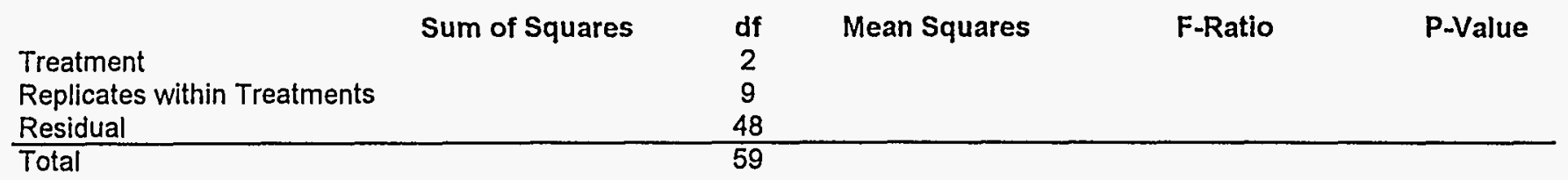

Mean Concentrations are expressed as $\mathrm{mg}$ element/ $\mathrm{kg}$ soil, $0-10 \mathrm{~cm}$ 
Table 1-3. Summary Statistics and ANOVA, Soil Calcium Concentrations, OU 11

Summary Statistics

\begin{tabular}{|c|c|c|c|c|c|c|c|}
\hline Treatment & Count & Average & Variance & Coefficient of Variation & Minimum & Maximum & Range \\
\hline Nonsprayed & 20 & 7.737 & 0.556369 & 9.64071 & 6.31 & 8.84 & 2.53 \\
\hline Reference & 20 & 7.7695 & 0.853973 & 11.894 & 5.16 & 8.95 & 3.79 \\
\hline Sprayed & 20 & 8.1955 & 0.446879 & 8.15679 & 7.13 & 9.88 & 2.75 \\
\hline
\end{tabular}

Analysis of Variance

\begin{tabular}{|c|c|c|c|c|c|}
\hline $\begin{array}{l}\text { Treatment } \\
\text { Replicates within Treatments } \\
\text { Residual }\end{array}$ & Sum of Squares & $\begin{array}{c}d f \\
2 \\
9 \\
48\end{array}$ & Mean Squares & F-Ratio. & P-Value \\
\hline Total & & 59 & & & \\
\hline
\end{tabular}

Mean Concentrations are expressed as $\mathrm{mg} \mathrm{Ca} / \mathrm{kg}$ soil, $0-10 \mathrm{~cm}$ 
Table 1-4. Analysis of Variance, oU 11 Total Vegetation Production

\begin{tabular}{|l|c|c|c|c|c|}
\hline Source & Sum of Squares & df & Mean Squares & F-Ratio & P-Value \\
\hline Treatment & 6106.117 & 2 & 3053.0587 & 1.73 & 0.2311 \\
\hline Replicates within Treatments & 15867.352 & 9 & 1763.0391 & 1.41 & 0.2084 \\
\hline Residual & 59811.84 & 48 & 1246.08 & & \\
\hline Total & 81785.309 & 59 & & & \\
\hline
\end{tabular}

\begin{tabular}{|l|c|c|}
\hline Treatment Means & $\mathrm{g} / \mathrm{m}^{\wedge} \mathbf{2}$ & $\mathrm{n}$ \\
\hline Nonsprayed & 146.8 & 20 \\
\hline Reference & 142.9 & 20 \\
\hline Sprayed & 166 & 20 \\
\hline
\end{tabular}

Table 1-5. Analysis of Variance, OU 11 Total Litter Mass

\begin{tabular}{|l|c|c|c|c|c|}
\hline Source & Sum of Squares & df & Mean Squares & F-Ratio & P-Value \\
\hline Treatment & 15513.712 & 2 & 7756.856 & 0.93 & 0.4265 \\
\hline Replicates within Treatments & 74406.032 & 9 & 8267.3369 & 1.43 & 0.2009 \\
\hline Residual & 276905.15 & 48 & 5768.8573 & & \\
\hline Total & 366824.9 & 59 & & & \\
\hline
\end{tabular}

\begin{tabular}{|l|c|c|}
\hline Treatment Means & g/m $\mathbf{m}^{\wedge} \mathbf{2}$ & $\mathrm{n}$ \\
\hline Nonsprayed & 195.2 & 20 \\
\hline Reference & 205.3 & 20 \\
\hline Sprayed & 233.3 & 20 \\
\hline
\end{tabular}


Table I-6. Summary Statistics and ANOVA, Plant Carbon Concentration, OU 11

Summary Statistics

\begin{tabular}{|c|c|c|c|c|c|c|c|}
\hline Treatment & Count & Average & Variance & Coefficient of Variation & Minimum & Maximum & Range \\
\hline Nonsprayed & 6 & 47.7002 & 0.794278 & 1.86839 & 45.938 & 48.405 & 2.467 \\
\hline Reference & 6 & 46.561 & 0.184264 & 0.921929 & 45.968 & 47.216 & 1.248 \\
\hline Sprayed & 6 & 47.1548 & 0.440374 & 1.40729 & 46.453 & 48.152 & 1.699 \\
\hline
\end{tabular}

Analysis of Variance

\begin{tabular}{cccccc} 
Source & Sum of Squares & df & Mean Squares & F-Ratio & P-Value \\
Between Groups & 3.89545 & 2 & 1.94773 & 4.12 & 0.0375 \\
Within Groups & 7.09458 & 15 & .472972 & \\
\hline Total (corr.) & 10.99 & 17 & &
\end{tabular}

Mean Concentrations are expressed as $\mathrm{g}$ C/ $100 \mathrm{~g}$ plant tissue 
Table 1-7. Summary Statistics and ANOVA, Plant Total Carbon, OU 11

Summary Statistics

\begin{tabular}{|c|c|c|c|c|c|c|c|}
\hline Treatment & Count & Average & Variance & Coefficient of Variation & Minimum & Maximum & Range \\
\hline Nonsprayed & 6 & 71.4783 & 373.931 & 27.0534 & 50.89 & 108.55 & 57.66 \\
\hline Reference & 6 & 58.65 & 136.994 & 19.9564 & 41.21 & 73.97 & 32.76 \\
\hline Sprayed & 6 & 77.1883 & 274.585 & 21.4677 & 57.04 & 103.17 & 46.13 \\
\hline
\end{tabular}

Analysis of Variance

\begin{tabular}{cccccc} 
Source & Sum of Squares & df & Mean Squares & F-Ratio & P-Value \\
Between Groups & 1081.68 & 2 & 540.84 & 0.1613 \\
Within Groups & 3927.55 & 15 & 261.837 & \\
\hline Total (corr.) & 5009.23 & 17 &
\end{tabular}

\section{Table 1-8. Summary Statistics and ANOVA, Total Litter Carbon, OU 11}

Summary Statistics

\begin{tabular}{|c|c|c|c|c|c|c|c|}
\hline Treatment & Count & Average & Variance & Coefficient of Variation & Minimum & Maximum & Range \\
\hline Nonsprayed & 6 & 91.3917 & 273.035 & 18.0802 & 65.88 & 113.68 & 47.8 \\
\hline Reference & 6 & 73.41 & 1851.77 & 58.619 & 23,46 & 141.25 & 117.79 \\
\hline Sprayed & 6 & 103.227 & 1711.41 & 40.0761 & 56.7 & 154.05 & 97.35 \\
\hline
\end{tabular}

Analysis of Variance

\begin{tabular}{cccccc} 
Source & Sum of Squares & df & Mean Squares & F-Ratio & P-Value \\
Between Groups & 2704.88 & 2 & 1352.44 & 1.06 & 0.3718 \\
Within Groups & 19181.1 & 15 & 1278.74 & & \\
\hline Total (corr.) & 21886.0 & 17 & &
\end{tabular}

Means are expressed as $\mathrm{g}$ carbon $/ \mathrm{m}^{\wedge} \mathbf{2}$ 
Table 1-9. Summary Statistics and ANOVA, Plant Nitrogen Concentration, OU 11

Summary Statistics

\begin{tabular}{|c|c|c|c|c|c|c|c|}
\hline Treatment & Count & Average & Variance & Coefficient of Variation & Minimum & Maximum & Range \\
\hline Nonsprayed & 6 & 0.9673 & 0.0256142 & 16.5455 & 0.8085 & 1.239 & 0.4305 \\
\hline Reference & 6 & 0.901717 & 0.0330658 & 20.166 & 0.624 & 1.1025 & 0.4785 \\
\hline Sprayed & 6 & 0.89735 & 0.0270516 & 18.3288 & 0.6695 & 1.1124 & 0.4429 \\
\hline
\end{tabular}

Analysis of Variance

\begin{tabular}{cccccc} 
Source & Sum of Squares & df & Mean Squares & F-Ratio & P-Value \\
Between Groups & 0.0184265 & 2 & 0.00921324 & 0.32 & 0.7293 \\
Within Groups & 0.428658 & 15 & 0.0285772 & & . \\
\hline Total (corr.) & 0.447084 & 17 & &
\end{tabular}

Table 1-10. Summary Statistics and ANOVA, Litter Nitrogen Concentration, OU 11

Summary Statistics

\begin{tabular}{|c|c|c|c|c|c|c|c|}
\hline Treatment & Count & Average & Variance & Coefficient of Variation & Minimum & Maximum & Range \\
\hline Nonsprayed & 6 & 0.87185 & 0.0139176 & 13.5313 & 0.7208 & 1.012 & 0.2912 \\
\hline Reference & 6 & 0.7938 & 0.0201475 & 17.8813 & 0.6825 & 1.0509 & 0.3684 \\
\hline Sprayed & 6 & 0.9098 & 0.0462542 & 23.639 & 0.6848 & 1.1978 & 0.513 \\
\hline
\end{tabular}

Analysis of Variance

\begin{tabular}{cccccc} 
Source & Sum of Squares & df & Mean Squares & F-Ratio & P-Value \\
Between Groups & 0.041976 & 2 & 0.020988 & 0.7744 \\
Within Groups & 0.401596 & 15 & 0.0267731 & & \\
\hline Total (corr.) & 0.443572 & 17 & &
\end{tabular}


Table 1-11. Summary Statistics and ANOVA, Plant Nitrogen Content, OU 11

Summary Statistics

\begin{tabular}{|c|c|c|c|c|c|c|c|}
\hline Treatment & Count & Average & Variance & Coefficient of Variation & Minimum & Maximum & Range \\
\hline Nonsprayed & 6 & 1.435 & 0.15439 & 27.3815 & 1.12 & 2.1 & 0.98 \\
\hline Reference & 6 & 1.105 & 0.02243 & 13.5535 & 0.9 & 1.26 & 0.36 \\
\hline Sprayed & 6 & 1.49167 & 0.232377 & 32.3165 & 0.82 & 1.99 & 1.17 \\
\hline
\end{tabular}

Analysis of Variance

\begin{tabular}{cccccc} 
Source & Sum of Squares & df & Mean Squares & F-Ratio & P-Value \\
Between Groups & 0.523244 & 2 & 0.261622 & 1.92 & 0.1812 \\
Within Groups & 2.04598 & 15 & 0.136399 & & . \\
\hline Total (corr.) & 2.56923 & 17 & &
\end{tabular}

Table 1-12. Summary Statistics and ANOVA, Litter Nitrogen Content, OU 11

Summary Statistics

\begin{tabular}{|c|c|c|c|c|c|c|c|}
\hline Treatment & Count & Average & Variance & Coefficient of Variation & Minimum & Maximum & Range \\
\hline Nonsprayed & 6 & 1.66667 & 0.177467 & 25.2761 & 1.23 & 2.32 & 1.09 \\
\hline Reference & 6 & 1.25 & 0.62056 & 63.0205 & 0.41 & 2.33 & 1.92 \\
\hline Sprayed & 6 & 2.00333 & 0.316387 & 28.0773 & 1.35 & 2.86 & 1.51 \\
\hline
\end{tabular}

Analysis of Variance

\begin{tabular}{cccccc} 
Source & Sum of Squares & df & Mean Squares & F-Ratio & P-Value \\
Between Groups & 1.70893 & 2 & 0.854467 & 2.3 & 0.1345 \\
Within Groups & 5.57207 & 15 & 0.371471 & & \\
\hline Total (corr.) & 7.281 & 17 & &
\end{tabular}

Means are expressed as $\mathrm{g}$ nitrogen $/ \mathrm{m}^{\wedge} \mathbf{2}$ 
Table 1-13 . Summary Statistics and ANOVA, Plant Potassium Concentration, OU 11

Summary Statistics

\begin{tabular}{|c|c|c|c|c|c|c|c|}
\hline Treatment & Count & Average & Variance & Coefficient of Variation & Minimum & Maximum & Range \\
\hline Nonsprayed & 6 & 6596.67 & 1329350 & 17.4781 & 4532 & 8085 & 3553 \\
\hline Reference & 6 & 5362.17 & 894979 & 17.6427 & 4200 & 6552 & 2352 \\
\hline Sprayed & 6 & 4635.33 & 1160240 & 23.2377 & 2987 & 5562 & 2575 \\
\hline
\end{tabular}

Analysis of Variance

\begin{tabular}{cccccc} 
Source & Sum of Squares & df & Mean Squares & F-Ratio & P-Value \\
Between Groups & 11798200 & 2 & 5899110 & 5.23 & 0.0189 \\
Within Groups & 16922900 & 15 & 1128190 & \\
\hline Total (corr.) & 28721100 & 17 & &
\end{tabular}

Table 1-14. Summary Statistics and ANOVA, Litter Potassium Concentration, OU 11

Summary Statistics

\begin{tabular}{|c|c|c|c|c|c|c|c|}
\hline Treatment & Count & Average & Variance & Coefficient of Variation & Minimum & Maximum & Range \\
\hline Nonsprayed & 6 & 1582.83 & 112159 & 21.1584 & 1166 & 2091 & 925 \\
\hline Reference & 6 & 1366.5 & 75149.5 & 20.061 & 1050 & 1695 & 645 \\
\hline Sprayed & 6 & 1316.6 & 147553 & 29.1756 & 939.6 & 1808 & 868.4 \\
\hline
\end{tabular}

Analysis of Variance

\begin{tabular}{cccccc} 
Source & Sum of Squares & df & Mean Squares & F-Ratio & P-Value \\
Between Groups & 240341 & 2 & 120170 & 1.08 & 0.3657 \\
Within Groups & 1674310 & 15 & 111620 & \\
\hline Total (corr.) & 1914650 & 17 & &
\end{tabular}

Means are expressed as $\mathrm{mg}$ potassium/ $\mathrm{kg}$ plant or litter $\mathrm{ti}$ 
Table I-15. Summary Statistics and ANOVA, Plant Potassium Content, OU 11

Summary Statistics

\begin{tabular}{|c|c|c|c|c|c|c|c|}
\hline Treatment & Count & Average & Variance & Coefficient of Variation & Minimum & Maximum & Range \\
\hline Nonsprayed & 6 & 983.847 & 87816.9 & 30.1205 & 659.86 & 1483.37 & .823 .51 \\
\hline Reference & 6 & 681.897 & 39727.8 & 29.23 & 369.6 & 969.89 & 600.29 \\
\hline Sprayed & 6 & 729.32 & 6551.45 & 11.0982 & 647.58 & 850.14 & 202.56 \\
\hline
\end{tabular}

Analysis of Variance

\begin{tabular}{cccccc} 
Source & Sum of Squares & df & Mean Squares & F-Ratio & P-Value \\
Between Groups & 316413 & 2 & 158207 & 3.54 & 0.0551 \\
Within Groups & 670481 & 15 & 44698.7 & & \\
\hline Total (corr.) & 986894 & 17 & &
\end{tabular}

Table 1-16. Summary Statistics and ANOVA, Litter Potassium Content, OU 11

Summary Statistics

\begin{tabular}{|c|c|c|c|c|c|c|c|}
\hline Treatment & Count & Average & Variance & Coefficient of Variation & Minimum & Maximum & Range \\
\hline Nonsprayed & 6 & 298.248 & 5072.81 & 23.8807 & 215.48 & 425.96 & 210.48 \\
\hline Reference & 6 & 210.19 & 15321.9 & 58.8904 & 72.38 & 377.5 & 305.12 \\
\hline Sprayed & 6 & 281.333 & 2727.85 & 18.5648 & 209.57 & 352.51 & 142.94 \\
\hline
\end{tabular}

Analysis of Variance

\begin{tabular}{cccccc} 
Source & Sum of Squares & df & Mean Squares & F-Ratio & P-Value \\
Between Groups & 26203.5 & 2 & 13101.8 & 1.70 & 0.2161 \\
Within Groups & 115613.0 & 15 & 7707.53 & & \\
\hline Total (corr.) & 141816.0 & 17 & &
\end{tabular}

Means are expressed as $\mathrm{mg}$ potassium/ $\mathrm{m}^{\wedge} \mathbf{2}$ 
Table 1-17. Summary Statistics and ANOVA, Plant Phosphorus Concentration, OU 11

Summary Statistics

\begin{tabular}{|c|c|c|c|c|c|c|c|}
\hline Treatment & Count & Average & Variance & Coefficient of Variation & Minimum & Maximum & Range \\
\hline Nonsprayed & 6 & 728.983 & 16620.3 & 17.6848 & 613.6 & 976.5 & 362.9 \\
\hline Reference & 6 & 668.65 & 7732.27 & 13.1509 & 509.6 & 745.5 & 235.9 \\
\hline Sprayed & 6 & 537.483 & 4928.62 & 17.6848 & 453.2 & 618 & 164.8 \\
\hline
\end{tabular}

Analysis of Variance

\begin{tabular}{cccccc} 
Source & Sum of Squares & df & Mean Squares & F-Ratio & P-Value \\
Between Groups & 115034 & 2 & 57517.1 & 5.89 & 0.0129 \\
Within Groups & 146406 & 15 & 9760.38 & & \\
\hline Total (corr.) & 261440 & 17 & &
\end{tabular}

Table I-18. Summary Statistics and ANOVA, Litter Phosphorus Concentration, OU 11

Summary Statistics

\begin{tabular}{|c|c|c|c|c|c|c|c|}
\hline Treatment & Count & Average & Variance & Coefficient of Variation & Minimum & Maximum & Range \\
\hline Nonsprayed & 6 & 596.583 & 7195.18 & 14.2184 & 449.4 & 676.5 & 227.1 \\
\hline Reference & 6 & 519.417 & 13128.5 & 22.0593 & 357 & 700.6 & 343.6 \\
\hline Sprayed & 6 & 481 & 17364 & 27.3955 & 378 & 700.6 & 322.6 \\
\hline
\end{tabular}

Analysis of Variance

\begin{tabular}{cccccc} 
Source & Sum of Squares & df & Mean Squares & F-Ratio & P-Value \\
Between Groups & 41580.1 & 2 & 20790 & 1.65 & 0.2242 \\
Within Groups & 188438 & 15 & 12562.6 & & \\
\hline Total (corr) & 230018 & 17 &
\end{tabular}

Means are expressed as $\mathrm{mg}$ potassium/ $\mathrm{kg}$ plant or litter 
Table 1-19. Summary Statistics and ANOVA, Plant Phosphorus Content, OU 11

Summary Statistics

\begin{tabular}{|c|c|c|c|c|c|c|c|}
\hline Treatment & Count & Average & Variance & Coefficient of Variation & Minimum & Maximum & Range \\
\hline Nonsprayed & 6 & 107.942 & 765.68 & 25.6351 & 78.72 & 148.34 & 69.62 \\
\hline Reference & 6 & 83.005 & 175.292 & 15.9506 & 63.76 & 100.28 & 36.52 \\
\hline Sprayed & 6 & 87.5333 & 346.668 & 21.2708 & 56.92 & 110.74 & 53.82 \\
\hline
\end{tabular}

Analysis of Variance

\begin{tabular}{cccccc} 
Source & Sum of Squares & df & Mean Squares & F-Ratio & P-Value \\
Between Groups & 2117.69 & 2 & 1058.84 & 2.47 & 0.1185 \\
Within Groups & 6438.2 & 15 & 429.213 & & $\cdot$ \\
\hline Total (corr.) & 8555.88 & 17 & &
\end{tabular}

Table 1-20. Summary Statistics and ANOVA, Litter Phosphorus Content, OU 11

Summary Statistics

\begin{tabular}{|c|c|c|c|c|c|c|c|}
\hline Treatment & Count & Average & Variance & Coefficient of Variation & Minimum & Maximum & Range \\
\hline Nonsprayed & 6 & 113.155 & 597.793 & 21.6074 & 82.33 & 151.75 & 69.42 \\
\hline Reference & 6 & 81.9033 & 3034.53 & 67.2581 & 26.84 & 163.58 & 136.74 \\
\hline Sprayed & 6 & 103.618 & 444.318 & 20.3428 & 78.14 & 125.55 & 47.41 \\
\hline
\end{tabular}

Analysis of Variance

Sum of Squares

3078.31

20383.2

23461.5

$\begin{array}{cccc}\text { df } & \text { Mean Squares } & \text { F-Ratio } & \text { P-Value } \\ 2 & 1539.16 & 1.13 & 0.3482 \\ 15 & 1358.88 & & \end{array}$

$15 \quad 1358.88$

Total (corr.)

Means are expressed as $\mathrm{mg}$ phosphorus $/ \mathrm{m}^{\wedge} 2$ 
Table I-21. Analysis of Variance, OU 11 Soil Nematode Fungal Feeders, $0.5 \mathrm{~cm}$ Depth

\begin{tabular}{|l|c|c|c|c|c|}
\hline Source & Sum of Squares & df & Mean Squares & F-Ratio & P-Value \\
\hline Treatment & 26451000 & 2 & 13225353 & 0.5 & 0.6173 \\
\hline Replicates within Treatments & 233750000 & 9 & 26368311 & 0.47 & 0.884 \\
\hline Residual & 2516200000 & 46 & 52537590 & & \\
\hline Total & 2777600000 & 57 & & & \\
\hline
\end{tabular}

\begin{tabular}{|l|c|c|}
\hline Treatment Means & \#/g soil & n \\
\hline Sprayed & 5280.33 & 20 \\
\hline Reference & 6293.64 & 18 \\
\hline Nonsprayed & 6890.63 & 20 \\
\hline
\end{tabular}

Table 1-22. Analysis of Variance, OU 11 Soil Nematode Bacterial Feeders, 0-5 cm Depth

\begin{tabular}{|l|c|c|c|c|c|}
\hline Source & Sum of Squares & df & Mean Squares & F-Ratio & P-Value \\
\hline Treatment & 163920000 & 2 & 81960732 & 2.06 & 0.1832 \\
\hline Replicates within Treatments & 357760000 & 9 & 39751054 & 1.01 & 0.443 \\
\hline Residual & 1763000000 & 45 & 39177211 & & \\
\hline Total & 2285000000 & 56 & & & \\
\hline
\end{tabular}

\begin{tabular}{|l|c|c|}
\hline Treatment Means & \#/g soil & n \\
\hline Sprayed & 7502.88 & 20 \\
\hline Reference & 4400.13 & 18 \\
\hline Nonsprayed & 3658.37 & 20 \\
\hline
\end{tabular}


Table 1-23. Analysis of Variance, OU 11 Soil Nematode Plant Feeders, $0.5 \mathrm{~cm}$ Depth

\begin{tabular}{|l|c|c|c|c|c|}
\hline Source & Sum of Squares & df & Mean Squares & F-Ratio & P-Value \\
\hline Treatment & 2232200.2 & 2 & 1116100.1 & 2.55 & 0.132 \\
\hline Replicates within Treatments & 3927985.8 & 9 & 436442.9 & 2.26 & 0.034 \\
\hline Residual & 8858920 & 46 & 192585.22 & & \\
\hline Total & 14972218 & 57 & & & \\
\hline
\end{tabular}

\begin{tabular}{|l|c|c|}
\hline Treatment Means & \#/g soil & $\mathbf{n}$ \\
\hline Sprayed & 494.39 & 20 \\
\hline Reference & 324.83 & 18 \\
\hline Nonsprayed & 27.16 & 20 \\
\hline
\end{tabular}

Table 1-24. Analysis of Variance, OU 11 Soil Nematode Omnivore/Predators, $0-5 \mathrm{~cm}$ Depth

\begin{tabular}{|l|c|c|c|c|c|}
\hline Source & Sum of Squares & df & Mean Squares & F-Ratio & P-Value \\
\hline Treatment & 3419043.8 & 2 & 1709521.9 & 3.27 & 0.0853 \\
\hline Replicates within Treatments & 4695908.8 & 9 & 521767.6 & 1.09 & 0.3827 \\
\hline Residual & 21848714 & 46 & 474972.04 & & \\
\hline Total & 29902271 & 57 & & & \\
\hline
\end{tabular}

\begin{tabular}{|l|c|c|}
\hline Treatment Means & \#/g soil & $\mathbf{n}$ \\
\hline Sprayed & 874.78 & 20 \\
\hline Reference & 465.11 & 18 \\
\hline Nonsprayed & 306.44 & 20 \\
\hline
\end{tabular}


Table 1-25. Analysis of Variance, OU 11 Soil Nematode Fungal Feeders, 5-10 cm Depth

\begin{tabular}{|l|c|c|c|c|c|}
\hline Source & Sum of Squares & df & Mean Squares & F-Ratio & P-Value \\
\hline Treatment & 44125000 & 2 & 22062495 & 0.34 & 0.7166 \\
\hline Replicates within Treatments & 573970000 & 9 & 63774067 & 1.65 & 0.127 \\
\hline Residual & 1768800000 & 46 & 38452284 & & \\
\hline Total & 2395100000 & 57 & & & \\
\hline
\end{tabular}

\begin{tabular}{|l|c|c|}
\hline Treatment Means & \#/g soil & $\mathbf{n}$ \\
\hline Sprayed & 6304.15 & 20 \\
\hline Reference & 5084.61 & 19 \\
\hline Nonsprayed & 7243.56 & 19 \\
\hline
\end{tabular}

Table 1-26. Analysis of Variance, OU 11 Soil Nematode Bacterial Feeders, 5-10 cm Depth

\begin{tabular}{|l|c|c|c|c|c|}
\hline Source & Sum of Squares & df & Mean Squares & F-Ratio & P-Value \\
\hline Treatment & 59824000 & 2 & 29912247 & 1.27 & 0.3246 \\
\hline Replicates within Treatments & 210630000 & 9 & 23403227 & 1.61 & 0.1395 \\
\hline Residual & 667070000 & 46 & 14501498 & & \\
\hline Total & 937150000 & 57 & & & \\
\hline
\end{tabular}

\begin{tabular}{|l|c|c|}
\hline Treatment Means & \#/g soil & $\mathbf{n}$ \\
\hline Sprayed & 6213.56 & 20 \\
\hline Reference & 3986.96 & 19 \\
\hline Nonsprayed & 4171.27 & 19 \\
\hline
\end{tabular}


Table 1-27. Analysis of Variance, OU 11 Soil Nematode Plant Feeders, 5-10 cm Depth

\begin{tabular}{|l|c|c|c|c|c|}
\hline Source & Sum of Squares & df & Mean Squares & F-Ratio & P-Value \\
\hline Treatment & 1742836.6 & 2 & 871418.3 & 3.56 & 0.0726 \\
\hline Replicates within Treatments & 2202337.9 & 9 & 244704.21 & 0.78 & 0.6297 \\
\hline Residual & 143.07755 & 46 & 311038.16 & & \\
\hline Total & 18331192 & 57 & & & \\
\hline
\end{tabular}

\begin{tabular}{|l|c|c|}
\hline Treatment Means & \#/g soil & $\mathbf{n}$ \\
\hline Sprayed & 606.47 & 20 \\
\hline Reference & 404.38 & 19 \\
\hline Nonsprayed & 182.54 & 19 \\
\hline
\end{tabular}

Table 1-28. Analysis of Variance, OU 11 Soil Nematode Omnivore/Predators, 5-10 cm Depth

\begin{tabular}{|l|c|c|c|c|c|}
\hline Source & Sum of Squares & df & Mean Squares & F-Ratio & P-Value \\
\hline Treatment & 694867.3 & 2 & 347433.65 & 1.81 & 0.218 \\
\hline Replicates within Treatments & 1724754.6 & 9 & 191639.4 & 0.88 & 0.5422 \\
\hline Residual & 9915705 & 46 & 215558.8 & & \\
\hline Total & 12349496 & 57 & & & \\
\hline
\end{tabular}

\begin{tabular}{|l|c|c|}
\hline Treatment Means & \#/g soil & $\mathbf{n}$ \\
\hline Sprayed & 546.96 & 20 \\
\hline Reference & 333.49 & 19 \\
\hline Nonsprayed & 302.18 & 19 \\
\hline
\end{tabular}


Table 1-29. Analysis of Variance, OU 11 Soil Invertebrate Arthropod General Predators,

\begin{tabular}{|l|c|c|c|c|c|}
\hline Source $0.5 \mathrm{~cm}$ Depth & Sum of Squares & df & Mean Squares & F-Ratio & P-Value \\
\hline Treatment & 1395102.1 & 2 & 697551.05 & 2.35 & 0.1501 \\
\hline Replicates within Treatments & 2661732.9 & 9 & 295748.1 & 2.47 & 0.0208 \\
\hline Residual & 5738106.4 & 48 & 119543.88 & & \\
\hline Total & 9794941.4 & 59 & & & \\
\hline
\end{tabular}

\begin{tabular}{|c|c|c|c|c|c|}
\hline Treatment Means & $\# / m^{\wedge} 2$ & $n$ & & & \\
\hline Nonsprayed & 163.334 & 20 & & & \\
\hline Reference & 263.334 & 20 & & & \\
\hline Sprayed & 525 & 20 & & & \\
\hline $0.5 \mathrm{~cm}$ Depth & & & & & \\
\hline Source & Sum of Squares & $\mathrm{df}$ & Mean Squares & F-Ratio & P-Value \\
\hline Treatment & 80219.1 & 2 & 40109.55 & 0.11 & 0.8973 \\
\hline Replicates within Treatments & 3290215.8 & 9 & 365579.53 & 4.9 & 0.0001 \\
\hline Residual & 3581208.4 & 48 & 74608.508 & & \\
\hline Total & 6951643.3 & 59 & & & \\
\hline
\end{tabular}

\begin{tabular}{|c|c|c|c|c|c|}
\hline Treatment Means & $\# / m^{\wedge} 2$ & $n$ & & & \\
\hline Nonsprayed & 280 & 20 & & & \\
\hline Reference & 203.334 & 20 & & & \\
\hline Sprayed & 281.666 & 20 & & & \\
\hline \multicolumn{6}{|c|}{$\begin{array}{l}\text { Table 1-31. Analysis of Variance, OU } 11 \text { Soil Invertebrate Total Arthropod Predators, } \\
0.5 \mathrm{~cm} \text { Depth }\end{array}$} \\
\hline Source & Sum of Squares & df & Mean Squares & F-Ratio & P-Value \\
\hline Treatment & 1654373.8 & 2 & 827186.9 & 0.79 & 0.4819 \\
\hline Replicates within Treatments & 9391785.1 & 9 & 1043531.7 & 4.84 & 0.0001 \\
\hline $\begin{array}{l}\text { Residual } \\
\end{array}$ & 10334232 & 48 & 215296.5 & & \\
\hline Total & 21380391 & 59 & & & \\
\hline
\end{tabular}

\begin{tabular}{|l|c|c|}
\hline \multicolumn{3}{|c|}{} \\
\hline Treatment Means & $\# / \mathrm{m}^{\wedge} 2$ & $\mathrm{n}$ \\
\hline Nonsprayed & 443.334 & 20 \\
\hline Reference & 466.668 & 20 \\
\hline Sprayed & 806.668 & 20 \\
\hline
\end{tabular}

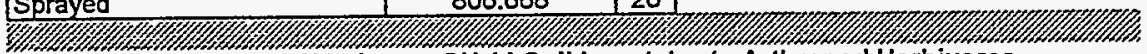

Table 1-32. Analysis of Variance, ou 11 Soil Invertebrate Arthropod Herbivores,

\begin{tabular}{|l|c|c|c|c|c|}
\hline Source $0.5 \mathrm{~cm}$ Depth & Sum of Squares & df & Mean Squares & F-Ratio & P-Value \\
\hline Treatment & 6035815 & 2 & 3017907.6 & 0.91 & 0.4344 \\
\hline Replicates within Treatments & 29652383 & 9 & 3294709.3 & 1.05 & 0.4137 \\
\hline Residual & $1.50 E+08$ & 48 & 3128555.5 & & \\
\hline Total & $1.86 E+08$ & 59 & & & \\
\hline
\end{tabular}

\begin{tabular}{|l|c|c|}
\hline Treatment Means & $\# / \mathrm{m}^{\wedge} \mathbf{2}$ & $\mathrm{n}$ \\
\hline Nonsprayed & 273.334 & 20 \\
\hline Reference & 883.334 & 20 \\
\hline Sprayed & 161.666 & 20 \\
\hline
\end{tabular}


Table 1-33. Analysis of Variance, OU 11 Soil Invertebrate Arthropod Detritivores 1, $0.5 \mathrm{~cm}$ Depth

\begin{tabular}{|l|c|c|c|c|c|}
\hline Source & Sum of Squares & df & Mean Squares & F-Ratio & P-Value \\
\hline Treatment & 2252453 & 2 & 1126226.4 & 0.59 & 0.5742 \\
\hline Replicates within Treatments & 17166428 & 9 & 1907380.9 & 5.23 & 0.0001 \\
\hline Residual & 17495135 & 48 & 364481.99 & & \\
\hline Total & 36914016 & 59 & & & \\
\hline
\end{tabular}

\begin{tabular}{|l|c|c|}
\hline Treatment Means & \#/m² & n \\
\hline Nonsprayed & 190 & 20 \\
\hline Reference & 583.334 & 20 \\
\hline Sprayed & 156.666 & 20 \\
\hline
\end{tabular}

Table 1-34. Analysis of Variance, OU 11 Soil Invertebrate Arthropod Detritivores 2,

0.5 cm Depth
\begin{tabular}{|l|c|c|c|c|c|}
\hline Source & Sum of Squares & df & Mean Squares & F-Ratio & P-Value \\
\hline Treatment & 26189585 & 2 & 13094792 & 1.38 & 0.2998 \\
\hline Replicates within Treatments & 85324786 & 9 & 9480532 & 9.63 & 0 \\
\hline Residual & 47212440 & 48 & 983592.5 & & \\
\hline Total & $1.59 E+08$ & 59 & & & \\
\hline
\end{tabular}

\begin{tabular}{|c|c|c|}
\hline Treatment Means & $\# / m^{\wedge} 2$ & $n$ \\
\hline Nonsprayed & 346.668 & 20 \\
\hline Reference & 649.999 & 20 \\
\hline Sprayed & 1875 & 20 \\
\hline
\end{tabular}

Table 135. Analysis of Variance, OU 11 Total Soil Invertebrate Arthropod Detritivores,

\begin{tabular}{|c|c|c|c|c|c|}
\hline Source & Sum of Squares & df & Mean Squares & F-Ratio & P-Value \\
\hline Treatment & $2.24 \mathrm{E}+07$ & 2 & 11192344 & 0.85 & 0.4557 \\
\hline Replicates within Treatments & $1.17 E+08$ & 9 & 13034120 & 10.22 & 0 \\
\hline Residual & 61207139 & 48 & 1275148.7 & & \\
\hline Total & $2.01 E+08$ & 59 & & & \\
\hline
\end{tabular}

\begin{tabular}{|l|c|c|}
\hline Treatment Means & $\# / \mathrm{m}^{\wedge} 2$ & $\mathrm{n}$ \\
\hline Nonsprayed & 536.667 & 20 \\
\hline Reference & 1233.33 & 20 \\
\hline Sprayed & 2031.67 & 20 \\
\hline
\end{tabular}

Table 1-36. Analysis of Variance, oU 11 Soil Invertebrate Arthropod Fungal Feeders 1, $0.5 \mathrm{~cm}$ Depth

\begin{tabular}{|l|c|c|c|c|c|}
\hline Source & Sum of Squares & df & Mean Squares & F-Ratio & P-Value \\
\hline Treatment & 916324.6 & 2 & 458162.28 & 0.47 & 0.637 \\
\hline Replicates within Treatments & 8691282.5 & 9 & 965698.05 & 1.87 & 0.0789 \\
\hline Residual & 24727137 & 48 & 515148.69 & & \\
\hline Total & 34334744 & 59 & & & \\
\hline
\end{tabular}

\begin{tabular}{|l|c|c|}
\hline Treatment Means & \#/m² & $\mathrm{n}$ \\
\hline Nonsprayed & 253.335 & 20 \\
\hline Reference & 553.333 & 20 \\
\hline Sprayed & 368.334 & 20 \\
\hline
\end{tabular}


Table 137. Analysis of Variance, OU 11 Soil lnvertebrate Arthropod Fungal Feeders 2, $0.5 \mathrm{~cm}$ Depth

\begin{tabular}{|l|c|c|c|c|c|}
\hline Source & Sum of Squares & df & Mean Squares & F-Ratio & P-Value \\
\hline Treatment & 4496452 & 2 & 2248226.1 & 0.6 & 0.5672 \\
\hline Replicates within Treatments & 33484258 & 9 & 3720473.1 & 1.4 & 0.2141 \\
\hline Residual & $1.27 \mathrm{E}+08$ & 48 & 2654628.5 & & \\
\hline Total & $1.65 \mathrm{E}+08$ & 59 & & & \\
\hline
\end{tabular}

\begin{tabular}{|l|c|c|}
\hline Treatment Means & $\# / \mathrm{m}^{\wedge} 2$ & $\mathrm{n}$ \\
\hline Nonsprayed & 1350 & 20 \\
\hline Reference & 2013.33 & 20 \\
\hline Sprayed & 1766.67 & 20 \\
\hline
\end{tabular}

Table 138. Analysis of Variance, OU 11 Total Soil Invertebrate Arthropod Fungal Feeder $0.5 \mathrm{~cm}$ Depth

\begin{tabular}{|l|c|c|c|c|c|}
\hline Source & Sum of Squares & df & Mean Squares & F-Ratio & P-Value \\
\hline Treatment & 9313428 & 2 & 4656714 & 0.81 & 0.4723 \\
\hline Replicates within Treatments & 51345737 & 9 & 5705081.9 & 1.42 & 0.2056 \\
\hline Residual & $1.93 \mathrm{E}+08$ & 48 & 4012628 & & \\
\hline Total & $2.53 \mathrm{E}+08$ & 59 & & & \\
\hline
\end{tabular}

\begin{tabular}{|l|c|c|}
\hline Treatment Means & $\# / \mathrm{m}^{\wedge} 2$ & $\mathrm{n}$ \\
\hline Nonsprayed & 1603.33 & 20 \\
\hline Reference & 2566.67 & 20 \\
\hline Sprayed & 2135 & 20 \\
\hline
\end{tabular}

Table 139. Analysis of Variance, oU 11 Total Soil invertebrate Mesostigmata, $0.5 \mathrm{~cm}$ Depth

\begin{tabular}{|l|c|c|c|c|c|}
\hline Source & Sum of Squares & df & Mean Squares & F-Ratio & P-Value \\
\hline Treatment & 1524704.3 & 2 & 762352.16 & 3.11 & 0.0939 \\
\hline Replicates within Treatments & 2204396.5 & 9 & 244932.95 & 2.57 & 0.0166 \\
\hline Residual & 4567097.4 & 48 & 95147.863 & & \\
\hline Total & 8296198.3 & 59 & & & \\
\hline
\end{tabular}

\begin{tabular}{|l|c|c|}
\hline Treatment Means & $\# / \mathrm{m}^{\wedge} \mathbf{2}$ & $\mathrm{n}$ \\
\hline Nonsprayed & 150.001 & 20 \\
\hline Reference & 186.667 & 20 \\
\hline Sprayed & 505 & 20 \\
\hline
\end{tabular}

Table 1-40. Analysis of Variance, OU 11 Total Soil invertebrate Prostigmata, $0.5 \mathrm{~cm}$ Depth

\begin{tabular}{|l|c|c|c|c|c|}
\hline Source & Sum of Squares & df & Mean Squares & F-Ratio & P-Value \\
\hline Treatment & 4358378 & 2 & 2179188.9 & 0.35 & 0.71 \\
\hline Replicates within Treatments & 55119878 & 9 & 6124430.9 & 2.02 & 0.0561 \\
\hline Residual & $1.45 \mathrm{E}+08$ & 48 & 3017778.2 & & \\
\hline Total & $2.04 \mathrm{E}+08$ & 59 & & & \\
\hline
\end{tabular}

\begin{tabular}{|l|c|c|}
\hline Treatment Means & $\# / \mathrm{m}^{\wedge} 2$ & $n$ \\
\hline Nonsprayed & 1630 & 20 \\
\hline Reference & 2273.33 & 20 \\
\hline Sprayed & 2080 & 20 \\
\hline
\end{tabular}


Table I-41. Analysis of Variance, OU 11 Total Soil Invertebrate Cryptostigmata,

0.5 cm Depth
\begin{tabular}{|l|c|c|c|c|c|}
\hline Source & Sum of Squares & df & Mean Squares & F-Ratio & P-Value \\
\hline Treatment & 25945442 & 2 & 12972721 & 1.36 & 0.3029 \\
\hline Replicates within Treatments & 85345675 & 9 & 9482853 & 9.56 & 0 \\
\hline Residual & 47566209 & 48 & 990962.69 & & \\
\hline Total & $1.59 E+08$ & 59 & & & \\
\hline
\end{tabular}

\begin{tabular}{|c|c|c|}
\hline Treatment Means & $\# m^{\wedge} 2$ & $n$ \\
\hline Nonsprayed & 346.667 & 20 \\
\hline Reference & 649.99 & 20 \\
\hline Sprayed & 1868.334 & 20 \\
\hline
\end{tabular}

Table 1-42. Analysis of Variance, OU 11 Total Soil Invertebrate Astigmata,

0.5 cm Depth
\begin{tabular}{|l|c|c|c|c|c|}
\hline Source & Sum of Squares & df & Mean Squares & F-Ratio & P-Value \\
\hline Treatment & 444.4222 & 2 & 222.21111 & 0.34 & 0.7164 \\
\hline Replicates within Treatments & 5777.6222 & 9 & 641.95803 & 0.86 & 0.5607 \\
\hline Residual & 35554.844 & 48 & 740.72593 & & \\
\hline Total & 41776.889 & 59 & & & \\
\hline
\end{tabular}

\begin{tabular}{|c|c|c|}
\hline Treatment Means & $\# / m^{\wedge} 2$ & $n$ \\
\hline Nonsprayed & 10 & 20 \\
\hline Reference & 3.33 & 20 \\
\hline Sprayed & 6.67 & 20 \\
\hline
\end{tabular}


Table 1-43. Analysis of Variance, OU 11 Soil Invertebrate Arthropod General Predators, 5-10 cm Depth

\begin{tabular}{|l|c|c|c|c|c|}
\hline Source & Sum of Squares & df & Mean Squares & F-Ratio & P-Value \\
\hline Treatment & 168996.4 & 2 & 84498.2 & 2.72 & 0.1187 \\
\hline Replicates within Treatments & 279054.08 & 9 & 31006.009 & 1.32 & 0.2485 \\
\hline Residual & 1121767.6 & 48 & 23370.157 & & \\
\hline Total & 1569818 & 59 & & & \\
\hline
\end{tabular}

\begin{tabular}{|c|c|c|c|c|c|}
\hline Treatment Means & $\# / m^{\wedge} 2$ & $n$ & & & \\
\hline Nonsprayed & 96.67 & 20 & & & \\
\hline Reference & 206.67 & 20 & & & \\
\hline Sprayed & 91.66 & 20 & & & \\
\hline \multicolumn{6}{|c|}{$\begin{array}{l}\text { Table 1-44. Analysis of Variance, OU } 11 \text { Soil Invertebrate Arthropod Predators, } \\
5-10 \mathrm{~cm} \text { Depth }\end{array}$} \\
\hline Source & Sum of Squares & $d f$ & Mean Squares & F-Ratio & P-Value \\
\hline Treatment & 28735.07 & 2 & 14367.533 & 0.98 & 0.4108 \\
\hline Replicates within Treatments & 131440.04 & 9 & 14604.449 & 3.34 & 0.003 \\
\hline Residual & 209638.84 & 48 & 4367.4759 & & \\
\hline Total & 369813.95 & 59 & & & \\
\hline
\end{tabular}

\begin{tabular}{|c|c|c|}
\hline Treatment Means & $\# / m^{\wedge} 2$ & $n$ \\
\hline Nonsprayed & 63.33 & 20 \\
\hline Reference & 66.67 & 20 \\
\hline Sprayed & 18.67 & 20 \\
\hline
\end{tabular}

Table 1-45. Analysis of Variance, OU 11 Soil Invertebrate Total Arthropod Predators,

5 -10 cm Depth
\begin{tabular}{|l|c|c|c|c|c|}
\hline Source & Sum of Squares & df & Mean Squares & F-Ratio & P-Value \\
\hline Treatment & 279200.21 & 2 & 139600.1 & 2.72 & 0.119 \\
\hline Replicates within Treatments & 461604.55 & 9 & 51289.39 & 1.99 & 0.0605 \\
\hline Residual & 1233628.4 & 48 & 25700.593 & & \\
\hline Total & 1974433.2 & 59 & & & \\
\hline
\end{tabular}

\begin{tabular}{|c|c|c|}
\hline Treatment Means & $\# / m^{\wedge} 2$ & $n$ \\
\hline Nonsprayed & 160 & 20 \\
\hline Reference & 273.33 & 20 \\
\hline Sprayed & 110.33 & 20 \\
\hline
\end{tabular}

Table 1-46. Analysis of Variance, OU 11 Soil Invertebrate Arthropod Herbivores,

$5-10 \mathrm{~cm}$ Depth
\begin{tabular}{|l|c|c|c|c|c|}
\hline Source & Sum of Squares & df & Mean Squares & F-Ratio & P-Value \\
\hline Treatment & 77457.249 & 2 & 38728.624 & 3.83 & 0.0623 \\
\hline Replicates within Treatments & 90825.693 & 9 & 10091.744 & 0.81 & 0.6019 \\
\hline Residual & 591781.87 & 48 & 12328.789 & & \\
\hline Total & 760064.81 & 59 & & & \\
\hline
\end{tabular}

\begin{tabular}{|l|c|c|}
\hline Treatment Means & $\# / \mathrm{m}^{\wedge} 2$ & $\mathrm{n}$ \\
\hline Nonsprayed & 96.67 & 20 \\
\hline Reference & 90 & 20 \\
\hline Sprayed & 17.33 & 20 \\
\hline
\end{tabular}


Table 1-47. Analysis of Variance, OU 11 Soil invertebrate Arthropod Detritivores 1, 5-10 cm Depth

\begin{tabular}{|l|c|c|c|c|c|}
\hline Source & Sum of Squares & df & Mean Squares & F-Ratio & P-Value \\
\hline Treatment & 4764.596 & 2 & 2382.2978 & 0.75 & 0.4958 \\
\hline Replicates within Treatments & 28240.533 & 9 & 3137.837 & 3.29 & 0.0034 \\
\hline Residual & 45725.422 & 48 & 952.61296 & & \\
\hline Total & 78730.551 & 59 & & & \\
\hline
\end{tabular}

\begin{tabular}{|l|c|c|}
\hline Treatment Means & $\# / \mathrm{m}^{\wedge} 2$ & $\mathrm{n}$ \\
\hline Nonsprayed & 23.33 & 20 \\
\hline Reference & 16.67 & 20 \\
\hline Sprayed & 2 & 20 \\
\hline
\end{tabular}

Table I-48. Analysis of Variance, OU 11 Soil Invertebrate Arthropod Detritivores 2, 5-10 cm Depth

\begin{tabular}{|l|c|c|c|c|c|}
\hline Source & Sum of Squares & df & Mean Squares & F-Ratio & P-Value \\
\hline Treatment & 4400295.3 & 2 & 2200147.7 & 3.39 & 0.0798 \\
\hline Replicates within Treatments & 5837079.9 & 9 & 648564.4 & 0.9 & 0.5301 \\
\hline Residual & 34467690 & 48 & 718076.87 & & \\
\hline Total & 44705065 & 59 & & & \\
\hline
\end{tabular}

\begin{tabular}{|l|c|c|}
\hline Treatment Means & $\# / \mathrm{m}^{\wedge} 2$ & $\mathrm{n}$ \\
\hline Nonsprayed i & 260 & 20 \\
\hline Reference & 703.33 & 20 \\
\hline Sprayed & 909 & 20 \\
\hline
\end{tabular}

Table 1-49. Analysis of Variance, OU 11 Total Soil Invertebrate Arthropod Detritivores, 5-10 cm Depth

\begin{tabular}{|l|c|c|c|c|c|}
\hline Source & Sum of Squares & df & Mean Squares & F-Ratio & P-Value \\
\hline Treatment & 4140825.8 & 2 & 2070412.9 & 3.34 & 0.082 \\
\hline Replicates within Treatments & 5570149.3 & 9 & 618905.5 & 0.85 & 0.5695 \\
\hline Residual & 34693808 & 48 & 722787.67 & & \\
\hline Total & 44404783 & 59 & & & \\
\hline
\end{tabular}

\begin{tabular}{|l|c|c|}
\hline Treatment Means & $\# / m^{\wedge} 2$ & $n$ \\
\hline Nonsprayed & 283.33 & 20 \\
\hline Reference & 720 & 20 \\
\hline Sprayed & 911 & 20 \\
\hline
\end{tabular}

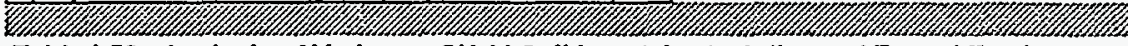

Table 1-50. Analysis of Variance, OU 11 Soil Invertebrate Arthropod Fungal Feeders 1, 5-10 cm Depth

\begin{tabular}{|l|c|c|c|c|c|}
\hline Source & Sum of Squares & df & Mean Squares & F-Ratio & P-Value \\
\hline Treatment & 186816.96 & 2 & 93408.481 & 2.13 & 0.1741 \\
\hline Replicates within Treatments & 393556.38 & 9 & 43728.486 & 2.41 & 0.0238 \\
\hline Residual & 869330.67 & 48 & 18111.056 & & \\
\hline Total & 1449704 & 59 & & & \\
\hline
\end{tabular}

\begin{tabular}{|l|c|c|}
\hline Treatment Means & \#/m² & n \\
\hline Nonsprayed & 73.33 & 20 \\
\hline Reference & 193.33 & 20 \\
\hline Sprayed & 76.67 & 20 \\
\hline
\end{tabular}


Table 1-51. Analysis of Variance, OU 11 Soil Invertebrate Arthropod Fungal Feeders 2, 5-10 cm Depth

\begin{tabular}{|l|c|c|c|c|c|}
\hline Source & Sum of Squares & df & Mean Squares & F-Ratio & P-Value \\
\hline Treatment & 1862135 & 2 & 931057.5 & 0.16 & 0.8481 \\
\hline Replicates within Treatments & 49918293 & 9 & 5546477 & 2.62 & 0.0148 \\
\hline Residual & $1.01 E+08$ & 48 & 2111160 & & \\
\hline Total & $1.53 \mathrm{E}+08$ & 59 & & & \\
\hline
\end{tabular}

\begin{tabular}{|c|c|c|c|c|c|}
\hline Treatment Means & $\# / m^{\wedge} 2$ & $\bar{n}$ & & & \\
\hline Nonsprayed & 1047 & 20 & & & \\
\hline Reference & 1333.33 & 20 & & & \\
\hline Sprayed & 910.67 & 20 & & & \\
\hline \multicolumn{6}{|c|}{$\begin{array}{l}\text { Table 1-52. Analysis of Variance, OU } 11 \text { Total Soil invertebrate Arthropod Fungal Feeder } \\
5-10 \mathrm{~cm} \text { Depth }\end{array}$} \\
\hline Source & Sum of Squares & df & Mean Squares & F-Ratio & P-Value \\
\hline Treatment & 3159048 & 2 & 1579523.9 & 0.25 & 0.7796 \\
\hline Replicates within Treatments & 55529695 & 9 & 6169966.1 & 2.8 & 0.01 \\
\hline Residual & $1.06 E+08$ & 48 & 2202676.2 & & \\
\hline Total & $1.64 \mathrm{E}+08$ & 59 & & & \\
\hline
\end{tabular}

\begin{tabular}{|l|c|c|}
\hline Treatment Means & $\# / \mathrm{m}^{\wedge} \mathbf{2}$ & $\mathrm{n}$ \\
\hline Nonsprayed & 1120 & 20 \\
\hline Reference & 1526.67 & 20 \\
\hline Sprayed & 987.33 & 20 \\
\hline
\end{tabular}

Table 1-53. Analysis of Variance, ou 11 Total Soil Invertebrate Mesostigmata, 5-10 cm Depth

\begin{tabular}{|l|c|c|c|c|c|}
\hline Source & Sum of Squares & df & Mean Squares & F-Ratio & P-Value \\
\hline Treatment & 118772.96 & 2 & 59386.478 & 2.65 & 0.1245 \\
\hline Replicates within Treatments & 201721.38 & 9 & 22413.486 & 1.35 & 0.2355 \\
\hline Residual & 794667.2 & 48 & 16555.567 & & \\
\hline Total & 1115161.5 & 59 & & & \\
\hline
\end{tabular}

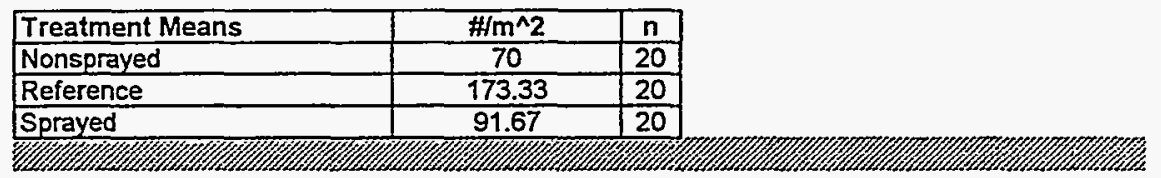

Table 1-54. Analysis of Variance, OU 11 Total Soil Invertebrate Prostigmata, 5-10 cm Depth

\begin{tabular}{|l|c|c|c|c|c|}
\hline Source & Sum of Squares & df & Mean Squares & F-Ratio & P-Value \\
\hline Treatment & 1980461 & 2 & 990230.7 & 0.17 & 0.8413 \\
\hline Replicates within Treatments & 50584765 & 9 & 5620529.4 & 2.65 & 0.0138 \\
\hline Residual & $1.01 \mathrm{E}+08$ & 48 & 2113815.7 & & \\
\hline Total & $1.54 \mathrm{E}+08$ & 59 & & & \\
\hline
\end{tabular}

\begin{tabular}{|l|c|c|}
\hline Treatment Means & $\# / \mathrm{m}^{\wedge} \mathbf{2}$ & $\mathrm{n}$ \\
\hline Nonsprayed & 1113.33 & 20 \\
\hline Reference & 1403.33 & 20 \\
\hline Sprayed & 966 & 20 \\
\hline
\end{tabular}


Table 1-55. Analysis of Variance, OU 11 Total Soil invertebrate Cryptostigmata, $5-10 \mathrm{~cm}$ Depth

\begin{tabular}{|l|c|c|c|c|c|}
\hline Source & Sum of Squares & df & Mean Squares & F-Ratio & P-Value \\
\hline Treatment & 4410999.7 & 2 & 2205499.9 & 3.37 & 0.0808 \\
\hline Replicates within Treatments & 5889393.8 & 9 & 654377.1 & 0.91 & 0.5167 \\
\hline Residual & 34161905 & 48 & 711705.36 & & \\
\hline Total & 44462299 & 59 & & & \\
\hline
\end{tabular}

\begin{tabular}{|l|c|c|}
\hline Treatment Means & $\# / \mathrm{m}^{\wedge} 2$ & $\mathbf{n}$ \\
\hline Nonsprayed & $\mathbf{2 5 6 . 6 7}$ & 20 \\
\hline Reference & 703.33 & 20 \\
\hline Sprayed & 905.67 & 20 \\
\hline
\end{tabular}


Table 1-56. Summary of All Analyses, oU 11

Treatment Effect Treatment Mean Rank Significant at alpha $=0.1$

\begin{tabular}{|c|c|c|}
\hline \multicolumn{3}{|l|}{ Soil } \\
\hline Total C & Yes & $\mathrm{S}>\mathrm{N}>\mathrm{R}$ \\
\hline Total N & Yes & $S>N>R$ \\
\hline Exchangeable K & No & $\mathrm{S}>\mathrm{N}>\mathrm{R}$ \\
\hline Exchangeable $\mathrm{Ca}$ & No & $\mathrm{S}>\mathrm{N}>\mathrm{R}$ \\
\hline Extractable P & No & $N>S>R$ \\
\hline Particle Size & No & $S=N=R$ \\
\hline Cation Exchange Capacity & No & $\mathrm{S}=\mathrm{N}=\mathrm{R}$ \\
\hline 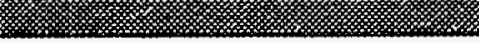 & & \\
\hline \multicolumn{3}{|l|}{ Biomass } \\
\hline Vegetation & No & $\mathrm{S}>\mathrm{N}>\mathrm{R}$ \\
\hline Litter & No & $S>R>N$ \\
\hline \multicolumn{3}{|l|}{ Nutrient Analyses } \\
\hline Vegetation C Concentration & Yes & $\mathrm{N}>\mathrm{S}>\mathrm{R}$ \\
\hline Vegetation C Content & No & $S>N>R$ \\
\hline Vegetation $\mathrm{N}$ Concentration & No & $N>R>S$ \\
\hline Vegetation N Content & No & $S>N>R$ \\
\hline Vegetation $\mathrm{K}$ Concentration & Yes & $N>R>S$ \\
\hline Vegetation K Content & Yes & $N>S>R$ \\
\hline Vegetation P Concentration & Yes & $N>R>S$ \\
\hline Vegetation P Content & No & $N>S>R$ \\
\hline Litter C Concentration & Not analyzed & \\
\hline Litter C Content & No & $\mathrm{S}>\mathrm{N}>\mathrm{R}$ \\
\hline Litter N Concentration & No & $S>N>R$ \\
\hline Litter $N$ Content & No & $S>N>R$ \\
\hline Litter K Concentration & No & $N>R>S$ \\
\hline Litter K Content & No & $N>S>R$ \\
\hline Litter P Concentration & No & $N>R>S$ \\
\hline Litter P Content & No & $N>S>R$ \\
\hline 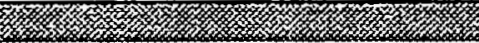 & 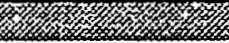 & 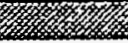 \\
\hline \multicolumn{3}{|l|}{ Soil Invertebrates } \\
\hline \multicolumn{3}{|l|}{ Nematode Functional Groups } \\
\hline Bacterial Feeders, $0-5 \mathrm{~cm}$ & No & $S>R>N$ \\
\hline Fungal Feeders, $0-5 \mathrm{~cm}$ & No & $N>R>S$ \\
\hline Omnivore/Predators, $0-5 \mathrm{~cm}$ & Yes & $S>R>N$ \\
\hline Plant Parasites, $0.5 \mathrm{~cm}$ & No & $S>R>N$ \\
\hline Bacterial Feeders, $5-10 \mathrm{~cm}$ & No & $S>N>R$ \\
\hline Fungal Feeders, $5-10 \mathrm{~cm}$ & No & $N>S>R$ \\
\hline Omnivore/Predators, $5-10 \mathrm{~cm}$ & No & $S>R>N$ \\
\hline Plant Parasites, $5-10 \mathrm{~cm}$ & Yes & $S>R>N$ \\
\hline
\end{tabular}


Table 1-56. Summary of All Analyses, OU 11

\begin{tabular}{|c|c|c|}
\hline • & $\begin{array}{c}\text { Treatment Effect } \\
\text { Significant at alpha }=0.1\end{array}$ & Treatment Mean Rank \\
\hline \multicolumn{3}{|l|}{ Arthropods } \\
\hline General Predators, $0.5 \mathrm{~cm}$ & No & $S>R>N$ \\
\hline Arthropod Predators, $0-5 \mathrm{~cm}$ & No & $S=N>R$ \\
\hline Total Predators, $0.5 \mathrm{~cm}$ & No & $S>R>N$ \\
\hline Herbivores, $0-5 \mathrm{~cm}$ & No & $R>N>S$ \\
\hline Detritivores $1,0-5 \mathrm{~cm}$ & No & $R>N>S$ \\
\hline Detritivores $2,0-5 \mathrm{~cm}$ & No & $S>R>N$ \\
\hline Total Detritivores, $0-5 \mathrm{~cm}$ & No & $S>R>N$ \\
\hline Fungal Feeders $1,0-5 \mathrm{~cm}$ & No & $R>S>N$ \\
\hline Fungal Feeders $2,0-5 \mathrm{~cm}$ & No & $\mathrm{R}>\mathrm{S}>\mathrm{N}$ \\
\hline Total Fungal Feeders, $0-5 \mathrm{~cm}$ & No & $R>S>N$ \\
\hline Mesostigmata, $0-5 \mathrm{~cm}$ & Yes & $S>R>N$ \\
\hline Prostigmata, $0-5 \mathrm{~cm}$ & No & $R>S>N$ \\
\hline Cryptostigmata, $0-5 \mathrm{~cm}$ & No & $S>R>N$ \\
\hline Astigmata, $0-5 \mathrm{~cm}$ & No & $N>S>R$ \\
\hline General Predators, $5-10 \mathrm{~cm}$ & No & $R>N>S$ \\
\hline Arthropod Predators, $5-10 \mathrm{~cm}$ & No & $R>N>S$ \\
\hline Total Predators, $5-10 \mathrm{~cm}$ & No & $R>N>S$ \\
\hline Herbivores, $5-10 \mathrm{~cm}$ & Yes & $N>R>S$ \\
\hline Detritivores $1,5-10 \mathrm{~cm}$ & No & $N>R>S$ \\
\hline Detritivores 2, $5-10 \mathrm{~cm}$ & Yes & $S>R>N$ \\
\hline Total Detritivores, $5-10 \mathrm{~cm}$ & Yes & $\mathrm{S}>\mathrm{R}>\mathrm{N}$ \\
\hline Fungal Feeders $1,5-10 \mathrm{~cm}$ & No & $R>S>N$ \\
\hline Fungal Feeders 2, 5-10 cm & No & $\mathrm{R}>\mathrm{N}>\mathrm{S}$ \\
\hline Total Fungal Feeders, $5-10 \mathrm{~cm}$ & No & $\mathrm{R}>\mathrm{N}>\mathrm{S}$ \\
\hline Mesostigmata, $5-10 \mathrm{~cm}$ & No & $\mathrm{R}>\mathrm{S}>\mathrm{N}$ \\
\hline Prostigmata, $5-10 \mathrm{~cm}$ & No & $R>N>S$ \\
\hline Cryptostigmata, $5-10 \mathrm{~cm}$ & Yes & $\mathrm{S}>\mathrm{R}>\mathrm{N}$ \\
\hline 20 & & \\
\hline \multicolumn{3}{|l|}{ Ecosystem Functions } \\
\hline Soil Nitrate Concentration & Yes & $\mathrm{S}>\mathrm{N}>\mathrm{R}$ \\
\hline Soil Ammonium Concentration & Yes & $N>R>S$ \\
\hline Potentially Respirable C & No & $S>R=N$ \\
\hline Potentially Mineralizable N & No & $N>R>S$ \\
\hline Microbial Biomass C & No & $S>R>N$ \\
\hline Microbial Biomass $\mathrm{N}$ & Yes & $\mathrm{S}>\mathrm{N}>\mathrm{R}$ \\
\hline Fine Particulate Organic C & Yes & $S>R=N$ \\
\hline Fine Particulate Organic $N$ & Yes & $S>N>R$ \\
\hline Microbial Biomass C / Total Soil C & No & $S>R>N$ \\
\hline Microbial Biomass N/ Total Soil N & No & $S>N>R$ \\
\hline Respirable Soil C / Total Soil Organic C & No & $\mathrm{R}>\mathrm{N}>\mathrm{S}$ \\
\hline Mineralizable Soil N / Total Soil N & Yes & $N>R>S$ \\
\hline Fine Particular Organic C / Total Organic C & No & $S=R>N$ \\
\hline Fine Particulate Organic N/ Total Organic $N$ & No & $S>R=N$ \\
\hline
\end{tabular}

